\title{
Strain energy density based failure criterion for GFRP coupons under tension and bending
}

\author{
Deepika Vadlamani \\ West Virginia University
}

Follow this and additional works at: https://researchrepository.wvu.edu/etd

\section{Recommended Citation}

Vadlamani, Deepika, "Strain energy density based failure criterion for GFRP coupons under tension and bending" (2007). Graduate Theses, Dissertations, and Problem Reports. 1814.

https://researchrepository.wvu.edu/etd/1814

This Thesis is protected by copyright and/or related rights. It has been brought to you by the The Research Repository @ WVU with permission from the rights-holder(s). You are free to use this Thesis in any way that is permitted by the copyright and related rights legislation that applies to your use. For other uses you must obtain permission from the rights-holder(s) directly, unless additional rights are indicated by a Creative Commons license in the record and/ or on the work itself. This Thesis has been accepted for inclusion in WVU Graduate Theses, Dissertations, and Problem Reports collection by an authorized administrator of The Research Repository @ WVU. For more information, please contact researchrepository@mail.wvu.edu. 


\title{
STRAIN ENERGY DENSITY BASED FAILURE CRITERION FOR GFRP COUPONS UNDER TENSION AND BENDING
}

\author{
Deepika Vadlamani
}

Thesis submitted to the

College of Engineering and Mineral Resources at

West Virginia University in partial fulfillment of the requirements

for the degree of

Master of Science

in

Mechanical Engineering

Nithi. T. Sivaneri, Ph.D., Chair

Hota V. S. GangaRao, Ph.D., Co-chair Jacky C. Prucz, Ph.D.

Department of Mechanical and Aerospace Engineering

\author{
Morgantown, West Virginia
}

2007

Keywords: Failure criteria, compression molding, GFRP, tension, bending, failure modes, strain energy density, ratios of longitudinal moduli, strength prediction 


\section{ABSTRACT \\ Strain Energy Density based Failure Criterion for GFRP Coupons under Tension and Bending}

Accurate prediction of failure strength is one of the major concerns in the design of fabric reinforced polymer composites. Though there are numerous failure criteria available, each criterion suits particular test data, and also lack of critical experimental results makes it difficult to assess the accuracy of these criteria. Hence, much research needs to be done to understand the mechanical characterization of fabric based polymer composites and develop a generalized theory considering the overall properties, so that the proposed theory is valid for a wide range of experimental data.

In this study, five different E-glass/vinyl ester symmetric laminates (unidirectional, bi-directional, tri-directional with Continuous Strand Mat (CSM), quadridirectional with and without CSM), manufactured using a compression molding process, and were tested under tension and bending in both the longitudinal and transverse directions. Bi-linear stress-strain response up to $90 \%$ of ultimate stress was observed for all composites with different fiber architectures, except for the tri-directional fabric composite with CSM tested in transverse direction, which showed a tri-linear stress-strain response. Strain energy densities, locations where a change of slope occurs in a bi-linear or tri-linear curve with respect to strains, ratios of longitudinal moduli, were evaluated for all test specimens at different strain levels. Consistency of test data was observed regarding the points where change of slope occurred, ratios of longitudinal moduli, etc. Also, it was found that the sum of the product of stiffness and strain energy density up to ultimate strain is constant.

For all composite materials with different fiber architectures except tri-directional fabric based composites with CSM tested in transverse direction, the first and second points where change of slope occurred were found to be $\left(\mathrm{K}_{1}\right) 0.34$, and $\left(\mathrm{K}_{2}\right) 0.87$, under tension and $\left(\mathrm{K}_{1}\right)$ 0.28, and $\left(\mathrm{K}_{2}\right) 0.88$, under bending, respectively. The ratios of the moduli were found to be $\left(\mathrm{K}_{\mathrm{E} 1}\right) 1.2$, and $\left(\mathrm{K}_{\mathrm{E} 1}\right) 1.27$ under tension and bending, respectively. In tri-directional composites with CSM tested in transverse direction three points where change of slope occurred were $\left(\mathrm{K}_{1}\right)$ 0.25, $\left(\mathrm{K}_{2}\right) 0.68$ and $\left(\mathrm{K}_{3}\right) 0.87$ for tension, and $\left(\mathrm{K}_{1}\right) 0.15,\left(\mathrm{~K}_{2}\right) 0.45$ and $\left(\mathrm{K}_{3}\right) 0.88$ for bending, respectively, and the ratios of the modulus were found to be $\left(\mathrm{K}_{\mathrm{E} 1}\right) 1.41,\left(\mathrm{~K}_{\mathrm{E} 2}\right) 1.47$ for tension and $\left(\mathrm{K}_{\mathrm{E} 1}\right) 1.56,\left(\mathrm{~K}_{\mathrm{E} 2}\right) 1.51$ for bending.

Based on the consistent experimental data, distress/damage mechanisms were identified and considered progressive starting from matrix micro-cracking, matrix microcracking leading to delamination, to fiber pull-out or fiber breakage (after crack interaction). The above distress/damage progressions have been used herein as a basis to the development of the proposed theory.

A strain energy density based failure criterion is proposed, and the model was used to predict strength, stresses and strains at various stages for different fiber architectures considered in this study. The experimental and predicted strains, stresses, and strengths at various damage stages were found to be conservative, i.e., within $10 \%$ error for all different fiber architectures. 


\section{DEDICATION}

To the person who is my best friend from childhood and a role model in my life, to my dearest sister - SriVidya Karthik - I love you very much.

To the person who formed an important pillar of my life from the very first day we met, to a friendship that I hope to sustain throughout my life, and to the wonderful person behind it all - Praveen Shankarnarayana - I extend my deepest thanks. 


\section{ACKNOWLEDGEMENTS}

As it is said that 'research is not a piece of cake' and it takes 'many hands to make a bright work', I would like to graciously thank many people for their contribution to various aspects of not only my thesis but also my graduate school life.

Dr. Hota Gangarao - I have enjoyed working with Dr.Hota throughout the three years he has been my advisor. Initially I was given the opportunity to work on different projects and I realized that the experience was invaluable and introduced me to different fields of work. Though, I had very difficult times working on my thesis, and sometimes I am sure there was very little progress; still, Dr.Hota was very patient and helpful. Dr. Hota has given me ample opportunity to grow professionally and I really appreciate his effort in trying to make me a core civil engineer by making me take some of the civil engineering courses. I am extremely grateful to Dr.Hota for supporting me with a research assistantship throughout the two and half years I worked with him, believing in me, pushing me forward in every stage, teaching me more than what was in the books and lectures, being more than a professor, and trying to bring the best of me, though in a hard way. In short, I have thoroughly enjoyed working with him and I thank him for everything he has done for me and wish him well for the future.

Drs. Sivaneri and Prucz - I feel that I had good combination of advisors, as they showed strong interest in my work. I appreciate their efforts in sparing their valuable time to be a part of my committee. Their suggestions during and after my defense are very much appreciated. I was also fortunate to take almost all the courses offered by Dr. Sivaneri, and he not only helped me with the courses he offered but also used to take some time and clear doubts in my other courses too. Thank you very much Dr. Sivaneri. I thank Dr. Prucz, for taking some valuable time from his busy schedule.

Dr. Vijay - I feel that Dr.Vijay is a man of almost limitless patience. Whenever I used to approach him with doubts, he used to give suggestions and clearly explain the pros and cons even when he was very busy. I deeply appreciate his constant encouragement especially the day before my defense, where he personally took his time to attend my mock and give me valuable suggestions, and further attending my defense, which really boosted my confidence. I am indebted for your valuable help. Thank you very much Dr.Vijay.

Vimala - She is the one who really shed light when my thesis was midst of darkness. When my thesis was going in a totally different direction and was going nowhere, Vimala was the one who showed lots of interest in my work and pointed me in the right direction. I really thank her for her words of encouragement and support till the last minute of my defense. She, along with Dr. Vijay, helped me with my thesis presentation slides and also suggested lots of changes in my oral presentation. Thank you very much Vimala, for being there like a strong pillar at all different phases of my thesis. I will never forget you.

Srinivas Alluri - I thank Srini for helping me with the electrical connections, which really helped in the testing of coupon specimens using the Instron machine. I really thank him for the times he helped me by giving some suggestions and helping me with my 
research. I am really grateful to Srini for giving his car, which really helped me in the last few months. It was so helpful when I used to work late in the night. I really thank you Srini for all the help you provided.

Dr. Woraphot Prachasaree I appreciate Woraphot for teaching me the lab preparation, coupon specimen testing in the laboratory, and also for guiding and supporting me throughout my experimentation. Whenever I approached him, he always used to help me in every way he could, and during experimentation, he used to be there until he made sure that I could handle the task.

David Turner, Jerry Nestor, Paul, Bill Comstock I am grateful to Dave for supporting me financially in my last semester. I feel that it had really helped me in completing my thesis. Also, I thank him for cutting my coupon specimens, without whom my thesis would not be possible. My extended thanks to Bill and Paul, who also helped me sometimes in cutting samples. Jerry is one of the best technicians I have ever known. I am thankful to him in many ways; he helped me many times in preparation of mold, and also helped me in cutting my samples. Jerry has patiently listened to what exactly I needed, and then had come up with effective and most of the times with inexpensive solutions, also he used to give me some suggestions and recommendations regarding manufacturing techniques. I really appreciate him for taking his time to attend my defense.

Sucharitha Bachchanna My first project was given under Sucharitha. Though I knew very little about the project, she was very patient and helpful.

Praveen The list of acknowledgements is in no particular order, because if it were, then I feel that Praveen deserves to be at the top. He was the first person whom I met during my course work in my first semester of my graduate school. I really cherish the moments I spent with him. He was there with me from the very first day we met. He was a very good friend, a philosopher, a guide and most of the times he was my weeping shoulder. I don't think anyone could help me the way he did. I really thank him for his caring support, words of encouragement, patience and knowledge of how to cheer and push me. His presence was a crucial part of this chapter in my life.

Msha, Shashi, and DJ are my good friends at WVU. I still remember the days when I used to feel low, Shashi used to take me to their house to cheer me up and give valuable suggestions, which I will never forget. DJ is always a welcoming person who gave me good advice when I needed it. When I was all alone Msha was the one who was really there and helped me out from my loneliness. I remember all that he has done and I thank him for being there for me. In short, I really thank them for cheering me at times and helping me be strong and think positively. Thank you so much guys for your unconditional support - especially in my social and moral aspects.

Kevin Ford and Dony I thank Kevin for giving some suggestions during my experimentation and Dony for helping me with the testing of my specimens. Thanks for staying with me late night at least during the initial stages.

Aneesh As far as my knowledge is concerned, he is the guy who gives finishing touches to everybody's thesis. I have no words to appropriately thank him for his endless help he 
has given during the final stages of my thesis write up. I really thank him for his time and outstanding editing and organizational skills.

Deepthi and Mahitha are the best roomies I ever had. I really had very good time with them, and I can never forget the way we spent time together. They were always proud of my success and worried about my falls. I really thank them for providing excellent company and a healthy learning environment. Thanks for reminding me to have fun sometimes. I really miss all the days we spent together. Special thanks to Vasavi, Hema and Sukanya for being very cooperative as roomies and helping me. And, I thank my special friend Meera for cheering me up sometimes. Also, Hari and Dilip thank you for the good company.

Gondle is one of my many good friends, whom I could count ask for help, no matter what type of work. Thank you for providing insights and assistance in times of dire need. Also, thank you very much for helping me with all the civil engineering courses.

Mantri I really thank him for his support and encouragement and I really appreciate for his help at times when I needed, and especially for teaching me to work on the strain gages.

Bhyrav for always offering help and I really appreciate for helping me with my resume and also for taking time to attend my defense. Dutta for helping me putting tabs, Ayman for helping me with my work sometimes, Reza for giving his desk to work, and Amar for teaching some experimental work, and also helping me with cleaning my lab space.

Family My heartfelt thanks to my dear parents and grandparents, for being my source of strength, for instilling good values, for their blessings and prayers, and for their endless and incomparable love. Without their endless love and sacrifices they have made for me over the years, this achievement would never have been a possible. I will always love you. I thank my favorite undergraduate professor Dr. D. Nageswara rao, for his suggestions regarding further studies and also for suggesting WVU as one of my options.

I really thank my sister SriVidya who has been my best friend from childhood, who was always there to constantly guide me wherever she was, and who lent a helping hand in every way she could. I am really lucky to have you as my sister. I would like to thank Venu, and Sirisha for providing a home away from home, and also babai and pinni for their parental affection. The reason I never felt homesick is because of their affection. Also, I would like to thank Seshuatha, Ravi mavayya, and Suresh annayya for their moral and financial support. Finally, to the most important person in my life, Harish, I really thank you very much for your final touch.

As I mentioned earlier, this research was supported by several individuals. I have tried to name all those who were most closely tied to my work. If I have inadvertently neglected to acknowledge anyone, I am sorry and I am really appreciative of all they did in support of my thesis. 


\section{TABLE OF CONTENTS}

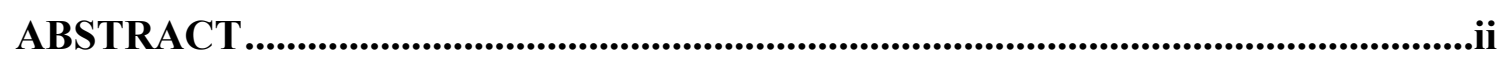

ACKNOWLEDGEMENTS ................................................................................ii

TABLE OF CONTENTS ................................................................................................... vii

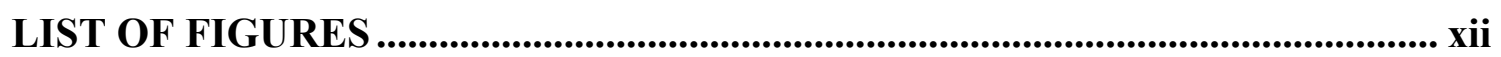

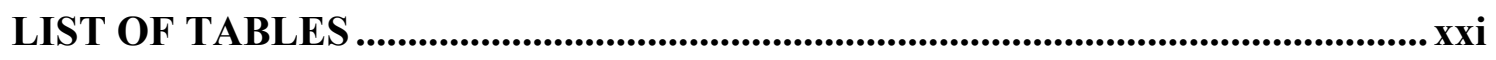

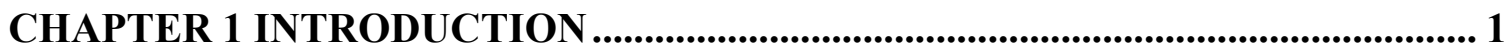

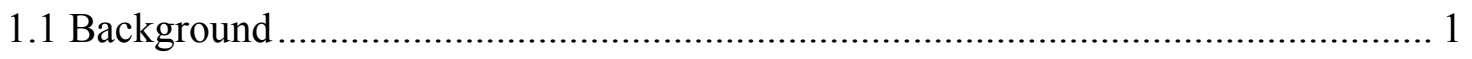

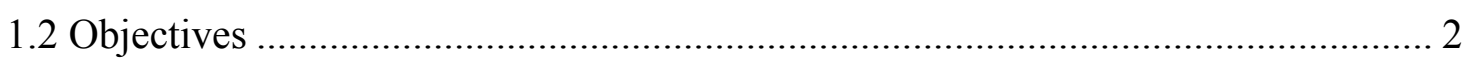

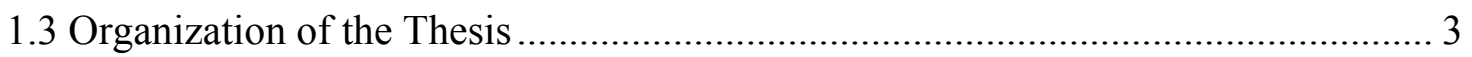

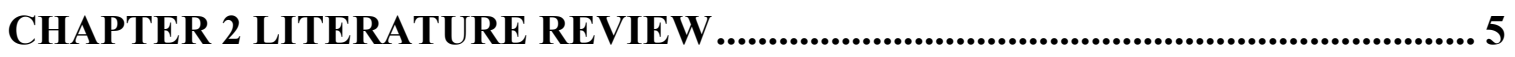

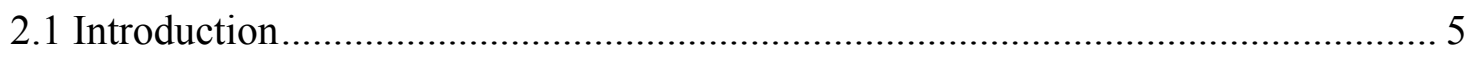

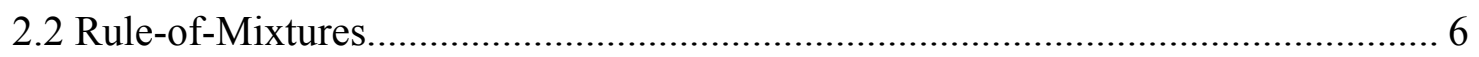

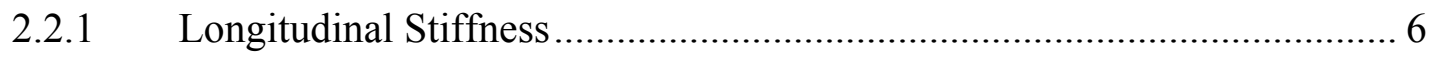

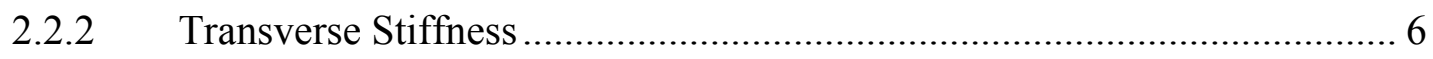

2.2.3 Uni-axial Longitudinal Strength ......................................................... 7

2.2.4 Uni-axial Transverse Strength ........................................................... 8

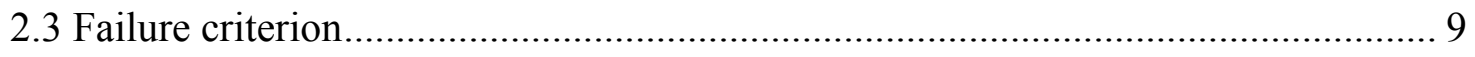

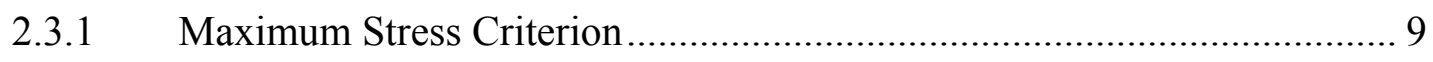

2.3.2 Maximum Strain Criterion .................................................................. 10

2.3.3 Tsai-Hill ................................................................................... 11

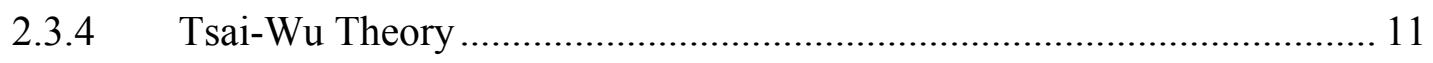

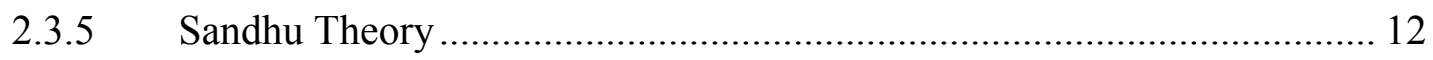

2.3.6 Puck-Schneider Theory ................................................................... 13

2.4 Failure Criterion in Fiber Reinforced Polymer Composites: (WWFE) ................... 15 


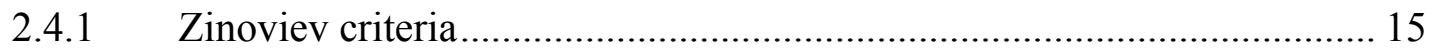

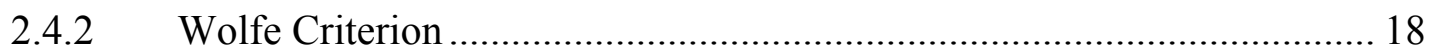

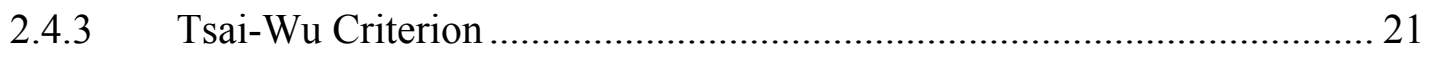

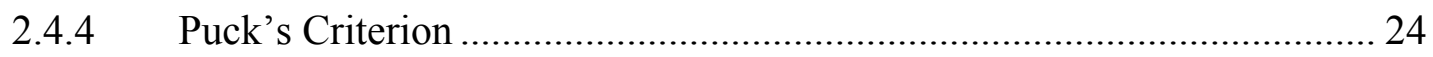

2.5 Parameter affecting strength and stiffness ....................................................... 27

2.5.1 Compression Processing ................................................................. 27

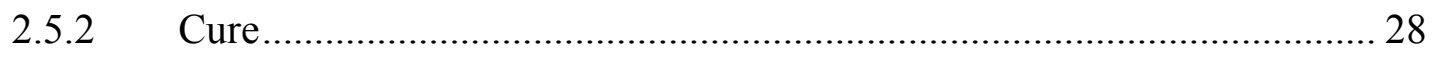

2.5.3 Fabric Density, Lay-up, FVF ........................................................... 29

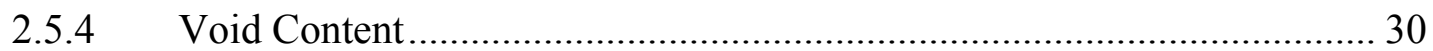

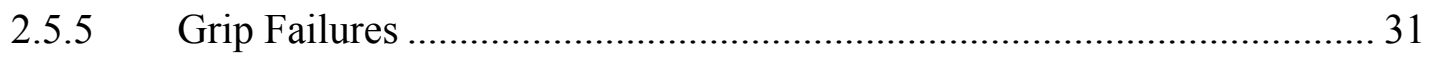

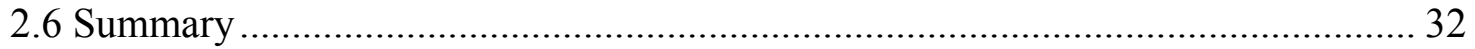

CHAPTER 3 MATERIALS AND MANUFACTURING OF TEST SPECIMENS . 33

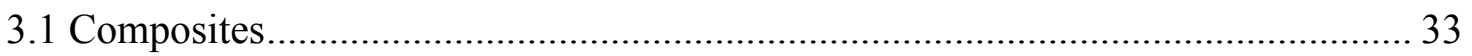

3.1.1 Classification of Composites ................................................................. 33

3.2 Classification of Polymer Matrices.................................................................. 34

3.2.1 Use of Thermoset Composites ................................................................ 34

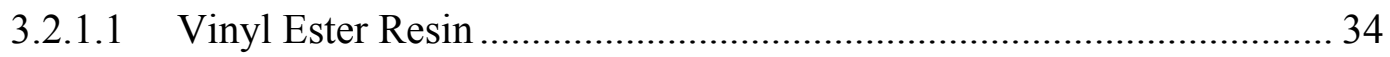

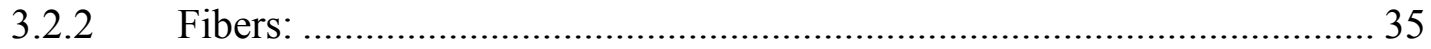

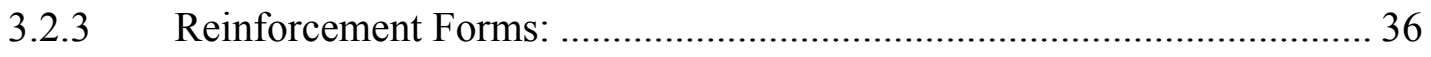

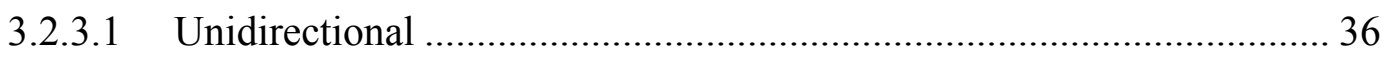

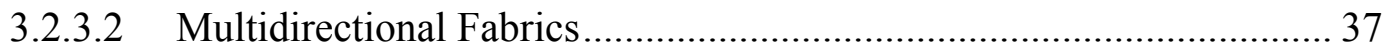

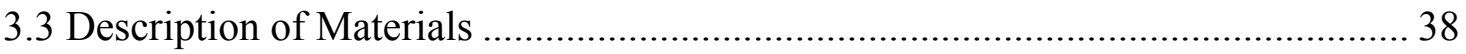

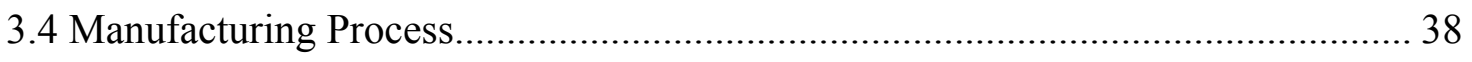

3.4.1 Compression Molding Process ………………………………............. 39

3.5 Fabrication of Composite Plate.......................................................................... 40

3.5.1 Procedure for Preparation of Composite Plate........................................... 40

3.6 Coupon Specimen Preparation............................................................................. 44

CHAPTER 4 EXPERIMENTATION............................................................................... 49

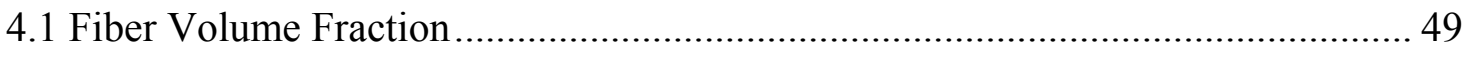




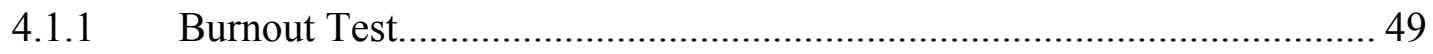

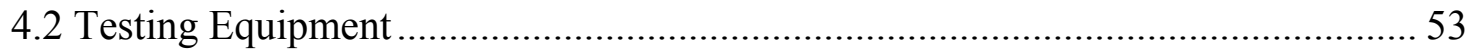

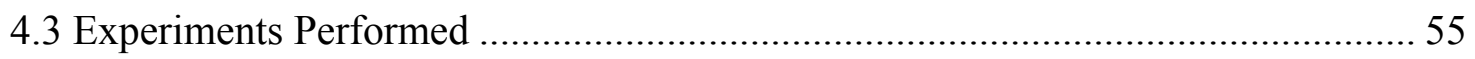

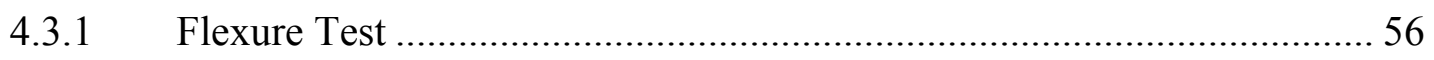

4.3.1.1 Four point Bending Test: ................................................................... 56

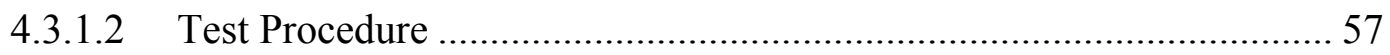

4.3.1.3 Strain Energy Calculation for Bending Test........................................... 60

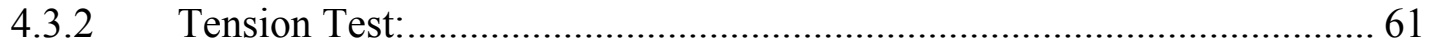

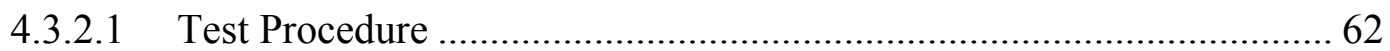

4.3.2.2 Strain energy calculations for tension test ......................................... 65

CHAPTER 5 DATA ANALYSIS AND RESULTS ..................................................... 66

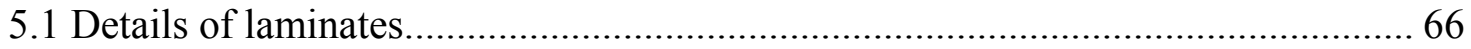

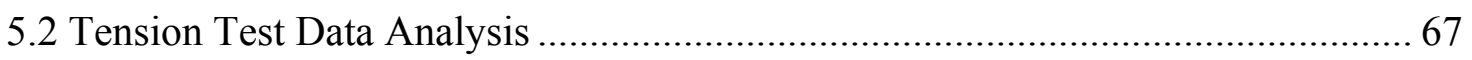

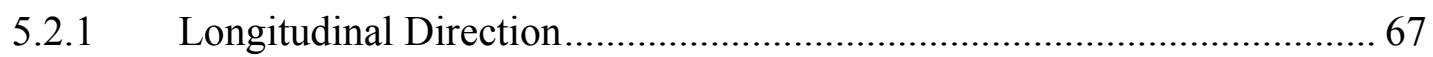

5.2.1.1 Unidirectional Coupon Specimens …………………………………..... 67

5.2.1.2 Cross-ply Coupon Specimens …………………................................... 69

5.2.1.3 Quadri-directional without CSM ....................................................... 73

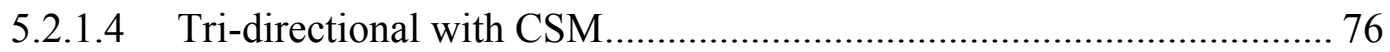

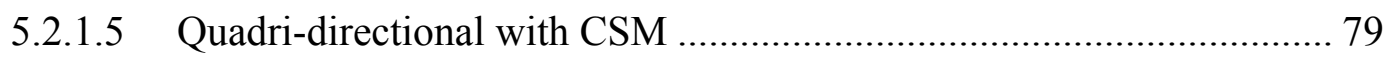

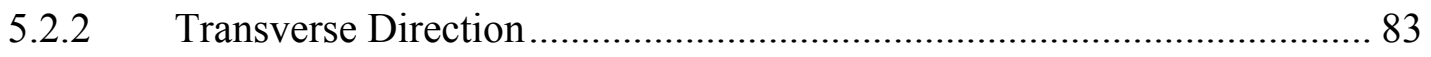

5.2.2.1 Unidirectional Coupon Specimens ………………………………........ 83

5.2.2.2 Quadri-directional without CSM ..................................................... 84

5.2.2.3 Tri-directional with CSM.................................................................. 87

5.2.2.4 Quadri-directional with CSM …………………............................... 91

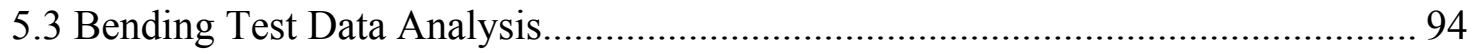

5.3.1 Four-Point Bending Test - Longitudinal Direction ................................... 94

5.3.1.1 Unidirectional Coupon Specimens ………………………………..... 94

5.3.2 Cross-ply Coupon Specimens ………………………………………….... 97

5.3.3 Quadri-directional without CSM ........................................................ 101

5.3.4 Tri-directional with CSM.................................................................... 106 


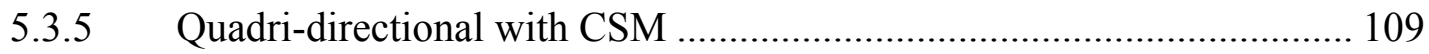

5.3.6 Four-Point Bending - Transverse Direction............................................. 115

5.3.6.1 Unidirectional Coupon Specimens ……………………………….... 115

5.3.6.2 Cross-ply Coupon Specimens ………………………………........ 116

5.3.6.3 Quadri-directional without CSM .................................................. 120

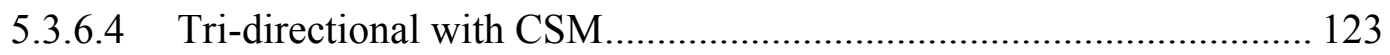

5.3.6.5 Quadri-directional with CSM ....................................................... 129

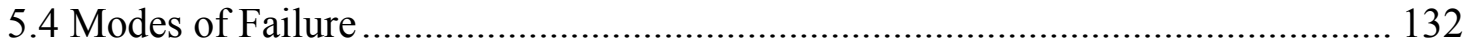

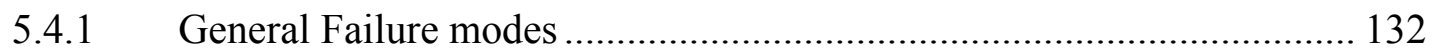

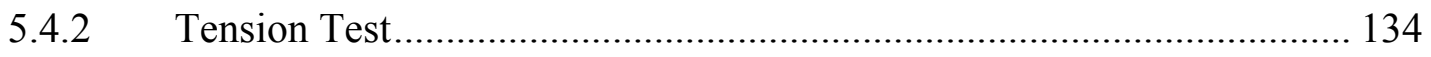

5.4.2.1 Longitudinal Direction..................................................................... 134

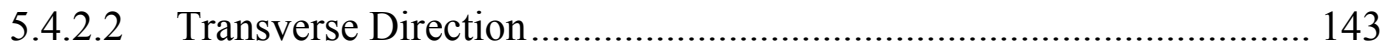

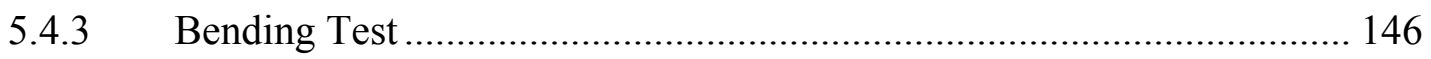

5.4.3.1 Longitudinal Direction............................................................... 147

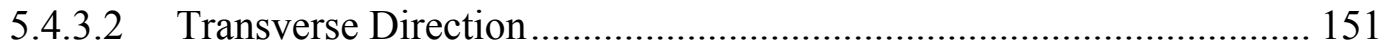

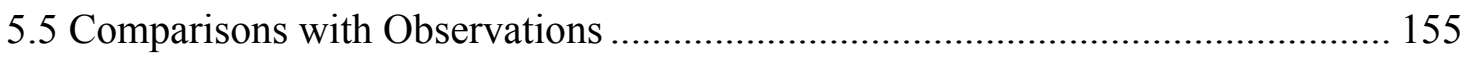

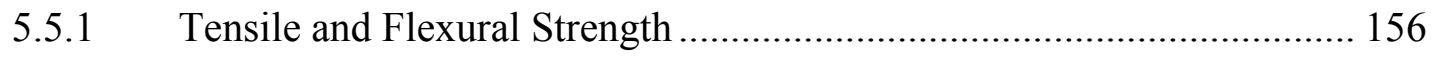

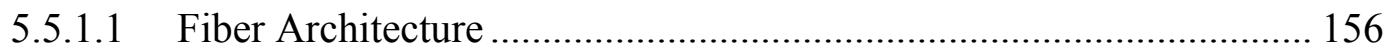

5.5.1.2 Fiber Volume Fraction.................................................................... 158

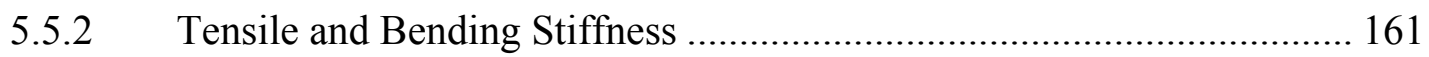

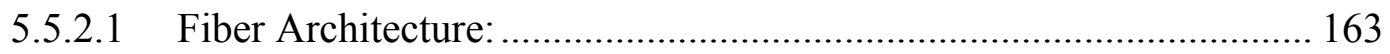

5.5.2.2 Fiber Volume Fraction................................................................... 165

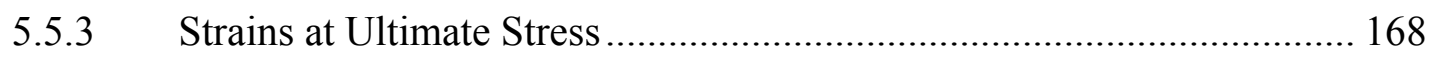

5.6 Special Case: Tri-directional composites with CSM tested in transverse direction

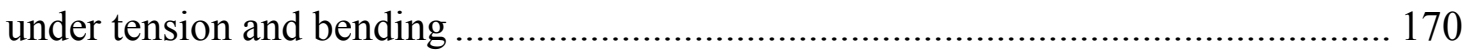

5.6.1 Tensile and Flexural Strength ......................................................... 170

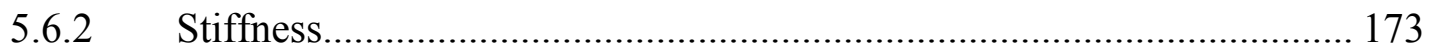

5.6.3 Strains at Ultimate Stress ................................................................. 176

CHAPTER 6 STRAIN ENERGY BASED FAILURE CRITERIA ......................... 180

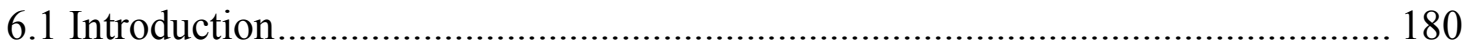




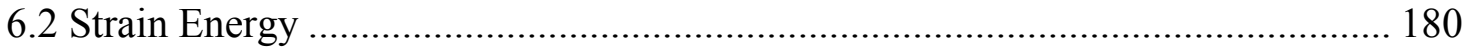

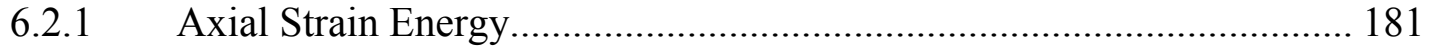

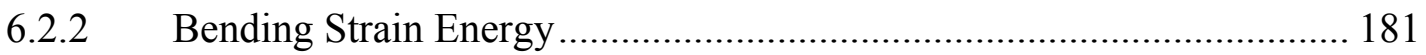

6.2.3 Principle of Energy Invariance ……………….................................. 181

6.3 Experimental Analysis .................................................................................... 182

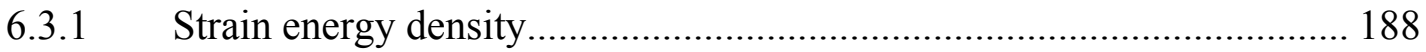

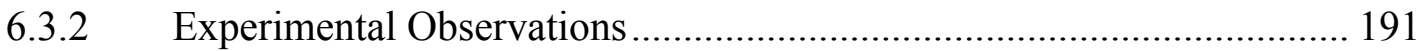

6.4 Development of failure model ....................................................................... 192

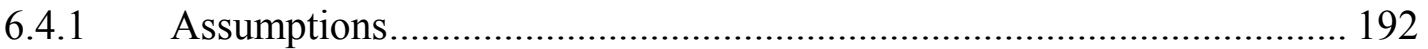

6.4.2 Strain energy density based model ....................................................... 195

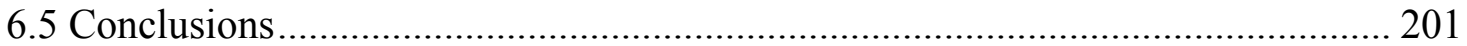

CHAPTER 7 CONCLUSIONS AND RECOMMENDATIONS ............................... 203

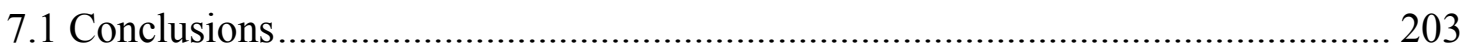

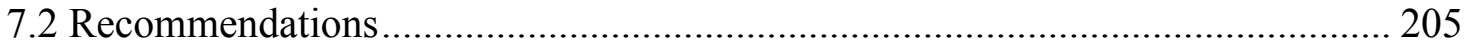

REFERENCES................................................................................................................... 207 


\section{LIST OF FIGURES}

Figure 2.1 Stress stain of angle ply laminate (Zinoviev, et al. 2004) .............................. 16

Figure 2.2 Stress-Strain Curves of Cross ply laminate under Uni-axial Tension (Zinoviev, et al. 2004) 18

Figure 2.3 stress strain curves Cross ply laminate under uni-axial tension (Butalia et al, 2004) 21

Figure 2.4 stress strain curves Cross ply laminate under uni-axial tension (Kuraishi et al, 2004) 24

Figure 2.5 Inter- Fiber Fracture Modes A, B, and C (Puck et al, 1969) 26

Figure 2.6 stress strain curves Cross ply laminate under uni-axial tension (Puck et al, 2004)

Figure 2.7 Flexural strength vs. number of ply of different woven linear density (Eng, et al. 2006) 30

Figure 2.8 Effect of different woven linear density on the flexural modulus of different number of woven ply (Eng, et al. 2006) 30

Figure 2.9 The dependence of the flexural strength on void content of the woven linear

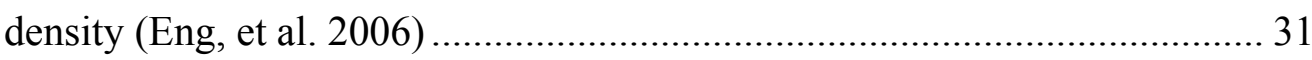

Figure 3.1: Hetron 922 L25 vinyl ester resin (Ashland Company, OH).......................... 35

Figure 3.2: Unidirectional Fabrics of 7 oz/yd2 (Owens Corning Inc)............................. 37

Figure 3.3 Schematic Diagram of Compression Molding Process ................................... 40

Figure 3.4 Stages involved in the manufacturing of composite plate................................ 44

Figure 3.5 Steps involved in the preparation of coupon specimen .................................. 46

Figure 3.6 Steps involved in the preparation and bonding of tabs to the coupon

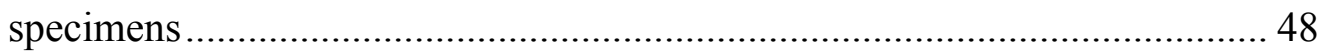

Figure 4.1 Stages involved in the resin burn-off test ................................................. 51

Figure 4.2 Baldwin universal testing machine........................................................... 53

Figure 4.3 Instron model 8501 servo-hydraulic material testing system......................... 54

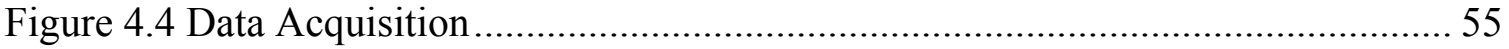

Figure 4.5 Schematic of Four-point Loading Flexure Test............................................... 56 
Figure 4.6 Load-Deflection Curve for uni-directional composite coupon specimen ....... 58

Figure 4.7 Stress-Strain Curve for uni-directional composite coupon specimen ............ 59

Figure 4.8 Stress-Strain Curve for unidirectional composite coupon specimen.............. 64

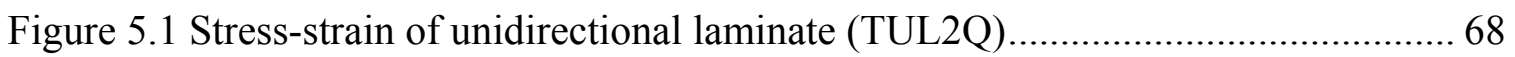

Figure 5.2 Stress -strain of unidirectional laminate (TUL2Q) until ultimate load .......... 68

Figure 5.3 Stress-strain of cross-ply laminate (TBL3H) ....................................... 70

Figure 5.4 Stress-strain of cross-ply laminate (TBL3H) until ultimate load .................. 70

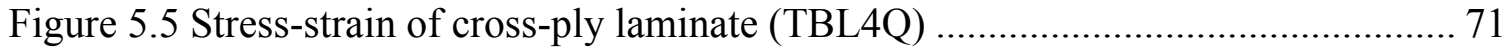

Figure 5.6 Stress-strain of cross-ply laminate (TBL4Q) until ultimate load ................... 71

Figure 5.7 Stress-strain of Quadri-directional without CSM (TQL1Q) ......................... 74

Figure 5.8 Stress-Strain of Quadri-directional without CSM (TQL1Q) until ultimate load 74

Figure 5.9 Stress-strain of Tri-directional with CSM (TTL1Q) …............................. 78

Figure 5.10 Stress-strain of Tri-directional with CSM (TTL1Q) until ultimate load...... 78

Figure 5.11 Stress-strain of quadri-directional with CSM laminate (TQWCL6Q) ......... 79

Figure 5.12 Stress-strain of Quadri-directional with CSM laminate (TQWCL6Q) until

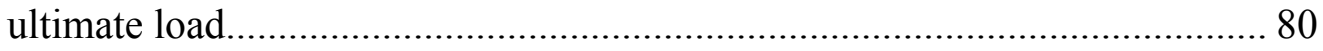

Figure 5.13 Stress-strain of quadri-directional with CSM laminate (TQWCL2H) ......... 80

Figure 5.14 Stress -strain of Quadri-directional with CSM laminate (TQWCL2H) until ultimate load in longitudinal direction ................................................. 81

Figure 5.15 Stress-strain of unidirectional laminate (TUT1Q) in transverse direction .... 83 Figure 5.16 Stress-strain of unidirectional laminate (TUT1Q) until ultimate load .......... 84

Figure 5.17 Stress-strain of quadri-directional laminate (TQT1Q) .............................. 85

Figure 5.18 Stress-strain of quadri-directional laminate (TQT1Q) until ultimate load.... 85

Figure 5.19 Stress-strain of tri-directional with CSM laminate (TTL4Q) ...................... 89

Figure 5.20 Stress-strain of tri-directional with CSM laminate (TTL4Q) until ultimate

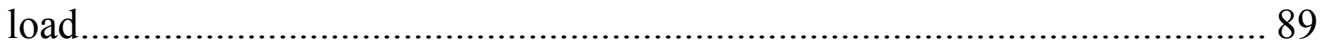

Figure 5.21 Stress-strain of tri-directional with CSM laminate (TTL3H) ..................... 90

Figure 5.22 Stress-strain of tri-directional with CSM laminate (TTL3H) until ultimate

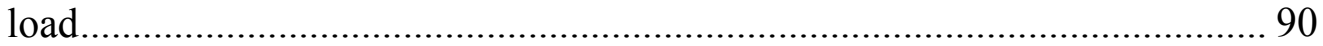

Figure 5.23 Stress-strain of quadri-directional with CSM laminate (TQWCT1Q) ......... 91 
Figure 5.24 Stress-strain of quadri-directional with CSM laminate (TQWCT1Q) until

ultimate load

Figure 5.25 Stress-strain of unidirectional laminate (BUL1Q-C) in longitudinal

direction 95

Figure 5.26 Stress-strain of unidirectional laminate (BUL1Q-C) until ultimate load in longitudinal direction. 95

Figure 5.27 Stress-strain of unidirectional laminate (BUL5Q-K) in longitudinal direction 96

Figure 5.28 Load - deflection of unidirectional laminate (BUL5Q-K) until ultimate load

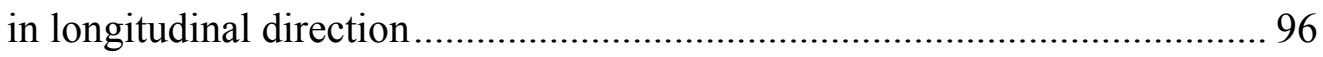

Figure 5.29 Stress-strain of cross-ply laminate (BBL1H) in longitudinal direction......... 99

Figure 5.30 Stress-strain of cross-ply laminate $(\mathrm{BBL} 1 \mathrm{H})$ until ultimate load in longitudinal direction 99

Figure 5.31 Load-deflection of cross ply laminate (BBL3H) in longitudinal direction . 100 Figure 5.32 Load-deflection of cross ply laminate (BBL3H) in longitudinal direction until ultimate load

Figure 5.33 Stress-strain of quadri-directional laminate (BQL1Q) in longitudinal direction

Figure 5.34 Stress-strain of quadri-directional laminate (BQL1Q) in longitudinal direction until ultimate load. 102

Figure 5.35 Stress-strain of quadri-directional laminate $(\mathrm{BQL1H})$ in longitudinal direction

Figure 5.36 Load-deflection of quadri-directional laminate (BQL1H) in longitudinal direction until ultimate load

Figure 5.37 Load-deflection of quadri-directional laminate (BQL6H) in longitudinal direction 103

Figure 5.38 Load-deflection of quadri-directional laminate (BQL6H) in longitudinal direction until ultimate load 104

Figure 5.39 Stress-strain of tri-directional composite with CSM (BTL1Q) in longitudinal direction 106 
Figure 5.40 Stress-strain of tri-directional composite with CSM (BTL1Q) in longitudinal direction until ultimate load.

Figure 5.41 Stress-strain of quadri-directional composite with CSM (BQWCL1Q) in

longitudinal direction 109

Figure 5.42 Stress-strain of quadri-directional composite with CSM (BQWCL1Q) in longitudinal direction until ultimate load.

Figure 5.43 Load-deflection of quadri-directional composite with CSM (BQWCL5Q) in longitudinal direction 110

Figure 5.44 Stress-strain of quadri-directional composite with CSM (BQWCL5Q) in longitudinal direction until ultimate load.

Figure 5.45 Stress-strain of quadri-directional composite with CSM (BQWCL2H) in longitudinal direction

Figure 5.46 Stress-strain of quadri-directional composite with CSM (BQWCL1H) in

longitudinal direction until ultimate load

Figure 5.47 Load-deflection of quadri-directional composite with CSM (BQWCL5H) in longitudinal direction

Figure 5.48 Load-deflection of quadri-directional composite with CSM (BQWCL5H) in longitudinal direction until ultimate load.

Figure 5.49 Stress-strain of unidirectional laminates (BUT3Q-C) in transverse direction

Figure 5.50 Stress-strain of unidirectional laminates (BUT3Q-C) in transverse direction until ultimate load

Figure 5.51 Stress-strain of cross-ply laminates (BBL2Q) in transverse direction

Figure 5.52 Stress-strain curve of cross-ply laminates (BBL2Q) in transverse direction until ultimate load

Figure 5.53 Load-deflection of cross-ply laminates (BBL5Q) in transverse direction

Figure 5.54 Load-deflection of cross-ply laminates (BBL5Q) in transverse direction until ultimate load 118

Figure 5.55 Stress-strain of quadri-directional laminates (BBL2Q) in transverse direction 
Figure 5.56 Stress-strain of quadri-directional laminates (BBL2Q) in transverse direction until ultimate load.

Figure 5.57 Stress-strain of tri-directional with CSM laminate (BTL4Q) in transverse direction

Figure 5.58 Stress-strain of tri-directional composite with CSM (BTL4Q) in transverse direction until ultimate load

Figure 5.59 Load-deflection of tri-directional with CSM (BTT5Q) in transverse direction

Figure 5.60 Load-deflection of tri-directional composite with CSM (BTT5Q) in transverse direction until ultimate load.

Figure 5.61 Stress-strain curve of tri-directional composite with CSM (BTT5H) in transverse direction

Figure 5.62 Stress-strain of tri-directional composite with CSM (BTT5H) in transverse direction until ultimate load 126

Figure 5.63 Load-deflection of tri-directional composite with CSM (BTT4H) in transverse direction

Figure 5.64 Load-deflection of tri-directional composite with CSM (BTT4H) in transverse direction until ultimate load.

Figure 5.65 Stress-strain curve of quadri-directional composites with CSM (BTQ1Q) in transverse direction 129

Figure 5.66 Stress-strain of quadri-directional composites with CSM (BTQ1Q) in transverse direction until ultimate load

Figure 5.67 Matrix cracking (Micrograph library, 2006) 132

Figure 5.68 Delamination and fiber fracture (Micrograph library, 2006) .... 133

Figure 5.69 Modes of failure due to different fiber orientation (Kaw ,2006)................ 134

Figure 5.70 Unidirectional composite samples failed near the gage length ................. 135

Figure 5.71 Unidirectional composite samples failed near grips..... 135

Figure 5.72 Premature failure of unidirectional samples where only outer layers were delaminated 136

Figure 5.73 Failure near the gage length in Crossply laminate 137

Figure 5.74 Cross ply laminate where fiber breakage on one side 138 
Figure 5.75 Cross ply laminate with fiber breakage on both sides

Figure 5.76 Cross ply laminate with fiber breakage on the both sides and delamination at the center (poor bonding) ......................................................................... 139

Figure 5.77 Cross ply laminate with delamination and fiber breakage on both sides .... 140

Figure 5.78 Grip failure of quadri-directional without CSM......................................... 141

Figure 5.79 Tri-directional with CSM Specimens failed near grips.............................. 142

Figure 5.80 Quadri-directional with CSM specimens failed near grips ....................... 143

Figure 5.81 Failed specimens of unidirectional laminates (only 90 degree fibers) ....... 143

Figure 5.82 Quadri directional without CSM failed near grips ................................... 144

Figure 5.83 Tri-directional with CSM specimens failed near gage length..................... 145

Figure 5.84 Tri-directional with CSM specimens failed near grips................................ 145

Figure 5.85 Failure of quadri-directional with CSM specimens near grips.................... 146

Figure 5.86 Failed samples of unidirectional laminates ................................................ 147

Figure 5.87 Failed samples of cross-ply laminates................................................... 148

Figure 5.88 Failed samples of quadri-directional without CSM laminates ................... 149

Figure 5.89 Failed samples of tri-directional with CSM laminates ................................ 150

Figure 5.90 Failed samples of quadri-directional with CSM laminates ......................... 151

Figure 5.91 : Failed samples of unidirectional laminates .............................................. 151

Figure 5.92 Failed samples of cross ply laminates ..................................................... 152

Figure 5.93 Failed samples of quadri-directional without CSM laminates .................... 153

Figure 5.94 Failed samples of tri-directional with CSM laminates ................................ 154

Figure 5.95 Failed samples of quadri-directional with CSM laminates of unidirectional

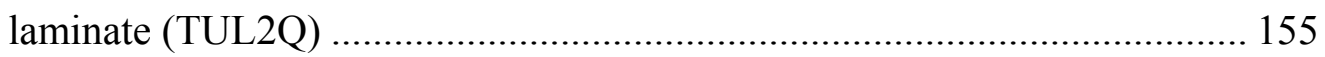

Figure 5.96 Fiber Architecture Vs Tensile Strength...................................................... 157

Figure 5.97 Fiber Architecture Vs Flexural Strength .................................................. 157

Figure 5.98 Tensile Strength Vs Effective FVF in Loading Direction........................... 158

Figure 5.99 Flexural Strength Vs Effective FVF in Loading Direction ......................... 159

Figure 5.100 Fiber Architecture Vs Specific Tensile Strength per Equivalent

FVF

Figure 5.101 Fiber Architecture Vs Specific Flexural Strength per Equivalent

FVF 
Figure 5.102 Fiber Architecture Vs Tensile Stiffness (Theoretical and Experimental) . 162

Figure 5.103 Fiber Architecture Vs Flexural Stiffness (Theoretical and Experimental) 163

Figure 5.104 Fiber Architecture Vs KE1 (Tensile Modulus Ratios) ............................. 164

Figure 5.105 Fiber Architecture Vs KE1 (Flexural Modulus Ratios) ........................... 164

Figure 5.106 Tensile Stiffness Vs Effective FVF in Loading Direction ...................... 165

Figure 5.107 Flexural Stiffness Vs Effective FVF in Loading Direction...................... 166

Figure 5.108 Fiber Architecture Vs Specific Tensile Stiffness per Equivalent FVF

(Theoretical and Experimental) .......................................................... 167

Figure 5.109 Fiber Architecture Vs Specific Flexural Stiffness per Equivalent FVF

(Theoretical and Experimental) ...................................................... 167

Figure 5.110 Fiber Architecture Vs Tensile Strains at Ultimate Stress ........................ 168

Figure 5.111 Fiber Architecture Vs Flexural Strains at Ultimate Stress

Figure 5.112 Fiber Architecture Vs Specific Tensile Strains per Equivalent FVF at

Ultimate Stress

Figure 5.113 Fiber Architecture Vs Specific Flexural Strains per Equivalent FVF at

Ultimate Stress

Figure 5.114 Fiber Architecture Vs Tensile Strength for tri-directional composites with

CSM in transverse direction.

Figure 5.115 Fiber Architecture Vs Flexural Strength for tri-directional composites with

CSM in transverse direction. 171

Figure 5.116 Fiber Architecture Vs Specific Tensile Strength per Equivalent FVF for tridirectional composites with CSM in transverse direction

Figure 5.117 Fiber Architecture Vs Flexural Strength for tri-directional composites with

CSM in transverse direction.

Figure 5.118 Fiber Architecture Vs Stiffness (theoretical and experimental) composites with CSM in transverse direction under tension. 173

Figure 5.119 Fiber Architecture Vs Stiffness (theoretical and experimental) composites with CSM in transverse direction under bending

Figure 5.120 Fiber Architecture Vs Specific Stiffness per Equivalent FVF (theoretical and experimental) composites with CSM in transverse direction under tension 
Figure 5.121 Fiber Architecture Vs Specific Stiffness per Equivalent FVF (theoretical and experimental) composites with CSM in transverse direction under bending.

Figure 5.122 Fiber Architecture Vs KE1 and KE2 composites with CSM in transverse direction under tension.

Figure 5.123 Fiber Architecture Vs KE1 and KE2 composites with CSM in transverse direction under bending

Figure 5.124 Fiber Architecture Vs Strains at Ultimate Stress of Tri-directional composites with CSM in transverse direction under tension

Figure 5.125 Fiber Architecture Vs Strains at Ultimate Stress of Tri-directional composites with CSM in transverse direction under bending

Figure 5.126 Fiber Architecture Vs Points where change of slope occurred $\left(\mathrm{K}_{1}\right.$ and $\left.\mathrm{K}_{2}\right)$ Strains at Ultimate Stress of Tri-directional composites with CSM in transverse direction under tension 178

Figure 5.127 Fiber Architecture Vs Points where change of slope occurred points (K1 and K2) Strains at Ultimate Stress of Tri-directional composites with CSM in transverse direction under bending 178

Figure 5.128 Fiber Architecture Vs Specific Strains per Equivalent FVF at Ultimate Stress of Tri-directional composites with CSM in transverse direction under tension 179

Figure 5.129 Fiber Architecture Vs Specific Strains per Equivalent FVF at Ultimate Stress of Tri-directional composites with CSM in transverse direction under bending. 179

Figure 6.1 Stress-Strain plot of various fiber architectures considered for the study

Figure 6.2 Typical Stress-Strain Curve of Multi-directional Fabric based

Composites 184

Figure 6.3 Stress-Strain plot of Unidirectional laminated Composite 185

Figure 6.4 Stress-Strain plot of Cross-ply laminated Composite 185

Figure 6.5 Stress-Strain plot of Tri-directional Composite with CSM 186

Figure 6.6 Stress-Strain plot of Quadri-directional Composite with CSM. 186 
Figure 6.7 Stress-Strain plot of Quadri-directional composite without CSM .............. 187

Figure 6.8 Stress-Strain plot of Tri-directional Composite with CSM ......................... 187

Figure 6.9 Typical Stress-Strain Curve of Tri-directional with CSM Composite .......... 199 


\section{LIST OF TABLES}

Table 2.1 Tensile test results with different clamp pressures Onal et al (2005)............. 28

Table 3.1 Fiber Architecture of the materials used in the study for tension test .............. 38

Table 3.2 Fiber architecture of the materials used in the study for bending test ............. 38

Table 5.1 Results of Unidirectional coupon specimens tested in longitudinal direction.. 69

Table 5.2 Results of Cross-ply Laminates tested in Longitudinal Direction .................... 72

Table 5.3 Tension Test Results of Quadri-directional without CSM Laminates in

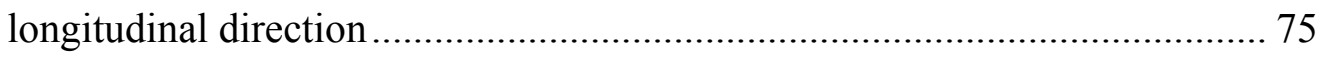

Table 5.4 Tension Test Results of Tri-directional with CSM in Longitudinal Direction. 77

Table 5.5 Tension Test Results of Quadri-directional with CSM Laminates in

Longitudinal Direction.

Table 5.6 Tension Test Results of Quadri-directional with CSM Laminates in

Longitudinal Direction

Table 5.7 Tension Test Results of Unidirectional Laminates in Transverse Direction.... 84

Table 5.8 Tension Test Results of Quadri-directional without CSM Laminate in

Transverse Direction

Table 5.9 Tension Test Results of Tri-directional with CSM Laminate in Transverse

Direction 88

Table 5.10 Tension Test Results of Tri-directional with CSM Laminate in Transverse

Direction 88

Table 5.11 Tension Test Results of quadri-directional with CSM laminates in Transverse

Direction 93

Table 5.12 Bending Test Results of Unidirectional Laminates in Longitudinal Direction

Table 5.13 Bending Test Results of Cross-ply Laminates in Longitudinal Direction...... 98

Table 5.14 Bending Test Results of Quadri-directional without CSM Laminates in

Longitudinal Direction.

Table 5.15 Bending Test Results of Tri-directional with CSM Laminates in Longitudinal

Direction 108 
Table 5.16 Bending Test Results of Quadri-directional with CSM Laminates in

Longitudinal Direction

Table 5.17 Bending Test Results of Unidirectional Laminates in Transverse Direction 115

Table 5.18 Bending Test Results of Cross-ply Laminates in Transverse Direction....... 119

Table 5.19 Bending Test Results of Quadri-directional without CSM Laminates in

Transverse Direction

Table 5.20 Bending Test Results of tri-directional with CSM Laminates in Transverse

Direction

Table 5.21 Bending Test Results of quadri-directional composites with CSM in

Transverse Direction

Table 6.1 Strain energy density of composites with different fiber architecture at different stages

Table 6.2 Strain energy density of tri-directional composites with CSM tested in transverse direction at different stages.

Table $6.3 \mathrm{~K}$ values for different fiber architectures

Table 6.4 K values for Tri-directional composite with CSM tested in transverse direction

Table 6.5 Ratios of Longitudinal Moduli for all fabric based composites under tension and bending

Table 6.6 Ratios of Longitudinal Moduli for tri-directional composites with CSM under tension and bending in transverse direction

Table 6.7 Theoretical modulus using different models

Table 6.8 Theoretical and Experimental Comparisons of Strains at Ultimate Stress of composites with different fiber architectures under tension and bending .... 198

Table 6.9 Theoretical and Experimental Comparisons of Strains at Ultimate Stress of tridirectional with CSM tested in transverse direction 201 


\section{CHAPTER 1}

\section{INTRODUCTION}

\subsection{BACKGROUND}

The need to develop products with increased durability and cost effectiveness has dramatically led to the development of advanced fabric/fiber reinforced composite materials. These fabric/fiber reinforced composites are being developed because they possess unique properties. The characteristics of such composites permit the material to be tailored to any desired shape while meeting the performance, durability and cost requirements - i.e. in terms of being lightweight; having high strength and stiffness to weight ratios; and providing good chemical, fatigue and corrosion resistances. These outstanding properties made composites to be the leading material in today's engineering applications. However, to maximize the use of the superior strength and stiffness of composite materials in the designs, failure mechanisms of composite materials have to be thoroughly understood.

In composite materials, several mechanisms can lead to the failure of a structure, and may vary with the type of loading. As loading increases, damage initiation, growth, accumulation and propagation occur progressively with the interaction of some of the mechanisms, such as matrix micro-cracking, matrix cracking, fiber pull-out, laminate delamination, local buckling, fiber breakage, etc. Damage initiation can occur prematurely due to potential manufacturing anomalies such as fiber kinks, voids, etc during lay-up of fabric and even due to inadequate cure. Initially, matrix failure modes are characterized by matrix micro-cracking at the junction where fibers are oriented, followed by cracks that run parallel to the fiber in plies that are not aligned in the loading direction (transverse matrix cracking). These cracks extend to adjacent plies, initiating delamination, and occur at the interface between plies. Delamination changes the material characteristics and ultimately the structure fails in the form of fiber breakage. The above mentioned damage modes are considered progressive with one mode leading to another.

As the damage progresses, stiffness of the material reduce thus redistributing the stress to 
the surrounding material. A comprehensive understanding of the failure mechanisms and thus developing failure criteria are important considerations for design of composite materials.

Though there are numerous theories available for unidirectional and fabric based composites, some of which are validated and successfully applied to various materials, where each theory suits a particular set of experimental data. Hence, much work needs to be done to understand the mechanical characterization (tension and bending) of fabric based composites and develop a generalized theory considering the overall properties so that the theory is valid for all experimental test data.

\subsection{OBJECTIVES}

The main objective of the thesis is to predict the failure strength of Glass Fiber Reinforced Polymer (GFRP) composites at coupon level under tension and bending. A mathematical model is proposed with strain energy as damage metric, to predict the failure strength based on experimental results. Also, stresses where distress/damage is expected to occur at can be quantified at various stages.

Tasks performed are:

1. Reviewing some of the prominent models that evaluate the failure strength of composite specimens

2. Manufacturing of GFRP plates (E-glass/Vinyl ester) using hand lay-up and compression molding machine

3. Preparing coupon specimens from plates fabricated in the laboratory, Constructed Facilities Center laboratory at West Virginia University (CFC-WVU) as per ASTM standard specifications

4. Conducting tension and bending tests on coupon specimens to find the maximum strength as per ASTM standard specifications

5. Comparing stress-strain behavior and failure modes of different fiber architecture

6. Investigating various parameters such as constituent properties, fiber orientation, stacking sequence, thickness, etc., affecting failure strength, stiffness and strains 
7. Developing a prediction model for fabric based FRP composite materials with strain energy concept under tension and bending based on the experiments

The experiments are conducted on E-glass/Vinyl ester coupon specimens under tension and bending up to ultimate load (it is considered as ultimate load in civil engineering terminology) as per ASTM standard specifications (D3639 for tension and D790 for bending). About 250 coupons specimens are manufactured from prepreg compression molding process for tension and bending, respectively. Specimens of different fiber architecture and various thicknesses are prepared for comparison purposes in both longitudinal and transverse directions. Fiber architectures include unidirectional $[0]_{\mathrm{N}}$, cross-ply $[0 / 90]_{\mathrm{NS}}$, tri-directional with Continuous Strand Mat (CSM) $[+45 / 0 /-$ $45 / \mathrm{CSM}]_{\mathrm{NS}}$, quadri-directional with and without CSM $[0 / 90 /+45 /-45]_{\mathrm{NS}}$ and $[0 / 90 /+45 /-$ $45 / \mathrm{CSM}]_{\mathrm{NS}}$.

\subsection{ORGANIZATION OF THE THESIS}

Chapter 2 discusses the strategy, process and findings with respect to the objective of predicting the failure strengths and its related existing theories. A review of existing failure theories is briefly mentioned along with the equations.

In Chapter 3, a brief review of the constituent materials and manufacturing process for this study is provided. Constituent materials include fiber and matrix, their properties, classification, composition etc. Further, manufacturing of glass finer-vinyl ester composite plates as well as the preparation of coupon specimens from the plate are described.

Chapter 4 describes the experimental program conducted on GFRP composite coupon specimens of different fiber architectures (unidirectional, bidirectional, tridirectional, and quadric-directional fabrics) subjected to tension and bending. Herein, description of the equipments used as well as the detail elaboration of technique employed for measuring fiber content is provided. Equations and calculations involved in determining the mechanical properties are also mentioned.

A comprehensive summary of results and data analysis are discussed in Chapter 5. Details of stress-strain plots of various architectures are studied and compared. 
Variations and parameters affecting the properties of the laminate as well as failure modes of all coupon specimens with different fiber architectures are discussed in detail.

A model for predicting the failure strength with strain energy as damage metric is proposed based on experimental results in Chapter 6. The procedure of the theoretical model along with key assumptions considered is also presented. Results obtained from experiments and from theoretical analysis are compared at different damage stages.

Conclusions and recommendations for future work are presented in Chapter 7. 


\section{CHAPTER 2}

\section{LITERATURE REVIEW}

This chapter focuses on critically reviewing of available literature on mechanical strengths of fiber reinforced polymer composites. Common methods to predict strength and stiffness of laminated composites are also dealt within this review. A brief description of some of the most widely used failure criteria is reviewed. In addition, some of the current leading failure theories for composite laminates reviewed by the organizers of World Wide Failure Exercise (WWFE) (Kaddour, et al. 2004) are discussed, followed by comparison of the theoretical prediction with the experimental data. Herein, emphasis is placed on cross-ply [0/90] E-glass/Epoxy laminates only.

\subsection{INTRODUCTION}

The mechanical properties of FRPs can be obtained from the experimental tests but sometimes the tests can be expensive and time consuming. One of the best approaches to obtain material properties is by using analytical means or theoretical models where applicable. A generalized theory should be developed taking into consideration that slight change in constituents and volume fractions may result in different mechanical properties, and should be validated with experiments until enough confidence is built on theoretical procedures on failure modes and failure strength predictions.

Most intuitive approach, i.e. mechanics of materials approach, is initially described for predicting strength and stiffness.

Following are the assumptions used in mechanics of material approach:

- perfect fiber-matrix bond (no inter-laminar shear lag)

- uniform spacing of fibers, without fiber kinks or breaks

- fiber and matrix follow Hook's Law

- no residual stresses

- no voids 


\subsection{RULE-OF-MIXTURES}

Mechanics of materials approach is used for obtaining stiffness and strength and are based on simple mechanical deformation and force equilibrium conditions.

\subsubsection{Longitudinal Stiffness}

For unidirectional composites, stiffness is usually obtained using rule-of-mixture (ROM) mechanics approach (Barbero, 1999). However, the stiffness obtained from experiments might be of lower value due to voids, fiber misalignment, and adverse influences.

$$
E_{1}=V_{f} \cdot E_{f}+\left(1-V_{f}\right) \cdot E_{m}
$$

where,

$\mathrm{E}_{1}=$ Modulus of elasticity in the fiber direction

$\mathrm{V}_{\mathrm{f}}=$ Fiber volume fraction

$\mathrm{E}_{\mathrm{f}}=$ Elastic modulus of fiber

$\mathrm{E}_{\mathrm{m}}=$ Elastic modulus of matrix

\subsubsection{Transverse Stiffness}

Transverse stiffness is obtained using inverse rule-of-mixtures (Barbero, 1999).

$$
\frac{1}{E_{2}}=\frac{V_{f}}{E_{f}}+\frac{\left(1-V_{f}\right)}{E_{m}}
$$

where,

$\mathrm{E}_{2}=$ Modulus of elasticity in the direction transverse to the unidirectional fibers

It was observed that the transverse modulus obtained by using inverse rule-ofmixtures is less accurate when compared with experimental data. Hopkins and Chamis developed a model based on the method of dividing representative volume element (RVE, which represents a unit cell with appropriate boundary conditions) into subregions (Barbero, 1999), which led to a better comparison with the 3D finite element model. 


$$
E_{2}=E_{m}\left[\left(1-V_{f}\right)+\frac{\sqrt{V_{f}}}{1-\sqrt{V_{f}} \cdot\left(1-E_{m} / E_{f}\right)}\right]
$$

The model was further modified separating the volume fraction into rule-ofmixtures arrangement (Kaw, 2006).

$$
E_{2}=\frac{E_{f} \cdot \sqrt{V_{f}}+\left(1-\sqrt{V_{f}}\right) \cdot E_{m}}{1-\sqrt{V_{f}}+V_{f}+\left(\sqrt{V_{f}}-V_{f}\right) \cdot \frac{E_{f}}{E_{m}}}
$$

Halpin-Tsai suggested semi-empirical approximations for predicting transverse stiffness (Barbero, 1999).

$$
\begin{gathered}
\frac{E_{2}}{E_{m}}=\frac{1+\xi \cdot \eta \cdot V_{f}}{1-\eta \cdot V_{f}} \\
\eta=\frac{\left(E_{f} / E_{m}\right)-1}{\left(E_{f} / E_{m}\right)+\xi}
\end{gathered}
$$

Where, $\xi$ is called the reinforcing factor and depends on fiber geometry, loading conditions, etc. For circular fibers in a square packing geometry, $\xi=2$. For rectangular fiber with cross section of length a and width $\mathrm{b}$ in a hexagonal packing geometry, $\xi=$ $2(\mathrm{a} / \mathrm{b})$.

\subsubsection{Uni-axial Longitudinal Strength}

Through using mechanics of material approach, uni-axial strength is obtained for two potential failure cases which are (Jones, 1990 and Manders, 1983):

Case I: If failure strain of matrix is higher than the fiber strain $\left(\varepsilon_{\mathrm{mu}}>\varepsilon_{\mathrm{fu}}\right)$, then fibers fail and transfer the stress onto the matrix. As the matrix cannot withstand the increase in load it results in failure of the whole laminate. Hence, accounting for strength of matrix up to its failure stress, and by using rule-of-mixtures approach:

$$
\sigma_{1}=V_{f} \cdot \sigma_{f}+\left(1-V_{f}\right) \cdot \sigma_{m @ f}
$$

where,

$$
\sigma_{1}=\text { Longitudinal axial stress of composites }
$$


$\sigma_{\mathrm{f}}=$ Longitudinal axial stress of fiber

$V_{f}=$ Volume fraction of the fiber

$\sigma_{\mathrm{maf}}=$ the matrix stress at fiber failure

Case II: If matrix failure strain is lower than that of fiber $\left(\varepsilon_{\mathrm{mu}}<\varepsilon_{\mathrm{fu}}\right)$, the composite stress is expressed as:

$$
\sigma_{1}=V_{f} \cdot \sigma_{f}+\left(1-V_{f}\right) \cdot \sigma_{m}
$$

Micro cracking occurs above the matrix failure strain. With gradual increase in load, micro cracking grows and the resisting load is re-distributed among the fibers. When matrix fails completely to carry excess load, then the failure strength is expressed as:

$$
\sigma_{1}=V_{f} \cdot \sigma_{f}
$$

\subsubsection{Uni-axial Transverse Strength}

Mechanics of materials approach for finding uni-axial transverse strength is given as follows (Kaw, 2006)

$$
\left(\varepsilon_{2}^{T}\right)_{u l t}=\left[\frac{d}{s} \frac{E_{m}}{E_{f}}+\left(1-\frac{d}{s}\right)\right]\left(\varepsilon_{m}^{T}\right)_{u l t}
$$

where,

$$
\begin{aligned}
& \left(\varepsilon_{m}^{T}\right)_{\text {ult }}=\text { ultimate tensile failure strain of the matrix } \\
& \mathrm{s}=\text { distance between center of fibers } \\
& \mathrm{d}=\text { diameter of fibers } \\
& \text { Ultimate transverse tensile strength is given by: } \\
& \left(\sigma_{2}^{T}\right)_{u l t}=E_{2}\left(\varepsilon_{2}^{T}\right)_{u l t}
\end{aligned}
$$

The above mentioned are the theoretical calculations of stresses and stiffnesses corresponding to unidirectional laminates. Also, it is impossible to find interactive stresses by the above methods. Since, a composite is typically subjected to complex 
loading, the above strength calculations are approximate and there are many parametric influences which are being neglected while deriving equations. Recognizing that a highly anisotropic composite will be subjected to complex loadings in practice, and it is expensive to conduct failure test(s) under wide range of stress states, the concept of failure criteria is developed to predict the strength of a laminate using strength data from uni-axial tests. Some of the prominent failure criteria are discussed in the following Section 2.3.

\subsection{FAILURE CRITERION}

For the last few decades, major effort has been directed in developing failure criteria for both unidirectional and multidirectional laminated composites. Currently, numerous failure criteria exist with some successfully validated, while others needing experimental validation. A succinct review of some of the prominent failure criteria, along with description and drawbacks are mentioned below.

These are considered as criteria and not theories because they do not attempt to explain failure modes, instead use mechanics of material approach to define the failure states.

\subsubsection{Maximum Stress Criterion}

This theory is similar to that of maximum normal stress theory by Rankine and maximum shear stress theory by Tresca applied to isotropic materials (Kaw, 2006). In this theory, failure is predicted in a composite ply, when any of the stress components in the principal material directions equals or exceeds the corresponding ultimate strengths as determined from simple unidirectional stress experiments.

$$
\begin{aligned}
& \sigma_{1}=X_{t} \text { or } X_{c} \\
& \sigma_{2}=Y_{t} \text { or } Y_{c} \\
& \tau_{12}=S
\end{aligned}
$$

$$
\sigma_{1}, \sigma_{2}, \tau_{12} \text { are principal stress components. }
$$

$\mathrm{X}, \mathrm{Y}$, and $\mathrm{S}$ are the strength in the fiber direction, perpendicular to the fiber direction and shear strength. 


\section{Features:}

- Unequal tensile and compressive strengths are usually allowed

- Onset of failure and mode of failure can be predicted.

\section{Drawbacks}

- There is no interaction between the stress components.

- It overestimates the stresses in some cases.

\subsubsection{Maximum Strain Criterion}

This theory is similar to normal strain theory by St.Venant and maximum shear stress theory by Tresca, to those applied to isotropic materials (Kaw, 2006). In this theory, failure of a composite ply takes place when one of the strains in principal material axes reaches its corresponding ultimate value determined from simple uni-axial test conditions.

The maximum strain is computed from the measured strength divided by the modulus.

$$
\begin{aligned}
& \varepsilon_{1}^{*}=\frac{X_{t}}{E_{1}} \varepsilon_{2}^{*}=\frac{Y_{t}}{E_{2}} \\
& \varepsilon_{1}^{*^{\prime}}=\frac{X_{c}}{E_{1}} \varepsilon_{2}^{*^{\prime}}=\frac{Y_{c}}{E_{2}} \\
& \varepsilon_{6}^{*}=\frac{S}{E_{6}}
\end{aligned}
$$

where, $\varepsilon_{2}, \varepsilon_{1}, \varepsilon_{6}$ are the strains corresponding to principal material axes and $\mathrm{E}_{6}$ is shear modulus

The sign of the normal strain component determines whether the tensile or compressive ultimate strain should be used.

$$
\begin{aligned}
& \varepsilon_{1}^{*}=\varepsilon_{1} \\
& \varepsilon_{2}^{*}=\varepsilon_{2}
\end{aligned} \varepsilon_{6}^{*}=\left|\varepsilon_{6}\right|
$$

If the strains are negative (compressive) then, 


$$
\begin{aligned}
& \varepsilon_{1}^{*}=\left|\varepsilon_{1}\right| \\
& \varepsilon_{2}^{*}=\left|\varepsilon_{2}\right|
\end{aligned}
$$

\section{Drawbacks:}

- There is no interaction between strains acting in the lamina.

- The strain predictions may not be accurate.

- Due to anisotropy of the material, maximum stress and maximum strain may not coincide.

\subsubsection{Tsai-Hill}

This is based on distortion energy failure of Von-Mises distortional energy yield criterion for isotropic materials, applied to anisotropic materials (Tsai, et al. 1965). The failure occurs when the formula is satisfied. In this theory, only onset of failure is predicted.

$$
\frac{\sigma_{1}^{2}}{\mathrm{X}^{2}}+\frac{\sigma_{1} \sigma_{2}}{\mathrm{Y}^{2}}-\left(\frac{\sigma_{2}^{2}}{\mathrm{Y}^{2}}\right)+\frac{\tau_{12}^{2}}{\mathrm{~S}^{2}}=1
$$

\section{Drawbacks (Nahas, et al. 1986):}

- Mode of failure is not predicted.

- Unequal tensile and compressive strengths are not allowed

\subsubsection{Tsai-Wu Theory}

$\mathrm{Wu}$ (1972) developed a simple tensor polynomial failure criterion for anisotropic materials. The theory postulates that a failure surface in the stress space is of the form

$$
\begin{aligned}
& F_{i} \sigma_{i}+F_{i j} \sigma_{i} \sigma_{j}=1 \\
& i, j=1,2, . .6
\end{aligned}
$$

Where, $F_{i}$ and $F_{i j}$ are the strength tensors of the second and fourth rank. Under plane stress conditions for an orthotropic lamina: 


$$
F_{1} \sigma_{1}+F_{2} \sigma_{2}+F_{6} \sigma_{6}+2 F_{12} \sigma_{1} \sigma_{2}+F_{11} \sigma_{1}^{2}+F_{22} \sigma_{2}^{2}+F_{66} \sigma_{6}^{2}=1
$$

The strength parameters are computed using the following formulae

$$
\begin{array}{ll}
F_{11}=\frac{1}{X_{t} X_{c}} & F_{1}=\frac{1}{X_{t}}+\frac{1}{X_{c}} \\
F_{22}=\frac{1}{Y_{t} Y_{c}} & F_{2}=\frac{1}{Y_{t}}+\frac{1}{Y_{c}} \\
F_{12}=F_{x y}^{*} \sqrt{F_{11} F_{22}} & F_{66}=\frac{1}{S^{2}}
\end{array}
$$

The interaction term $F_{12}$ represents the interaction between normal stresses in the 1 and 2 directions $\mathrm{F}_{\mathrm{xy}}^{*}$ is the normalization term and it can assume values between -1 and 1. Tsai-Wu theory is a special case of the quadratic polynomial failure criteria.

When $\mathrm{F}_{\mathrm{xy}}^{*}=-0.5$ Tsai-Wu Theory

$\mathrm{F}^{*}{ }_{\mathrm{xy}}=0$ Hoffman theory

$\mathrm{F}_{\mathrm{xy}}^{*}=1$ Chamis Theory

$F_{i}$ and $F_{i j}$ are second and fourth order strength tensors. The non-interaction

F terms are related to the engineering strengths. Narayanaswami and Adelman (Nahas, 1986) used the criterion with same interaction term as 0 and found that the experimental results are in good agreement with the theoretical predictions.

\section{Drawbacks (Nahas, 1986):}

- The interaction terms $(F)$ are to be obtained from biaxial tests.

- Constraint for interaction terms is $\mathrm{F}_{\mathrm{ii}} \mathrm{F}_{\mathrm{jj}}-\mathrm{F}_{\mathrm{ij}}{ }^{2}>0$

\subsubsection{Sandhu Theory}

This theory is based on total strain energies to be used in conjunction with nonlinear behavior of composite materials' analysis (Sandhu, 1974). Assuming strain energies as independent parameters, the failure criterion for orthotropic materials is expressed as 


$$
\begin{aligned}
& \sum_{i=1,2,6} \frac{1}{K_{i}}\left[\int_{\varepsilon_{i}} \sigma_{i} d \varepsilon_{i}\right]^{m_{i}}=1 \\
& K_{i}=\left[\int_{\varepsilon_{i}^{u}} \sigma_{i} d \varepsilon_{i}\right]^{m_{i}} i=1,2,6 \\
& \left(\frac{\int_{\varepsilon_{1}} \sigma_{1} d \varepsilon_{1}}{\int_{\varepsilon_{1}^{u}} \sigma_{1} d \varepsilon_{1}}\right)^{m_{1}}+\left(\frac{\int_{\varepsilon_{2}} \sigma_{2} d \varepsilon_{2}}{\int_{\varepsilon_{2}^{u}} \sigma_{2} d \varepsilon_{2}}\right)^{m_{2}}+\left(\frac{\int_{\varepsilon_{6}} \sigma_{6} d \varepsilon_{6}}{\int_{\varepsilon_{6}^{u}} \sigma_{6} d \varepsilon_{6}}\right)^{m_{6}}=1 \\
& \varepsilon_{\mathrm{i}}=\text { the current strain components, } \\
& \mathrm{m}_{\mathrm{i}}=\text { parameters define the shape of the failure surface in the strain-energy space } \\
& \mathrm{K}_{\mathrm{i}}=\text { material characteristics }
\end{aligned}
$$

The shape of the failure surface given by this equation depends on $\mathrm{m}_{1}, \mathrm{~m}_{2}$ and $\mathrm{m}_{6}$.

For spherical $\mathrm{m}_{1}=\mathrm{m}_{2}=\mathrm{m}_{6}=2$

For pyramidal surface $\mathrm{m}_{1}=\mathrm{m}_{2}=\mathrm{m}_{6}=1$.

\section{Drawbacks (Nahas, 1986):}

Biaxial strengths have to be performed to find shape factors.

\subsubsection{Puck-Schneider Theory}

In this criterion, strengths of the constituent materials are considered, though interaction formulae are used (Puck, et al. 1969). Three types of failure namely, the fracture of the fiber, yield of the matrix and the adhesive failure of the interface are taken into account. 


$$
\begin{aligned}
& \frac{\sigma_{1}}{X_{f}}=1 \\
& \left(\frac{\sigma_{1}}{X_{m}}\right)^{2}+\left(\frac{\sigma_{2}}{Y_{m}}\right)^{2}+\left(\frac{\tau_{12}}{S_{m}}\right)^{2}-\frac{\sigma_{1} \sigma_{2}}{3 X_{m} Y_{m}}=1 \\
& \frac{\sigma_{2}}{Y_{i}}+\frac{\tau_{21}^{2}}{S_{i}^{2}}=1---------------(A) \\
& \left(\frac{\sigma_{2}^{2}}{Y_{m}^{2}}\right)+\left(\frac{\tau_{21}^{2}}{S_{m}^{2}}\right)=1-------------(B) \\
& \frac{\sigma_{2}^{2}}{Y_{t} Y_{c}}+\sigma_{2} \frac{Y_{c}-Y_{t}}{Y_{t} Y_{c}}+\frac{\tau_{21}^{2}}{S_{m}^{2}}=1---------(C)
\end{aligned}
$$

f, $\mathrm{m}, \mathrm{i}$, denotes fiber, matrix, and the interface.

\section{Drawbacks:}

- Some authors stated that this theory did not give good results in some cases and some modifications have to be done (Nahas, 1986).

The above mentioned theories are some of the common failure theories being utilized in practice. Most of the criterion are modified by different authors and involved complex scenarios. Some of the current modified failure theories are discussed in the next section.

Few mechanisms and criterion summarized in the work carried out by WWFE edited by Kaddour et al (2004) are dealt with briefly and focus is placed on the theoretical prediction of cross-ply failure and failure processes involved. 


\subsection{FAILURE CRITERION IN FIBER REINFORCED POLYMER COMPOSITES: (WWFE)}

\subsubsection{Zinoviev criteria}

Zinoviev et al (2004), employed Maximum Stress theory by considering unloading behavior of cracked laminates, and geometric nonlinearities due to fiber orientation in each ply. The model developed is used for describing coupled deformation and failure processes, and predicting stresses for specific failure modes of multilayered hybrid composites under plane stress conditions. Under different loading conditions, stress-strain curves as well as failure envelopes for multilayered composites are also predicted. STRAN program is developed based on the model.

In this model, failure criteria for two different cases were considered:

\section{a) Isolated unidirectional ply:}

According to the model, the ply is within the elastic zone when the following conditions are satisfied, or else the ply is fails.

$$
\begin{aligned}
& F_{-1} \leq \sigma_{1} \leq F_{+1}, \\
& F_{-2} \leq \sigma_{2} \leq F_{+2}, \\
& \left|\tau_{12}\right| \leq F_{12}
\end{aligned}
$$

Where, $\mathrm{F}_{+1}-$ Longitudinal ultimate tensile stress

$\mathrm{F}_{+2}-$ Transverse ultimate tensile stress

$\mathrm{F}_{-1}$ - Longitudinal ultimate compressive stress

$\mathrm{F}_{-2}-$ Transverse ultimate compressive stress

$\mathrm{F}_{12}$ - Ultimate in-plane shear stress

\section{b) Unidirectional ply within a Laminate}

According to the ply model, in a composite laminate, there exists a group of intermediate states in between homogeneous phase to complete broken phase, called 
material with cracked state (matrix cracking). This intermediate state is further subdivided into 1) open crack and 2) closed crack states.

The matrix cracking is assumed to be a result of interaction between shear and transverse tension. Ply behavior is affected by cracks under transverse tension and shear, irrespective of their cause of appearance (open or closed cracks). The following are the conditions for occurrence of matrix cracking.

$$
\begin{aligned}
& \left|\tau_{12}^{*}\right|=F_{12}, \sigma_{2}^{*} \leq F_{+2} \\
& \sigma_{2}^{*}=F_{+2},\left|\tau_{12}^{*}\right| \leq F_{12}
\end{aligned}
$$

where, $\sigma_{2}>0$ open cracks

$$
\sigma_{2}<0 \text { closed cracks }
$$

A typical behavior of an angle-ply laminate is explained with the following stressstrain curve (see Figure 2.1). The curve is divided into three different stages namely:

Stage I represents the first linear part of the curve which corresponds to stiffness properties.

Stage II represents the knee of the curve and corresponds to the conditions for occurrence of first ply failure.

Stage III represents stiffness characteristics of the material following the first stage.

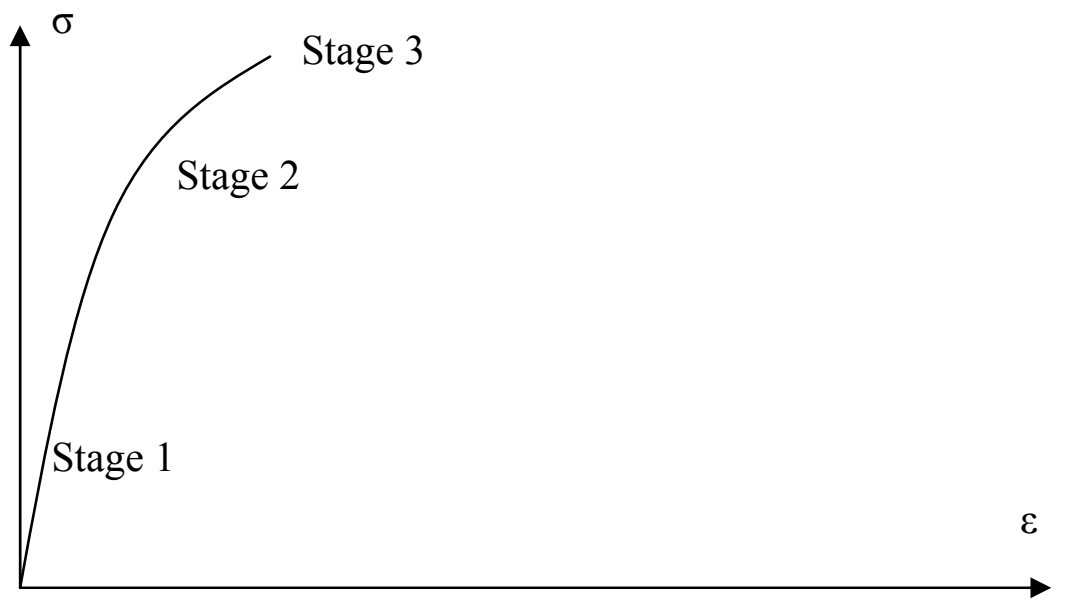

Figure 2.1 Stress stain of angle ply laminate (Zinoviev, et al. 2004) 


\section{Drawbacks (Kaddour, et al. 2004):}

- Residual thermal stresses are ignored completely. But, multidirectional laminates that are cured at elevated temperature will develop thermally induced residual stresses.

- The model did not account for material non-linearity.

- Combination of matrix, transverse and shear failure roles in the failure process are not considered.

- Does not account for large deformations.

\section{c) Case Study of Cross-ply Laminates}

\section{Comparison with experiments}

Theoretical and experimental stress-strain curve of cross-plied GFRP Eglass/MY750 laminate under uni-axial tension is shown in Figure 2.2. Transverse $\left(90^{\circ}\right)$ plies fail resulting in slight decrease in effective modulus (Stage I), followed by failure of $0^{\circ}$ plies through transverse tension (Stage II). The total failure of the laminate is considered to take place with the failure of $0^{\circ}$ plies in longitudinal tension (Stage III).

The theoretical model was compared with experimental results submitted by WWFE organizers, and the correlation was found to be satisfactory. However, the reduction in stiffness, observed in the experimental curve, was not explained in the model. The final strength prediction as per the failure criteria was found to be $8 \%$ higher than the experimental value.

The organizers of WWFE (Kaddour et al, 2004), found that the criterion was best at predicting initial failure stages in multidirectional laminates. The failure envelopes for unidirectional lamina, as well as for multi-directional laminates were found to be reasonably good. 


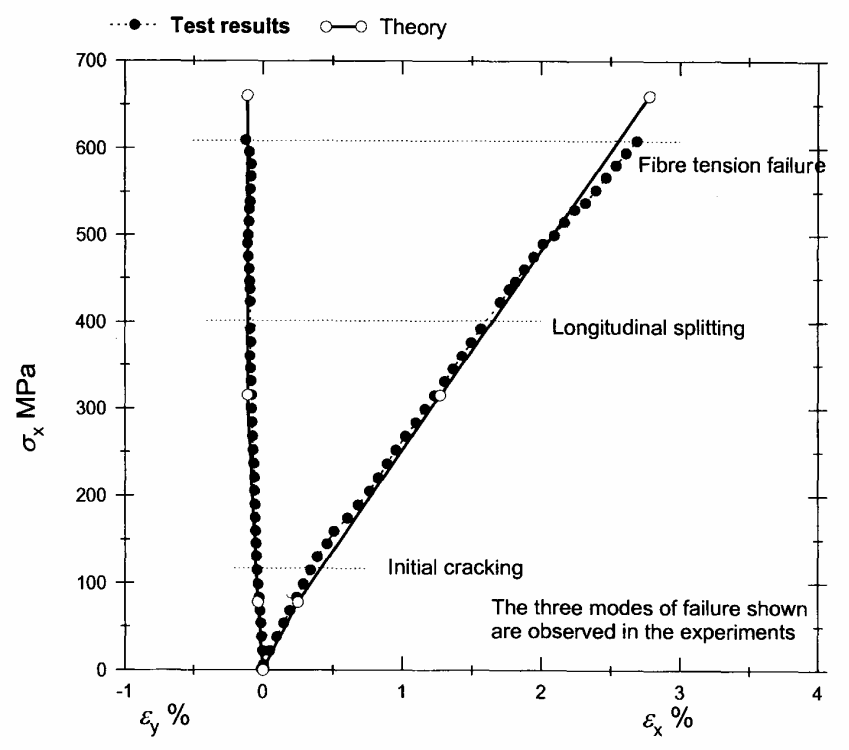

Figure 2.2 Stress-Strain Curves of Cross ply laminate under Uni-axial Tension (Zinoviev, et al. 2004)

\subsubsection{Wolfe Criterion}

Wolfe et al (2004), extended Sandhu's strain energy based failure theory for describing the behavior of laminated composites. With computed longitudinal, transverse and shear energies and comparison of the calculated values with the experimental results, the onset and progression of failure in laminates of different thickness and fiber orientation was predicted. In case of orthotropic material, to account for non-linearity, an iterative incremental constitutive law combined with strain-energy based failure criterion (Sandhu) was incorporated.

General form of strain energy based failure criterion for non-linear orthotropic materials is:

$$
\begin{aligned}
& \sum_{i=1,2,6} \frac{1}{K_{i}}\left[\int_{\varepsilon_{i}} \sigma_{i} d \varepsilon_{i}\right]^{m_{i}}=1 \\
& K_{i}=\left[\int_{\varepsilon_{i}^{u}} \sigma_{i} d \varepsilon_{i}\right]^{m_{i}} i=1,2,6
\end{aligned}
$$




$$
\left(\frac{\int \varepsilon_{1} \sigma_{1} d \varepsilon_{1}}{\int_{\varepsilon_{1}^{u}} \sigma_{1} d \varepsilon_{1}}\right)^{m_{1}}+\left(\frac{\int_{\varepsilon_{2}} \sigma_{2} d \varepsilon_{2}}{\int_{\varepsilon_{2}^{u}} \sigma_{2} d \varepsilon_{2}}\right)^{m_{2}}+\left(\frac{\int \sigma_{6} \sigma_{6} d \varepsilon_{6}}{\int_{\varepsilon_{6}^{u}} \sigma_{6} d \varepsilon_{6}}\right)^{m_{6}}=1
$$

where,

$\mathrm{K}_{\mathrm{i}}$ is defined for the uni-axial tension (or compression), transverse tension (or compression) and shear.

$\mathrm{m}_{1}, \mathrm{~m}_{2}$ and $\mathrm{m}_{6}$ determine the shape of the failure surface in strain energy space and $\mathrm{m}_{\mathrm{i}}>=0$.

The approximate upper bound values for $\mathrm{m}_{\mathrm{i}}$ is 2 when $\mathrm{m}_{1}=\mathrm{m}_{2}=\mathrm{m}_{6}$, and correspond to maximum stress criterion. The shape of the failure surface given by equation 2.3 depends on $\mathrm{m}_{1}, \mathrm{~m}_{2}$ and $\mathrm{m}_{6}$.

For spherical surface $\mathrm{m}_{1}=\mathrm{m}_{2}=\mathrm{m}_{6}=2$

For pyramidal surface $\mathrm{m}_{1}=\mathrm{m}_{2}=\mathrm{m}_{6}=1$.

Herein, both matrix failure and fiber failure modes were considered. From equation 2.22, failure of a ply is determined. Longitudinal strain energy ratio (LSER) is computed as:

$$
L S E R=\frac{\left(\int_{\varepsilon_{1}^{u}} \sigma_{1} d \varepsilon_{1}\right)^{m_{1}} \times 100}{\sum_{i=1,2,6}\left(\frac{\int_{\varepsilon_{i}} \sigma_{i} d \varepsilon_{i}}{\int_{\varepsilon_{1}^{u}} \sigma_{i} d \varepsilon_{i}}\right)^{m_{1}}}
$$


Critical LSER value is assumed and compared with calculated LSER value. Fiber failure occurs when LSER is greater than the critical LSER; otherwise it is inferred as matrix failure.

After first ply failure, the mechanisms by which loads were redistributed among remaining plies of the laminate were considered. In the model, sudden unloading, gradual unloading, and perfectly plastic behavior techniques are incorporated. Ply is assumed to have failed if the calculated strains exceed the ultimate strain in the longitudinal direction (fiber failure) or in the transverse or shear direction (matrix failure).

\section{Assumptions:}

- The shape energy factors $\left(\mathrm{m}_{\mathrm{i}}\right)$ are all unity due to unavailability of experimental data

- Critical LSER value is assumed as $10 \%$ based on experimental observations

- Sudden unloading mechanism is employed for failed plies

- The calculated strains in any lamina are presumed not to exceed the ultimate strains unless experimentally proved

\section{Drawbacks (Kaddour, et al. 2004):}

- Intermediate mode of failure was not predicted.

- Cannot be used for large deformations.

- Residual thermal stresses are ignored completely.

\section{Case Study of Cross-ply Laminates}

\section{Comparison with experiments}

Predicted and experimental stress-strain response of $[0 / 90]_{\mathrm{S}}$ laminate under longitudinal tensile loading is shown in Figure 2.3. The behavior of the curve is linear except at failure of the plies where the strains suddenly increase due to unloading of the failed plies. The mechanism of failure is as follows: 'after $90^{\circ}$ plies exceed maximum allowable transverse tensile strain first ply failure occurred, $0^{\circ}$ plies were under transverse compressive strain but the non-slip condition at the interface causes a net 
transverse tensile stress to occur in the 0 plies. The final failure occurs due to transverse failure of the $0^{\circ}$ plies (Wolfe et al, 2004)'. A 15\% difference between predicted and experimental value was observed.

The organizers of WWFE, Kaddour et al (2004), found that using the criterion initial failure strengths for the multidirectional laminates were in quite good agreement with experimental results.

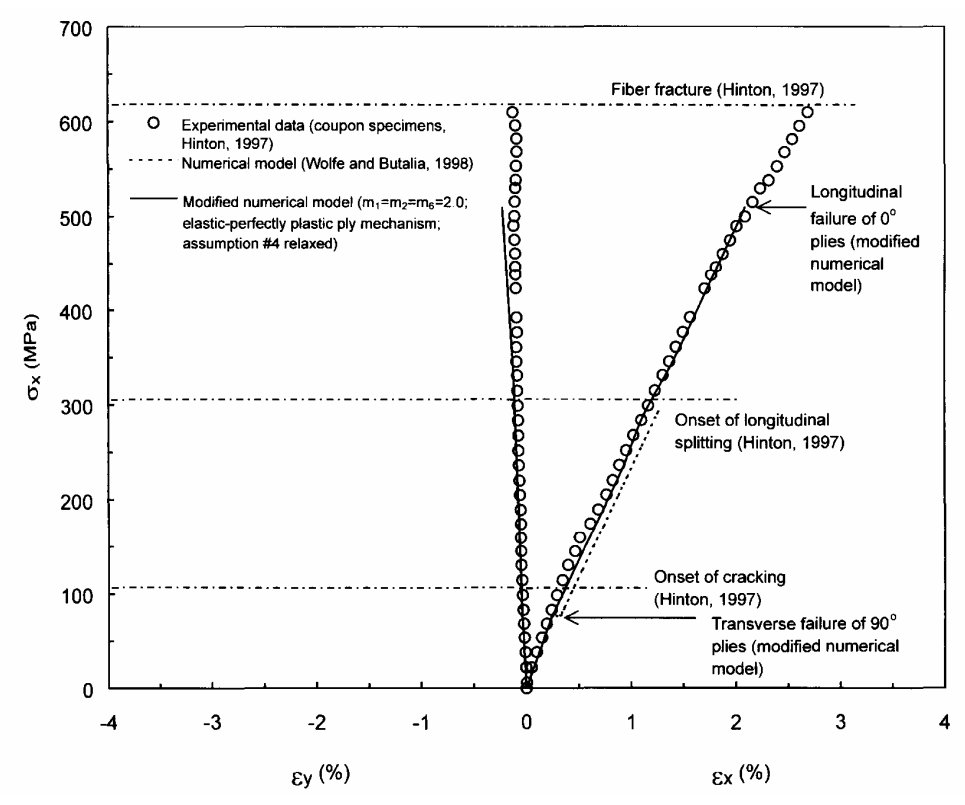

Figure 2.3 stress strain curves Cross ply laminate under uni-axial tension (Butalia et al, 2004)

\subsubsection{Tsai-Wu Criterion}

Progressive quadratic failure criterion (Liu, et al. 2004 and Kuraishi, et al. 2004) is employed for a laminate to evaluate the ply-by-ply and point-by-point strength analysis.

General 2D representation of quadratic failure criterion:

$$
\frac{\sigma_{x}^{2}}{X X^{\prime}}+\frac{\sigma_{y}^{2}}{Y Y^{\prime}}+\frac{2 F_{x y}^{*}}{\sqrt{X X^{\prime} Y Y^{\prime}}}+\frac{\sigma_{s}^{2}}{S^{2}}+\left[\frac{1}{X}-\frac{1}{X^{\prime}}\right] \sigma_{x}+\left[\frac{1}{Y}-\frac{1}{Y^{\prime}}\right] \sigma_{y}=1
$$

Interaction Term 
$F_{x y}^{*}=\frac{F_{x y}}{\sqrt{F_{x x} F_{y y}}}$

For closed envelopes

$-1 \leq F_{x y}^{*} \leq 1$

$\mathrm{X}=$ longitudinal tensile strength

$X^{\prime}=$ longitudinal compressive strength

$\mathrm{Y}=$ transverse tensile strength

$\mathrm{Y}^{\prime}=$ longitudinal compressive strength

$\mathrm{S}=$ longitudinal shear strength

An average value of -0.5 was considered for this failure criterion, which is reasonable for all materials in reference to von-misses model.

In this model, for predicting failure envelopes and stress/strain curves, linear analysis was considered. Secant modulus was used in case of non-linear stress-strain curves and failure strain is obtained by the ratio of failure strength and secant modulus. The model presumed that two states of plies occur. First is initial, intact and continuous state. The other is a degraded state, where micro cracks followed by complete matrix and fiber failure take place.

'Micro cracking is assumed to takes place instantaneously where high stress in ply occurs within a limited region. As the plies are still intact, the laminate still carries the prevailing load. In this model, micro cracking in a ply is incorporated by reducing transverse and shear moduli maintaining longitudinal stiffness. The extent of reduction is a function of number of cracks at saturation measured by their density or aspect ratio (Liu, et al. 2004 and Kuraishi, et al. 2004).’

For degraded plies, new set of strength parameters using three adjustable factors are established:

- Matrix degradation factor $\mathrm{E}_{\mathrm{m}}$

- Fiber degradation factor $\mathrm{E}_{\mathrm{f}}$ 
- Longitudinal compressive strength reduction exponent $\mathrm{n}$

With these degradation factors, progressive failure scenario is developed.

\section{Progressive Failure:}

Based on the ply having minimum or the lowest strength ratio among the plies, first ply failure is determined. When the transverse strain of a failed ply is positive, then matrix cracking is assumed to occur, but if the transverse strain is negative or zero, then the material is still intact without any cracking and the failure mode will be fiber dominated. Appropriate degradation factors are applied to determine the reduced matrix or fiber modulus.

Ply-by-ply progressive failure is continued until maximum load is reached, and thus ultimate load of the laminate is determined.

\section{Limitations (Kaddour, et al. 2004)}

- Complicated failure process.

- Delamination of the homogenization of micro cracking is not focused.

\section{Case Study of Cross-ply Laminates}

\section{Comparison with experiments}

$\mathrm{E}_{\mathrm{m}}=0.15$

$\mathrm{E}_{\mathrm{f}}=0.01$

$\mathrm{n}=0.1$

Predicted and experimental stress-strain curves of cross-ply laminates are shown in Figure 2.4. Theoretical and experimental values are in good agreement, including the onset of longitudinal splitting.

In WWFE, (Kaddour et al., 2004), found that using the criterion initial and final failure strengths were in good agreement with experimental results. 


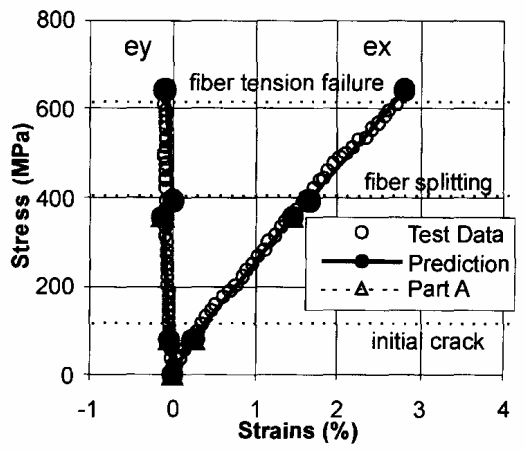

Figure 2.4 stress strain curves Cross ply laminate under uni-axial tension (Kuraishi et al, 2004)

\subsubsection{Puck's Criterion}

Puck et al (2004) employed two independent fracture criteria i.e. inter-fiber fracture (IFF-micro cracking) and fiber fracture (IFF). Crack initiation as well as direction of cracks was also predicted. After crack initiation, continuous and gradual loss of stiffness is accounted for. The IFF criterion makes a distinction between three different failure modes (A, B, and $\mathrm{C})$ under plane stress conditions.

\section{Inter-Fiber Failure (IFF)}

Single fibers break under uni-axial tensile stress before fracture of fibers occurs leading to ultimate failure when maximum strength is reached. These breaks in fibers cause damage in the form of de-bonding of fiber and matrix and micro cracking in the matrix. This phenomenon is explained as inter-fiber failure.

\section{Different Modes}

MODE A: When perpendicular transverse cracks appear in the lamina under tensile stress with or without in-plane shear stress.

$$
\begin{aligned}
& \sqrt{\left(\frac{\sigma_{n}}{R_{\perp}^{(+) A}}\right)^{2}+\left(\frac{\sigma_{2}}{R_{\perp}^{(+) A A}}\right)^{2}+\left(1-\frac{p_{\perp I I}^{(+)}}{R_{\perp I I}^{A}} R_{\perp I I}^{(+) A}\right)^{2}}+\frac{p_{\perp I I}^{(+)}}{R_{\perp I I}^{A}} \sigma_{2}=1 \\
& \sigma_{2} \geq 0
\end{aligned}
$$

where, 
$\sigma_{n}$ - normal stress acting on the potential fracture plane

$\sigma_{2}$ - normal stress in a unidirectional layer

$\tau_{21}$ - shear stress of a unidirectional layer in a elastic symmetry

$R_{\perp}^{(+) A}$ - Fracture resistance of the action place against its fracture due to transverse tensile stressing

$p_{\perp I I}^{(+)}$- Slope of the $\left(\sigma_{\mathrm{n} 1}, \tau_{\mathrm{n} 1}\right)$ fracture envelope for $\sigma_{\mathrm{n} 1} \geq 0$ at $\sigma_{\mathrm{n}}=0$

$R_{\perp I I}^{A}$ - fracture resistance of the stress action plane against its fracture due to transverse parallel shear stressing

$p$ - slope of the fracture envelope

$R$ - fracture resistance

$R_{\perp \perp}^{A}$ - fracture resistance of the stress action plane against its fracture due to transverse shear stressing

MODE B: It also denotes perpendicular transverse cracks, but they appear under in-plane shear stress with small transverse compression stress.

$$
\sqrt{\left(\frac{\tau_{21}}{R_{\perp I I}^{A}}\right)^{2}+\left(\frac{p}{R}\right)^{2} \sigma_{2}^{2}}+\frac{p}{R} \sigma_{2}=1
$$

MODE C: It indicates the onset of oblique cracks when the material is under significant transverse compression.

$$
\begin{aligned}
& \frac{1}{2\left[1+\left(\frac{p}{R}\right) R_{\perp \perp}^{A}\right]}\left[\left(\frac{\tau_{21}}{R_{\perp I I}^{A}}\right)^{2}+\left(\frac{\sigma_{2}}{R_{\perp \perp}^{A}}\right)^{2}\right] \frac{R_{\perp \perp}^{A}}{\left(-\sigma_{2}\right)}+\frac{\sigma_{1}}{\sigma_{1 D}}=1 \\
& \sigma_{2} \geq 0
\end{aligned}
$$

Figure 2.5 shows fracture curve for $\sigma_{1}=0$, representing three different fracture modes A, B, C. 


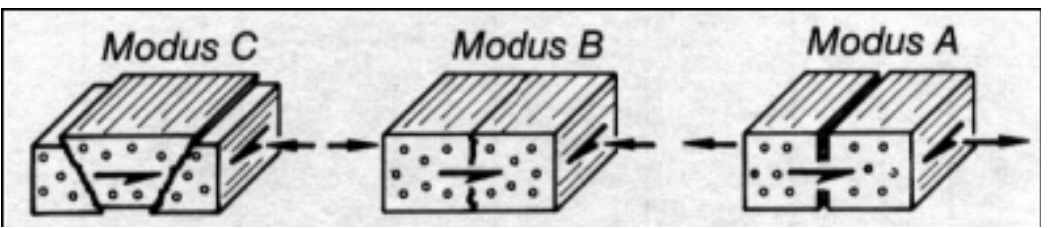

Figure 2.5 Inter- Fiber Fracture Modes A, B, and C (Puck et al, 1969)

\section{Limitations (Kaddour, et al. 2004)}

- Theory unable to predict large deformations

\section{Case Study of Cross-ply Laminates}

\section{Comparison with experiments}

Theoretical and experimental behavior of 0/90 E-glass/My750 epoxy laminate under uni-axial tensile loading is shown in Figure 2.6. Three stages of failure were observed. Initially, 90 plies fail in IFF (Mode A) as first ply failure, followed by failure of 0 plies in IFF Mode A and finally failure of total laminate.

In WWFE, Kaddour et al.(2004), found that using the criterion, theoretical failure envelopes for unidirectional as well as multidirectional laminates were also generally in good agreement with the predicted values. 


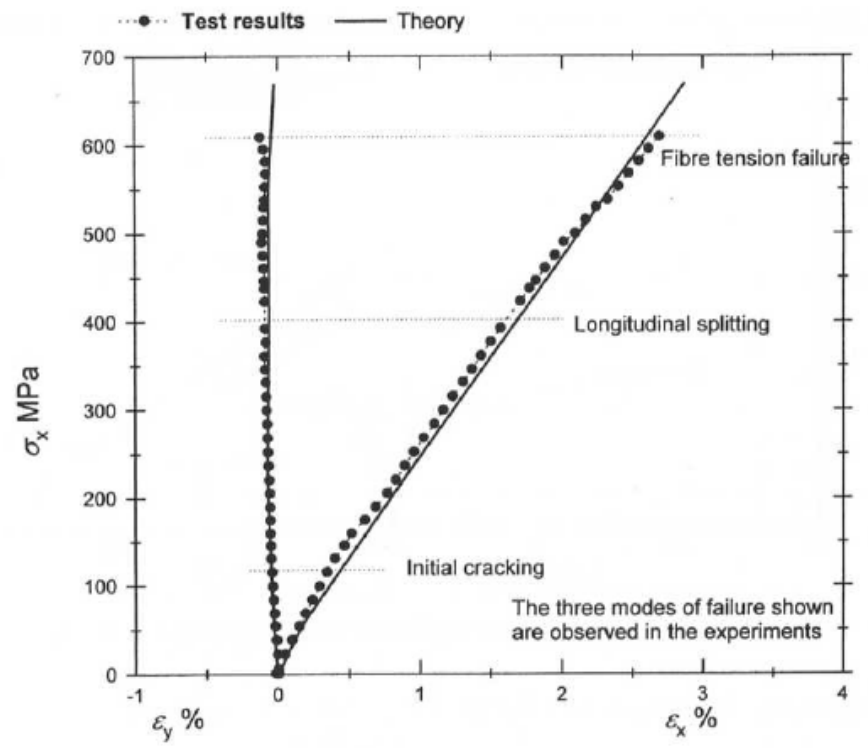

Figure 2.6 stress strain curves Cross ply laminate under uni-axial tension (Puck et al, 2004)

\subsection{PARAMETER AFFECTING STRENGTH AND STIFFNESS}

Apart from type of resin and fiber, there are many factors which affect the strength and stiffness of a composite, some of which are reviewed and discussed below.

\subsubsection{Compression Processing}

Selection of manufacturing methods by which a composite is fabricated is an important factor for design. The process has a critical influence on material properties, cost, reliability, etc. An important consideration in all processes is minimization of voids, which has a deleterious effect on properties. The optimum processing parameters of composite manufacturing for different manufacturing techniques were studied by several authors (Onal, et al. 2005). Herein, study is limited to only compression molding process.

Compression molding is one of the most widely used cost-saving processes in thermoset composite manufacturing. Onal et al (2005), studied the production parameters of compression molding such as curing time, curing temperature, clamp pressure etc., for E-glass/epoxy woven composites $(\mathrm{FVF}=39 \%)$. The samples ( 0.04 " thick) were fabricated with 9 layers of 1670 Tex E-glass yarns. EPON 828 epoxy resin and EPICURE 3140 hardener were used and in order to reduce void content, a BDK555 air 
release agent. ANOVA (Analysis Of Variance) is performed for investigating significance of each variable.

The manufacturing parameters of the compression molding technique selected and the tensile stresses and strains obtained were tabulated in the Table 2.1. It is seen from the table that the tensile stress value increased until 193MPa clamp pressure and then reduced. The strain value reduced at $77 \mathrm{MPa}$ clamp pressure and increased until $193 \mathrm{MPa}$, and there reduced after that, implying that the clamp pressure improves the material strength up to a certain extent. On the other hand, the author mentioned that lack of clamp pressure increases the strain with a relatively lower stress, which could be attributed to less matrix-reinforcement integration and impregnation. Therefore the material can be prone to lower stiffness. It was found that a clamp pressure of $193 \mathrm{MPa}$ gives superior mechanical strength.

Table 2.1 Tensile test results with different clamp pressures Onal et al (2005).

\begin{tabular}{|c|c|c|c|}
\hline Variables & Strain (\%) & $\begin{array}{c}\text { Stress } \\
\text { (Mpa) }\end{array}$ & $\begin{array}{c}\text { Young's modulus } \\
\text { (Mpa) }\end{array}$ \\
\hline Clamp Pressure ( Mpa) \\
\hline 0 & 3.248 & 175.06 & 6289.35 \\
\hline 77 & 3.147 & 194.763 & 7035.24 \\
\hline 116 & 3.273 & 199.648 & 7000.13 \\
\hline 154 & 3.376 & 236.909 & 1917.51 \\
\hline 193 & 3.608 & 258.576 & 8066.3 \\
\hline 232 & 3.541 & 251.369 & 7999.71 \\
\hline
\end{tabular}

\subsubsection{Cure}

As thermosetting matrix is used for fabrication of composite coupon specimens, the performance of the matrix is affected by the complete cure of the resin. Improperly cured matrix results in poor physical and mechanical properties.

Now-a-days, thick composites have been in demand in industry applications such as marine, aerospace, transportation, and infrastructure application. Thermosetting composites are highly exothermic, the double bonds in the resin break during reaction, releasing the stored heat energy, and accelerating the reaction, through excess heat 
generation. The excess heat easily escapes in case of thin laminates. Because of low thermal conductivity of composites, heat cannot escape from the center of thick composites in short time, thus creating temperature overshoot at the center. This may lead to uneven cure, shrinkage, and variations in resin viscosity resulting in non-uniform consolidation.

Some new processing techniques that address these problems are being developed. White and Kim (1996) developed the staged curing technique and continuous curing technique. Both the techniques avoid non-uniform consolidation and thermal spiking inside a composite but they may lead to long process time and more wastage of resin. Trial and error methods with simulation or expert systems which can control the exothermic temperature at the center of thick composites are being used. Model based optimization is also being used as a less expensive and less time-consuming means of investigating different cure cycles. Jiang et al (2006) suggested that pre-catalyzing fabric method applied for manufacturing of thick composites using hand lay-up process resulted in better degree of curing. In this study, E-glass woven roving fabric $\left(18 \mathrm{oz} / \mathrm{yd}^{2}\right)$ was the reinforcement and Dow Derakane 411-350 vinyl ester resin was used as matrix. It was found that the degree of cure can be improved to be more than $97 \%$ by leaving the samples for more than five weeks in ambient temperature.

\subsubsection{Fabric Density, Lay-up, FVF}

Eng et al (2006), studied the effect of different linear densities 50,150, and 200

$\mathrm{g} / \mathrm{m}^{2}\left(1.5 \mathrm{oz} / \mathrm{yd}^{2}, 2.9 \mathrm{oz} / \mathrm{yd}^{2}, 4.4 \mathrm{oz} / \mathrm{yd}^{2}\right)$ of woven E-glass fabrics reinforced in epoxy resin (EPON 862) on flexure properties. Variations of flexural strength and modulus observed with increase in the densities are shown in Figure 2.7 and Figure 2.8, respectively. It was observed that the strength and modulus increased with fiber content

The author stated that the weakest point is at the interface region where the failure initiation takes place due to stress concentration and lead to failure of the composite. And, thus concluded that the specimens with higher fiber volume content and minimum interlacing would result in higher flexure strength and modulus. 


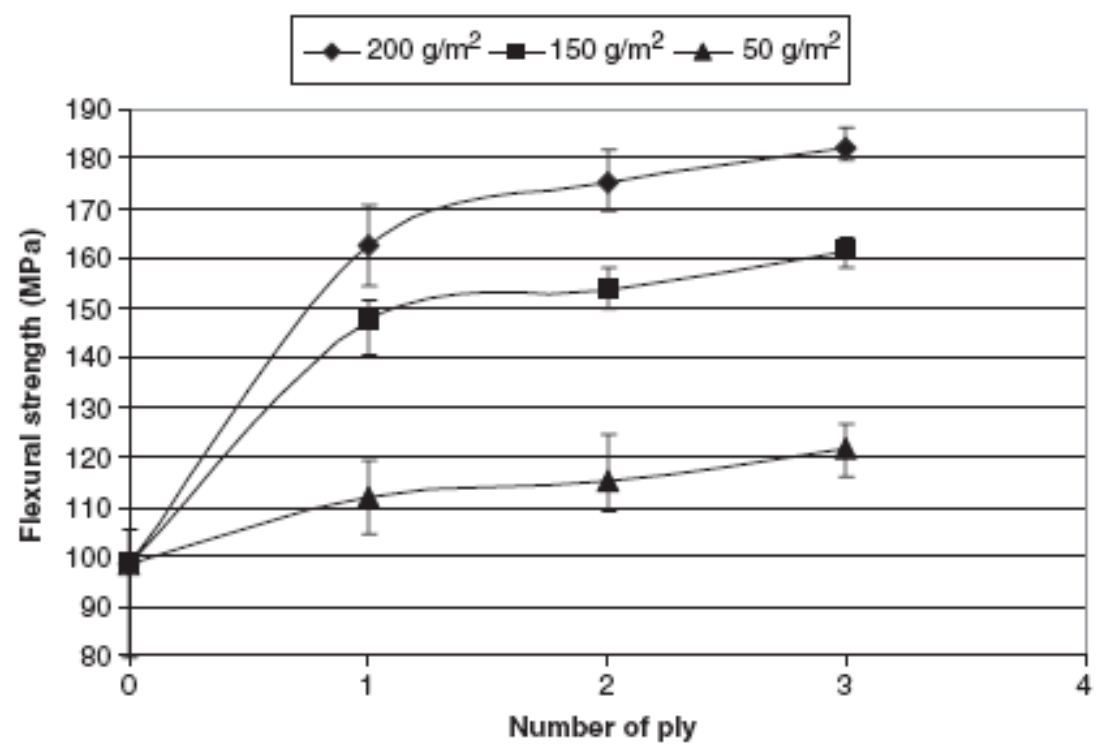

Figure 2.7 Flexural strength vs. number of ply of different woven linear density (Eng, et al. 2006)

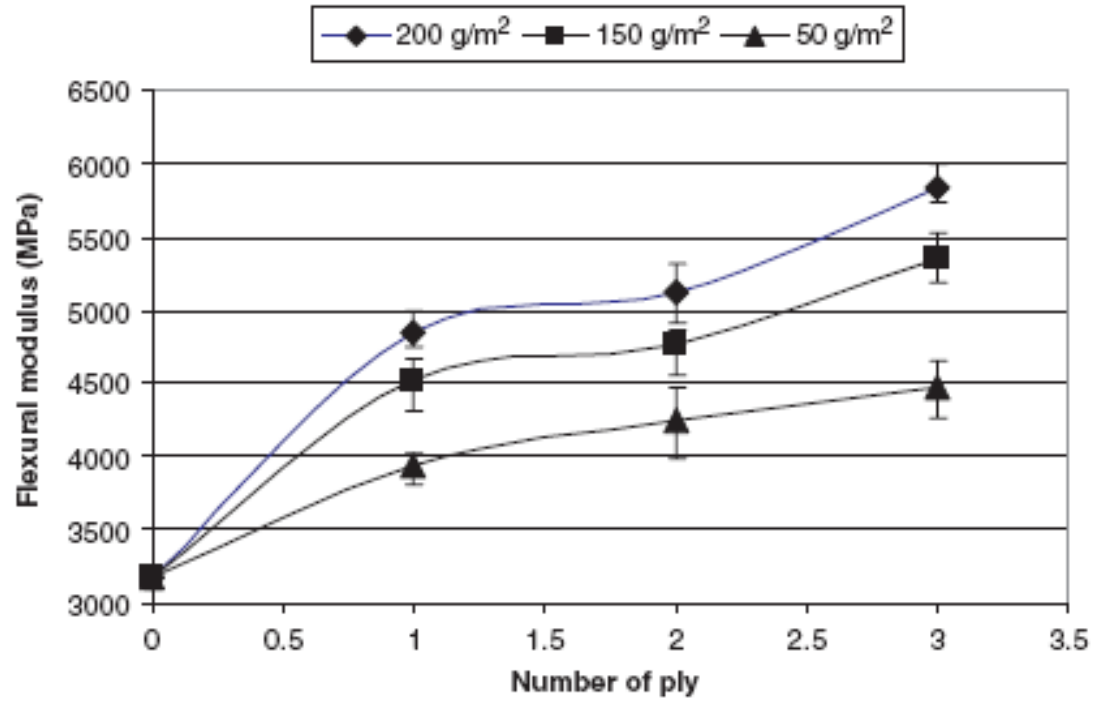

Figure 2.8 Effect of different woven linear density on the flexural modulus of different number of woven ply (Eng, et al. 2006)

\subsubsection{Void Content}

Eng et al (2006), observed that void content is high in composite specimens with higher density fabrics fabricated using hand-lay up process. Figure 2.9 The dependence of the flexural strength on void content of the woven linear density (Eng, et al. 
2006)shows the correlations between flexure strength and void content of different woven linear densities.

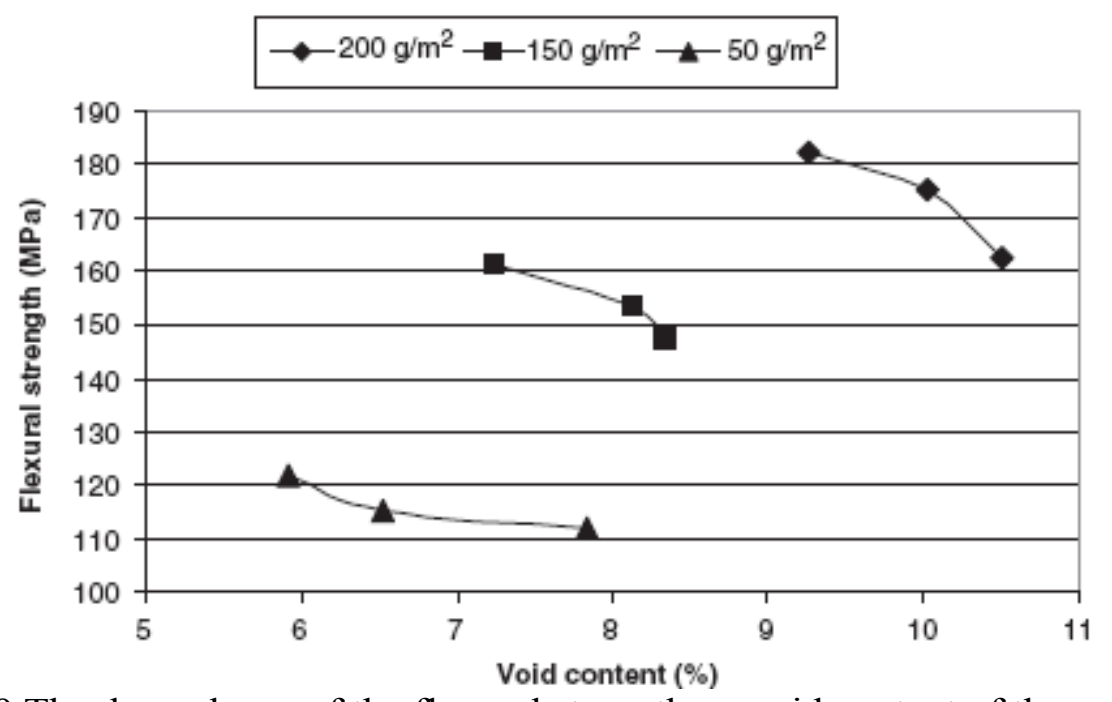

Figure 2.9 The dependence of the flexural strength on void content of the woven linear density (Eng, et al. 2006)

As seen from Figure 2.9, the authors (Eng, et al. 2006) concluded for each of the woven densities, as void content increased, the flexure strength decreased. However, on the whole, the flexure strength increased with increasing void content implying that the strength depends not only on voids, but also on type of matrix, fiber, ply orientation, and fiber volume fraction.

\subsubsection{Grip Failures}

Grip failures observed in the FRP composite tension test coupons are quite high. As it is unlikely that a universal test coupon shape could be developed which would work for all composite lay-ups, different geometries are suggested for different materials. The highest percentage of grip failures involved the unidirectional $0^{\circ}$ fabric materials (Mandell, et al. 1997).

Adams (2006), mentioned that either the specimen should be as thin as practically possible or the grip length should be longer so that clamping force is distributed over a 
larger area, but it becomes increasingly difficult to grip the specimen uniformly as length increases. Owing to all these factors, bonded tabs are widely used to minimize the stress concentration induced by the grips, though they are not considered as the best method. ASTM 3039 suggested square tabs and tabs with taper angle $>=5^{\circ}$ and in some cases tabs with taper angle $>90^{\circ}$. However, it was found by Adams (2006) that there was not much difference in testing of unidirectional specimens with square tabs and with taper angle $>=5^{\circ}$. But, Mandell, et al. (1997), mentioned that tapering the thickness of the coupon by at least $40 \%$ worked well for unidirectional materials instead of using bonded tabs onto coupons which may result in tab failures.

\subsection{SUMMARY}

Even though numerous failure criteria are present, and some are successfully validated over a wide range experimental data, each model has its own constraints regarding the particular type of data being used. Much focus is being placed to develop a generalized model by incorporating the limitations of each criterion.

The current study aims to provide a generalized model which can be used to predict the failure strength of GFRP specimens under tension and bending using strain energy as damage metric. Owing to all the concerns mentioned in the literature, a few of the many factors are considered starting from the lay-up, manufacturing process, density of the fabric, fiber volume fraction, up to the testing of the samples. 


\section{CHAPTER 3}

\section{MATERIALS AND MANUFACTURING OF TEST SPECIMENS}

This chapter deals with a brief description of constituent materials such as type of matrix, fiber, classification, and composition, emphasizing the constituent material properties and their individual contribution towards properties of composites. Also, an overview on the some of the manufacturing techniques available is discussed. Further, details of the types of fabrics and resins, and processing methods employed for fabrication of composite plate along with coupon preparation is provided.

\subsection{COMPOSITES}

Polymer composites are being developed because no homogeneous material is found to possess all the desired properties for a given application. They have unique mechanical and physical properties, which can be tailored to meet the requirements of a particular application, while providing better resistance to corrosion, oxidation and wear. Though the initial costs are high, the manufacturing processes are well adapted for large integration of parts, thus reducing manufacturing costs (Barbero, 1998).

Basically, composites consist of two or more distinct materials (reinforcing materials, resin binder (matrix), fillers, etc.) bonded together to form a new material. Fibers are reinforced with resins and lead to better axial and bending strengths. Matrix acts as a binding agent and protects the fibers, and transfers shear and the other loads among the fibers. Typically, matrix has lower strength, stiffness, and density compared to fibers, but the combination of the two results in high strength and stiffness. Additives are added in used to ease manufacturing process and impart special properties for a composite.

\subsubsection{Classification of Composites}

They are classified based on either matrix or fiber. Polymer matrix composites (PMCs), metal matrix composites (MMCs), ceramic matrix composites (CMCs), and carbon/carbon composites (CCCs) are the commonly available in market. Classification 
in relation to fibers is distinguished based on the size and shape of fibers, orientations and interlocking mechanisms of fibers and the constituents. They are either fibrous (continuous or whiskers) reinforced composites or particulate (flakes or filled/skeletal) reinforced composites. Currently, polymer matrix composites are most widely used class of composites.

\subsection{CLASSIFICATION OF POLYMER MATRICES}

Polymer matrices typically are of two types: thermoplastic and thermosetting polymers. Thermoplastic polymers have the ability to regain their original state upon addition of heat i.e., above the glass transition temperature. While, thermosetting polymers undergo chemical reactions during curing which crosslinking of the polymer molecules takes place. Once crosslinked, thermosets become permanently hard and simply undergo chemical decomposition under excessive heat.

\subsubsection{Use of Thermoset Composites}

Even though thermoplastic resin have many advantages such as longer shelf life, higher strain to failure, ability to be repaired, reshaped and reused, use of thermoplastics introduces problem of fiber penetration into the matrix, high matrix viscosity causing dealignment of reinforcing fibers, as well as void formation within the final composite product. Thermosetting polymers, on the other hand, have greater abrasion resistance and dimensional stability compared to thermoplastic polymers. Hence, for the past few decades, fiber reinforced composite materials are being fabricated using thermosetting matrices.

\subsubsection{Vinyl Ester Resin}

Thermosetting resins include epoxies, polyamides, phenolics, polyesters, vinyl ester etc. One of the most generally used thermosetting materials is vinyl ester. Many of its advantages are: 1) exhibiting best properties of epoxies and unsaturated polyesters, 2) handling/processing easily at room temperature with mechanical properties similar to epoxy resins, 3) offering better chemical resistance and greater control over cure rate and reaction conditions, 4) providing excellent thermal and mechanical performance. Vinyl 
esters are used most commonly for transportation, automobile, infrastructure, military, aerospace applications, etc.

In this study, Hetron 922 L25 vinyl ester resin (Ashland Company, OH) shown in Figure 3.1, is the thermosetting matrix material for fabrication of composite plates.

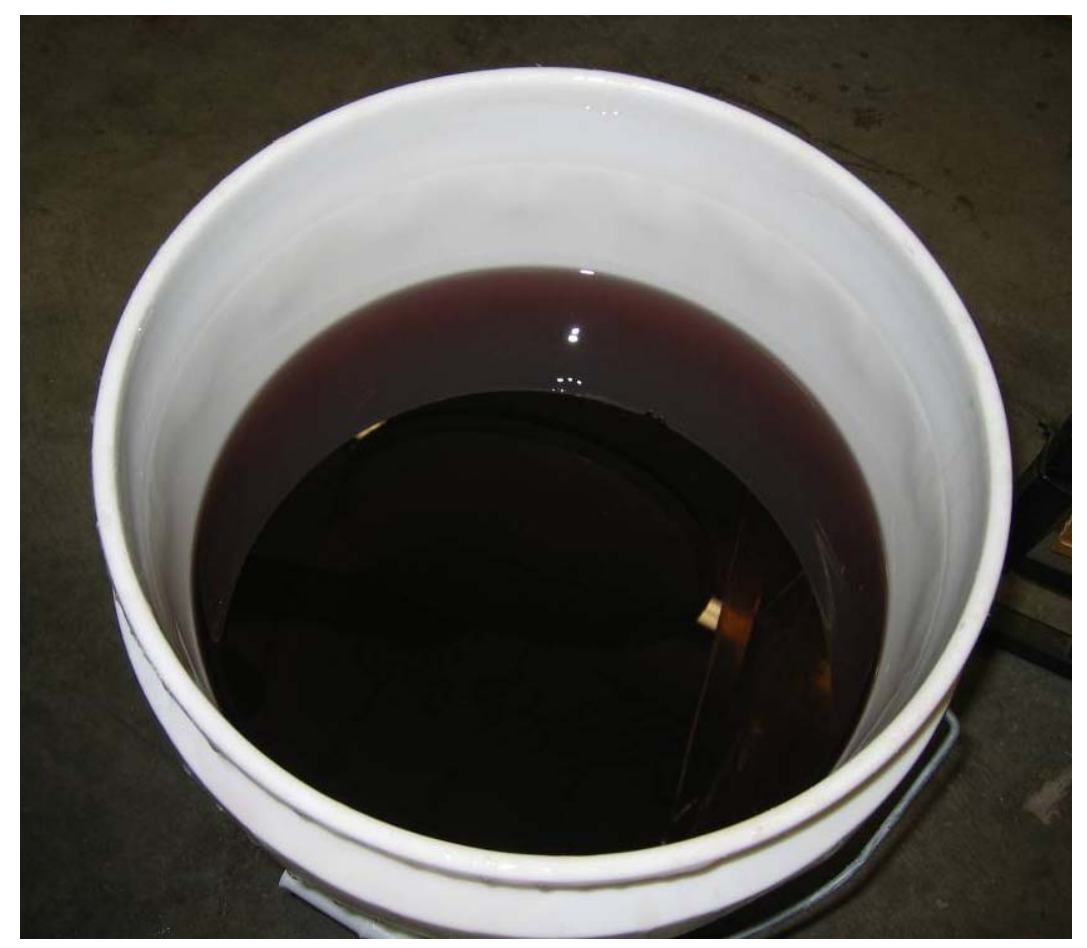

Figure 3.1: Hetron 922 L25 vinyl ester resin (Ashland Company, OH)

\subsubsection{Fibers:}

The most commonly used fibers are carbon, glass, and aramid. Glass fiber reinforcements are widely used for fiber reinforced composites because of: 1) low cost, 2) high strength-to-weight ratio, 3) good dimensional stability, 4) resistance to heat, 5) resistance to corrosion, 6) electrical insulation properties, and 7) ease of fabrication.

Glass fibers are produced by thoroughly mixing silica, borates and a few additional chemicals at $1600{ }^{\circ} \mathrm{C}$, and then drawing the monofilaments of glass from a furnace containing molten glass. These are later quenched and cooled by air or water. The hair-like filaments are coated with chemical mixture called sizing, which ensures good adhesion of the fibers with resin and also protects filaments from abrasion. After fiber 
dependent sizing is applied, filaments are wound in bundles to form a strand of glass fiber.

The composition of glass can be varied depending on the requirement of the end product. Some of the different glass compositions available are E-glass, S-glass, C-glass, A-glass, D-glass, L-glass, and M-glass. E-glass is mostly used due to its low-alkali composition and superior insulation properties.

\subsubsection{Reinforcement Forms:}

As the glass filaments are extremely fragile, they are supplied in a wide variety of reinforcement forms, such as strands, rovings, yarns, milled fiber, chopped strands, continuous or chopped mats, woven fabrics, braided fabrics, knitted fabrics etc. Materials used for reinforcements are designed to serve the fabrication process and end product requirements.

\subsubsection{Unidirectional}

Tapes, rovings, tow sheets, are considered as unidirectional fibers. Fibers are aligned parallel to each other in one direction or another direction, and have maximum performance along the aligned direction. Unidirectional fabrics are also available wherein the majority of fibers run in one direction (warp), while polyester or Kevlar thread or some other low grade material is made to run in the other direction (weft) in order to hold the warp fibers in position. Usually, the contribution of weft fibers is negligible. Typically, the density of unidirectional fabrics is very low; hence requires more lay-ups

for most of the applications. The unidirectional fibers used for this study were of $7 \mathrm{oz} / \mathrm{yd}^{2}$ (See Figure 3.2: Unidirectional Fabrics of 7 oz/yd2 (Owens Corning Inc)(Owens Corning Inc.), and $12 \mathrm{oz} / \mathrm{yd}^{2}$ (unknown) density. 


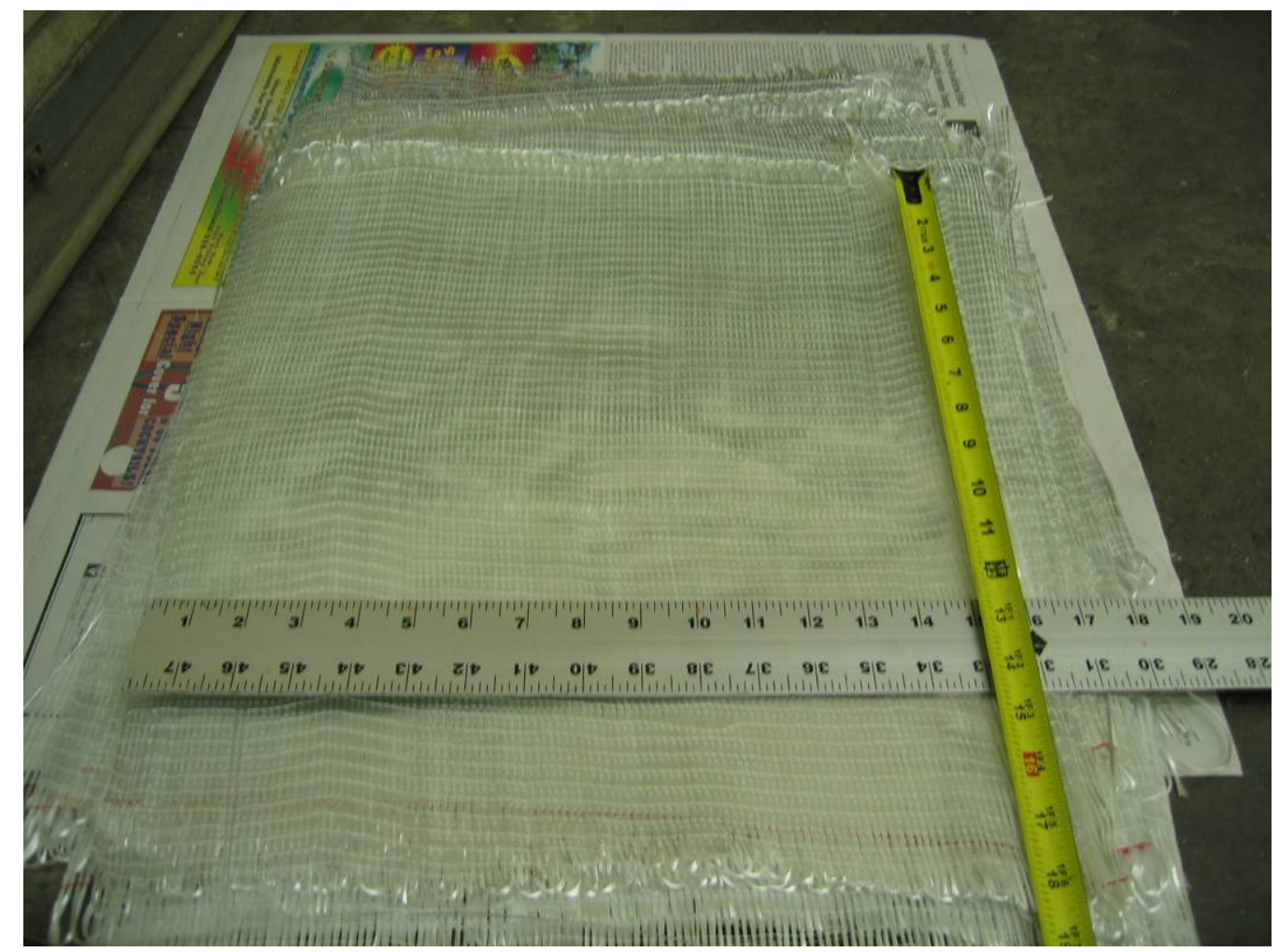

Figure 3.2: Unidirectional Fabrics of $7 \mathrm{oz} / \mathrm{yd} 2$ (Owens Corning Inc)

\subsubsection{Multidirectional Fabrics}

Multidirectional fabric based laminate composites are replacing unidirectional laminates primarily due to better performance in different directions. In multidirectional type of plies, fibers can take different forms of architecture such as woven, stitched (knitted), or braided.

\section{Stitched Fabrics}

Stitched fabrics are one of the mostly used fabrics in structural applications, as they are non-crimped, and also provide better orientation with the increase in the lay-up. They are produced by assembling the layers of aligned fibers. The fiber orientations available are 0,90 , and \pm 45 direction. The whole lay-up is then sewn together, allowing high modulus in tension and bending. 


\section{Continuous Strand Mats (CSM)}

Continuous strand mats are made from fiber glass strands randomly looped fibers, are held together with a binder. It has good wet-out (in case of thermosets), tailored to different shapes, and has good physical properties. Though CSM is used for variety of applications, it is used in combination with woven rovings, woven fabric, stitched fabric etc, to gain adequate stability and for better desirable properties. They assist in obtaining desired properties mainly in transverse direction of the end-product.

Owing to all the above, in this study, multidirectional E-glass fabrics were used. For comparison purposes, unidirectional, cross ply, tri-directional with CSM, and quadridirectional with and without CSM were the stitched fabrics utilized.

\subsection{DESCRIPTION OF MATERIALS}

Fabrics used for this study were unidirectional, cross ply (0/90), tri-directional (45/90/45/CSM), and quadri-directional (0/90/+45/-45) and (0/90/45/-45/CSM). The resin used was Hetron 922-25L vinyl ester resin (Ashland Company, OH). Different fiber architecture, thickness, and number of layers of the coupon specimens are tabulated in Tables 3.1 and 3.2 for tension and bending, respectively.

Table 3.1 Fiber Architecture of the materials used in the study for tension test Error! Not a valid link.

Table 3.2 Fiber architecture of the materials used in the study for bending test Error! Not a valid link.

\subsection{MANUFACTURING PROCESS}

There are wide varieties of manufacturing processes practiced starting from hand lay up technique to automated mass production systems like filament windings, etc. The manufacturing processes are classified as open mold process, and closed mold process. 
Open Mold Process: Includes spray-up or hand lay-up processes. These are the simplest and oldest processes. Each ply is either sprayed with resin or brushed on the top and bottom of the fabric, thus wetting out the laminate. In order to remove excess resin, a squeeze is used after laying up the fabric.

Closed Mold Process: Includes resin transfer molding, pultrusion, vacuum bag molding, compression molding, injection molding, autoclave molding, filament winding etc. These processes take place in a closed chamber. The liquid resin or prepreg form may be handled manually or pumped into the container for the curing step.

\subsubsection{Compression Molding Process}

This is the oldest and most commonly used process in automobile industry. Typically, a compression mold is a vertically orientated hydraulic press consisting of two platens and the force. The mold in the shape of the part to be molded is to be placed in between the two platens, where it is compressed (under pressure) depending on the part geometry. The mold is closed under pressure, compressing the material for several hours until it is cured (in this study). The curing is done either at elevated temperature or room temperature. At elevated temperatures, the heat of the mold softens the resin under pressure and forms the shape of the mold.

For this study, hand lay-up in conjunction with compression molding process was used for the fabrication of composite plate. This process produces a composite plate with uniform thickness, good fiber wet-out and negligible porosity. Schematic diagram of compression molding process used for the fabrication of composite plate is shown in Figure 3.3. 


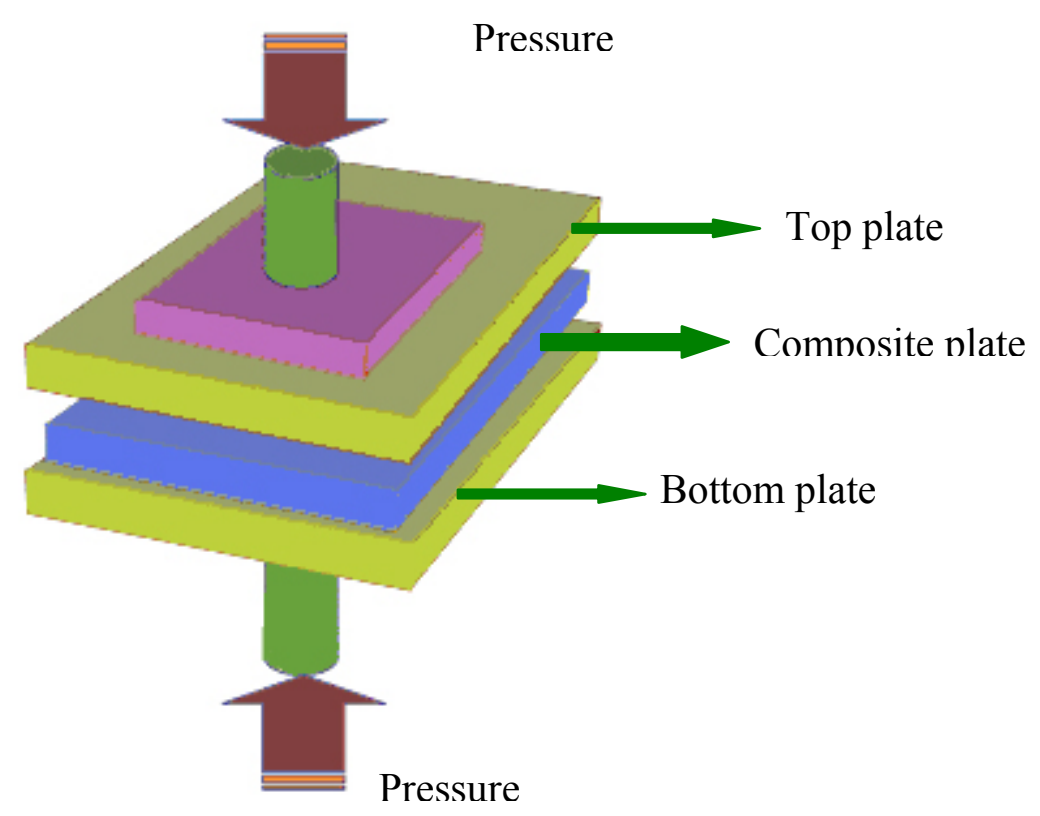

Figure 3.3 Schematic Diagram of Compression Molding Process

\subsection{FABRICATION OF COMPOSITE PLATE}

Various GFRP composite plates with different fiber architectures (unidirectional, bi-directional, tri-directional with CSM, and quadri-directional with and without CSM), and different thicknesses $(0.15 \%, 0.25$ ", and 0.35 ") were prepared. E-glass and Vinyl ester were used as reinforcement and matrix, and the resulting composite plate is manufactured using prepreg compression molding process. The plates were cut in longitudinal as well as transverse directions and were tested in both tension and bending.

\subsubsection{Procedure for Preparation of Composite Plate}

A clean flat surface was necessary when manufacturing a plate, as it forms the top and bottom texture of the plate. Therefore, two aluminum plates with slightly greater dimensions than the required plate were used. For easy removal of the plate, wax sheet was placed on the flat surface and de-molding agent (Loctite) was sprayed on the wax sheet. The fabrics were cut approximately 17"X12" (length X width) and 12"X12" for tension and bending tests, respectively. Proper care was taken when handling the fabrics, so as to avoid damage and distortion of fibers. Clean and non-sticky brush and serrated rollers were used in order to coat resin on the fabric. Hetron 922H-25 vinyl ester resin 
(Ashland Company, $\mathrm{OH}$ ) was poured into a beaker and mixed with initiator in appropriate proportions as per material safety and data sheet, where the quantity depends on the size of the plate prepared. The initiator used was methyl ethyl ketone peroxide (MEKP) and the catalyst was cobalt octate, which was already added to Hetron 922 L25 vinyl ester resin. The rate of polymerization can be increased by increasing the MEKP concentration. Typically, $1.25 \%$ to $1.75 \%$ (1 $2 / 3$ ounce to $21 / 3$ ounces per gallon) is the mix ratio.

Initially resin was applied on the wax sheet. A layer of fabric was placed on top of the wax sheet and resin was applied using brush. The serrated roller was used to ensure proper wet out and compaction, and removal of any entrapped air in the fabric. Then a second layer was flipped upside-down and was placed on top of the first layer, and the above procedure was repeated. As the composite plate manufactured was symmetric, even number of layers were used. For multidirectional laminates, even numbered layers were placed upside-down to make the laminate symmetric. After last layer was laid and appropriate amount of resin was poured, it was covered with a wax sheet and, de-molding agent was sprayed, and a flat aluminum plate was placed on the top to ensure a good flat surface. The whole set up was placed in a container and was compressed in 50-ton capacity compression molding press (PHI) by applying 10 to 15 ton load for 3 to 4 hours, until it was cured at room temperature. Container was primarily used, to collect the excess resin that oozes out under compression. About 25 composite plates with different fiber architectures and thickness were prepared using the above compression molding process.

Procedure for the manufacturing of composite plate was carried in a fume hood with exhaust system. Gloves, respiratory mask and glasses were used for safety purposes. Different stages involved in the fabrication of composite plate are shown in Figure 3.4. 


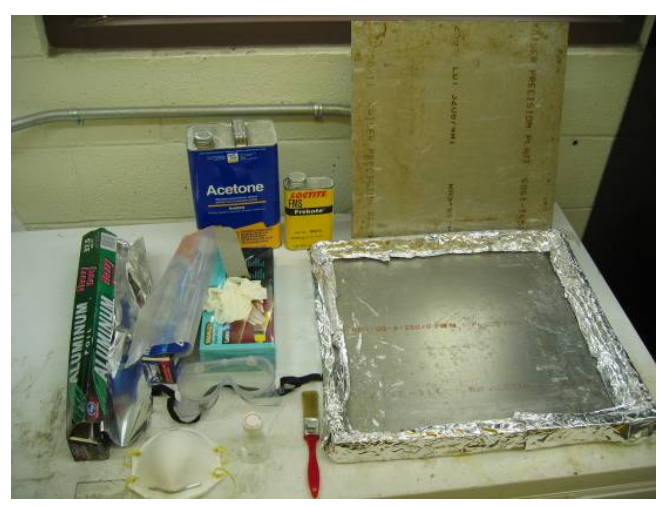

(a) Accessories

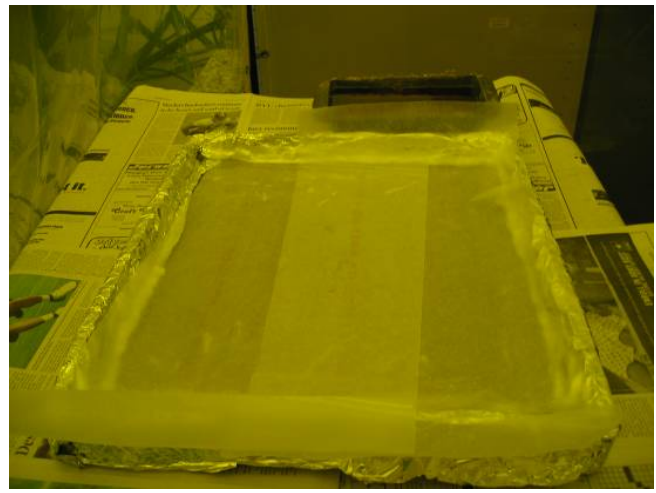

(c) Wax paper placed on the Aluminum plate for ease removal of the Plate manufactured

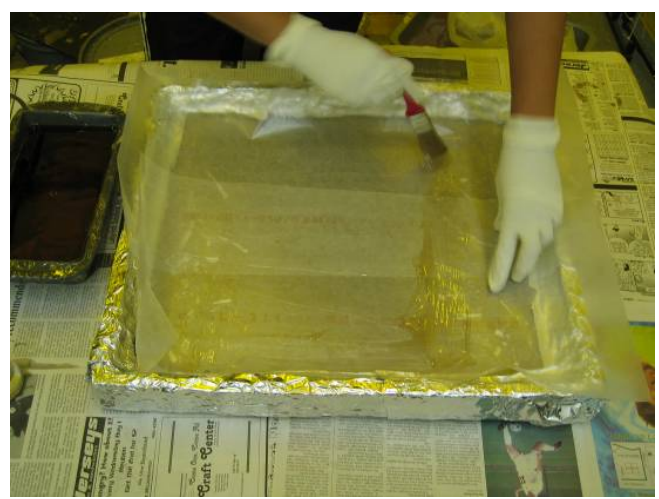

(e) Applying first coat of resin on wax paper

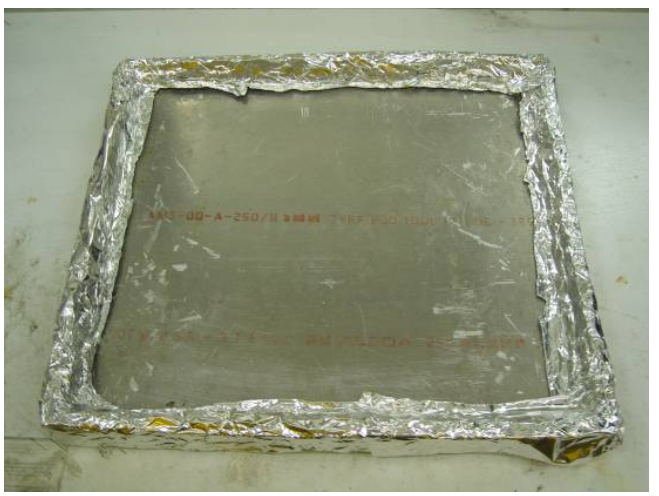

(b) Aluminum plate placed at the bottom for surface texture.

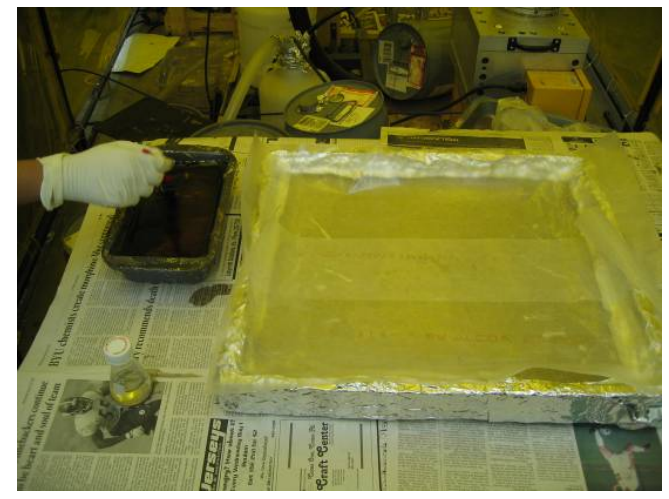

(d) Resin being mixed with MEKP

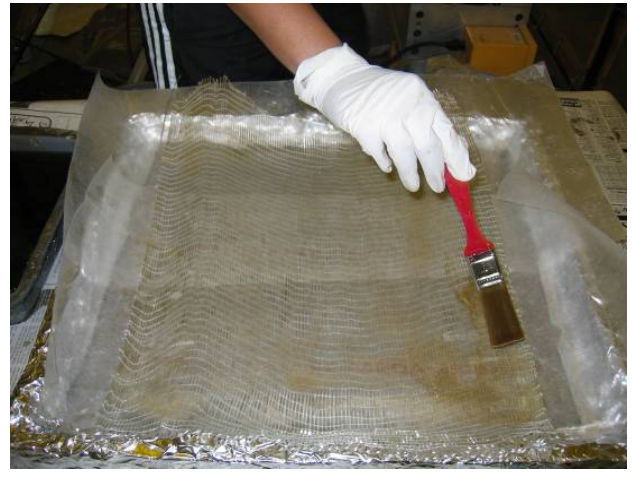

(f) After placing the first layer, resin is applied on the top using a brush for proper fiber wet out 


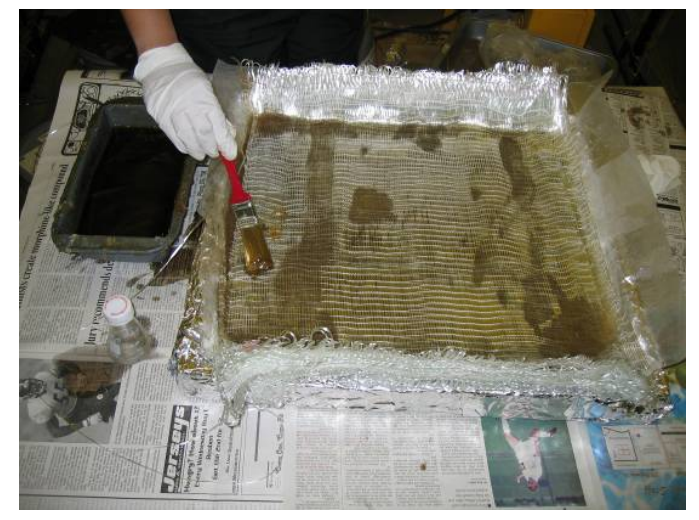

(g) The same procedure being continued (coat of resin on the fabric using brush)

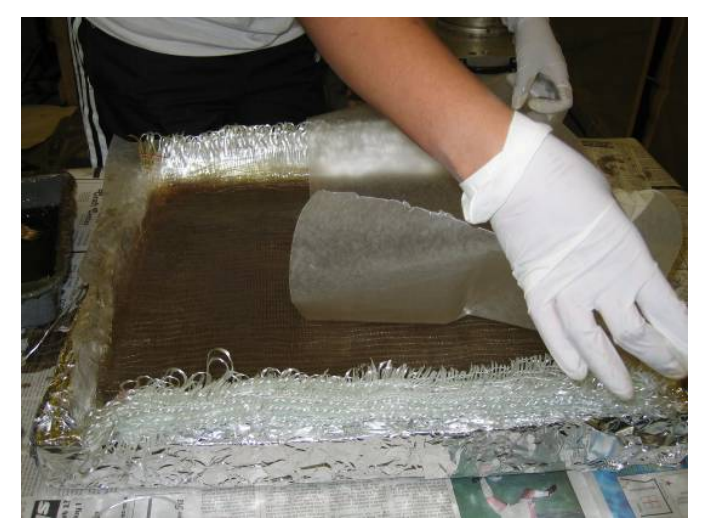

(i) Placing the wax paper on the top of last layer

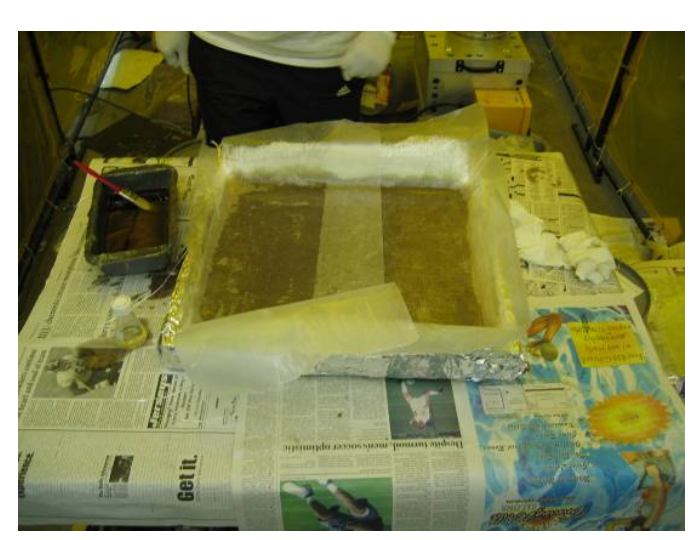

(j) After placing the wax paper

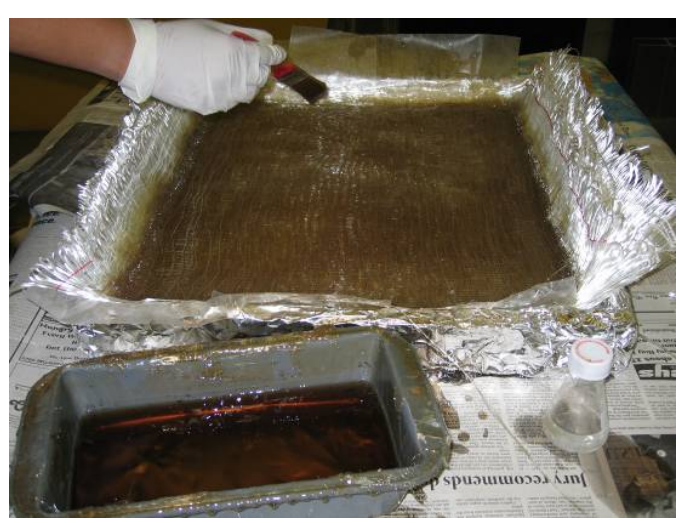

(h) Coating the last layer

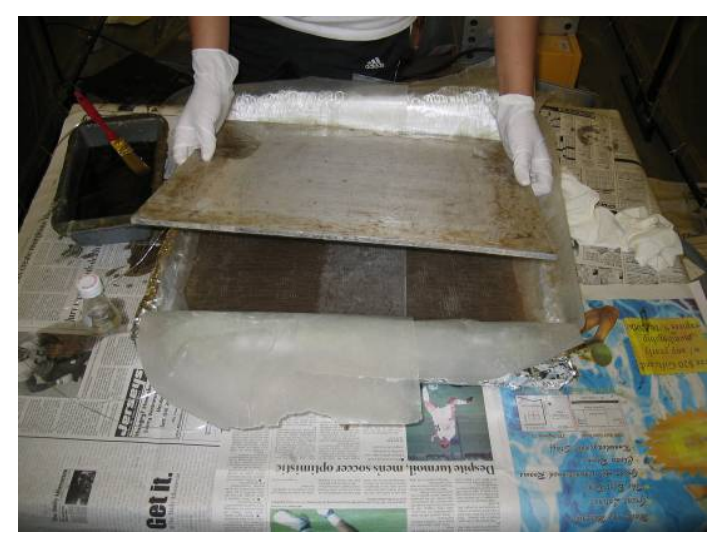

(k) Aluminum plate placed on the top of the lay-up for uniform surface texture

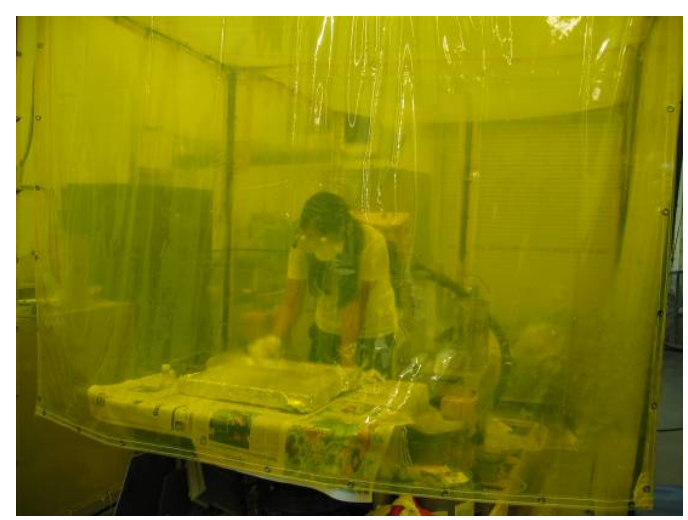

(1) Whole process carried out inside a fume hood 


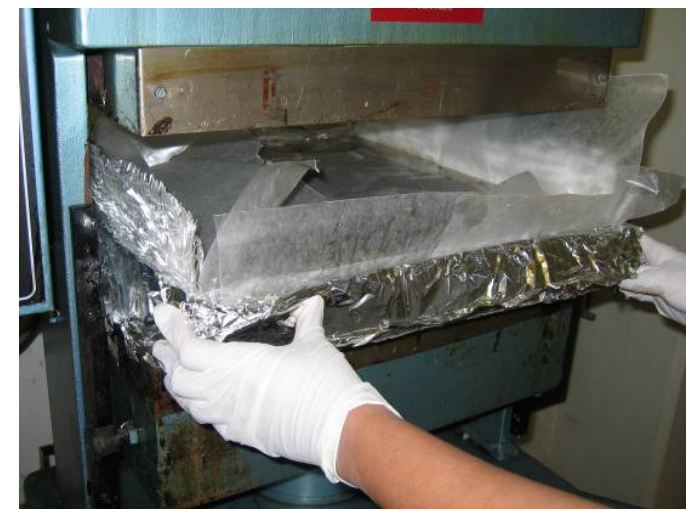

(m) Placing the mold in the compression press

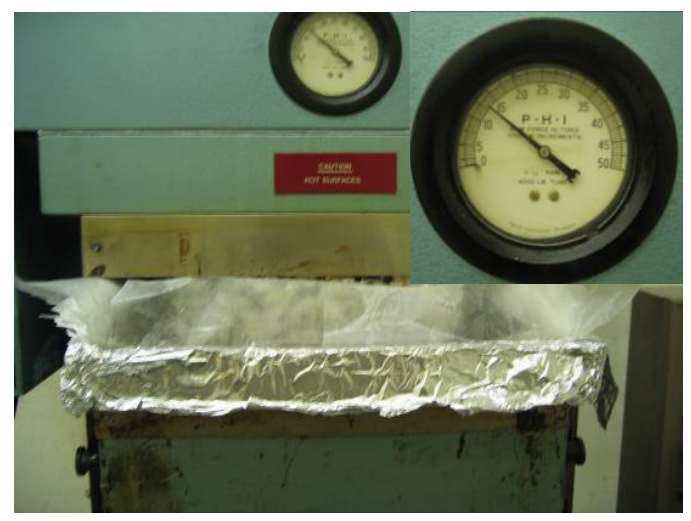

(o) After applying load (10 - 15 tons)

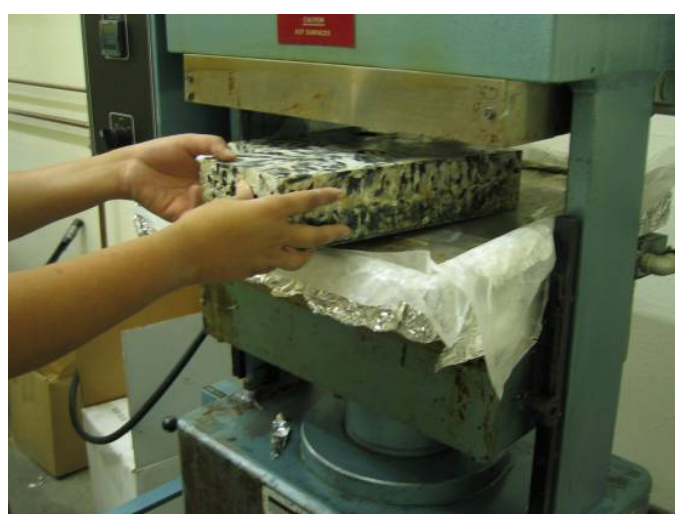

(n) Placing spacers

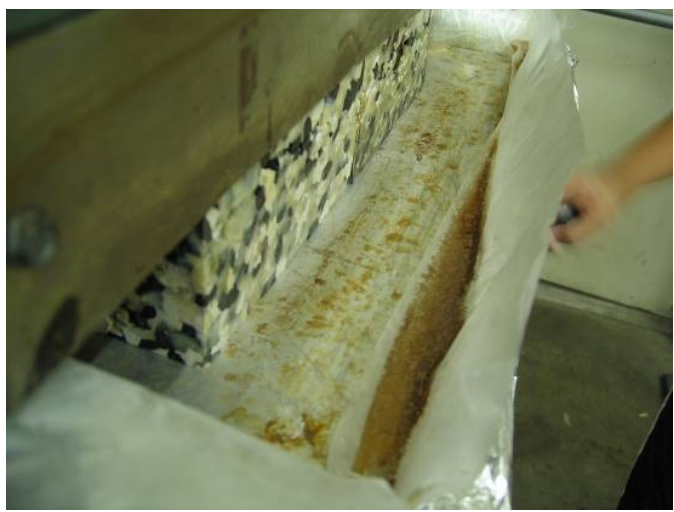

(p) Extra resin oozing out due to compression

Figure 3.4 Stages involved in the manufacturing of composite plate

\subsection{COUPON SPECIMEN PREPARATION}

The final product (composite plate) obtained by using compression molding process has uneven edges due to resin oozing out during compression. Hence, the edges were trimmed off. The plates were cut into coupon specimens depending on the dimensions required for tension and bending. Coupon specimens prepared from the plates were rectangular in shape and cut in longitudinal and transverse direction as per ASTM standard specifications using diamond tipped table-saw and carbide tipped band saw. Tables 3.1 and 3.2 presents an overview of the fiber architecture and dimensions of each specimen used and the type of testing performed in the laboratory. Manufacturing and testing was carried out in the laboratory at CFC, WVU. 
For tension test, the specimens were cut from 17"X12" plate into 16"X1" coupon specimens for both $0.25 "$ and $0.35 "$ thick plates. But, while testing for tension in transverse direction 11"X1" specimens were cut from 12"X12" plate. However, for bending test, 10 "X1" specimens were cut for 0.5 " thick plate, and 8 "X1" specimens were cut for 0.25 " thick plate for both longitudinal and transverse directions. All the specimens tested in transverse direction were approximately quarter inch thick.

For tension test, fiberglass tabs were used on either ends of specimen on the gripping area to reduce the stress concentration generated by wedge grips. The tab dimensions used for tri-directional and quadri-directional specimens were 4"x1", and for cross- ply coupon specimens, dimensions were 5"X1". The thickness of the tabs was maintained at $0.25 \%$. But for coupon specimens cut in transverse directions, the tab length was 3"X1" or $21 / 2$ "X1" depending on the length of the test specimen with a tab thickness of .125". Initially, tab area of coupon specimens as well as surface of a tab to be bonded was slightly ground using grinding machine for proper adhesion. Two different adhesives superglue and Pliogrip (Ashland Company, $\mathrm{OH}$ ) were used to bond the tabs to coupon specimens. A very thin layer of adhesive was applied on the coupon specimens as well as the tab material and were bonded using C-clamps. Curing time (proper adhesion between the tab and coupon specimen) was 24 hours. After curing, clamps were removed and specimens with irregular surface near the tab area due to adhesive oozing were smoothened and were checked for uniformity in thickness at various locations near the tab using Vernier calipers.

Coupons were labeled in accordance with the type of testing, fiber architecture and specimen number. The required dimensions such as width and thickness were measured at various locations using digital Vernier calipers and average value was considered. The tab preparation and bonding of the tabs to the specimens are shown in Figure 3.6. 


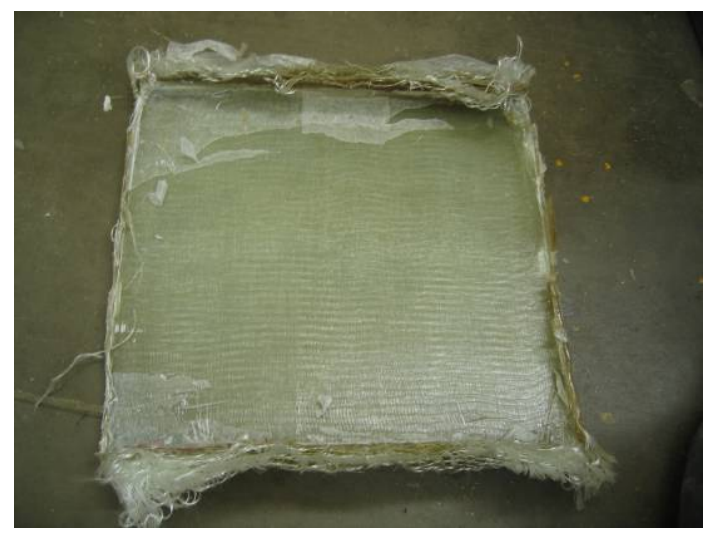

(a) GFRP plate after de-molding

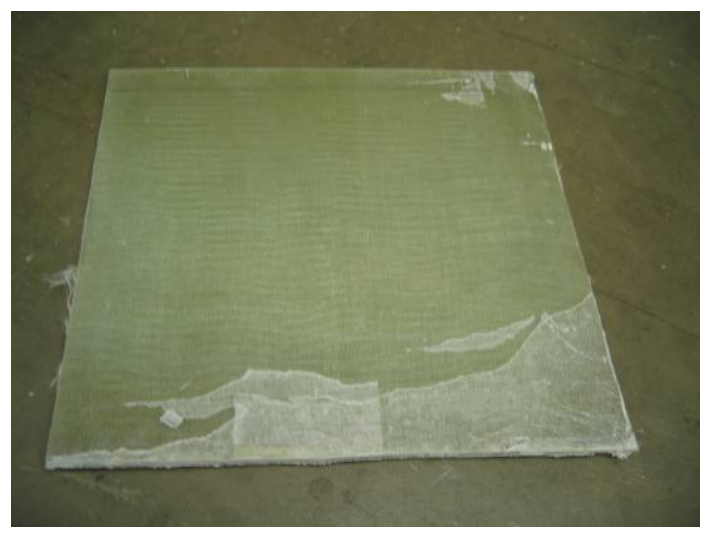

(c) After trimming of the edges

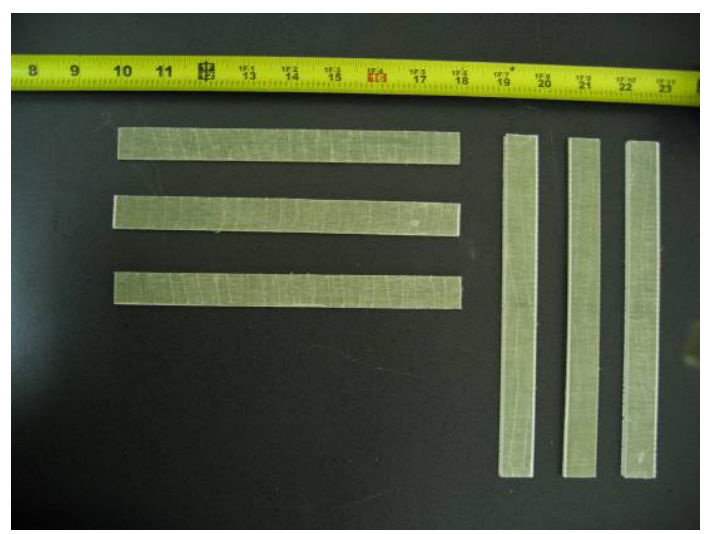

(e) Coupons cut in longitudinal and transverse directions for bending test

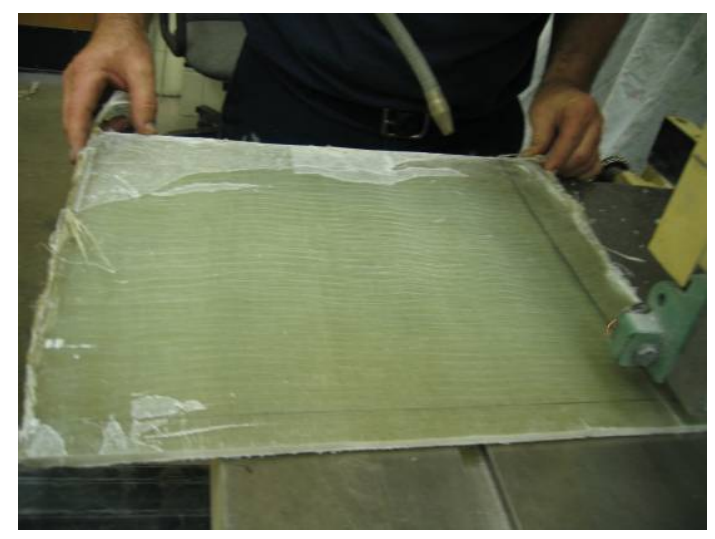

(b) Trimming uneven edges

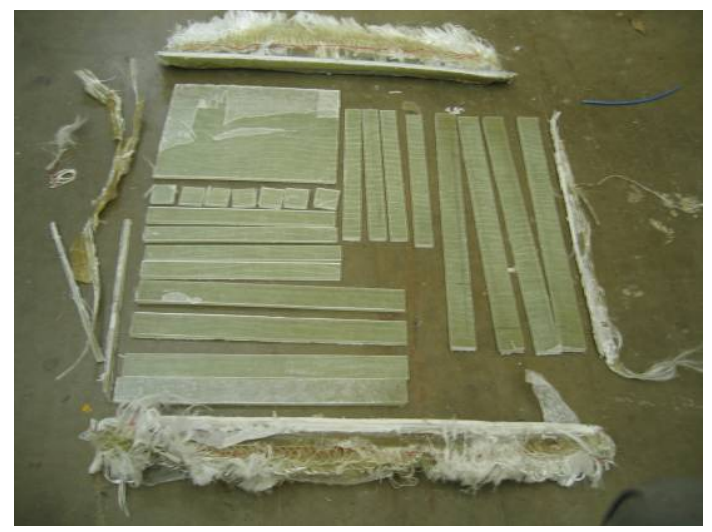

(d) Coupon specimens cut from the plate

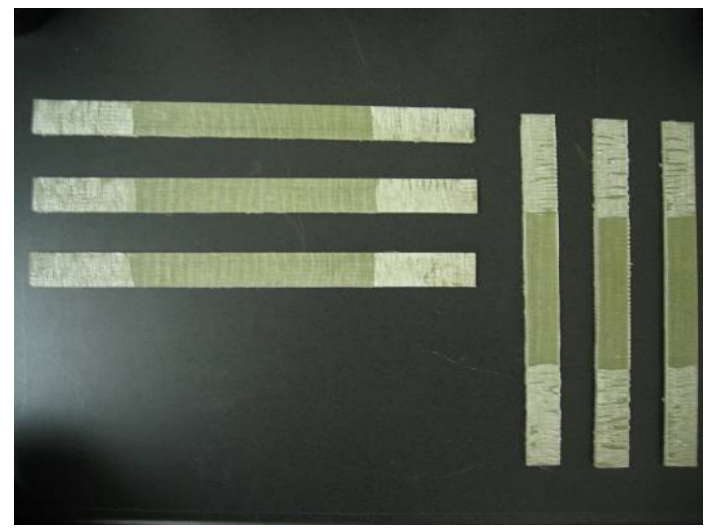

(f) coupons cut in longitudinal and transverse directions for tension test (after grinding tab areas)

Figure 3.5 Steps involved in the preparation of coupon specimen 


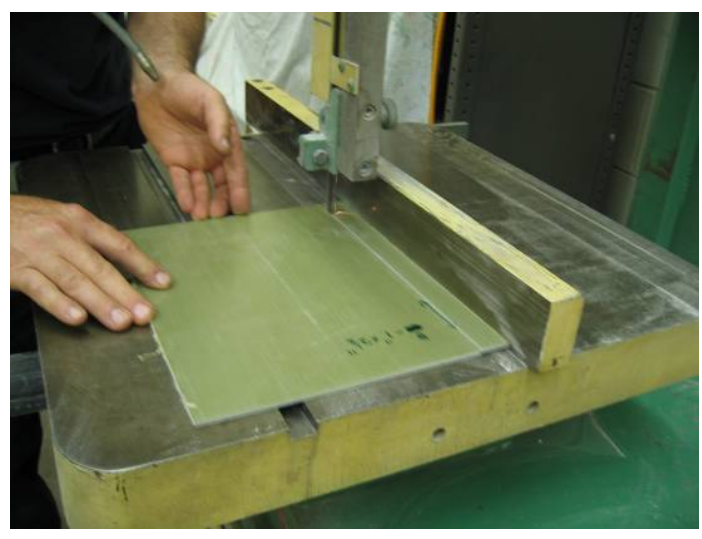

(a) Cutting the tab material using a band saw

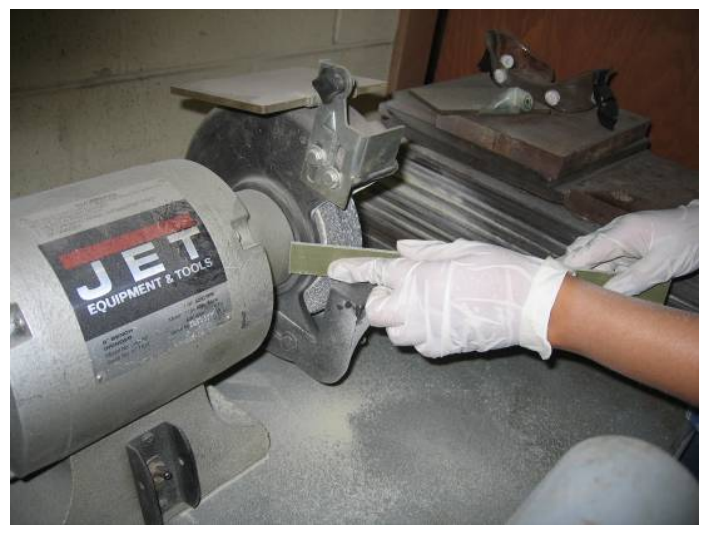

(c) Grinding the tab area of the specimen

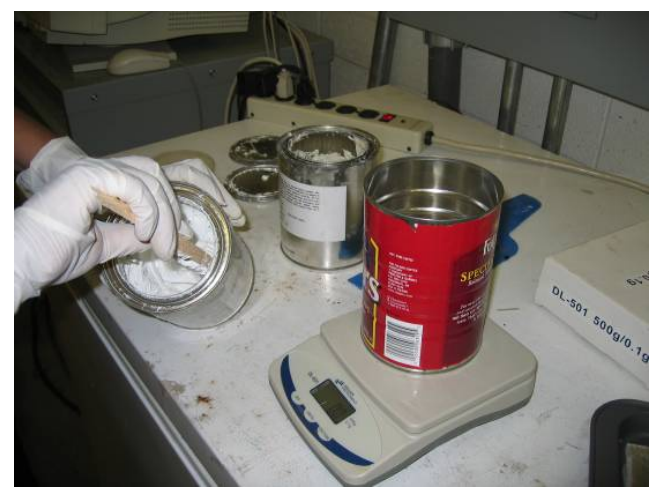

(e) Adhesive preparation (weighing and mixing two parts) for bonding tabs

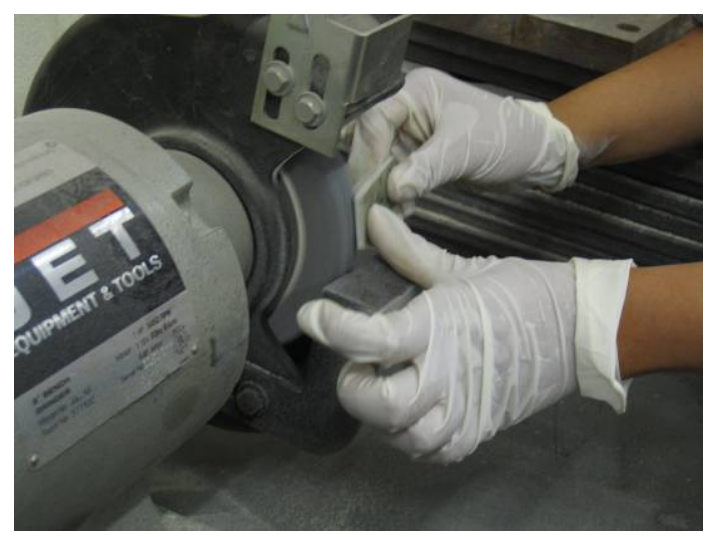

(b) Grinding tab surface

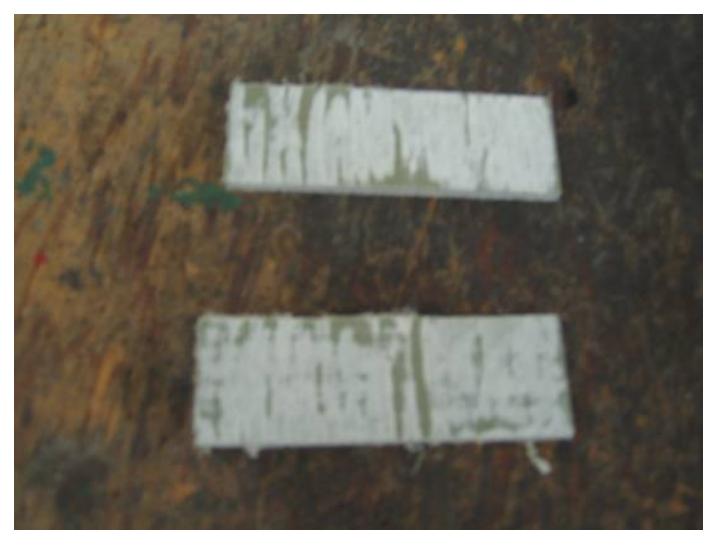

(d) Ground tabs

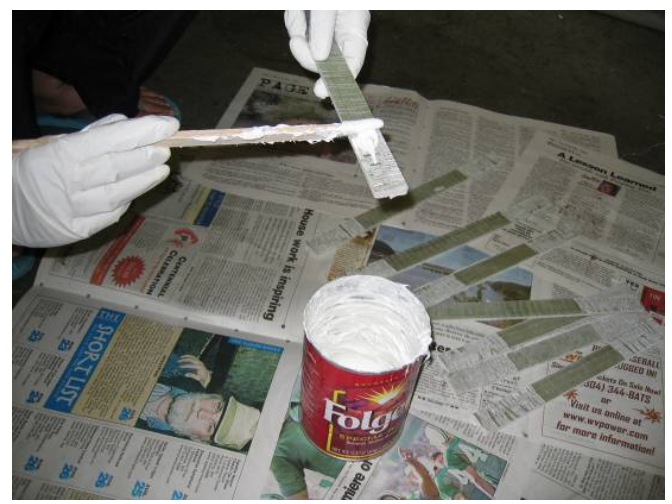

(f) Applying adhesive on the tension coupons 


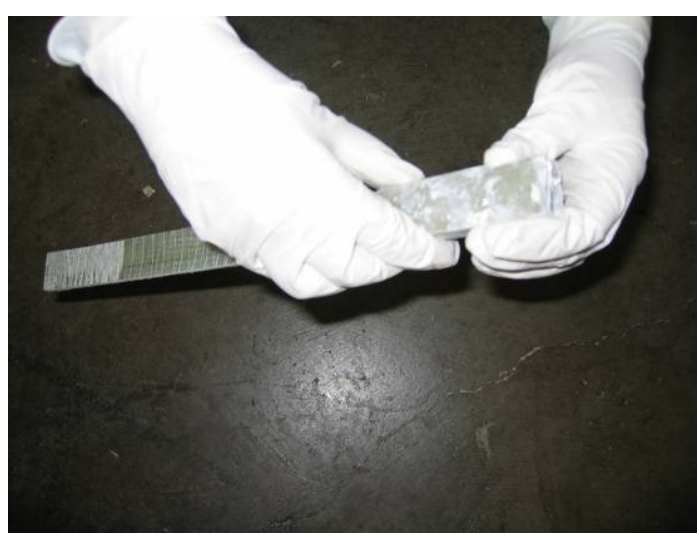

(g) Bonding tabs on a tension coupon

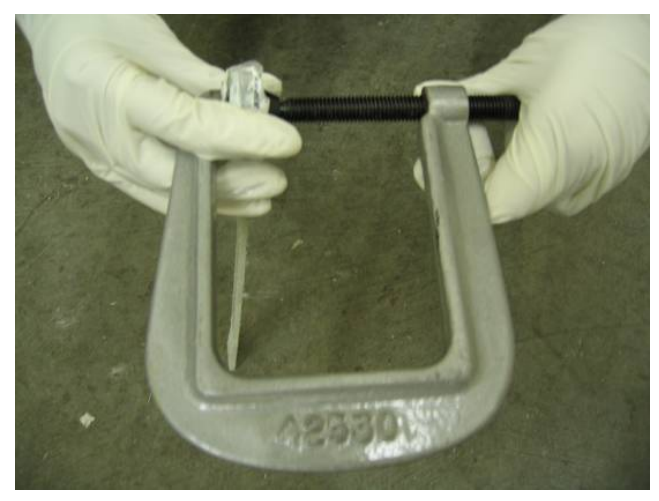

(i) C-clamps used for bonding after applying adhesive

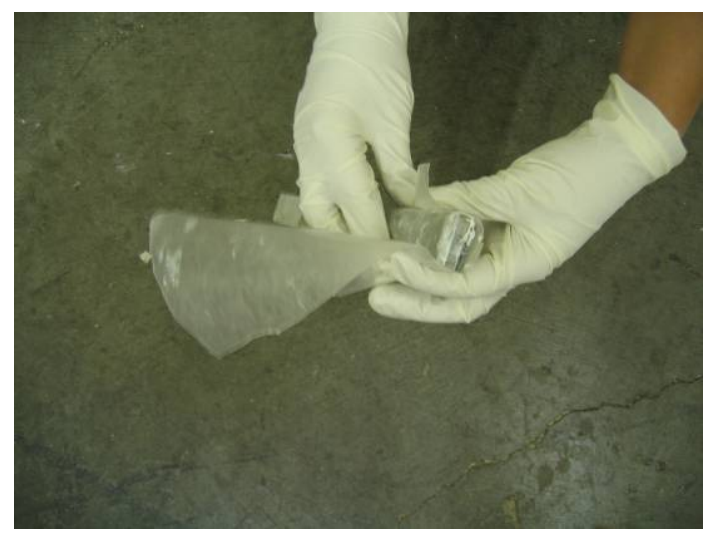

(h) Placing wax paper around the tab area for ease removal of clamps

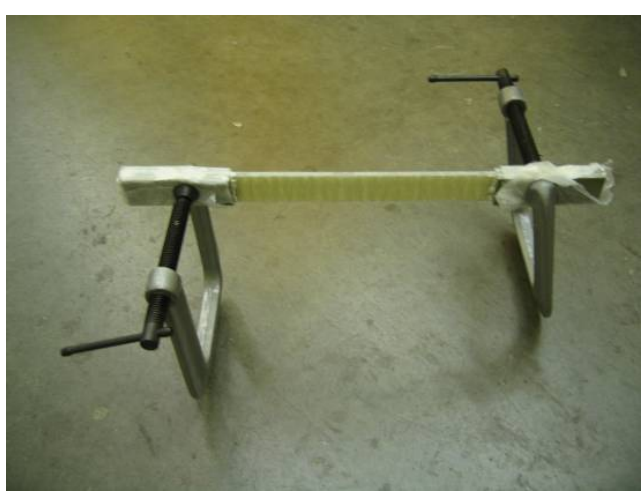

(j) C-clamps used on both the sides

Figure 3.6 Steps involved in the preparation and bonding of tabs to the coupon specimens 


\section{CHAPTER 4}

\section{EXPERIMENTATION}

This chapter reviews the type of experiments conducted at CFC laboratory, WVU to determine the behavior of glass fiber-vinyl ester composites at coupon level. A brief description of the equipment utilized in the laboratory is also mentioned. Detailed procedures of each type of testing along with the required equations, and calculations involved presented. Method to determine the fiber content of the fabricated samples for this study is also discussed in terms of "burn test". Further, principles of functioning of optical microscope and surface examination microscope of coupons through are described to provide an understanding of the breadth of experimental work carried out in this research effort.

\subsection{FIBER VOLUME FRACTION}

As strength of composite typically is in direct proportion with fiber content, a quantitative measure of fiber content is essential. As per ASTM D3171 standard test method for fiber content in a composite using matrix "burn-off testing" was selected.

\subsubsection{Burnout Test}

Three 1"x1" samples of known volume were used. The samples were cut from the same plates that were used to prepare the tensile and bending test coupons. Initially, the dimensions (length, width and thickness) of each sample were measured using digital Vernier calipers (0.001" accuracy) and then weighed using a digital weighing balance ( 0.05 gms). The weighed samples were placed in a crucible and weighed again. The samples were then kept in a muffle furnace and were ignited $\left(575^{\circ} \mathrm{C}\right)$, wherein, the resin vaporizes leaving the glass fibers unaffected. Vaporization of the resin takes about 3-4 hours. Then the left out glass fabric was cooled and weighed along with the crucible for

fiber volume content. Average fiber volume fraction of the three samples was considered. The various stages involved in the resin burn-off test are shown in Figure 4.1. 


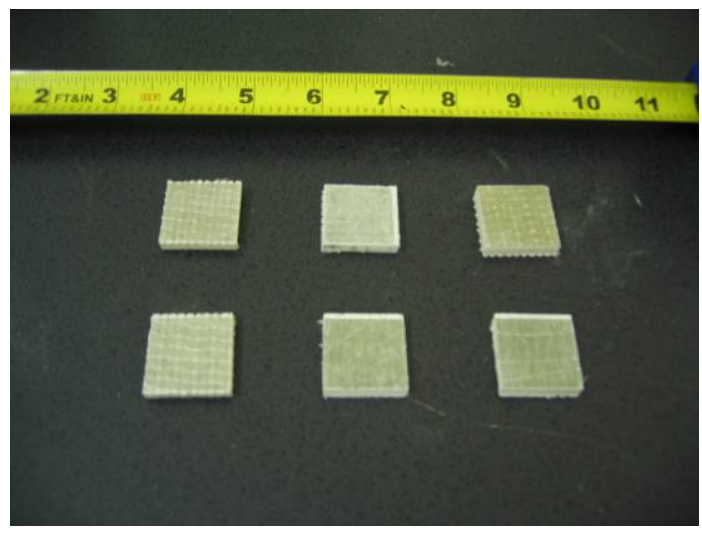

(a) Coupon specimens used for burn out test

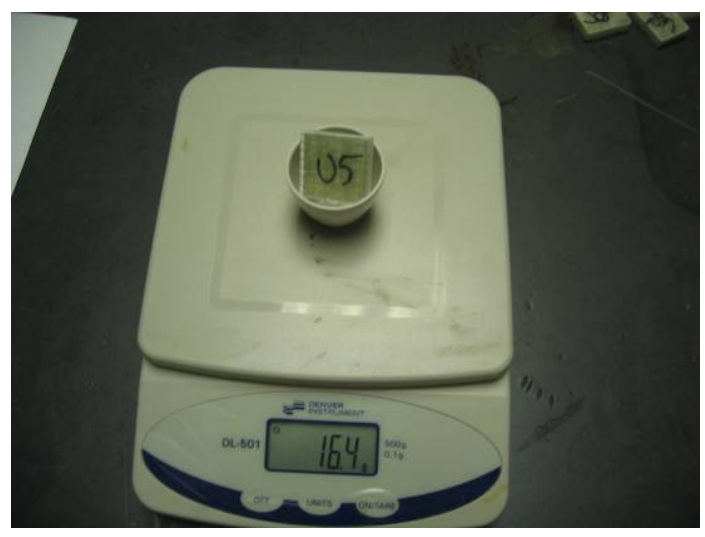

(c) Weighing the specimen along with the crucible

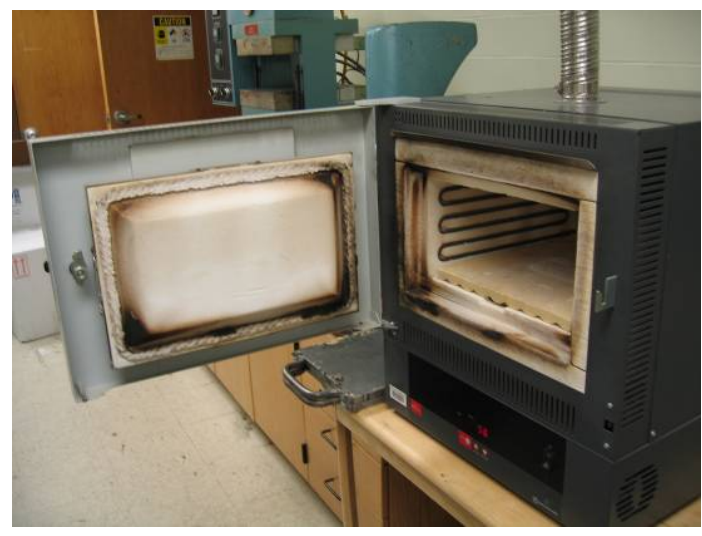

(e) Muffle furnace used for burn out test

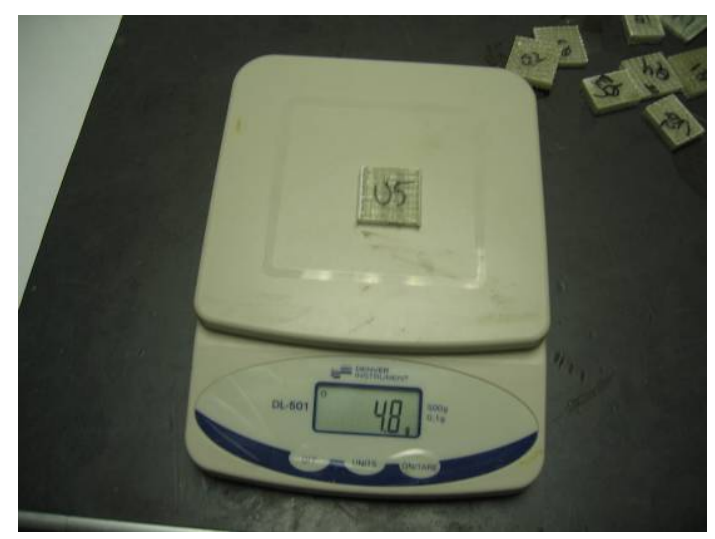

(b) Weighing the specimen

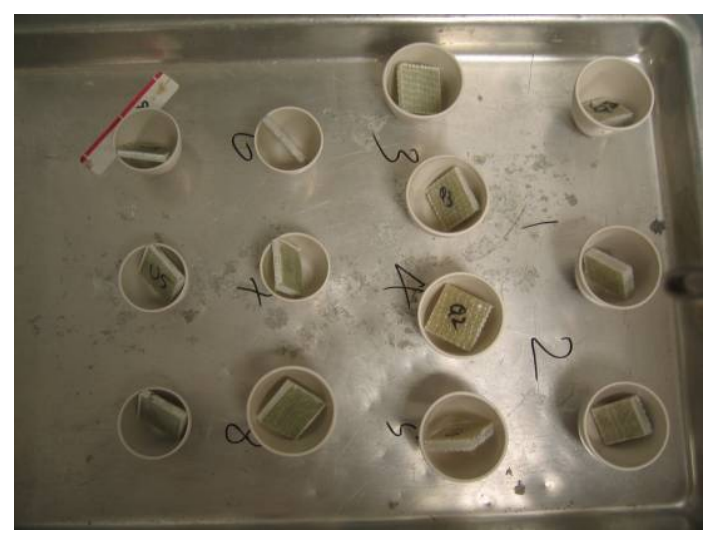

(d) Specimens placed in crucibles

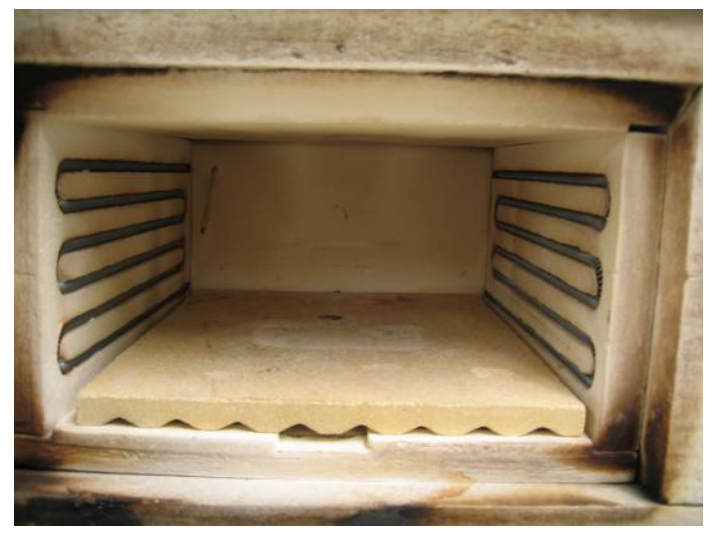

(f) Inside the muffle furnace 


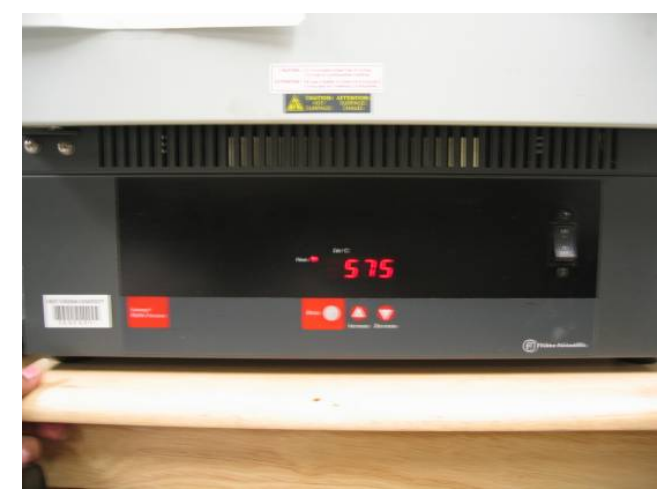

(g) Preheated temperature set at $575^{\circ} \mathrm{C}$

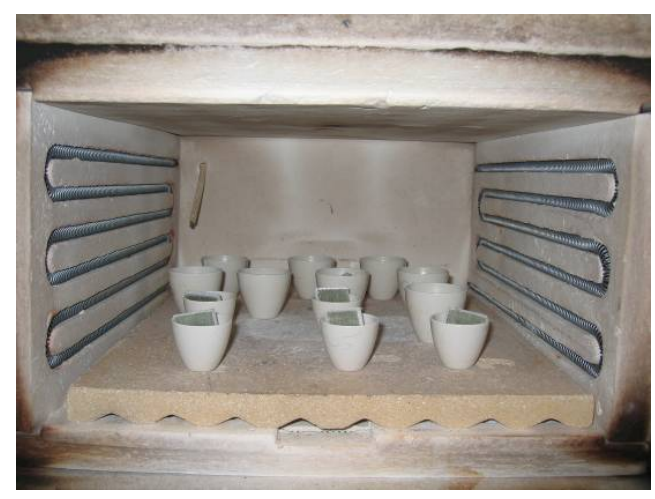

(i) After placing the specimens with crucibles inside the furnace

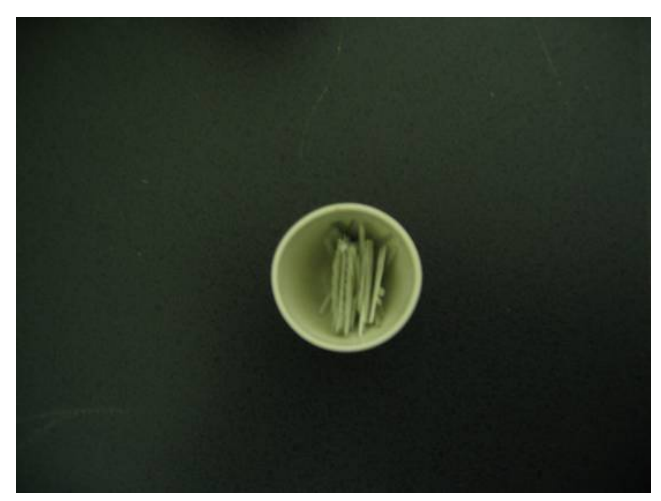

(k) Crucible with fibers alone after resin burn off

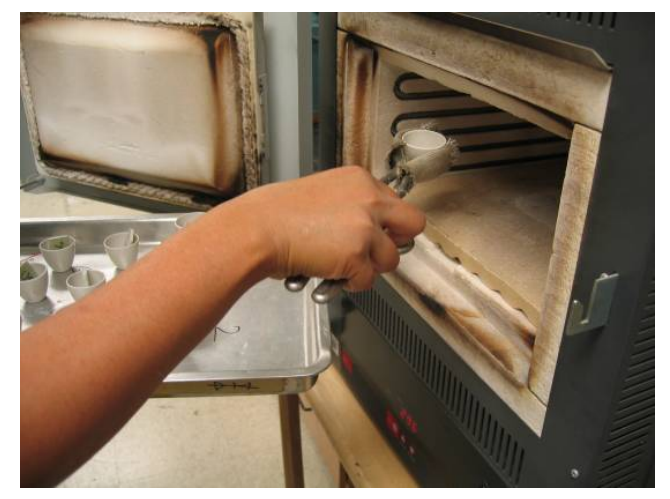

(h) Placing specimens along with the crucible in the furnace

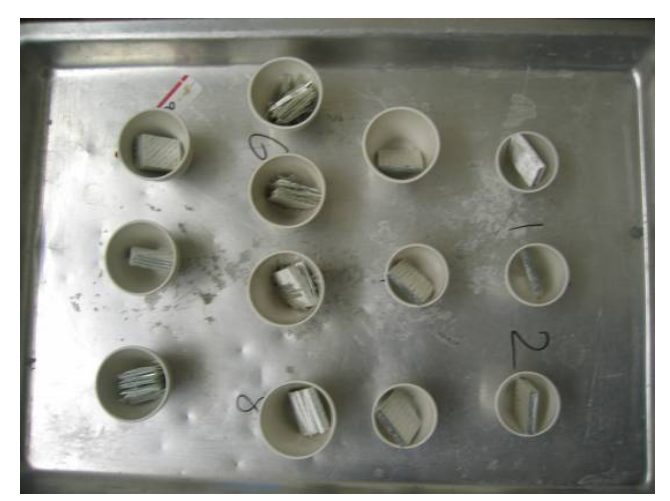

(j) Specimens along with crucible after resin burn-off

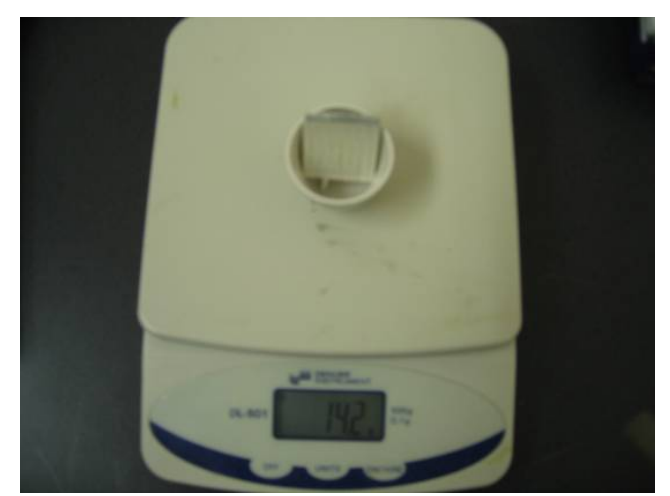

(1) Weighing the crucible and fibers after resin burn off

Figure 4.1 Stages involved in the resin burn-off test 


\section{Fiber Volume Fraction Calculations:}

Length of Specimen - L in cm

Width of Specimen - W in cm

Thickness of Specimen - $\mathrm{T}$ in $\mathrm{cm}$

Density of glass fiber $-\rho$ in gm/cc $(2.552 \mathrm{gm} / \mathrm{cc})($ Barbero, 1998)

Weight of sample $-\mathrm{W}_{\mathrm{s}}$ in gm

Weight of sample + Weight of the crucible $-\mathrm{W}_{\mathrm{s}+\mathrm{c}}$ in gm

Weight of fabric + Weight of crucible $-\mathrm{W}_{\mathrm{f}+\mathrm{c}}$ in gm

$F V F=\frac{W_{f+c}-\left(W_{s+c}-W_{s}\right)}{\rho L W T} \times 100$

where, FVF represents the percentage of fiber volume content present in the composite sample.

\section{Sample Calculations:}

Specimen -Quadri-directional without CSM (Q1)

$\mathrm{L}=2.65 \mathrm{~cm}$

$\mathrm{W}=2.53 \mathrm{~cm}$

$\mathrm{T}=0.57 \mathrm{~cm}$

$\rho=2.552 \mathrm{~g} / \mathrm{cc}$

$\mathrm{W}_{\mathrm{s}}=6.3 \mathrm{gm}$

$\mathrm{W}_{\mathrm{s}+\mathrm{c}}=26.7 \mathrm{gm}$

$\mathrm{W}_{\mathrm{f}+\mathrm{c}}=20.4 \mathrm{gm}$ 
$F V F=\frac{W_{f+c}-\left(W_{s+c}-W_{s}\right)}{\rho L W T} \times 100=44.52$

\subsection{TESTING EQUIPMENT}

Mechanical testing equipment used for this study: a) Baldwin Universal Testing Machine for conducting tension tests, b) Instron 8501 machine for conducting bending and tension tests, and c) data acquisition system for recording strain, and load data.

Baldwin universal testing machine (Figure 4.2) having a 200,000 lbs maximum load capacity is usually used to test for tension, compression, and bending or flexure strength. The load applied is measured by means of dial indicator which is connected to pressure capsule. The load rate can be adjusted during the test procedure. Different jigs and grips are available for tensile, compression, and bending tests. Shims are used for adjusting to specimen thickness. However, same shim sizes on each side should be placed in order for the grips to remain in the center. Herein, Baldwin machine was used only for tension test. Strain gages were mounted on test specimens under tension in longitudinal direction. Data acquisition system was used to record load and strain data.

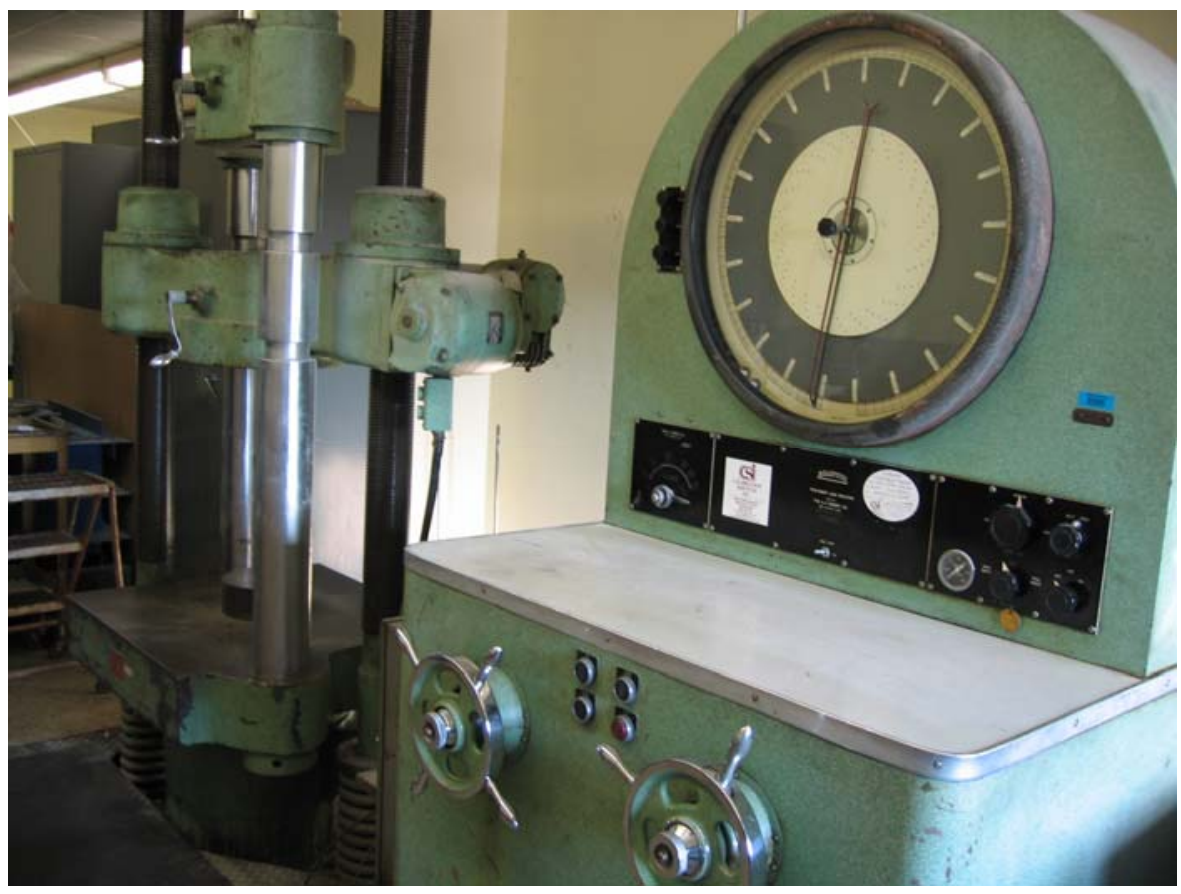

Figure 4.2 Baldwin universal testing machine 
Instron model 8501 servo-hydraulic material testing system (Figure 4.3) has $1000-\mathrm{kN}$ (22 kip) maximum load capacity and is used to conduct broad range of testing such as compression, tension, bending, shear, and fatigue. The force applied to the specimen is sensed by in-built strain gage type load cell placed on the stationary top cross-head, wherein the analog signals from the load cell are amplified and converted into a digital signal. The machine is operated by the control panel of the computer, where the readings are displayed and are transmitted to the data acquisition computer for data collection using WaveMaker® software. The displacement is determined from grip position. However, elongation or strain of a specimen under tension can be monitored by extensometer or strain gage. Bending tests and some tension tests for coupons cut in transverse direction were carried out using Instron 8501 testing machine.

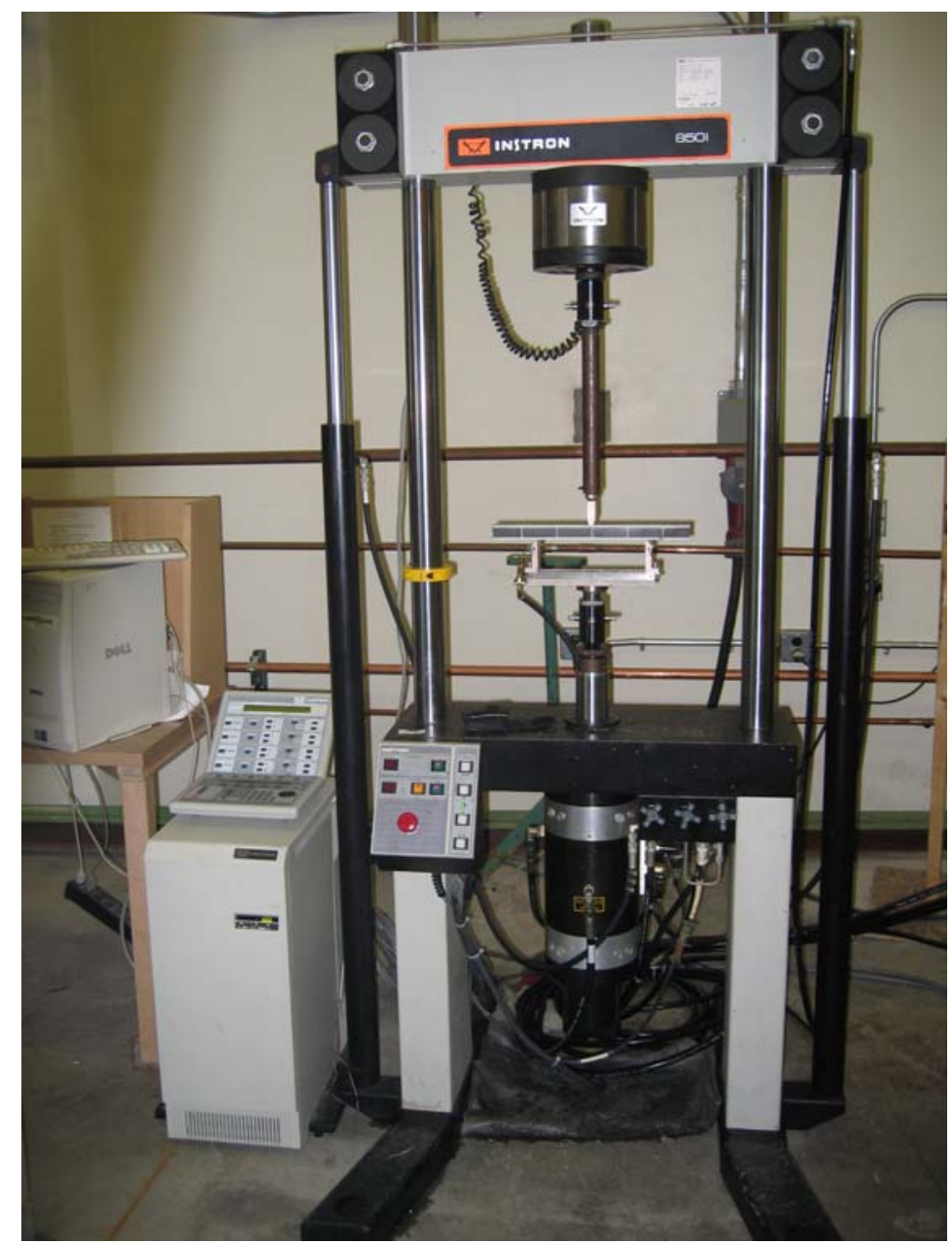

Figure 4.3 Instron model 8501 servo-hydraulic material testing system 
Data acquisition (Figure 4.4) is independent of the testing machine to allow any system to operate with any test machine. It collects and stores instantaneous data such as strain, load, deflection, etc. Strain gage lead wires and load connections were connected to the Model 5000 scanner (Vishay Micro-measurements Inc), which was further connected to the computer with relevant software. The loading was done through testing machine with a programmable controller and the corresponding loadings for strains were recorded using the data acquisition system. The recorded data was reduced to an MS Excel format and further data analysis was carried out.

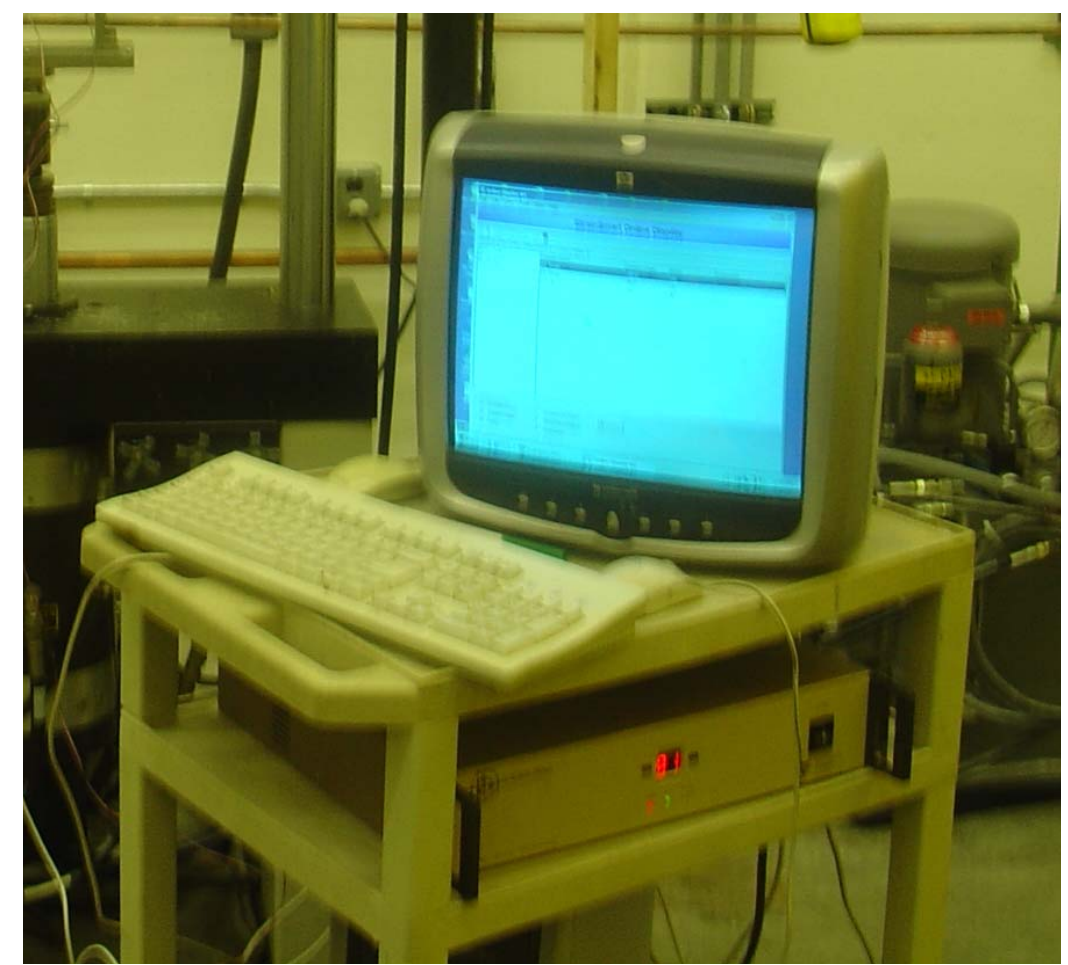

Figure 4.4 Data Acquisition

\subsection{EXPERIMENTS PERFORMED}

Usually, mechanical characterization of materials is being carried out by conducting different types of static tests on coupon specimens. Out of which, tension and flexure tests are the most general and useful tests for determining the behavior of the material. These tests measure behavioral properties, especially stress-strain plots, which are unique identifiers of each material tested. Hence, experimental evaluations, herein 
were used not only to determine the material properties but also to develop a new model based on the results. All tests were performed as per ASTM standard specifications.

\subsubsection{Flexure Test}

A flexure test method measures the flexural response under three or four point bending conditions. Both the flexure tests are commonly used for composite materials.

In this study, a four-point bending scheme was chosen, because it ensures constant bending moment and minimal shear between the load spans. The bending deflection was measured in the mid-span of the samples in relation to inner supports. These data analysis are discussed in Chapter 5.

\subsubsection{Four point Bending Test:}

In a four-point bending test method i.e., a simply supported bar loaded with a concentrated load $\mathrm{P} / 2$ at two positions of span $\mathrm{L}$, and is also known as quarter point loading. A schematic representation of the test, as per ASTM test standard D6272 (2005), and D790 (2005), is shown in Figure 4.5.
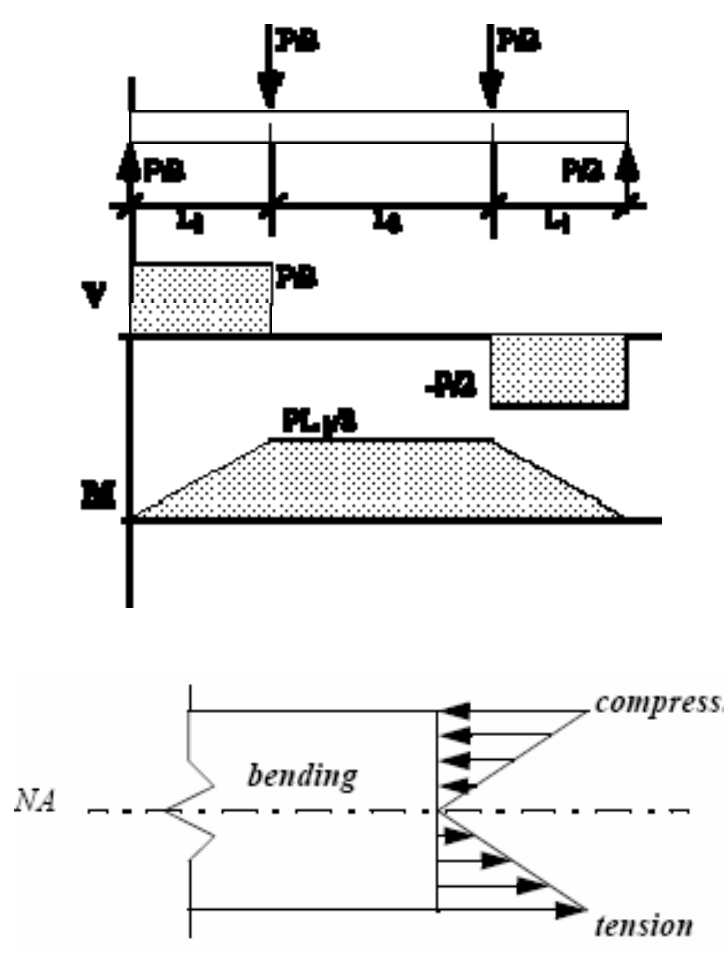

Figure 4.5 Schematic of Four-point Loading Flexure Test 


\subsubsection{Test Procedure}

Specimens with different fiber architecture (uni-directional, cross-ply, tridirectional with CSM, and quadri-directional with and without CSM) were prepared with two different thickness ( 0.25 in and 0.5 in) using hand lay-up combined with compression molding process and were tested for bending in transverse and longitudinal directions to determine the flexural properties of the material, as per test method of the ASTM 790 (2005) and ASTM 6272 (2005) specifications. The aspect ratios for all the specimens were above 16 with load-span ratio of $\mathrm{L} / 3$, for four-point bending test. An over hang of 1 " on either side was provided to prevent the specimen from slipping through the supports. All tests were displacement controlled at actuator rate of $0.1 \mathrm{in} / \mathrm{min}$, which corresponds to strain rate of $0.01 \mathrm{in} / \mathrm{in} / \mathrm{min}$ using a $22 \mathrm{kip}$ servo hydraulic test machine (Instron model 8501). The data from the tests were used to obtain the flexural modulus and flexural strength according to the procedures detailed in ASTM standard D790 and D6272.

The following were the steps involved in performing bending tests.

- The specimen geometry was measured using digital Vernier calipers. Width and thickness were measured at different locations all over the sample and then average value was considered.

- The specimen was placed on the supports and was aligned properly. Strain readings were obtained from strain gage connected to the data acquisition system and also corresponding load readings were recorded. Deflection readings were obtained with respect to the actuator movement.

- Testing program was then started after inputting all the needed data, such as file name, units, etc. The Instron machine was zeroed for calibration and the loading of the specimen at a rate of $0.1 \mathrm{in} / \mathrm{min}$ was performed. The loading was continued until failure occurred.

- The procedure was repeated for each specimen. Stress-Strain and Load-Deflection were plotted for each test. Experimental values of stiffness, elastic limit, bending strength, and bending strain for each specimen were obtained and tabulated. 
In order to check for linearity of the stress-strain plots, initially strain gages were mounted at the top and bottom on three specimens of each type of architecture and thickness. Incremental loads (30\%, $60 \%$, and $80 \%$ of ultimate load) were applied on each of these specimens and then taken to ultimate load and it is continued until the specimen reaches its fracture load. Remaining specimens were taken directly to fracture load and for the corresponding load, deflection at the center was measured. Specimen deflection was measured by actuator displacement. Load, displacement and strain readings were recorded by a computer data acquisition system and curves were plotted with load as the ordinate. A typical load-deflection and stress-strain curves for uni-directional composite coupon specimens are shown in Figures 4.6 and 4.7, respectively. The stress-strain behavior for different fiber architectures, is detailed in Chapter 5 .

Unidirectional Laminates $[0]_{19 S}$ L5

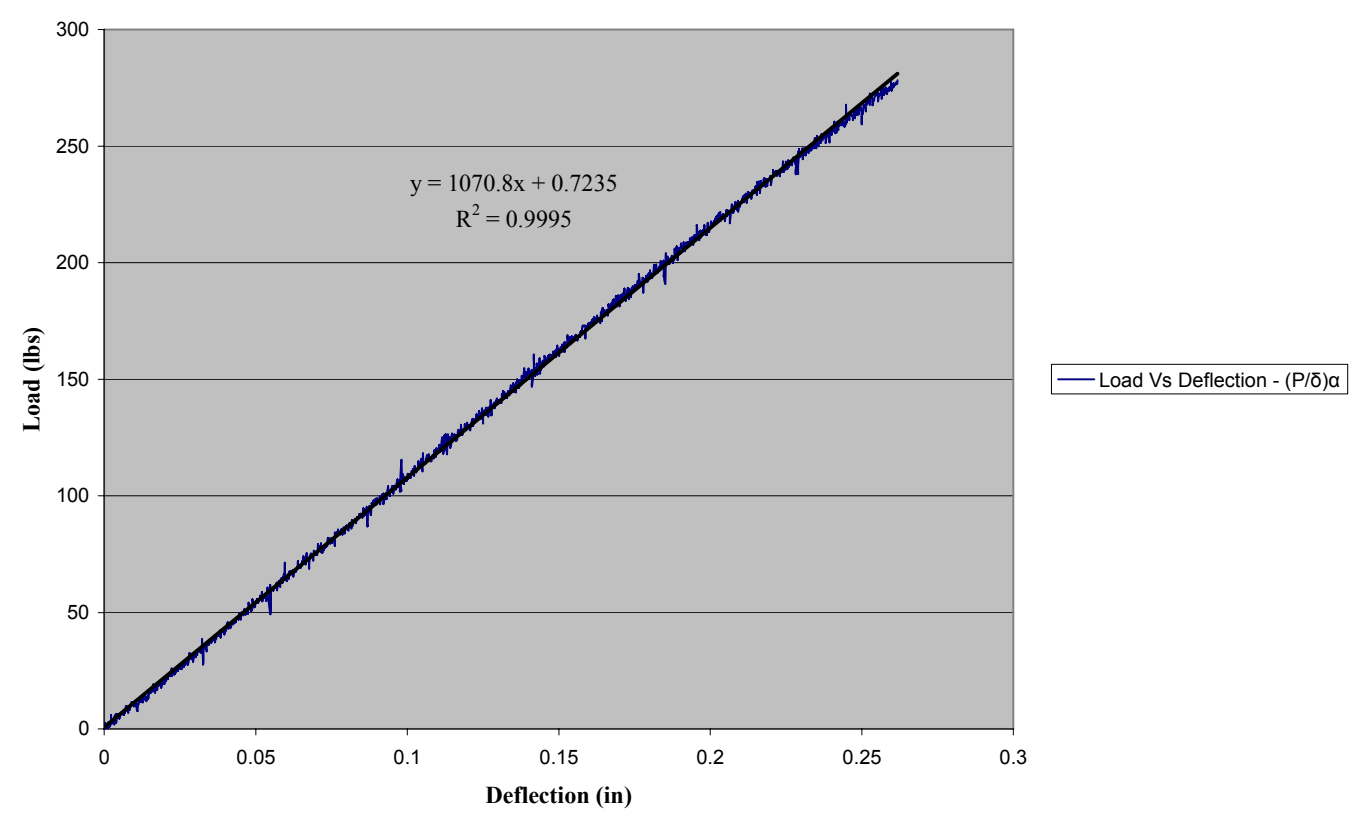

Figure 4.6 Load-Deflection Curve for uni-directional composite coupon specimen 
Unidirectional Laminates - $[0]_{28 \mathrm{~S}} \mathrm{L1}$

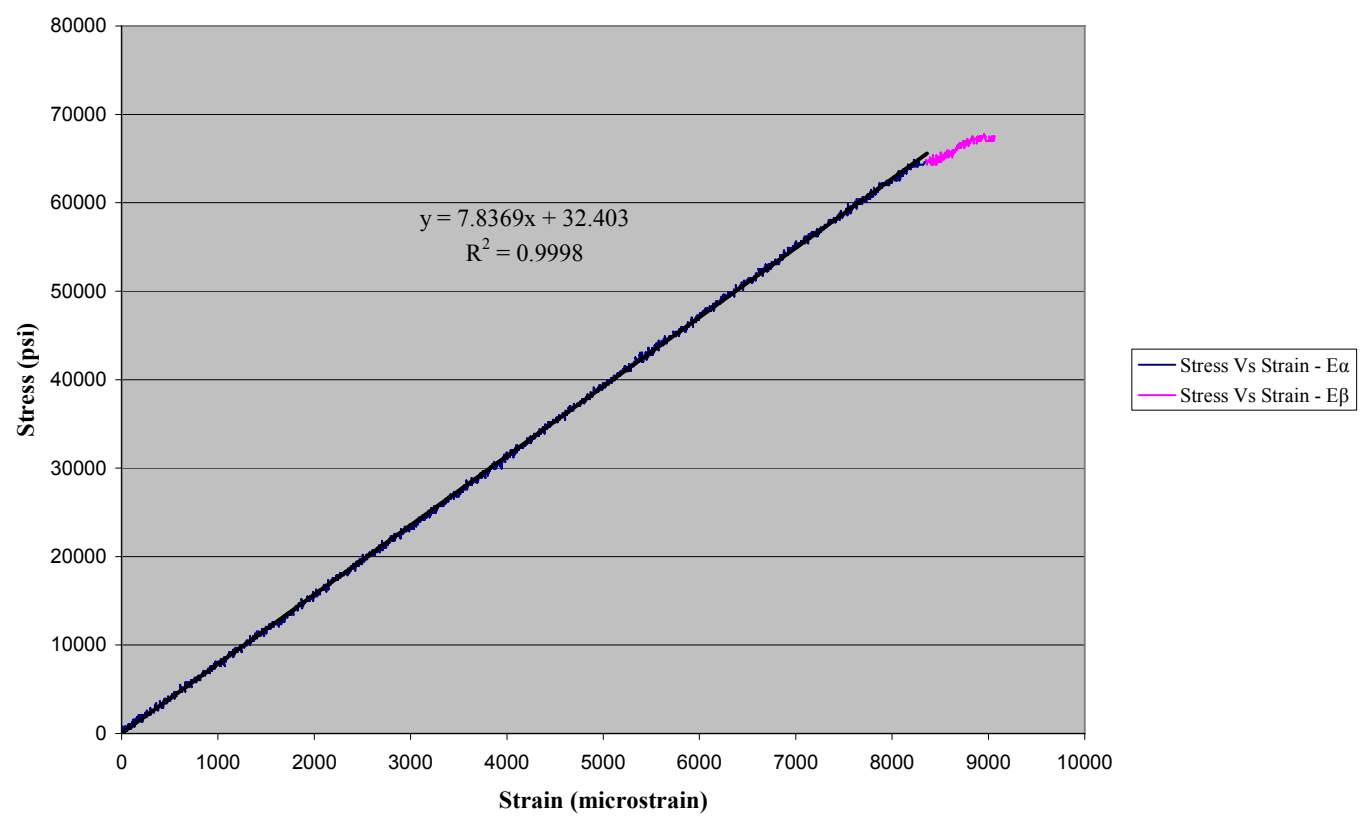

Figure 4.7 Stress-Strain Curve for uni-directional composite coupon specimen

\section{Formulae for Four-Point Bending Test:}

The formula for computing flexural modulus as per ASTM Test D6272 and D790 is based on the equation, which implicitly assumes that all deformation is contributed by bending, and any shear deflection is ignored.

Bending modulus (from stress-strain curve): $E_{x}^{B}=\frac{23 L^{3} m}{108 b d^{3}}$

Bending Modulus (from load-deflection curve): $E_{x}^{B}=\frac{23 P L^{3}}{108 b \delta d^{3}} \mathrm{psi}$

The flexural strength, is given by $\sigma_{u l t}=\frac{P L}{b d^{2}}$

where, $\mathrm{P}$ is the maximum load. 
Ultimate Stress: $\sigma_{\text {ult }}=\frac{M C}{I} \mathrm{psi}$

$\mathrm{m}=\mathrm{P} / \delta=$ Slope of Elastic Zone of Load Vs Deflection curve (lbs vs. in/in) (i.e., the slope of tangent to the initial straight-line portion of the load - deflection curve.)

Ess $=\sigma / \varepsilon=$ Bending Modulus obtained from the slope of Elastic Zone of Stress Vs Strain curve (psi vs. microstrain) (i.e., the slope of tangent to the initial straight-line portion of the stress-strain curve.)

$\mathrm{L}=$ Span Length of the specimen (in)

$\mathrm{L} 1=\mathrm{L} 2=\mathrm{L} / 3=$ Load Span (in)

$\mathrm{I}=$ Moment of Inertia $\left(\mathrm{in}^{4}\right)=\mathrm{bd}^{3} / 12$

$b=$ Width of specimen (in)

$\mathrm{d}=$ Thickness of the specimen (in)

$\mathrm{M}=$ Bending Moment (lbs-in) $=\mathrm{PL} / 6$

$\mathrm{C}=$ distance from Outer Compression/Tension surface to the Neutral Axis (in)

$\varepsilon=$ Strain (microstrain) (strain gage readings)

$\sigma_{\text {ult }}=$ Ultimate Stress (psi)

\subsubsection{Strain Energy Calculation for Bending Test}

Strain energy under bending was obtained by calculating area under loaddeflection curve. Hence, for strain gage mounted samples, the strain readings are converted into deflection readings and area under load-deflection curve was calculated. A sub-routine was written in MATLAB for importing EXCEL data and for finding the area using trapezoidal rule. The following are the steps involved in calculating strains from deflections and hence area of the curve. 
For four-point bending: $\varepsilon=\frac{108 \times \delta \times d \times 10^{6}}{23 L^{2}}$

\subsubsection{Tension Test:}

This is the most fundamental test for mechanical characterization of composite materials. Modulus of elasticity, elongation, tensile strength and other properties are determined.

The stress and strain initially increase linearly relationship and the slope of the stress - strain curve represents elastic portion of a test specimen. The linear slope of the line is referred to as modulus of elasticity or Young's modulus. It is a measure of stiffness of a given material. The normal strains are measured using extensometer or strain gage. Usually, from a tensile test, load versus strain curve is drawn, which is then converted into stress versus strain curve. Since engineering stress is obtained by dividing the load with constant area, the engineering stress-strain graph will have nearly the same shape as the load-strain curve.

In order to ensure better results, specimen dimensions and shape, grip selection, tabs, etc., are some of the important factors to be considered.

\section{Dimensions:}

Even though ASTM D3039 specifies the dimensions of the specimens to be tested under tension, it limits to only $1 / 8$ th inch thick specimens. As the specimen thickness considered in this study accounts for $1 / 4$ inch and 3/8th in thick specimens, after many trial and errors, 16"X1" (16 inch in length and 1" wide) dimension specimens are considered and tested under tension.

\section{Shape:}

As the specimens considered in this study were cut from 17"X12" plate, rectangular specimens of size 16 "X1" were considered for testing. However, while testing samples with dog-bone geometry, the edge of the tab may shear-off or crush at higher loading conditions. Therefore, most of these specimens require double tabs to be 
bonded on both sides at the ends. The tabs distribute gripping stresses and prevent specimen failure caused by grip jaws. Even bevel angled $\left(7^{\circ}-10^{\circ}\right)$ tabs can be used for better results. But, herein, straight edge tabs were used as the grips used to hold the specimens in both Baldwin universal testing machine and Instron 8501 are straight edged.

The above-mentioned are the factors to be considered to avoid having a break or fracture within the area being gripped.

\subsubsection{Test Procedure}

As in bending, coupon specimens with different fiber architecture (unidirectional, cross-ply, tri-directional with CSM, and quadric-directional with and without CSM) and thickness $(\sim 0.25$ " and $0.35 ")$ were tested for tension in longitudinal and transverse direction. All the tests were carried out as per ASTM 3039 (2005) specifications. Coupon specimens cut in longitudinal direction and of 0.25 " and 0.35 " thickness were tested in Baldwin universal testing machine, and some specimens (0.2" thick) were tested in Instron 8501 hydraulic machine at $0.1 \mathrm{in} / \mathrm{min}$ displacement rate. As the Baldwin universal testing machine was manually operated, the displacement control was approximately maintained at $0.1 \mathrm{in} / \mathrm{min}$.

The following were the steps performed for conducting a typical tension test.

- Initially, the width and thickness were measured at several locations along the length of each specimen to determine the average cross-sectional dimensions and recorded.

- Gage length of one inch was marked on each specimen for mounting extensometer. The strain readings were directly obtained from the computer connected to the Instron 8501 model. In case of strain gages, the readings were recorded from data acquisition system (external system) connected to Baldwin universal testing machine.

- The specimen was then placed in the grips and was firmly attached to ensure against slipping during operation. 
- Extensometer was attached to the specimen (when needed) and all the readings such as, strain, load, position, etc., were zeroed for calibration purposes. The pin attached to the extensometer was removed before beginning the test.

- After inputting the required data such as file name, units, etc., the load was applied with a load rate of $0.1 \mathrm{in} / \mathrm{min}$. The loading was continued until failure of the sample.

- The procedure was repeated for each specimen. Stress-Strain and Load-Deflection were plotted for each test. Experimental values of stiffness, elastic limit, tensile strength, and tensile strain for each specimen were obtained and tabulated.

Eight specimens of each type of fiber architecture were tested for tension. Out of which, strain gages were mounted on either side along the longitudinal direction for three specimens, and were subjected to incremental loads $(30 \%, 60 \%, 80 \%$ and $100 \%$ of ultimate load). For the remaining specimens, only one gage was mounted and was taken directly to ultimate load. Load and strain readings were recorded in computer data acquisition system and curves were plotted with load as ordinate. Strain gages were mounted for specimens tested in Baldwin universal testing machines, whereas for specimens tested in Instron 8501, extensometer was used to record strain data. A typical stress-strain curve for uni-directional composite coupon specimens is shown in Figure 4.8. The stress-strain curves vary with different fiber architecture, which are described in detail in Chapter 5. 


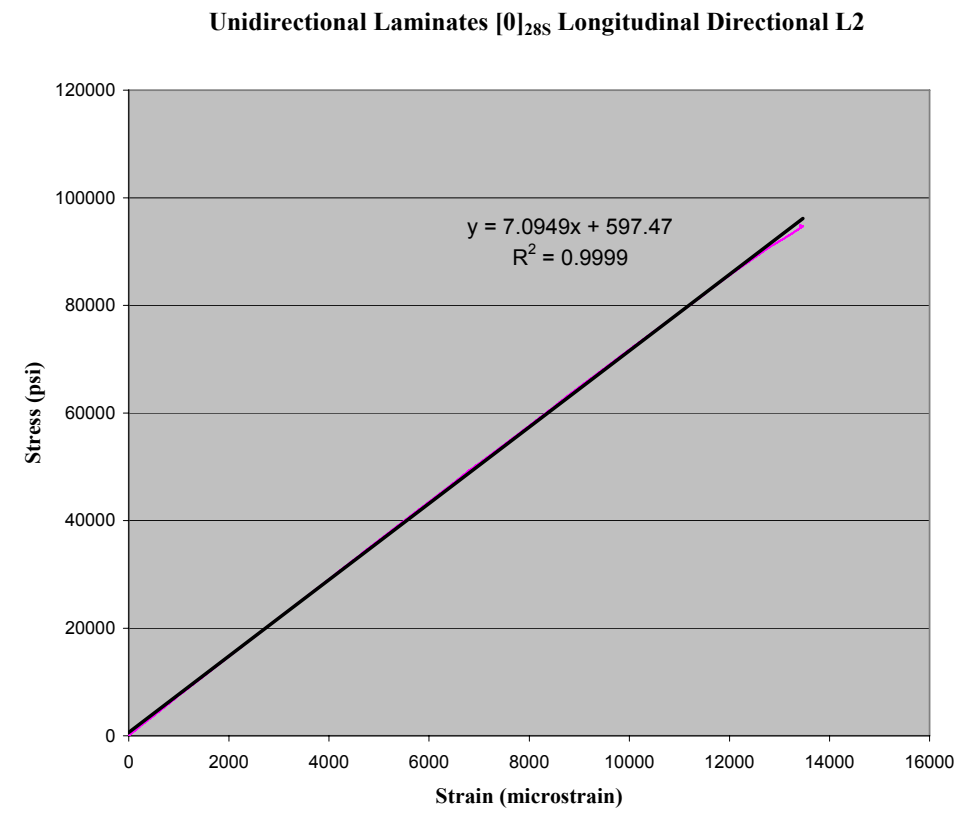

Figure 4.8 Stress-Strain Curve for unidirectional composite coupon specimen

\section{Tension Test Calculations:}

Tensile strength is given by

$\sigma_{u l t}=\frac{P_{u l t}}{W T} \quad(\mathrm{psi})$

The normal stress is calculated as:

$\sigma=\mathrm{P} / \mathrm{A}(\mathrm{psi})$

where, $\mathrm{P}=$ applied load on the specimen (lbs)

$\mathrm{W}=$ Width of specimen (in)

$\mathrm{T}=$ Thickness of specimen (in)

$\mathrm{A}=\mathrm{W} \times \mathrm{T}=$ Cross-sectional area of the specimen $\left(\mathrm{in}^{2}\right)$

$\mathrm{L}=$ Gage length (in)

$E_{\mathrm{ss}}=\sigma / \varepsilon=$ Tensile modulus obtained from slope of elastic zone of Stress Vs. Strain curve 
(psi Vs microstrain) (i.e., the slope of tangent to the initial straight-line portion of the stress-strain curve.)

\subsubsection{Strain energy calculations for tension test}

Strain energy per unit volume is obtained by calculating the area under the stressstrain curve. Further, the area is multiplied with volume of the specimen, in order to get the strain energy of the specimen. A sub-routine was written in MATLAB for importing EXCEL data and for finding area using the trapezoidal rule.

About 250 coupons were tested in both tension and bending in two principal directions i.e., longitudinal and transverse direction. From each test, stress-strain or loaddeflection curves were generated to determine the mechanical properties of glass fiber reinforced composites. Descriptive statistics of the experimental data including modes of failure, and development of theory based on the data are detailed in Chapter 5. 


\section{CHAPTER 5}

\section{DATA ANALYSIS AND RESULTS}

This chapter explores trends in static resistance of laminated coupon specimens, utilizing tension and bending test data and identifies the underlying mechanisms responsible for failure. Over 250 specimens made of glass fiber reinforced composites were tested for tension and bending at coupon level in both the longitudinal and transverse directions. A detailed systematic study of stress-strain plots of different coupon specimens is performed. Failure modes of all coupon specimens were investigated and described briefly. Comparisons of results, significant variations in stress - strain trends and parameters affecting the laminate properties are discussed separately.

\subsection{DETAILS OF LAMINATES}

Fiber architectures considered for this study are:

Unidirectional laminate [0] made of continuous fibers were considered as a basic building block for the multidirectional laminates

Cross-ply laminates

$[0 / 90]_{\mathrm{NS}}$ (longitudinal)

$[90 / 0]_{\mathrm{NS}}($ transverse)

Tri-directional with CSM laminates

$[45 / 0 /-45 / \mathrm{CSM}]_{\mathrm{NS}}$ (longitudinal)

$$
\text { [45/90/-45/CSM }]_{\mathrm{NS}} \text { (transverse) }
$$

Quadri-directional without laminates

$[0 / 90 /+45 /-45]_{\text {NS }}$ (longitudinal)

$$
[90 / 0 /+45 /-45]_{\mathrm{NS}} \text { (transverse) }
$$

Quadri-directional with CSM laminates 
$[0 / 90 /+45 /-45 / \mathrm{CSM}]_{\mathrm{NS}}$ (longitudinal)

$[90 / 0 /+45 /-45 / \mathrm{CSM}]_{\mathrm{NS}}$ (transverse)

All the laminates were fabricated with vinyl ester resin using compression molding process.

\subsection{TENSION TEST DATA ANALYSIS}

Over 80 specimens with different fiber architectures and thicknesses were tested in both longitudinal and transverse directions. Samples are labeled according to the type of test, fabric type, specimen number, direction of loading, and thickness. For instance, sample labeled as TUL3Q implies, Tension test of Unidirectional composite specimens in Longitudinal direction (in terms of sample preparation), sample number being 3 and is

about Quarter inch thick. As the specimens were initially tested for appropriate tab length, which resulted in bond failure much prior to the ultimate load; data of some samples were intentionally ignored.

\subsubsection{Longitudinal Direction}

\subsubsection{Unidirectional Coupon Specimens}

Zero degree unidirectional laminates of 0.16 " and 0.2 " thick were fabricated with $7 \mathrm{oz} / \mathrm{yd}^{2}$ and $12 \mathrm{oz} / \mathrm{yd}^{2}$ densities, respectively. Stress-strain curve of TUL2Q unidirectional composite coupon specimen under tension in longitudinal direction is shown in Figure 5.1. As can be seen from the Figure 5.2, the stress-strain is linear almost to the ultimate load. The slope of linear portion represents stiffness of the specimen and is obtained from linear regression curve fit. Coupon specimens of different fabric densities were tested and the results are tabulated in Table 5.1.

Stiffness was calculated theoretically using rule-of-mixtures (ROM). Stress was computed as mentioned in Chapter 4, Section 4.3.2. However, it was found from literature review (Chapter 2, Section 2.2.3), that stresses obtained from the experiments in unidirectional laminates conducted at CFC, WVU resulted in lower values, which may be attributed to inappropriate gage length and tab length used. As seen from the Table 5.1, the ultimate stresses obtained for 58\% FVF are higher than the stresses obtained for $70 \%$ 
FVF, which is due to inappropriate gage length and tab length, and also due to insufficient fiber wet out. Strain gages attached on the surface in some cases failed to record the strain data before the specimen broke, which is because of the delamination of first ply leading to strain gage failure and also possibility of remaining plies to take further loads.

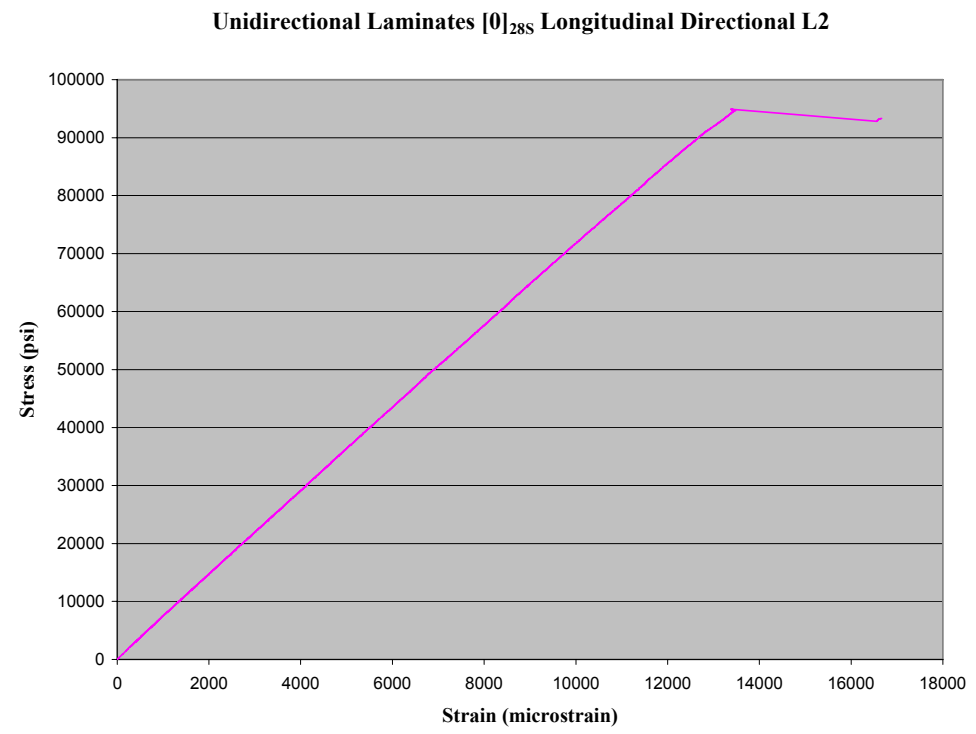

Figure 5.1 Stress-strain of unidirectional laminate (TUL2Q)

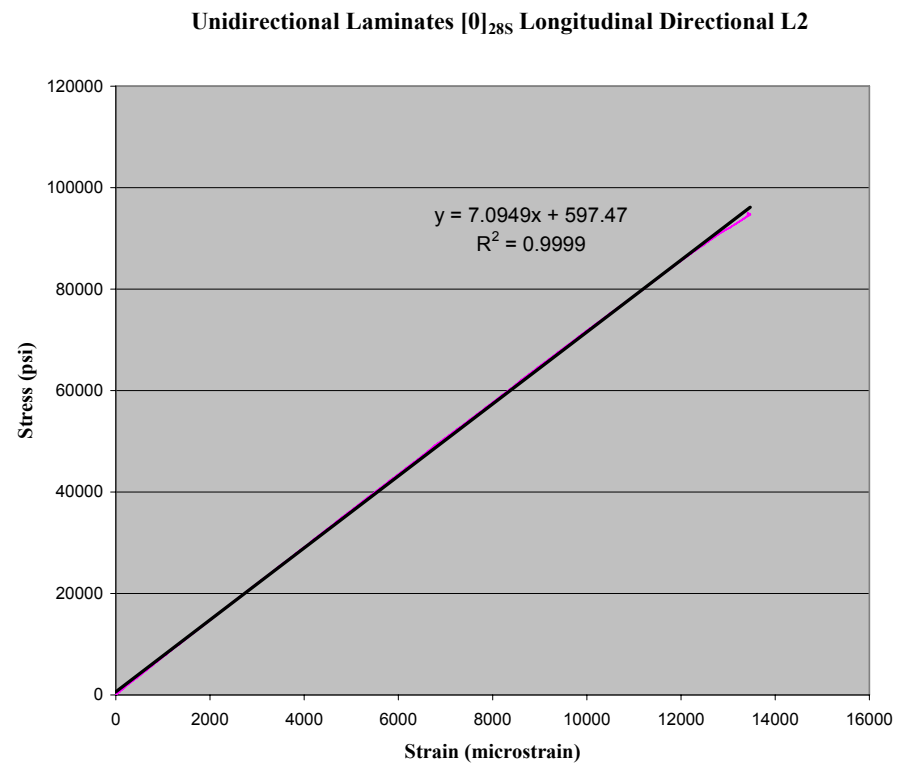

Figure 5.2 Stress -strain of unidirectional laminate (TUL2Q) until ultimate load 
Table 5.1 Results of Unidirectional coupon specimens tested in longitudinal direction

\begin{tabular}{|c|c|c|c|c|c|c|c|c|c|c|}
\hline $\begin{array}{c}\text { Material - } \\
\text { ID }\end{array}$ & $\begin{array}{l}\text { Lay-up } \\
\text { /Direction }\end{array}$ & $\begin{array}{l}\text { Density } \\
\left(o z / y d^{2}\right)\end{array}$ & $\begin{array}{r}F V F \\
(\%)\end{array}$ & $\begin{array}{l}F V F- \\
X(\%)\end{array}$ & $\begin{array}{c}\text { Stress } \\
(\text { Ksi) }\end{array}$ & $\begin{array}{l}\text { Ethe } \\
\text { (msi) }\end{array}$ & $\begin{array}{c}\text { Ult Load } \\
\text { (lbs) }\end{array}$ & $\begin{array}{c}\text { Max } \\
\text { Strain } \\
(\%)\end{array}$ & $\begin{array}{c}E \alpha \\
(m s i)\end{array}$ & $\begin{array}{c}\text { Area } \\
\left(\text { in }^{2}\right)\end{array}$ \\
\hline TUL3Q & \multirow{5}{*}{$\begin{array}{l}0^{\circ}-19 \\
\text { layers }\end{array}$} & \multirow{5}{*}{12} & \multirow{5}{*}{57.57} & \multirow{5}{*}{57.57} & 98.45 & \multirow{5}{*}{6.25} & 20647.08 & 1.80 & 6.27 & 0.21 \\
\hline TUL4Q & & & & & 103.53 & & 20292.95 & 1.53 & 6.78 & 0.20 \\
\hline TUL5Q & & & & & 104.79 & & 21909.61 & 1.69 & 6.13 & 0.21 \\
\hline TUL7Q & & & & & 102.97 & & 20816.44 & 1.54 & 6.87 & 0.20 \\
\hline TUL8Q & & & & & 94.05 & & 19800.26 & 1.76 & 6.63 & 0.21 \\
\hline NTUL2Q & \multirow{2}{*}{$\begin{array}{l}0^{\circ}-28 \\
\text { layers }\end{array}$} & & \multirow{2}{*}{69.61} & \multirow{2}{*}{69.61} & 94.93 & \multirow{2}{*}{7.45} & 14861.86 & 1.34 & 7.09 & 0.16 \\
\hline NTUL4Q & & & & & 91.56 & & 15171.07 & 1.36 & 6.95 & 0.17 \\
\hline
\end{tabular}

\subsubsection{Cross-ply Coupon Specimens}

Figure 5.3 and Figure 5.5 represent stress-strain curves of TBL3H and TBL4Q cross-ply laminated coupon specimens under tension in longitudinal direction and of 0.35 " and 0.25 " (approx) thick, respectively. As is evident from the Figure 5.4 and Figure 5.6, the stress-strain curves include two typical regions: 1) the stress increased nearly linearly with the increase of strain; 2) the stress showed a second almost linear rapid increase with the increase of the strain. A third change of slope which may not be a linear portion was observed in only some coupon specimens (Figure 5.6) and represents roughly last $10 \%$ of the ultimate load. This occurred with a very small amount of increase in stress, hence up to $90 \%$ of ultimate load was considered for computations. The linear slopes were obtained from linear regression curve fit and correspond to the stiffness of the specimen. The results of cross-ply coupon specimens tested for tension in longitudinal direction are tabulated in Table 5.2. Stress was computed as mentioned in Chapter 4, Section 4.3.2 at both $90 \%$ of ultimate load, and also at ultimate load, and was found to be $60 \mathrm{ksi}$ ( $90 \%$ ultimate load) for $47 \% \mathrm{FVF}$. Corresponding strains were also tabulated. Strains at failure stress varied from $1.9 \%$ to $2.2 \%$. 
Cross-ply Laminates $[0 / 90]_{28 s} \mathrm{L3}$

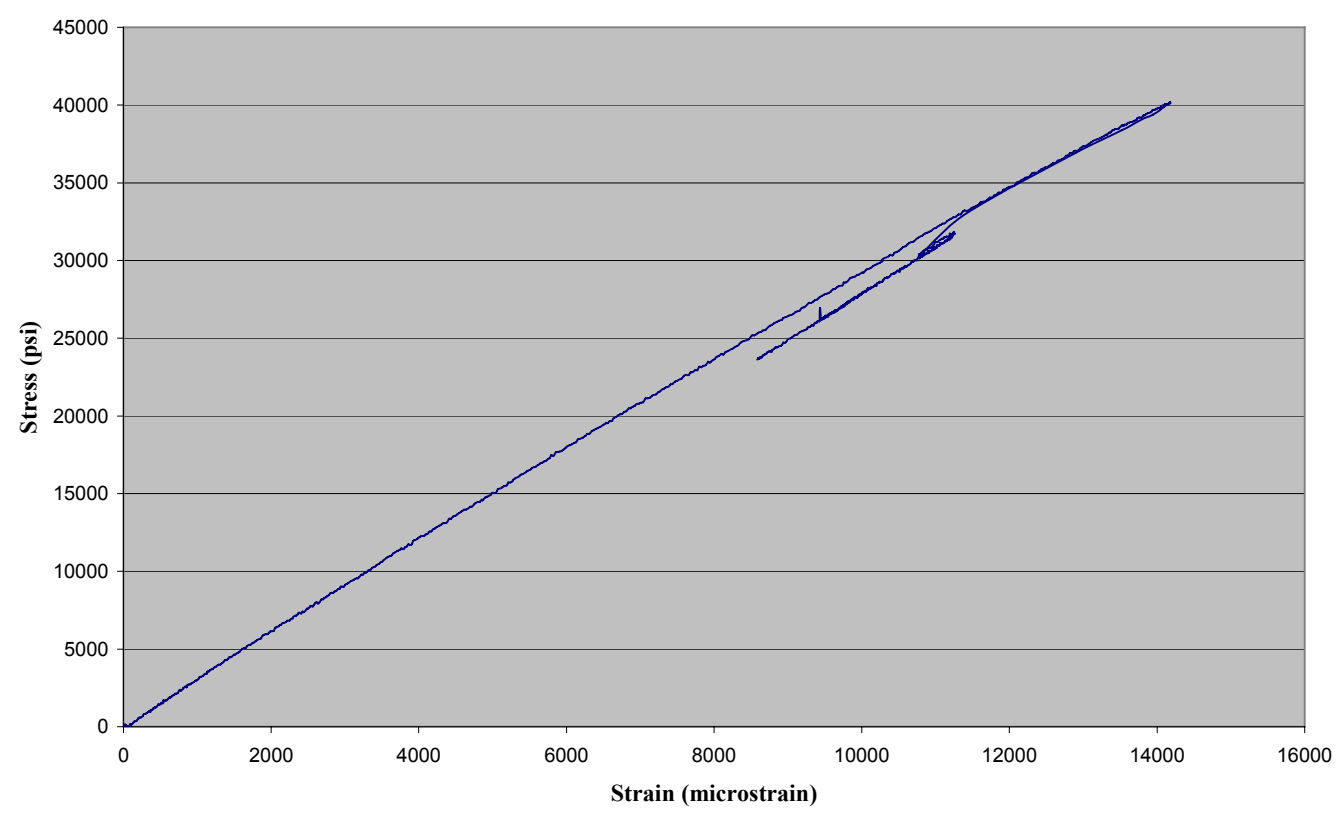

Figure 5.3 Stress-strain of cross-ply laminate (TBL3H)

Cross-ply Laminates $[0 / 90]_{28 \mathrm{~S}} \mathrm{L3}$

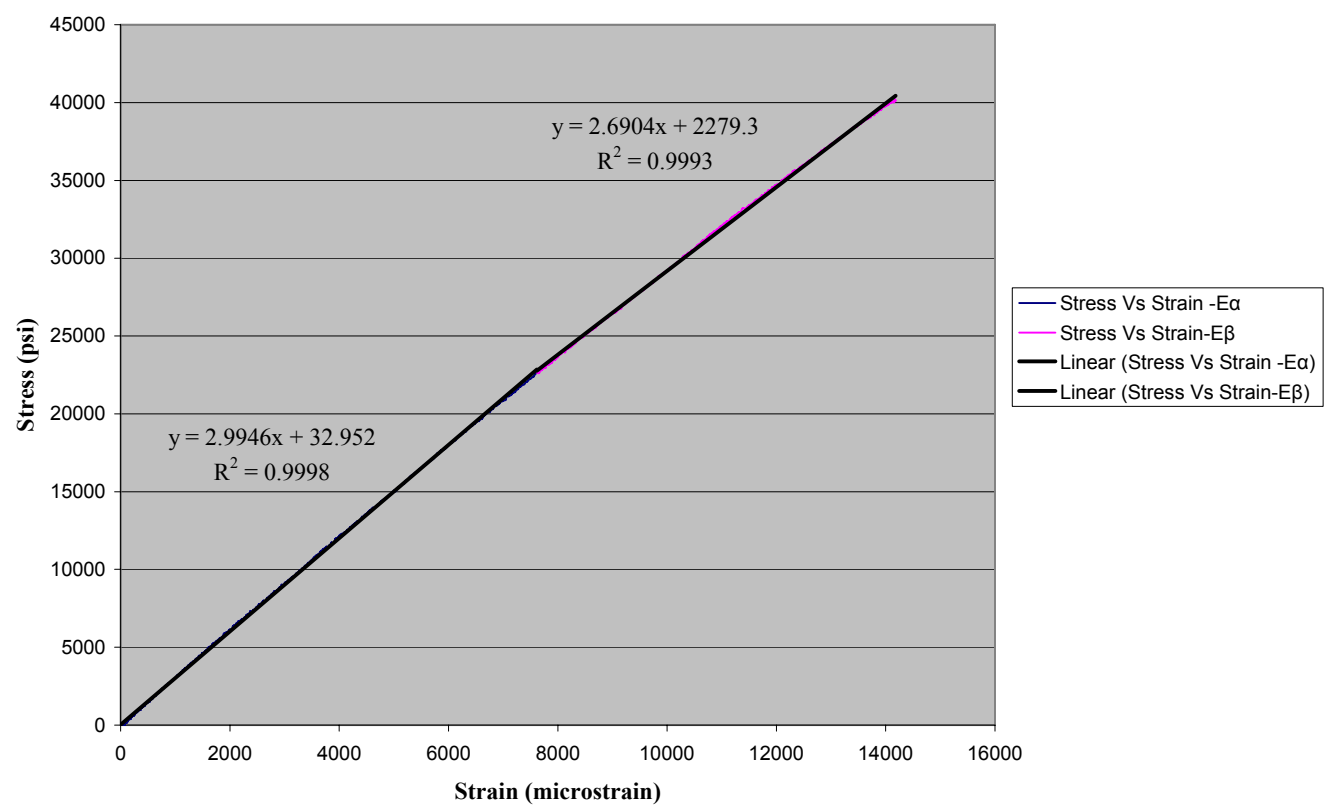

Figure 5.4 Stress-strain of cross-ply laminate (TBL3H) until ultimate load 
Cross-ply Laminates L4 $[0 / 90]_{18 s}$

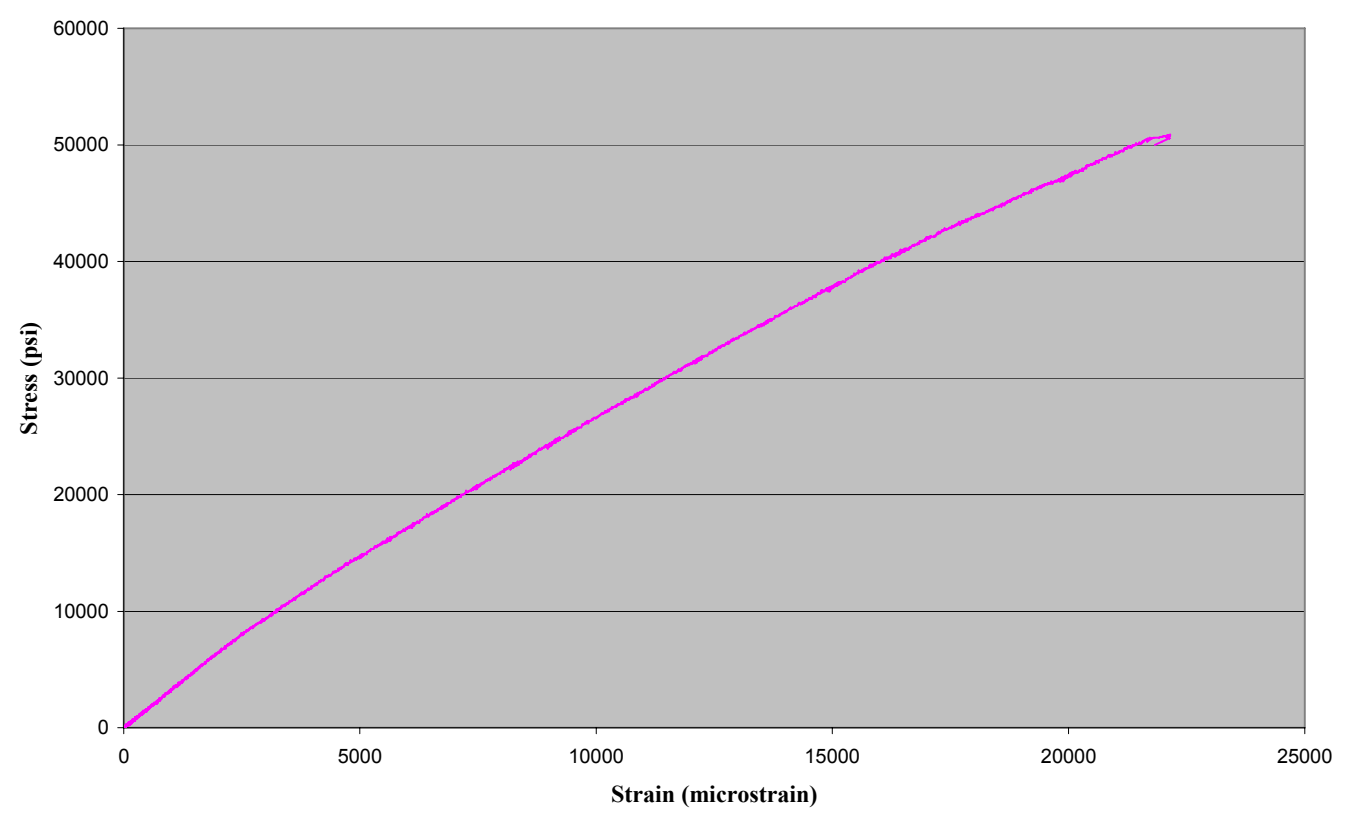

Figure 5.5 Stress-strain of cross-ply laminate (TBL4Q)

Cross-ply Laminates L4 $[0 / 90]_{18 \mathrm{~S}}$

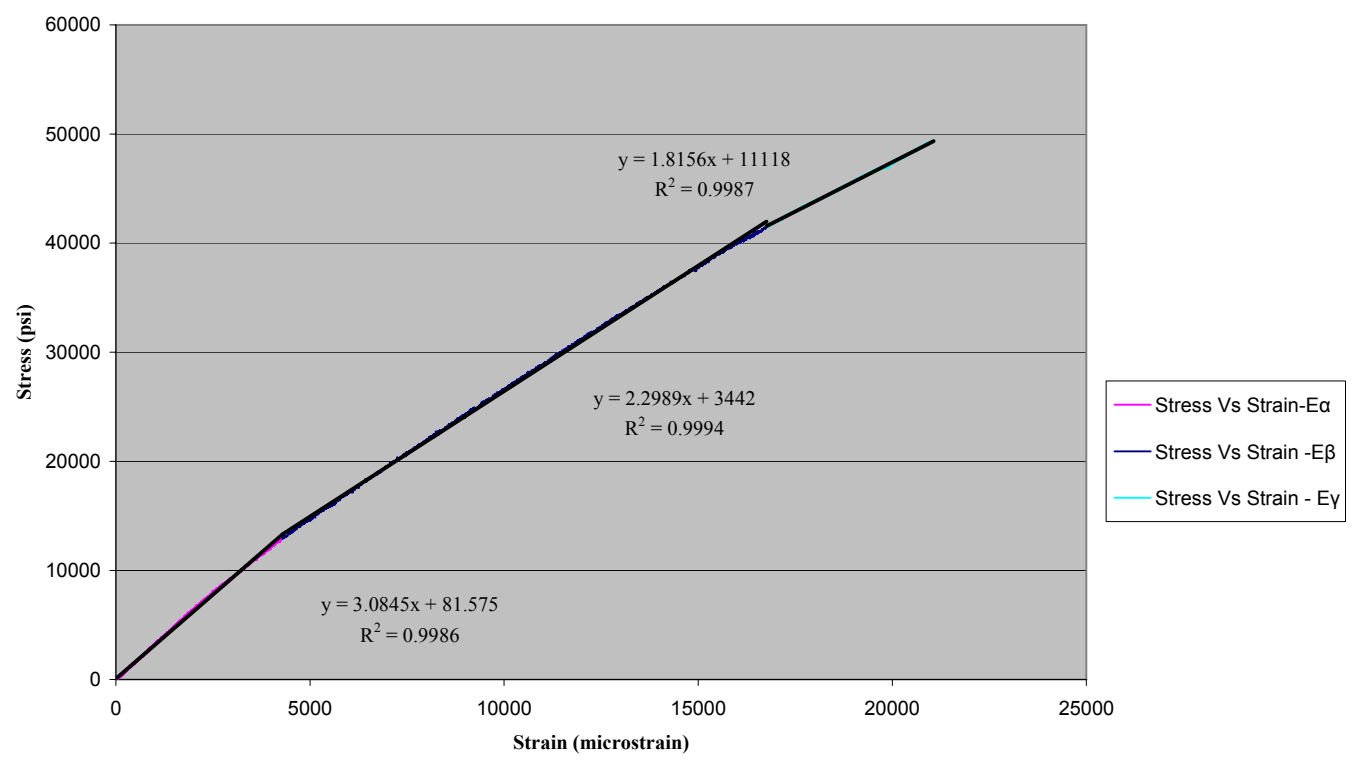

Figure 5.6 Stress-strain of cross-ply laminate (TBL4Q) until ultimate load 
Table 5.2 Results of Cross-ply Laminates tested in Longitudinal Direction

\begin{tabular}{|c|c|c|c|c|c|c|c|c|c|c|c|c|c|c|c|}
\hline $\begin{array}{c}\text { Material } \\
I D\end{array}$ & $\begin{array}{c}\text { Lay-up } \\
(F A)\end{array}$ & $\begin{array}{c}F V \\
F \\
(\%)\end{array}$ & $\begin{array}{c}F V F- \\
\boldsymbol{X} \\
(\%)\end{array}$ & $\begin{array}{c}E_{t h e} \\
\text { (msi) }\end{array}$ & $\begin{array}{c}90 \% \\
\text { Ultim } \\
\text { ate } \\
\text { Load } \\
\text { (kips) }\end{array}$ & $\begin{array}{c}\text { Ultim } \\
\text { ate } \\
\text { Load } \\
\text { (kips) }\end{array}$ & $\begin{array}{c}\text { Strain } \\
\text { at } \\
90 \% \\
\text { Ultim } \\
\text { ate } \\
\text { Load } \\
(\%)\end{array}$ & $\begin{array}{c}\text { Strain } \\
\text { at } \\
\text { Ultim } \\
\text { ate } \\
\text { Load } \\
(\%)\end{array}$ & $\begin{array}{c}\text { Strain } \\
\text { at } F- \\
B i \\
(\%)\end{array}$ & $F-B i$ & $\begin{array}{c}\text { Stress } \\
0 \\
90 \% \\
\text { Ultim } \\
\text { ate } \\
\text { Load } \\
\text { (ksi) }\end{array}$ & $\begin{array}{c}\text { Stress } \\
\text { at } \\
\text { Ultim } \\
\text { ate } \\
\text { Load } \\
\text { (ksi) }\end{array}$ & $\begin{array}{c}E_{\alpha} \\
(m s i)\end{array}$ & $\begin{array}{c}E_{\beta} \\
\text { (msi) }\end{array}$ & $E_{a} / E_{\beta}$ \\
\hline TBL2H & \multirow{11}{*}{$\begin{array}{c}0 / 90 \\
0^{\circ}-5.76 \\
\mathrm{oz}^{\circ} \mathrm{yd}^{2} \\
\mathbf{9 0}^{\circ}-6 \\
\mathrm{oz} / \mathrm{yd}^{2}\end{array}$} & \multirow{4}{*}{49} & \multirow{4}{*}{24} & \multirow{4}{*}{2.75} & 18.63 & 20.7 & 1.9 & 2.26 & 0.5 & 0.27 & 55.02 & 61.15 & 3.21 & 2.7 & 1.19 \\
\hline TBL4H & & & & & 16.85 & 18.72 & 1.72 & 1.94 & 0.36 & 0.21 & 53.26 & 59.14 & 3.46 & 3.11 & 1.11 \\
\hline TBL5H & & & & & 19.52 & 21.69 & 2.19 & 2.53 & 0.71 & 0.33 & 58.36 & 64.85 & 3.02 & 2.51 & 1.2 \\
\hline TBL6H & & & & & 17.42 & 19.35 & 1.81 & 2.08 & 0.49 & 0.27 & 51.63 & 57.33 & 3.06 & 2.71 & 1.13 \\
\hline TBL2Q & & \multirow{7}{*}{45} & \multirow{7}{*}{22} & \multirow{7}{*}{2.56} & 10.2 & 11.33 & 1.82 & 2.05 & 0.46 & 0.25 & 46.77 & 51.92 & 3.12 & 2.47 & 1.27 \\
\hline TBL3Q & & & & & 11.85 & 13.16 & 2.00 & 2.33 & 0.75 & 0.38 & 54.08 & 60.05 & 2.95 & 2.56 & 1.15 \\
\hline TBL4Q & & & & & 10.16 & 11.28 & 1.91 & 2.21 & 0.42 & 0.22 & 45.83 & 50.9 & 3.1 & 2.3 & 1.35 \\
\hline TBL5Q & & & & & 11.62 & 12.91 & 2.1 & 2.5 & 0.6 & 0.29 & 52.58 & 58.43 & 3.03 & 2.29 & 1.32 \\
\hline TBL6Q & & & & & 10.31 & 12.08 & 1.63 & 2.35 & 0.55 & 0.34 & 49.87 & 58.43 & 3.15 & 2.83 & 1.11 \\
\hline TBL7Q & & & & & 11.91 & 13.24 & 2.05 & 2.22 & 0.64 & 0.31 & 54.19 & 60.21 & 3.11 & 2.46 & 1.27 \\
\hline TBL8Q & & & & & 9.66 & 11.45 & 1.65 & 1.96 & 0.65 & 0.4 & 46.55 & 55.15 & 3.1 & 2.68 & 1.16 \\
\hline
\end{tabular}




\section{Points where change of slope occurred}

The curve is a bilinear curve (Figure 5.4 and Figure 5.6) which implies that there is only one location where the change of slope occurs. In some cases, the second slope was observed to be linear till $90 \%$ of ultimate stress. Herein, point where change of slope occurred is defined as the ratio of strains at change of slope to the strains at $90 \%$ of ultimate stress. It was observed to be around 0.3. The first change of slope location point in the slope is hypothesized to be due to matrix micro-cracking of layers and the specimen still remained intact with matrix micro cracks until sufficient delamination occurred to cause separation of layers. Even after delamination, the specimen continued to take further load and form cracks until the failure of a coupon into two parts. Initiation of delamination of layers occurred beyond $90 \%$ of ultimate stress, and before the first ply failure. Detailed explanation of the mode of failure of coupon specimens is dealt within Section 5.4. Experimental stiffness value was found from stress-strain plot. The first modulus was obtained up to the point where first change of slope occurred using linear regression curve fit. The second modulus was obtained in the similar fashion by using linear regression curve fit starting from the point where first change in slope occurred to beyond $90 \%$ ultimate load depending on the linearity of the slope.

\subsubsection{Quadri-directional without CSM}

Quadri-directional without CSM composite specimens were prepared by using 10 layers of $0 / 9024 \mathrm{oz} / \mathrm{yd}^{2}$ fabric, out of which 5 layers were cut in the direction of $45^{\circ}$ and the whole lay-up was made quadri-directional and symmetric. The composite plate was $[0 / 90 /+45 /-45]_{5 \mathrm{~s}}$ and was cut in longitudinal direction, the first layer being $0^{\circ}$. Figure 5.7 represents a typical stress-strain curve of quadri-directional fabric based coupon specimen. It is evident from Figure 5.9 that the curve is almost bi-linear similar to the case of cross-ply laminates; however, the results for quadri-directional are different from cross-ply due to different fiber architecture and fiber volume fraction. As in some cases third linear slope was observed beyond $90 \%$ of ultimate load, for generalization purposes, calculations were computed based on $90 \%$ of the ultimate load and the results were compared. Stress at $90 \%$ ultimate load obtained was in the range of $30 \mathrm{ksi}$ for $45 \% \mathrm{FVF}$, while the corresponding strains were ranging from $1.25 \%$ to $1.4 \%$ as shown in Table 5.3 . 
Stiffnesses from the slopes were obtained using linear regression curve fit. The point where change of slope occurred with respect to strains was found to be 0.34 .

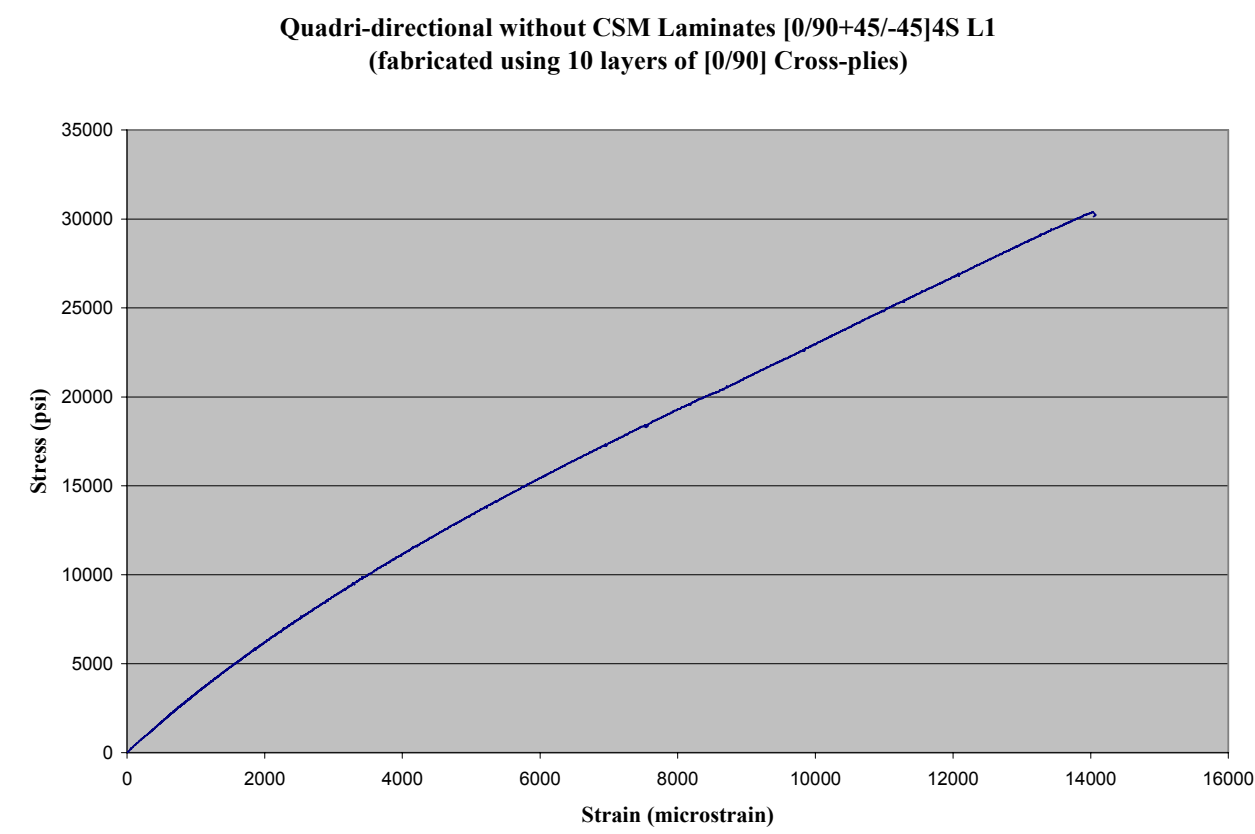

Figure 5.7 Stress-strain of Quadri-directional without CSM (TQL1Q)

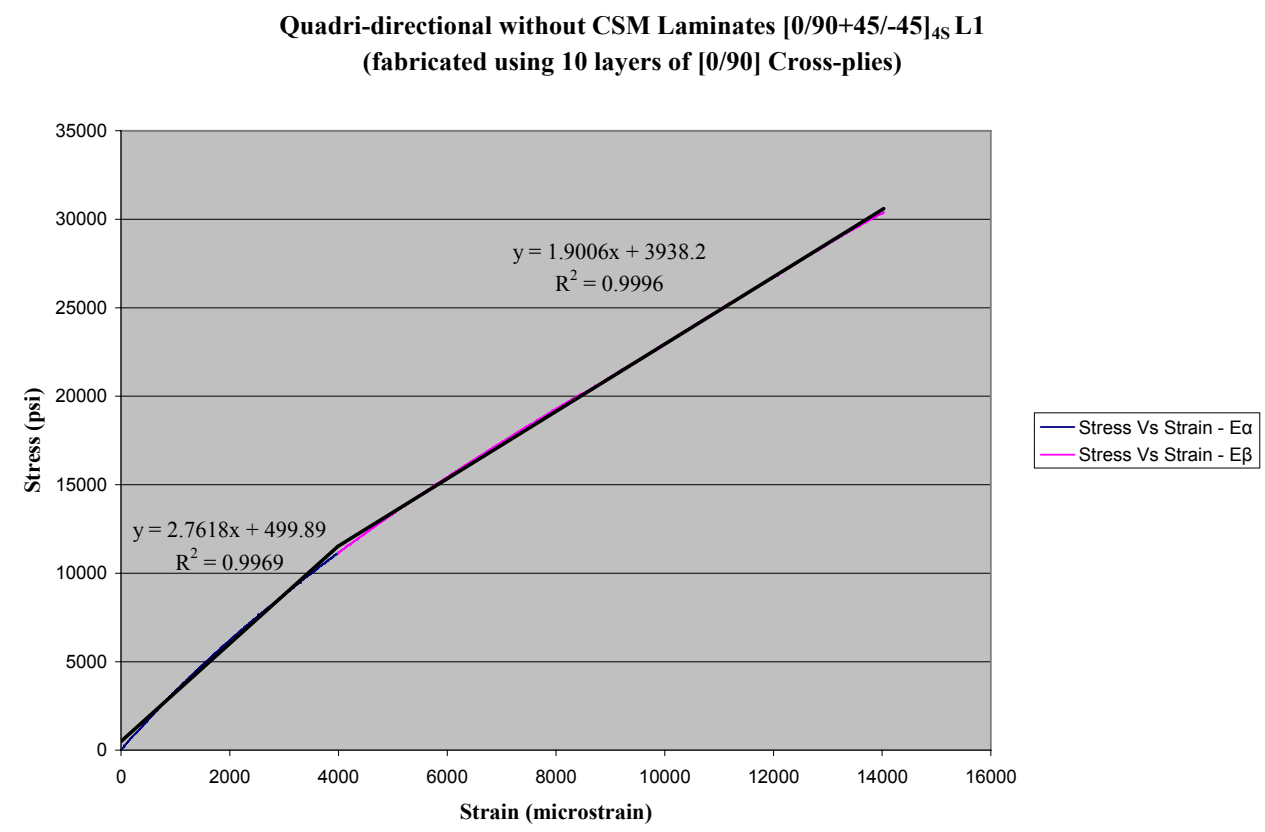

Figure 5.8 Stress-Strain of Quadri-directional without CSM (TQL1Q) until ultimate load 
Table 5.3 Tension Test Results of Quadri-directional without CSM Laminates in longitudinal direction

\begin{tabular}{|c|c|c|c|c|c|c|c|c|c|c|c|c|c|c|}
\hline & Material & $\begin{array}{l}\text { Density } \\
\left(o z / y d^{2}\right)\end{array}$ & $\begin{array}{c}F V F \\
(\%)\end{array}$ & $\begin{array}{c}F V F \\
-X \\
(\%)\end{array}$ & $\begin{array}{c}E_{t h e} \\
\text { (msi) }\end{array}$ & $\begin{array}{c}\text { Strain } \\
\text { at } \\
90 \% \\
\text { Ultim } \\
\text { ate } \\
(\%)\end{array}$ & $\begin{array}{c}\text { Strain } \\
\text { at } \\
\text { Ultimat } \\
\text { e Load } \\
(\%)\end{array}$ & $\begin{array}{c}\text { Strain } \\
\text { at } \\
F-B i \\
(\%)\end{array}$ & $F-B i$ & $\begin{array}{c}\text { Stress at } \\
90 \% \\
\text { Ultimate } \\
\text { load } \\
\text { (ksi) }\end{array}$ & $\begin{array}{c}\text { Stress } \\
\text { at } \\
\text { Ultimat } \\
\text { e Load } \\
\text { (ksi) }\end{array}$ & $\begin{array}{c}E_{\alpha} \\
(m s i)\end{array}$ & $\begin{array}{c}E_{\beta} \\
(m s i)\end{array}$ & $E_{\alpha} / E_{\beta}$ \\
\hline TQWOCL1Q & \multirow{3}{*}{$\begin{array}{l}0 / 90 / \pm 45 \\
10 \text { Layers }\end{array}$} & \multirow{3}{*}{$\begin{array}{c}\mathbf{0}^{\circ}- \\
11.52 \\
\mathbf{9 0}^{\circ}- \\
12.16\end{array}$} & \multirow{3}{*}{44} & \multirow{3}{*}{22} & \multirow{3}{*}{2.57} & 1.23 & 1.40 & 0.39 & 0.32 & 27.36 & 30.40 & 2.76 & 1.90 & 1.45 \\
\hline TQWOCL2Q & & & & & & 1.06 & 1.19 & 0.44 & 0.42 & 27.75 & 30.82 & 2.97 & 2.28 & 1.30 \\
\hline TQWOCL3Q & & & & & & 1.22 & 1.37 & 0.36 & 0.30 & 28.71 & 31.90 & 2.94 & 2.05 & 1.43 \\
\hline
\end{tabular}




\subsubsection{Tri-directional with CSM}

The coupon specimens of tri-directional fabric configuration with CSM were prepared from 4 layers of $53 \mathrm{oz} / \mathrm{yd}^{2}$ fabric cut in the longitudinal direction, with first layer as $45^{\circ}$. Figure 5.9 represents a typical stress-strain curve of tri-directional with CSM composite coupon specimen. As seen from Figure 5.10 the curve is almost bi-linear where the last $10 \%$ of ultimate load was neglected, as in some cases beyond $90 \%$ of ultimate load some irregularities in the curve were observed. Stresses were computed as detailed in Chapter 4 Section 4.3.2, and were found to be around 60ksi (corresponding to $90 \%$ of ultimate load) for $53 \%$ FVF as shown in Table 5.4. Strains were found to be in the range $2.1 \%$. Stiffness from the each of the linear curve was obtained by using linear regression fit. The point where change of slope occurred was found to be 0.25 with respect to the strains. 
Table 5.4 Tension Test Results of Tri-directional with CSM in Longitudinal Direction

\begin{tabular}{|c|c|c|c|c|c|c|c|c|c|c|c|c|c|c|}
\hline Material & Material & $\begin{array}{l}\text { Density } \\
\left(o z / y d^{2}\right)\end{array}$ & $\begin{array}{c}F V F \\
(\%)\end{array}$ & $\begin{array}{c}F V F \\
-X \\
(\%)\end{array}$ & $\begin{array}{l}\text { Ethe } \\
\text { (msi) }\end{array}$ & $\begin{array}{c}\text { Strain } \\
\text { at } 90 \% \\
\text { Ultimate } \\
(\%)\end{array}$ & $\begin{array}{c}\text { Strain } \\
\text { at } \\
\text { Ultimat } \\
e \\
(\%) \\
\end{array}$ & $\begin{array}{c}\text { Strain } \\
\text { at } F-B i \\
\quad(\%)\end{array}$ & $F-B i$ & $\begin{array}{c}\text { Stress } \\
\text { at } 90 \% \\
\text { Ultimat } \\
e \\
(\mathrm{ksi}) \\
\end{array}$ & $\begin{array}{c}\text { Stress } \\
\text { at } \\
\text { Ultima } \\
\text { te } \\
(\mathrm{ksi}) \\
\end{array}$ & $E \alpha$ & $E \boldsymbol{\beta}$ & $\begin{array}{l}E \alpha / \\
E \beta\end{array}$ \\
\hline NTL1 & \multirow{3}{*}{$\begin{array}{c}\text { 45/0/-45/CSM } \\
4 \text { layers }\end{array}$} & \multirow{3}{*}{$\begin{array}{c}45^{\circ}- \\
11.44 \\
90^{\circ}- \\
17.28 \\
\text { CSM- } \\
13.5\end{array}$} & 58 & 38 & 4.24 & 2.08 & 2.13 & .53 & 0.25 & 60.35 & 66.13 & 3.43 & 2.68 & 1.28 \\
\hline NNTL1 & & & 56 & 37 & 4.09 & 1.75 & 2.01 & 0.31 & 0.18 & 49.62 & 55.11 & 3.13 & 2.67 & 1.17 \\
\hline NNTL2 & & & 56 & 37 & 4.09 & 1.80 & 2.00 & 0.59 & 0.33 & 52.30 & 58.08 & 3.34 & 2.70 & 1.24 \\
\hline
\end{tabular}


Tri-directional with CSM Laminates $[45 / 0 /-45 / C S M]_{4 S} \mathrm{L1}$

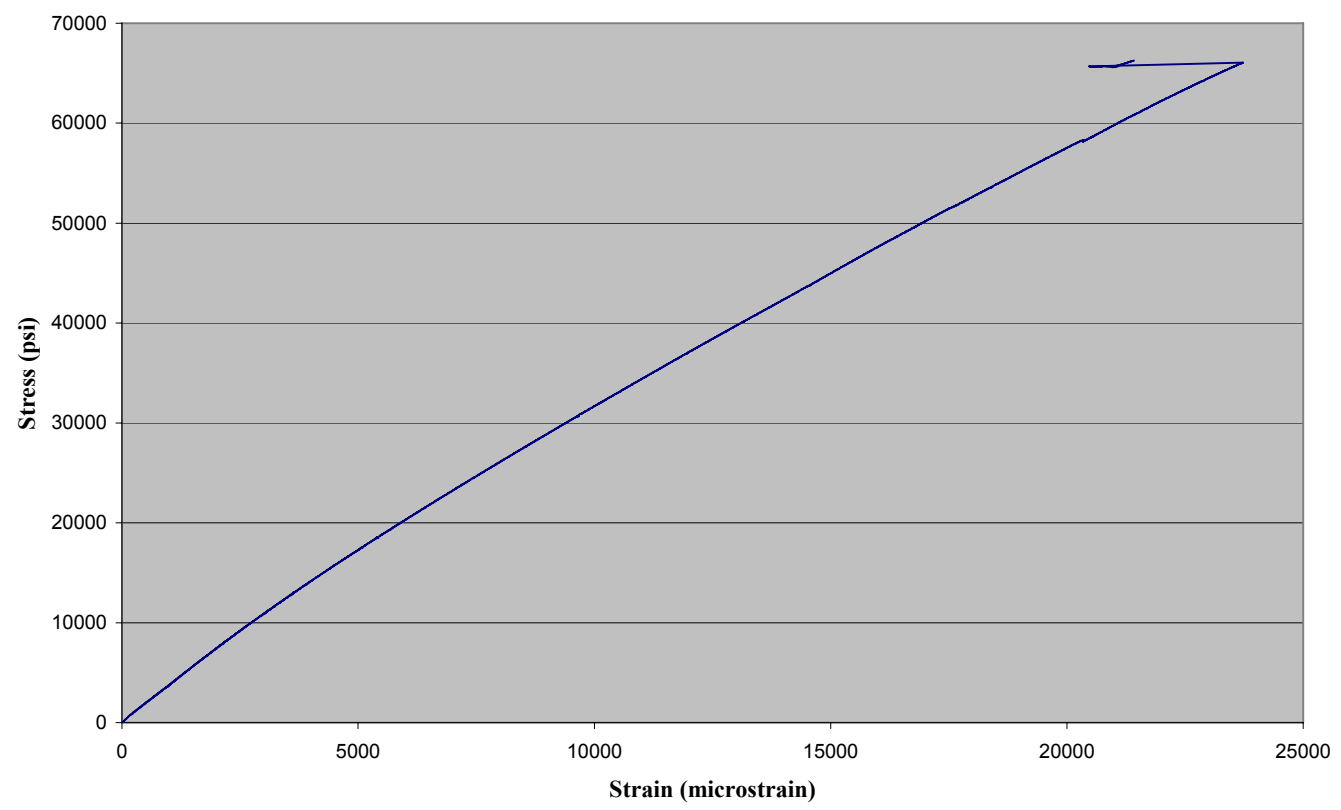

Figure 5.9 Stress-strain of Tri-directional with CSM (TTL1Q)

Tri-directional with CSM Laminates $[45 / 0 /-45 / C S M]_{4 S} \mathrm{L1}$

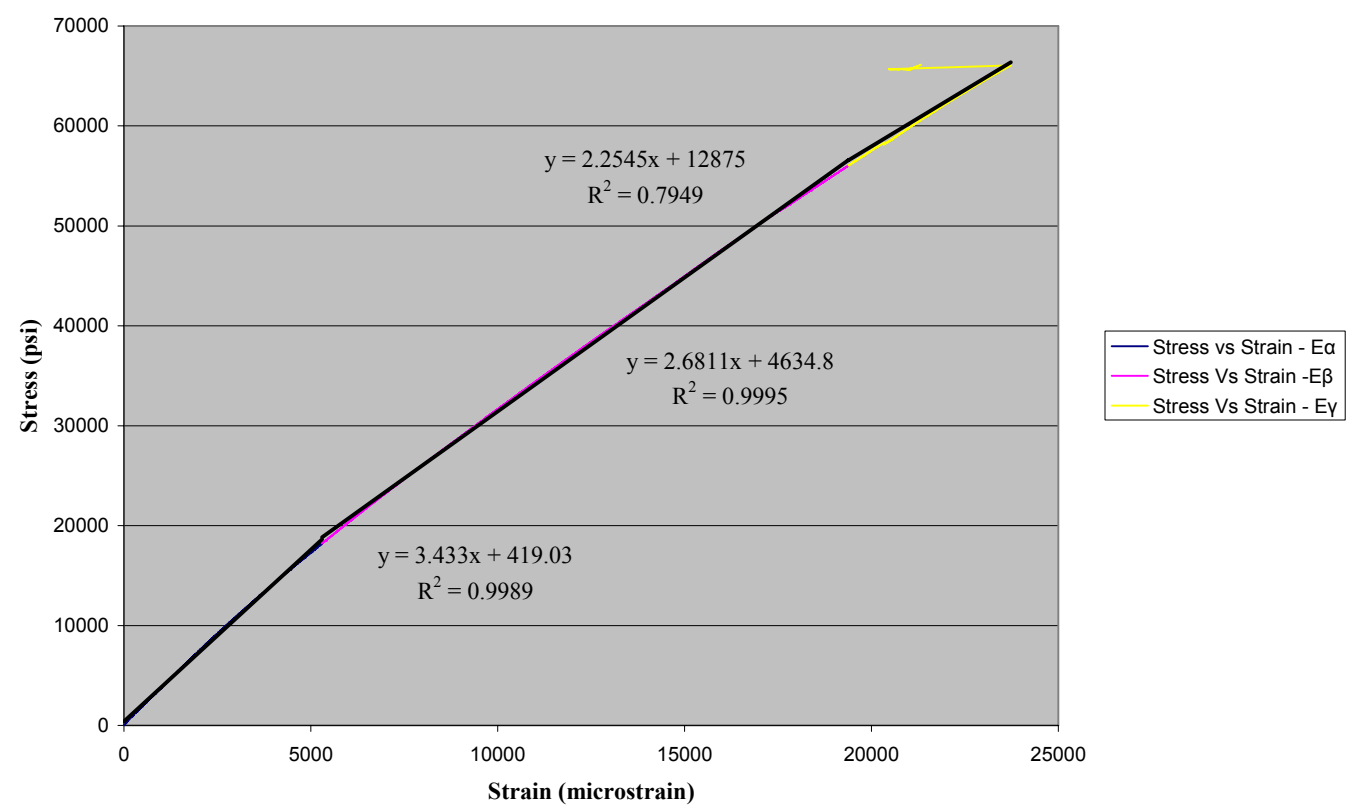

Figure 5.10 Stress-strain of Tri-directional with CSM (TTL1Q) until ultimate load 


\subsubsection{Quadri-directional with CSM}

Coupon specimens with this fiber architecture are made of 6 layers and 4 layers of $63 \mathrm{oz} / \mathrm{yd}^{2}$ fabric and are of $0.35 "$ and $0.25 "$ thick, respectively, with $0^{\circ}$ being the outermost layer. Stress-strain curves of TQL6Q and TQL2H - quadri-directional with CSM of 0.25 " and 0.35 " thick (apporx.) are shown in Figure 5.11 and Figure 5.13. Figure 5.12 and Figure 5.14 showed almost bi-linear curves beyond $90 \%$ of ultimate load. In some cases, a third slope was observed beyond 90\% ultimate load. Hence, for computation purposes, only up to $90 \%$ of ultimate load and its corresponding values were considered. The values are tabulated in Table 5.5. Stresses (90\% ultimate load) calculated were in the range of $45 \mathrm{ksi}$ for $55 \%$ FVF. Strains observed were around $1.7 \%$. Stiffness was obtained from the slope of the bi-linear curve using linear regression fit. The point where change of slope occurred was found to be 0.35 .

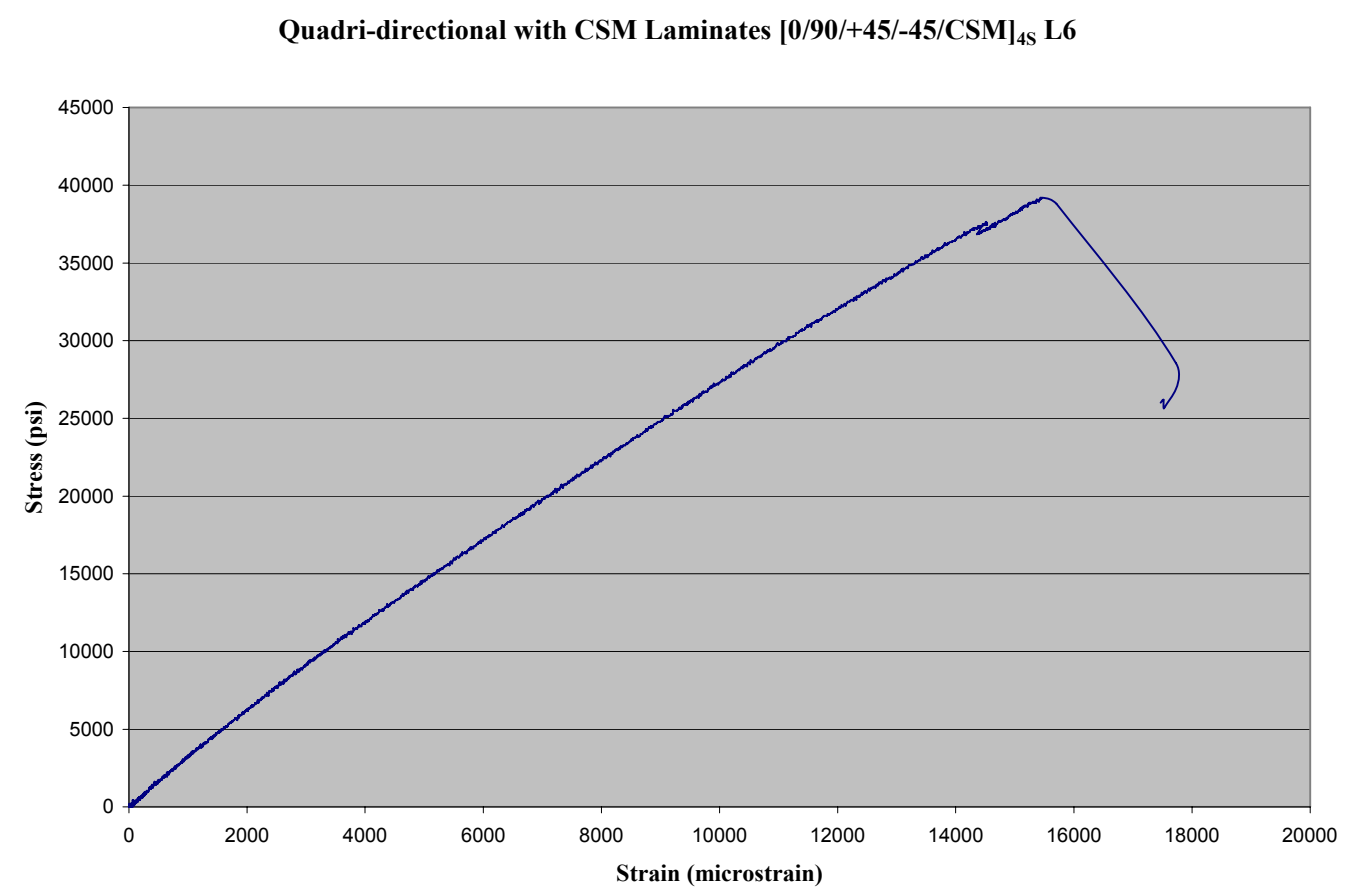

Figure 5.11 Stress-strain of quadri-directional with CSM laminate (TQWCL6Q) 
Quadri-directional with CSM Laminates $[0 / 90 /+45 /-45 / C S M]_{4 S} \mathrm{L6}$

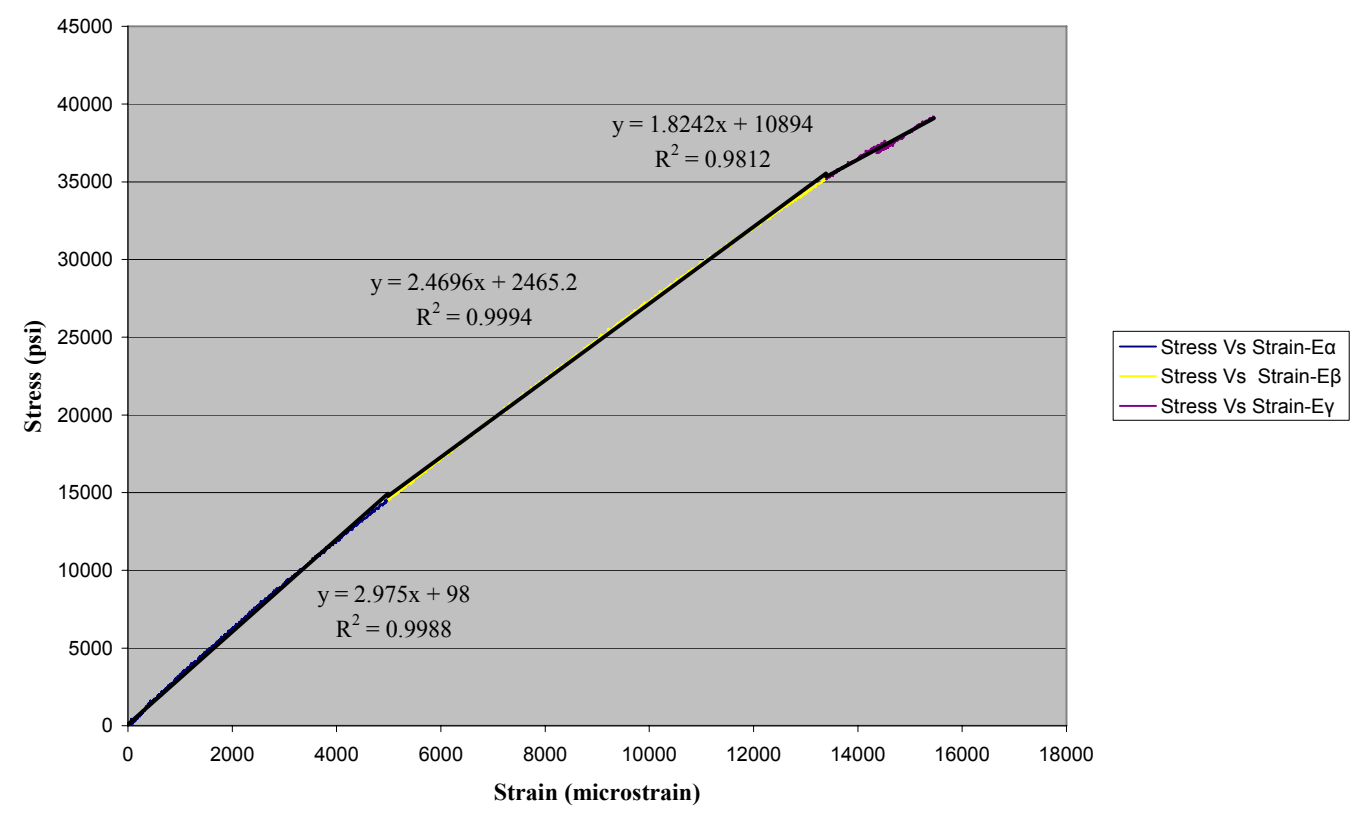

Figure 5.12 Stress-strain of Quadri-directional with CSM laminate (TQWCL6Q) until ultimate load

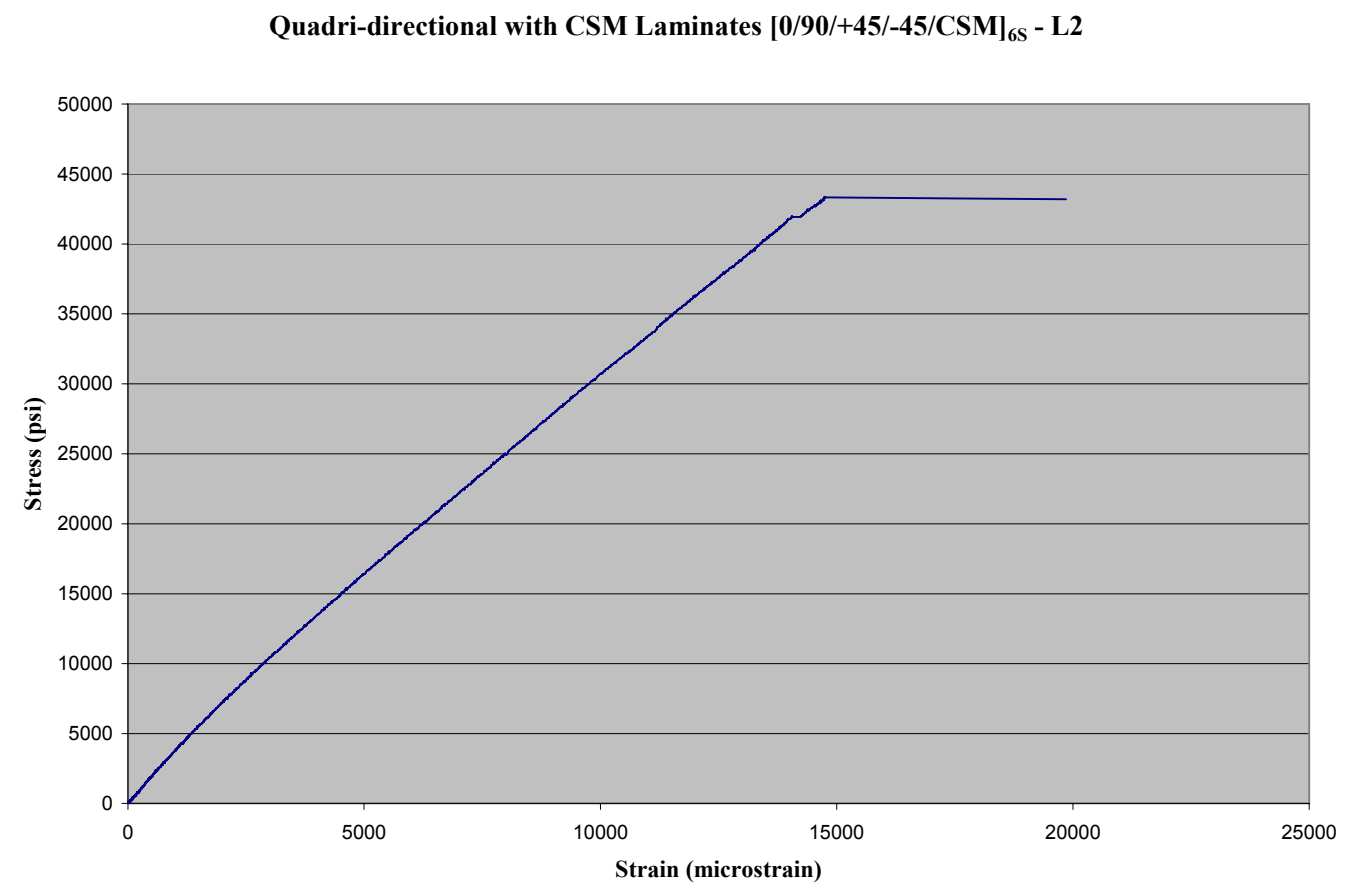

Figure 5.13 Stress-strain of quadri-directional with CSM laminate (TQWCL2H) 


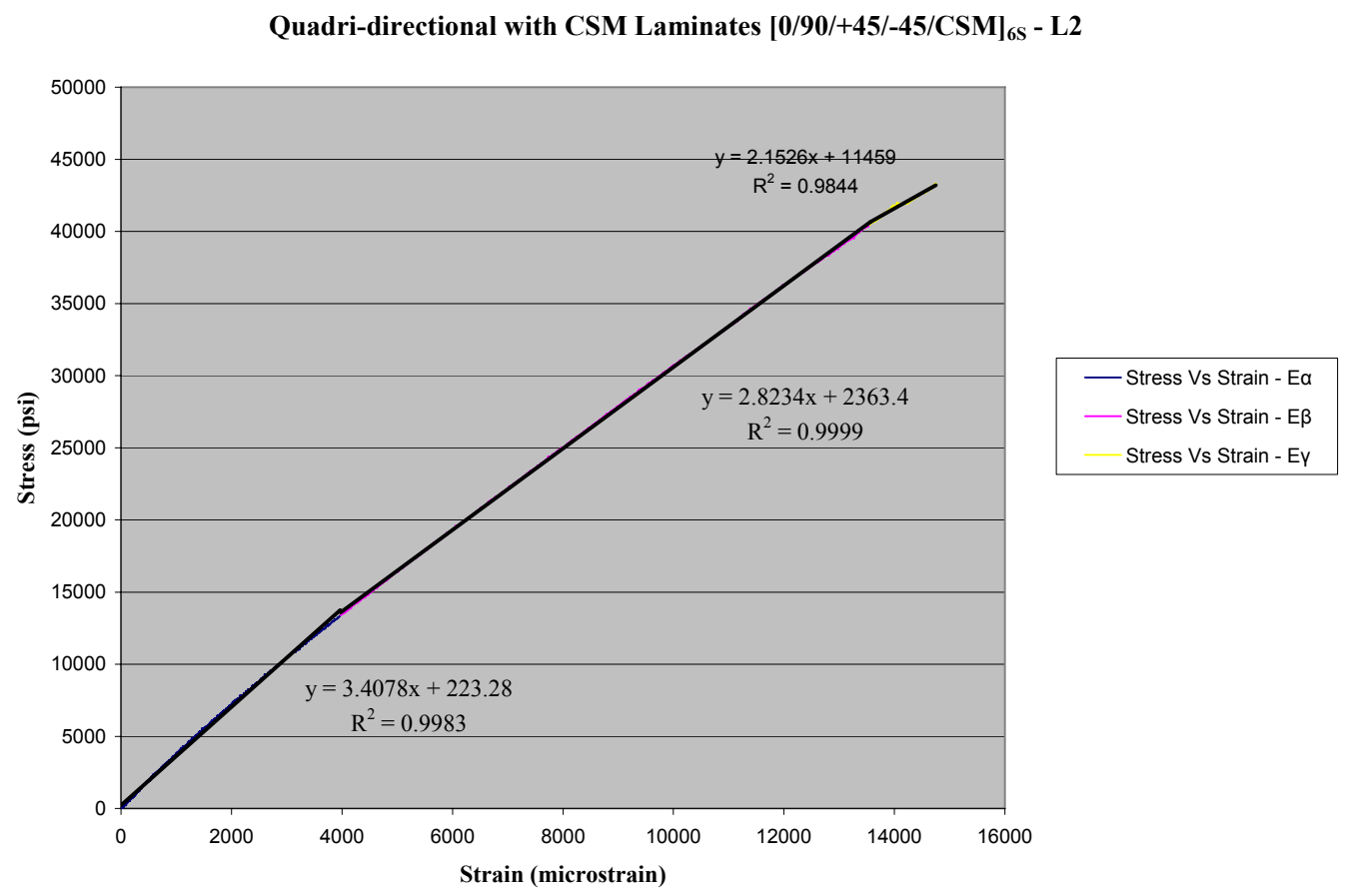

Figure 5.14 Stress -strain of Quadri-directional with CSM laminate (TQWCL2H) until ultimate load in longitudinal direction 
Table 5.5 Tension Test Results of Quadri-directional with CSM Laminates in Longitudinal Direction

\begin{tabular}{|c|c|c|c|c|c|c|c|c|c|c|c|c|c|c|}
\hline & Material & $\begin{array}{l}\text { Density } \\
\left(o z / y d^{2}\right)\end{array}$ & $\begin{array}{c}F V F \\
(\%)\end{array}$ & $\begin{array}{c}F V F- \\
X \\
(\%)\end{array}$ & $\begin{array}{l}\text { Ethe } \\
\text { (msi) }\end{array}$ & $\begin{array}{c}\text { Strain } \\
\text { at } 90 \% \\
\text { Ultimat } \\
e \\
(\%)\end{array}$ & $\begin{array}{c}\text { Strain } \\
\text { at } \\
\text { Ultimat } \\
e \\
(\%)\end{array}$ & $\begin{array}{c}\text { Strain } \\
\text { at } \\
F-B i \\
(\%)\end{array}$ & $F-B i$ & $\begin{array}{c}\text { Stress } \\
\text { at } 90 \% \\
\text { Ultimat } \\
\text { e load } \\
\text { (ksi) }\end{array}$ & $\begin{array}{c}\text { Stress } \\
\text { at } \\
\text { Ultimat } \\
e \\
\text { (ksi) }\end{array}$ & $\begin{array}{c}E \alpha \\
(m s i)\end{array}$ & $\begin{array}{c}E \beta \\
\text { (msi) }\end{array}$ & $\begin{array}{c}E \alpha / E \\
\beta\end{array}$ \\
\hline TQL2H & \multirow{4}{*}{$\begin{array}{c}0 / 90 / \pm 45 / \\
\text { CSM }\end{array}$} & \multirow{4}{*}{$\begin{array}{c}0^{\circ}-15.71 \\
90^{\circ}-14.08 \\
45^{\circ}-9.04 \\
\text { CSM-13.5 }\end{array}$} & 54 & 28 & 3.14 & 1.34 & 1.47 & 4603.64 & 0.34 & 39.07 & 43.33 & 3.41 & 2.82 & 1.21 \\
\hline TQL3H & & & 54 & 28 & 3.14 & 1.42 & 1.64 & 4740.91 & 0.33 & 39.42 & 43.26 & 3.08 & 2.62 & 1.17 \\
\hline TQL4H & & & 54 & 28 & 3.14 & 1.57 & 1.74 & 5548.74 & 0.35 & 42.96 & 47.66 & 3.24 & 2.70 & 1.20 \\
\hline TQL7H & & & 54 & 28 & 3.14 & 1.62 & 1.53 & 6020.14 & 0.37 & 41.86 & 58.67 & 3.00 & 2.27 & 1.32 \\
\hline TQL8H & \multirow[t]{2}{*}{6 layers } & \multirow{2}{*}{ Total 61.37} & 54 & 28 & 3.14 & 1.74 & 1.98 & 4669.53 & 0.27 & 46.97 & 52.16 & 3.40 & 2.52 & 1.35 \\
\hline TQL9H & & & 54 & 28 & 3.14 & 1.66 & 1.81 & 7467.44 & 0.45 & 46.63 & 51.69 & 3.45 & 2.55 & 1.36 \\
\hline
\end{tabular}

Table 5.6 Tension Test Results of Quadri-directional with CSM Laminates in Longitudinal Direction

\begin{tabular}{|c|c|c|c|c|c|c|c|c|c|c|c|c|c|c|}
\hline & Material & $\begin{array}{l}\text { Density } \\
\left(o z / y d^{2}\right)\end{array}$ & $\begin{array}{c}F V F \\
(\%)\end{array}$ & $\begin{array}{c}F V F- \\
X \\
(\%)\end{array}$ & $\begin{array}{l}\text { Ethe } \\
\text { (msi) }\end{array}$ & $\begin{array}{c}\text { Strain at } \\
90 \% \\
\text { Ultimate } \\
(\%)\end{array}$ & $\begin{array}{c}\text { Strain } \\
\text { at } \\
\text { Ultimate } \\
(\%)\end{array}$ & $\begin{array}{c}\text { Strain } \\
\text { at } F-B i \\
(\%)\end{array}$ & $F-B i$ & $\begin{array}{c}\text { Stress } \\
\text { at } 90 \% \\
\text { Ultimat } \\
\text { e load } \\
\text { (ksi) }\end{array}$ & $\begin{array}{c}\text { Stress } \\
\text { at } \\
\text { Ultim } \\
\text { ate } \\
\text { (ksi) }\end{array}$ & $\begin{array}{c}E \alpha \\
(m s i)\end{array}$ & $\begin{array}{c}E \beta \\
(m s i)\end{array}$ & $E \alpha / E \beta$ \\
\hline TQL2Q & \multirow{6}{*}{$\begin{array}{c}\text { 0/90/+45/- } \\
\text { 45/CSM } \\
4 \text { layers } \\
\text { Longi }\end{array}$} & \multirow{6}{*}{$\begin{array}{c}0-15.71 \\
90-14.08 \\
45-9.04 \\
\text { CSM-13.5 } \\
\text { Tot-61.37 }\end{array}$} & 55 & 28 & 3.19 & 1.70 & 19308 & 6322.11 & 0.37 & 44.15 & 49.03 & 3.12 & 2.60 & 1.20 \\
\hline TQL4Q & & & 55 & 28 & 3.19 & 1.59 & 17714 & 5156.09 & 0.32 & 40.13 & 44.55 & 2.91 & 2.33 & 1.25 \\
\hline TQL5Q & & & 55 & 28 & 3.19 & 1.40 & 15968 & 4826.82 & 0.34 & 37.04 & 41.03 & 3.06 & 2.49 & 1.23 \\
\hline TQL6Q & & & 55 & 28 & 3.19 & 1.34 & 14718 & 4989.64 & 0.37 & 35.30 & 39.20 & 2.99 & 2.49 & 1.20 \\
\hline TQL7Q & & & 55 & 28 & 3.19 & 1.34 & 15287 & 4546.76 & 0.34 & 36.82 & 40.70 & 3.31 & 2.48 & 1.34 \\
\hline TQL8Q & & & 55 & 28 & 3.19 & 1.58 & 18135 & 4555.89 & 0.29 & 39.02 & 43.29 & 2.99 & 2.25 & 1.33 \\
\hline
\end{tabular}




\subsubsection{Transverse Direction}

\subsubsection{Unidirectional Coupon Specimens}

Unidirectional fabrics of density $7 \mathrm{oz} / \mathrm{yd}^{2}$ were fabricated using vinyl ester resin and were cut in transverse direction so that the whole lay up has only $90^{\circ}$ fabric. Stressstrain curve for unidirectional composites in transverse direction is shown in Figure 5.15. Since only $90^{\circ}$ fibers were present, all the samples failed at very small loads. Ultimate stresses and corresponding strains were also very low and were in the range of $2 \mathrm{ksi}$ and $0.15 \%$. Figure 5.16 shows a linear relation until failure of the specimen and stiffness was found from linear regression fit.

Unidirectional Laminates $[0]_{28 \mathrm{~S}} \mathrm{T3}$

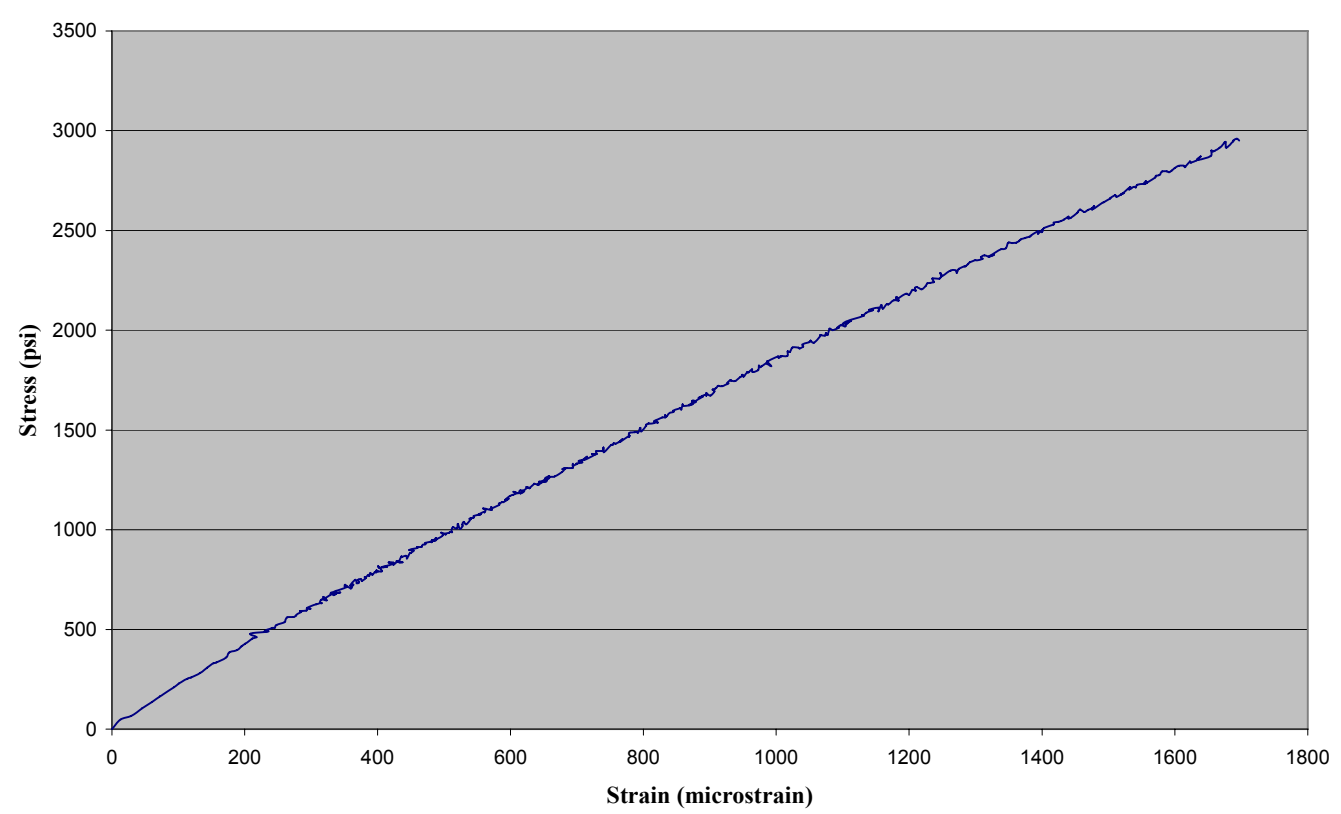

Figure 5.15 Stress-strain of unidirectional laminate (TUT1Q) in transverse direction 
Unidirectional Laminates $[0]_{28 \mathrm{~S}} \mathrm{T3}$

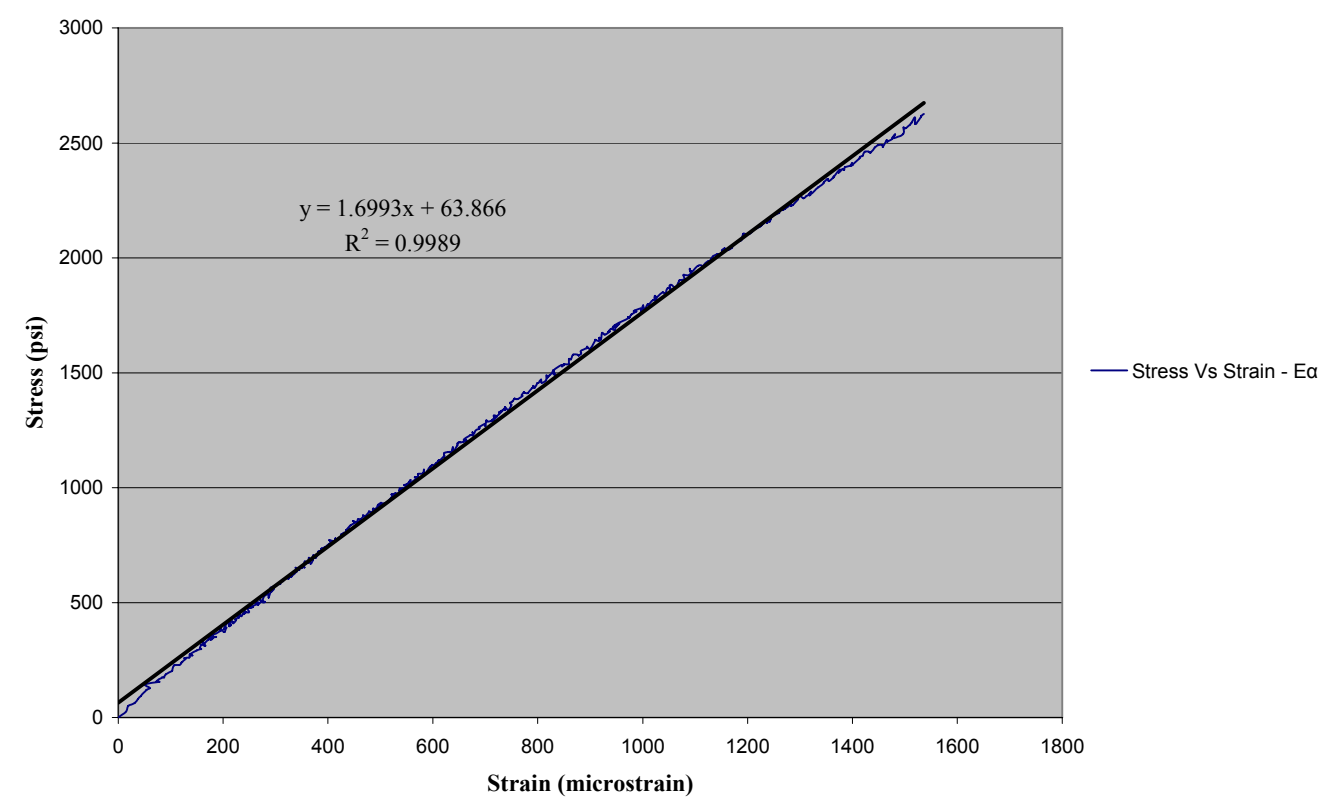

Figure 5.16 Stress-strain of unidirectional laminate (TUT1Q) until ultimate load

Table 5.7 Tension Test Results of Unidirectional Laminates in Transverse Direction

\begin{tabular}{|c|c|c|c|c|c|c|c|c|c|c|c|}
\hline & Material & $\begin{array}{c}F V F \\
(\%)\end{array}$ & $\begin{array}{c}F V F- \\
X \\
(\%)\end{array}$ & $\begin{array}{l}\text { Ethe } \\
\text { (msi) }\end{array}$ & $\begin{array}{c}\text { Load- } \\
90 \% \\
\text { Ultim } \\
\text { ate } \\
\text { (lb) }\end{array}$ & $\begin{array}{c}\text { Ultim } \\
\text { ate } \\
\text { Load } \\
\text { (lb) }\end{array}$ & $\begin{array}{c}\text { Strain } \\
\text { at } \\
90 \% \\
\text { Ultim } \\
\text { ate } \\
(\%)\end{array}$ & $\begin{array}{c}\text { Strain } \\
\text { at } \\
\text { Ultim } \\
\text { ate } \\
(\%)\end{array}$ & $\begin{array}{c}\text { Stress } \\
\text { at } \\
90 \% \\
\text { Ultim } \\
\text { ate } \\
\text { load } \\
\text { (ksi) }\end{array}$ & $\begin{array}{c}\text { Stress } \\
\text { at } \\
\text { Ultim } \\
\text { ate } \\
\text { (ksi) }\end{array}$ & $\begin{array}{c}E \alpha \\
(m s i)\end{array}$ \\
\hline UT3 & \multirow{2}{*}{$\begin{array}{c}\text { Unis } \\
28 \text { Layers } \\
90^{\circ}-6.8 \\
\text { oz }^{\prime} \mathrm{yd}^{2}\end{array}$} & 70 & 0 & 0.15 & 409.4 & 453.5 & 1.37 & 1.53 & 2.37 & 2.63 & 1.70 \\
\hline UT4 & & 70 & 0 & 0.15 & 286.0 & 315.8 & 1.50 & 1.64 & 1.43 & 1.57 & 0.94 \\
\hline
\end{tabular}

\subsubsection{Quadri-directional without CSM}

Ten layers of $0 / 90$ fabric with density $12 \mathrm{oz} / \mathrm{yd} 2$ were fabricated with vinyl ester resin. Five of the ten layers were cut in the direction of $45^{\circ}$ to achieve \pm 45 orientation and make the whole lay up symmetric and quadri-directional. Figure 5.17 represents stressstrain curve of TQT2Q - quadri-directional composite specimen in transverse direction. Figure 5.18 showed a bi-linear curve obtained from linear regression fit. Stresses at $90 \%$ ultimate load obtained were in the range of $40 \mathrm{ksi}$, slightly higher than the longitudinal direction coupon specimens for the same FVF (45\%) as shown from Table 5.7. 
Corresponding strains were in the range of $1.8 \%$. The point where change of slope occurred with respect to the strains is 0.34 .

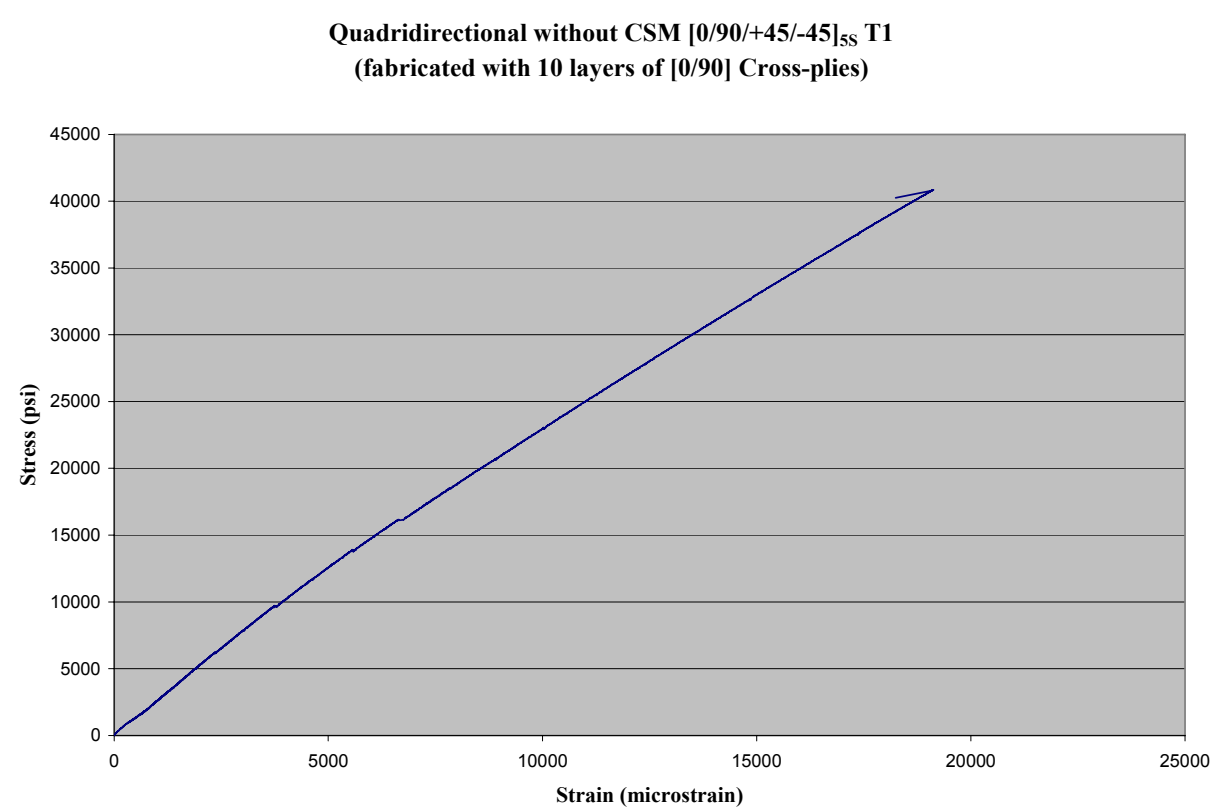

Figure 5.17 Stress-strain of quadri-directional laminate (TQT1Q)

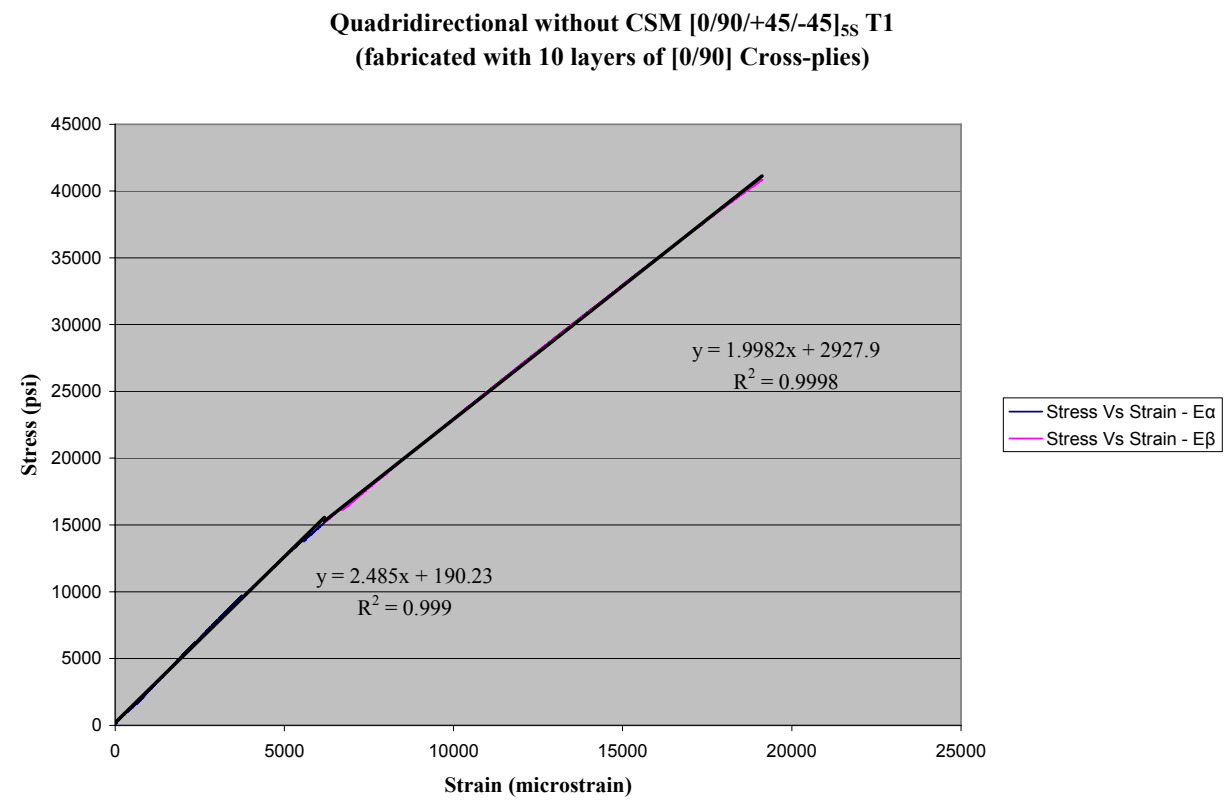

Figure 5.18 Stress-strain of quadri-directional laminate (TQT1Q) until ultimate load 
Table 5.8 Tension Test Results of Quadri-directional without CSM Laminate in Transverse Direction

\begin{tabular}{|c|c|c|c|c|c|c|c|c|c|c|c|c|c|c|}
\hline & Material & $\begin{array}{l}\text { Fabric } \\
\text { Density } \\
\left(o z / y d^{2}\right)\end{array}$ & $\begin{array}{c}F V F \\
(\%)\end{array}$ & $\begin{array}{c}F V F- \\
X \\
(\%)\end{array}$ & $\begin{array}{c}E_{t h e} \\
\text { (msi) }\end{array}$ & $\begin{array}{c}\text { Strain } \\
\text { at } 90 \% \\
\text { Ultima } \\
\text { te } \\
(\%)\end{array}$ & $\begin{array}{c}\text { Strain } \\
\text { at } \\
\text { Ultimat } \\
e \\
(\%) \\
\end{array}$ & $\begin{array}{c}\text { Strain } \\
\text { at } \\
F-B i \\
(\%)\end{array}$ & $F-B i$ & $\begin{array}{c}\text { Stress } \\
\text { at } 90 \% \\
\text { Ultimat } \\
\text { e load } \\
\text { (ksi) }\end{array}$ & $\begin{array}{c}\text { Stress } \\
\text { at } \\
\text { Ultimat } \\
e \\
\text { (ksi) } \\
\end{array}$ & $\begin{array}{c}E \alpha \\
\text { (msi) }\end{array}$ & $\begin{array}{c}E \beta \\
\text { (msi) }\end{array}$ & $\begin{array}{c}E \alpha / \\
E \beta\end{array}$ \\
\hline QWOCT1 & \multirow[t]{3}{*}{$90 / 0 / \pm 45$} & \multirow{3}{*}{$\begin{array}{c}0^{\circ}-11.52 \\
90^{\circ}-2.16 \\
\text { Total-23.68 }\end{array}$} & 44 & 22 & 2.63 & 1.69 & 1.91 & 0.71 & 0.42 & 36.79 & 40.86 & 2.44 & 1.99 & 1.22 \\
\hline QWOCT2 & & & 44 & 22 & 2.63 & 1.59 & 1.82 & 0.43 & 0.27 & 36.58 & 40.64 & 2.99 & 2.05 & 1.46 \\
\hline QWOCT3 & & & 44 & 22 & 2.63 & 1.60 & 1.83 & 0.53 & 0.33 & 35.15 & 39.05 & 2.65 & 1.92 & 1.38 \\
\hline
\end{tabular}




\subsubsection{Tri-directional with CSM}

Coupon specimens with two different thicknesses, approximately half-inch, and quarter-inch were considered, which were manufactured using 10 layers and 6 layers of 53oz/yd2, respectively. Figure 5.19 and Figure 5.21 represent typical stress-strain curves of tri-directional with CSM composite coupon specimen of 0.25 " (approx) and 0.35" (approx) thick, respectively. As seen from Figure 5.20 and Figure 5.22, three nearly linear slopes were observed instead of two, which might are attributed to absence of $0^{\circ}$ fibers. The linear portion represents the stiffness and was found by using linear regression curve fit. In most of the cases, fourth line, which is nearly linear, was observed. However, it was beyond $90 \%$ of ultimate load. Hence for all specimens, only $90 \%$ of ultimate load and its corresponding stress and strain values were considered for further calculations and evaluations. Stresses obtained were about 22ksi (90\% ultimate load) for 58\% FVF. Corresponding strains were in the range of $1.65 \%$ to $1.8 \%$ with first point where change of slope occurred was at around 0.18 , and second point where the change of slope occurred was around 0.52 . 
Table 5.9 Tension Test Results of Tri-directional with CSM Laminate in Transverse Direction

\begin{tabular}{|c|c|c|c|c|c|c|c|c|c|c|c|c|c|c|}
\hline & Material & $\begin{array}{l}\text { Fabric } \\
\text { Density } \\
\left(o z / y d^{2}\right)\end{array}$ & $\begin{array}{c}F V F \\
(\%)\end{array}$ & $\begin{array}{c}F V F- \\
X \\
(\%)\end{array}$ & Ethe & $\begin{array}{c}\text { Strain } \\
\text { at } 90 \% \\
\text { Ultimat } \\
e \\
(\%) \\
\end{array}$ & $\begin{array}{c}\text { Strain } \\
\text { at } \\
\text { Ultimat } \\
e \\
(\%) \\
\end{array}$ & $\begin{array}{c}\text { Strain } \\
\text { at } F-B i \\
\quad(\%)\end{array}$ & $\begin{array}{c}\text { Strain } \\
\text { at } S-B i \\
(\%)\end{array}$ & $F-B i$ & $\begin{array}{c}E \alpha \\
\text { (msi) }\end{array}$ & $\begin{array}{c}E \beta \\
(m s i)\end{array}$ & $\begin{array}{c}E \gamma \\
\text { (msi) }\end{array}$ & $E \alpha / E \beta$ \\
\hline TTT3H & \multirow{6}{*}{$\begin{array}{c}\text { 45/90/- } \\
\text { 45/CSM } \\
10 \text { layers } \\
\text { Trans }\end{array}$} & \multirow{6}{*}{$\begin{array}{c}45-11.44 \\
90-17.28 \\
\text { CSM-13.5 } \\
\text { SY-1.39 } \\
\text { Tot-53.06 }\end{array}$} & 56 & 19 & 2.20 & 1.78 & 2.18 & 0.272 & 0.94 & 0.15 & 1.95 & 1.34 & 0.88 & 1.46 \\
\hline TTT4H & & & 56 & 19 & 2.20 & 1.56 & 1.87 & 0.22 & 0.85 & 0.14 & 2.39 & 1.43 & 0.87 & 1.67 \\
\hline TTT5H & & & 56 & 19 & 2.20 & 1.78 & 2.18 & 0.26 & 0.71 & 0.15 & 2.20 & 1.32 & 0.88 & 1.67 \\
\hline TTT6H & & & 56 & 19 & 2.20 & 1.50 & 1.78 & 0.23 & 0.59 & 0.16 & 2.48 & 1.51 & 0.90 & 1.64 \\
\hline TTT7H & & & 56 & 19 & 2.20 & 1.44 & 1.73 & 0.25 & 0.82 & 0.18 & 2.12 & 1.48 & 0.94 & 1.43 \\
\hline TTT9H & & & 56 & 19 & 2.20 & 1.65 & 1.94 & 0.37 & 0.84 & 0.23 & 1.91 & 1.33 & 1.09 & 1.43 \\
\hline
\end{tabular}

Table 5.10 Tension Test Results of Tri-directional with CSM Laminate in Transverse Direction

\begin{tabular}{|c|c|c|c|c|c|c|c|c|c|c|c|c|c|c|}
\hline & Material & $\begin{array}{l}\text { Fabric } \\
\text { Density } \\
\left(o z / y d^{2}\right)\end{array}$ & $\begin{array}{c}F V F \\
(\%)\end{array}$ & $\begin{array}{c}F V F- \\
X \\
(\%)\end{array}$ & $\begin{array}{l}\text { Ethe } \\
\text { (msi) }\end{array}$ & $\begin{array}{c}\text { Strain } \\
\text { at } 90 \% \\
\text { Ultimat } \\
e \\
(\%) \\
\end{array}$ & $\begin{array}{c}\text { Strain } \\
\text { at } \\
\text { Ultimat } \\
e \\
(\%) \\
\end{array}$ & $\begin{array}{c}\text { Strain } \\
\text { at } F-B i \\
(\%)\end{array}$ & $\begin{array}{c}\text { Strain } \\
\text { at } S-B i \\
(\%)\end{array}$ & $F-B i$ & $\begin{array}{c}E \alpha \\
\text { (msi) }\end{array}$ & $\begin{array}{c}E \beta \\
\text { (msi) }\end{array}$ & $\begin{array}{c}E \gamma \\
\text { (msi) }\end{array}$ & $E \alpha / E \beta$ \\
\hline TTT2Q & \multirow{6}{*}{$\begin{array}{c}45 / 90 /- \\
45 / \mathrm{CSM} \\
6 \text { layers } \\
\text { Trans }\end{array}$} & \multirow{6}{*}{$\begin{array}{c}45-11.44 \\
90-17.28 \\
\text { CSM-13.5 } \\
\text { Tot-53.06 }\end{array}$} & 59 & 20 & 2.31 & 1.62 & 1.88 & 0.30 & 0.78 & 0.19 & 2.15 & 1.28 & 0.84 & 1.68 \\
\hline TTT4Q & & & 59 & 20 & 2.31 & 1.65 & 1.95 & 0.23 & 0.68 & 0.14 & 2.30 & 1.36 & 0.87 & 1.69 \\
\hline TTT5Q & & & 59 & 20 & 2.31 & 1.66 & 2.06 & 0.35 & 1.16 & 0.21 & 2.04 & 1.32 & 0.83 & 1.54 \\
\hline TTT6Q & & & 59 & 20 & 2.31 & 1.63 & 1.96 & 0.43 & 1.36 & 0.26 & 1.71 & 1.17 & 0.70 & 1.47 \\
\hline TTT7Q & & & 59 & 20 & 2.31 & 1.48 & 1.75 & 0.31 & 0.90 & 0.21 & 1.86 & 1.34 & 0.83 & 1.39 \\
\hline TTT8Q & & & 59 & 20 & 2.31 & 1.69 & 1.93 & 0.24 & 0.70 & 0.15 & 2.18 & 1.34 & 0.89 & 1.63 \\
\hline
\end{tabular}


Tri-directional with CSM Laminates - $[45 / 90 /-45 / C S M]_{4 S}-$ L4

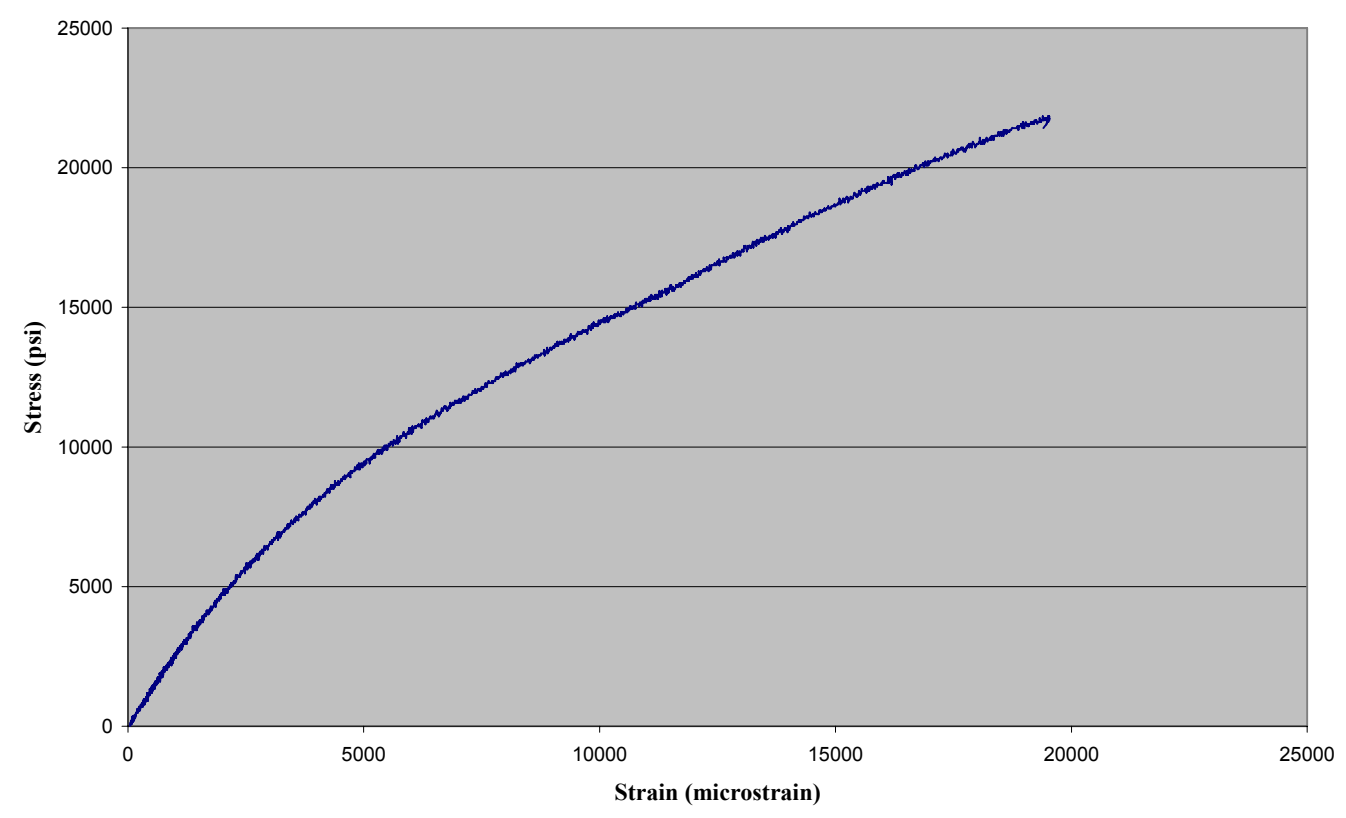

Figure 5.19 Stress-strain of tri-directional with CSM laminate (TTL4Q)

Tri-directional with CSM Laminates - $[45 / 90 /-45 / C S M]_{4 S}-$ L4

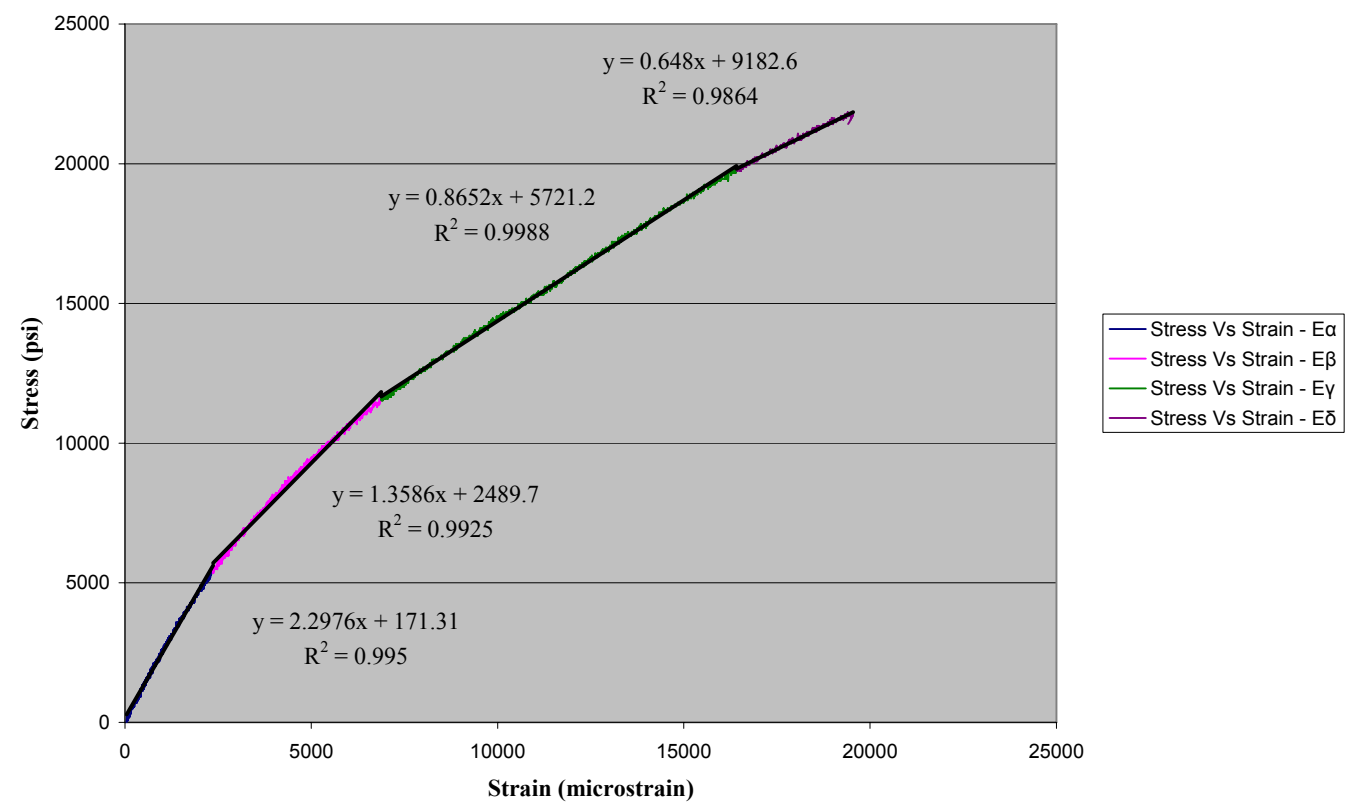

Figure 5.20 Stress-strain of tri-directional with CSM laminate (TTL4Q) until ultimate load 
Tri-directional with CSM Laminates $[45 / 90 /-45 / C S M]_{10 S} \mathrm{L3}$

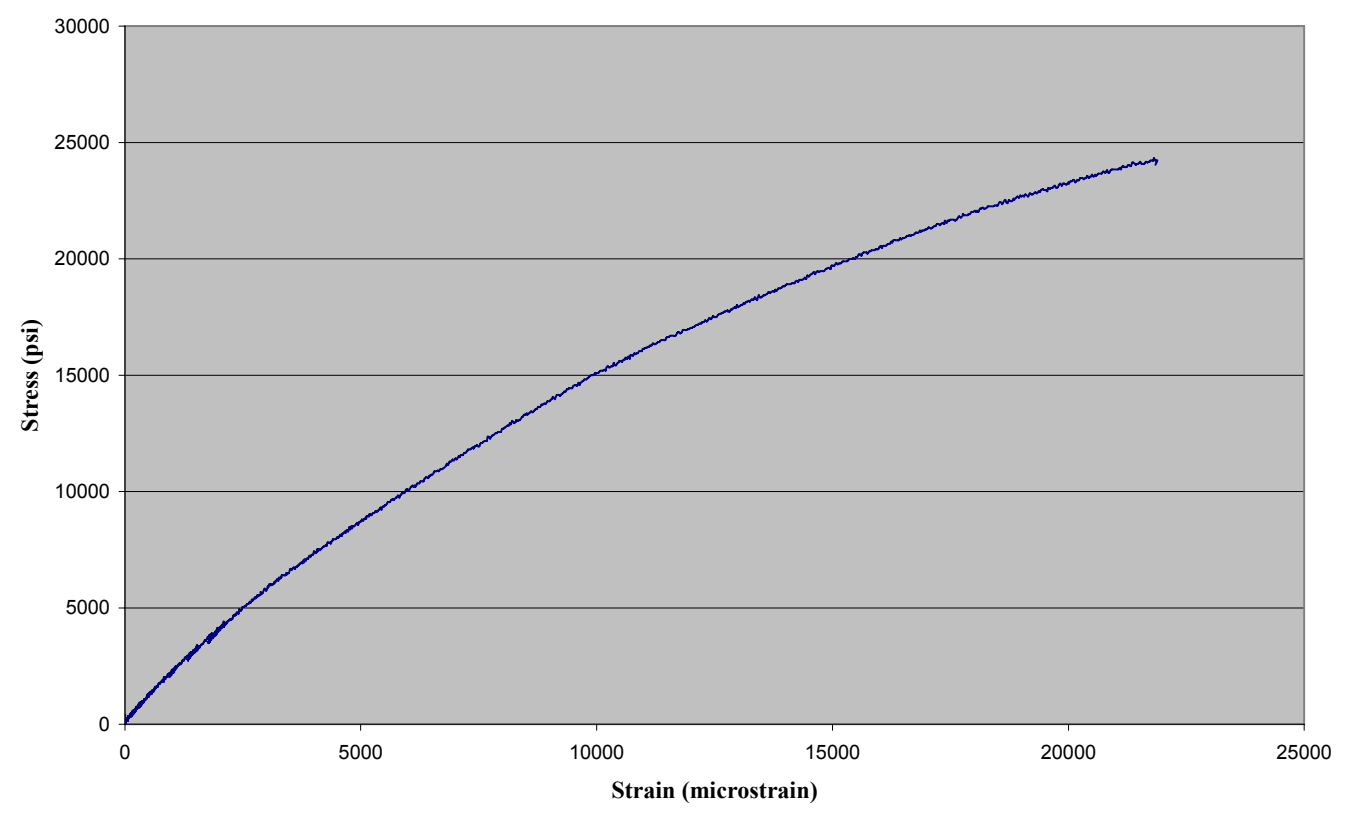

Figure 5.21 Stress-strain of tri-directional with CSM laminate (TTL3H)

Tri-directional with CSM Laminates $[45 / 90 /-45 / C S M]_{10 S} \mathrm{L3}$

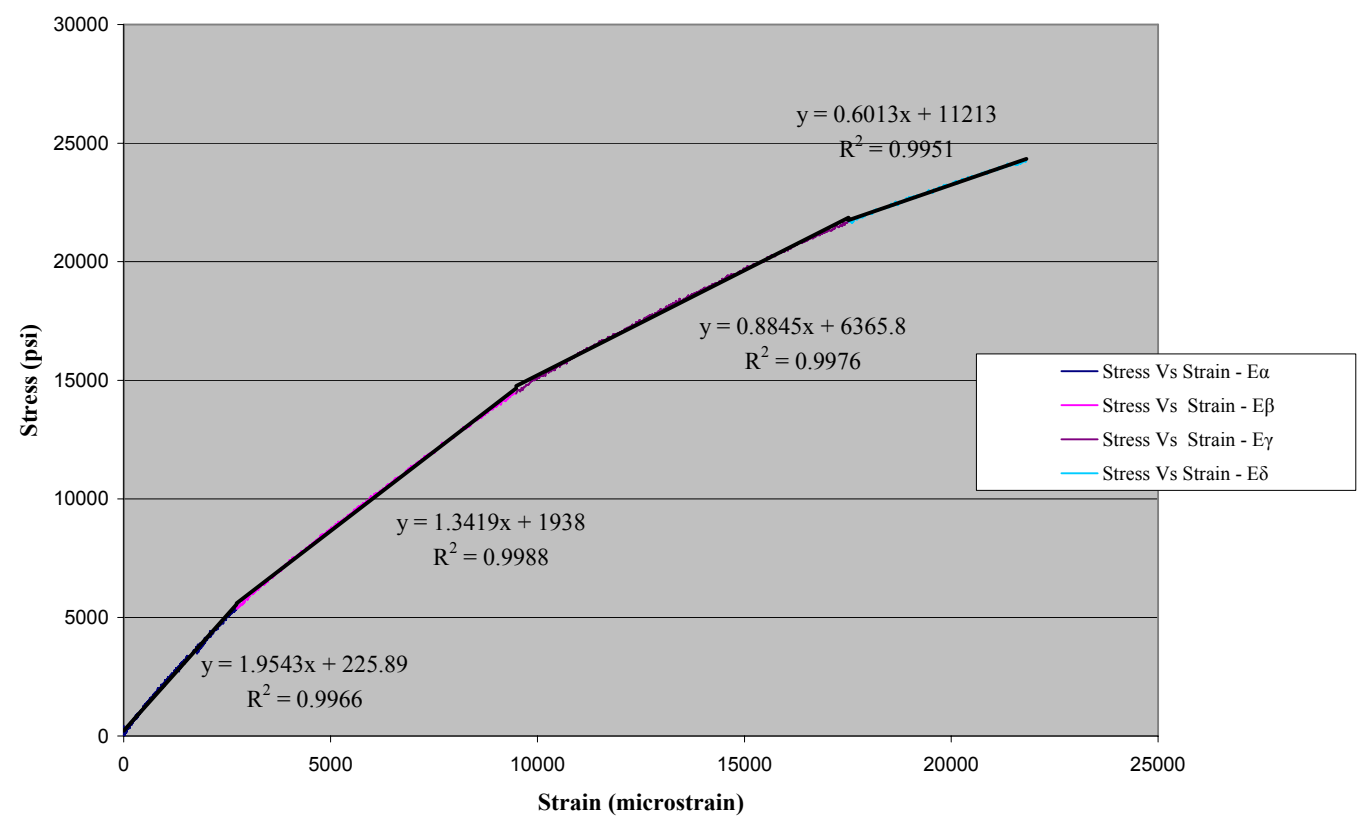

Figure 5.22 Stress-strain of tri-directional with CSM laminate (TTL3H) until ultimate load 


\subsubsection{Quadri-directional with CSM}

Coupon specimens were manufactured with 4 layers of $61 \mathrm{oz} / \mathrm{yd} 2$ fabric density. Stress-strain curve for TQL6Q - coupons of quadri-directional fabrics with CSM - cut in transverse direction, is shown in Figure 5.23. A nearly bi-linear curve as shown in Figure 5.24 was observed similar to other cases and the modulus from the curves was obtained using linear regression curve fit. In some cases, beyond $90 \%$ of ultimate load, a nearly third linear curve was observed. However, the third linear portion was neglected for analysis. Until $90 \%$ of ultimate load, corresponding stresses and strains were considered for calculation purposes and tabulated in Table 5.9. Strains ( $90 \%$ ultimate load) were in the range of $1.8 \%$ to $2.0 \%$. Point where change of slope occurred with respect to the strains was around 0.26 . Stresses computed as mentioned in the Chapter 4, section, were about $44 \mathrm{ksi}$ ( $90 \%$ ultimate load) for 55\% FVF.

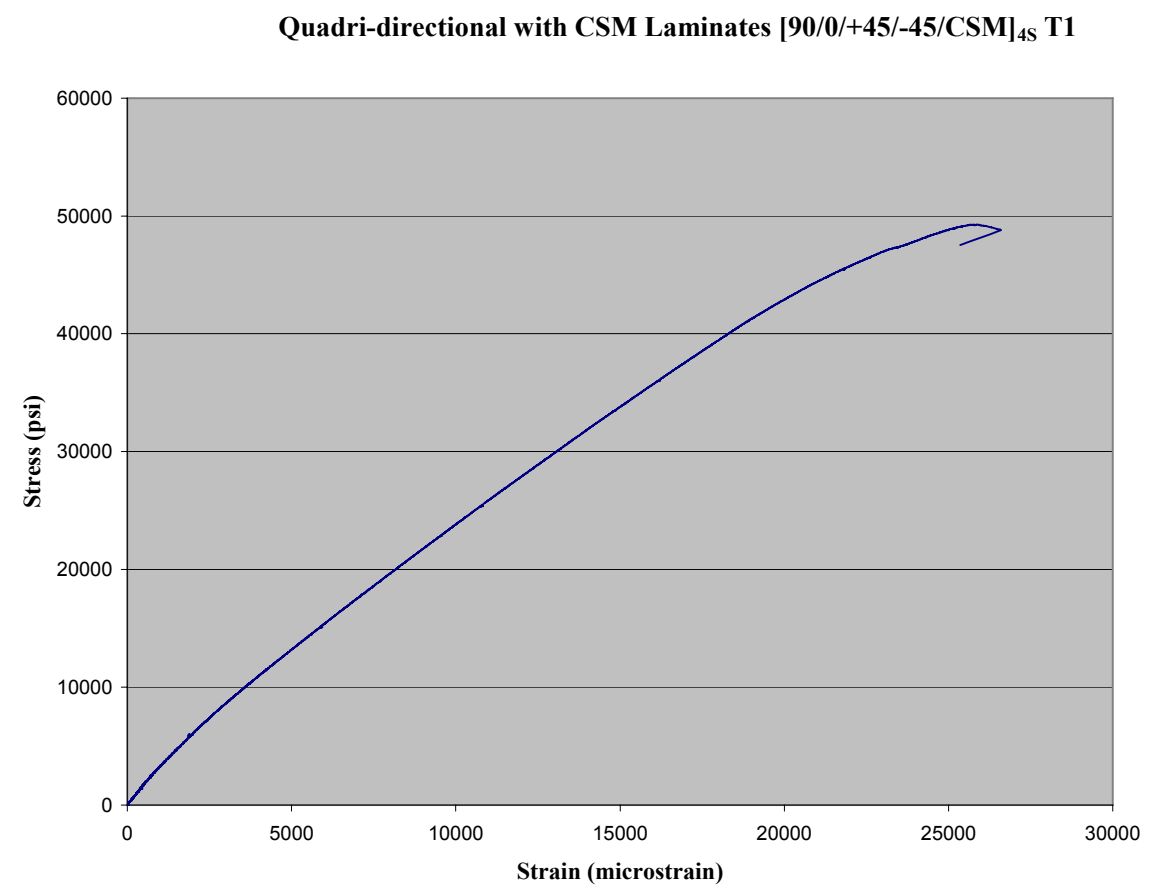

Figure 5.23 Stress-strain of quadri-directional with CSM laminate (TQWCT1Q) 


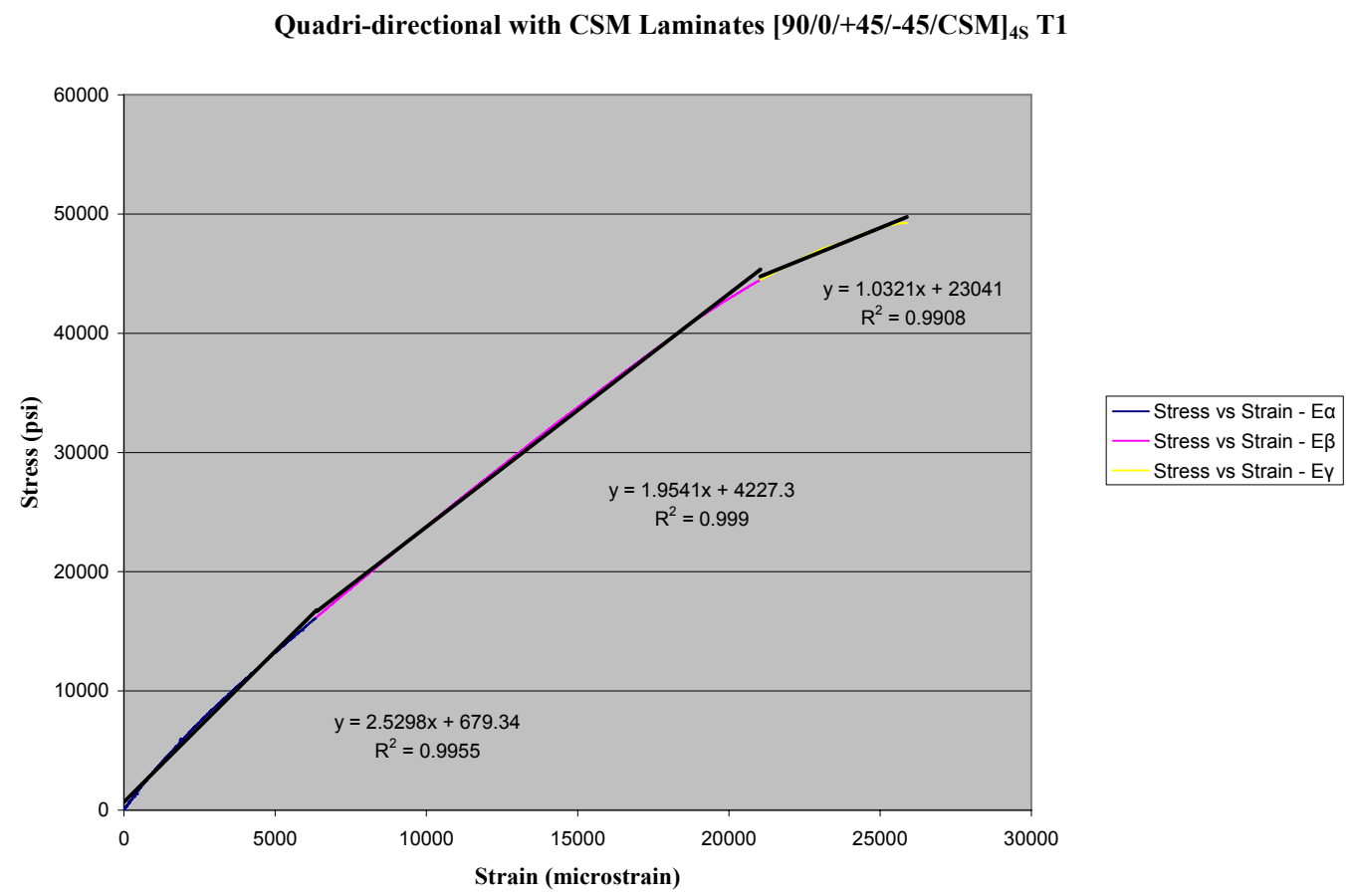

Figure 5.24 Stress-strain of quadri-directional with CSM laminate (TQWCT1Q) until ultimate load 
Table 5.11 Tension Test Results of quadri-directional with CSM laminates in Transverse Direction

\begin{tabular}{|c|c|c|c|c|c|c|c|c|c|c|c|c|c|c|}
\hline & Material & $\begin{array}{l}\text { Fabric } \\
\text { Density } \\
\left(o z / y d^{2}\right)\end{array}$ & $\begin{array}{c}F V F \\
(\%)\end{array}$ & $\begin{array}{c}F V F- \\
X \\
(\%)\end{array}$ & $\begin{array}{l}\text { Ethe } \\
\text { (msi) }\end{array}$ & $\begin{array}{c}\text { Strain at } \\
90 \% \\
\text { Ultimate } \\
(\%)\end{array}$ & $\begin{array}{c}\text { Strain } \\
\text { at } \\
\text { Ultimat } \\
e \\
(\%) \\
\end{array}$ & $\begin{array}{c}\text { Strain } \\
\text { at } F-B i \\
(\%)\end{array}$ & $F-B i$ & $\begin{array}{c}\text { Stress at } \\
90 \% \\
\text { Ultimate } \\
\text { load } \\
\text { (ksi) }\end{array}$ & $\begin{array}{c}\text { Stress } \\
\text { at } \\
\text { Ultimat } \\
e \\
(k s i) \\
\end{array}$ & $\begin{array}{c}E \alpha \\
(m s i)\end{array}$ & $\begin{array}{c}E \beta \\
(m s i)\end{array}$ & $E \alpha / E \beta$ \\
\hline NQT1 & \multirow{3}{*}{$\begin{array}{c}90 / 0 / \pm 45 / \\
\text { CSM } \\
4 \text { layers } \\
\text { Trans }\end{array}$} & \multirow{3}{*}{$\begin{array}{c}0-15.71 \\
90-14.08 \\
45-9.04 \\
\text { CSM-13.5 }\end{array}$} & 54 & 26 & 2.99 & 1.79 & 2.37 & 0.36 & 0.20 & 38.38 & 42.59 & 3.16 & 2.08 & 1.52 \\
\hline NNTQ2 & & & 56 & 29 & 3.25 & 1.75 & 2.10 & 0.59 & 0.34 & 43.69 & 48.41 & 2.69 & 1.97 & 1.36 \\
\hline NNTQ1 & & & 56 & 29 & 3.25 & 2.09 & 2.58 & 0.64 & 0.30 & 44.73 & 49.65 & 2.53 & 1.95 & 1.29 \\
\hline
\end{tabular}




\subsection{BENDING TEST DATA ANALYSIS}

Over 100 specimens of different fiber architectures were tested both in longitudinal and transverse direction under four-point bending test (see Table 4.2). About 15 specimens of different fiber architecture were tested for 3-point bending test in order to evaluate shear effects and are described in section 5.5.

\subsubsection{Four-Point Bending Test - Longitudinal Direction}

\subsubsection{Unidirectional Coupon Specimens}

Typical stress-strain and load-deflection curves of unidirectional composite coupons under bending in longitudinal direction are shown in Figure 5.25 and Figure 5.27. It is evident from Figure 5.26 and Figure 5.28 that the stress-strain and load deflection was linear almost to the ultimate stress and ultimate load, respectively. The slope of a stress-strain curve gives the stiffness of the specimen. In case of loaddeflection curve, the linear slope was taken and then solved for stiffness by converting load to engineering stress.

Strength, stiffness, load, strain, dimensions, fiber architecture, etc, were tabulated in Table 5.10. Strain gages were attached on three specimens to record strains. For the remaining specimens, load and deflection data were recorded. 28 layer coupons with 7 $\mathrm{oz} / \mathrm{yd}_{2}$, and 19 layer coupons with $12 \mathrm{oz} / \mathrm{yd}_{2}$ were prepared with vinyl ester resin and tested in bending. Stresses were computed as explained in Chapter 4, section 4.1.3, and corresponding strains were noted. The stresses were found to be $45 \mathrm{ksi}(90 \%$ ultimate load) for $65 \% \mathrm{FVF}$, and $60 \mathrm{ksi}$ ( $90 \%$ ultimate load) for $70 \% \mathrm{FVF}$. Strains were very low and are in the range of $0.8 \%$. 
Unidirectional Laminates - $[0]_{28 \mathrm{~S}} \mathrm{L1}$

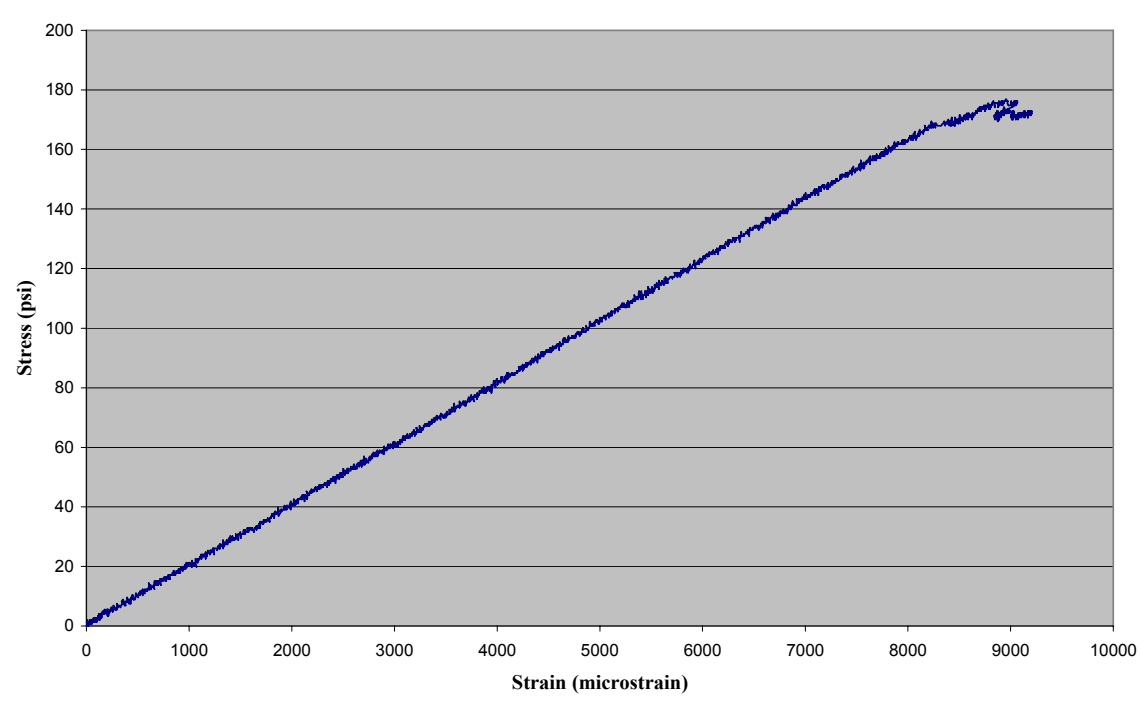

Figure 5.25 Stress-strain of unidirectional laminate (BUL1Q-C) in longitudinal direction Unidirectional Laminates - $[0]_{28 \mathrm{~S}} \mathrm{L1}$

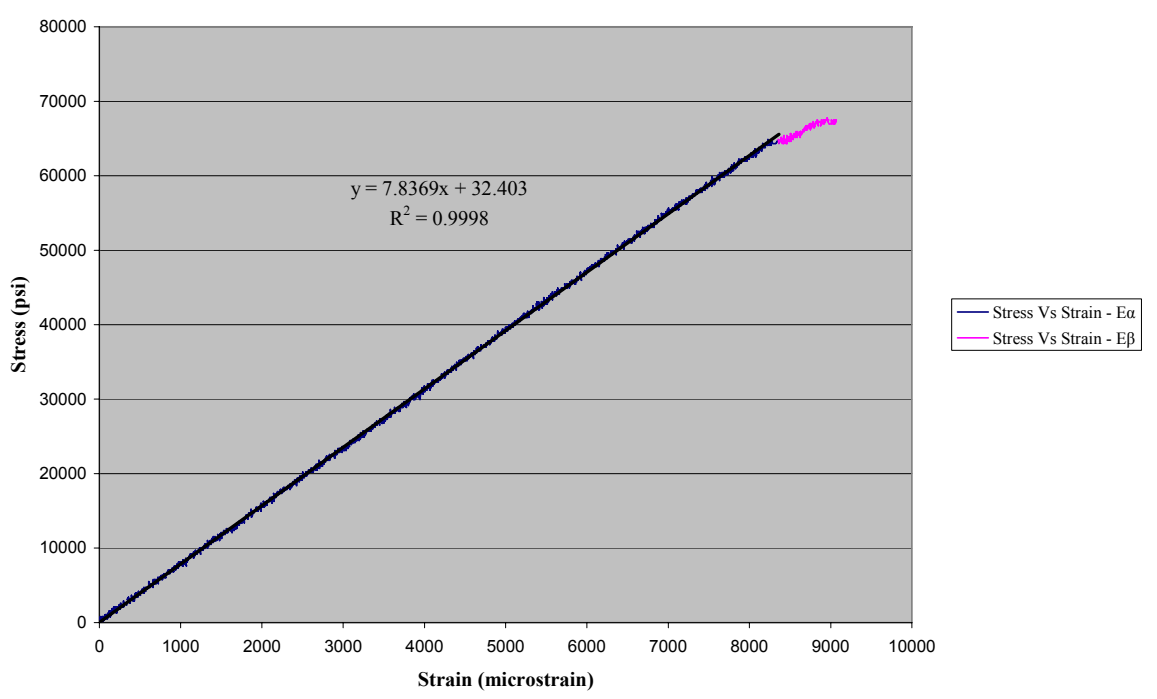

Figure 5.26 Stress-strain of unidirectional laminate (BUL1Q-C) until ultimate load in longitudinal direction 


\section{Unidirectional Laminates $[0]_{19 \mathrm{~s}} \mathrm{L5}$}

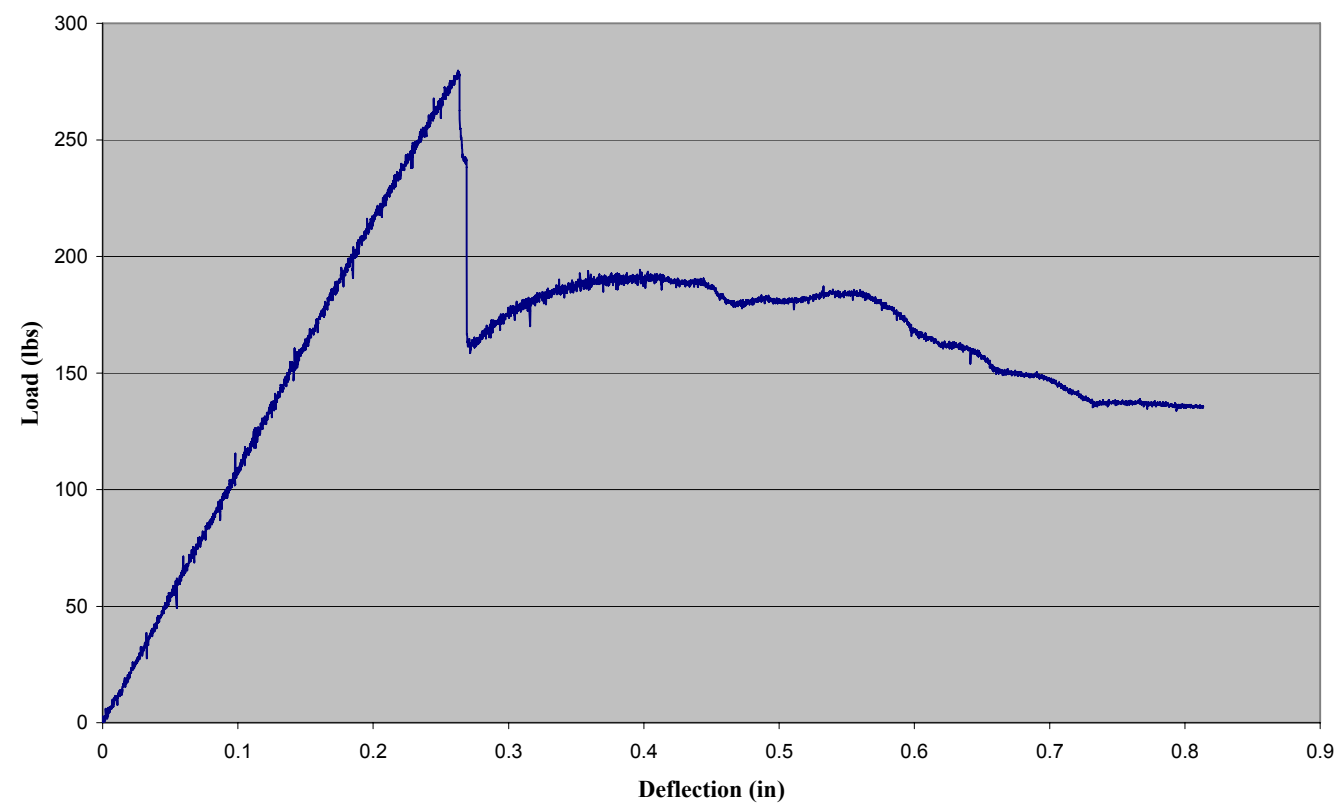

Figure 5.27 Stress-strain of unidirectional laminate (BUL5Q-K) in longitudinal direction

Unidirectional Laminates $[0]_{19 \mathrm{~S}} \mathrm{L5}$

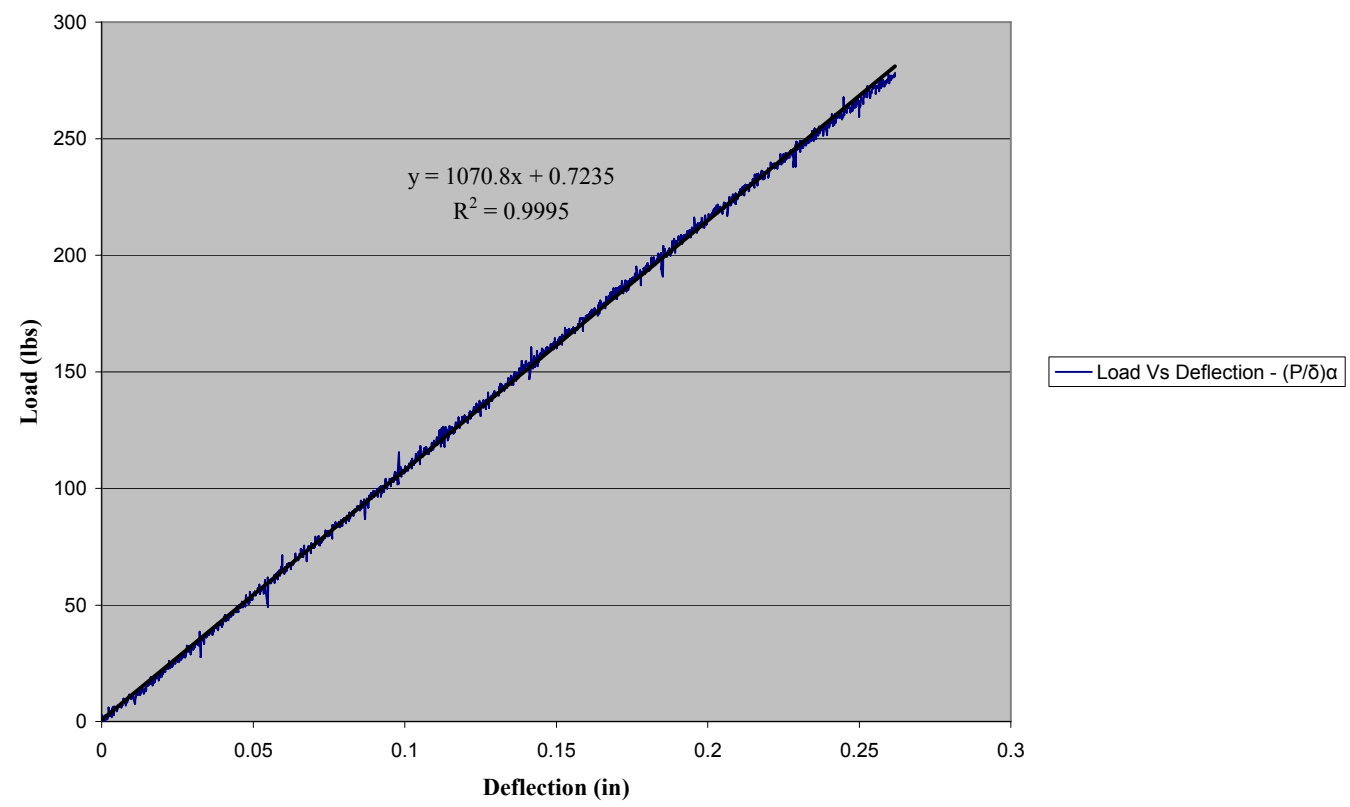

Figure 5.28 Load - deflection of unidirectional laminate (BUL5Q-K) until ultimate load in longitudinal direction 
Table 5.12 Bending Test Results of Unidirectional Laminates in Longitudinal Direction

\begin{tabular}{|c|c|c|c|c|c|c|c|c|c|c|}
\hline & Material & $\begin{array}{c}\text { Fabric } \\
\text { Density } \\
\left(o z / y d^{2}\right)\end{array}$ & $\begin{array}{l}F V F \\
(\%)\end{array}$ & $\begin{array}{c}F V F- \\
X \\
(\%)\end{array}$ & $\begin{array}{l}\text { Ethe } \\
\text { (msi) }\end{array}$ & $\begin{array}{c}\text { Strain } \\
\text { at 90\% } \\
\text { Ultimate } \\
\text { (\%) }\end{array}$ & $\begin{array}{c}\text { Strain } \\
\text { at } \\
\text { Ultimate } \\
\text { Load } \\
(\%) \\
\end{array}$ & $\begin{array}{c}\text { Stress at } \\
90 \% \\
\text { Ultimate } \\
\text { (ksi) }\end{array}$ & $\begin{array}{c}\text { Stress at } \\
\text { Ultimate } \\
(\text { ksi })\end{array}$ & $\begin{array}{c}E \alpha \\
(m s i)\end{array}$ \\
\hline BUL1-4 & \multirow{3}{*}{$\begin{array}{c}\text { Unis } \\
28 \text { layers }\end{array}$} & \multirow{3}{*}{$0-6.8$} & 70 & 70 & 7.45 & 0.77 & 0.90 & 60.67 & 67.50 & 7.84 \\
\hline BUL3-4 & & & 70 & 70 & 7.45 & 0.83 & 0.84 & 68.90 & 76.55 & 8.28 \\
\hline BUL4-4 & & & 70 & 70 & 7.45 & 0.78 & 0.91 & 61.67 & 68.38 & 7.83 \\
\hline BUQL2 & \multirow{10}{*}{$\begin{array}{l}\text { Unis } \\
19 \\
\text { Layers }\end{array}$} & \multirow{10}{*}{$0-12$} & 65 & 65 & 7.02 & 0.64 & 0.73 & 46.83 & 51.91 & 7.61 \\
\hline BUQL3 & & & 65 & 65 & 7.02 & 0.54 & 0.60 & 40.86 & 45.36 & 7.52 \\
\hline BUQL4 & & & 65 & 65 & 7.02 & 0.59 & 0.80 & 42.25 & 47.05 & 7.40 \\
\hline BUQL5 & & & 65 & 65 & 7.02 & - & - & 48.85 & 54.36 & 8.00 \\
\hline BUQL6 & & & 65 & 65 & 7.02 & - & - & 50.70 & 56.36 & 7.78 \\
\hline BUQL7 & & & 65 & 65 & 7.02 & - & - & 39.64 & 43.92 & 8.64 \\
\hline BUQL8 & & & 65 & 65 & 7.02 & - & - & 44.73 & 49.68 & 8.36 \\
\hline BUQL9 & & & 65 & 65 & 7.02 & - & - & 50.06 & 55.63 & 8.43 \\
\hline BUQL10 & & & 65 & 65 & 7.02 & - & - & 45.60 & 50.56 & 8.06 \\
\hline BUQL12 & & & 65 & 65 & 7.02 & - & - & 44.40 & 49.37 & 8.31 \\
\hline BNUL1 & \multirow{3}{*}{$\begin{array}{c}\text { Unis } \\
19 \\
\text { Layers }\end{array}$} & \multirow{3}{*}{$0-12$} & 61 & 61 & 6.64 & 0.75 & 0.86 & 49.91 & 55.28 & 6.65 \\
\hline BNUL4 & & & 61 & 61 & 6.64 & - & - & 51.88 & 57.55 & 7.62 \\
\hline BNUL5 & & & 61 & 61 & 6.6421 & - & - & 46.20 & 51.30 & 7.72 \\
\hline
\end{tabular}

\subsubsection{Cross-ply Coupon Specimens}

Twenty layer composites of bi-directional fabric [0/90] of $24 \mathrm{oz} / \mathrm{yd}^{2}$ density with vinyl ester resin were used for the fabrication of cross-ply coupon specimens. The whole lay-up was placed symmetric with $0^{\circ}$ plies as outermost layers. Typical stress-strain and load-deflection curves shown in Figure 5.29 and Figure 5.31. Figure 5.30 and Figure 5.32 represent stress-strain and load-deflection curves up to the ultimate load, and it is evident that the curve was almost a bi-linear curve where the modulus is obtained by linear regression curve fit. For load-deflection curve, the slope value is solved for modulus of the specimen. Beyond $90 \%$ of ultimate load, some irregularities in the curve were observed. Hence for consistency and computational ease only $90 \%$ of ultimate load and its corresponding values (stresses, strains, etc.,) were considered. Stresses were found in the range of $60 \mathrm{ksi}$ ( $90 \%$ ultimate load) for $61 \% \mathrm{FVF}$. Corresponding strains were in the range of $1.8 \%$ to $2.0 \%$. Point where change of slope occurred with respect to strains was around 0.4 
Table 5.13 Bending Test Results of Cross-ply Laminates in Longitudinal Direction

\begin{tabular}{|c|c|c|c|c|c|c|c|c|c|c|c|c|c|c|}
\hline & Material & $\begin{array}{l}\text { Fabric } \\
\text { Density } \\
\left(o z / y d^{2}\right)\end{array}$ & $\begin{array}{c}F V F \\
(\%)\end{array}$ & $\begin{array}{c}F V F- \\
\boldsymbol{X} \\
(\%)\end{array}$ & $\begin{array}{l}\text { Ethe } \\
\text { (msi) }\end{array}$ & $\begin{array}{c}\text { Strain at } \\
F-B i \\
(\%)\end{array}$ & $\begin{array}{c}\text { Strain } \\
\text { at } 90 \% \\
\text { Ultimat } \\
e \\
(\%) \\
\end{array}$ & $\begin{array}{c}\text { Strain } \\
\text { at } \\
\text { Ultimat } \\
\text { e Load } \\
(\%)\end{array}$ & $F-B i$ & $\begin{array}{c}\text { Stress } \\
\text { at } 90 \% \\
\text { Ultimat } \\
e \\
\text { (ksi) }\end{array}$ & $\begin{array}{c}\text { Stress } \\
\text { at } \\
\text { Ultim } \\
\text { ate } \\
\text { (ksi) }\end{array}$ & $\begin{array}{c}E \alpha \\
(m s i)\end{array}$ & $\begin{array}{c}E \beta \\
(m s i)\end{array}$ & $E \alpha / E \beta$ \\
\hline BBL1H & \multirow{10}{*}{$\begin{array}{c}90 / 0 \\
20 \text { layers } \\
\text { Trans }\end{array}$} & \multirow{10}{*}{$\begin{array}{c}0-11.52 \\
90-12.16 \\
\text { Tot- } \\
23.68\end{array}$} & 61 & 30 & 3.30 & 0.68 & 1.73 & 1.95 & 0.40 & 64.52 & 71.58 & 3.98 & 3.57 & 1.11 \\
\hline BBL2H & & & 61 & 30 & 3.30 & 0.64 & 1.49 & 1.68 & 0.43 & 55.77 & 61.96 & 3.98 & 3.55 & 1.12 \\
\hline BBL5H & & & 61 & 30 & 3.30 & 0.69 & 1.77 & 1.94 & 0.40 & 58.87 & 65.41 & 3.58 & 3.18 & 1.13 \\
\hline BBL3H & & & 61 & 30 & 3.30 & - & - & - & - & 61.51 & 68.38 & 4.12 & 3.64 & 1.13 \\
\hline BBL6H & & & 61 & 30 & 3.30 & - & - & - & - & 47.10 & 52.35 & 3.27 & 2.84 & 1.15 \\
\hline BBL7H & & & 61 & 30 & 3.30 & - & - & - & - & 51.13 & 56.73 & 3.37 & 2.94 & 1.14 \\
\hline BBL8H & & & 61 & 30 & 3.30 & - & - & - & - & 62.62 & 69.56 & 4.19 & 3.63 & 1.16 \\
\hline BBL10H & & & 61 & 30 & 3.30 & - & - & - & - & 66.71 & 74.14 & 4.28 & 3.69 & 1.16 \\
\hline BBL11H & & & 61 & 30 & 3.30 & - & - & - & - & 57.18 & 63.51 & 3.75 & 3.29 & 1.14 \\
\hline BBL12H & & & 61 & 30 & 3.30 & - & - & - & - & 45.96 & 51.08 & 3.14 & 2.77 & 1.13 \\
\hline
\end{tabular}


Cross Ply Laminates $[0 / 90]_{20 S} \mathrm{L1}$

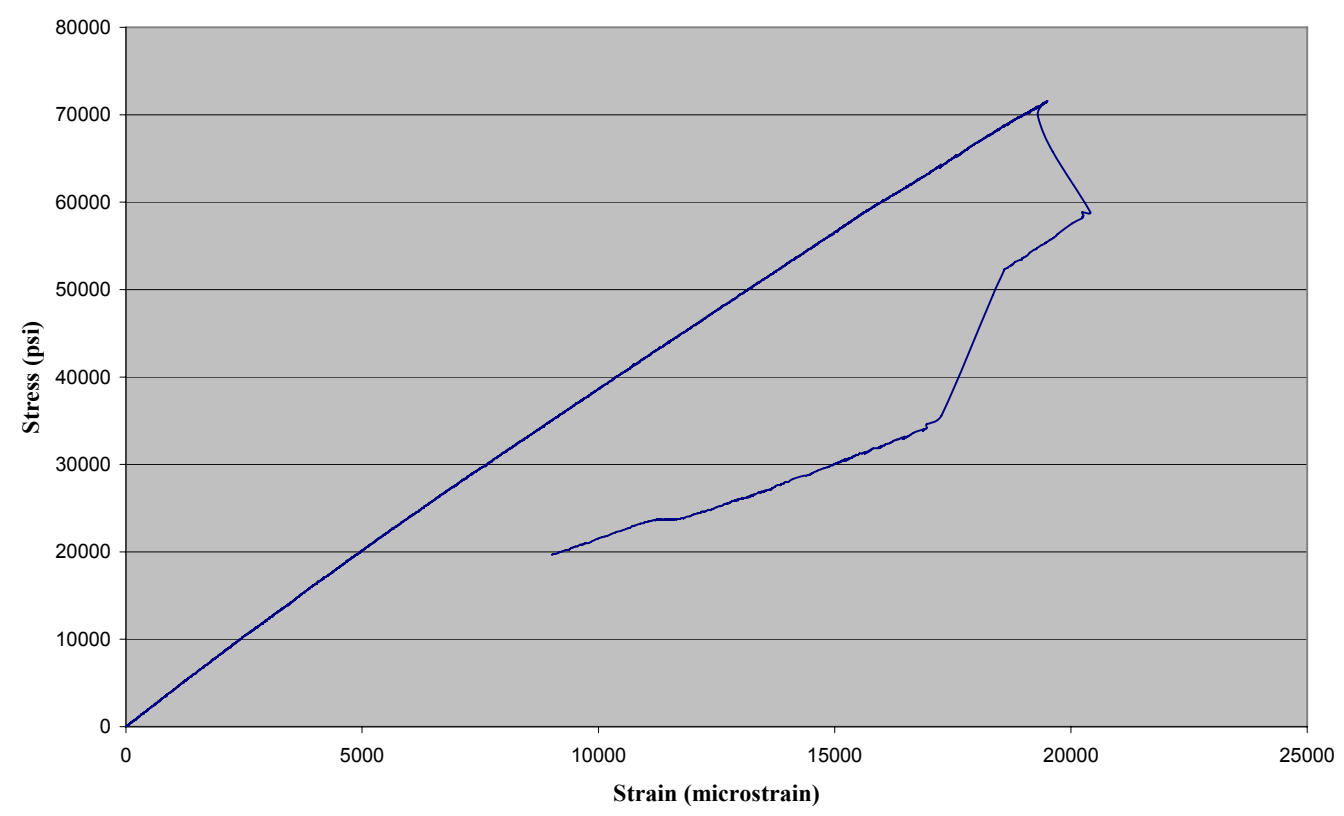

Figure 5.29 Stress-strain of cross-ply laminate (BBL1H) in longitudinal direction

Cross Ply Laminates $[0 / 90]_{20 \mathrm{~S}} \mathrm{L1}$

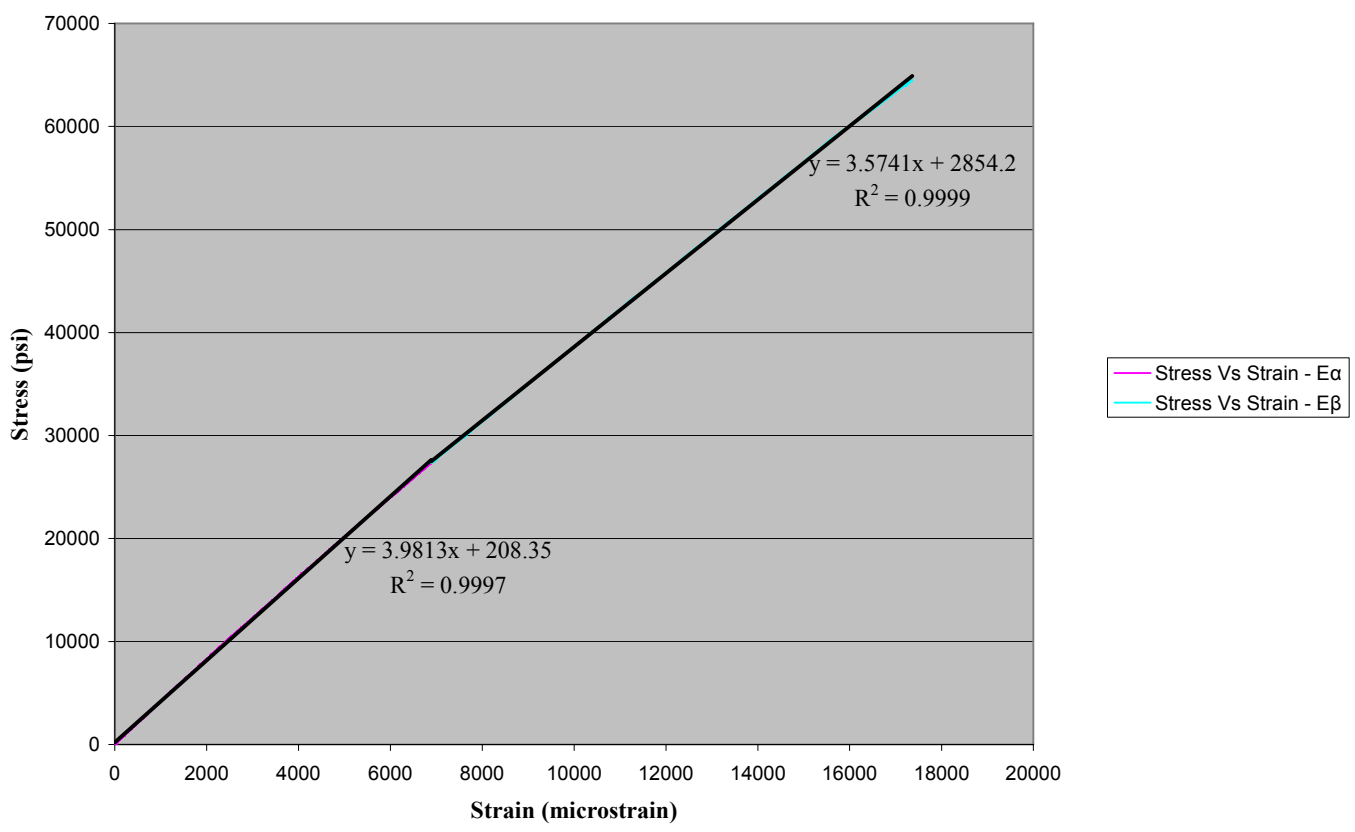

Figure 5.30 Stress-strain of cross-ply laminate (BBL1H) until ultimate load in longitudinal direction 
Cross-ply Laminates $[0 / 90]_{20 S} \mathrm{L3}$

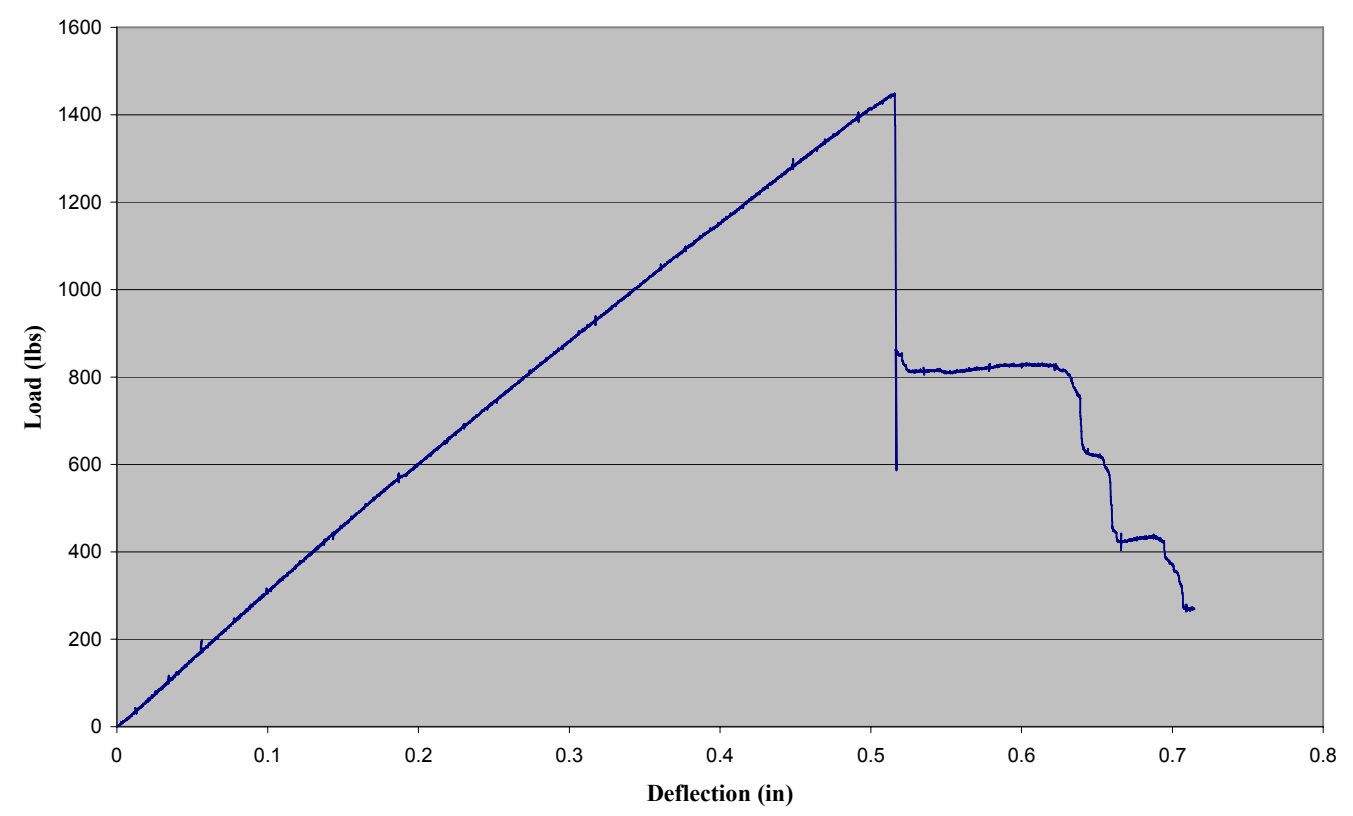

Figure 5.31 Load-deflection of cross ply laminate (BBL3H) in longitudinal direction

Cross-ply Laminates $[0 / 90]_{20 \mathrm{~S}} \mathrm{L3}$

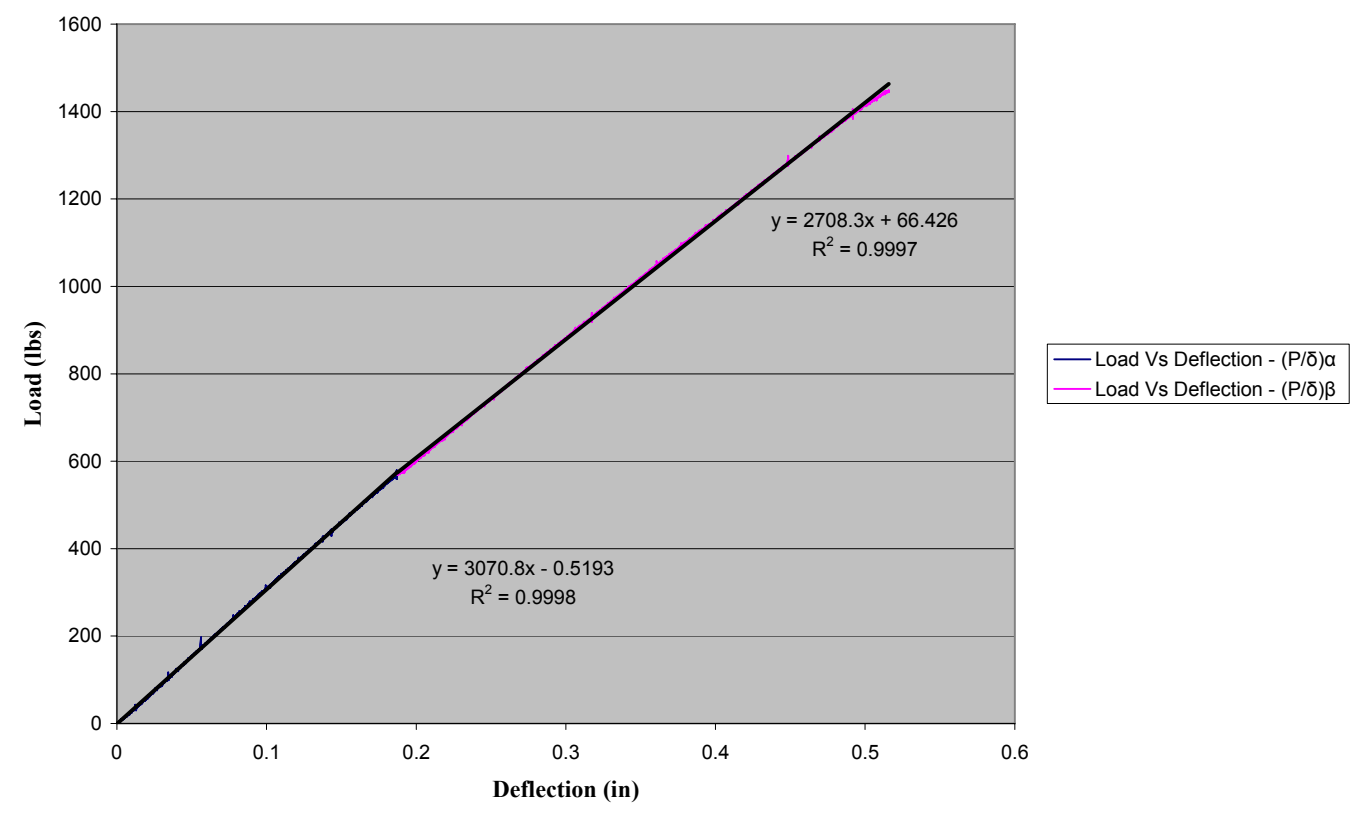

Figure 5.32 Load-deflection of cross ply laminate (BBL3H) in longitudinal direction until ultimate load 


\subsubsection{Quadri-directional without CSM}

Five of ten layers of $0 / 9024 \mathrm{oz} / \mathrm{yd}^{2}$ fabric, cut in the direction of 45 were used to prepare quadri-directional composite specimens without CSM. Sixteen layers of 39 $\mathrm{oz} / \mathrm{yd}^{2}$ stitched fabric were also used with vinyl ester resin to make the laminate half-inch (approx) thick composite. The whole lay-up was made symmetric, with $0^{\circ}$ fibers as the outermost layer. Figure 5.33 and Figure 5.35 represent typical stress-strain curves of quadri-directional fabric based coupon specimen. Figure 5.37 represents a typical loaddeflection curve of half-inch (approx) quadri-directional composite coupon specimen. Figure 5.34 and Figure 5.36 showed almost a bi-linear trend in stress-strain, where the moduli were found using linear regression curve fit. Similarly, Figure 5.38 showed a bilinear load-deflection curve. In some cases, a third slope was observed beyond $90 \%$ of ultimate load; hence the last $10 \%$ of the load for all specimens were neglected. Stresses obtained were in the range of $42 \mathrm{ksi}(90 \%$ ultimate load) for $45 \%$ FVF for quadridirectional $\left(24 \mathrm{oz} / \mathrm{yd}^{2}\right)$ coupon specimens which are made with two pre-preg plies, but for un-crimped quadri-directional specimens $(39 \mathrm{oz} / \mathrm{yd} 2)$, the stresses were in the range of $45 \mathrm{ksi}$ ( $90 \%$ ultimate load) for $58 \% \mathrm{FVF}$. Corresponding strains were in the range of $1.4 \%$ to $1.52 \%$ for pre-pregs and $1.6 \%$ to $1.8 \%$ for un-crimped quadri-directional fabricated composite specimens. The point where change of slope occurred with reference to the strains was found to be 0.48 and 0.39 , respectively of ultimate strain $\left(\varepsilon_{\mathrm{p}}\right)$.

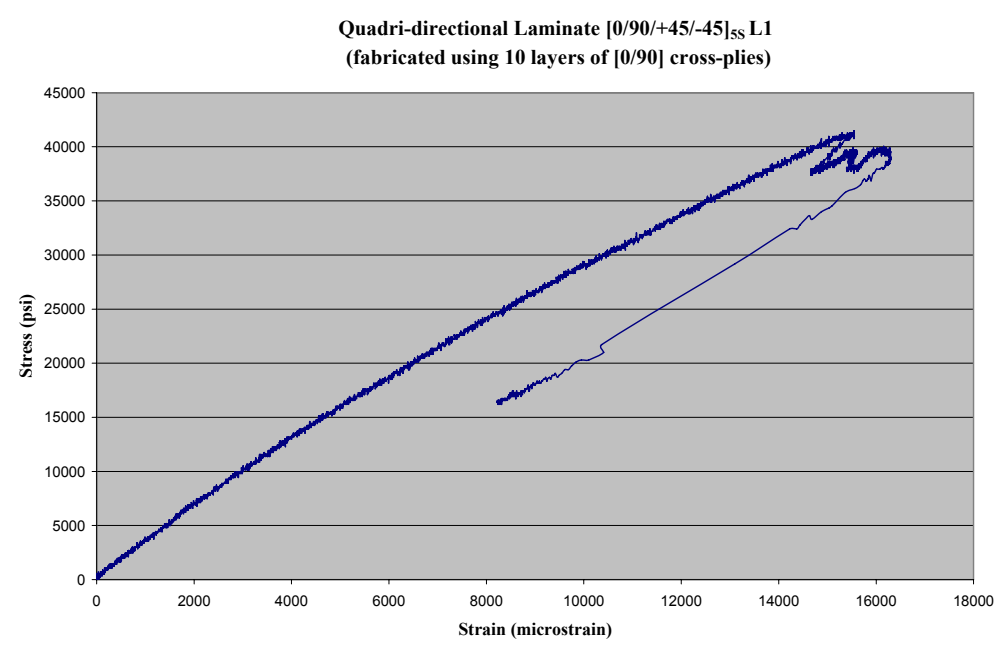

Figure 5.33 Stress-strain of quadri-directional laminate (BQL1Q) in longitudinal direction 


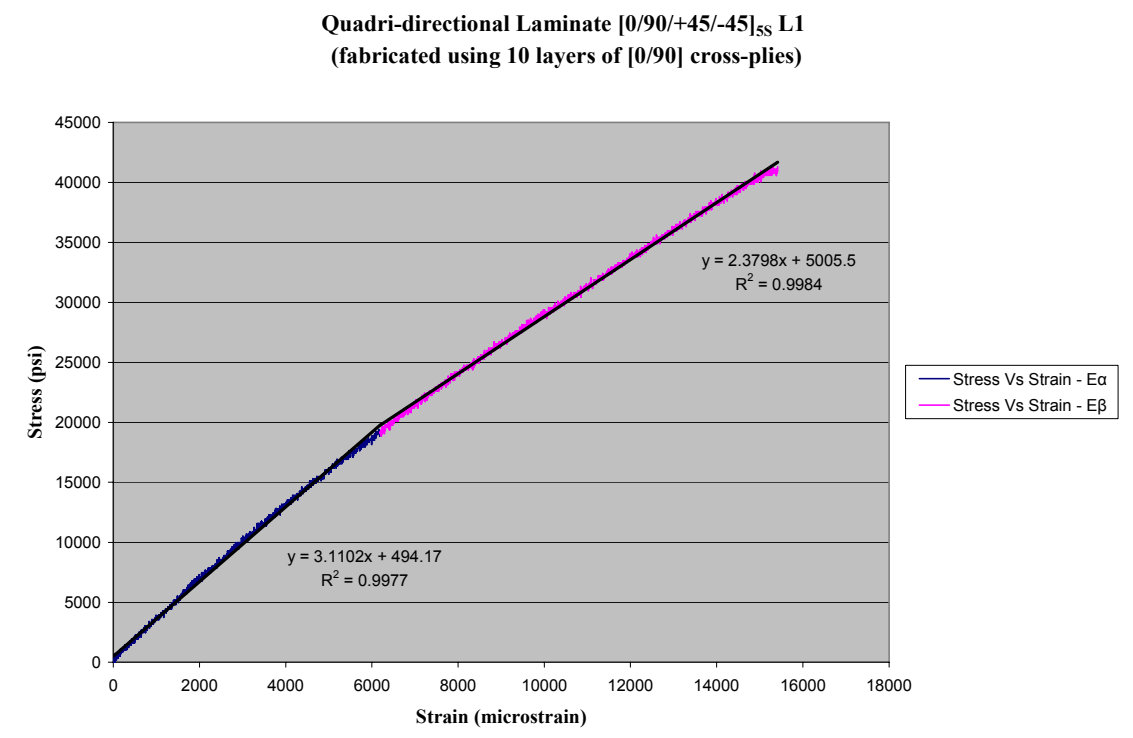

Figure 5.34 Stress-strain of quadri-directional laminate (BQL1Q) in longitudinal direction until ultimate load

Quadri-directional Laminates $[0 / 90 /+45 /-45 / C S M]_{16 S}$ L1

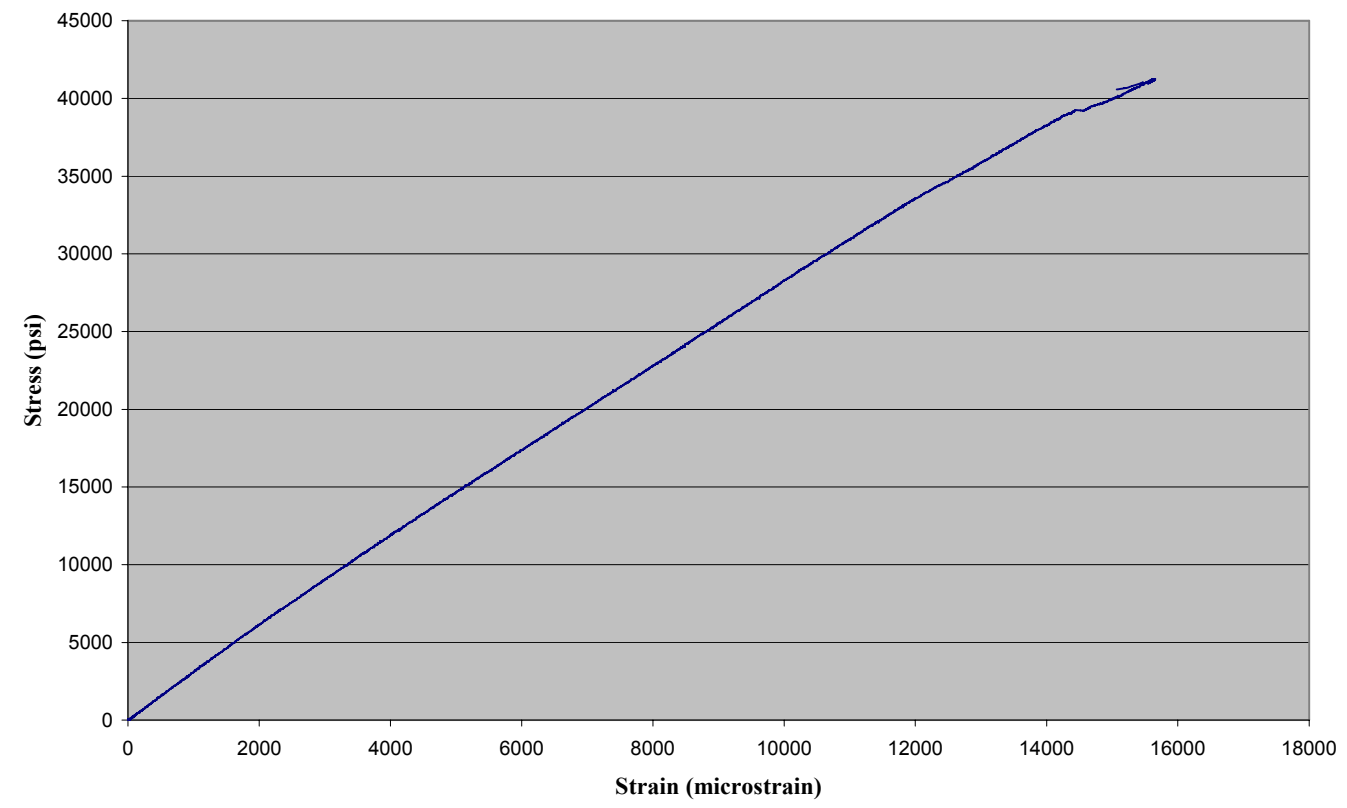

Figure 5.35 Stress-strain of quadri-directional laminate (BQL1H) in longitudinal direction 
Quadri-directional Laminates $[0 / 90 /+45 /-45 / C S M]_{16 S} \mathrm{L1}$

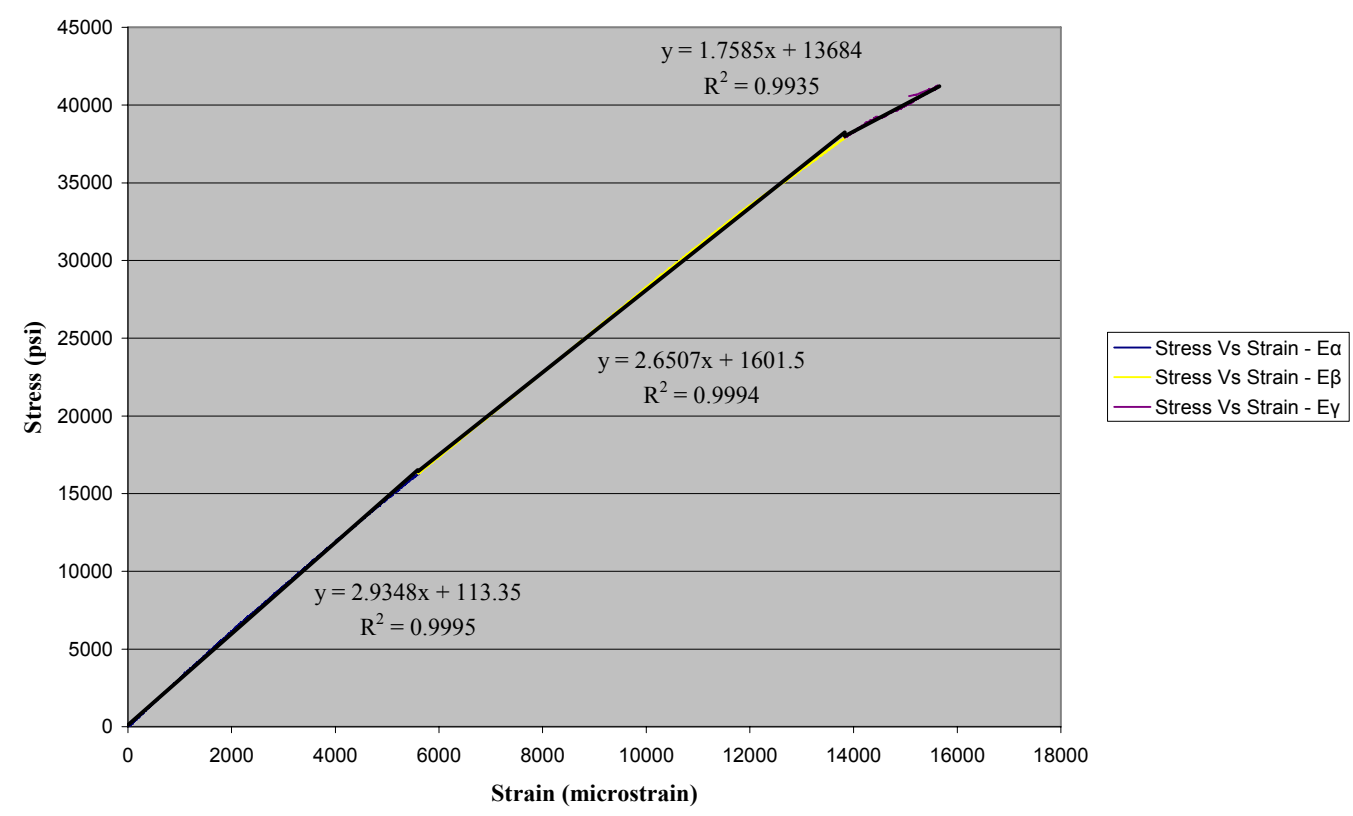

Figure 5.36 Load-deflection of quadri-directional laminate (BQL1H) in longitudinal direction until ultimate load

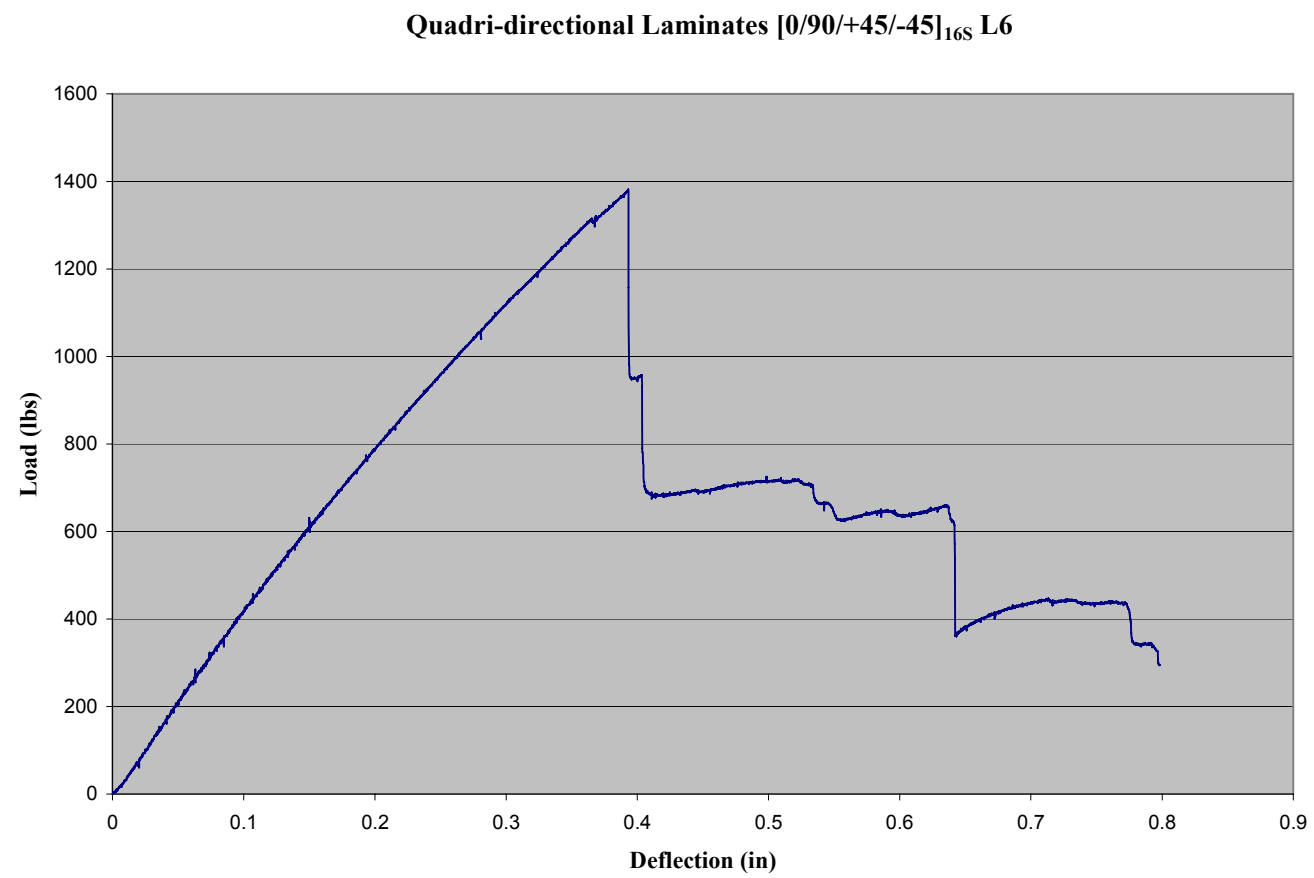

Figure 5.37 Load-deflection of quadri-directional laminate (BQL6H) in longitudinal direction 


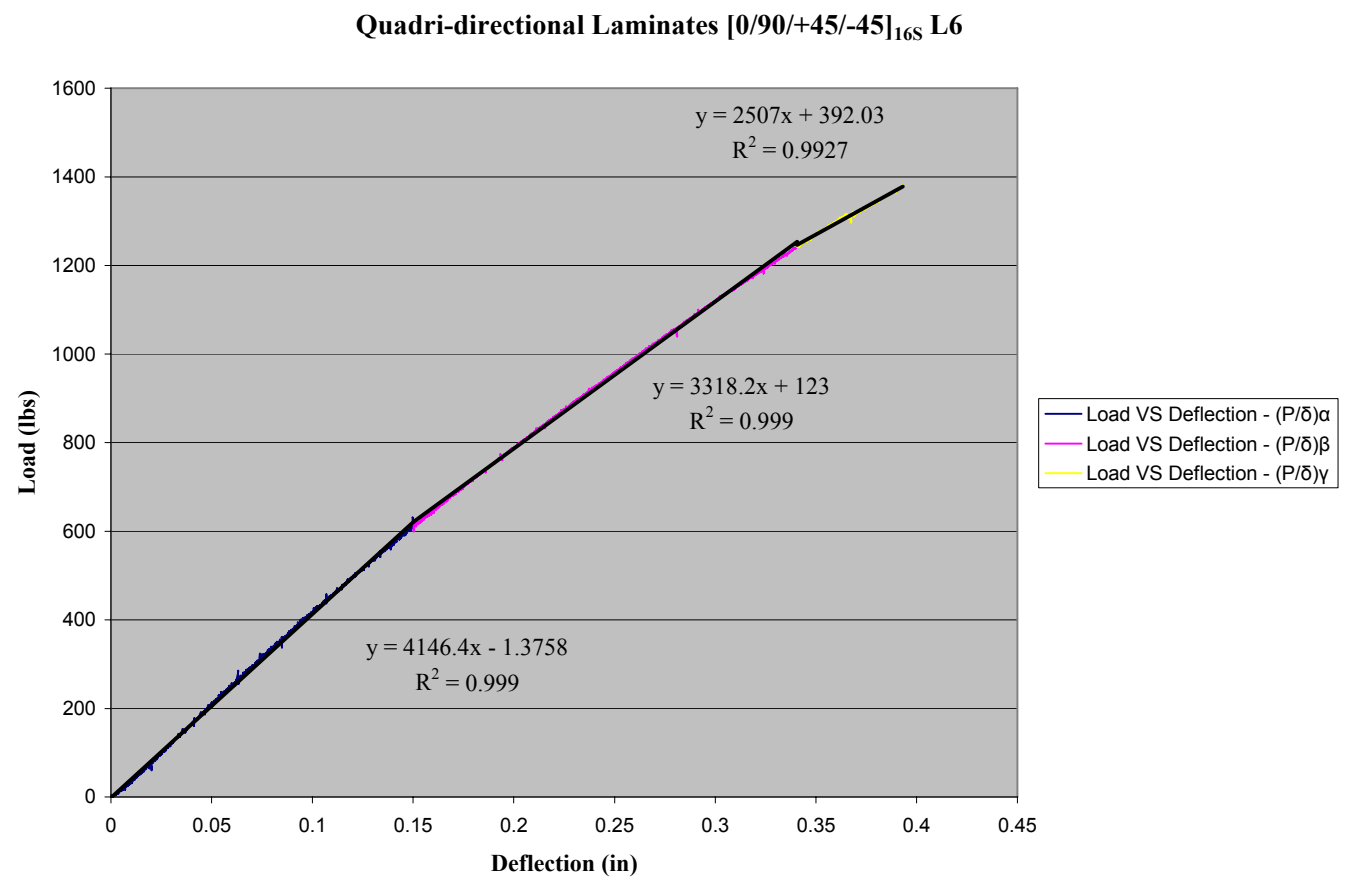

Figure 5.38 Load-deflection of quadri-directional laminate (BQL6H) in longitudinal direction until ultimate load 
Table 5.14 Bending Test Results of Quadri-directional without CSM Laminates in Longitudinal Direction

\begin{tabular}{|c|c|c|c|c|c|c|c|c|c|c|c|c|c|c|}
\hline & Material & $\begin{array}{l}\text { Fabric } \\
\text { Density } \\
\left(o z / y d^{2}\right)\end{array}$ & $\begin{array}{c}F V F \\
(\%)\end{array}$ & $\begin{array}{c}F V F- \\
X \\
(\%)\end{array}$ & $\begin{array}{l}\text { Ethe } \\
\text { (msi) }\end{array}$ & $\begin{array}{c}\text { Strain } \\
\text { at } F-B i \\
\quad(\%)\end{array}$ & $\begin{array}{c}\text { Strain } \\
\text { at } 90 \% \\
\text { Ultimat } \\
e \\
((\%) \\
\end{array}$ & $\begin{array}{c}\text { Strain } \\
\quad \text { at } \\
\text { Ultimat } \\
\text { e Load } \\
(\%)\end{array}$ & $F-B i$ & $\begin{array}{c}\text { Stress } \\
\text { at } 90 \% \\
\text { Ultimat } \\
e \\
(\mathrm{ksi})\end{array}$ & $\begin{array}{c}\text { Stress } \\
\text { at } \\
\text { Ultim } \\
\text { ate } \\
\text { (ksi) }\end{array}$ & $\begin{array}{c}E \alpha \\
(m s i)\end{array}$ & $\begin{array}{c}E \beta \\
\text { (msi) }\end{array}$ & $E \alpha / E \beta$ \\
\hline BQHL1 & \multirow{9}{*}{$\begin{array}{c}0 / 90 /+45 / \\
-45 \\
16 \text { layers } \\
\text { Longi }\end{array}$} & \multirow{9}{*}{$\begin{array}{c}0-13.21 \\
45-8.06 \\
90-10.24 \\
\text { Tot-39.57 }\end{array}$} & 57 & 31 & 3.45 & 0.58 & 1.51 & 1.74 & 0.39 & 37.24 & 41.25 & 2.93 & 2.65 & 1.11 \\
\hline BQHL3 & & & 57 & 31 & 3.45 & & & & & 41.79 & 46.39 & 3.44 & 2.82 & 1.22 \\
\hline BQHL5 & & & 57 & 31 & 3.45 & & & & & 44.24 & 49.16 & 3.72 & 3.03 & 1.23 \\
\hline BQHL6 & & & 57 & 31 & 3.45 & & & & & 42.09 & 46.76 & 3.33 & 2.67 & 1.25 \\
\hline BQHL7 & & & 57 & 31 & 3.45 & & & & & 44.04 & 48.92 & 3.31 & 2.56 & 1.29 \\
\hline BQHL8 & & & 57 & 31 & 3.45 & & & & & 40.61 & 45.11 & 3.30 & 2.69 & 1.23 \\
\hline BQHL9 & & & 57 & 31 & 3.45 & & & & & 48.16 & 53.47 & 4.63 & 3.71 & 1.25 \\
\hline BQHL10 & & & 57 & 31 & 3.45 & & & & & 37.07 & 41.16 & 3.21 & 2.58 & 1.25 \\
\hline BQHL11 & & & 57 & 31 & 3.45 & & & & & 36.53 & 40.61 & 3.23 & 2.65 & 1.22 \\
\hline BQW/OCL3-4 & \multirow{3}{*}{$\begin{array}{c}0 / 90 /+45 / \\
-45 \\
10 \text { Layers }\end{array}$} & \multirow{3}{*}{$\begin{array}{c}0-11.52 \\
90-12.16 \\
\text { Tot-23.68 }\end{array}$} & 44 & 22 & 2.57 & 0.63 & 1.29 & 1.47 & 0.49 & 37.84 & 42.00 & 3.19 & 2.61 & 1.22 \\
\hline BQW/OCL2-4 & & & 44 & 22 & 2.57 & 0.62 & 1.38 & 1.56 & 0.45 & 38.91 & 43.09 & 3.17 & 2.51 & 1.26 \\
\hline BQW/OCL1-4 & & & 44 & 22 & 2.57 & 0.62 & 1.36 & 1.54 & 0.45 & 37.21 & 41.31 & 3.11 & 2.38 & 1.31 \\
\hline
\end{tabular}




\subsubsection{Tri-directional with CSM}

Four layers of 53oz/yd2 fabric were with fabricated vinyl ester resin. A typical stress-strain curve of tri-directional composite with CSM is shown in Figure 5.39. Figure 5.40 showed almost bi-linear curve, neglecting the last $10 \%$ of ultimate load. Stresses computed were found to be $58 \mathrm{ksi}$ ( $90 \%$ ultimate load) for $56 \% \mathrm{FVF}$, while corresponding strains were in the range of $1.8 \%$ to $2.1 \%$. The point where change of slope occurred was found to be 0.4 with reference to the strains. Stiffness from the curve was obtained by using linear regression fit curve.

Tri-directional with CSM Laminates $[45 / 0 /-45 / C S M]_{4 S} \mathrm{L1}$

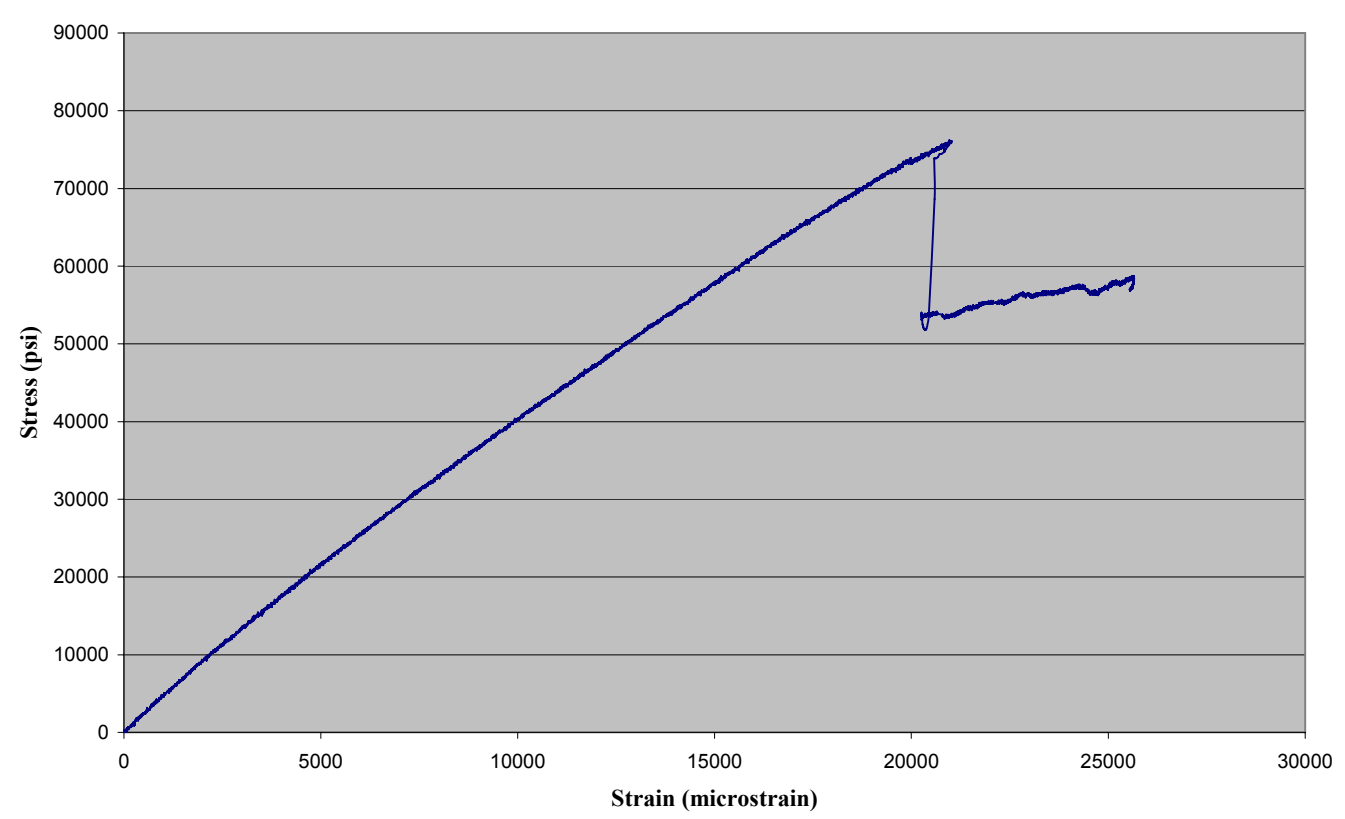

Figure 5.39 Stress-strain of tri-directional composite with CSM (BTL1Q) in longitudinal direction 
Tri-directional with CSM Laminates $[45 / 0 /-45 / C S M]_{4 S} \mathrm{~L} 1$

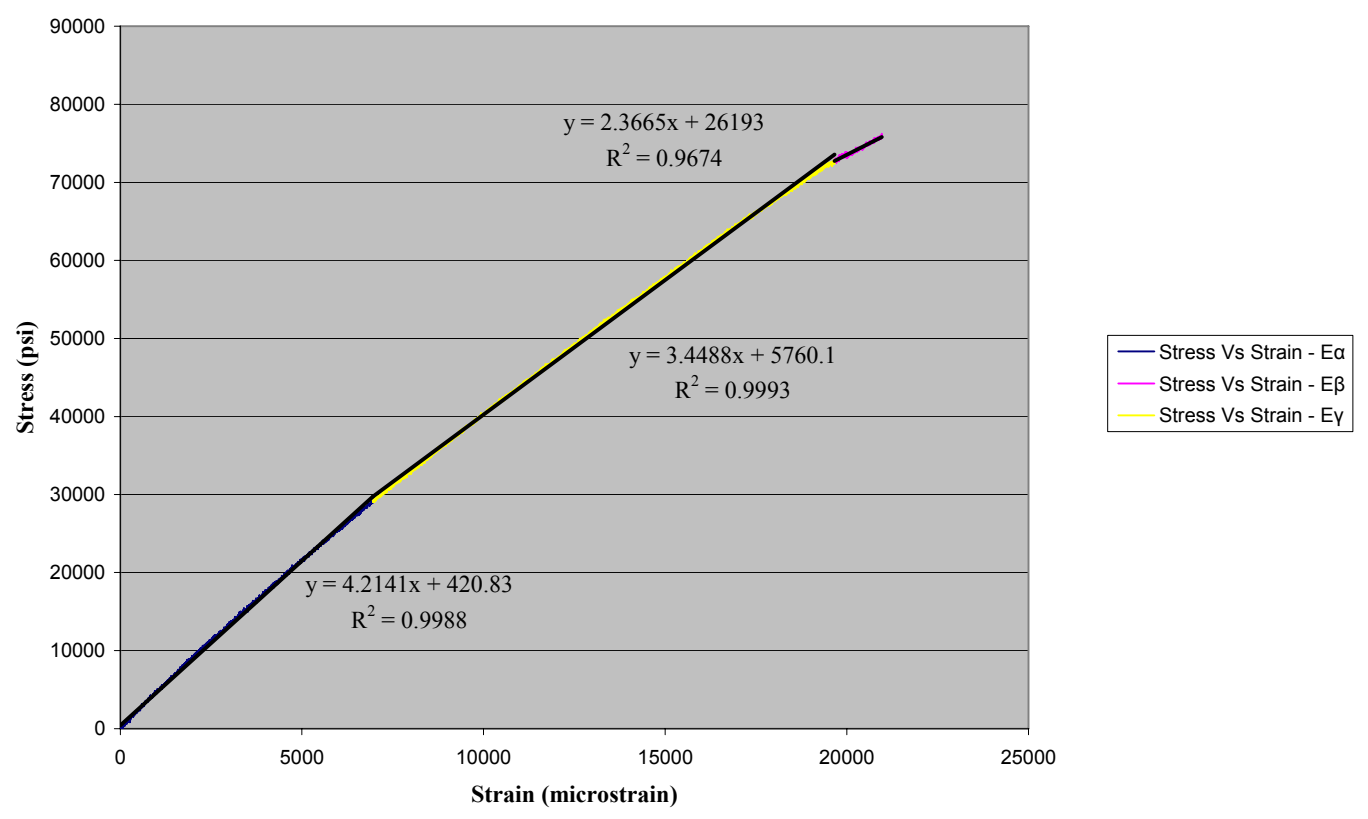

Figure 5.40 Stress-strain of tri-directional composite with CSM (BTL1Q) in longitudinal direction until ultimate load 
Table 5.15 Bending Test Results of Tri-directional with CSM Laminates in Longitudinal Direction

\begin{tabular}{|c|c|c|c|c|c|c|c|c|c|c|c|c|c|c|}
\hline & Material & $\begin{array}{l}\text { Fabric } \\
\text { Density } \\
\left(o z / y d^{2}\right)\end{array}$ & $\begin{array}{c}F V F \\
(\%)\end{array}$ & $\begin{array}{c}F V F \\
-X \\
(\%)\end{array}$ & $\begin{array}{l}\text { Ethe } \\
\text { (msi) }\end{array}$ & $\begin{array}{c}\text { Strain } \\
\text { at } F-B i \\
(\%)\end{array}$ & $\begin{array}{c}\text { Strain } \\
\text { at 90\% } \\
\text { Ultimat } \\
e \\
(\%) \\
\end{array}$ & $\begin{array}{c}\text { Strain } \\
\text { at } \\
\text { Ultimat } \\
\text { e Load } \\
(\%)\end{array}$ & $F-B i$ & $\begin{array}{c}\text { Stress at } \\
90 \% \\
\text { Ultimate }\end{array}$ & $\begin{array}{c}\text { Ultim } \\
\text { ate } \\
\text { Stress }\end{array}$ & $\begin{array}{c}E \alpha \\
(m s i)\end{array}$ & $\begin{array}{c}E \beta \\
(m s i)\end{array}$ & $E \alpha / E \beta$ \\
\hline A1 TL1 & \multirow{3}{*}{$\begin{array}{c}\text { 45/0/- } \\
\text { 45/CSM } \\
4 \text { layers }\end{array}$} & \multirow{3}{*}{$\begin{array}{c}45-11.44 \\
45-11.44 \\
90-17.28 \\
\text { CSM-13.5 }\end{array}$} & 58 & 38 & 4.24 & 0.69 & 1.83 & 2.09 & 0.38 & 68.64 & 76.23 & 4.21 & 3.45 & 1.22 \\
\hline LT1 & & & 56 & 37 & 4.09 & 0.57 & 1.48 & 1.85 & 0.39 & 49.54 & 55.04 & 3.65 & 3.11 & 1.17 \\
\hline LT2 & & & 56 & 37 & 4.09 & 0.67 & 1.68 & 1.92 & 0.40 & 53.99 & 59.99 & 3.49 & 2.98 & 1.17 \\
\hline
\end{tabular}




\subsubsection{Quadri-directional with CSM}

Six layers and four layers of $63 \mathrm{oz} / \mathrm{yd} 2$ density fabric were used with vinyl ester to form 0.35 " (approx) and 0.25 " (approx) thick composite coupon specimens, with $0^{\circ}$ being the outermost ply. Figure 5.41 and Figure 5.45 represent typical stress-strain curves. Typical load-deflection curves are shown in Figure 5.43 and Figure 5.47. Figure 5.42, Figure 5.44, Figure 5.46, and Figure 5.48 showed bi-linear slopes of quadri-directional composite test specimens with CSM. A third slope was observed beyond $90 \%$ of ultimate load in some cases. Hence, for further calculations and computational ease only up to $90 \%$ of ultimate load and corresponding strain values were considered. Stresses obtained were in the range of $55 \mathrm{ksi}(90 \%$ ultimate load) for $56 \% \mathrm{FVF}$. Corresponding strains observed were in the range of $1.55 \%$ to $1.9 \%$. The point where change of slope occurred with reference to strains was found to be 0.32 . Stiffness was obtained by using linear regression curve fit from the bi-linear curve. In case of load-deflection curve, the slope of the curve is treated as for stiffness.

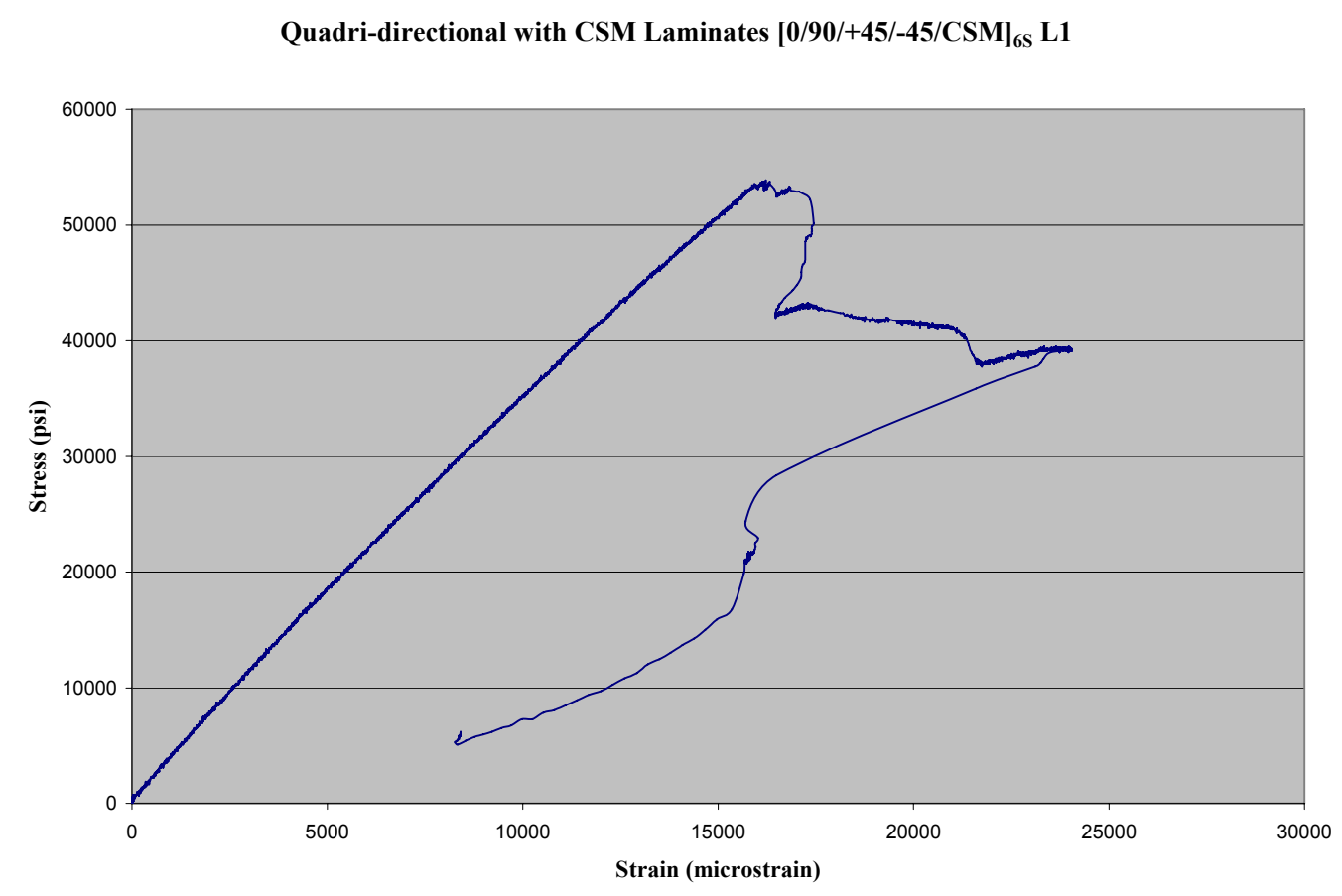

Figure 5.41 Stress-strain of quadri-directional composite with CSM (BQWCL1Q) in longitudinal direction 


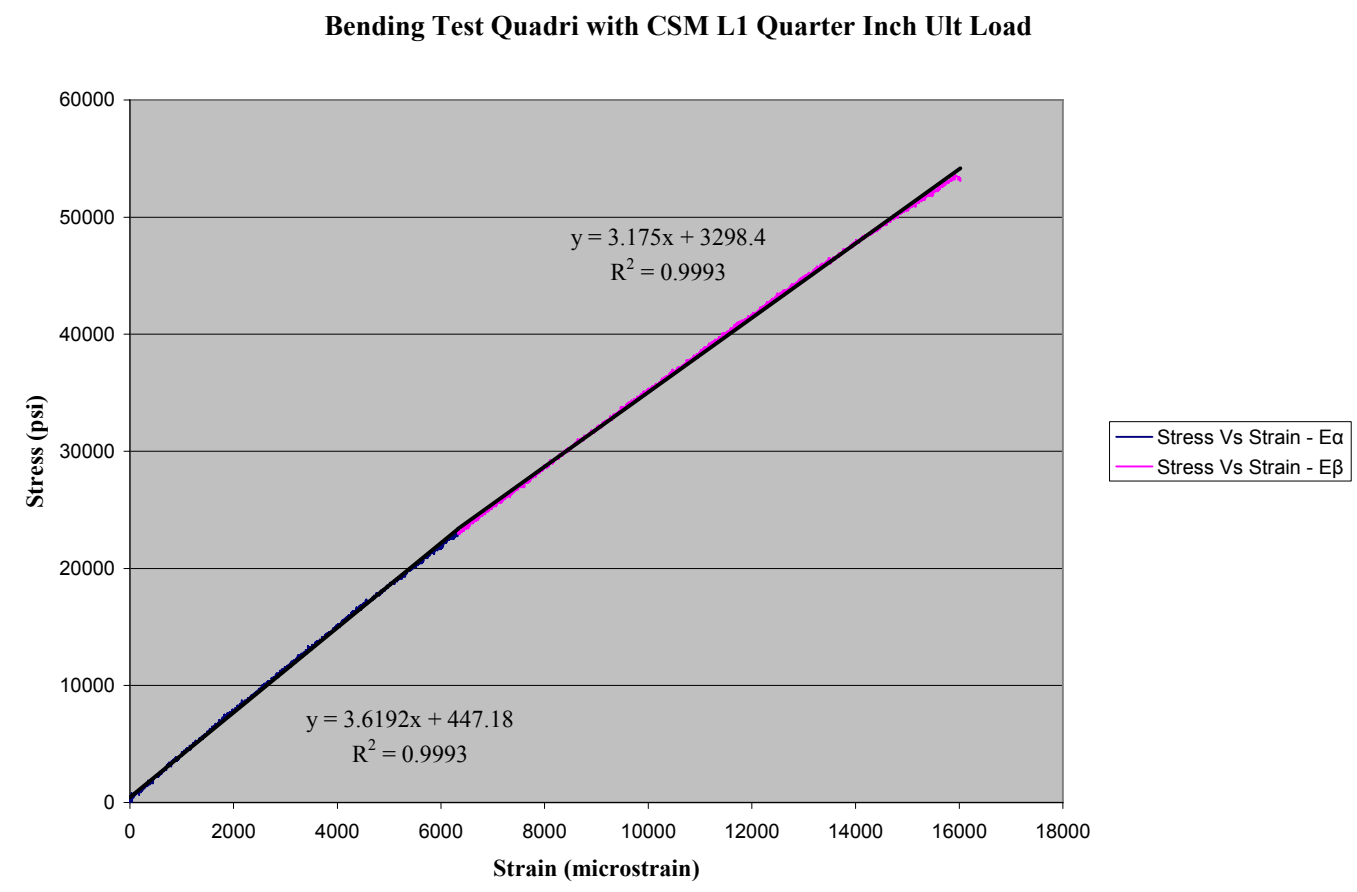

Figure 5.42 Stress-strain of quadri-directional composite with CSM (BQWCL1Q) in longitudinal direction until ultimate load

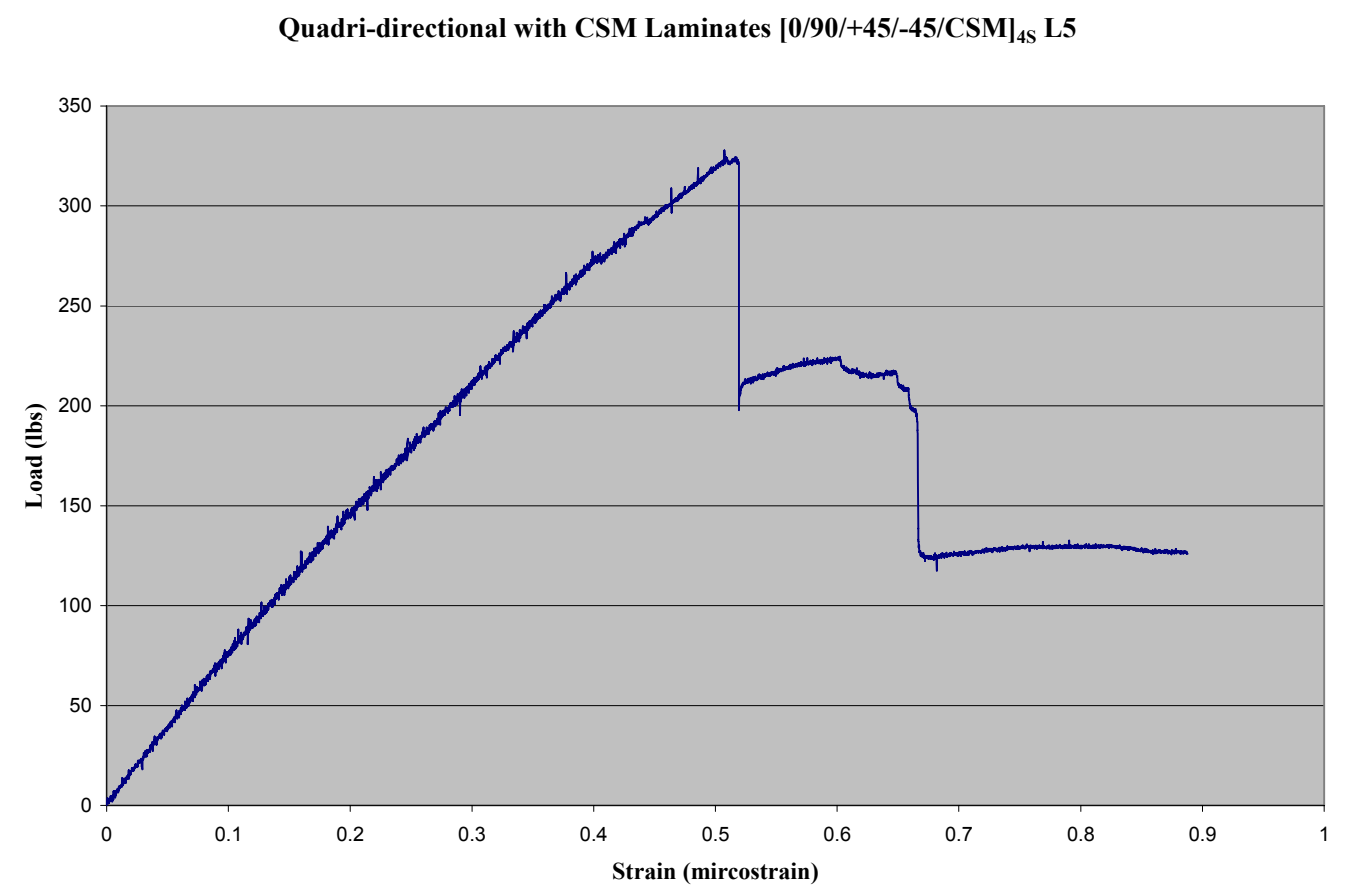

Figure 5.43 Load-deflection of quadri-directional composite with CSM (BQWCL5Q) in longitudinal direction 
Quadri-directional with CSM Laminates $[0 / 90 /+45 /-45 / C S M]_{4 S}$ L5

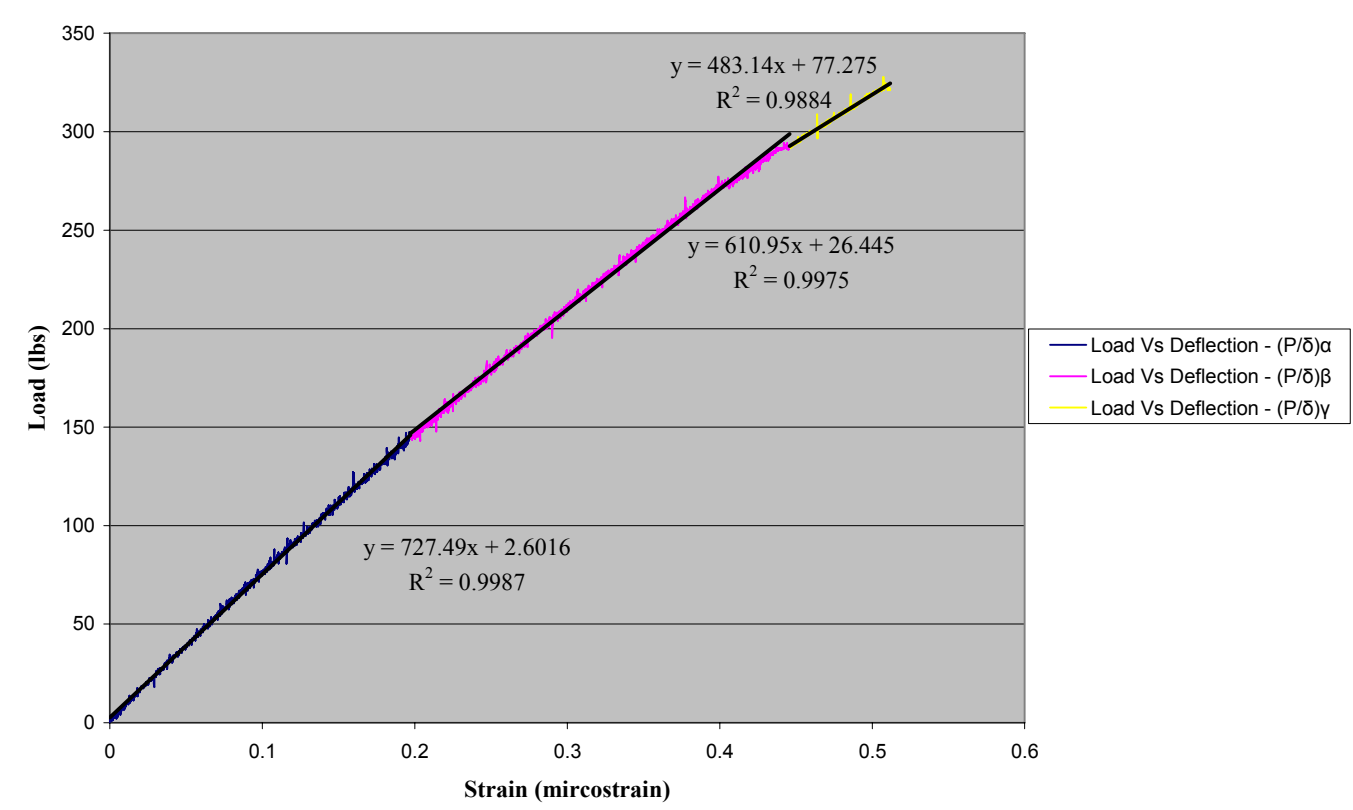

Figure 5.44 Stress-strain of quadri-directional composite with CSM (BQWCL5Q) in longitudinal direction until ultimate load

Quadri-directional with CSM $[0 / 90 /+45 /-45 / C S M]_{6 S}$ L2

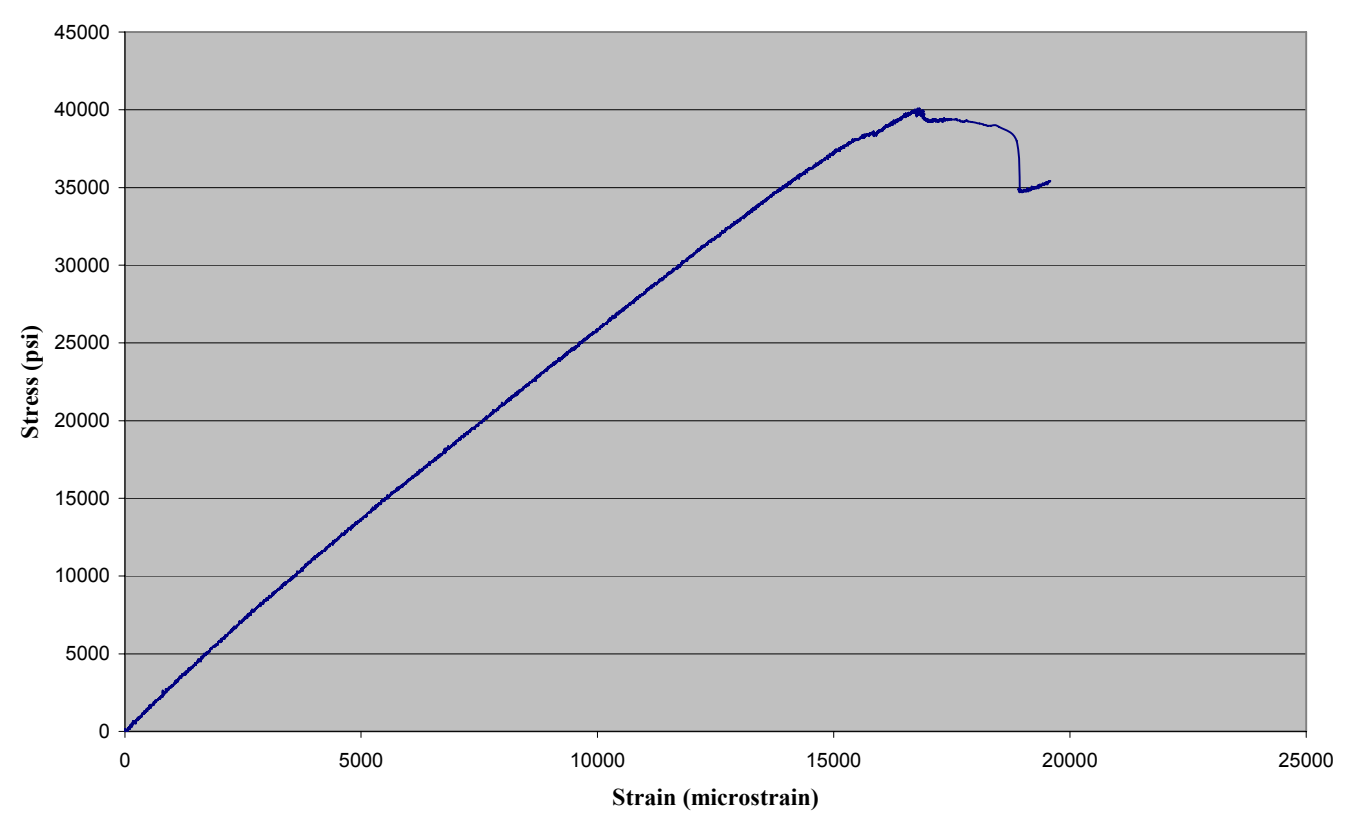

Figure 5.45 Stress-strain of quadri-directional composite with CSM (BQWCL2H) in longitudinal direction 
Quadri-directional with CSM Laminates $[0 / 90 /+45 /-45 / C S M]_{6 S} \mathrm{L2}$

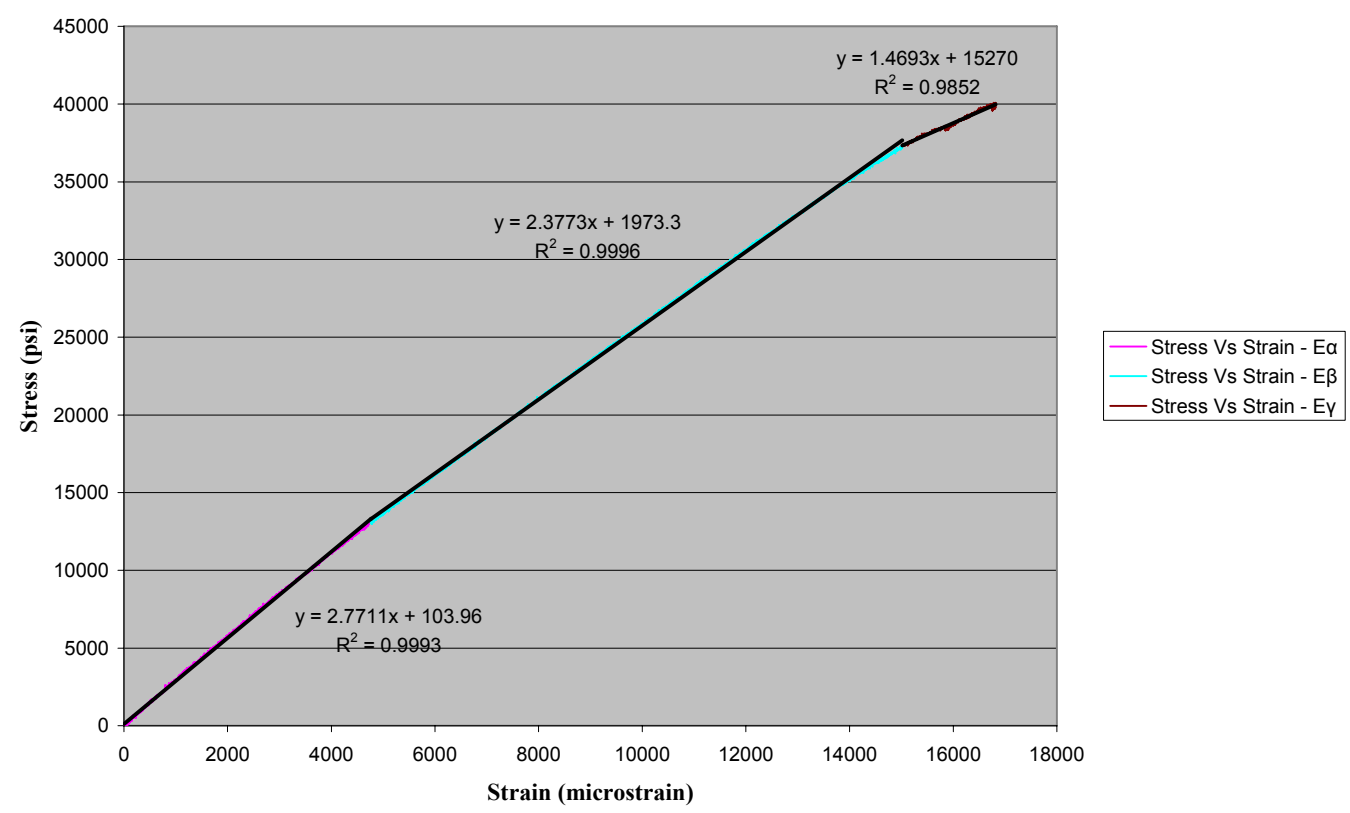

Figure 5.46 Stress-strain of quadri-directional composite with CSM (BQWCL1H) in longitudinal direction until ultimate load

Quadri-directional with CSM Laminates $[0 / 90 /+45 /-45 / \text { CSM }]_{6 \mathrm{~S}} \mathrm{L5}$

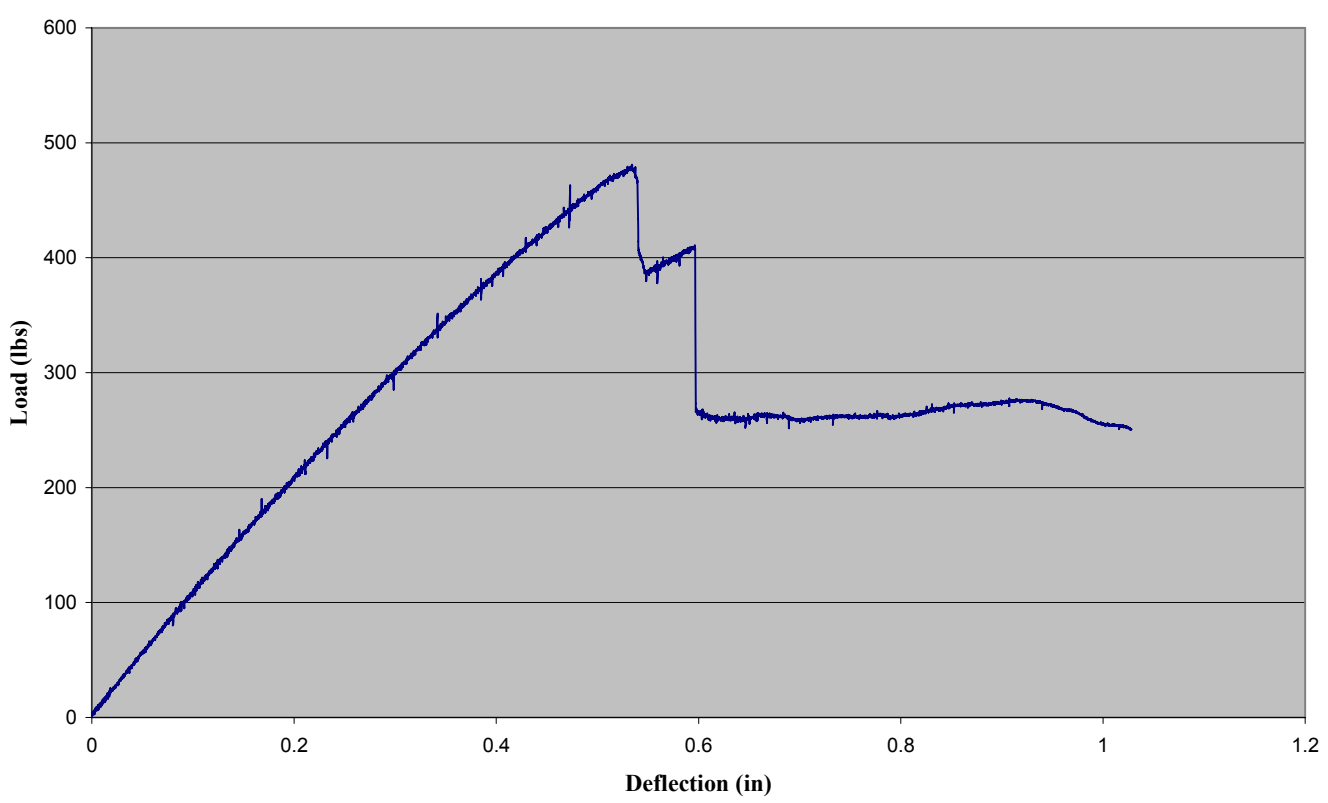

Figure 5.47 Load-deflection of quadri-directional composite with CSM (BQWCL5H) in longitudinal direction 


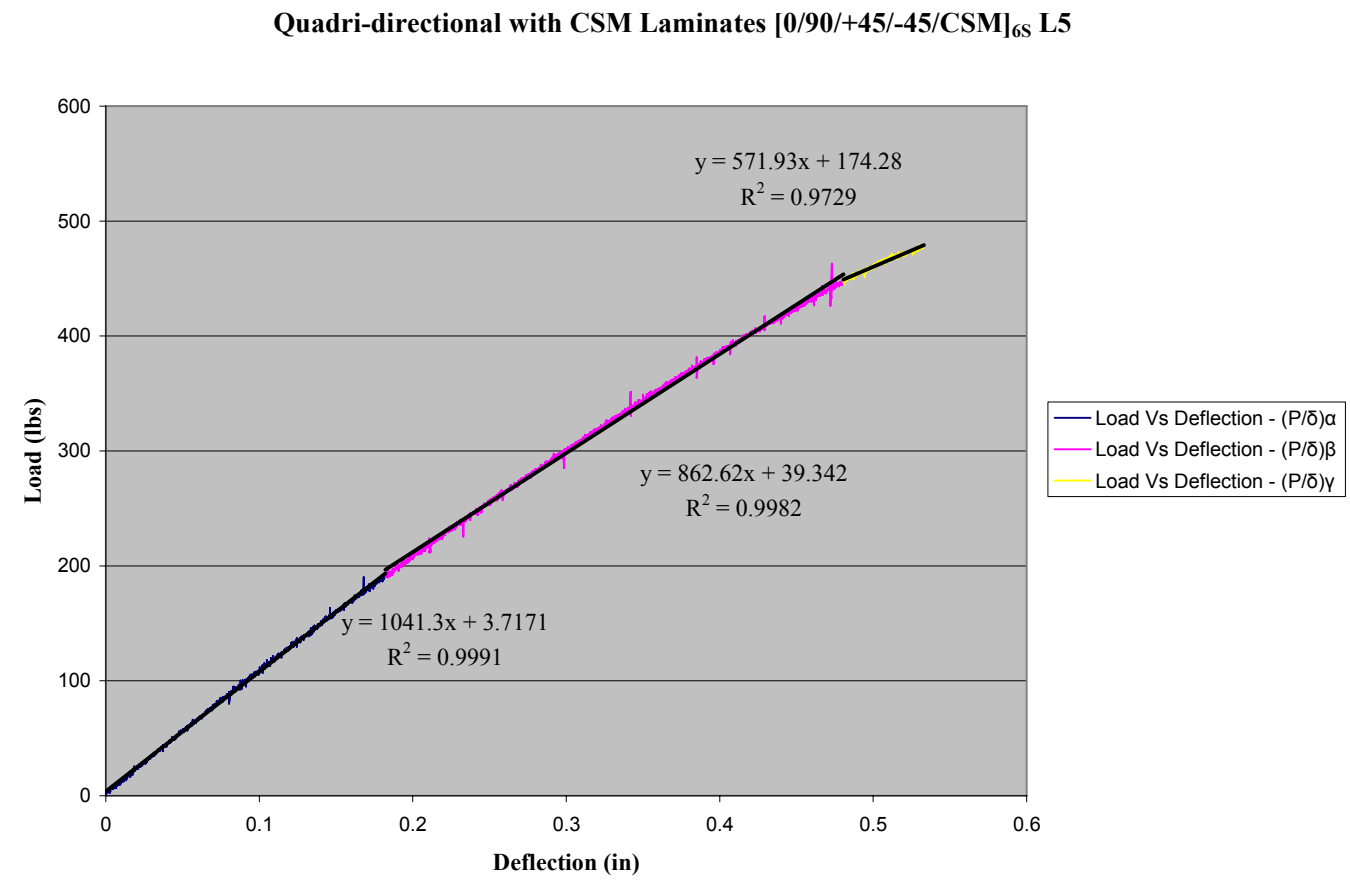

Figure 5.48 Load-deflection of quadri-directional composite with CSM (BQWCL5H) in longitudinal direction until ultimate load 
Table 5.16 Bending Test Results of Quadri-directional with CSM Laminates in Longitudinal Direction

\begin{tabular}{|c|c|c|c|c|c|c|c|c|c|c|c|c|c|c|}
\hline & Material & $\begin{array}{l}\text { Fabric } \\
\text { Density } \\
\left(o z / y d^{2}\right)\end{array}$ & $\begin{array}{c}F V F \\
(\%)\end{array}$ & $\begin{array}{c}F V F \\
-X \\
(\%)\end{array}$ & $\begin{array}{l}\text { Ethe } \\
\text { (msi) }\end{array}$ & $\begin{array}{c}\text { Strain } \\
\text { at } F-B i \\
(\%)\end{array}$ & $\begin{array}{c}\text { Strain } \\
\text { at } 90 \% \\
\text { Ultimat } \\
e \\
(\%)\end{array}$ & $\begin{array}{c}\text { Strain } \\
\text { at } \\
\text { Ultimat } \\
e \\
\text { Load( } \\
\%) \\
\end{array}$ & $F-B i$ & $\begin{array}{c}\text { Stress } \\
\text { at } 90 \% \\
\text { Ultima } \\
\text { te } \\
\text { (ksi) }\end{array}$ & $\begin{array}{c}\text { Ultima } \\
\text { te } \\
\text { stress } \\
\text { (ksi) }\end{array}$ & $\begin{array}{c}E \alpha \\
(m s i)\end{array}$ & $\begin{array}{c}E \beta \\
(m s i)\end{array}$ & $E \alpha / E \beta$ \\
\hline BQL2H & \multirow{7}{*}{$\begin{array}{c}\text { 0/90/+45/- } \\
45 / \mathrm{CSM} \\
10 \text { layers } \\
\text { Longi }\end{array}$} & \multirow{7}{*}{$\begin{array}{c}0-15.71 \\
90-14.08 \\
45-9.04 \\
\text { CSM-13.5 } \\
\text { Tot-61.37 }\end{array}$} & 58 & 30 & 3.32 & 0.47 & 1.44 & 1.68 & 0.33 & 46.64 & 51.83 & 2.66 & 2.34 & 1.14 \\
\hline BQL5H & & & 58 & 30 & 3.32 & & & & & 42.54 & 47.24 & 4.33 & 3.58 & 1.21 \\
\hline BQL6H & & & 58 & 30 & 3.32 & & & & & 44.82 & 49.75 & 4.11 & 3.28 & 1.25 \\
\hline BQL7H & & & 58 & 30 & 3.32 & & & & & 47.87 & 53.10 & 4.83 & 4.09 & 1.18 \\
\hline BQL8H & & & 58 & 30 & 3.32 & & & & & 44.87 & 49.87 & 3.58 & 2.94 & 1.22 \\
\hline BQL9H & & & 58 & 30 & 3.32 & & & & & 39.55 & 43.90 & 4.39 & 3.64 & 1.21 \\
\hline BQL11H & & & 58 & 30 & 3.32 & & & & & 49.72 & 55.15 & 4.05 & 3.34 & 1.21 \\
\hline BQL1Q & \multirow{8}{*}{$\begin{array}{c}\text { 0/90/+45/- } \\
\text { 45/CSM } \\
\text { 4 layers } \\
\text { Longi }\end{array}$} & \multirow{8}{*}{$\begin{array}{c}0-15.71 \\
90-14.08 \\
45-9.04 \\
\text { CSM-13.5 } \\
\text { Tot-61.37 }\end{array}$} & 56 & 29 & 3.25 & 0.63 & 1.42 & 1.62 & 0.44 & 48.58 & 53.88 & 3.62 & 3.18 & 1.14 \\
\hline BQL2Q & & & 56 & 29 & 3.25 & 0.38 & 1.57 & 1.85 & 0.24 & 50.95 & 56.49 & 3.38 & 3.12 & 1.08 \\
\hline BQL3Q & & & 56 & 29 & 3.25 & 0.41 & 1.64 & 1.89 & 0.25 & 54.72 & 60.79 & 3.46 & 3.05 & 1.14 \\
\hline BQL4Q & & & 56 & 29 & 3.25 & & & & & 56.39 & 62.54 & 4.36 & 3.54 & 1.23 \\
\hline BQL5Q & & & 56 & 29 & 3.25 & & & & & 48.74 & 54.16 & 4.24 & 3.56 & 1.19 \\
\hline BQL6Q & & & 56 & 29 & 3.25 & & & & & 53.86 & 59.84 & 4.35 & 3.58 & 1.21 \\
\hline BQL7Q & & & 56 & 29 & 3.25 & & & & & 51.30 & 56.91 & 4.15 & 3.46 & 1.20 \\
\hline BQL8Q & & & 56 & 29 & 3.25 & & & & & 53.73 & 59.60 & 4.28 & 3.63 & 1.18 \\
\hline
\end{tabular}




\subsubsection{Four-Point Bending - Transverse Direction}

\subsubsection{Unidirectional Coupon Specimens}

Unidirectional composite coupons were fabricated using $7 \mathrm{oz} / \mathrm{yd} 2$ fabric with vinyl ester resin and were cut in transverse direction so that the coupon specimen contains only $90^{\circ}$ fibers. A typical stress-strain curve for these specimens was shown in Figure 5.49. All the samples failed at a very low load, which was attributed to the absence of $0^{\circ}$ fibers. Stresses and strains at ultimate load were also very low and were in the range of $6 \mathrm{ksi}$ and $0.3 \%$, respectively for $70 \%$ FVF. Figure 5.50 shows a linear relation of stress-strain curve until failure and the stiffness was computed from linear regression curve fit.

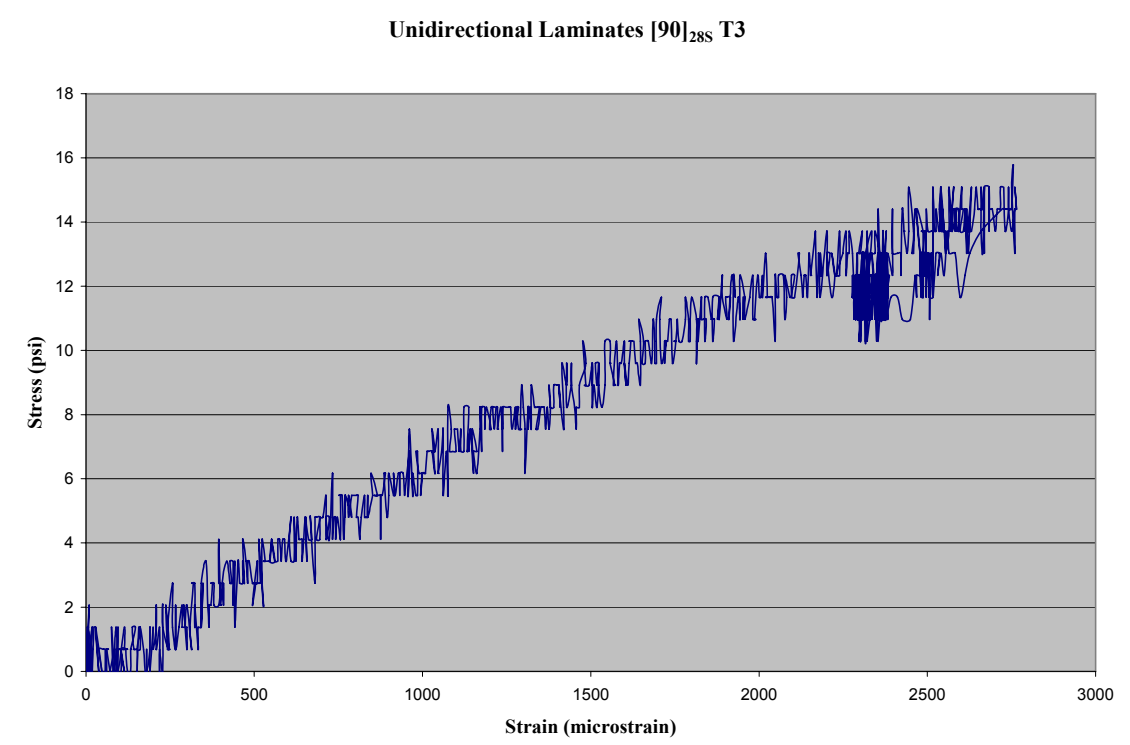

Figure 5.49 Stress-strain of unidirectional laminates (BUT3Q-C) in transverse direction

Table 5.17 Bending Test Results of Unidirectional Laminates in Transverse Direction

\begin{tabular}{|c|c|c|c|c|c|c|c|c|}
\hline & Material & $\begin{array}{c}\text { Fabric } \\
\text { Density } \\
\left(o z / y d^{2}\right)\end{array}$ & $\begin{array}{c}F V F \\
(\%)\end{array}$ & $\begin{array}{c}F V F-X \\
\text { (\%) }\end{array}$ & $\begin{array}{l}\text { Ethe } \\
\text { (msi) }\end{array}$ & $\begin{array}{c}\text { Strain at } \\
90 \% \\
\text { Ultimate } \\
(\%)\end{array}$ & $\begin{array}{c}\text { Strain at } \\
\text { Ultimate } \\
\text { Load } \\
\text { (\%) }\end{array}$ & $\begin{array}{c}E \alpha \\
(m s i)\end{array}$ \\
\hline BUT1-4 & \multirow{3}{*}{$\begin{array}{c}\text { Unis } \\
28 \text { Layers } \\
\text { Longi }\end{array}$} & \multirow{3}{*}{$0-6.8$} & 70 & 0 & 0.15 & 0.27 & 0.27 & 1.95 \\
\hline BUT3-4 & & & 70 & 0 & 0.15 & 0.27 & 0.27 & 2.04 \\
\hline BUT4-4 & & & 70 & 0 & 0.15 & 0.33 & 0.34 & 1.83 \\
\hline
\end{tabular}


Unidirectional Laminates $[90]_{28 \mathrm{~S}} \mathrm{T3}$

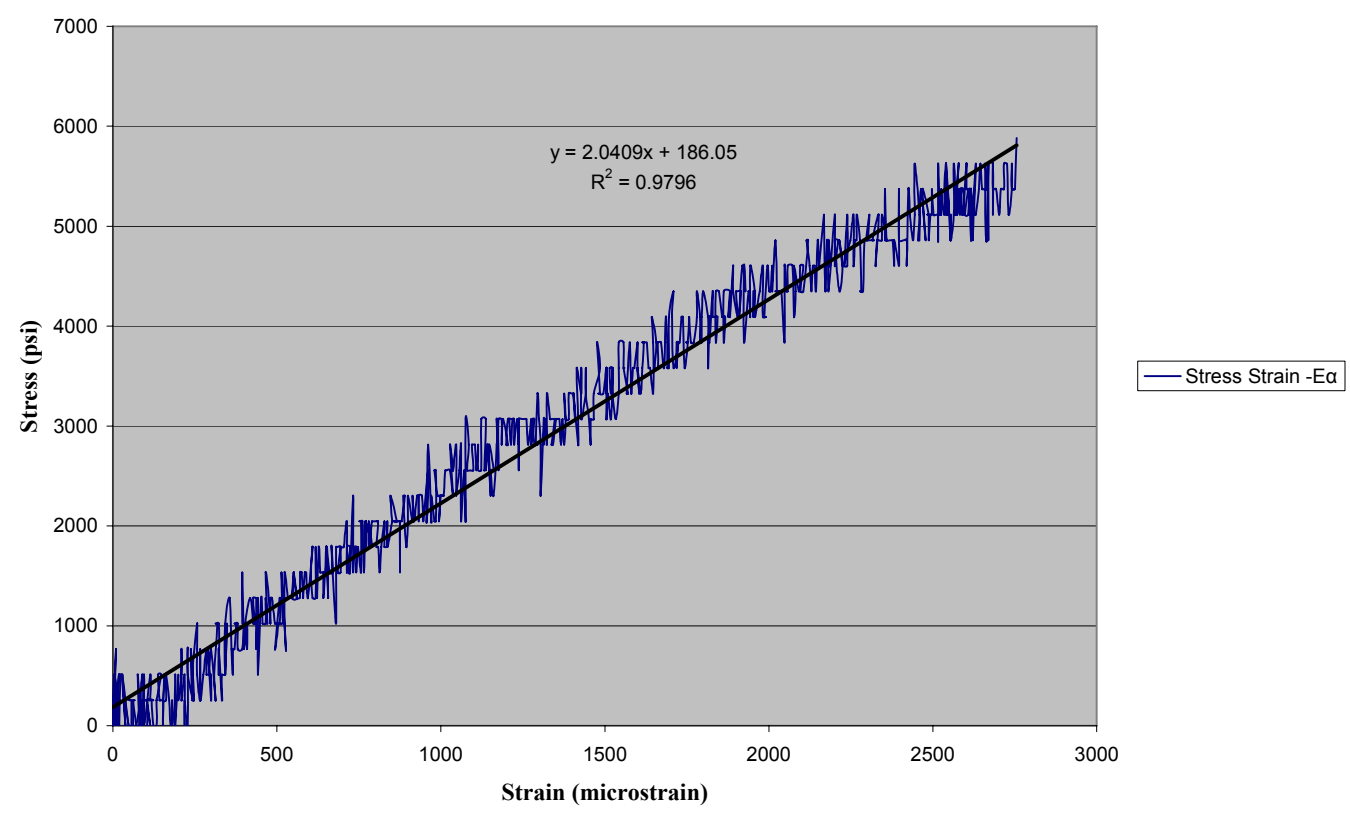

Figure 5.50 Stress-strain of unidirectional laminates (BUT3Q-C) in transverse direction until ultimate load

\subsubsection{Cross-ply Coupon Specimens}

Twenty-two layers of $0 / 90$ fabric with $12 \mathrm{oz} / \mathrm{yd}^{2}$ was used to manufacture coupons with vinyl ester resin. The specimens were cut in longitudinal direction with $90^{\circ}$ as the outermost ply. The whole lay-up was made symmetric. Figure 5.51 and Figure 5.53 represents a typical stress-strain and load-deflection curves, respectively. Figure 5.52 and Figure 5.54 shows bi-linear curves and the moduli were obtained by using linear regression curve fit. For load-deflection curves, the value of the slope was taken and converted to stiffness. For some specimens, beyond $90 \%$ of ultimate load, a third slope was observed. Hence, for computational purposes, only up to $90 \%$ of ultimate load and its corresponding values were considered. Stresses (90\% ultimate load) were found to be in the range of $44 \mathrm{ksi}$ for $37 \% \mathrm{FVF}$ and, corresponding strains being in the range of $1.5 \%$ to $1.7 \%$. The point where change of slope occurred was around 0.4 . 
Cross-ply Laminates $[0 / 90]_{22 \mathrm{~S}} \mathrm{~L} 2$

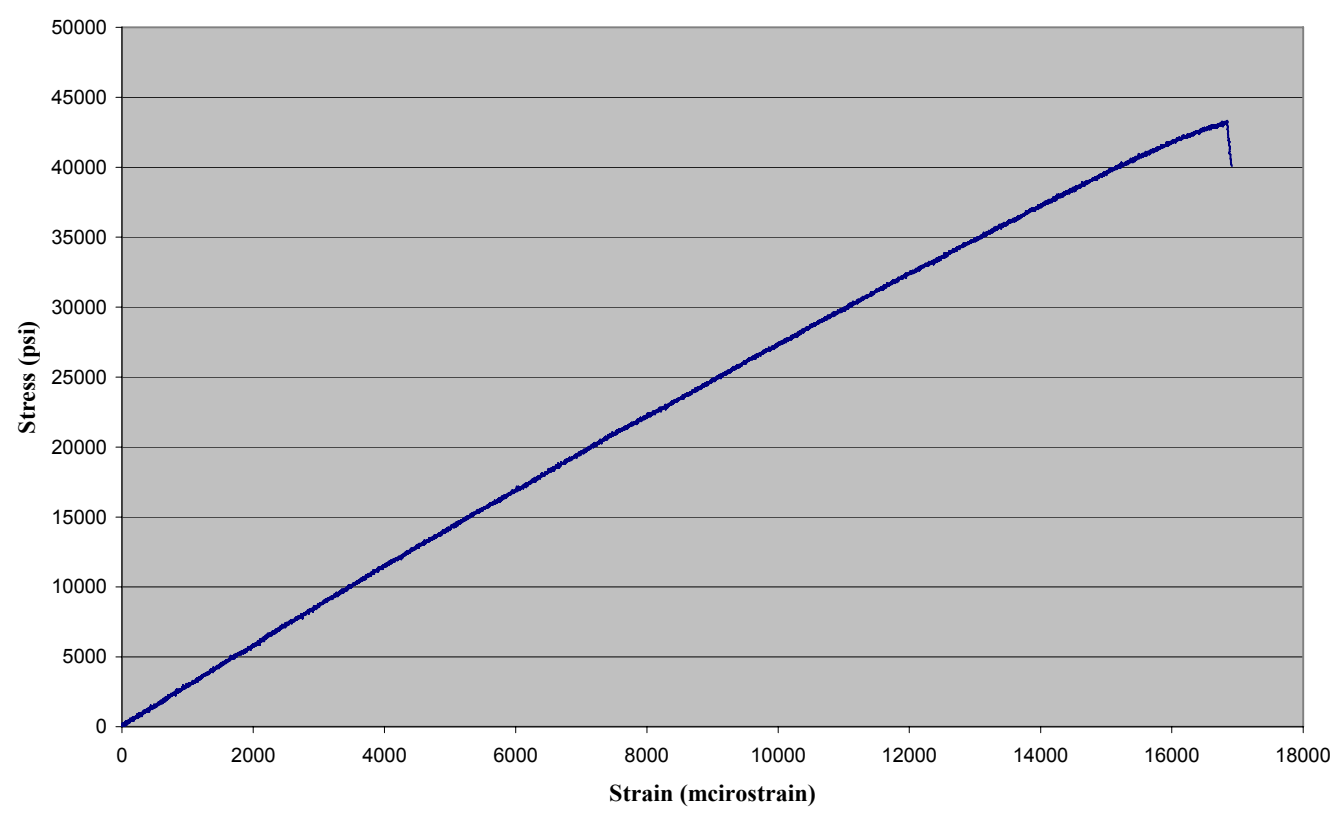

Figure 5.51 Stress-strain of cross-ply laminates (BBL2Q) in transverse direction

Cross-ply Laminates $[0 / 90]_{22 S} \mathrm{~L} 2$

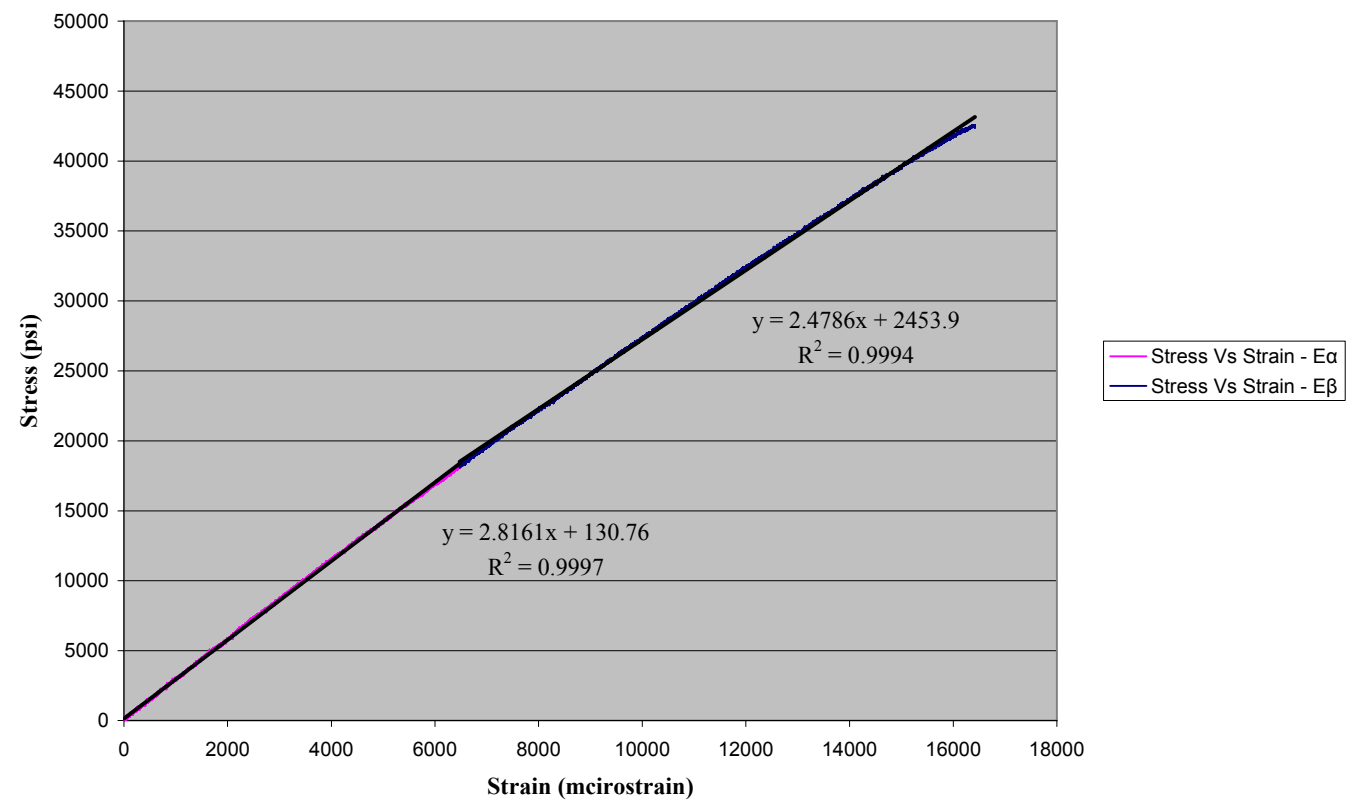

Figure 5.52 Stress-strain curve of cross-ply laminates (BBL2Q) in transverse direction until ultimate load 
Cross ply Laminates $[0 / 90]_{22 \mathrm{~S}} \mathrm{L5}$

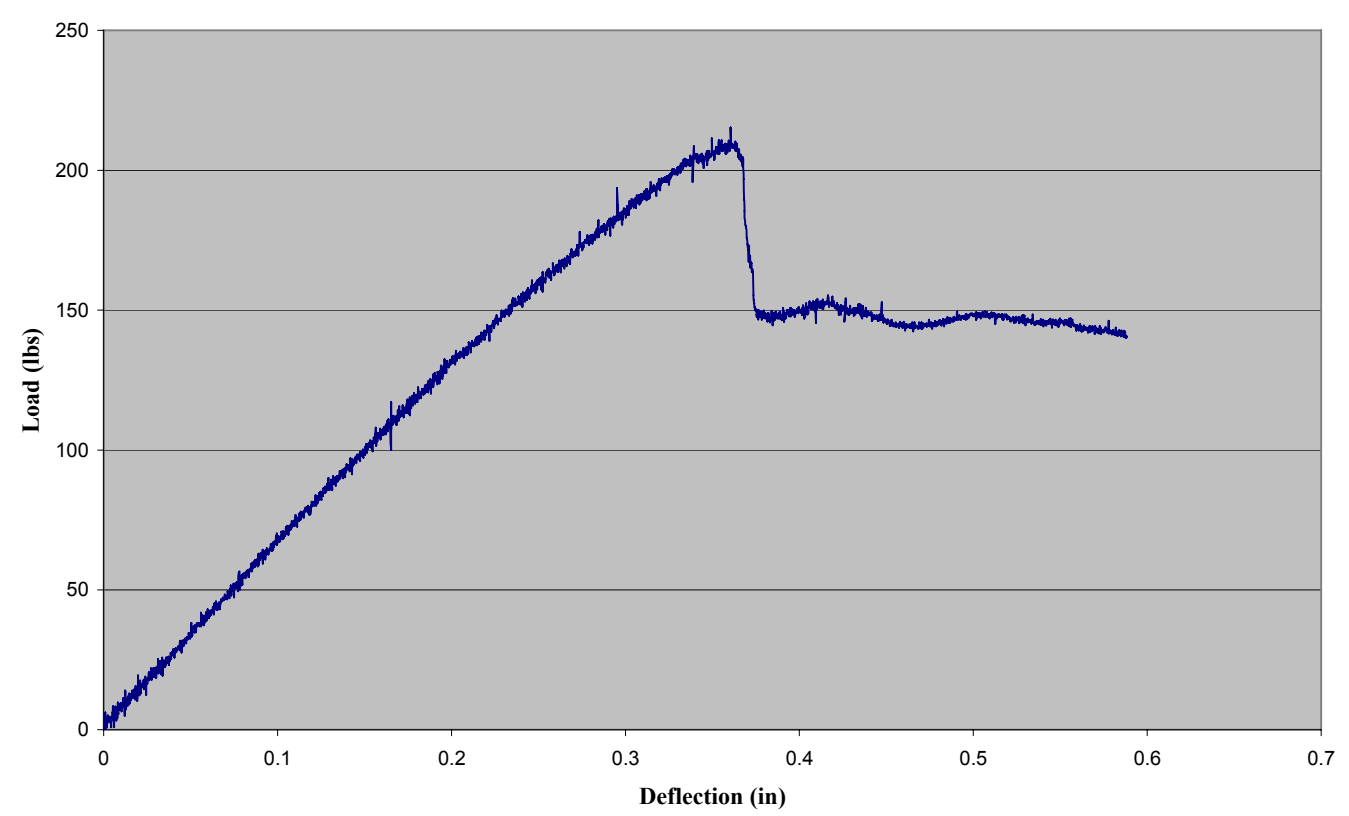

Figure 5.53 Load-deflection of cross-ply laminates (BBL5Q) in transverse direction

Cross ply Laminates $[0 / 90]_{22 \mathrm{~S}} \mathrm{L5}$

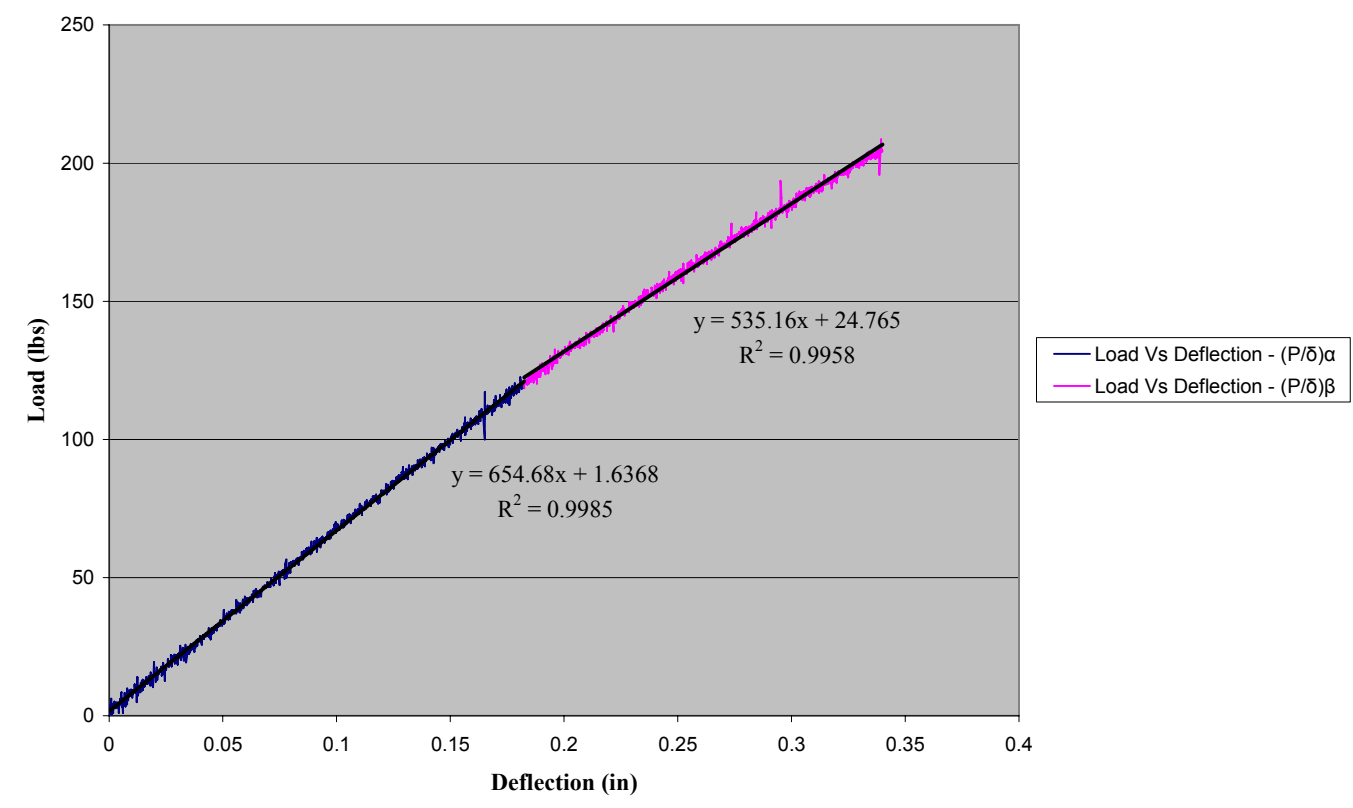

Figure 5.54 Load-deflection of cross-ply laminates (BBL5Q) in transverse direction until ultimate load 
Table 5.18 Bending Test Results of Cross-ply Laminates in Transverse Direction

\begin{tabular}{|c|c|c|c|c|c|c|c|c|c|c|c|c|c|c|}
\hline & Material & $\begin{array}{l}\text { Fabric } \\
\text { Density } \\
\left(o z / y d^{2}\right)\end{array}$ & $\begin{array}{c}F V F \\
(\%)\end{array}$ & $\begin{array}{c}F V F- \\
X \\
(\%)\end{array}$ & $\begin{array}{l}\text { Ethe } \\
\text { (msi) }\end{array}$ & $\begin{array}{c}\text { Strain } \\
\text { at } F-B i \\
(\%)\end{array}$ & $\begin{array}{c}\text { Strain } \\
\text { at } 90 \% \\
\text { Ultimat } \\
e \\
(\%)\end{array}$ & $\begin{array}{l}\text { Strain } \\
\text { at } \\
\text { Ultimat } \\
\text { e Load } \\
\text { (\%) }\end{array}$ & $F-B i$ & $\begin{array}{c}\text { Stress } \\
\text { at } 90 \% \\
\text { Ultimat } \\
e \\
(\text { ksi })\end{array}$ & $\begin{array}{c}\text { Stress } \\
\text { at } \\
\text { Ultimat } \\
e \\
\text { (ksi) }\end{array}$ & $\begin{array}{c}E \alpha \\
(m s i)\end{array}$ & $\underset{(m s i)}{E \beta}$ & $E \alpha / E \beta$ \\
\hline BBL2Q & \multirow{5}{*}{$\begin{array}{c}\text { 0/90 } \\
22 \text { layers } \\
\text { Longi }\end{array}$} & \multirow{5}{*}{$\begin{array}{c}0-5.76 \\
90-6.08 \\
\text { SY-0.56 } \\
\text { Tot-11.84 }\end{array}$} & 37 & 18 & 2.21 & 0.64 & 1.47 & 1.68 & 0.44 & 39.02 & 43.34 & 2.82 & 2.48 & 1.14 \\
\hline BBL4Q & & & 37 & 18 & 2.21 & 0.70 & 1.64 & 1.70 & 0.43 & 65.58 & 67.12 & 4.15 & 3.65 & 1.14 \\
\hline BBL6Q & & & 37 & 18 & 2.21 & - & - & - & - & 42.80 & 47.56 & 3.04 & 2.67 & 1.14 \\
\hline BBL7Q & & & 37 & 18 & 2.21 & - & - & - & - & 42.96 & 47.71 & 2.94 & 2.58 & 1.14 \\
\hline BBL8Q & & & 37 & 18 & 2.21 & - & - & - & - & 34.03 & 37.86 & 3.34 & 2.76 & 1.21 \\
\hline
\end{tabular}




\subsubsection{Quadri-directional without CSM}

Ten layers of $0 / 90$ fabric with density $12 \mathrm{oz} / \mathrm{yd} 2$ was used as reinforcement with vinyl ester resin for the fabrication of coupon specimens. $\pm 45^{\circ}$ lay up was achieved by cutting $0 / 90$ fabric in the $45^{\circ}$ orientation. Figure 5.55 represents a typical stress-strain curve of quadri-directional composite specimen in transverse direction, the outermost layer being $90^{\circ}$ plies. Figure 5.56 shows a bi-linear curve, where the stiffness was obtained from the slope using linear regression curve fit. Stresses obtained were in the range of $40 \mathrm{ksi}$ ( $90 \%$ ultimate load) for $44 \% \mathrm{FVF}$, and were found to be slightly lower than the specimens cut in the longitudinal direction. Corresponding strains were found to be in the range of $1.42 \%$ to $1.7 \%$. The point where change of slope occurred with reference to strains was 0.48 .

Quadri-directional with CSM Laminates $[90 / 0 /+45 /-45 / C S M]_{4 \mathrm{~S}} \mathrm{T1}$

(fabricated using 10 layers of $[0 / 90]$ cross-plies)

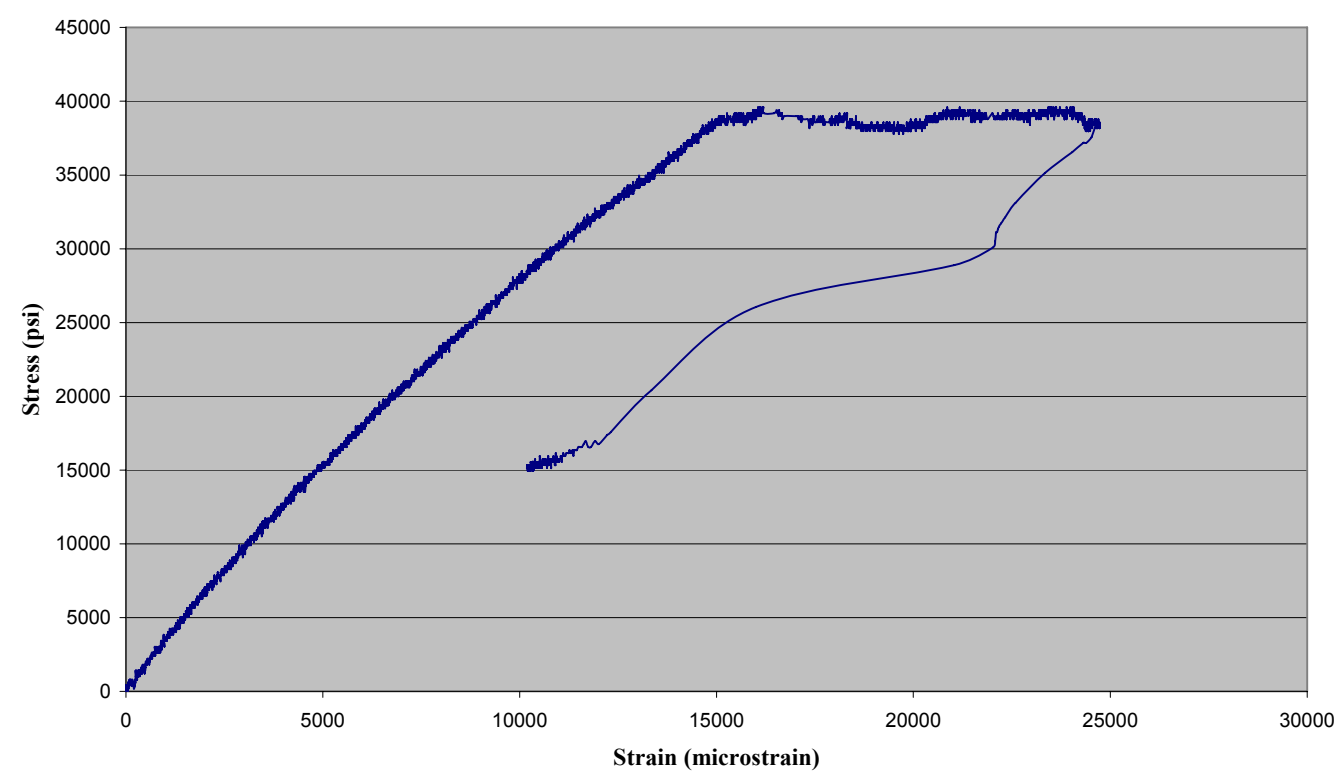

Figure 5.55 Stress-strain of quadri-directional laminates (BBL2Q) in transverse direction 
Quadri-directional with CSM Laminates $[90 / 0 /+45 /-45 / C S M]_{4 \mathrm{~S}} \mathrm{~T} 1$

(fabricated using 10 layers of $[0 / 90]$ cross-plies)

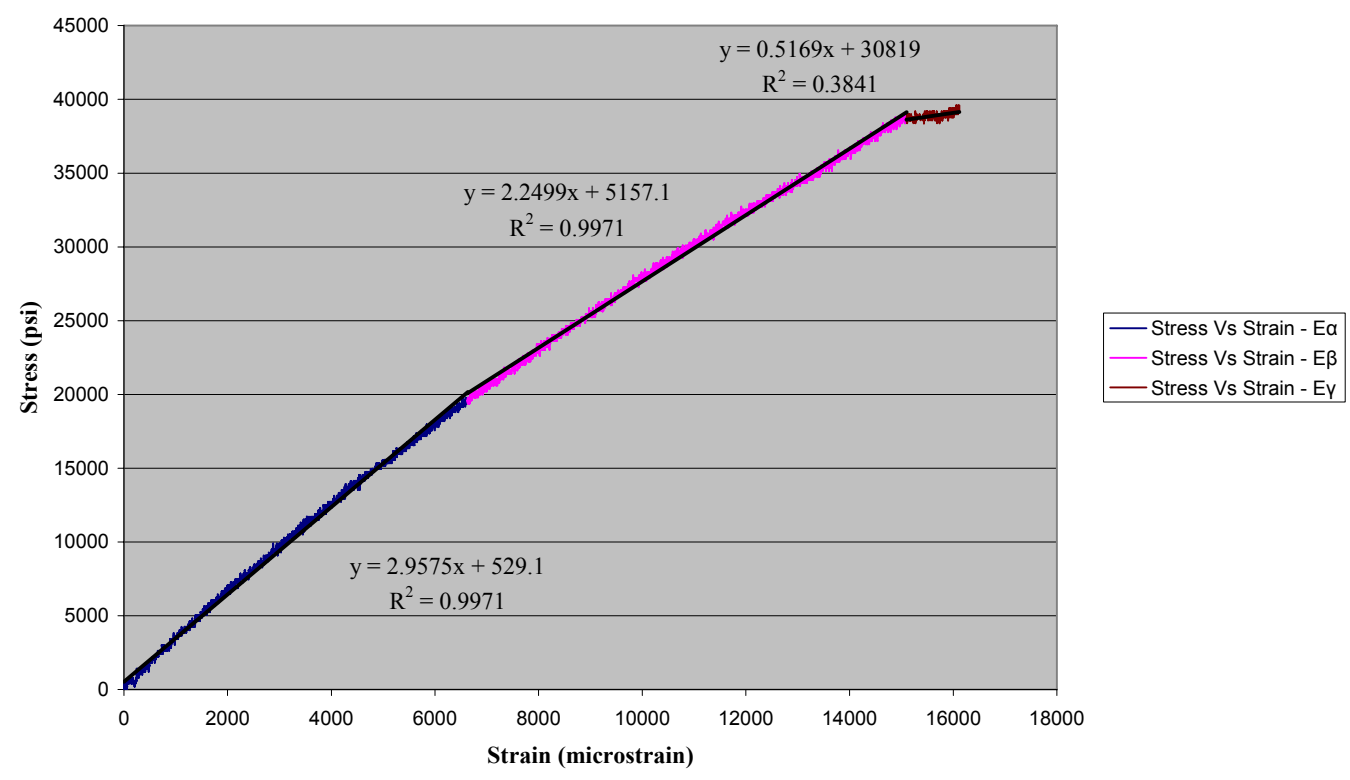

Figure 5.56 Stress-strain of quadri-directional laminates (BBL2Q) in transverse direction until ultimate load 
Table 5.19 Bending Test Results of Quadri-directional without CSM Laminates in Transverse Direction

\begin{tabular}{|c|c|c|c|c|c|c|c|c|c|c|c|c|c|c|}
\hline & Material & $\begin{array}{l}\text { Fabric } \\
\text { Density } \\
\left(o z / y d^{2}\right)\end{array}$ & $\begin{array}{c}F V F \\
(\%)\end{array}$ & $\begin{array}{c}F V F- \\
X \\
(\%)\end{array}$ & $\begin{array}{l}\text { Ethe } \\
\text { (msi) }\end{array}$ & $\begin{array}{l}\text { Strain at } \\
\text { F-Bi(\%) }\end{array}$ & $\begin{array}{c}\text { Strain } \\
\text { at } 90 \% \\
\text { Ultimat } \\
e \\
(\%)\end{array}$ & $\begin{array}{c}\text { Strain } \\
\text { at } \\
\text { Ultimat } \\
\text { e Load } \\
(\%)\end{array}$ & $F-B i$ & $\begin{array}{c}\text { Stress } \\
\text { at } \\
90 \% \\
\text { Ultim } \\
\text { ate }(k s \\
\quad i\end{array}$ & $\begin{array}{c}\text { Stress } \\
\text { at } \\
\text { Ultim } \\
\text { ate } \\
\text { (ksi }\end{array}$ & $\begin{array}{c}E \alpha \\
(m s i)\end{array}$ & $\begin{array}{c}E \beta \\
\text { (msi) }\end{array}$ & $\begin{array}{c}E \alpha / \\
E \beta\end{array}$ \\
\hline BQW/OCT1-4 & \multirow{3}{*}{$\begin{array}{c}0 / 90 /+45 /- \\
45 \\
10 \text { Layers }\end{array}$} & \multirow{3}{*}{$\begin{array}{c}0-11.52 \\
90- \\
12.16\end{array}$} & 44 & 22 & 2.57 & 0.66 & 1.36 & 1.61 & 0.49 & 35.55 & 39.59 & 2.96 & 2.25 & 1.31 \\
\hline BQW/OCT2-4 & & & 44 & 22 & 2.57 & 0.69 & 1.47 & 1.65 & 0.47 & 36.56 & 40.69 & 2.89 & 2.13 & 1.36 \\
\hline BQW/OCT3-4 & & & 44 & 22 & 2.57 & 0.69 & 1.43 & 1.72 & 0.48 & 36.26 & 40.26 & 2.91 & 2.31 & 1.26 \\
\hline
\end{tabular}




\subsubsection{Tri-directional with CSM}

Eight layers and four layers of fabric with density 53oz/yd2 were used with vinyl ester to manufacture half-inch (approx), and quarter-inch (approx) thick specimens, respectively. Typical stress-strain curves are shown in Figure 5.57 and Figure 5.61. Figure 5.59 and Figure 5.63 show typical and load-deflection curves. Instead of bi-linear curve, almost a tri-linear curve was observed from Figure 5.58, Figure 5.60, Figure 5.62, and Figure 5.64, which was attributed to less amount of fibers contributing in loading direction. In some cases, fourth slopes were observed beyond $90 \%$ of ultimate load and hence, for all specimens, only up to $90 \%$ of ultimate load and corresponding stresses and strains were considered in our evaluation. Stresses obtained were in the range of $30 \mathrm{ksi}$ ( $90 \%$ ultimate load) for $48 \%$ FVF. Corresponding strains obtained were in the range of $2 \%$, and the point where change of slope occurred was found to be 0.3 .

Tri-directional with CSM Laminates $[45 / 90 /-45 / C S M]_{4 S}$ T4

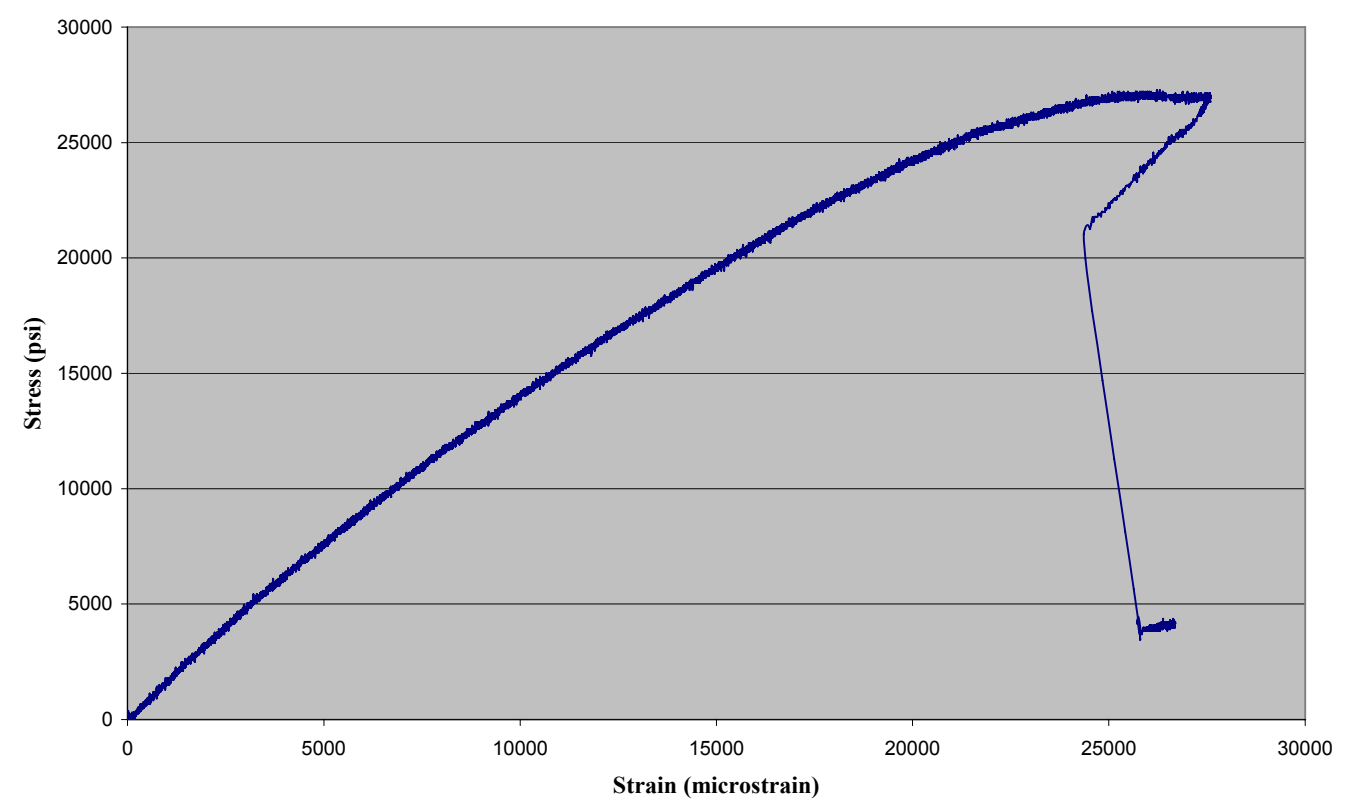

Figure 5.57 Stress-strain of tri-directional with CSM laminate (BTL4Q) in transverse direction 
Tri-directional with CSM Laminates $[45 / 90 /-45 / C S M]_{4 \mathrm{~S}} \mathrm{~T} 4$

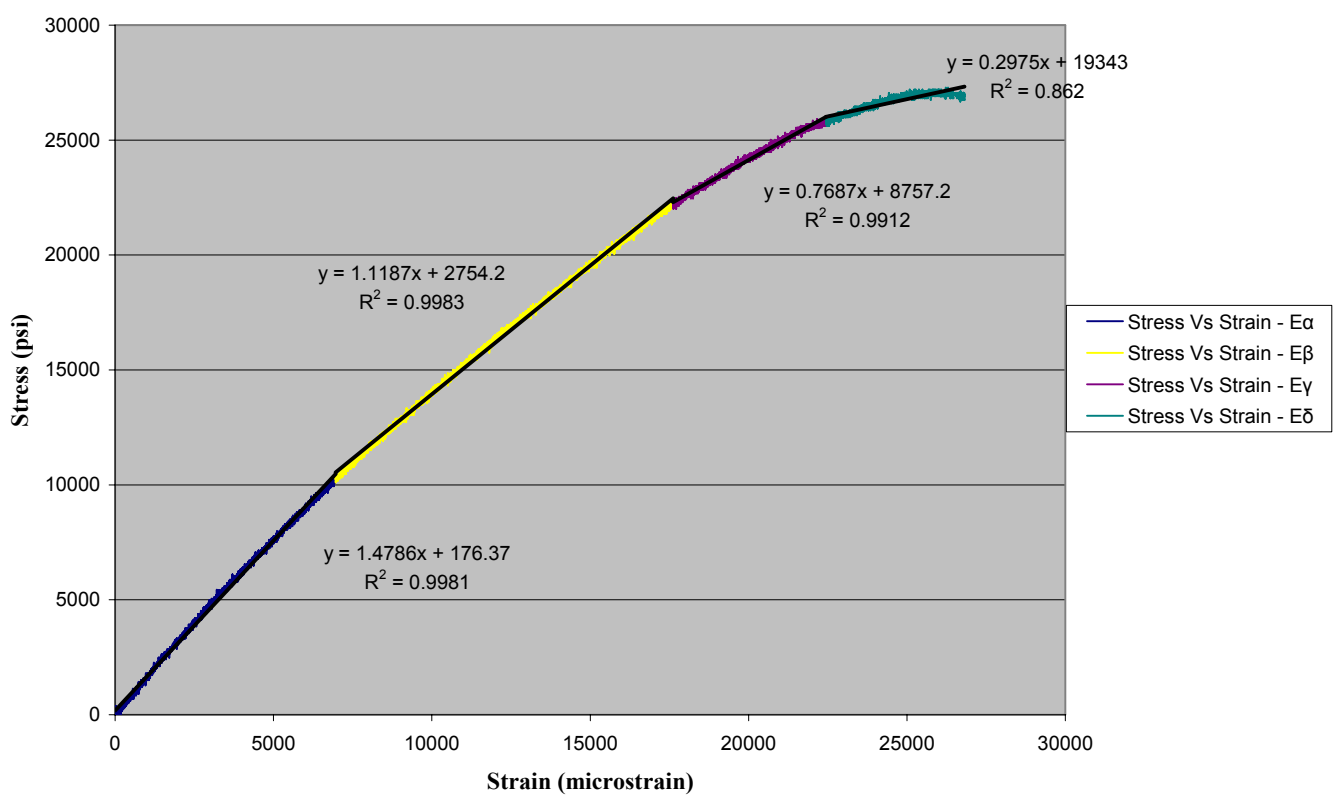

Figure 5.58 Stress-strain of tri-directional composite with CSM (BTL4Q) in transverse direction until ultimate load

Tri-directional with CSM Laminates $[45 / 90 /-45 / C S M]_{10 \mathrm{~S}} \mathrm{~T} 4$

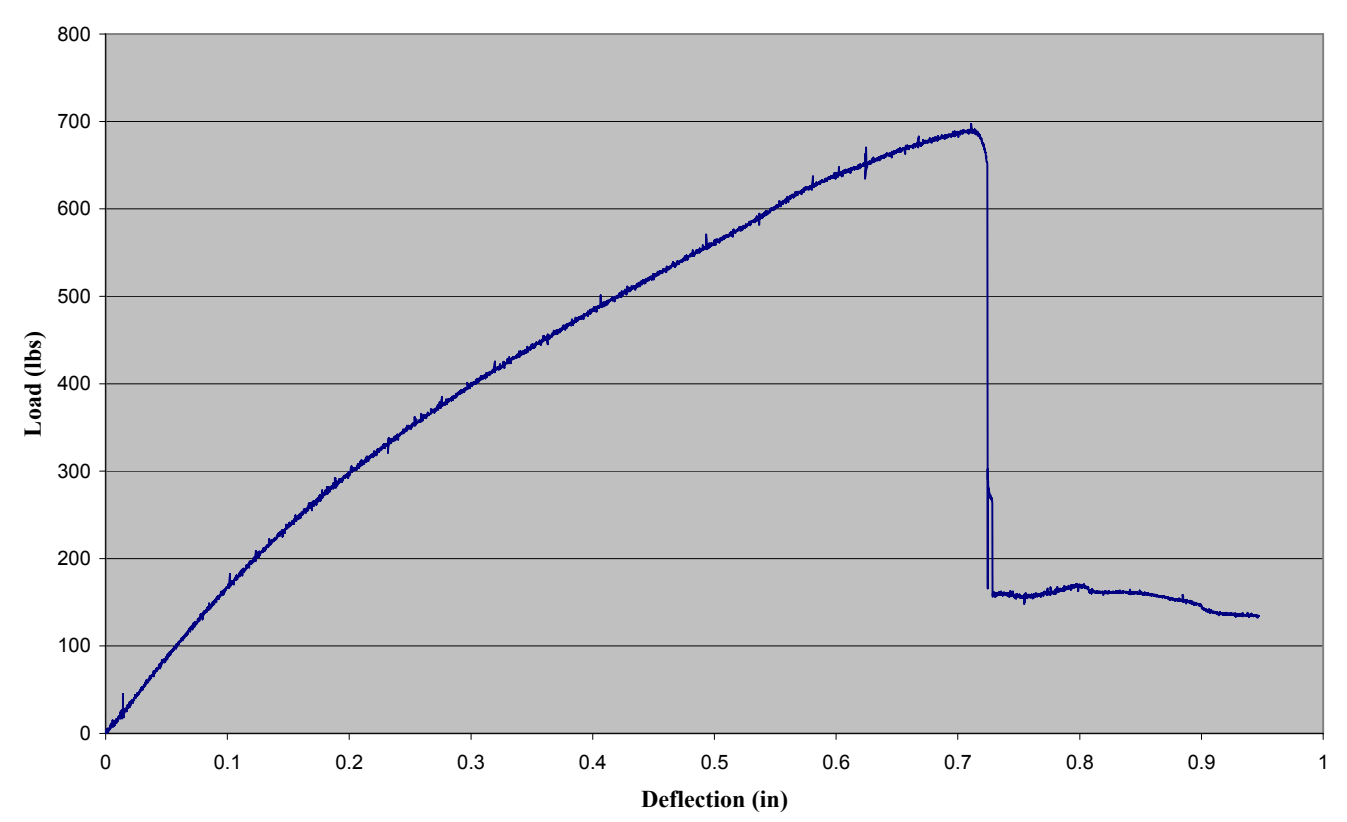

Figure 5.59 Load-deflection of tri-directional with CSM (BTT5Q) in transverse direction 
Tri-directional with CSM $[45 / 90 /-45 / C S M]_{4 S}$ T5

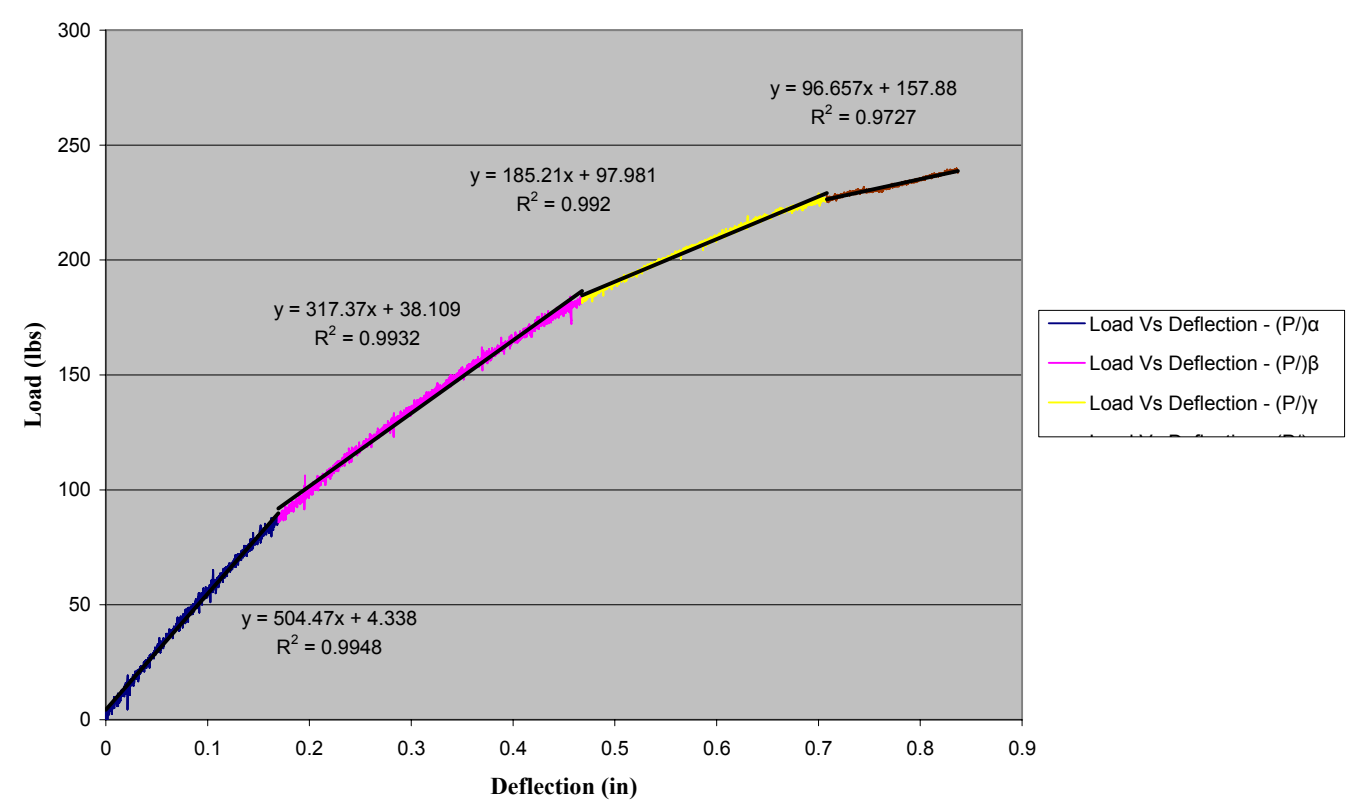

Figure 5.60 Load-deflection of tri-directional composite with CSM (BTT5Q) in transverse direction until ultimate load

Tri-directional with CSM Laminates $[45 / 90 /-45 / C S M]_{10 S}$ L5

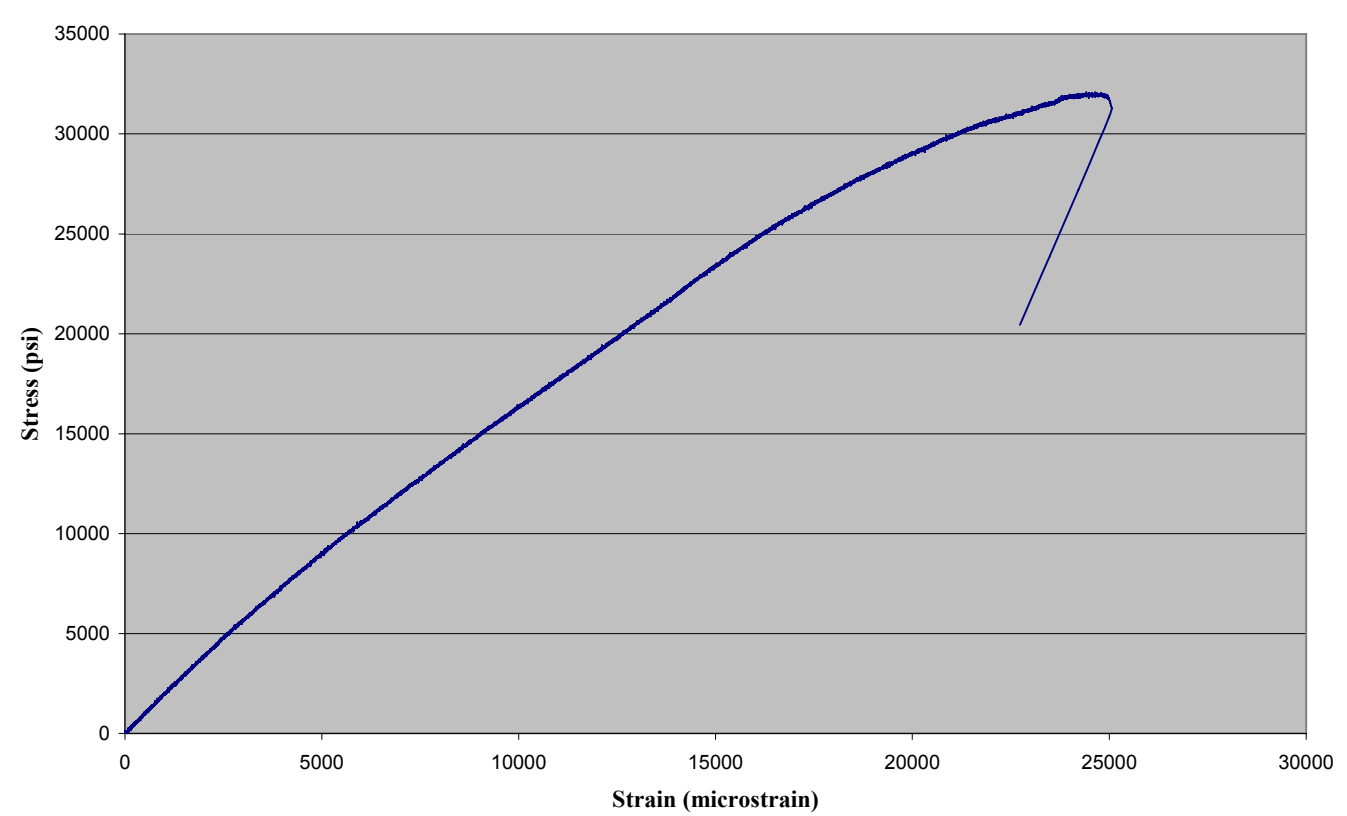

Figure 5.61 Stress-strain curve of tri-directional composite with CSM (BTT5H) in transverse direction 
Tri-directional with CSM Laminates $[45 / 90 /-45 / C S M]_{10 S} \mathrm{L5}$

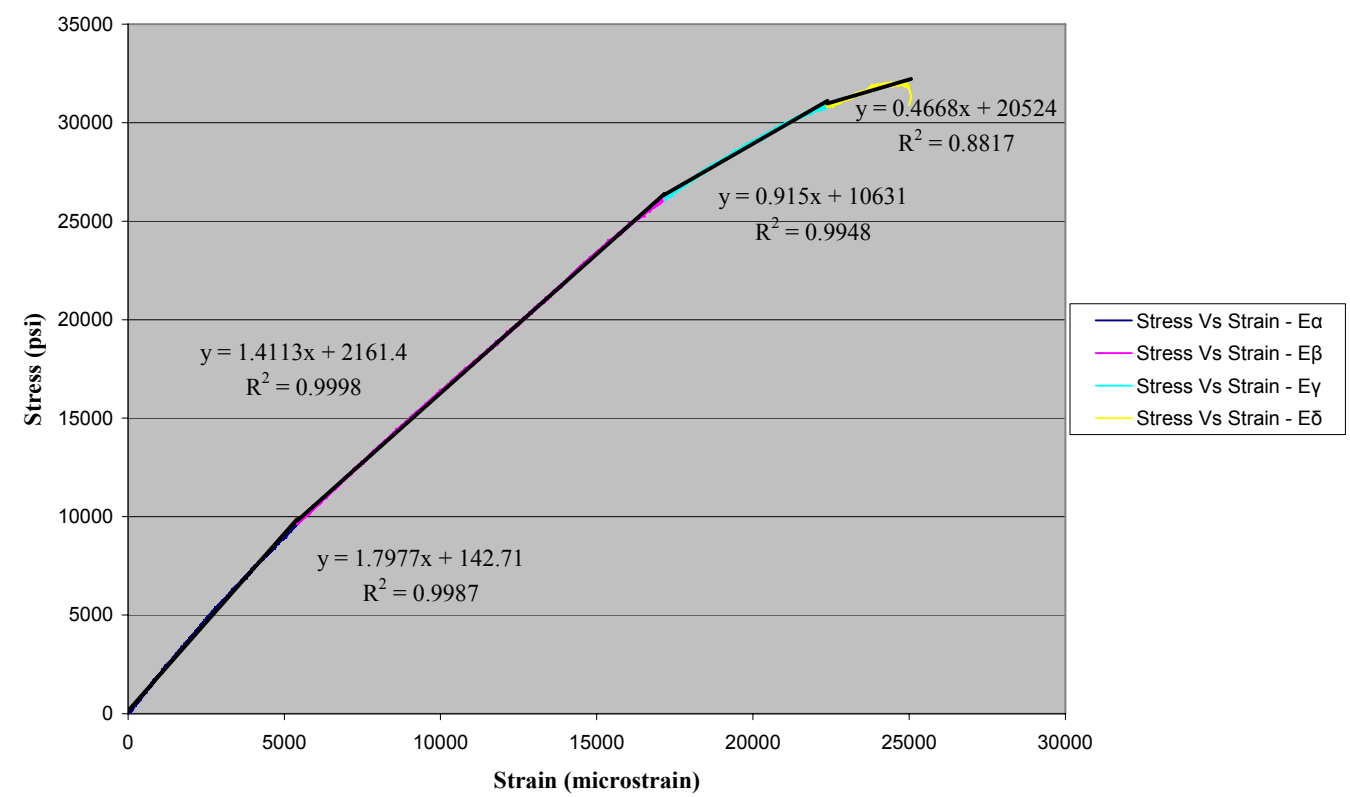

Figure 5.62 Stress-strain of tri-directional composite with CSM (BTT5H) in transverse direction until ultimate load

Tri-directional with CSM Laminates $[45 / 90 /-45 / C S M]_{10 \mathrm{~s}} \mathrm{~T} 4$

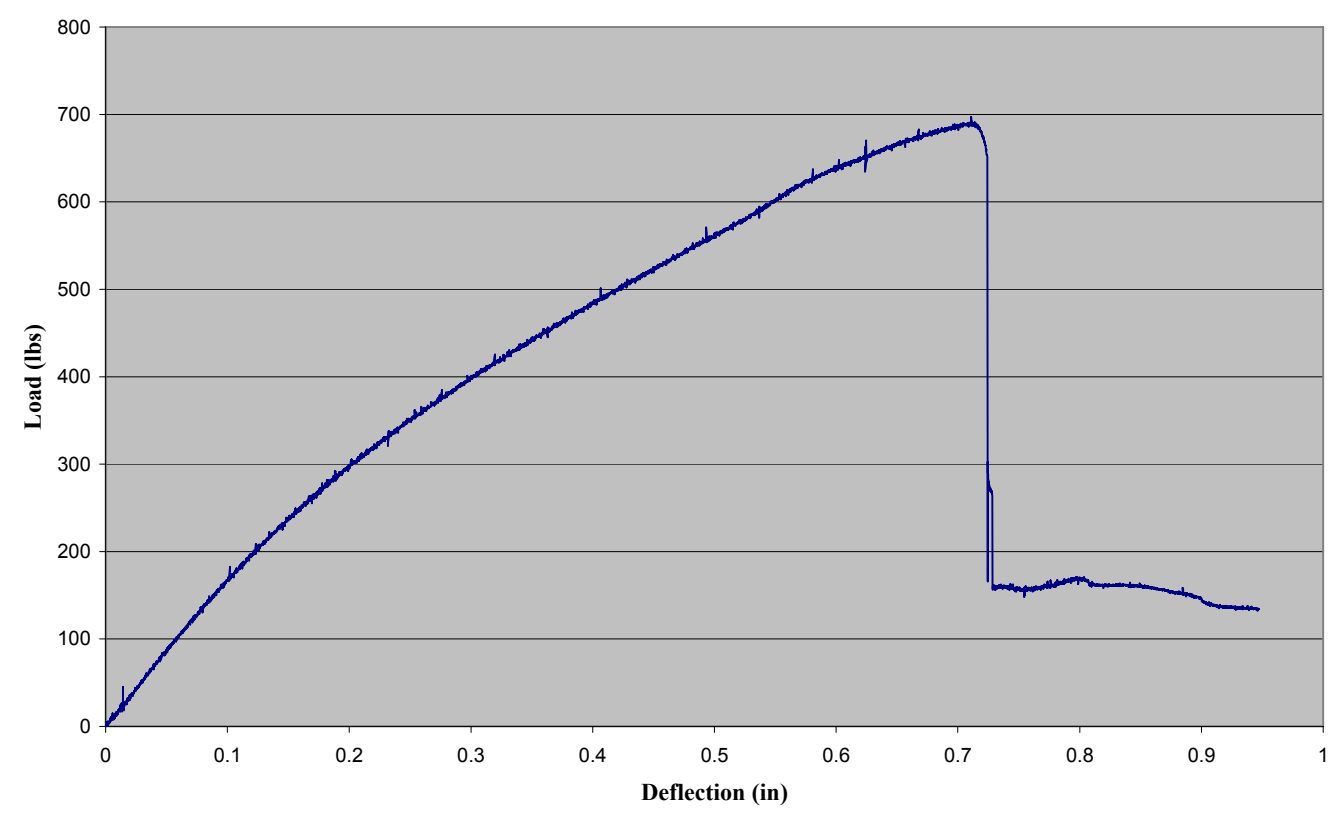

Figure 5.63 Load-deflection of tri-directional composite with CSM (BTT4H) in transverse direction 
Tri-directional with CSM Laminates $[45 / 90 /-45 / C S M]_{10 S}$ T4

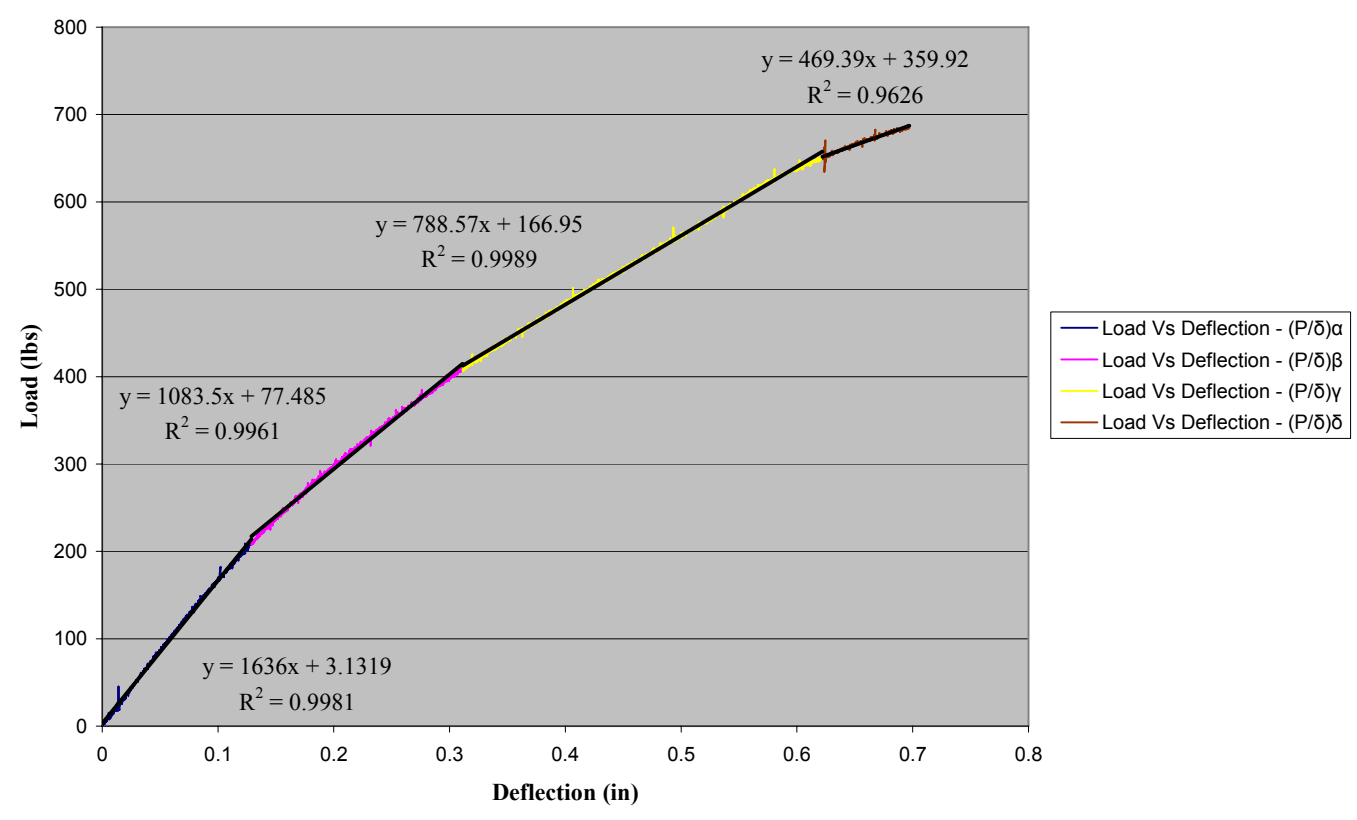

Figure 5.64 Load-deflection of tri-directional composite with CSM (BTT4H) in transverse direction until ultimate load 
Table 5.20 Bending Test Results of tri-directional with CSM Laminates in Transverse Direction

\begin{tabular}{|c|c|c|c|c|c|c|c|c|c|c|c|c|c|c|c|c|}
\hline & Material & $\begin{array}{l}\text { Fabric } \\
\text { density } \\
\left(o z / y d^{2}\right)\end{array}$ & $\begin{array}{c}F V \\
F \\
(\%)\end{array}$ & $\begin{array}{c}F V F- \\
X \\
(\%)\end{array}$ & $\begin{array}{l}\text { Ethe } \\
\text { (msi) }\end{array}$ & $\begin{array}{c}\text { Strai } \\
\boldsymbol{n} \text { at } \\
\text { F-Bi } \\
(\%)\end{array}$ & $\begin{array}{c}\text { Strain } \\
\text { at } S-B i \\
(\%)\end{array}$ & $\begin{array}{c}\text { Strain } \\
\text { at } 90 \% \\
\text { Ultima } \\
\text { te } \\
(\%)\end{array}$ & $\begin{array}{c}\text { Strain } \\
\text { at } \\
\text { Ultima } \\
\text { te } \\
\text { Load } \\
(\%)\end{array}$ & $F-B i$ & $\begin{array}{c}\text { Stress } \\
\text { at } \\
90 \% \\
\text { Ultim } \\
\text { ate } \\
\text { (ksi) } \\
\end{array}$ & $\begin{array}{c}\text { Stress } \\
\text { at } \\
\text { Ultim } \\
\text { ate } \\
\text { (ksi) }\end{array}$ & $\begin{array}{c}E \alpha \\
(m s i)\end{array}$ & $\begin{array}{c}E \beta \\
\text { (msi) }\end{array}$ & $\begin{array}{c}E \gamma \\
\text { (msi) }\end{array}$ & $\begin{array}{c}E \boldsymbol{\alpha} \\
/ E \boldsymbol{\beta}\end{array}$ \\
\hline BTT5H & \multirow{15}{*}{$\begin{array}{c}\text { 45/90/- } \\
\text { 45/CSM } \\
8 \text { layers }\end{array}$} & \multirow{15}{*}{$\begin{array}{c}45-11.44 \\
90-17.28 \\
\text { CSM- } \\
13.5 \\
\text { Tot- } \\
53.66\end{array}$} & 50 & 17 & 2.03 & 0.62 & 1.71 & 1.98 & 2.44 & 0.31 & 28.87 & 32.08 & 1.77 & 1.41 & 0.92 & 1.26 \\
\hline BTT7H & & & 50 & 17 & 2.03 & 0.58 & 1.58 & 1.94 & 2.34 & 0.30 & 28.89 & 32.07 & 1.58 & 1.13 & 0.79 & 1.39 \\
\hline BTT11H & & & 50 & 17 & 2.03 & 0.59 & 1.48 & 1.69 & 2.08 & 0.35 & 29.09 & 32.32 & 1.94 & 1.67 & 1.27 & 1.16 \\
\hline BTT4H & & & 50 & 17 & 2.03 & - & - & - & - & - & 31.25 & 34.68 & 2.33 & 1.54 & 1.12 & 1.51 \\
\hline ВTT6H & & & 50 & 17 & 2.03 & - & - & - & - & - & 30.55 & 33.91 & 2.30 & 1.58 & 1.06 & 1.45 \\
\hline BTT8H & & & 50 & 17 & 2.03 & - & - & - & - & - & 30.70 & 34.09 & 2.22 & 1.59 & 1.06 & 1.40 \\
\hline ВTT9H & & & 50 & 17 & 2.03 & - & - & - & - & - & 29.57 & 32.80 & 2.31 & 1.62 & 1.12 & 1.43 \\
\hline BTT10H & & & 50 & 17 & 2.03 & - & - & - & - & - & 30.98 & 34.35 & 2.34 & 1.70 & 1.17 & 1.38 \\
\hline BTT2Q & & & 44 & 15 & 1.85 & 0.56 & 1.65 & 2.02 & 2.65 & 0.28 & 23.34 & 25.90 & 1.49 & 1.11 & 0.71 & 1.35 \\
\hline BTT3Q & & & 44 & 15 & 1.85 & 0.68 & 1.68 & 2.16 & 2.55 & 0.32 & 23.80 & 26.39 & 1.22 & 0.87 & 0.57 & 1.40 \\
\hline BTT4Q & & & 44 & 15 & 1.85 & 0.71 & 1.86 & 2.07 & 2.62 & 0.35 & 24.57 & 27.28 & 1.48 & 1.12 & 0.77 & 1.32 \\
\hline BTT5Q & & & 44 & 15 & 1.85 & & & & & & 27.82 & 30.90 & 1.96 & 1.23 & 0.72 & 1.59 \\
\hline A2 TT1 & & & 58 & 20 & 2.27 & 0.46 & 1.22 & 1.97 & 2.62 & 0.23 & 24.34 & 26.97 & 1.94 & 1.19 & 0.83 & 1.63 \\
\hline TT1 & & & 58 & 20 & 2.27 & 0.48 & 1.22 & 2.03 & 2.62 & 0.24 & 29.18 & 32.49 & 2.25 & 1.47 & 0.93 & 1.53 \\
\hline TT2 & & & 58 & 20 & 2.27 & 0.49 & 1.28 & 1.96 & 2.69 & 0.25 & 29.40 & 32.60 & 2.29 & 1.52 & 1.03 & 1.51 \\
\hline
\end{tabular}




\subsubsection{Quadri-directional with CSM}

Four layers of $61 \mathrm{oz} / \mathrm{yd} 2$ fabric with lay up were used along with vinyl ester resin for manufacturing of coupon specimens. A typical stress-strain curve of quadridirectional fabric composite with CSM along transverse direction was shown in Figure 5.65. A nearly bi-linear curve was observed in Figure 5.66. Stiffness was obtained for the two linear curves using linear regression curve fit. For some specimens, a third slope was observed beyond $90 \%$ of ultimate load and was neglected. Corresponding stresses and strains till $90 \%$ of ultimate load were considered, and were observed to be in the range of $36 \mathrm{ksi}$ with $55 \%$ FVF. Strains were in the range of $1.6 \%$ to $1.8 \%$, with 0.22 as the point where change of slope occurred in reference to strains.

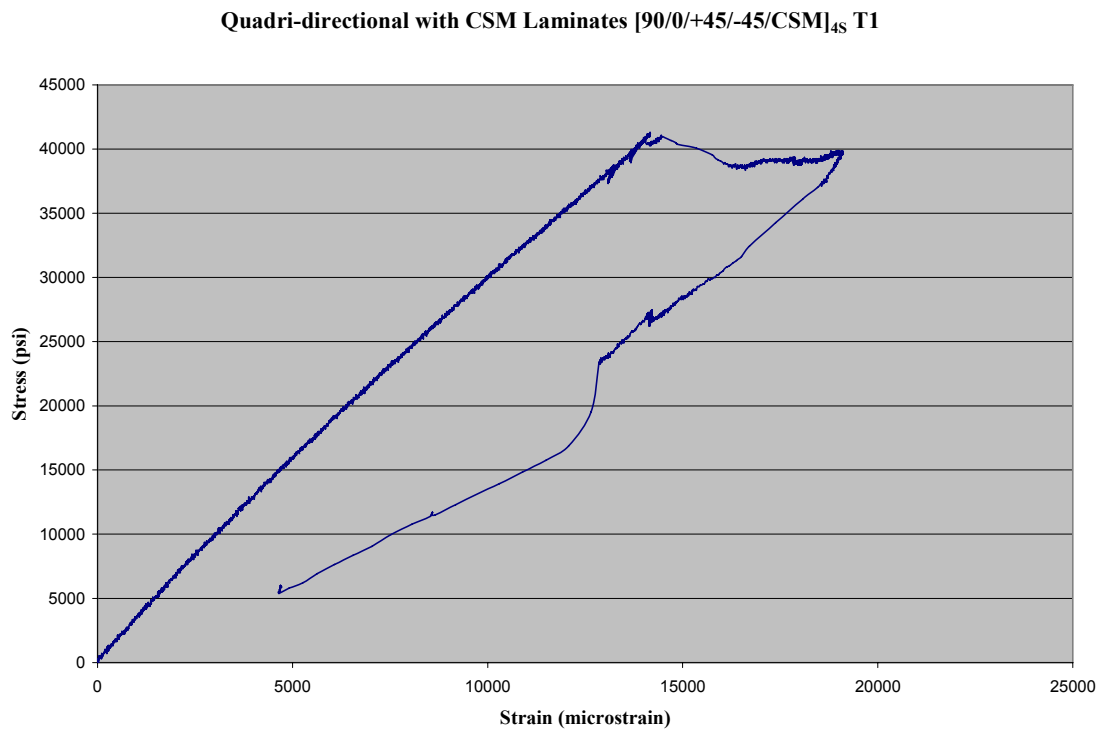

Figure 5.65 Stress-strain curve of quadri-directional composites with CSM (BTQ1Q) in transverse direction 
Quadri-directional with CSM Laminates $[90 / 0 /+45 /-45 / C S M]_{4 S}$ T1

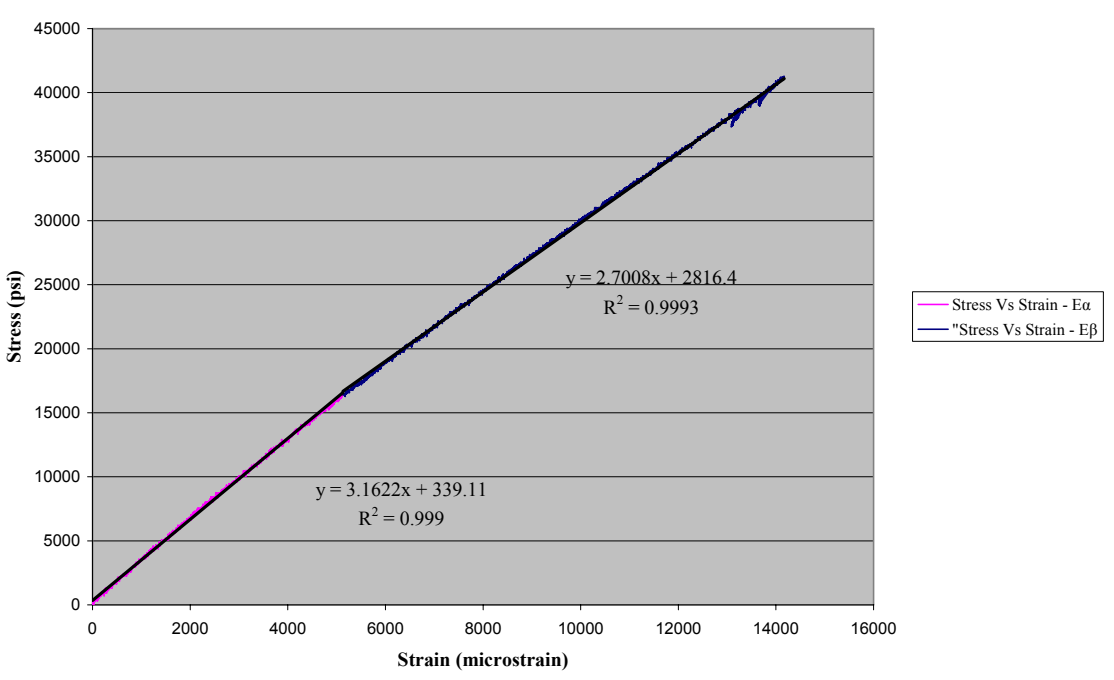

Figure 5.66 Stress-strain of quadri-directional composites with CSM (BTQ1Q) in transverse direction until ultimate load 
Table 5.21 Bending Test Results of quadri-directional composites with CSM in Transverse Direction

\begin{tabular}{|c|c|c|c|c|c|c|c|c|c|c|c|c|c|c|}
\hline & Material & $\begin{array}{l}\text { Fabric } \\
\text { density } \\
\left(o z / y d^{2}\right)\end{array}$ & $\begin{array}{c}F V F \\
(\%)\end{array}$ & $\begin{array}{c}F V F- \\
X \\
(\%)\end{array}$ & $\begin{array}{l}\text { Ethe } \\
\text { (msi) }\end{array}$ & $\begin{array}{c}\text { Strain } \\
\text { at } F-B i \\
(\%)\end{array}$ & $\begin{array}{c}\text { Strain } \\
\text { at } 90 \% \\
\text { Ultimat } \\
e \\
(\%) \\
\end{array}$ & $\begin{array}{c}\text { Strain } \\
\text { at } \\
\text { Ultimat } \\
\text { e Load } \\
(\%)\end{array}$ & $F-B i$ & $\begin{array}{c}\text { Stress } \\
\text { at } 90 \% \\
\text { Ultima } \\
\text { te } \\
(\mathrm{ksi}) \\
\end{array}$ & $\begin{array}{c}\text { Stress } \\
\text { at } \\
\text { Ultima } \\
\text { te } \\
(\mathrm{ksi}) \\
\end{array}$ & $\begin{array}{c}E \alpha \\
(m s i)\end{array}$ & $\begin{array}{c}E \beta \\
(m s i)\end{array}$ & $E \alpha / E \beta$ \\
\hline B1Q-Tr & \multirow{3}{*}{$\begin{array}{c}4 \text { layers } \\
90 / 0 /+45 /- \\
45 / \mathrm{CSM} \\
4 \text { layers }\end{array}$} & \multirow{3}{*}{$\begin{array}{c}90-14.08 \\
0-15.71 \\
45-9.04 \\
\text { CSM-13.5 }\end{array}$} & 54 & 26 & 2.99 & 0.42 & 1.58 & 1.77 & 0.27 & 27.76 & 30.80 & 2.90 & 2.20 & 1.31 \\
\hline TQ1 & & & 56 & 27 & 3.09 & 0.51 & 1.27 & 1.41 & 0.40 & 37.22 & 41.29 & 3.16 & 2.70 & 1.17 \\
\hline TQ2 & & & 56 & 27 & 3.09 & 0.44 & 1.78 & 2.14 & 0.25 & 31.67 & 35.21 & 3.01 & 2.64 & 1.14 \\
\hline
\end{tabular}




\subsection{MODES OF FAILURE}

As composites are subjected to a variety of load conditions, different failure modes (damages) are observed. Different lay-up configurations result in variations in stiffness, failure stresses, also failure modes. Sometimes, the damage progressively increases degrading the material properties resulting in failure of the material without reaching its ultimate stress. Also, failure modes differ with the type of loading. Some of the failure modes of laminated composites are: fibers pull out, ply failure, matrix cracking, laminate explosion, and delamination. Out of which, delamination failures are one of the most common failure modes, as most of the fiber reinforced composites are manufactured by laying stack of fibers, and inadequate resin wet out at the interface between the layers is the main source of delamination. Further, manufacturing defects and voids also assist in damage inanition.

\subsubsection{General Failure modes}

\section{a) Matrix cracking:}

This is also called transverse cracking, as the crack grows parallel to the fiber and in the thickness direction of the laminate. This is considered as the first stage of failure mode (see Figure 5.67).

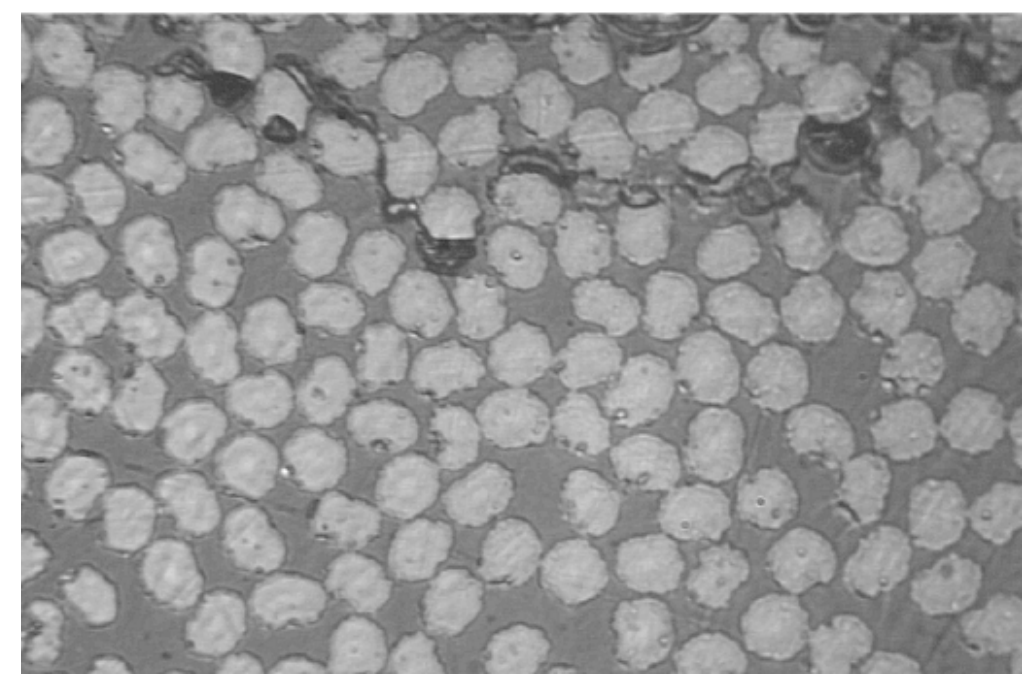

Figure 5.67 Matrix cracking (Micrograph library, 2006) 


\section{b) Delamination:}

It is regarded as de-bonding of the layers. Basically, it is a crack which runs parallel to the fiber direction at the interface between adjacent layers. The prediction of the initiation of a delamination is often related to the occurrence of transverse cracking. (see Figure 5.68)

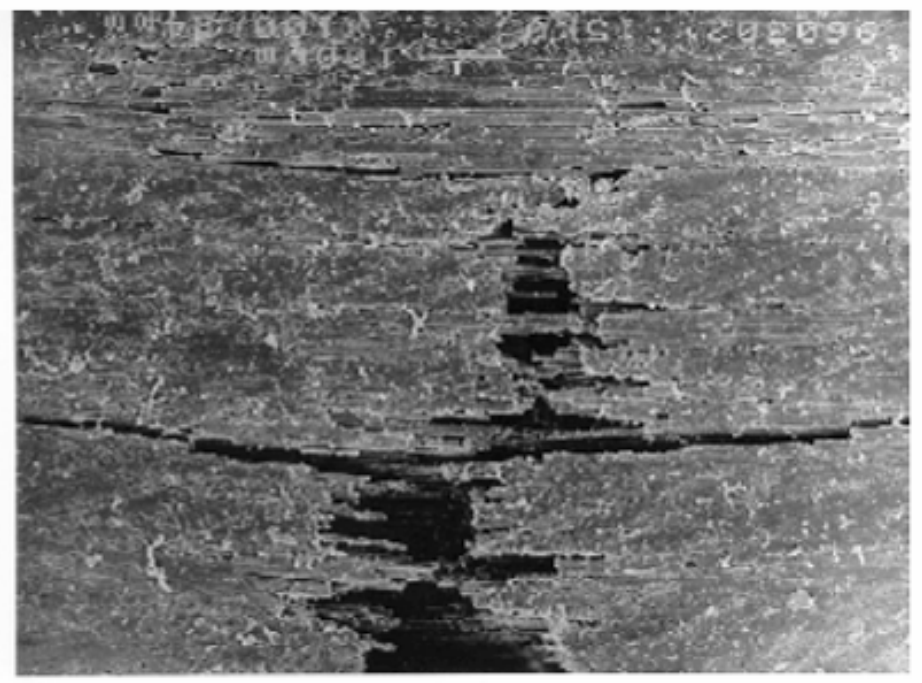

Figure 5.68 Delamination and fiber fracture (Micrograph library, 2006)

\section{c) Fiber Breakage:}

This is usually regarded as the final stage of failure mode. In some cases fiber related failure involve local buckling of fiber, or fiber pull-out (see Figure 5.68).

\section{Effect of fiber orientation}

The following are the possible modes of failure for composites with continuous reinforced fibers:

Case A: Longitudinal tensile fracture failure (parallel to the fibers - $0^{\circ}$ reinforcement) as shown in Figure 5.69- A

Case B: Shear failure of the matrix (due to large shear stress acting parallel to the fibers $-45^{\circ}$ fibers) as shown in Figure 5.69- B 
Case C: Transverse tensile failure of the matrix or fiber-matrix interface (when stresses perpendicular to the fibers $-90^{\circ}$ fibers) as shown in Figure 5.69- C

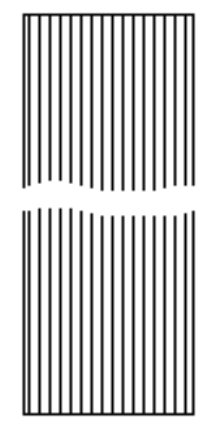

A

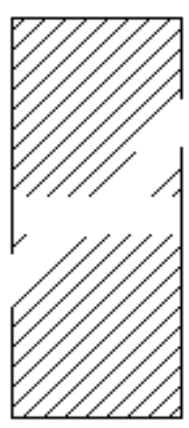

B

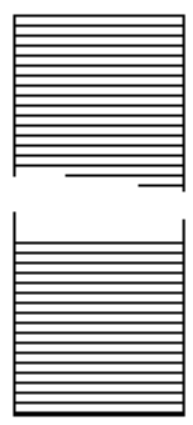

$\mathrm{C}$

Figure 5.69 Modes of failure due to different fiber orientation (Kaw ,2006)

In this study, failure mode of set of specimens with different fiber architectures observed under tension and bending are mentioned in detail and are limited to this thesis.

\subsubsection{Tension Test}

\subsubsection{Longitudinal Direction}

\section{a) Unidirectional Laminates:}

Specimens with $12 \mathrm{oz} / \mathrm{yd} 2$ density had initial delamination of lay-up through-out gage length followed by breakage of fibers. For some specimens, fiber breakage is observed near the center of the gage length (Figure 5.70) leading to almost pure tension failure, but for others the breakage was near grips, leading to premature failure attributed to bending (Figure 5.71).

In case of $7 \mathrm{oz} / \mathrm{yd} 2$ density coupon specimens, there was delamination of outer layers through-out the gage length, and there was gradual decrease in load leading to premature failure (Figure 5.72). The stresses obtained are very less, implying that there was more amount of bending.

In all the cases, delamination occurred beyond $90 \%$ ultimate load followed by fiber breakage, indicating that the stress-strain curve is linear almost till the ultimate load as shown in Figure 5.2. 


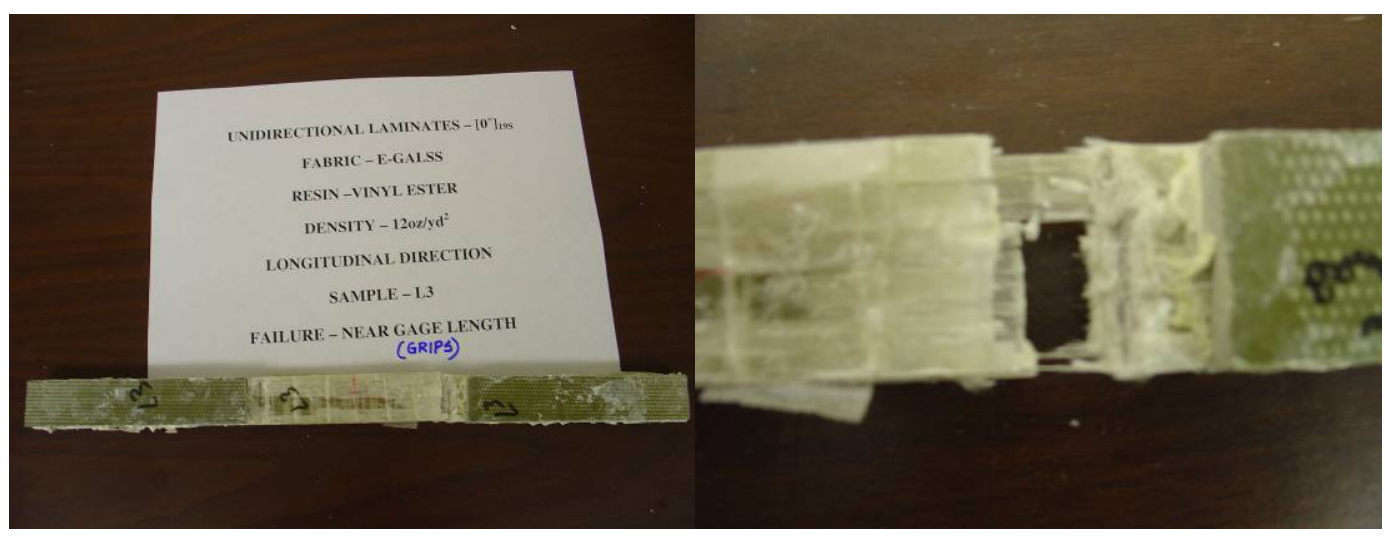

Figure 5.70 Unidirectional composite samples failed near the gage length

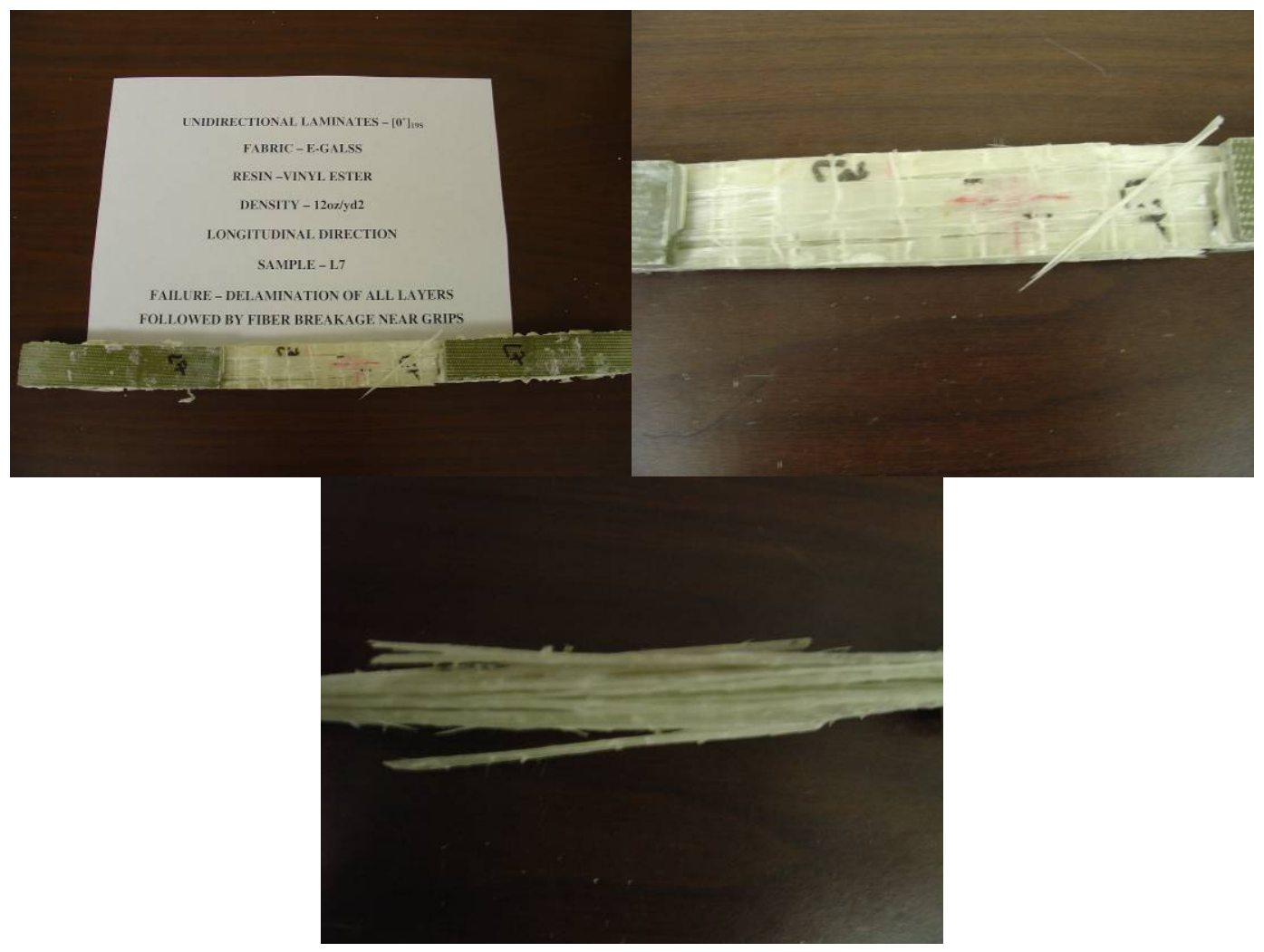

Figure 5.71 Unidirectional composite samples failed near grips 


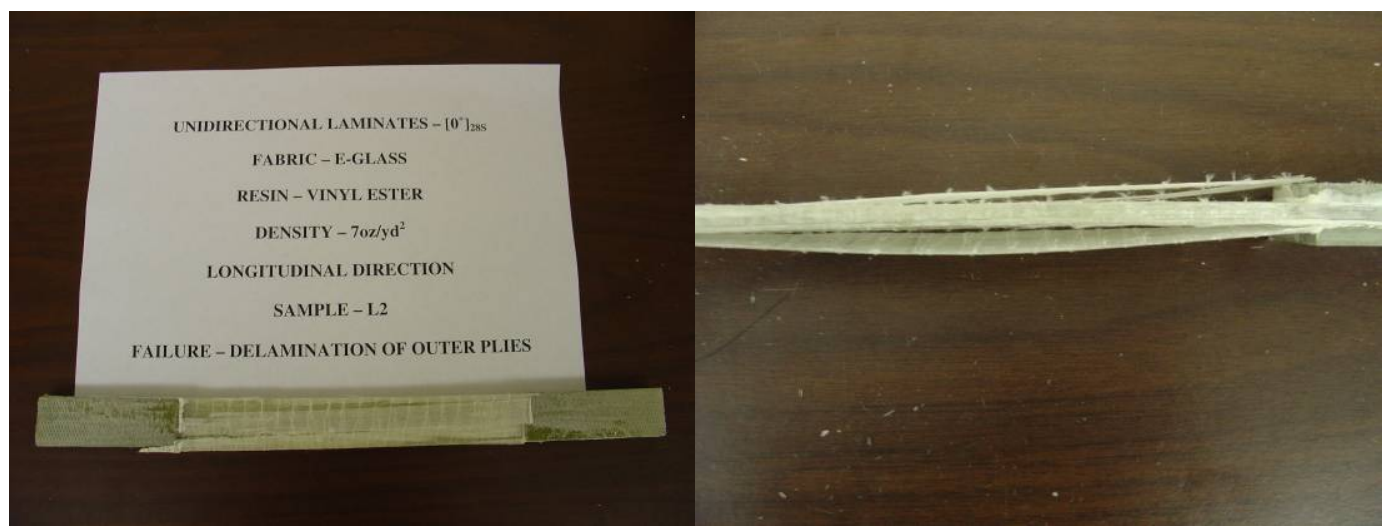

Figure 5.72 Premature failure of unidirectional samples where only outer layers were delaminated

\section{b) Cross-ply Laminates:}

Matrix cracking in 90 degree plies occurred followed by 0 degree ply failure. Though modes of failure were almost same in all the test specimens, following are some conventional failure modes observed from test specimens.

Case 1) Mode of failure was same and the failure occurred near the center resulting in a pure tension failure. (Figure 5.73)

Case 2) Failure occurred near one end of grips, which is attributed to the stress concentration due to geometric discontinuity at the tab end and the difference of material properties among the adhesive, tabs, and the composite material. (Figure 5.74)

Case 3) Failure occurred on both sides near the grips, which is again attributed to stress concentration. (Figure 5.75)

Case 4) Apart from failure on both sides near grips, delamination along the center layer throughout the gage length was also observed, which might be due to poor bonding between layers. (Figure 5.76)

Case 5) Delamination of the outer layers through-out the gage length is observed, apart from specimen breakage on both the sides near the grips. This is due to some amount of bending involved during testing. (Figure 5.77)

As seen from Figure 5.4, it is evident that it is a bi-linear curve till almost $90 \%$ ultimate load. The change of slope was observed at about 0.3 with respect to strains as 
explained in section. This point is where the orientation of fibers in different directions cause stress concentration leading to matrix micro-cracking. Then, delamination beyond $90 \%$ ultimate load took place followed by fiber breakage.

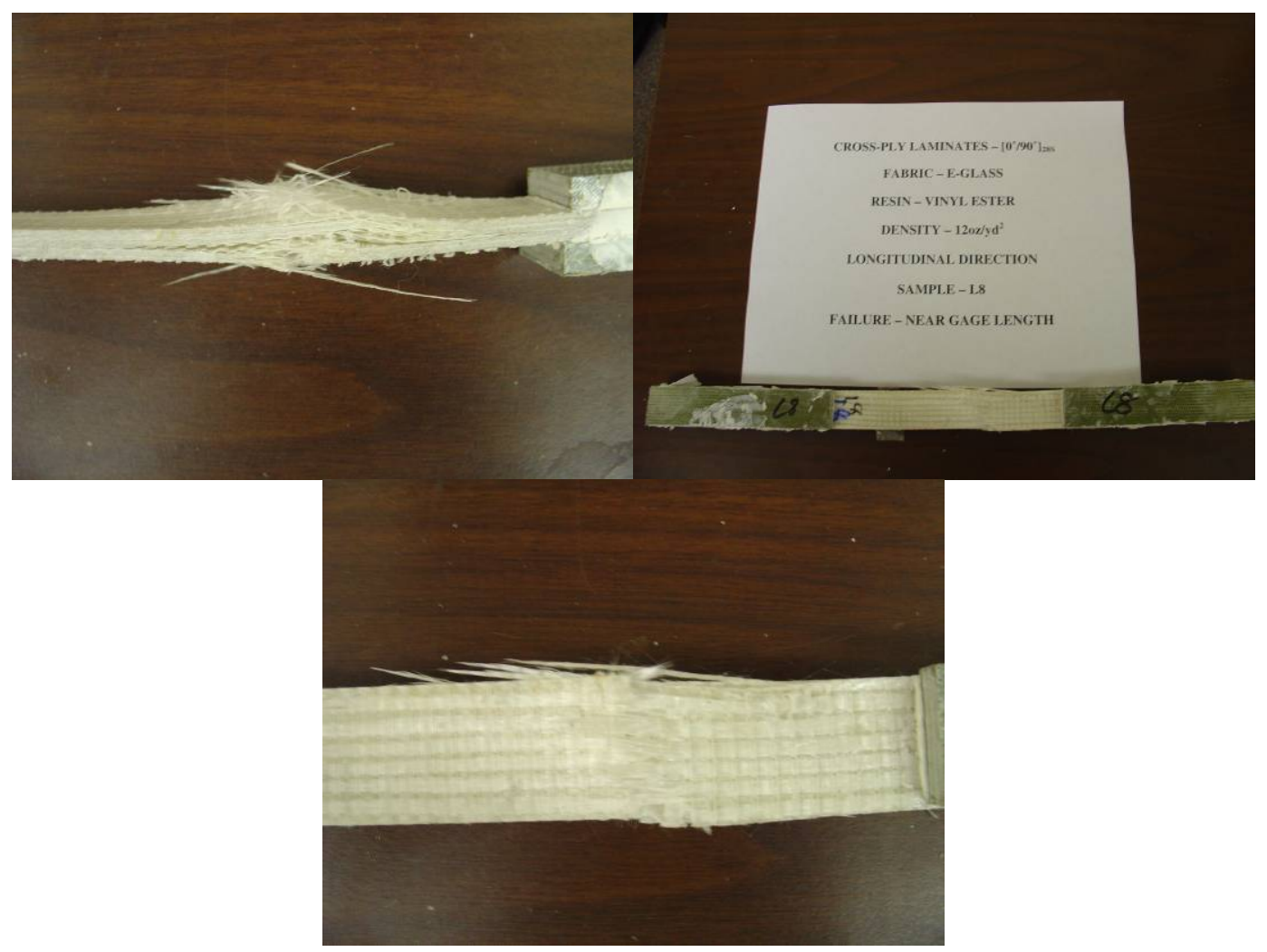

Figure 5.73 Failure near the gage length in Crossply laminate 

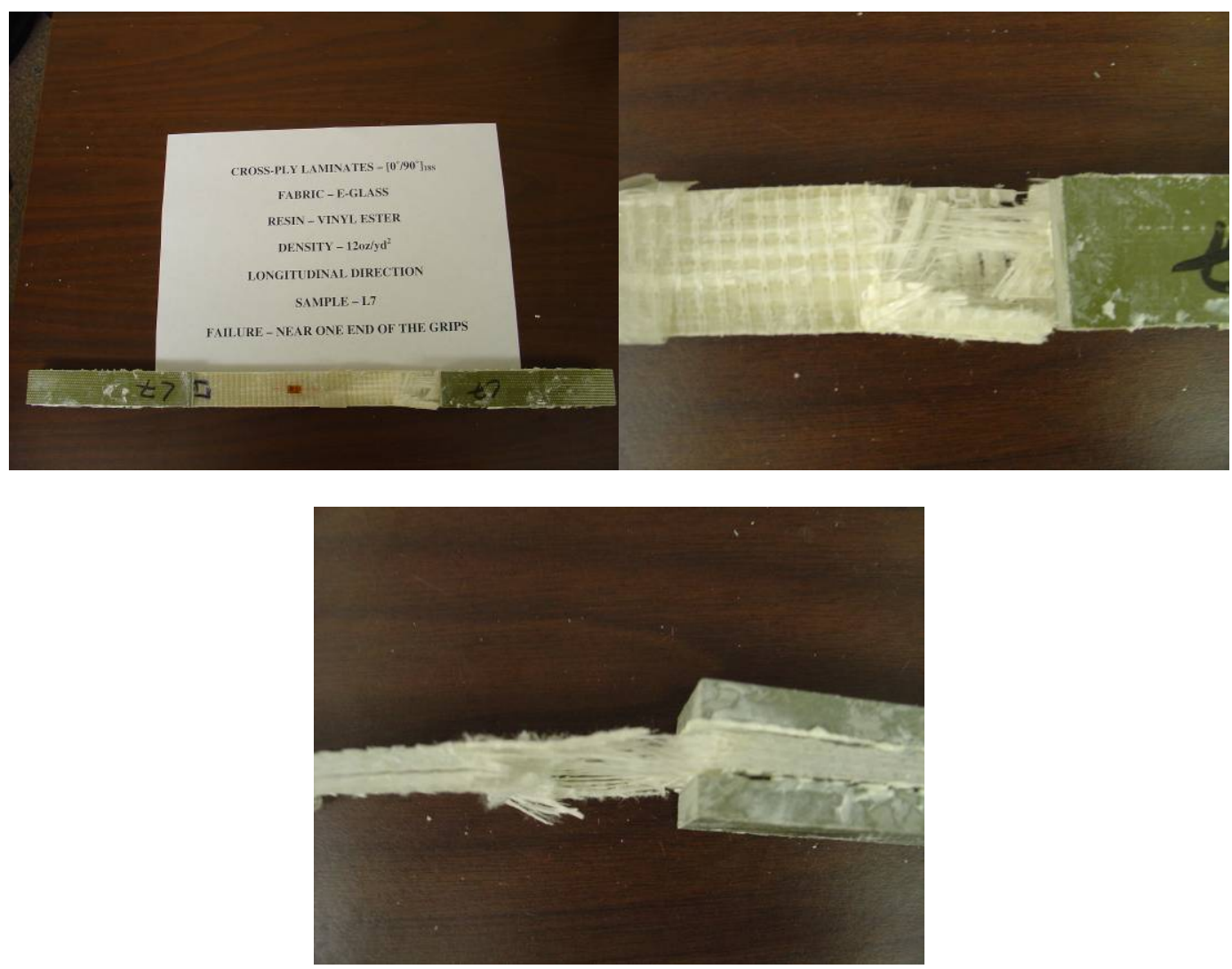

Figure 5.74 Cross ply laminate where fiber breakage on one side 


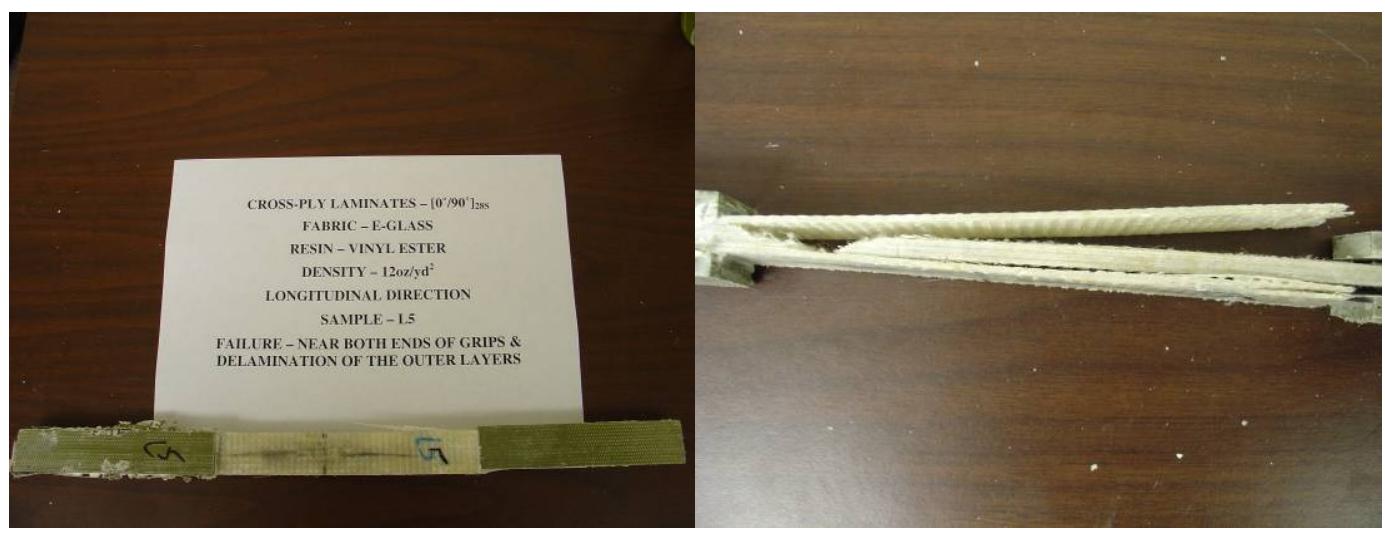

Figure 5.75 Cross ply laminate with fiber breakage on both sides
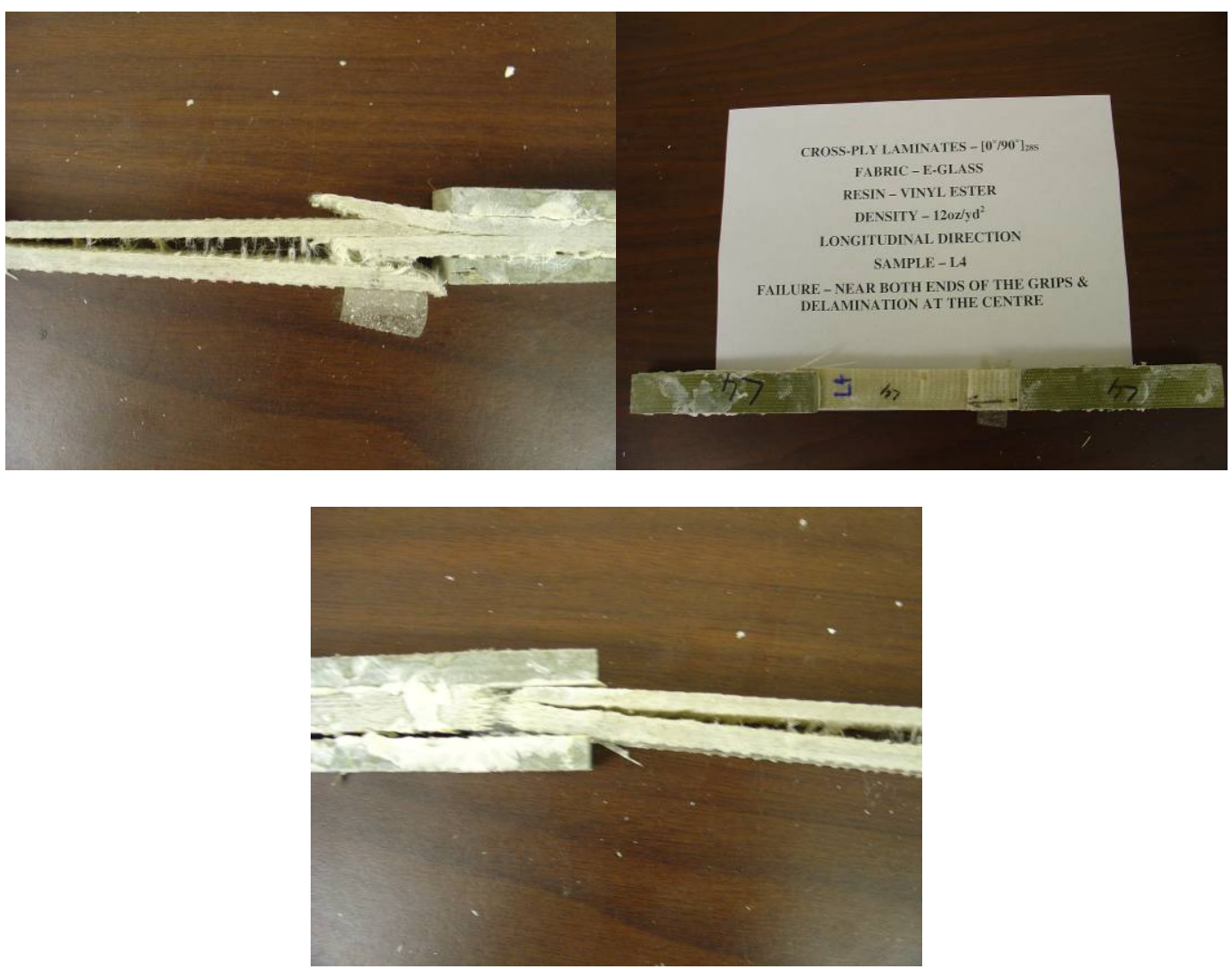

Figure 5.76 Cross ply laminate with fiber breakage on the both sides and delamination at the center (poor bonding) 


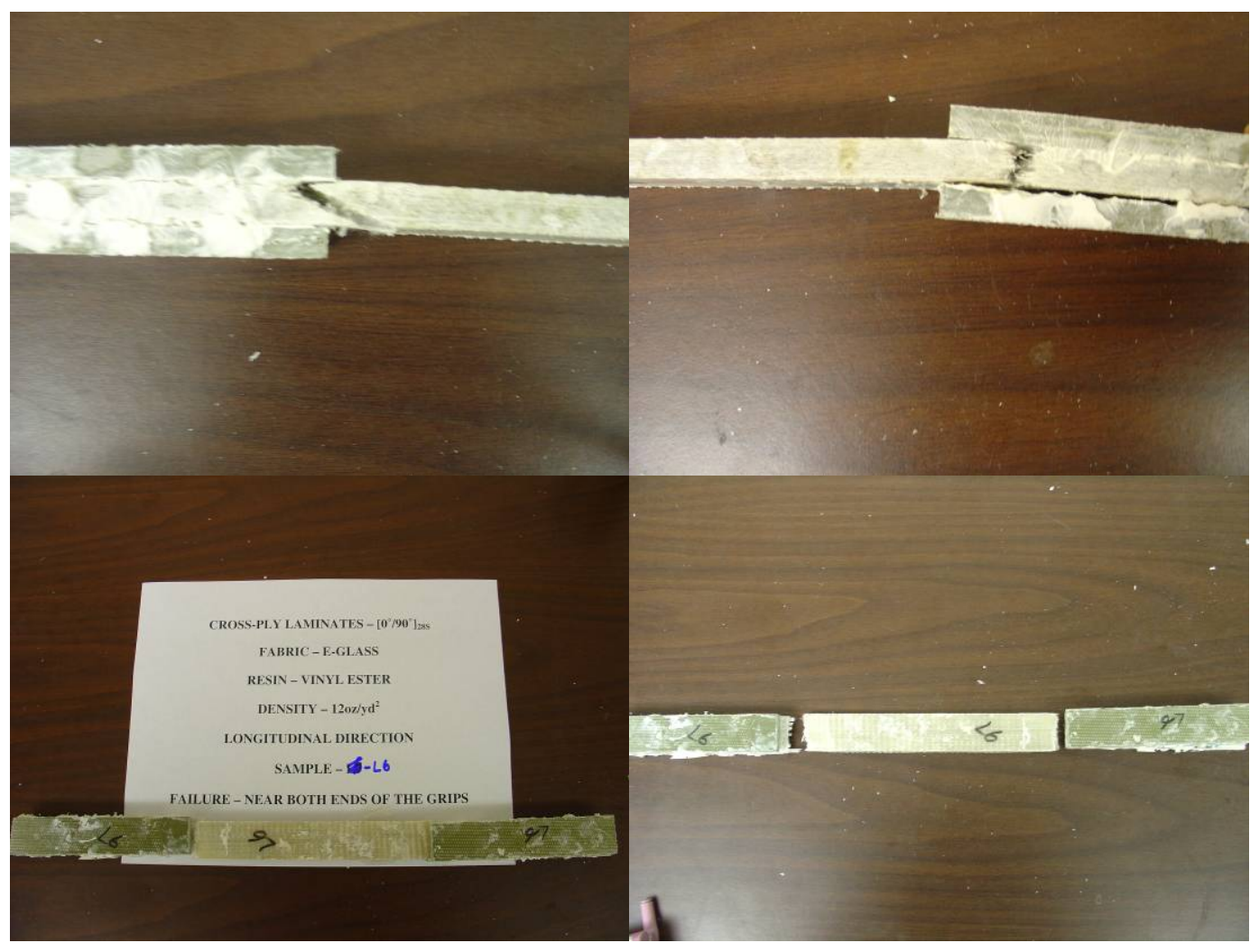

Figure 5.77 Cross ply laminate with delamination and fiber breakage on both sides

\section{c) Quadri-directional without CSM}

Initially stress concentration leading to local matrix micro-cracking due to fibers oriented in different directions occurred near the failed portion. Then, matrix cracking in 90 degree plies took place followed by matrix failure in the direction of \pm 45 degree plies. Finally, 0 degree fibers failed leading to failure of the specimen. However, all the test specimens failed near grips due to stress concentration and bending effect. (Figure 5.78)

From Figure 5.8, it is seen that at the point where change of slope occurred was 0.34 , matrix micro-cracking occurred. After redistribution of stresses, matrix cracking in 90 degree plies followed by failure of \pm 45 degree beyond $90 \%$ ultimate load and finally failure of 0 degree fibers was occurred. 


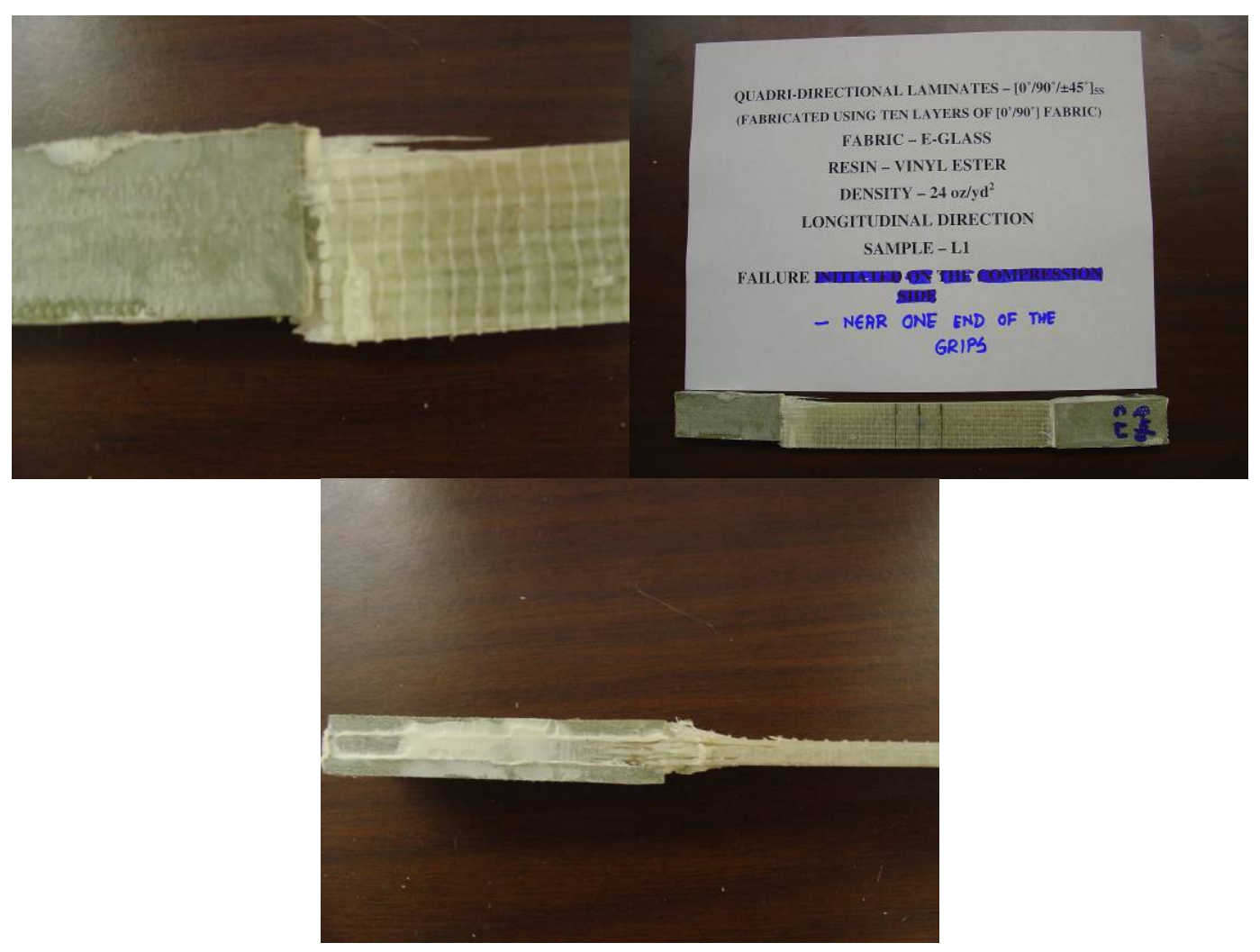

Figure 5.78 Grip failure of quadri-directional without CSM

\section{d) Tri-directional composite with CSM}

The lay up of composites with CSM was carried out was with stitched fabric consisting of 0 degree, \pm 45 degree plies and CSM. Initially \pm 45 degrees fiber failure was noted, leading to slight delamination of all layers near the failure portion, which is followed by failure of 0 degree plies.

As shown in Figure 5.10, two nearly linear slopes were observed and the point where change in slope occurred was around $25 \%$ of its strain at ultimate load. This point is attributed to matrix micro-cracking and eventual cracking in $90^{\circ}$ plies. Later, failure of angled ply laminates occurred followed by 0 degree ply failures resulting in the failure of the specimen. However, all specimens failed near grips (Figure 5.79) which is attributed to the combination of bending and stress concentration effects. 


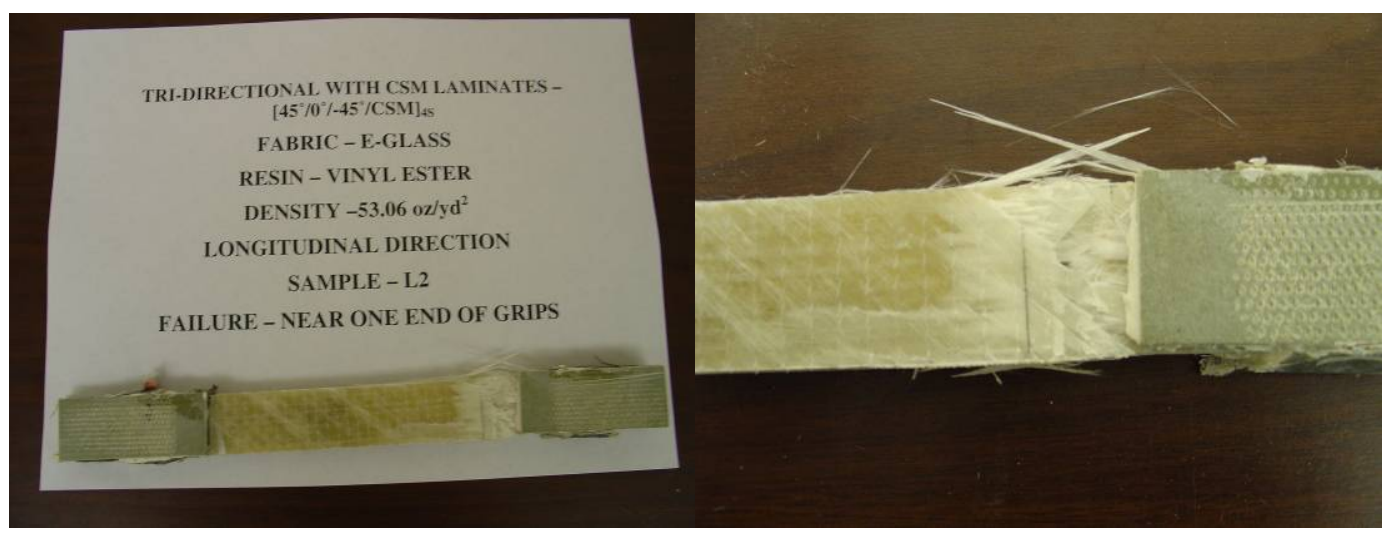

Figure 5.79 Tri-directional with CSM Specimens failed near grips

\section{e) Quadri-directional with CSM}

As the lay-up was fabricated with 0, 90, +/-45degree plies and CSM (stitched fabric), initially matrix micro-cracking, matrix cracking in 90 degree plies causing delamination through-out gage length, followed by cracking in the direction of $+/-45$ degrees and finally 0 degree ply failure.

From Figure 5.12, it was seen that at 0.35 point (change in slope occurred), matrix micro-cracking took place. After stress redistribution, the failure occurred due to matrix cracking in 90 degree plies causing delamination of all layers starting from center towards the ends through-out gage length. Then, matrix cracking in the direction of \pm 45 degree plies occurred followed by 0 degree plies failure leading to sudden decrease in the load. Some specimens failed near grips due to combination of bending and stress concentration effects as shown in Figure 5.80. 


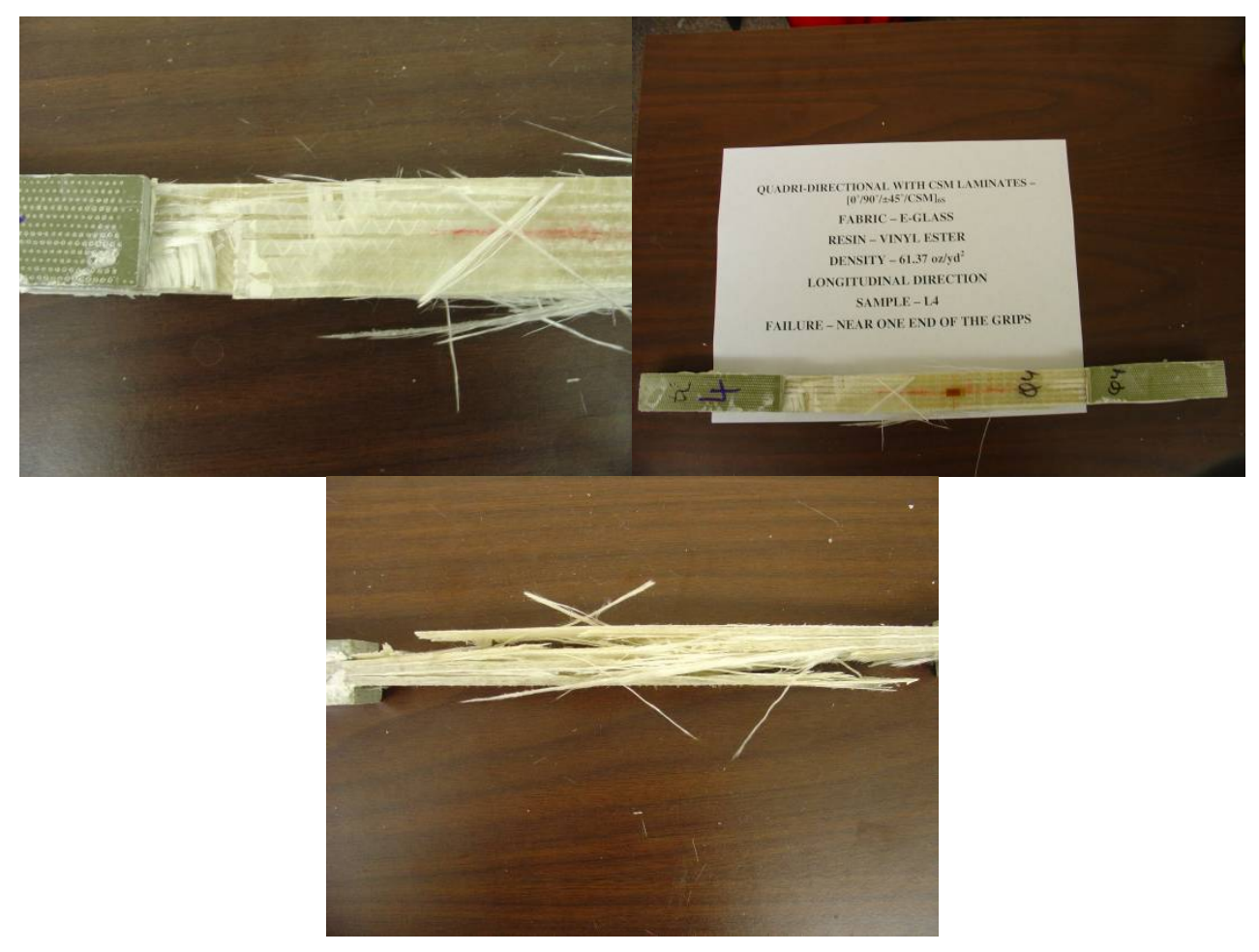

Figure 5.80 Quadri-directional with CSM specimens failed near grips

\subsubsection{Transverse Direction}

\section{a) Unidirectional Laminates}

The mode of failure is primarily due to matrix cracking, with fibers remaining intact. Since only 90 degree fibers are present, the failure of the resin led to the failure of the laminate. The specimens failed within the gage length and grip length as shown Figure 5.81 .

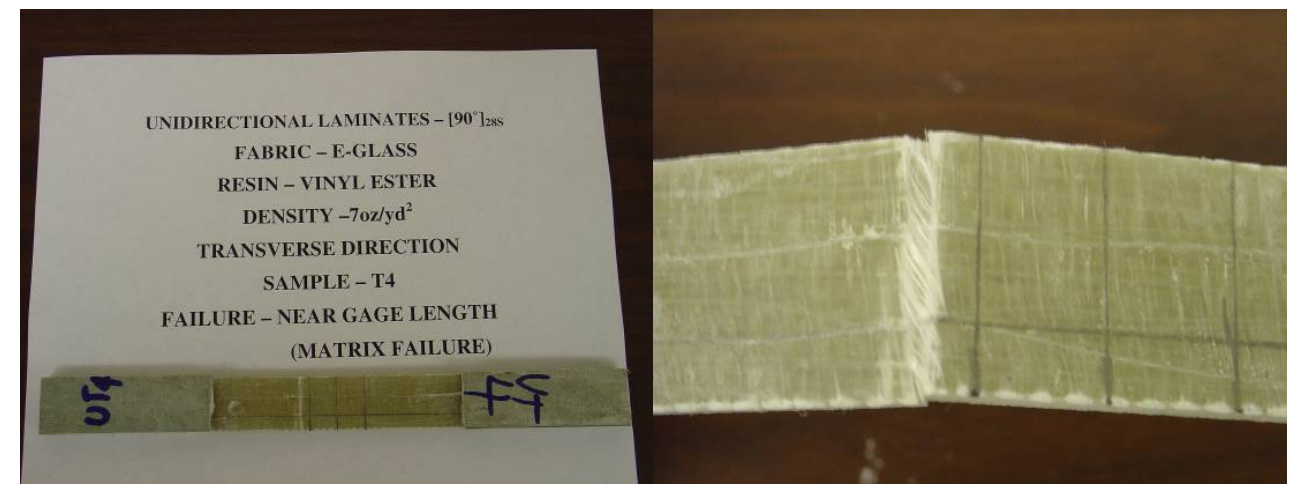

Figure 5.81 Failed specimens of unidirectional laminates (only 90 degree fibers) 


\section{b) Quadri-directional without CSM}

The failure mode was same as observed in quadri-directional composite laminates without CSM specimens cut in longitudinal direction. As mentioned, matrix cracking in 90 degrees, followed by cracking of fibers in the direction of \pm 45 degree, leading to fibers followed by delamination over the failed portion. Finally failing of 0 degree fibers leading to specimen failure occurred.

Two slopes were observed in the stress vs. strain curve as shown in Figure 5.18, where first point where change in slope occurred (34\% of $\left.\varepsilon_{\mathrm{p}}\right)$, matrix micro-cracking is predicted. After stress redistribution among the remaining plies, cracking in 90 degree plies and cracking in the direction of 45 degree occurred beyond ultimate load. Then, failure of 0 degree plies took place leading to laminate failure. The specimen failed near grips due to stress concentration and bending effects as shown in Figure 5.82.

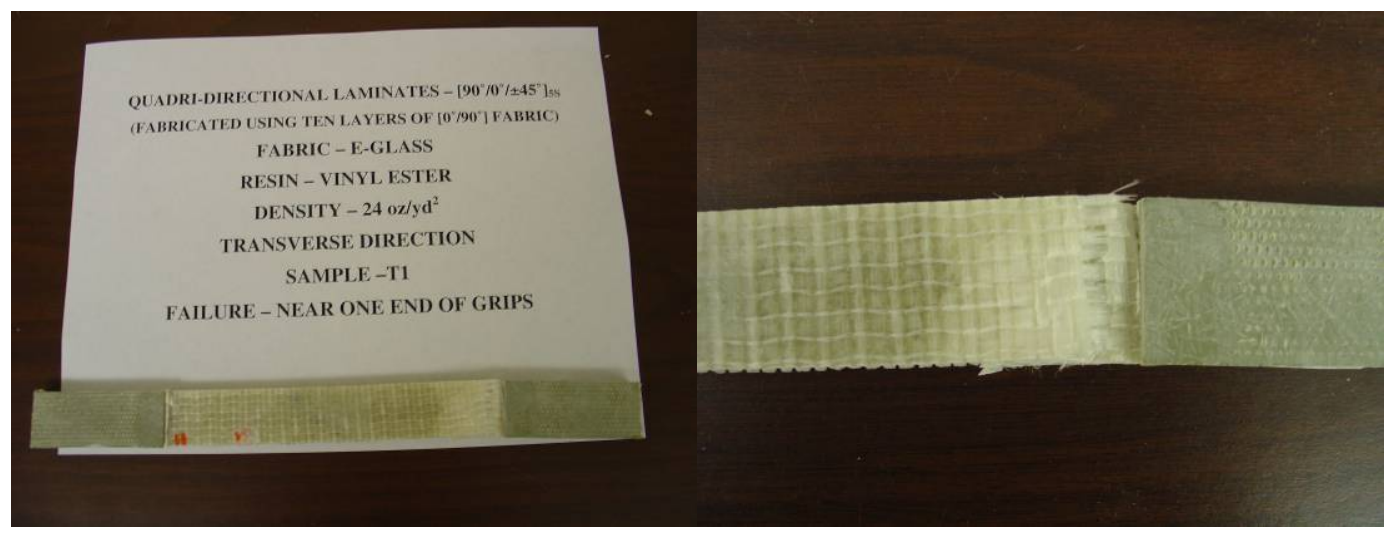

Figure 5.82 Quadri directional without CSM failed near grips

\section{c) Tri-directional with CSM}

Matrix cracking in 90 degree plies occurs followed by cracking in the direction of 45 degree due to presence of $+/-45$ degree plies failure. In some cases, pure tension failure was observed near the center of gage length (Figure 5.83). For remaining samples, failure occurred near the grips, which is attributed to stress concentration (Figure 5.84) and bending effect.

Three nearly linear stress-strain plots are observed in Figure 5.20, where the first point where change in slope occurred was at 0.18 , with matrix micro-cracking of the composite specimen. It was then followed by matrix cracking in 90 degree failure at point 
0.52 (change in slope occurred). And, beyond 90\% ultimate load, cracking in the direction of \pm 45 degree plies occurred leading to final failure of the specimen.

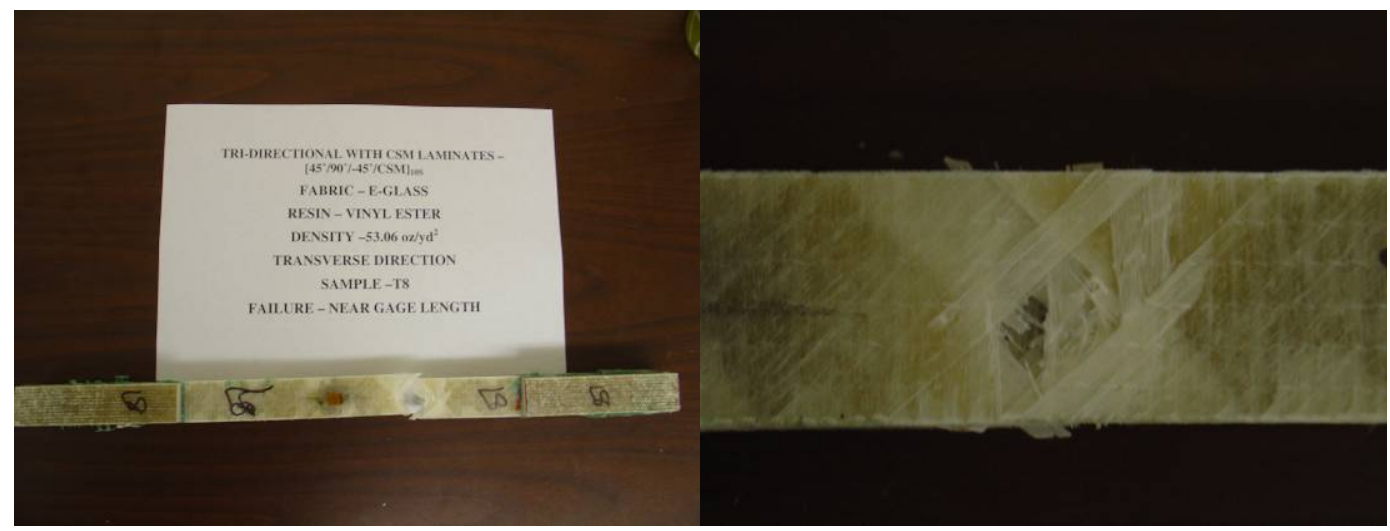

Figure 5.83 Tri-directional with CSM specimens failed near gage length

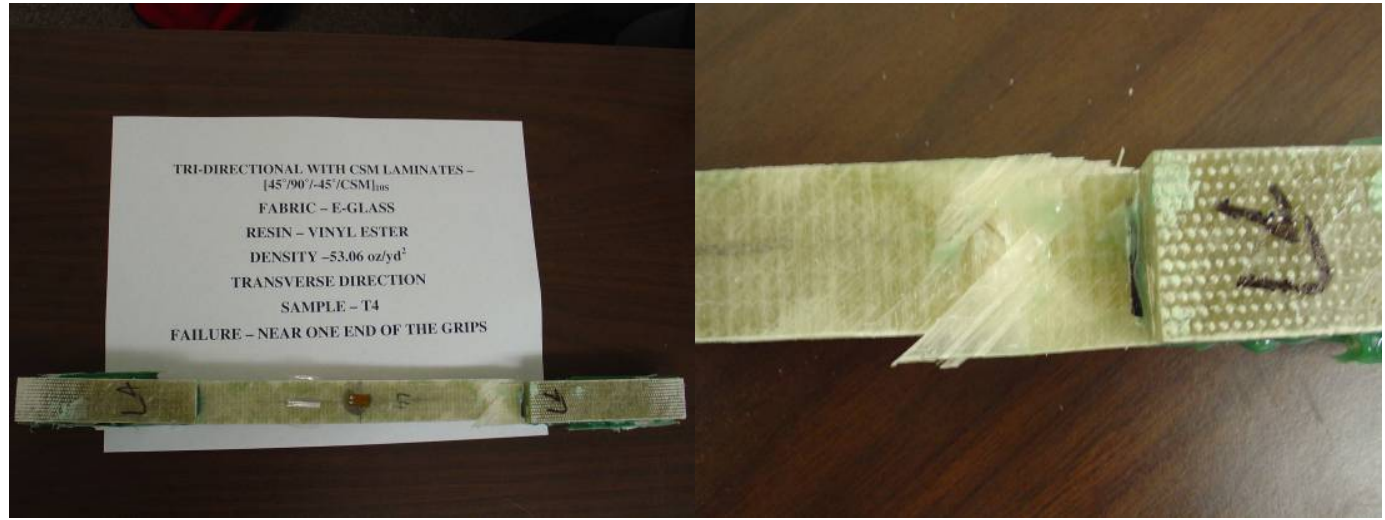

Figure 5.84 Tri-directional with CSM specimens failed near grips

\section{d) Quadri-directional with CSM}

The mode of failure was same as quadri-directional specimens cut in longitudinal direction are shown in Figure 5.85.

It is seen that at 0.32 point where change of slope occurred in stress-strain curve (Figure 5.24), matrix micro-cracking is anticipated. After stress redistribution, the failure occurred with matrix cracking in 90 degree plies causing delamination from center towards ends through-out gage length. This was followed by cracking in the direction of \pm 45 degree plies followed by 0 degree ply failure leading to sudden decrease in the load. 


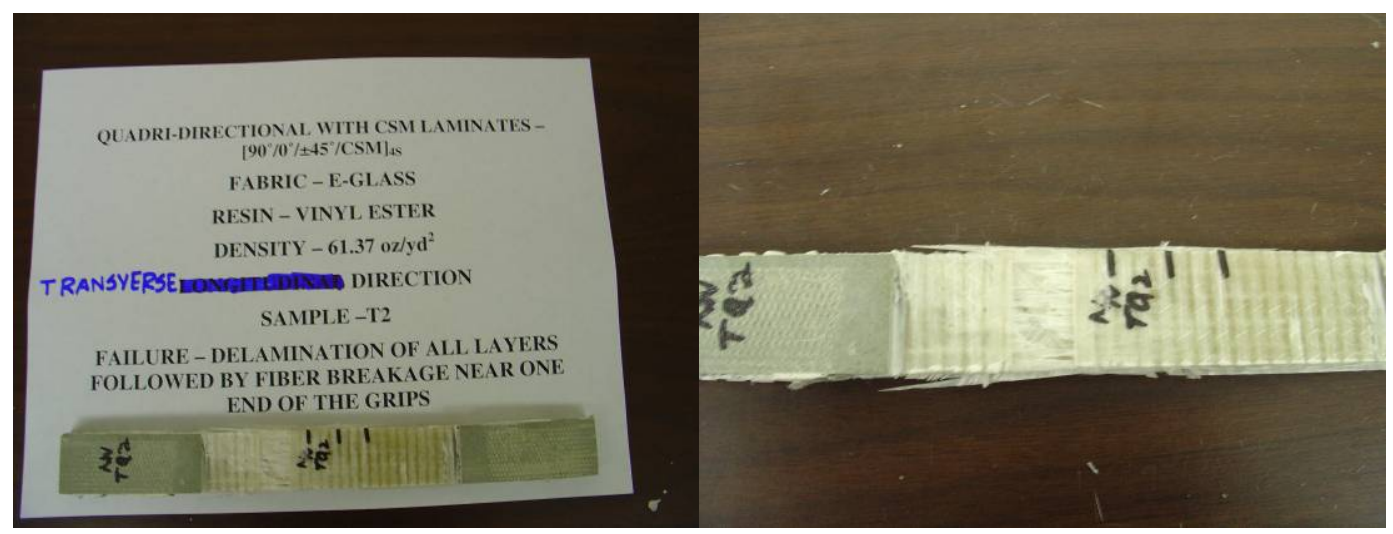

Figure 5.85 Failure of quadri-directional with CSM specimens near grips

In order to achieve pure tension failure minimizing bending effects, specimens with longer gage length and proper aspect ratio are to be used.

\subsubsection{Bending Test}

All test specimens tested under bending, failed in similar fashion for all fiber architectures except for tri-directional with CSM laminates in transverse direction. The sequence of failure began with matrix micro-cracking attributed to stress concentration due to different ply orientation, resin whitening followed by resin cracking (transverse cracking) prior to reaching ultimate load, thus initiating delamination. Then delamination led to fiber-buckling of the outermost layer on compression side (first ply failure), with progressive delamination over the failed portion extending almost towards the center. This is attributed to the shift in the neutral axis. Then, the bottom fibers failed due to fiber breakage and delamination, and the delamination progressed towards the centre along the thickness direction from the bottom. However, for tri-directional specimens, with CSM laminates tested in transverse direction, the failure mode is same; the only difference is that the failure occurred initially on the tension side followed by the failure on the compression side. The failure was quite visible in specimens fabricated with high density fabrics rather than low-density fabrics. In all specimens, failure occurred within the loading zone of four point bending fixtures. 


\subsubsection{Longitudinal Direction}

\section{a) Unidirectional Coupon Specimens}

As all are 0 degree plies, there was slight delamination of the top layer leading to fiber buckling, followed by progressive delamination towards the center. The failure due to delamination then started from tension side and progressed towards the center. The failed portion was very small and was not clearly visible which is attributed to the density of the fabric being very low ( $7 \mathrm{oz} / \mathrm{yd} 2$ and $12 \mathrm{oz} / \mathrm{yd} 2)$. Even though matrix cracking occurred, it was not significant as is evident from the stress-strain curve shown in Figure 5.26 (absence of no change in slope). Figure 5.86 shows failed samples of unidirectional $0^{\circ}$ laminates.

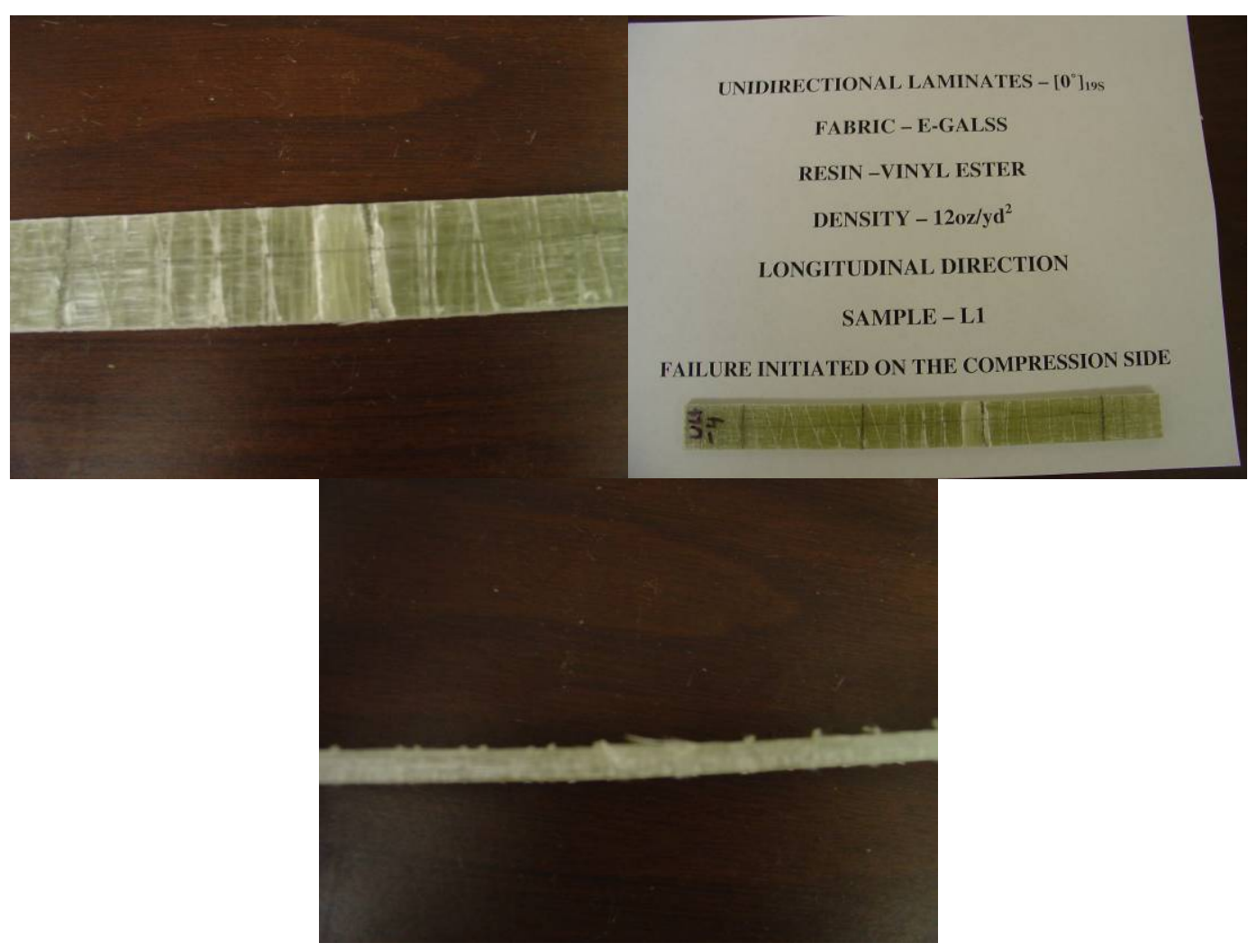

Figure 5.86 Failed samples of unidirectional laminates

\section{b) Cross-ply Laminates}

Matrix micro-cracking followed by cracking in the 90 degree fibers adjacent to the outermost 0 degree layer occurred. Then, delamination and fiber buckling of the 0 degree ply took place. Like in unidirectional laminate composite specimens, failure 
(delamination) of cross ply laminates with fabric density $12 \mathrm{oz} / \mathrm{yd} 2$ was not clearly observed.

From Figure 5.30, first point where change of slope was observed was around $0.42 \varepsilon_{\mathrm{p}}$, where matrix micro-cracking is anticipated. Then, matrix cracking in 90 degree plies followed by whitening of the resin and delamination took place leading to first ply failure. (Figure 5.87)

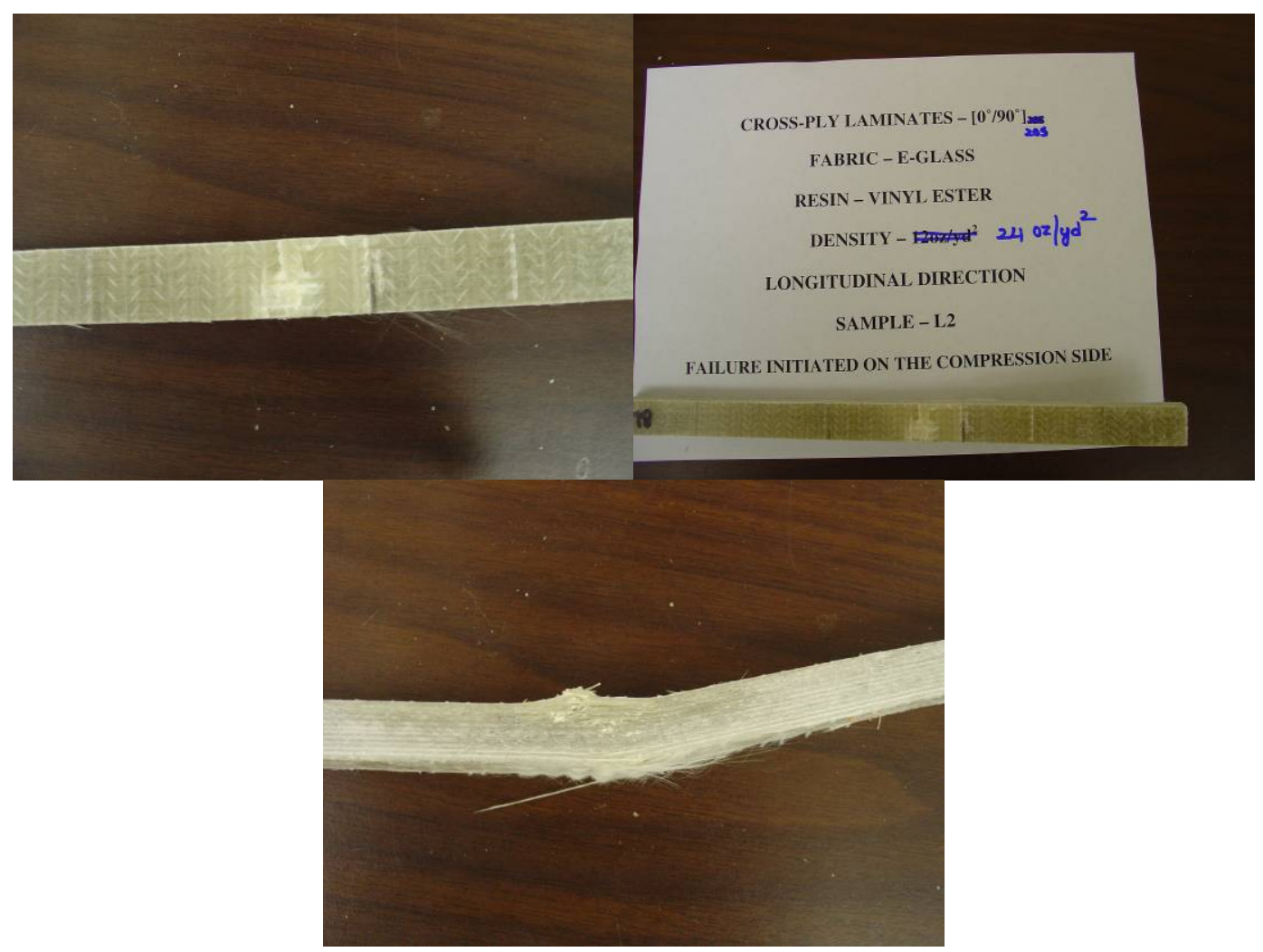

Figure 5.87 Failed samples of cross-ply laminates

\section{c) Quadri-directional without CSM}

Lay-up comprised $0,90, \pm 45$ and were fabricated using all $0 / 90$ fabrics of density $24 \mathrm{oz} / \mathrm{yd} 2.0^{\circ}$ layers formed the top layer. Progressive delamination of composite specimens was clearly visible. (Figure 5.88)

Point where change of slope occurred was at 0.4 (shown in Figure 5.34), where matrix micro-cracking occurred, followed by matrix cracking in 90 degree plies leading to delamination and local buckling in 0 degree fibers beyond $90 \%$ ultimate load. 


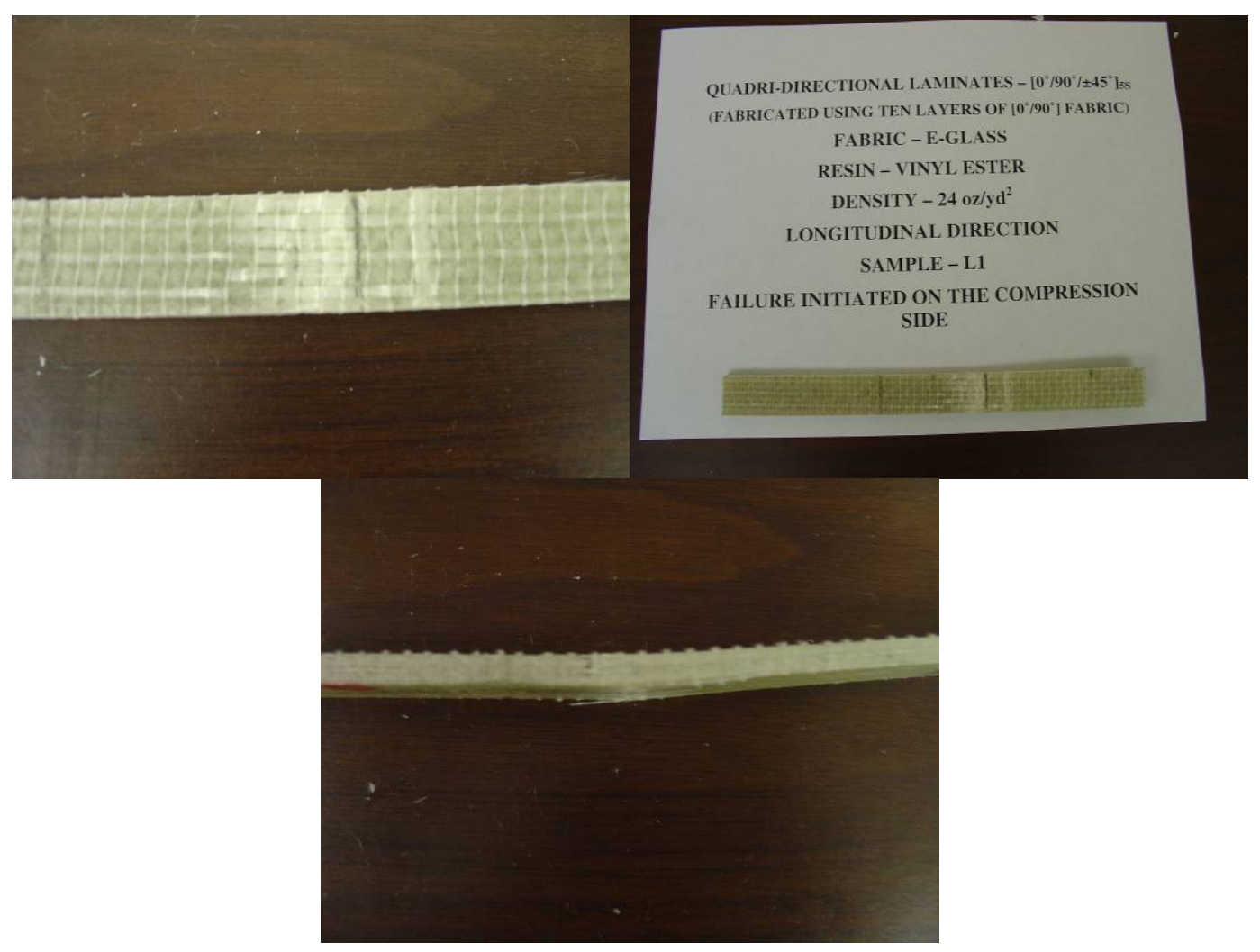

Figure 5.88 Failed samples of quadri-directional without CSM laminates

\section{e) Tri-directional with CSM Laminates}

Lay-up consisted of $0, \pm 45$, and CSM plies stitched together, and 45 degree plies forms the top layer. The density of the fabric is $54 \mathrm{oz} / \mathrm{yd} 2$; hence progressive delamination is visible for both quarter-inch and half-inch thick specimens.

From stress-strain curve (Figure 5.40), it was observed that 0.4 is the point where change of slope occurred and matrix micro-cracking had occurred initially, followed by cracking of the top layer consisting $45^{\circ}$ plies, thus leading to first ply failure. (Figure 5.89) 


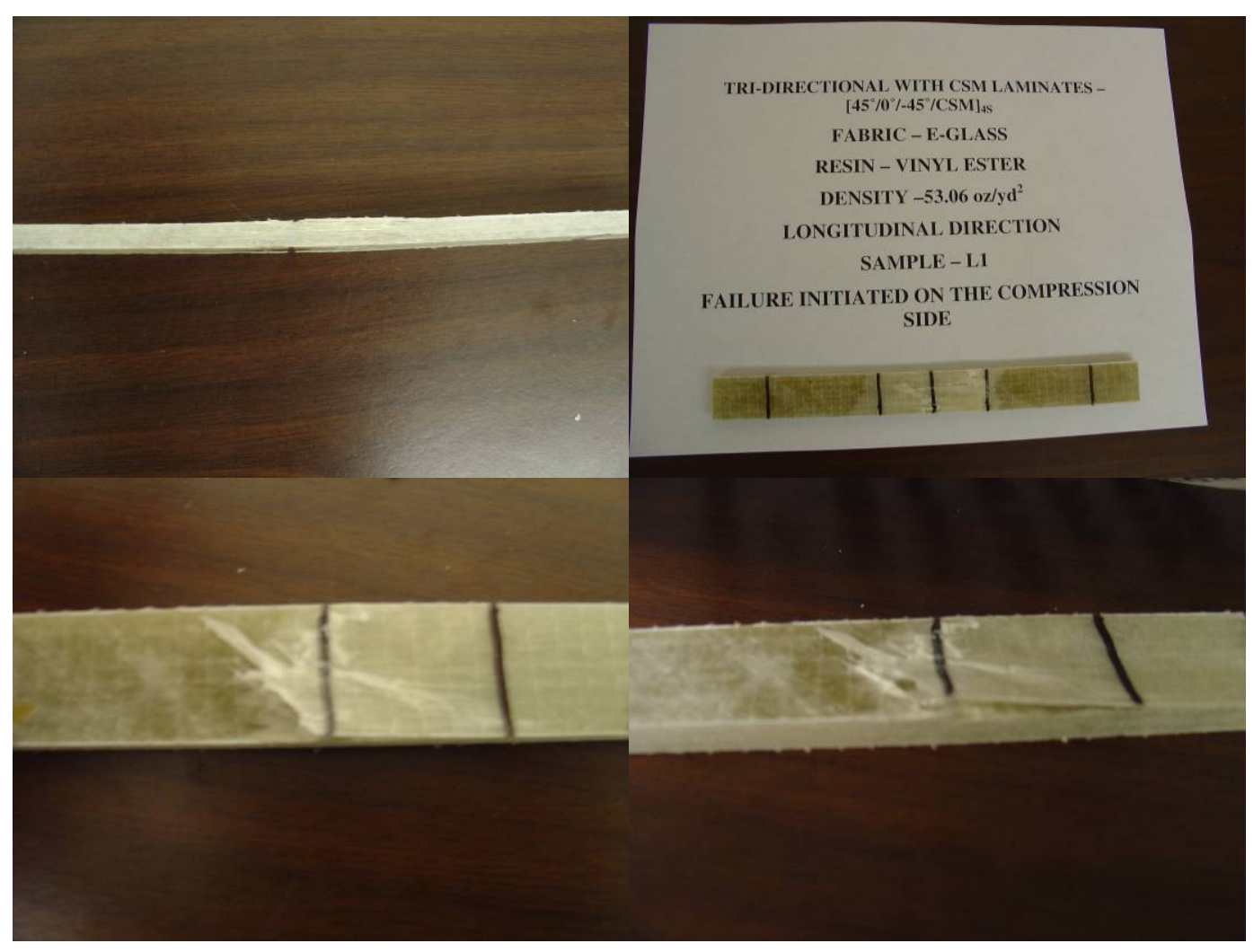

Figure 5.89 Failed samples of tri-directional with CSM laminates

\section{d) Quadri-directional composites with CSM Laminates}

The fabric density being 62oz/yd2, failure mode (progressive delamination) was quite visible. From stress-strain curve (Figure 5.42), it was observed that the point where change of slope occurred was at $0.34 \varepsilon_{\mathrm{p}}$, where matrix micro-cracking occurred, followed by cracking of 90 degree plies, leading to delamination and local fiber buckling of 0 degree plies of the outermost layer, thus leading first ply failure. (Figure 5.90). 


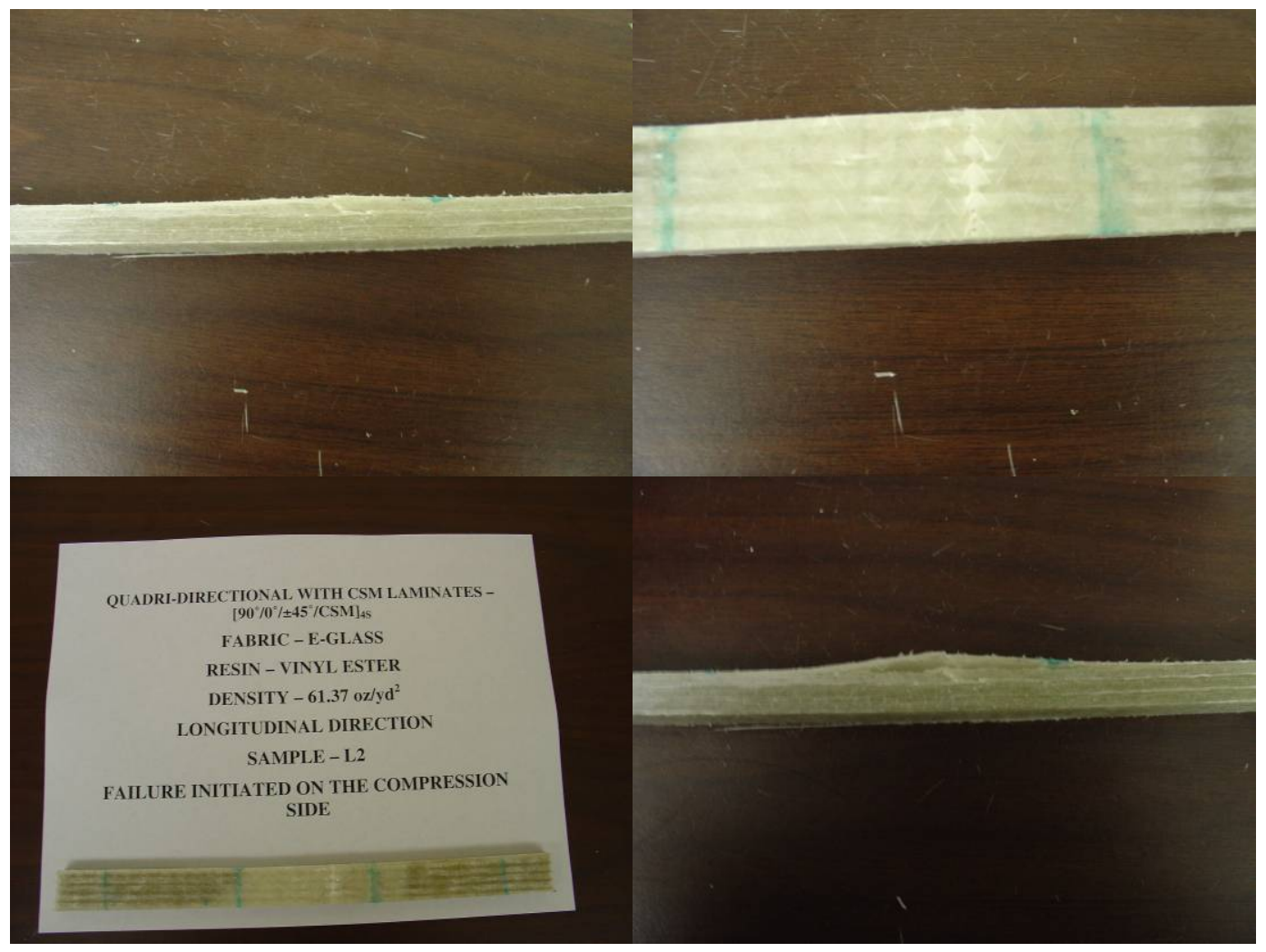

Figure 5.90 Failed samples of quadri-directional with CSM laminates

\subsubsection{Transverse Direction}

\section{a) Unidirectional Laminates}

Since the laminate comprised $90^{\circ}$ plies, the failure is matrix dominated failure and is shown in Figure 5.91.

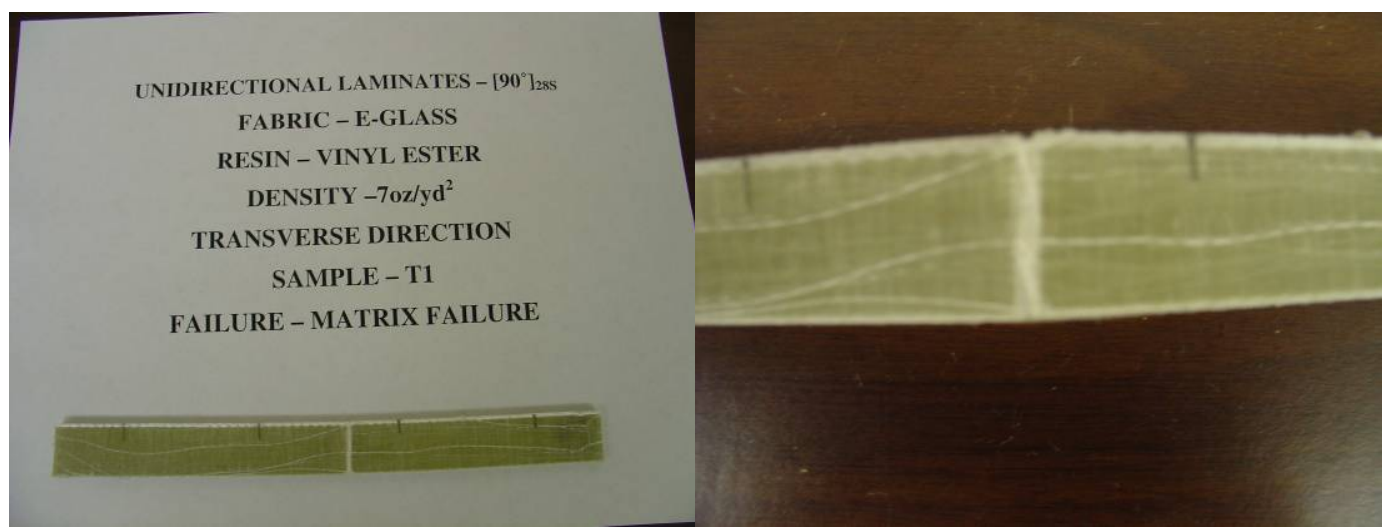

Figure 5.91 : Failed samples of unidirectional laminates 


\section{b) Cross-ply Laminates}

Laminate thickness is $0.5^{\prime \prime}$ and $90^{\circ}$ plies forms the outermost layer. Matrix microcracking at 0.41 point where change of slope occurred was observed (shown in Figure 5.52), followed by cracking in 90 degree fibers of the top ply leading to first ply failure. Later, local buckling of $0^{\circ}$ plies due to delamination took place. The failure mode (progressive delamination) was visible as shown in Figure 5.92.

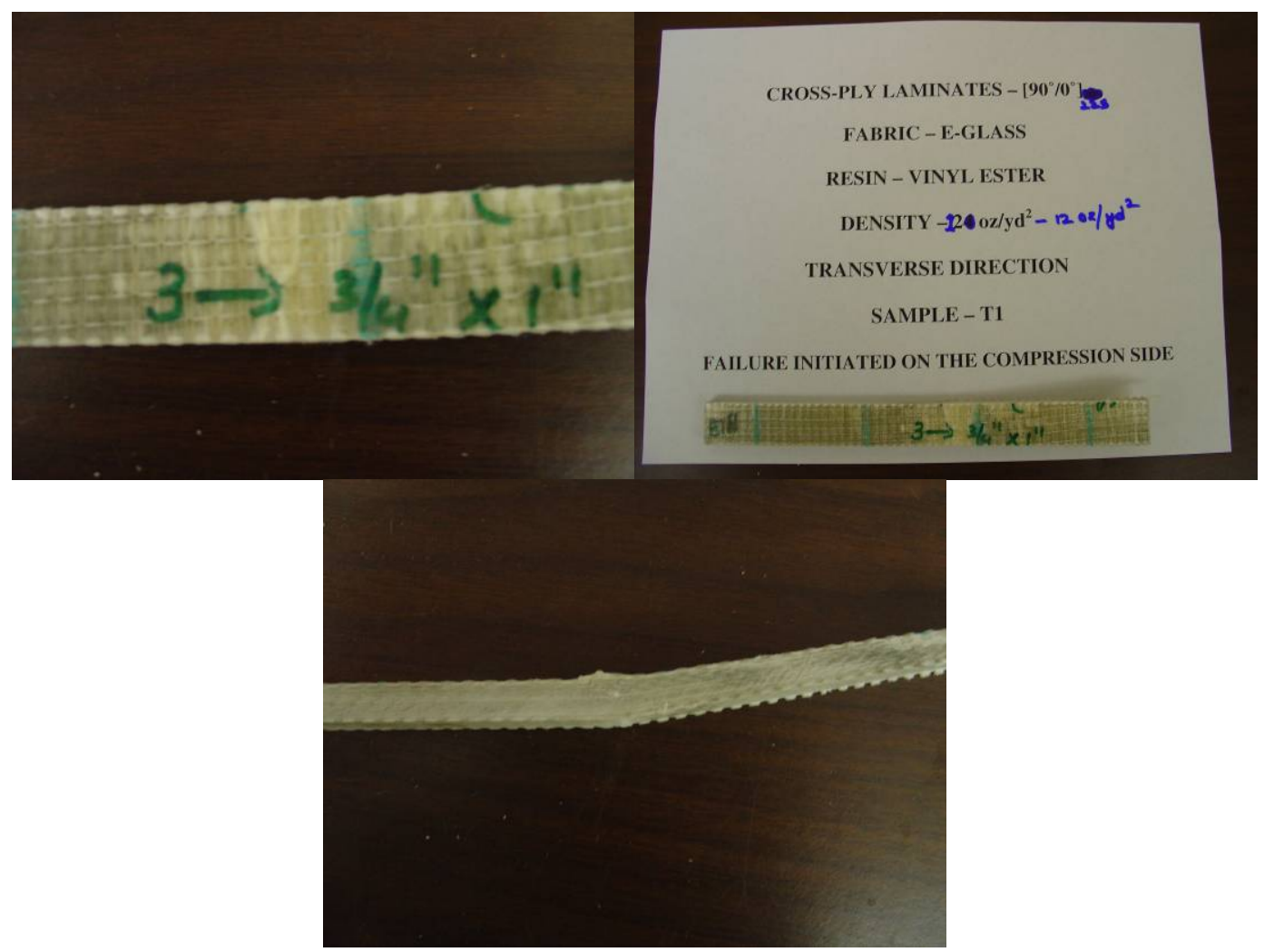

Figure 5.92 Failed samples of cross ply laminates

\section{c) Quadri-directional without CSM Laminates}

In this laminate, 90 degree fibers form the outermost layer. At 0.48 point where change of slope occurred, matrix micro-cracking occurred (shown in Figure 5.56) followed by matrix cracking in $90^{\circ}$ plies. After redistribution of stresses within the remaining plies, at beyond $90 \%$ ultimate load, buckling of $0^{\circ}$ fibers took place due to delamination resulting in first ply failure. The failure mode (progressive delamination) was shown in Figure 5.93. 


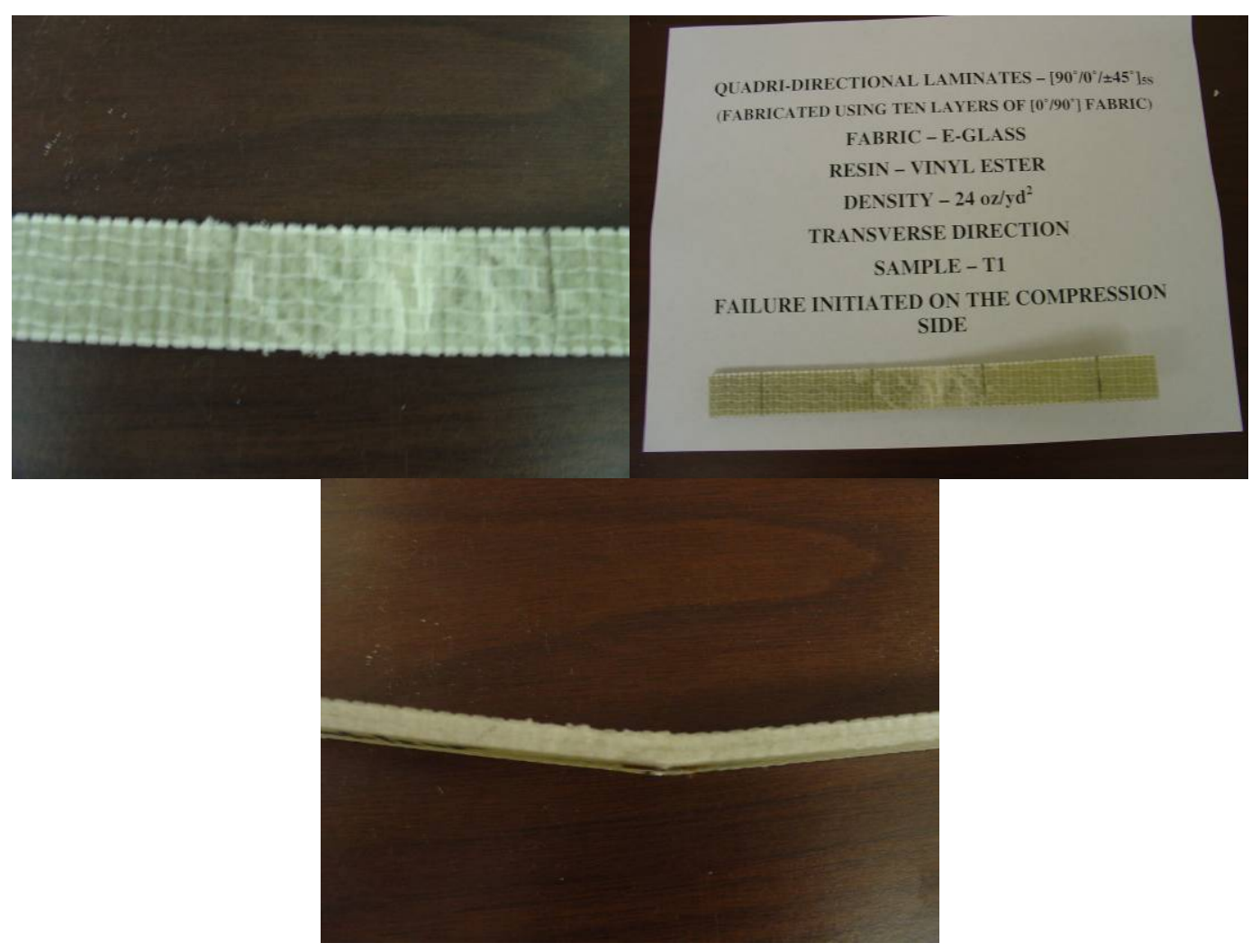

Figure 5.93 Failed samples of quadri-directional without CSM laminates

\section{d) Tri-directional with CSM Laminates}

The outermost ply in this laminate is $45^{\circ}$. At 0.3 , first point where change of slope occurred matrix micro-cracking occurred. Second point occurred at 0.65 (shown in Figure 5.58) where matrix cracking in 90 degree plies might have taken place, followed by delamination and cracking in the direction of 45 degree of the outermost ply. The failure mode (progressive delamination) was visible as shown in Figure 5.95. 


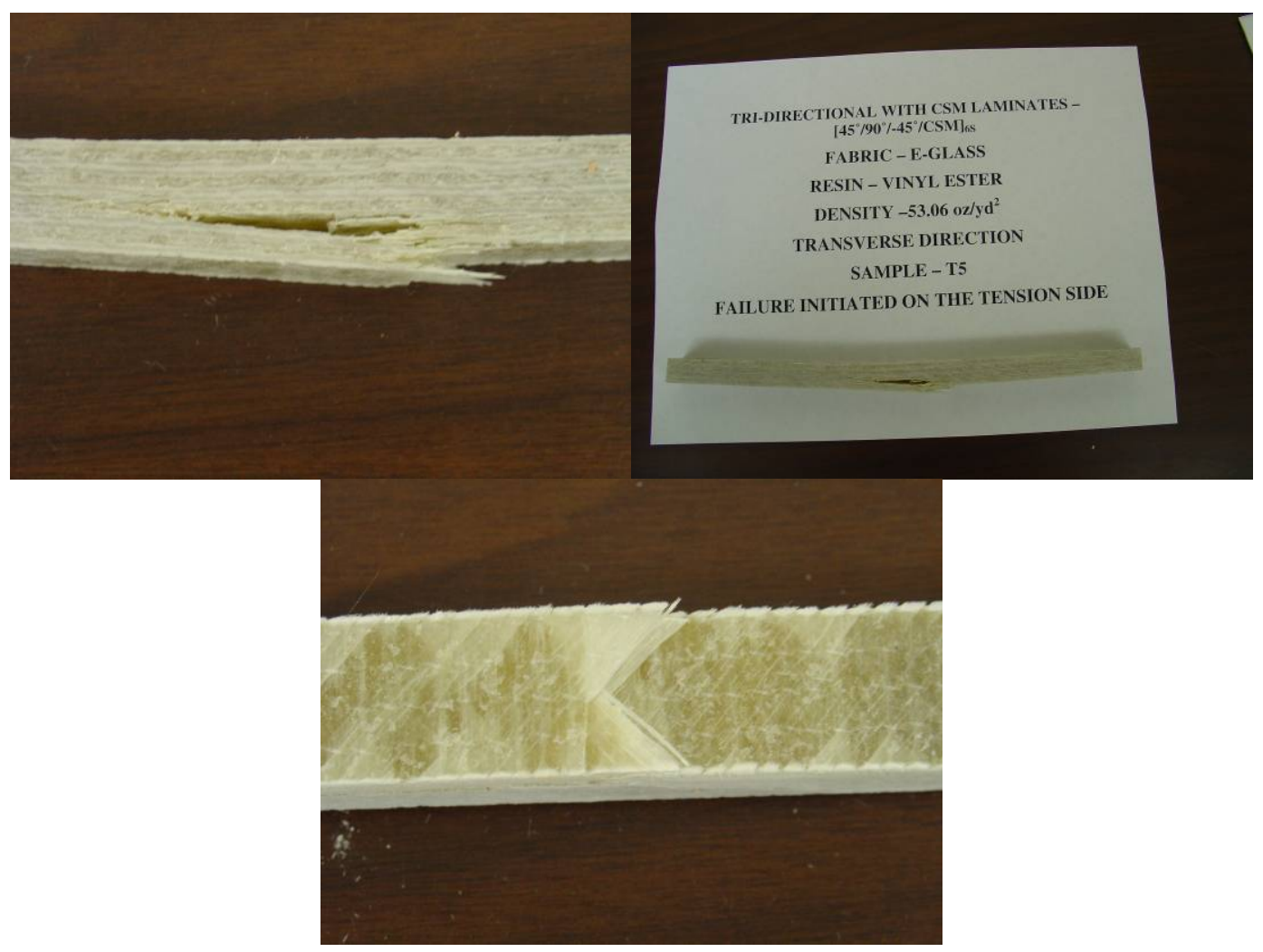

Figure 5.94 Failed samples of tri-directional with CSM laminates

\section{e) Quadri-directional with CSM Laminates}

Again, in this case, $90^{\circ}$ fibers form the outermost layer. At 0.33 point where change of slope occurred, matrix micro-cracking occurred (see Figure 5.66). Beyond 90\% ultimate load, cracking in 90 degree plies took place leading to first ply failure. (Figure 5.95) 


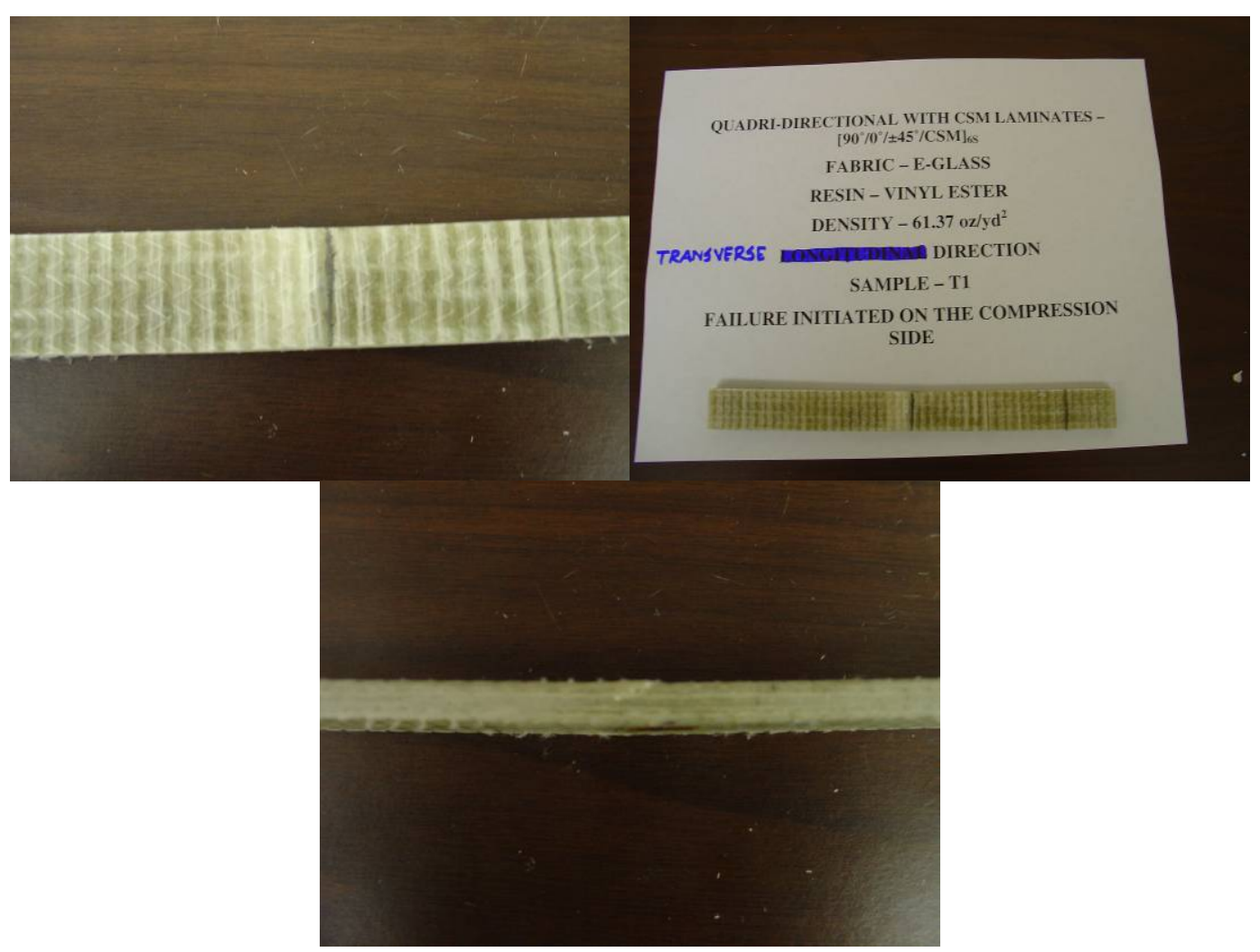

Figure 5.95 Failed samples of quadri-directional with CSM laminates of unidirectional laminate (TUL2Q)

\subsection{COMPARISONS WITH OBSERVATIONS}

The static performance of FRP composites largely depends on fiber orientation, stacking sequence, thickness, and fiber volume content in addition to types of fiber and matrix, and manufacturing processes. In this study, coupon specimens fabricated with Eglass fibers and vinyl ester resin using compression molding process are evaluated. Initially, comparisons with observations of tension and bending test results of bidirectional composites (tested in longitudinal and transverse directions), tri-directional with CSM (tested in longitudinal direction), quadri-directional with and without CSM (tested in longitudinal and transverse directions) are discussed in detail. Later, focus is shifted to the observations of tri-directional composites with CSM (tested in transverse direction) and is dealt with as a special case. 


\subsubsection{Tensile and Flexural Strength}

\subsubsection{Fiber Architecture}

Tensile strength and bending strength corresponding to different fiber architectures of GFRP composites are shown in Figure 5.96 and Figure 5.97, respectively.

If the ply orientations with the smallest strength are on the outside layers where the flexural stresses are the largest, then they fail at lower bending loads than those with the highest ply strength in the outer layers. Hence, flexural strength can be improved by changing the order of stacking sequence. But, strength does not alter much with the stacking sequence in case of tension.

Unidirectional composites have maximum possible strength in the loading direction but have minimum strength in the transverse direction. In cross-ply laminates, only fibers in the loading direction contribute to the strength of the composite, hence it is less compared to unidirectional composites, if the overall FVF is accounted for in the computation and comparison.

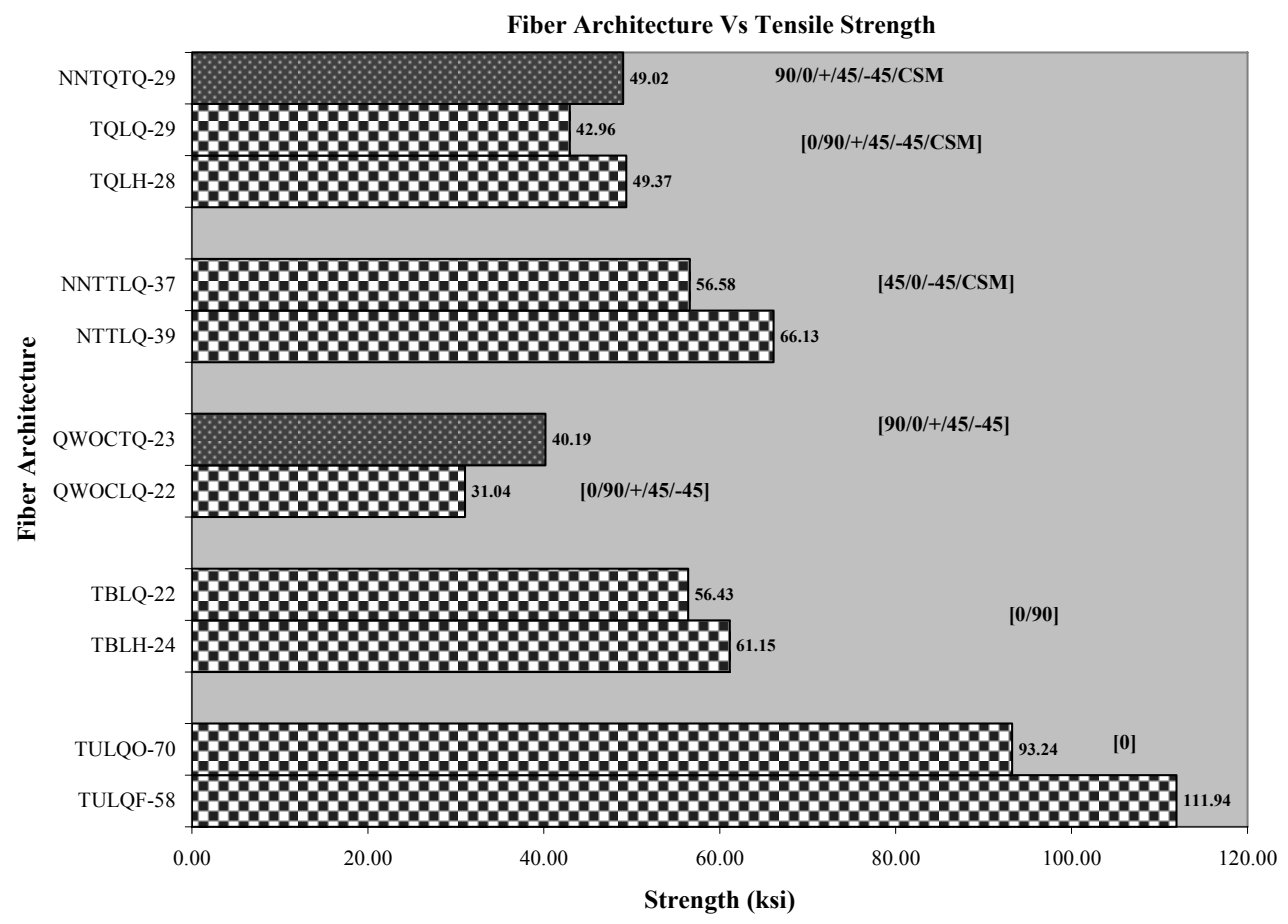


Figure 5.96 Fiber Architecture Vs Tensile Strength

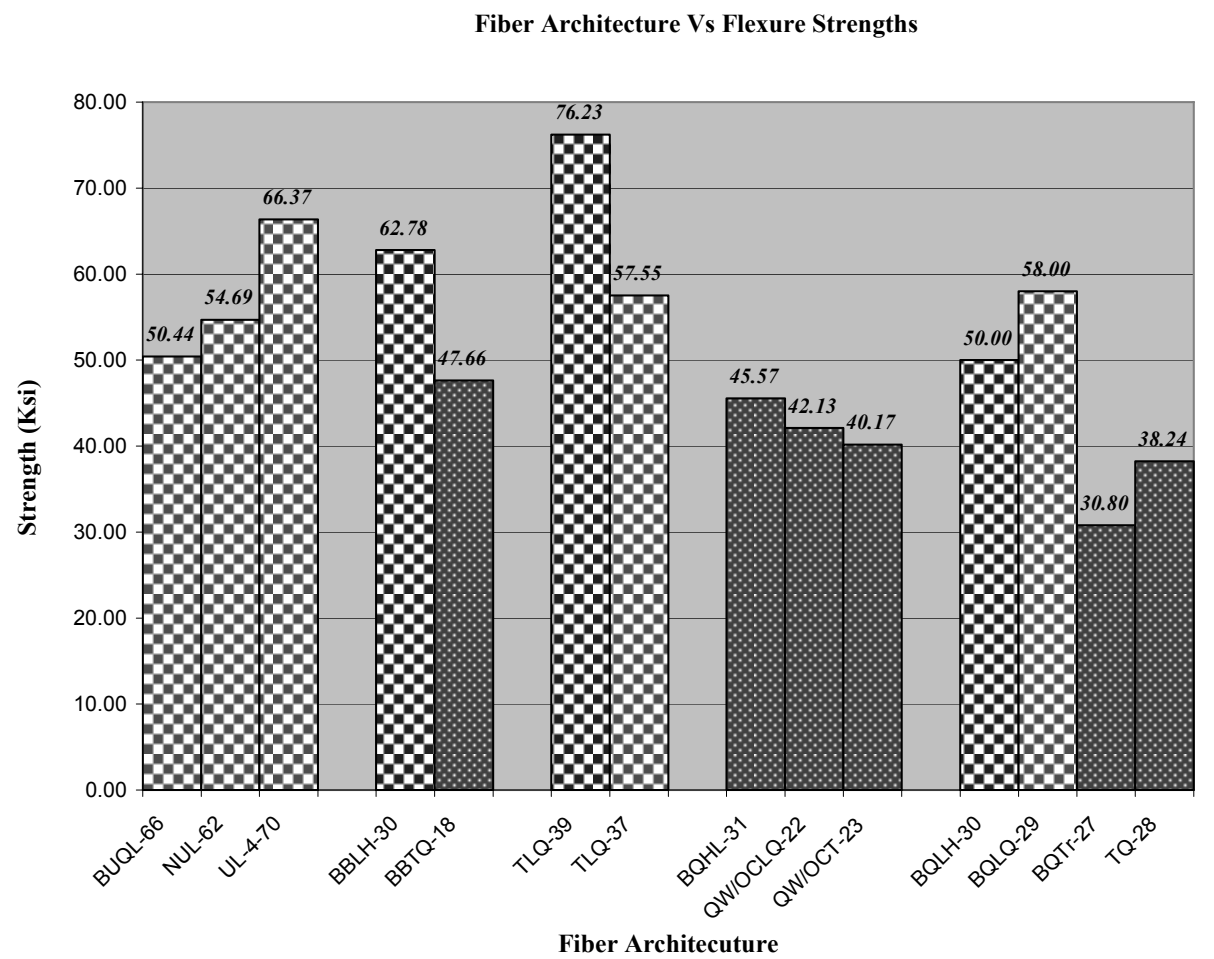

Figure 5.97 Fiber Architecture Vs Flexural Strength

For quadri-directional composites (quasi-isotropic), the strength is expected to be same in both longitudinal $[0 / 90 / \pm 45]_{\mathrm{NS}}$ and transverse $[90 / 0 / \pm 45]_{\mathrm{NS}}$ directions, but from the Table 5.3 and Table 5.7 it is observed that strength in transverse direction is higher than in longitudinal direction by $20 \%$. This is attributed to the misalignment of \pm 45 fibers as in this case, $0 / 90$ ply is manually cut in $+/-45$ degree direction so that the laminate is quadri-directional with $[0 / 90 /+45 /-45]_{\mathrm{NS}}$ lay-up. Also, as the fabric is not $100 \%$ balanced the fiber volume fraction in the loading direction may be the affecting parameter.

Similarly, quadri-directional composites with CSM $[0 / 90 /+45 /-45 / \mathrm{CSM}]_{\mathrm{NS}}$ in longitudinal direction are expected to have same strength as in transverse direction. However, small variations are observed which might be due to improper distribution of CSM on the stitched fabric and also possible misalignment of fibers during fabrication process. 


\subsubsection{Fiber Volume Fraction}

In this study, it was observed that as the fiber volume content (15\% to $45 \%)$ in the loading direction increases, the strength (tension and bending) of the composite increases (see Figure 5.98 and Figure 5.99).

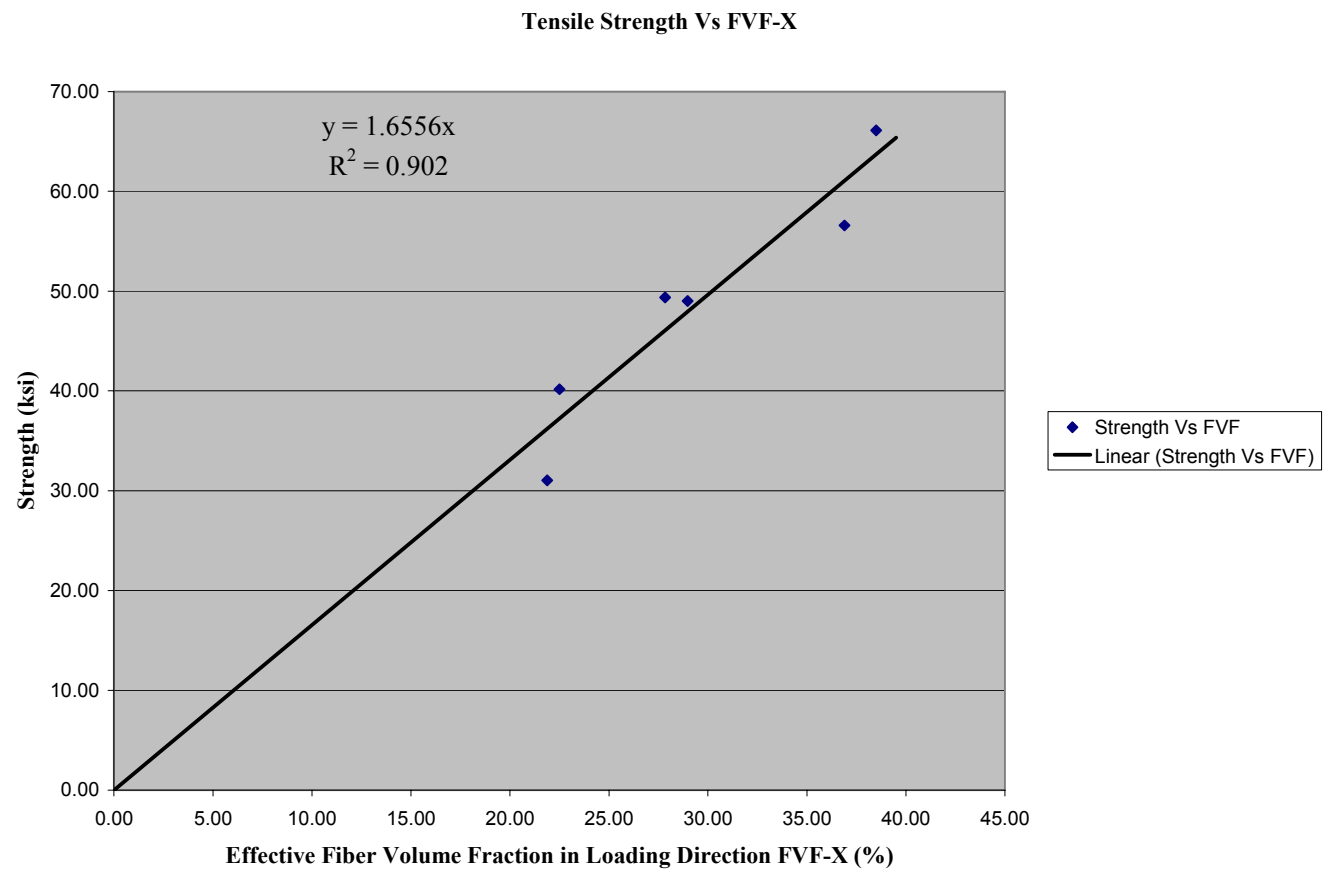

Figure 5.98 Tensile Strength Vs Effective FVF in Loading Direction 


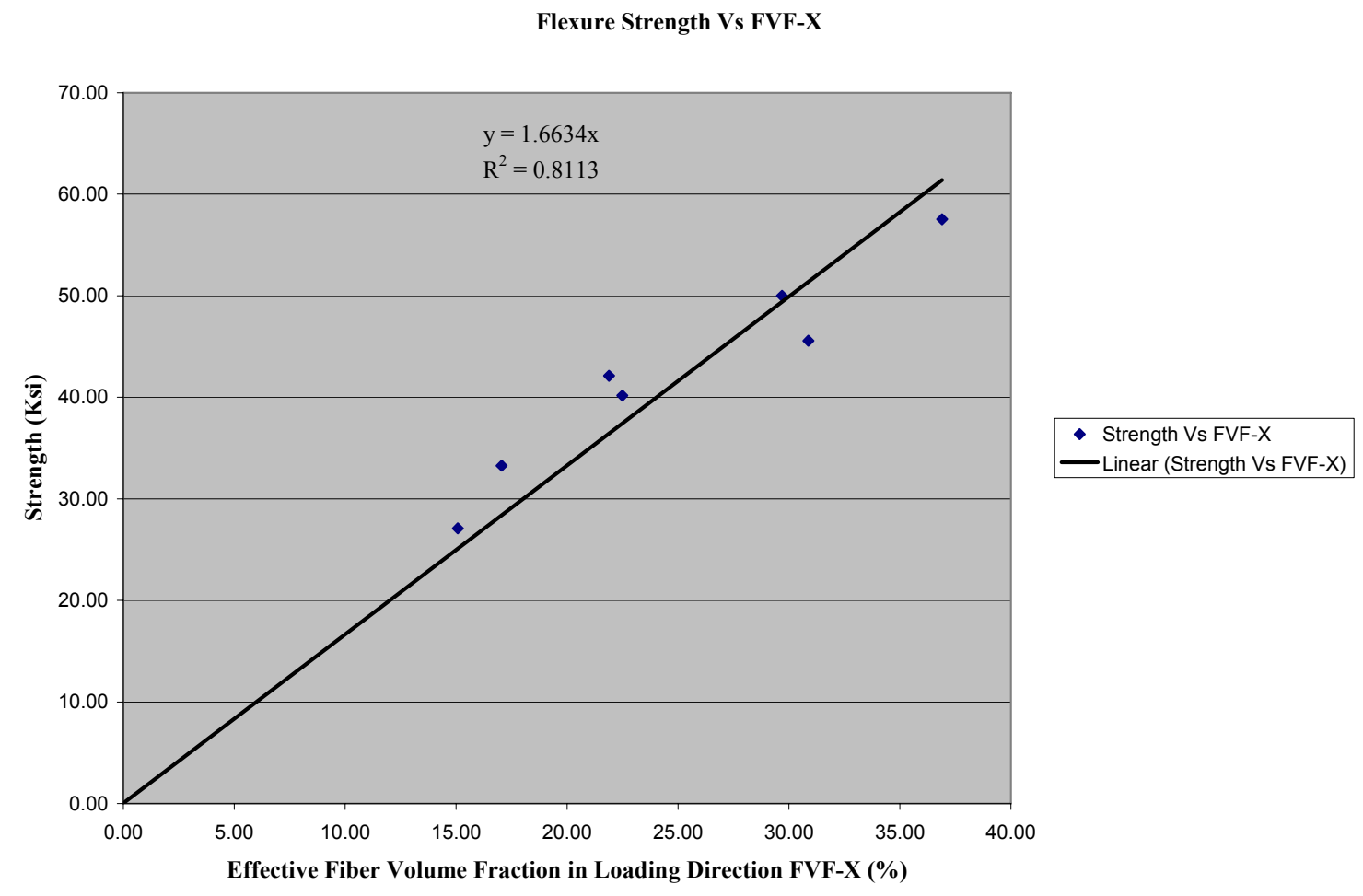

Figure 5.99 Flexural Strength Vs Effective FVF in Loading Direction

Specific stresses with respect to effective FVF in loading direction in case of tension and bending are shown in Figure 5.100 and Figure 5.101. It is observed clearly from the plots that as the fiber volume fraction increase, failure stress per volume content decreases. 


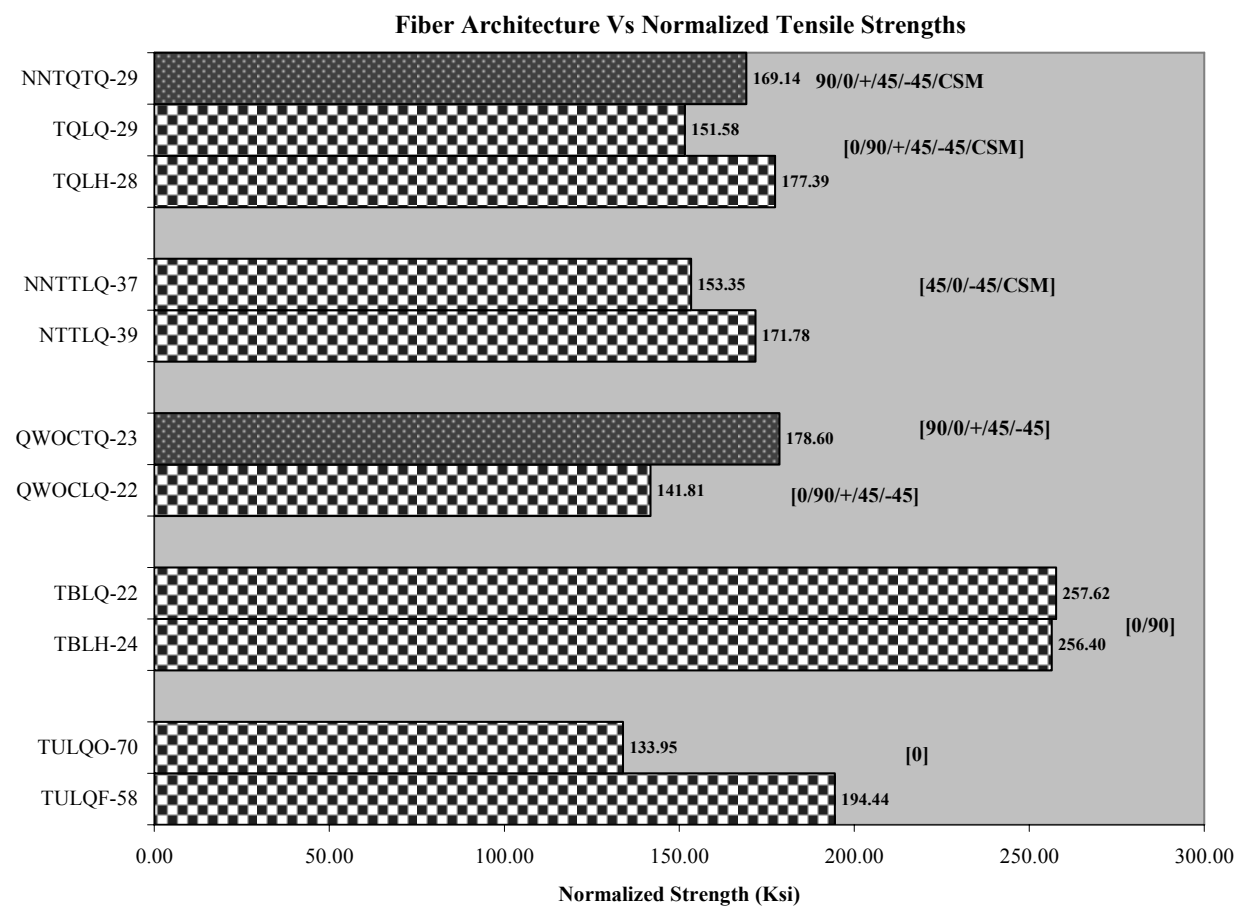

Figure 5.100 Fiber Architecture Vs Specific Tensile Strength per Equivalent FVF

Fiber Architecture Vs Normalized Flexural Strengths

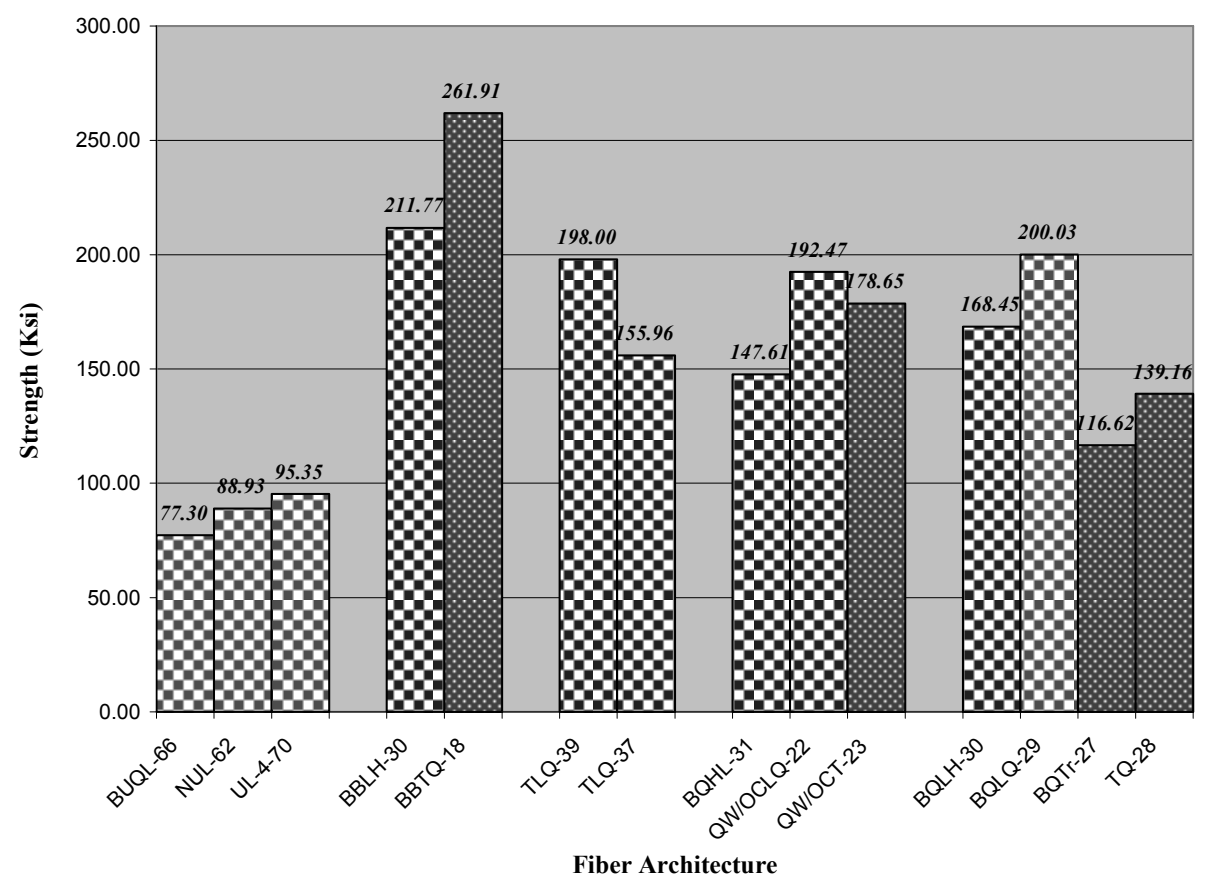

Figure 5.101 Fiber Architecture Vs Specific Flexural Strength per Equivalent FVF 
For unidirectional composites, it is found that the tensile strengths obtained are $112 \mathrm{ksi}$ for $\mathrm{FVF}$ of $58 \%$, while it is $94 \mathrm{ksi}$ for $70 \% \mathrm{FVF}$ which is attributed to inappropriate gage length and tab length and insufficient fiber wet out (Figure 5.96). Also from the mode of failure described in Section 5.4.2.1, it can be noted that the failure is attributed to bending and not 'pure' tension.

In case of cross-ply composites, quadri-directional composites with and without CSM, tri-directional composites with CSM, the tensile and bending strength results are found to be higher with the increase in percent of FVF. However, small variations in strengths are observed which might be due to misalignment of fibers, and edge effects.

\section{Factors influencing strengths with respect to resin content:}

- The theoretical maximum percent of fiber volume with respect to contact area of fibers and resin is around $81 \%$. Hence, composite specimens with lower FVFs have higher degree of wet out than those with higher FVFs.

- In case of unidirectional composites $[0]_{\mathrm{N}}$, with $70 \% \mathrm{FVF}$, the failure strength is lower than 0.7 times the failure strength of glass fibers.

- From the tensile and bending strengths shown in Figures 5.96 and 5.97, even though the coupon specimens did not exceed above 70\% FVF (which is less than the threshold limit i.e., 81\%), lower FVF in the loading direction based specimens resulted in higher stress to failure.

- The lower failure strengths (tensile and bending) are attributed: a) inherent defects resulting from a fabrication process such as voids, misalignment of fibers; $b$ ) inadequate amount of resin between the fibers leading to delamination and local bending, resulting in improper transfer of stresses from one ply to another.

- For tension tests, outer layers fail much sooner than the expected ultimate strength which is due to shear lag mechanisms.

\subsubsection{Tensile and Bending Stiffness}

The theoretical and experimental stiffnesses of composites with different fiber architectures (except tri-directional composite with CSM tested in transverse direction) under tension and bending are shown in Figure 5.102 and Figure 5.103 Theoretical 
modulus $\left(\mathrm{E}_{\mathrm{ROM}}\right)$ is obtained using rule of mixtures considering the effective fiber volume fraction in the loading direction. The experimental stiffnesses are calculated from the tangents of stress-strain curves. $E_{\alpha}$, and $E_{\beta}$, correspond to the first tangent modulus and second tangent modulus of non-linear (which is nearly a bi-linear in all cases) stressstrain curve.

The second tangent modulus in most of the cases is close to the theoretical predictions using rule-of-mixtures $\left(\mathrm{E}_{\mathrm{ROM}}\right)$, but is typically lower than the first tangent modulus. This indicates that the fibers other than the loading direction, also contribute to the stiffness. The above trends are valid for all fabric based composites and not unidirectional composites.

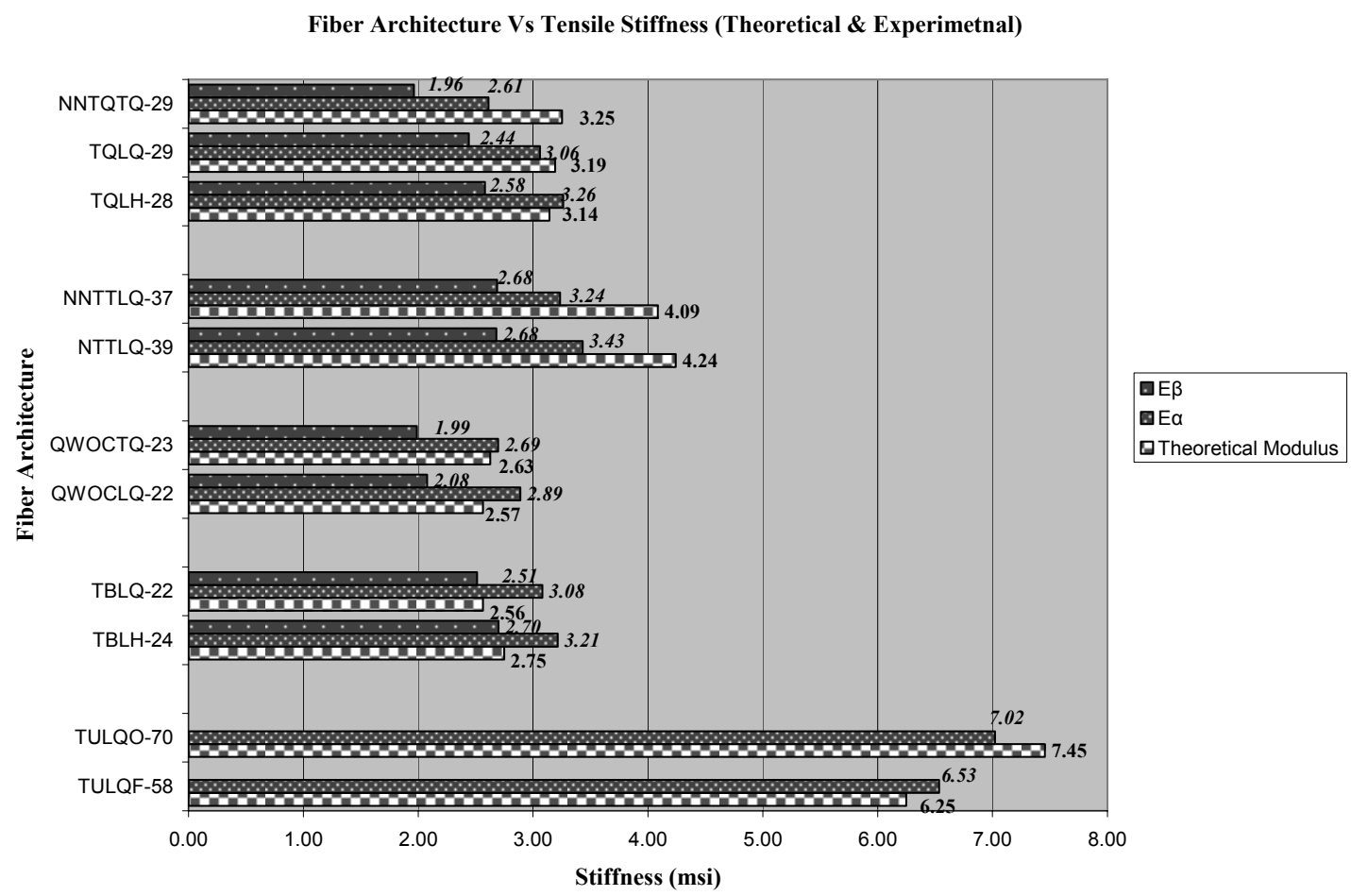

Figure 5.102 Fiber Architecture Vs Tensile Stiffness (Theoretical and Experimental) 


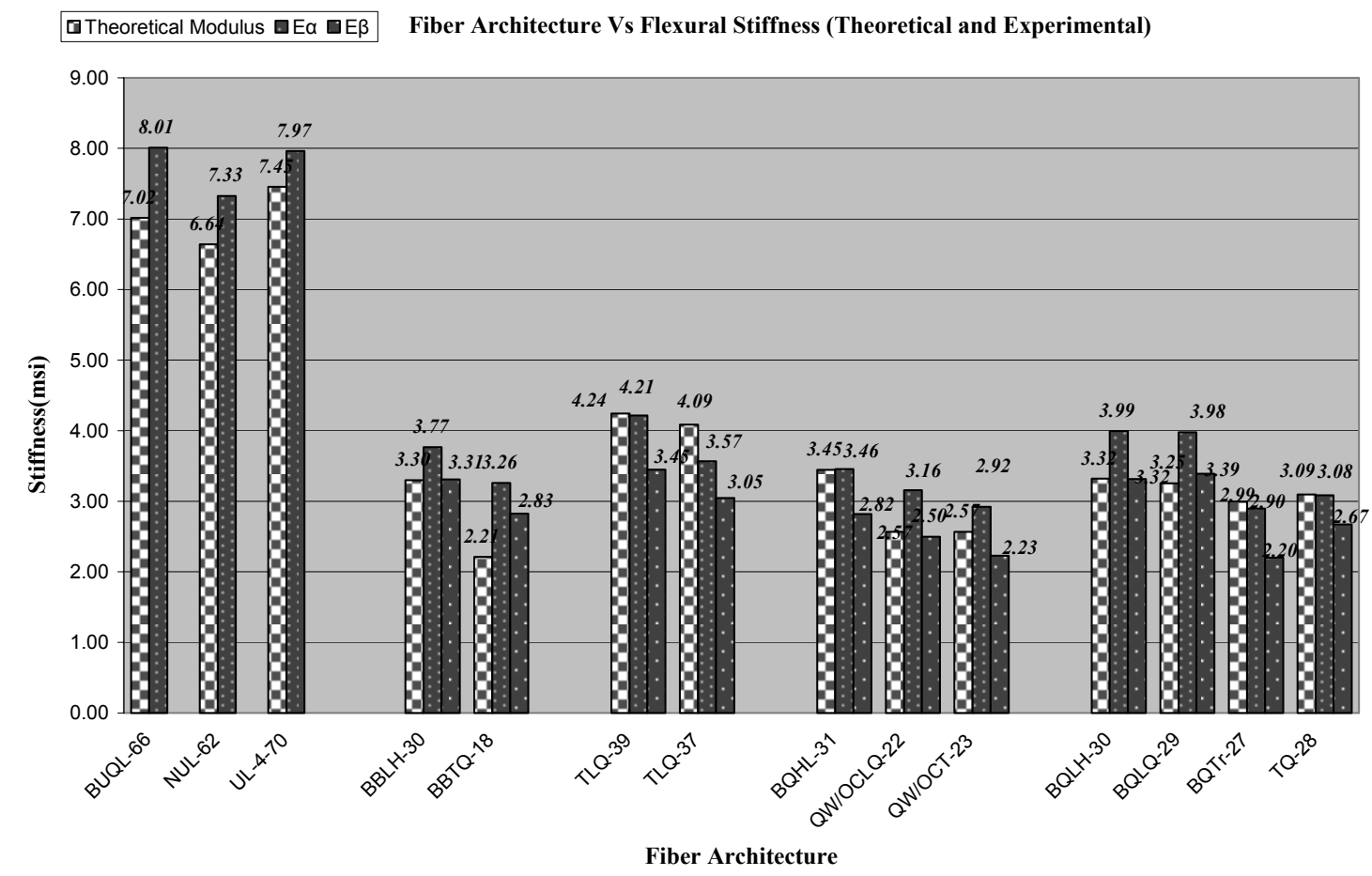

Figure 5.103 Fiber Architecture Vs Flexural Stiffness (Theoretical and Experimental)

\subsubsection{Fiber Architecture:}

Unidirectional composites with $0^{\circ}$ plies provide maximum stiffness than multidirectional composites because of maximum volume content in the loading direction. These composites do not exhibit any change of slope up to failure stress.

Quadri-directional composites without CSM fabricated using 40oz/yd2 fabric and tested under bending exhibited $\mathrm{E}_{\mathrm{ROM}}$ being equal to $\mathrm{E}_{\alpha}$, which is attributed to improper wet out and inadequate bond between fibers, leading to lower strengths and stiffness than expected. 


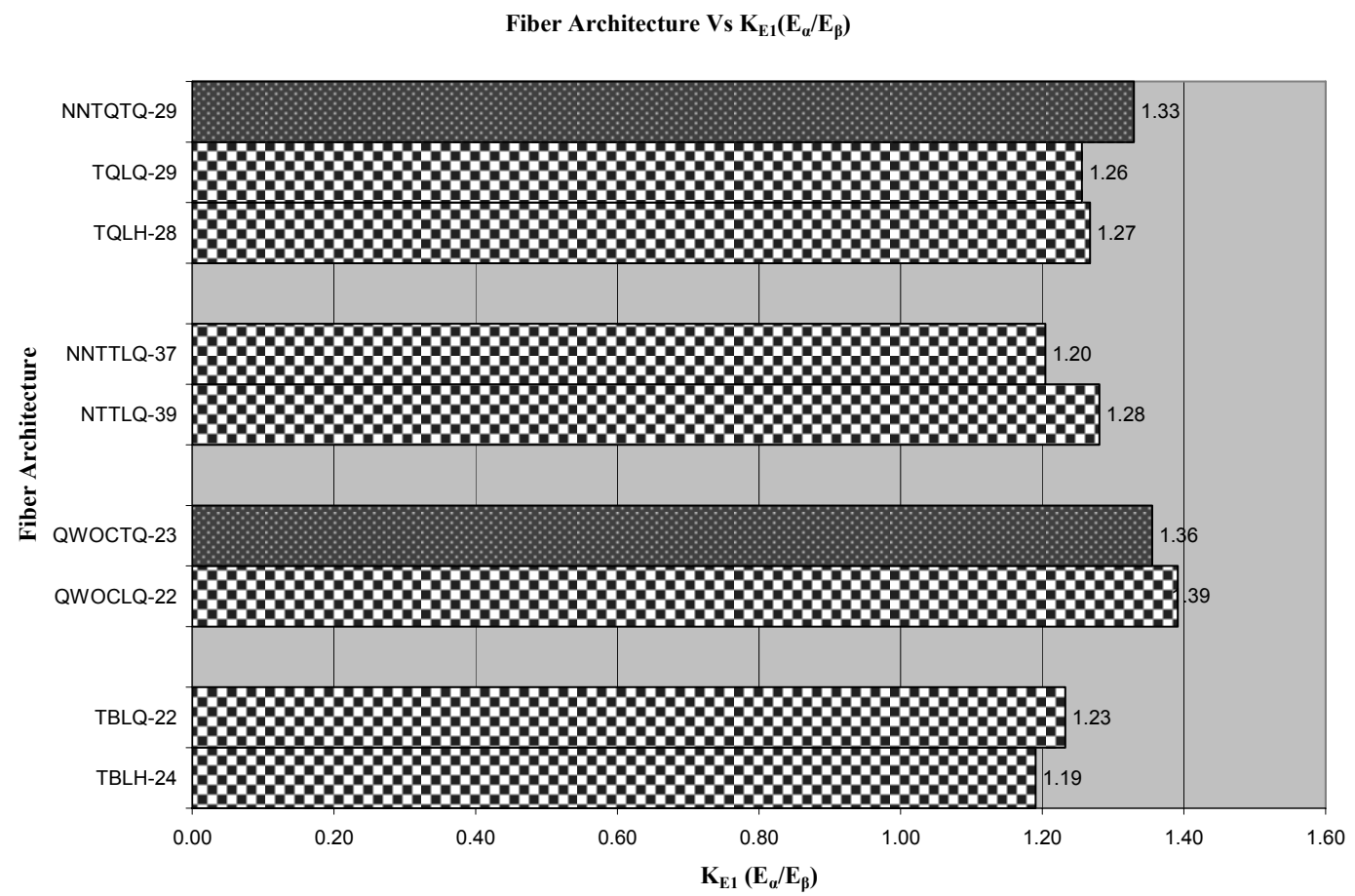

Figure 5.104 Fiber Architecture Vs KE1 (Tensile Modulus Ratios)

Fiber Architecture Vs $\mathrm{K}_{\mathrm{E} 1}\left(\mathrm{E}_{\alpha} / \mathrm{E}_{\beta}\right)$

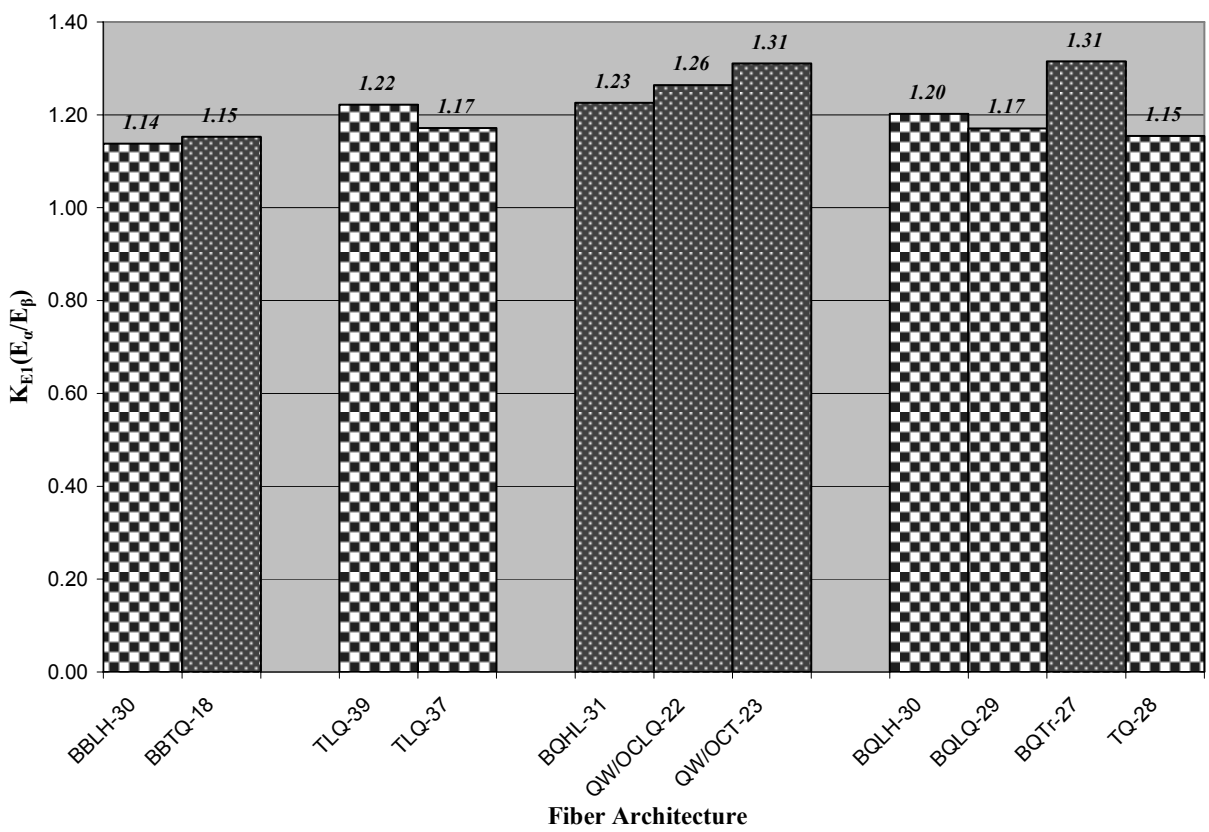

Figure 5.105 Fiber Architecture Vs KE1 (Flexural Modulus Ratios) 
Figure 5.104 and Figure 5.105, reveal that for all fiber-architectures the $\mathrm{K}_{\mathrm{E} 1}$ $\left(\mathrm{E}_{\alpha} / \mathrm{E}_{\beta}\right)$ value is 1.20 and 1.27 for tension and bending, respectively with standard deviation around $5 \%$.

\subsubsection{Fiber Volume Fraction}

It is evident from Figure 5.106 and Figure 5.107 that as fiber volume fraction in the loading direction increases; modulus increases and follows the expected trends. For all fiber architectures as tested through this program, the stiffnesses are in good agreement because with the increase in fiber volume fraction in loading direction the stiffnesses increased accordingly. However, any minor variations can be attributed be due to misalignment of fibers, edge effects due to cutting, inadequate wet out, etc.

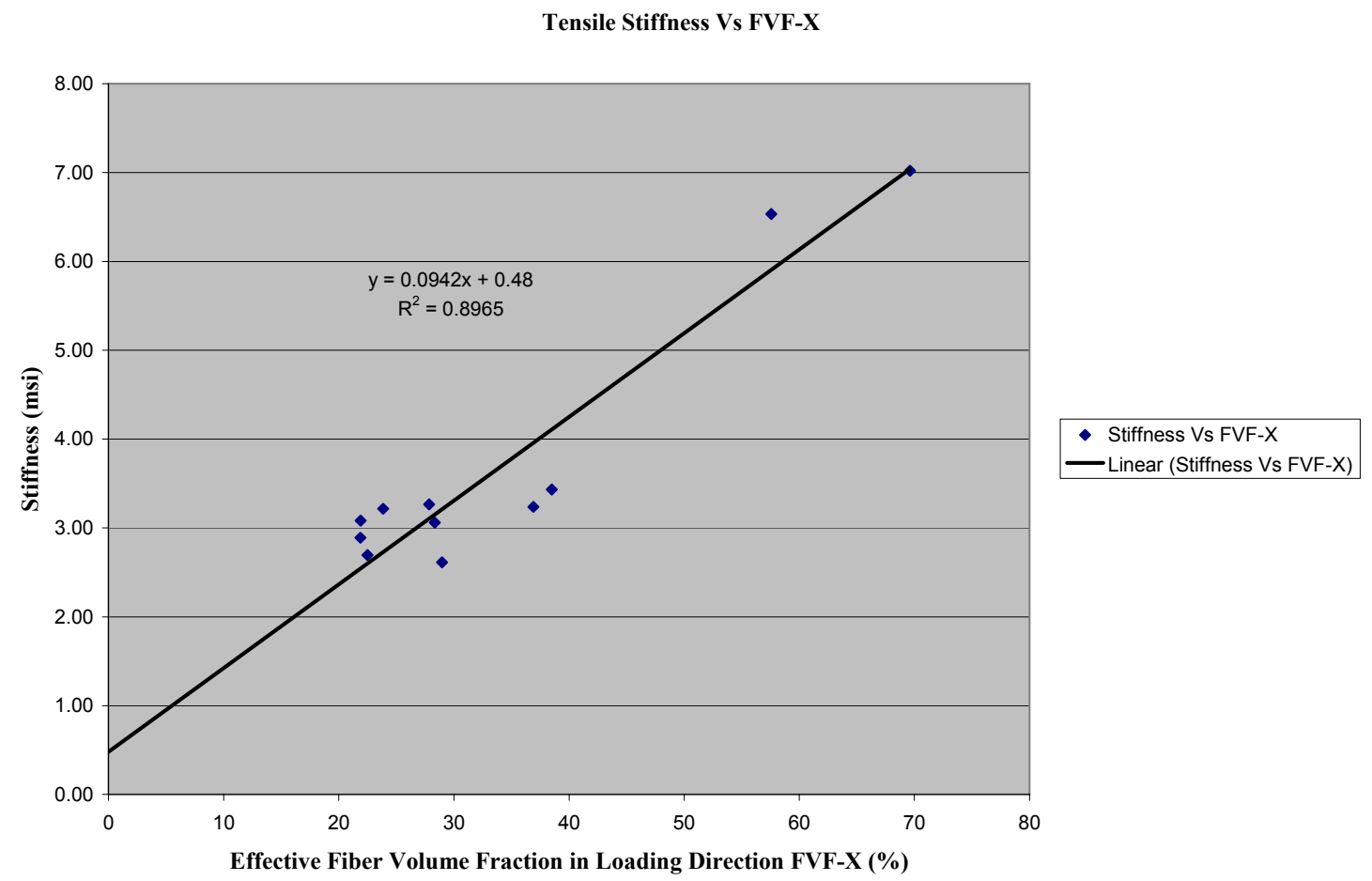

Figure 5.106 Tensile Stiffness Vs Effective FVF in Loading Direction 
Flexural Stiffness Vs FVF-X

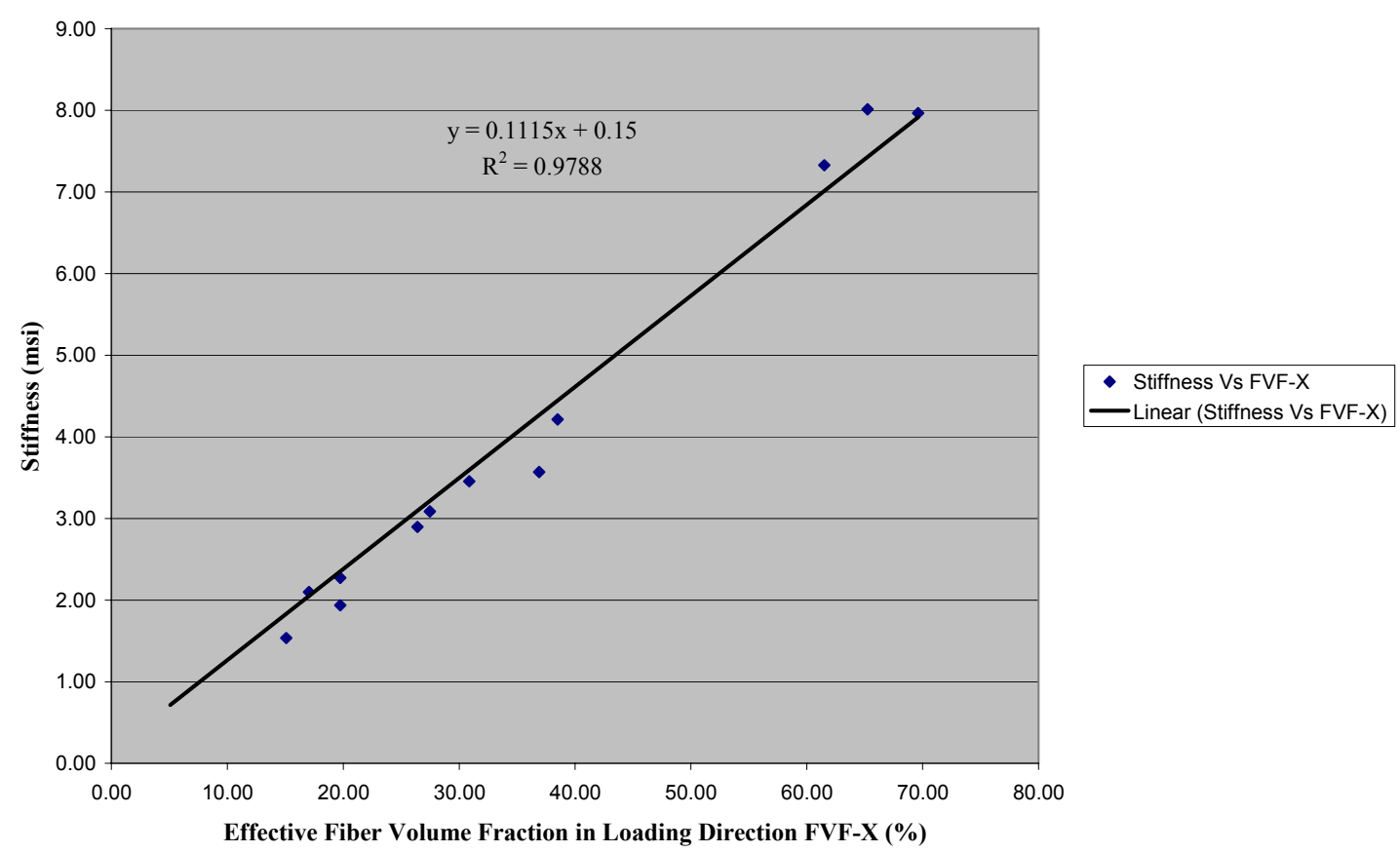

Figure 5.107 Flexural Stiffness Vs Effective FVF in Loading Direction

Specific stiffnesses per equivalent FVF in case of tension and bending are shown in Figure 5.108 and Figure 5.109. It is observed clearly from the plots, for all fiber architectures, specific second tangent modulus per equivalent FVF is almost constant $8.53(\mathrm{msi} / \mathrm{FVF})$ and $10.11(\mathrm{msi} / \mathrm{FVF})$ under tension and bending, respectively. As expected, these moduli should be nearly identical to the stiffness of glass fibers. However, lower stiffness of these composites under tension is attributed to misalignment of fibers. Misalignment effects are not going to be as significant under bending as they are under tension. 


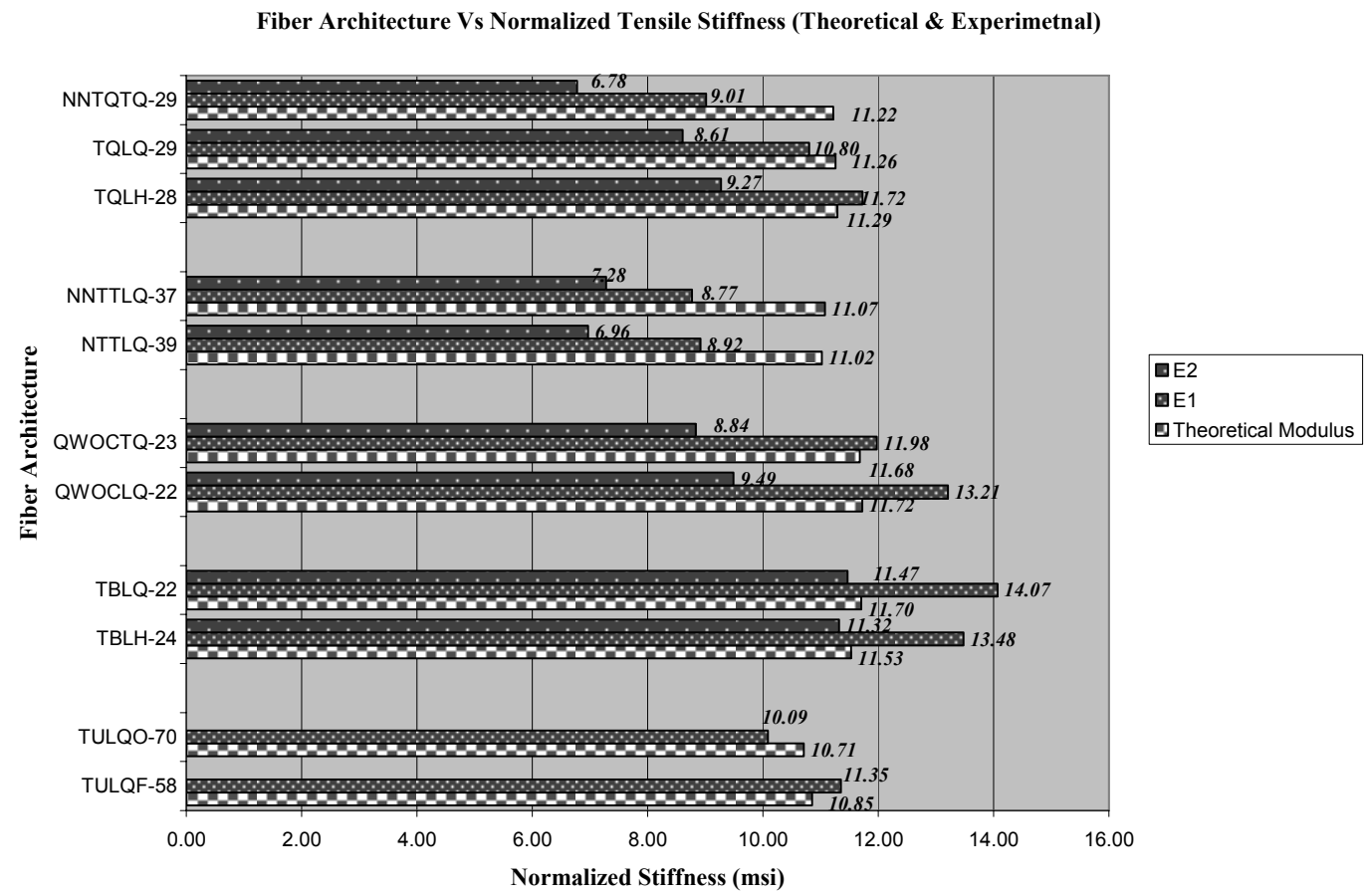

Figure 5.108 Fiber Architecture Vs Specific Tensile Stiffness per Equivalent FVF (Theoretical and Experimental)

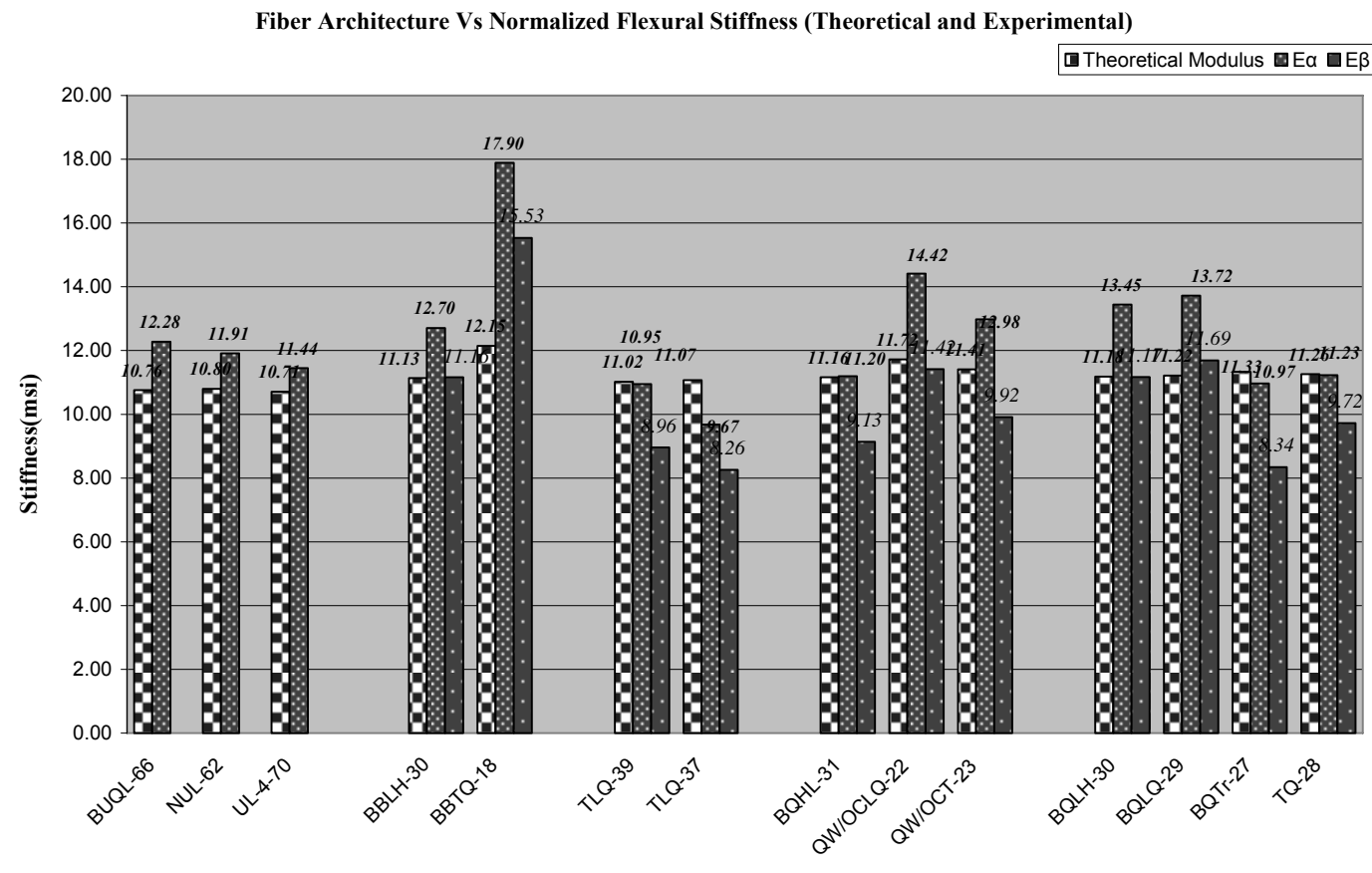

Fiber Architecture

Figure 5.109 Fiber Architecture Vs Specific Flexural Stiffness per Equivalent FVF (Theoretical and Experimental) 


\subsubsection{Strains at Ultimate Stress}

In this study, strains at ultimate stresses for unidirectional composites are observed to be lower than those with fabric based composites. This is attributed to the possibility of matrix splitting between fibers with higher FVF. But, in case of fabric based composites, matrix begins to soften due to the stiffening effects of the fibers oriented in different directions other than the loading direction.

Figure 5.110 and Figure 5.111 show the variation of first points where change of slope occurred with reference to strains for different fiber architectures. It is seen that the first point where change of slope occurred are almost same for samples tested in longitudinal and transverse directions, though different under bending and tension. The first point (location where change of slope occurred) in case of tension is around 0.34, and around 0.28 under bending. The difference in stiffness changes (due to change of slope) is attributed to uni-axial versus multi-axial states of stress under tension versus bending.

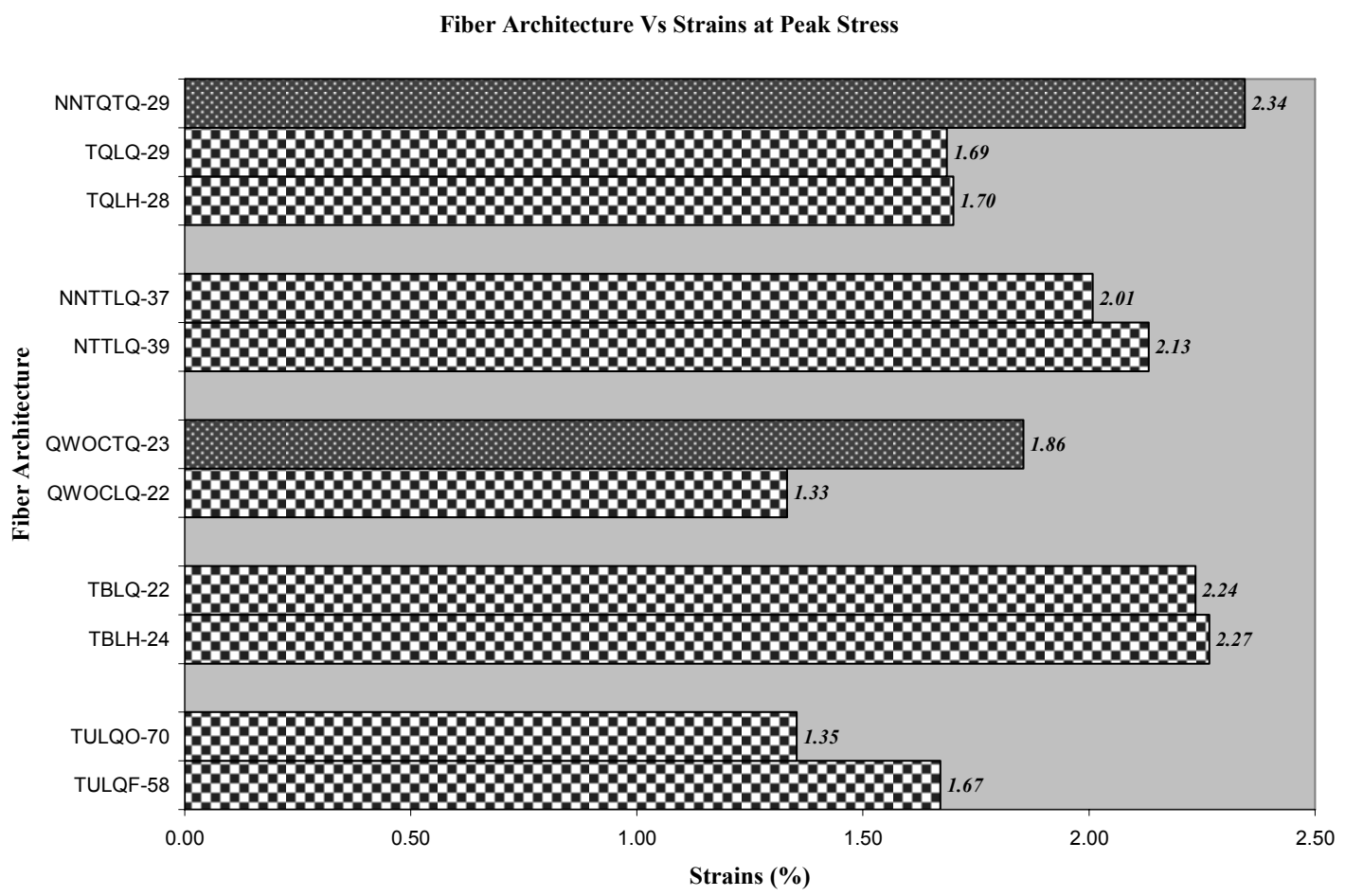

Figure 5.110 Fiber Architecture Vs Tensile Strains at Ultimate Stress 


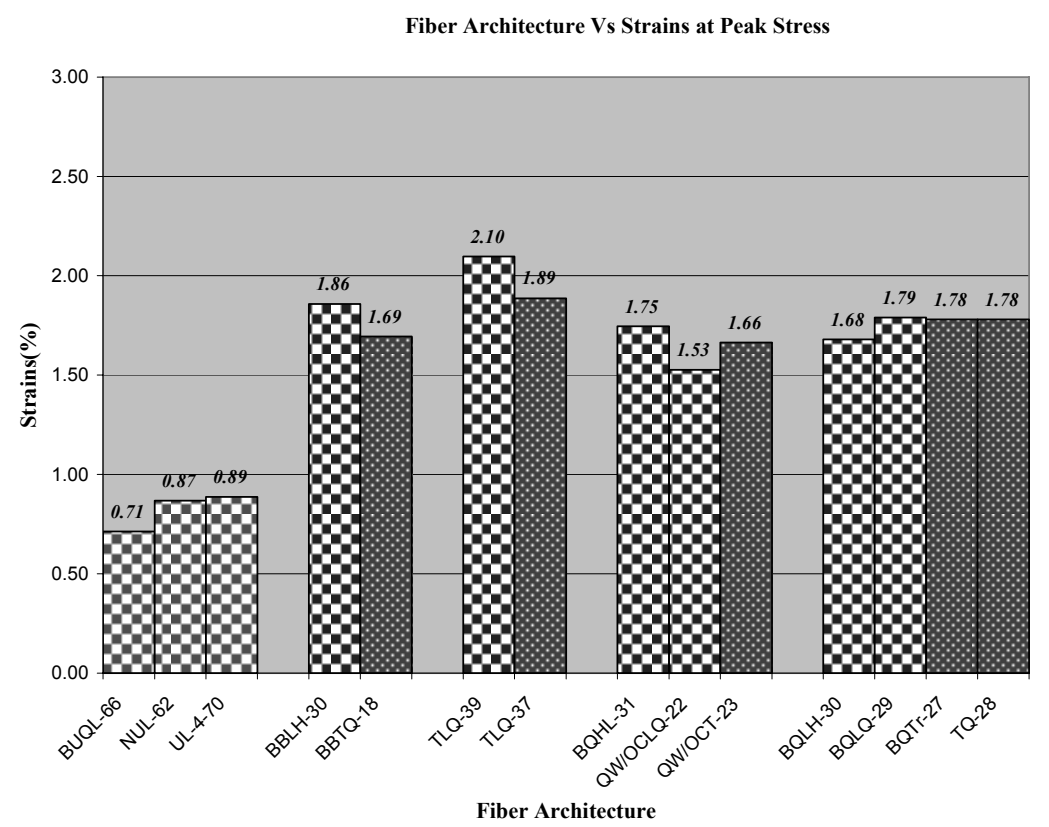

Figure 5.111 Fiber Architecture Vs Flexural Strains at Ultimate Stress

Specific strains per equivalent FVF in case of tension and bending are shown in Figure 5.112 and Figure 5.113, which revealed that failure strains per volume content are lower for higher FVF.

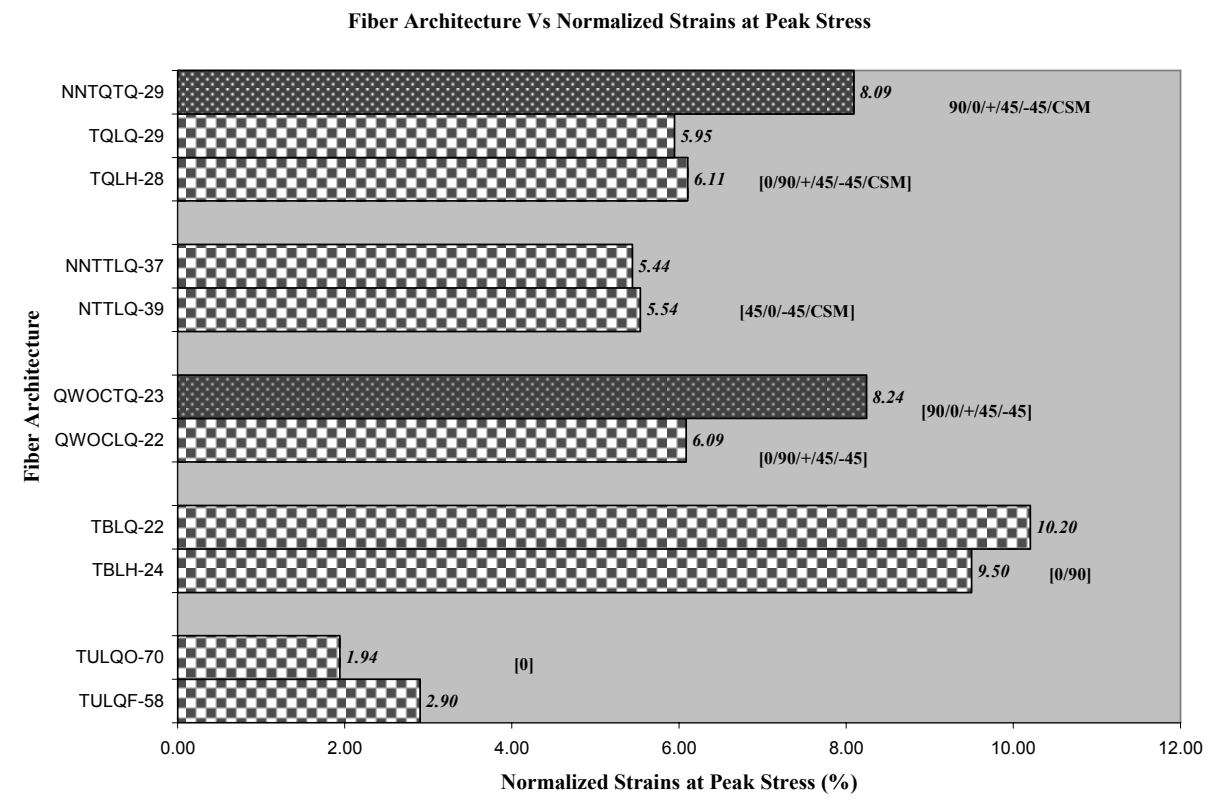

Figure 5.112 Fiber Architecture Vs Specific Tensile Strains per Equivalent FVF at Ultimate Stress 


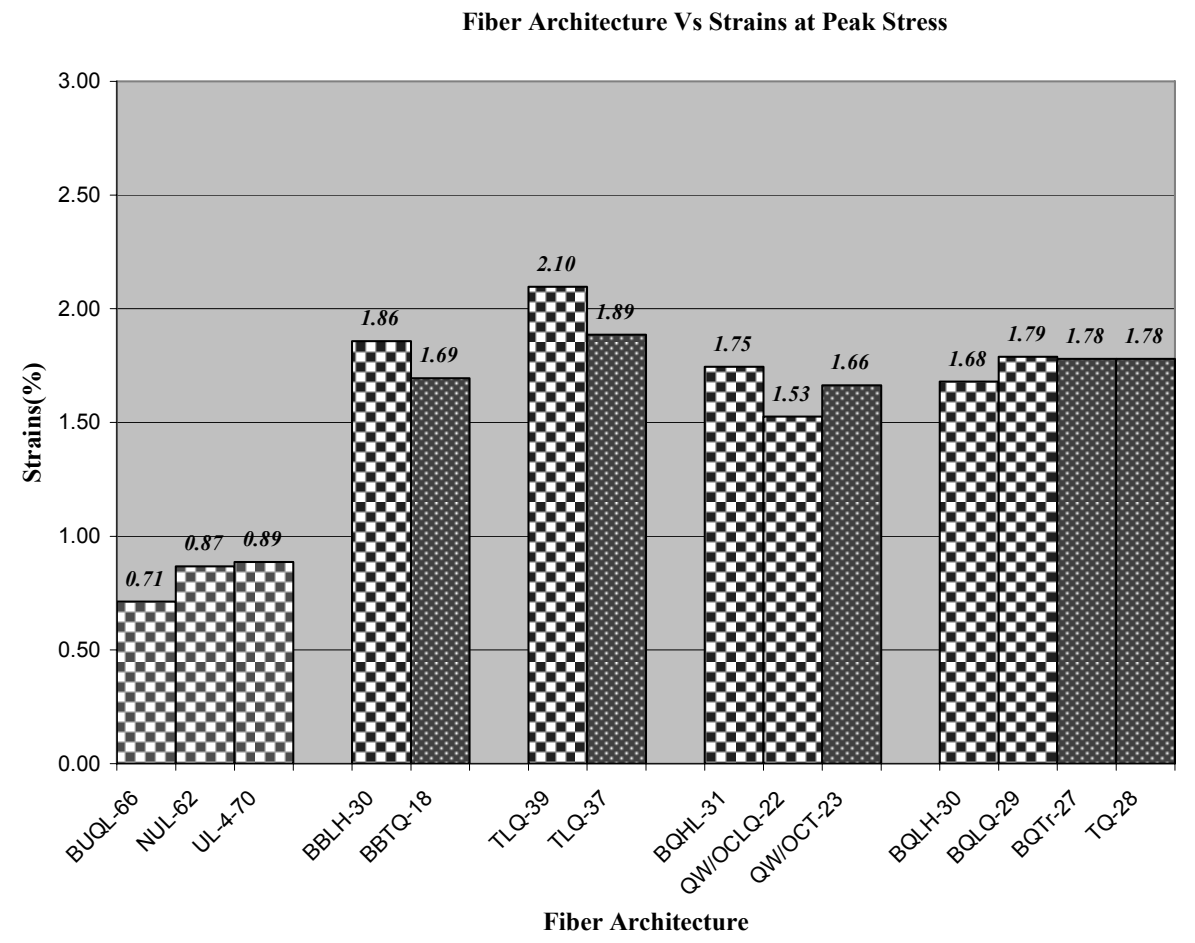

Figure 5.113 Fiber Architecture Vs Specific Flexural Strains per Equivalent FVF at Ultimate Stress

\subsection{SPECIAL CASE: TRI-DIRECTIONAL COMPOSITES WITH CSM TESTED IN TRANSVERSE DIRECTION UNDER TENSION AND BENDING}

\subsubsection{Tensile and Flexural Strength}

Figure 5.114 and Figure 5.115 show the tensile and bending strengths of tridirectional composites with CSM. Specific strengths with respect to fibers contributing in the loading direction for tension and bending are shown in Figure 5.116 and Figure 5.117 , and are found to be around $121 \mathrm{ksi} / \mathrm{FVF}$, and $185 \mathrm{ksi} / \mathrm{FVF}$, respectively. 


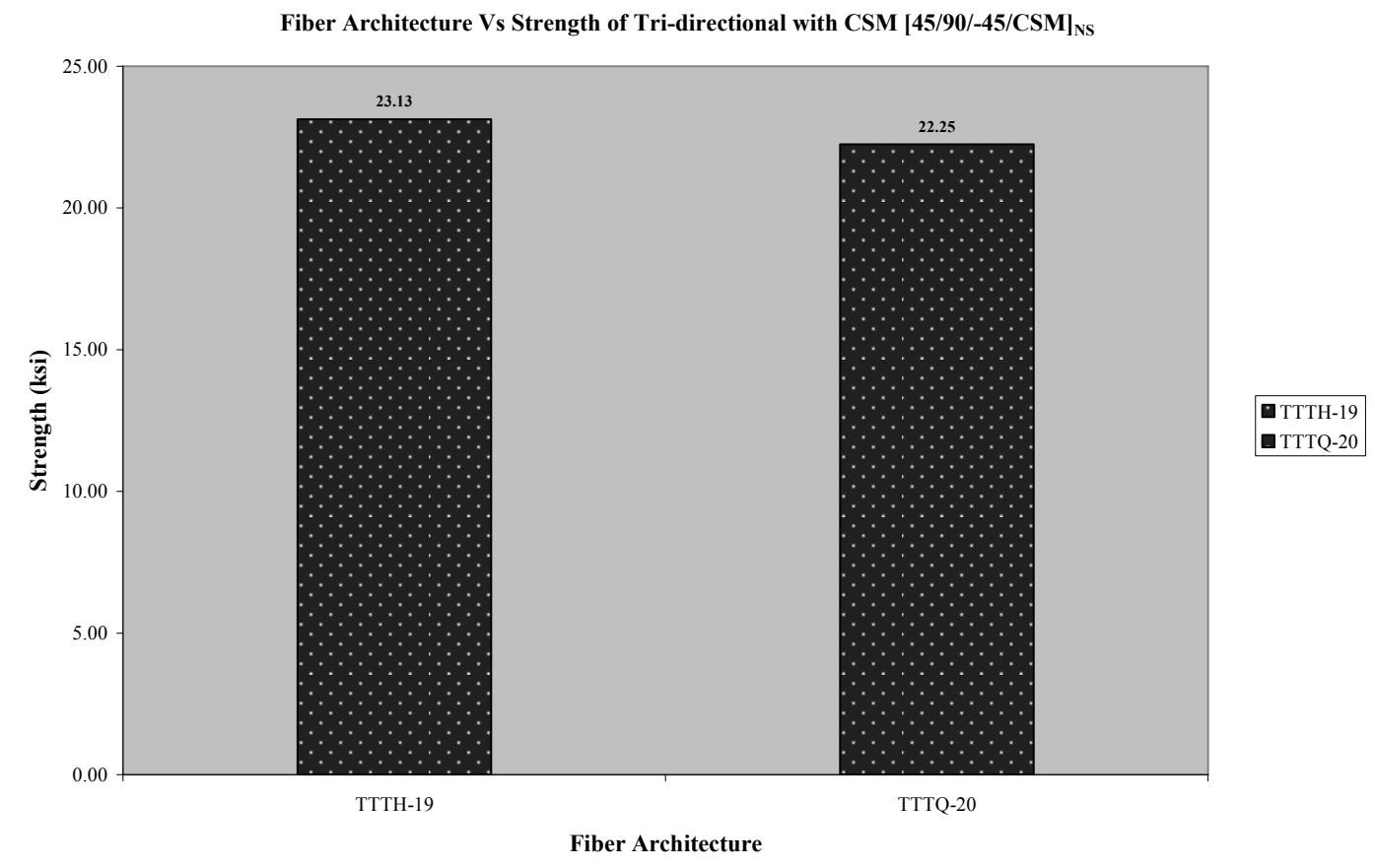

Figure 5.114 Fiber Architecture Vs Tensile Strength for tri-directional composites with CSM in transverse direction

Fiber Architecture Vs Strengths of Tri-direcetional with CSM [45/90/-45/CSM $]_{\mathrm{NS}}$

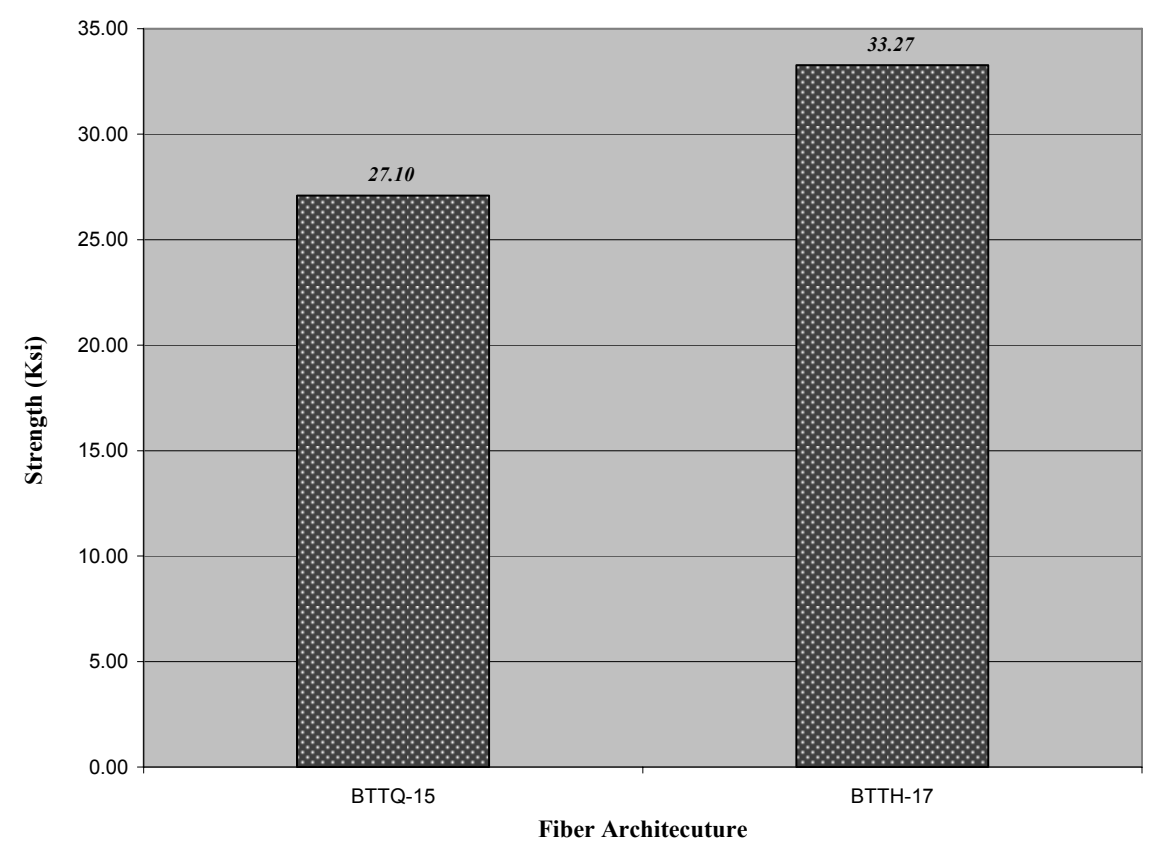

Figure 5.115 Fiber Architecture Vs Flexural Strength for tri-directional composites with CSM in transverse direction 


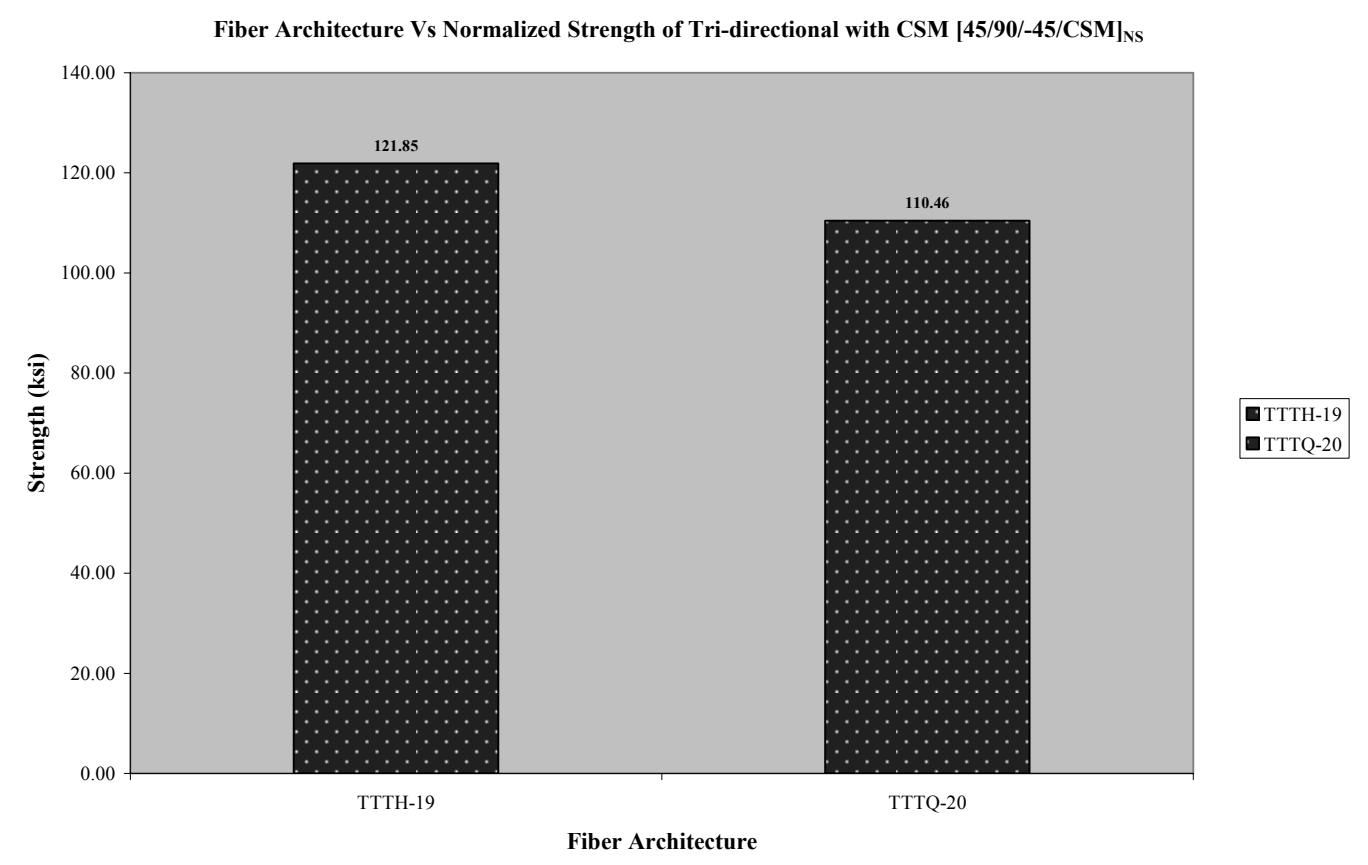

Figure 5.116 Fiber Architecture Vs Specific Tensile Strength per Equivalent FVF for tridirectional composites with CSM in transverse direction

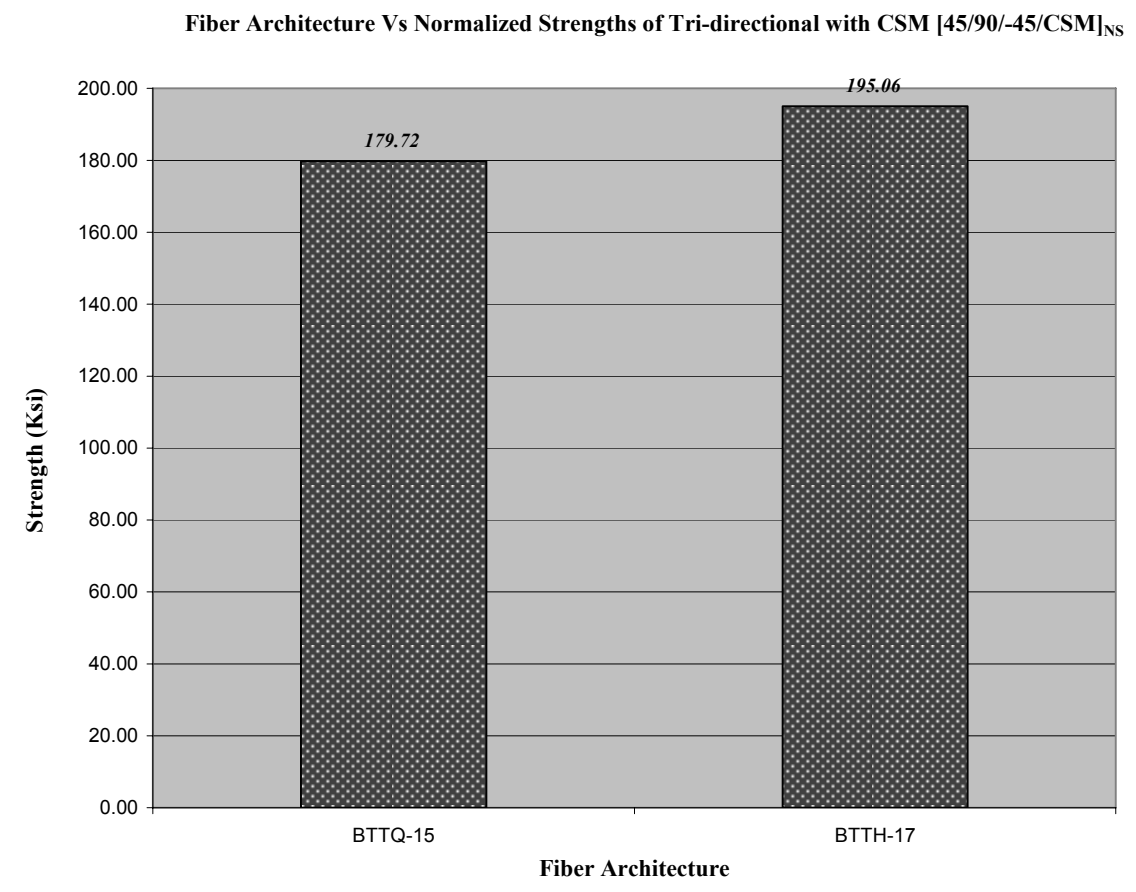

Figure 5.117 Fiber Architecture Vs Flexural Strength for tri-directional composites with CSM in transverse direction 


\subsubsection{Stiffness}

Herein, the theoretical stiffness obtained using rule-of-mixtures $\left(\mathrm{E}_{\mathrm{ROM}}\right)$ is almost equal to the initial tangent modulus $\left(\mathrm{E}_{\alpha}\right)$ in tension as well as in bending, which is attributed to low fiber volume fraction in loading direction, thus showing matrix dominant behavior. The theoretical stiffness (EROM), and longitudinal moduli $\left(\mathrm{E}_{\alpha}, \mathrm{E}_{\beta}\right.$, Ey) obtained from the experiments under tension and bending are shown in Figures 5.23 and 5.24. Specific stiffnesses per equivalent FVF for tension and bending with respect to fiber volume fraction in loading direction under tension and bending are shown in Figure 5.120 and Figure 5.121, and are found to be in the range $10.80 \mathrm{msi} / \mathrm{FVF}$ and 11.24 msi/FVF, for tension and bending, respectively. As expected the specific stiffness per equivalent fiber volume fraction for both tension and bending should be almost equal to the stiffness of the fibers, however, the small variations is due to misalignment of fibers, improper wet out, etc. Ratios of first modulus to the second $\left(K_{E 1}\right)$, and second to the third $\left(\mathrm{K}_{\mathrm{E} 2}\right)$ are found to be in the range of 1.41 , and 1.47 , for tension, and 1.56 and 1.51 for bending, respectively (Figure 5.122 and Figure 5.123).

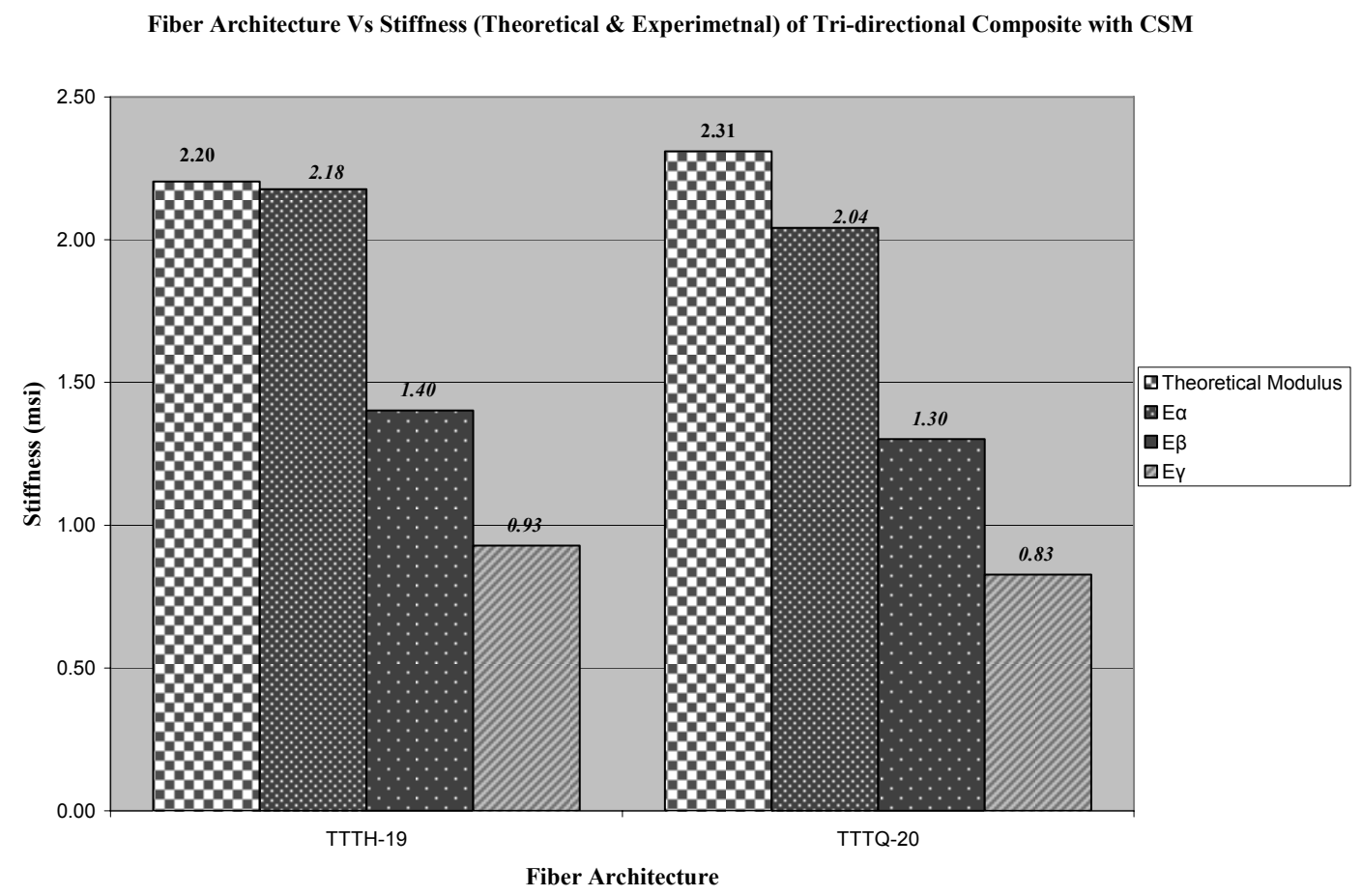

Figure 5.118 Fiber Architecture Vs Stiffness (theoretical and experimental) composites with CSM in transverse direction under tension 


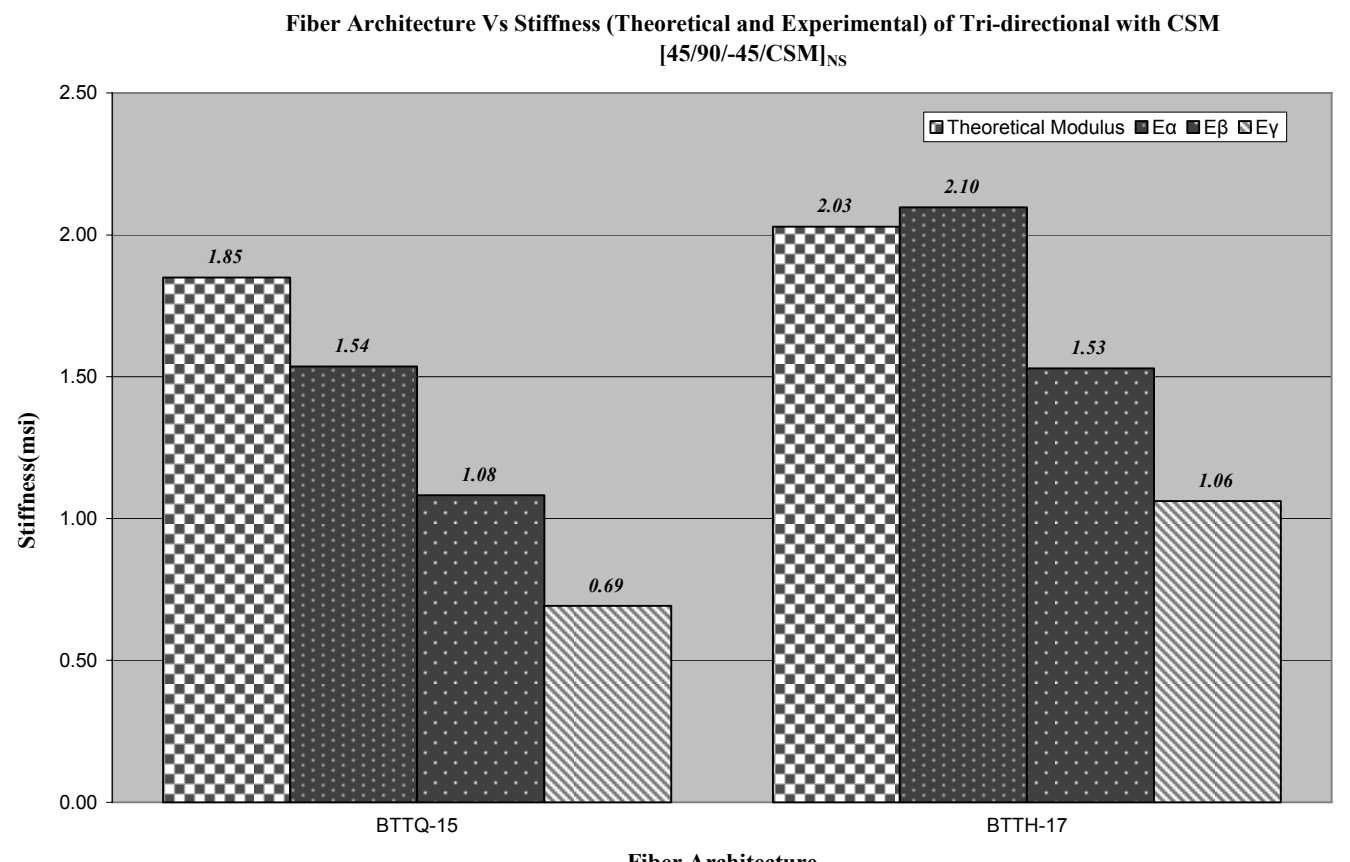

Figure 5.119 Fiber Architecture Vs Stiffness (theoretical and experimental) composites with CSM in transverse direction under bending

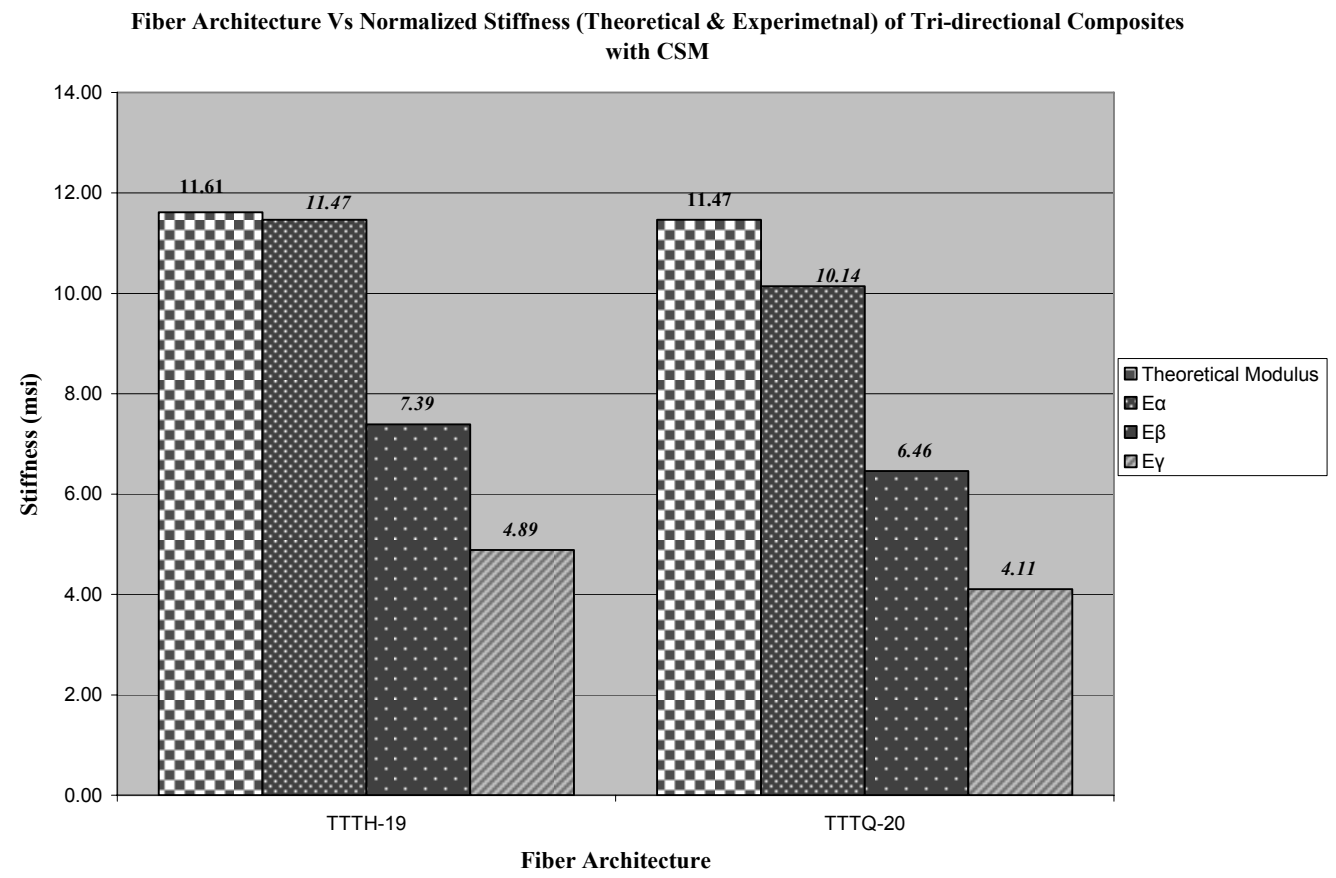

Figure 5.120 Fiber Architecture Vs Specific Stiffness per Equivalent FVF (theoretical and experimental) composites with CSM in transverse direction under tension 


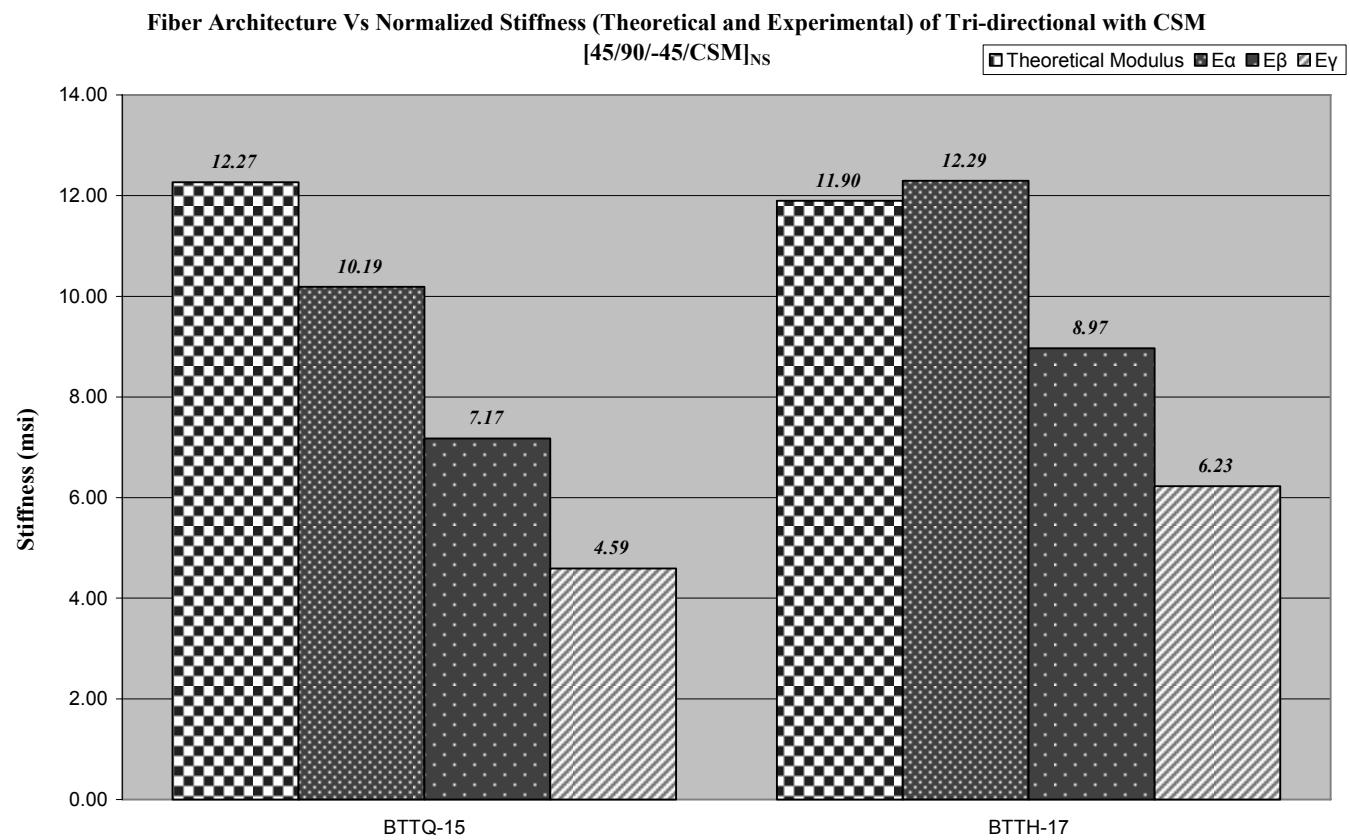

Fiber Architecture

Figure 5.121 Fiber Architecture Vs Specific Stiffness per Equivalent FVF (theoretical and experimental) composites with CSM in transverse direction under bending

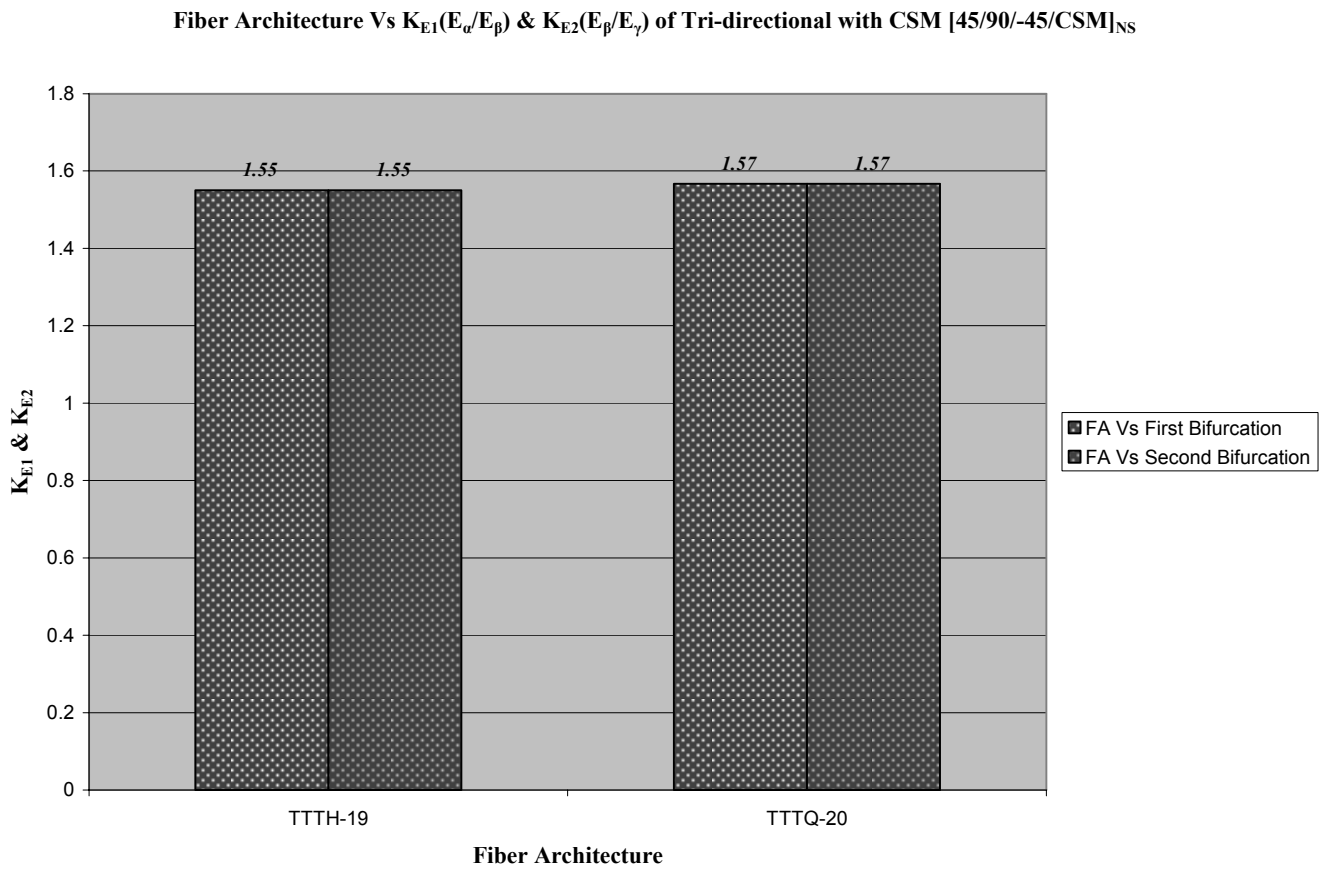

Figure 5.122 Fiber Architecture Vs KE1 and KE2 composites with CSM in transverse direction under tension 


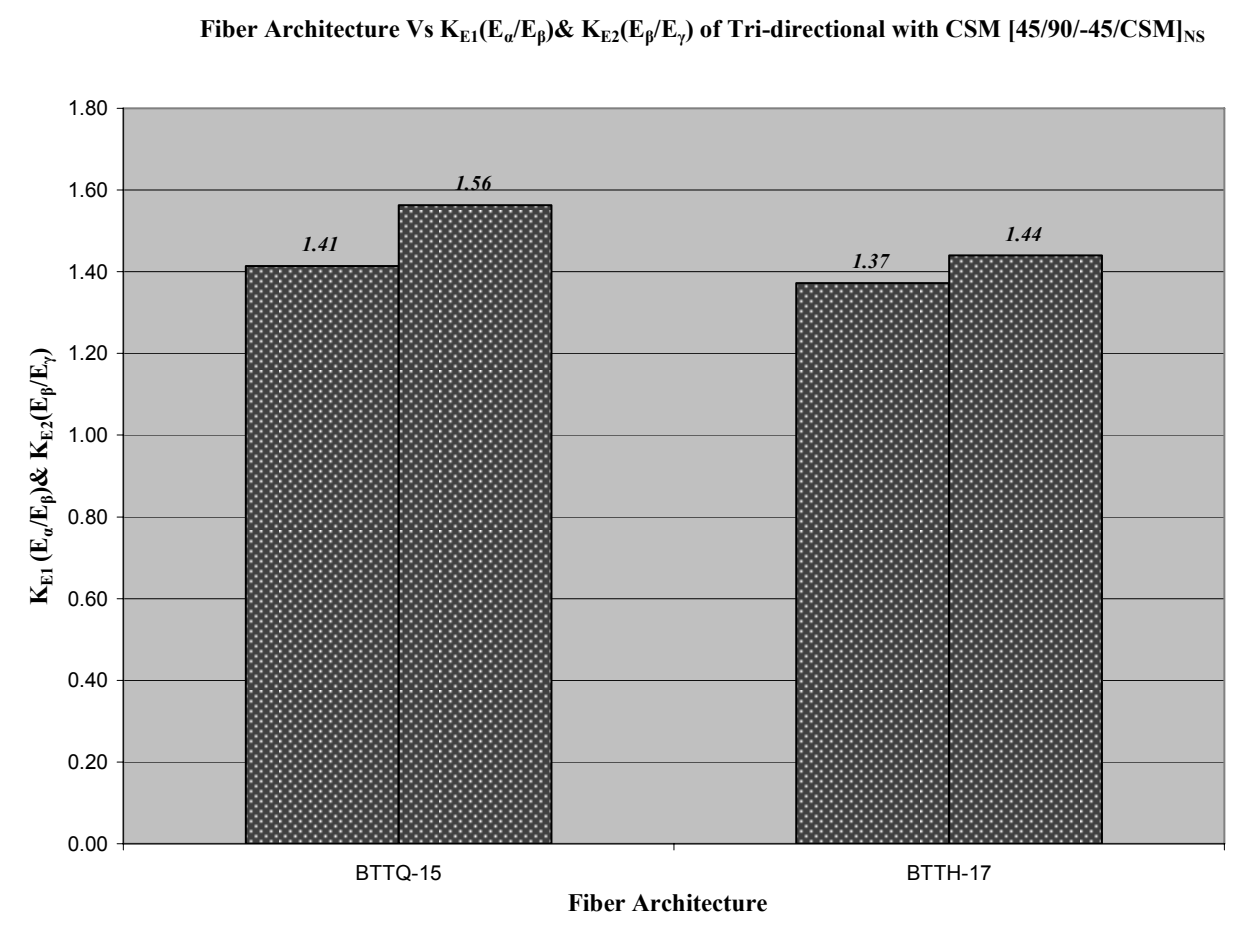

Figure 5.123 Fiber Architecture Vs KE1 and KE2 composites with CSM in transverse direction under bending

\subsubsection{Strains at Ultimate Stress}

The strains at ultimate stress of tri-directional composite with CSM under tension and bending are shown in Figure 5.124 and Figure 5.125, respectively. The variation of first points where change in slope occurred with reference to strains under tension and bending are shown in Figure 5.126 and Figure 5.127. The first and second points (locations where change in slope occurred) under tension are around $\left(\mathrm{K}_{1}\right) 0.25$ and $\left(\mathrm{K}_{2}\right)$ 0.68, while $\left(\mathrm{K}_{1}\right) 0.15$ and $\left(\mathrm{K}_{2}\right) 0.45$ for bending, respectively (Figure 5.126 Figure 5.127). Specific strains per equivalent FVF in case of tension and bending are shown in Figure 5.128 and Figure 5.129. 
Fiber Architecture Vs Strains at Peak Stress of Tri-directional with CSM $[45 / 90-45 / C S M]_{N S}$

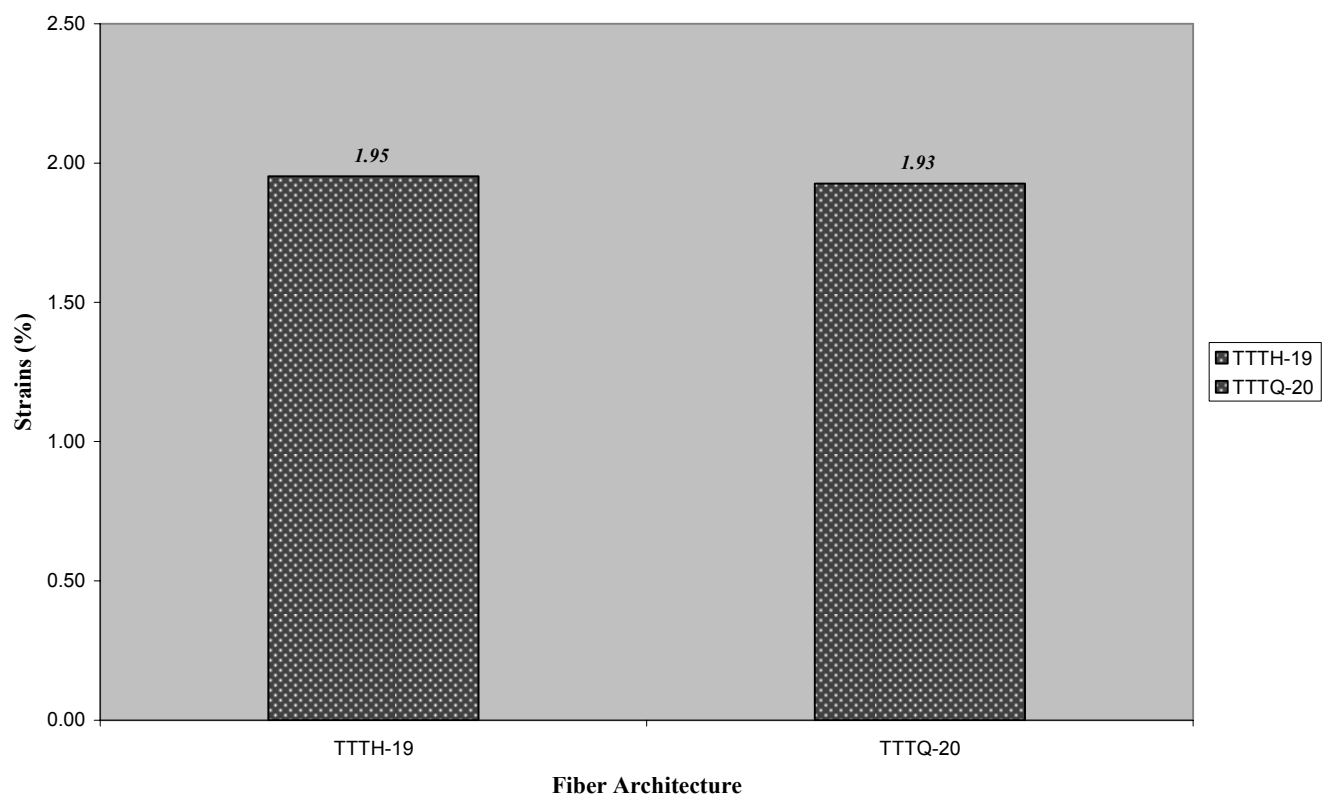

Figure 5.124 Fiber Architecture Vs Strains at Ultimate Stress of Tri-directional composites with CSM in transverse direction under tension

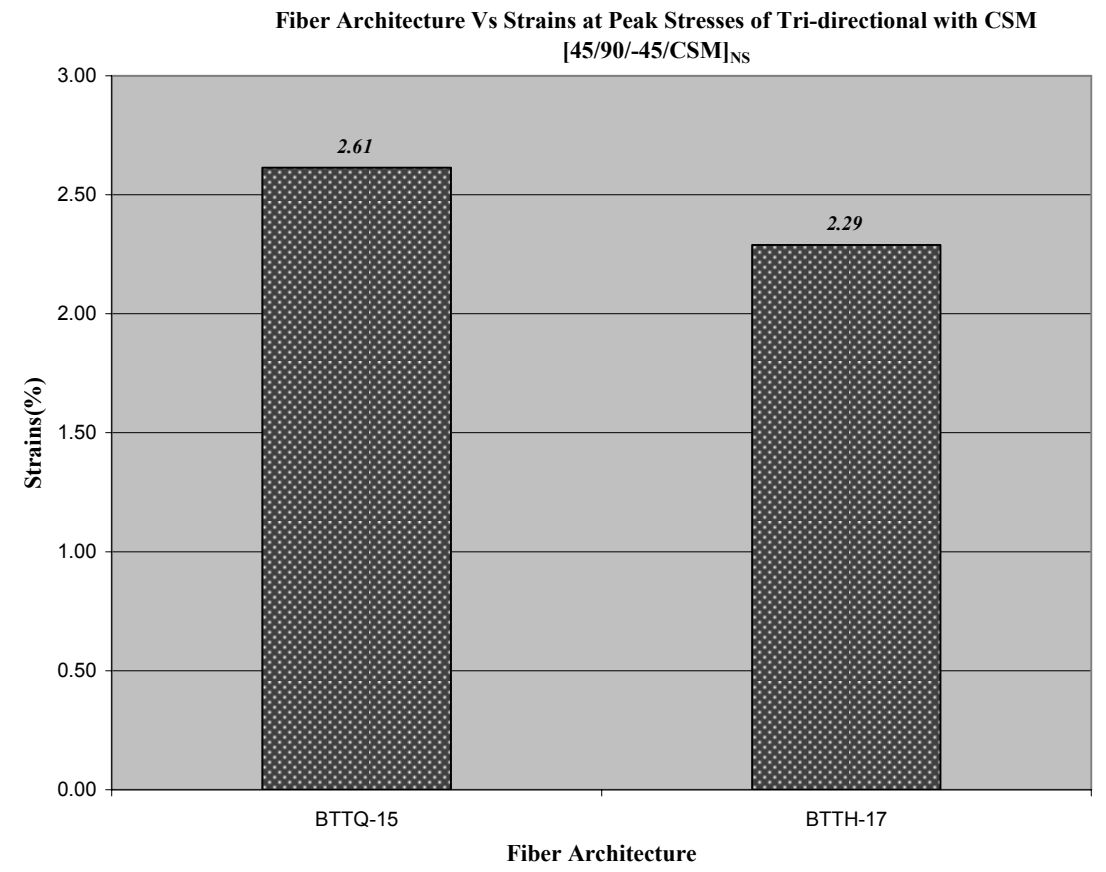

Figure 5.125 Fiber Architecture Vs Strains at Ultimate Stress of Tri-directional composites with CSM in transverse direction under bending 


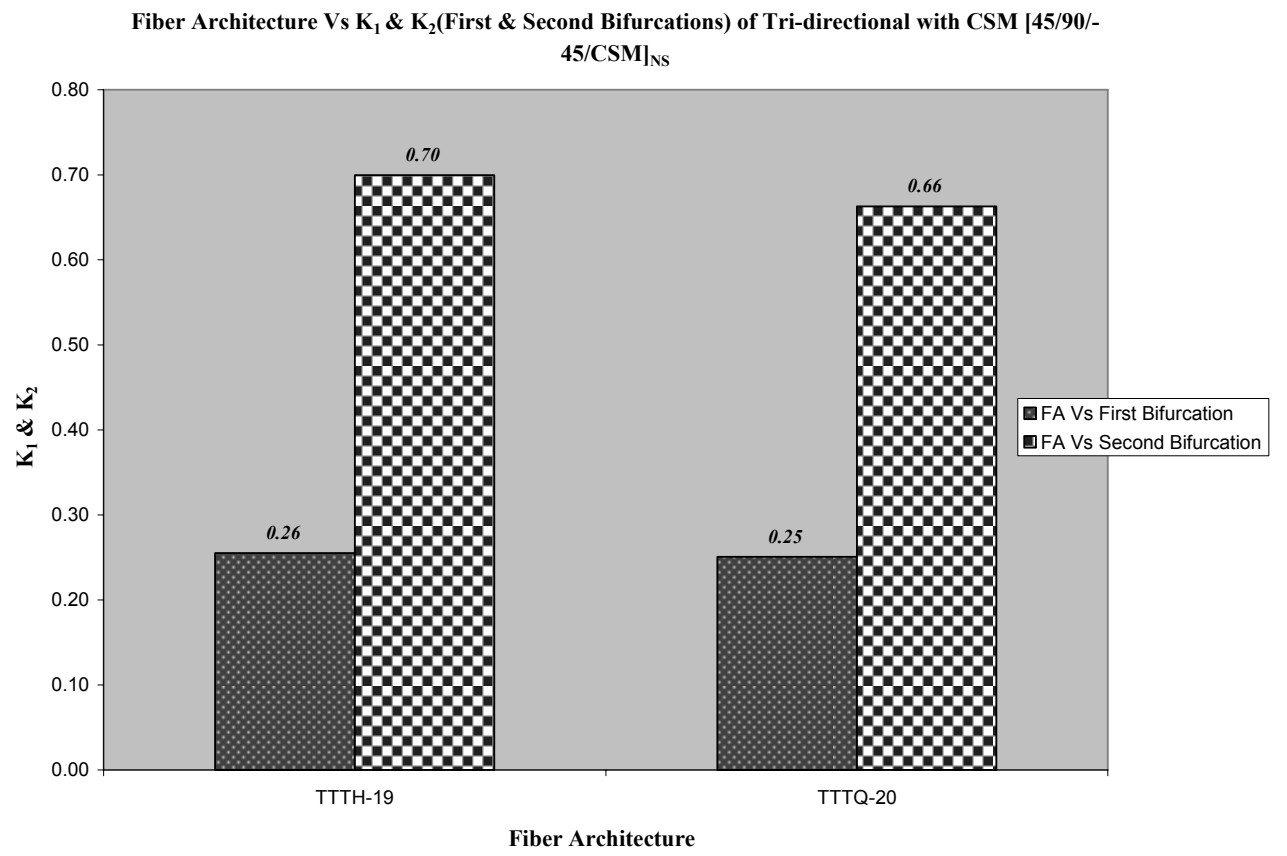

Figure 5.126 Fiber Architecture Vs Points where change of slope occurred $\left(\mathrm{K}_{1}\right.$ and $\left.\mathrm{K}_{2}\right)$ Strains at Ultimate Stress of Tri-directional composites with CSM in transverse direction under tension

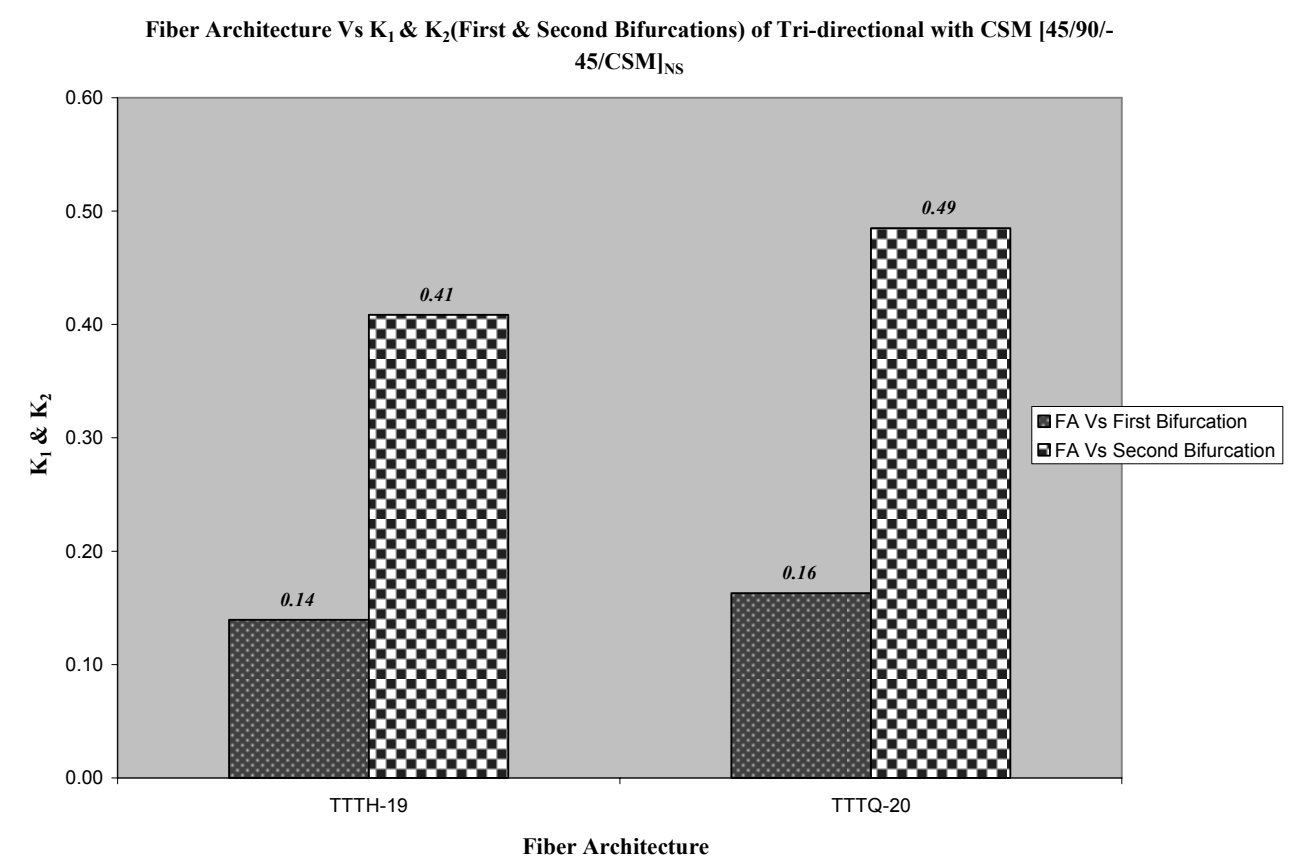

Figure 5.127 Fiber Architecture Vs Points where change of slope occurred points (K1 and K2) Strains at Ultimate Stress of Tri-directional composites with CSM in transverse direction under bending 
Fiber Architecture Vs Normalized Strains at Peak Stress of Tri-directional with CSM $[45 / 90-45 / C S M]_{N s}$

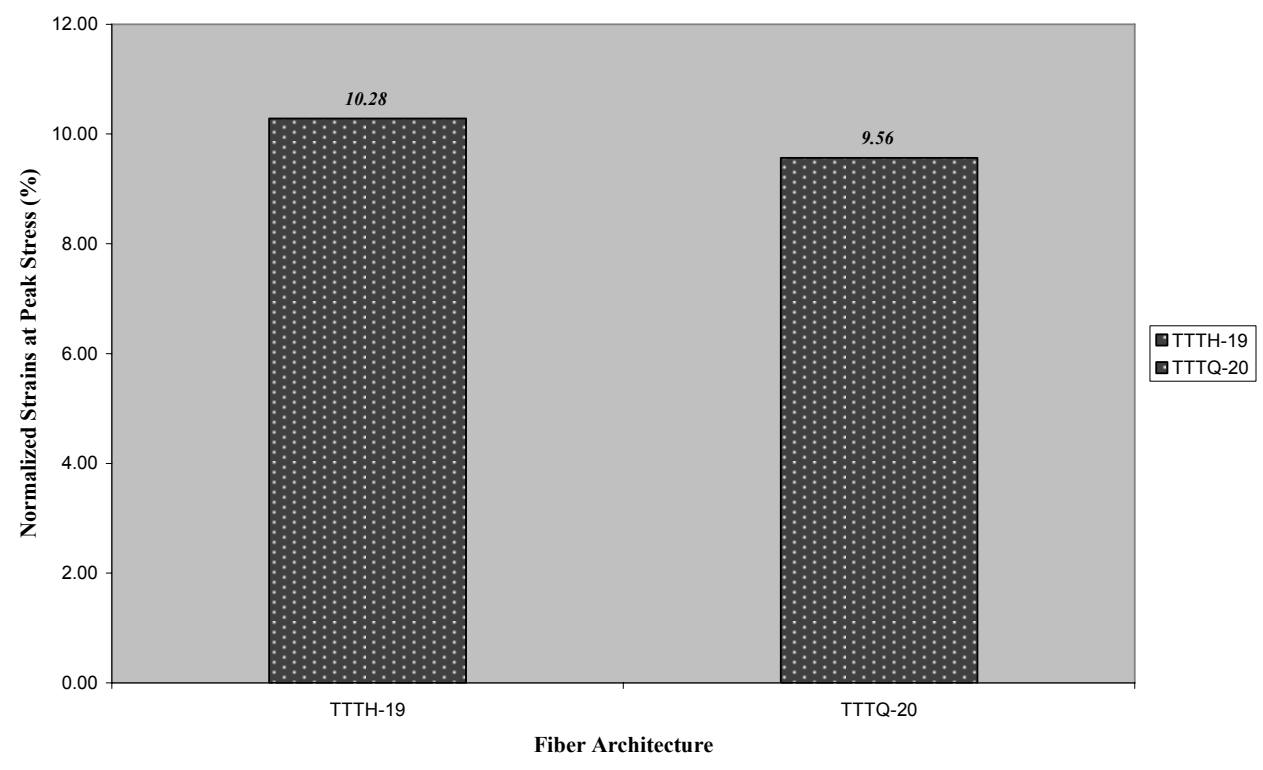

Figure 5.128 Fiber Architecture Vs Specific Strains per Equivalent FVF at Ultimate Stress of Tri-directional composites with CSM in transverse direction under tension

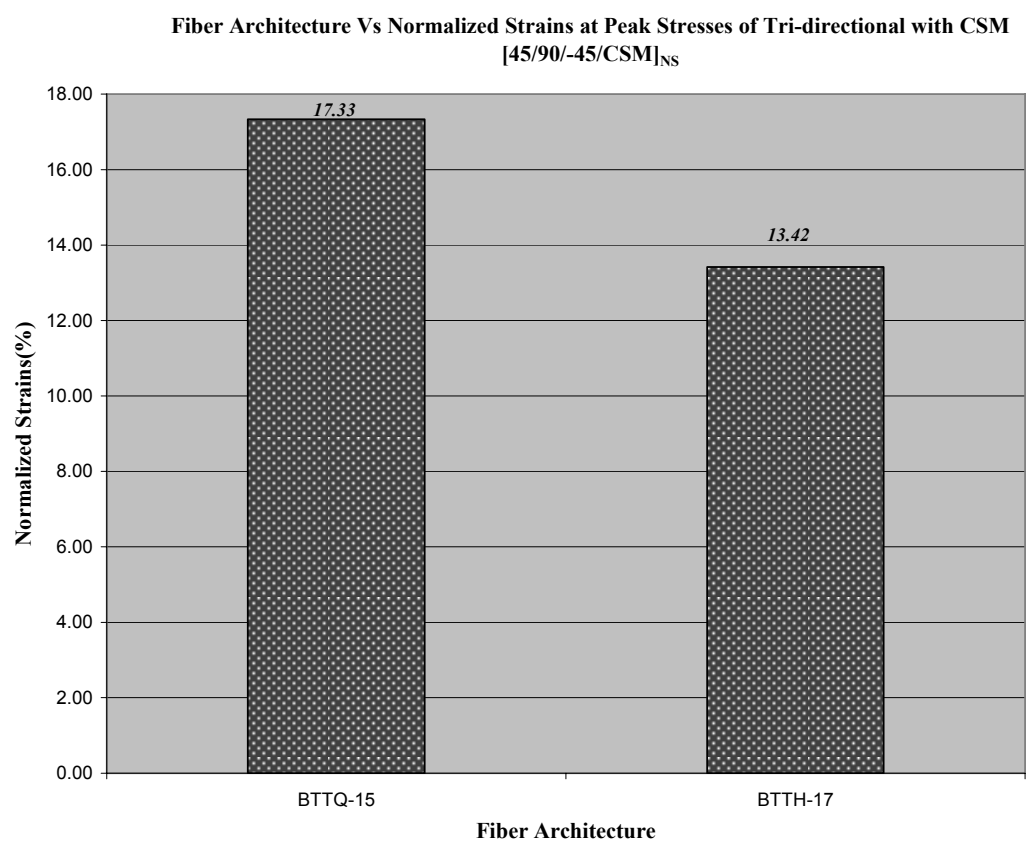

Figure 5.129 Fiber Architecture Vs Specific Strains per Equivalent FVF at Ultimate Stress of Tri-directional composites with CSM in transverse direction under bending 


\section{CHAPTER 6}

\section{STRAIN ENERGY BASED FAILURE CRITERIA}

\subsection{INTRODUCTION}

Failure testing of composite specimens under complex load states is expensive and time consuming, hence, the concept of failure criteria is developed herein for predicting failure strength. The developed theory is based on experimental data obtained from uni-axial tension testing, and bending. Some of the current criteria dealt with mechanics based, and others with strain-energy based approaches.

In the present study, five different polymer composites with E-glass fabrics (unidirectional, bi-directional, tri-directional with CSM, and quadric-directional with and without CSM), and vinyl ester resin were fabricated using compression molding process were tested under tension and bending. A strength failure prediction model is introduced with strain energy as damage metric, using strain at ultimate stress of GFRP composites at coupon level.

\subsection{STRAIN ENERGY}

Strain energy is one of the fundamental concepts in structural mechanics, where its principles are being widely used in practical applications to determine the response of a structure under various loading conditions. It is defined as the energy stored within a material, when deformed under load. Strain energy stored in a bar is equal to the work done on the bar under external loads and in the absence of energy losses, such as friction, damping or heat transfer, etc.

Strain energy density is considered as the indicative of material as it is the total strain energy per unit volume thus avoiding the dimensions of the material. Hence, in test cases, where load-deflection is considered, corresponding stress-strain curves are used to calculate the strain energy density of the curve. 


\subsubsection{Axial Strain Energy}

Axial strain energy of a prismatic bar under linear stress - strain curve is given by:

$$
U_{T}=\frac{P^{2} L}{2 A E}
$$

where,

$\mathrm{P}=$ applied load (lbs)

$\mathrm{L}=$ the gage length (in)

$\mathrm{A}=$ Area of the specimen $=\mathrm{bd}\left(\mathrm{in}^{2}\right)$

$\mathrm{b}=$ Width of the specimen (in)

$\mathrm{d}=$ Thickness of the specimen (in)

$\mathrm{E}=$ Elastic modulus (psi)

\subsubsection{Bending Strain Energy}

Bending strain energy of a prismatic bar under linear stress - strain distribution is given by:

$$
U_{B}=\int_{0}^{L} \frac{M^{2} d x}{2 E I}
$$

where,

$\mathrm{M}=\mathrm{PL} / 6$ (Four-Point Bending with Load-Span ratio of L/3)

$\mathrm{P}=$ applied load (lbs)

$\mathrm{L}=$ the span length (in)

$\mathrm{I}=$ Moment of Inertia of the specimen $=\mathrm{bd}^{3} / 12\left(\mathrm{in}^{4}\right)$

\subsubsection{Principle of Energy Invariance}

In fiber reinforced polymer composites, strain energy resisted by the material is the expended work done by the material when load is applied causing distress within to 
the material. As the loading increases, the internal makeup such as bonding, stress concentration, stiffness variation, etc., varies; hence leads to distress and damage, with mechanisms such as matrix micro-cracking, matrix micro-cracking, delamination, local bending and buckling, and eventual fiber breakage. Matrix distress initiation and damage (delamination) initiation, its growth, accumulation and propagation including debonding or pull-out are considered progressive, leading from by one mechanism (as mentioned above) leading to another.

The energy resisted by the composite material, due to progressive distress and damage, is primarily found to be a function of: 1) strain at different load levels including ultimate stress 2) induced stress type and rate, and 3) mechanical properties of the composite material. The mechanical properties depend on manufacturing process, constituent material types, voids, curing rate, fiber volume fraction, and others.

\subsection{EXPERIMENTAL ANALYSIS}

Stress-strain plots (Figure 6.1) of different fiber architectures revealed that fiber orientation plays a vital role in their non-linear behavior. For example, unidirectional composites (Figure 6.2) are found to be nearly linear up to their ultimate stresses, implying that stress is almost linear with respect to strain, in both the longitudinal and transverse directions under tension or bending. Unidirectional composites are tested for comparison purposes with fabric based composites. However, the strain energy computations for unidirectional composites are not considered for comparison with fabric based composites because of inconsistent stress-strain responses. In some test specimens, strains at ultimate stresses were not recorded due to delamination of outer layers leading to strain gage failure prior reaching ultimate stress (see Chapter 5, Section 5.2.1.1). 


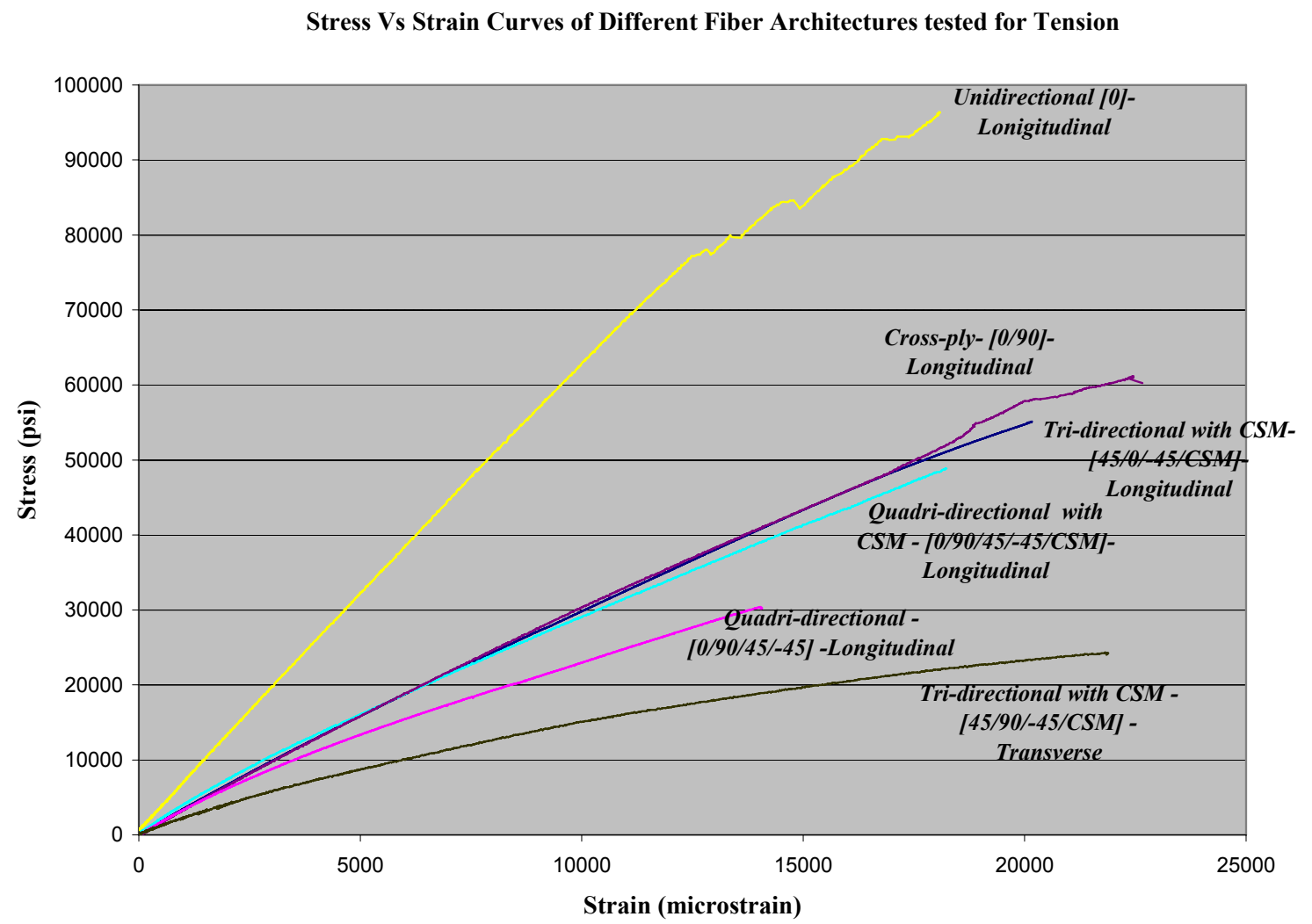

Figure 6.1 Stress-Strain plot of various fiber architectures considered for the study

Stress-strain curves for all other fiber architectures tested under bending or tension in the longitudinal direction are found to have two nearly linear curves up to around $90 \%$ of ultimate stress (Figures 6.3 to 6.6), except for tri-directional composites with CSM which are tested in transverse direction. The tri-directional coupons with CSM exhibited three linear curves (Figure 6.7) up to around 90\% ultimate load under bending as well as tension. In most of the cases, the linearity was observed between $90 \%$ of ultimate load and the ultimate load, while in some cases, non-linearity beyond $90 \%$ ultimate load was observed. 


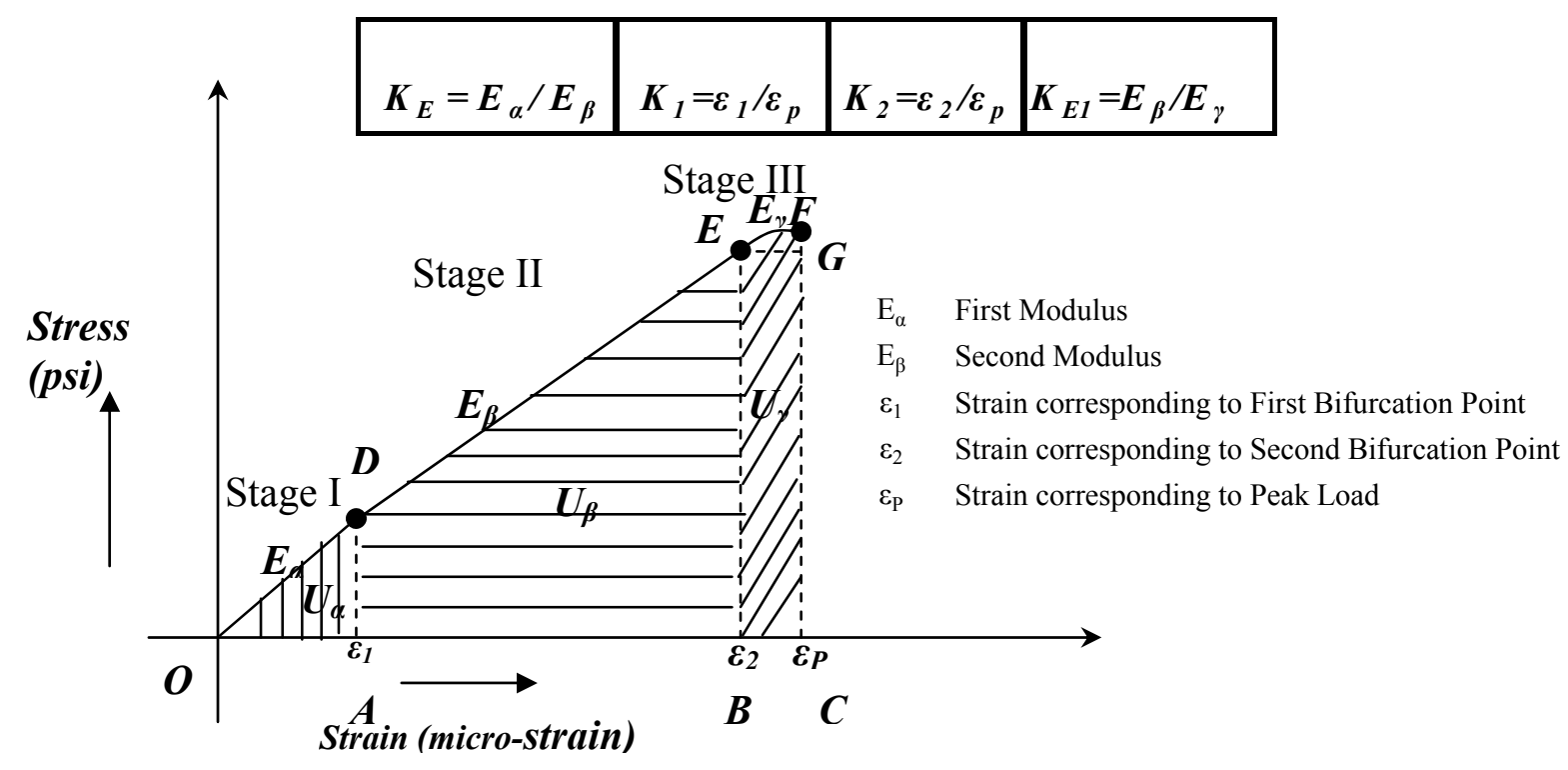

Figure 6.2 Typical Stress-Strain Curve of Multi-directional Fabric based Composites

Typical stress-strain plots of multi-directional fabric based composite considered in this study for the development of theoretical model is shown in Figure 6.2. The locations where change of slope occurs are identified by the ratios of strain at that particular point to the strain at ultimate stress. Since there are two or more points, the first point represented as $\mathrm{K}_{1} \varepsilon_{\mathrm{p}}$, second point represented as $\mathrm{K}_{2} \varepsilon_{\mathrm{p}}$, and so on. The first point $\left(\varepsilon_{1}\right.$ $\left.=\mathrm{K}_{1} \varepsilon_{\mathrm{p}}\right)$ is hypothesized to be due to matrix micro-cracking. The last point $\left(\varepsilon_{3}=\mathrm{K}_{3} \varepsilon_{\mathrm{p}}\right.$ in case of tri-directional composite with CSM tested in transverse direction, or $\varepsilon_{2}=\mathrm{K}_{2} \varepsilon_{\mathrm{p}}$ in case of all other fiber architectures) corresponding to ultimate stress and results in delamination/fiber breakage. The intermediate points (For example, $\varepsilon_{2}=\mathrm{K}_{2} \varepsilon_{\mathrm{p}}$ in case tridirectional composite with CSM tested in transverse direction) are attributed to further distress causing matrix micro-cracking and matrix micro-cracking. Soon after matrix micro-cracking, micro crack growth starts to take place and leads to inter-connections of micro-cracks. In addition, the ratios of first modulus and second modulus $\left(\mathrm{E}_{\alpha} / \mathrm{E}_{\beta}\right)$, second and third $\left(\mathrm{E}_{\beta} / \mathrm{E}_{\gamma}\right)$, and so forth, are represented as $\mathrm{K}_{\mathrm{E} 1}, \mathrm{~K}_{\mathrm{E} 2}, \mathrm{~K}_{\mathrm{E} 3}$, and so on, respectively. All the $\mathrm{K}$ values for different fiber architectures are tabulated at required points in Table 6.3 and Table $6.4 \mathrm{~K}$ values for Tri-directional composite with CSM tested in transverse direction. The first point at which the linear fit is tangent to the stress-strain curve is identified as the end of Stage I. Stage II is defined up to the second point where the linear 
fit is tangent from the point where Stage I ends, and the non-linear portion is regarded as the last stage, which represents the last $10 \%$ of ultimate load.

Unidirectional $[0]_{19 S}$ Longitudinal Directional

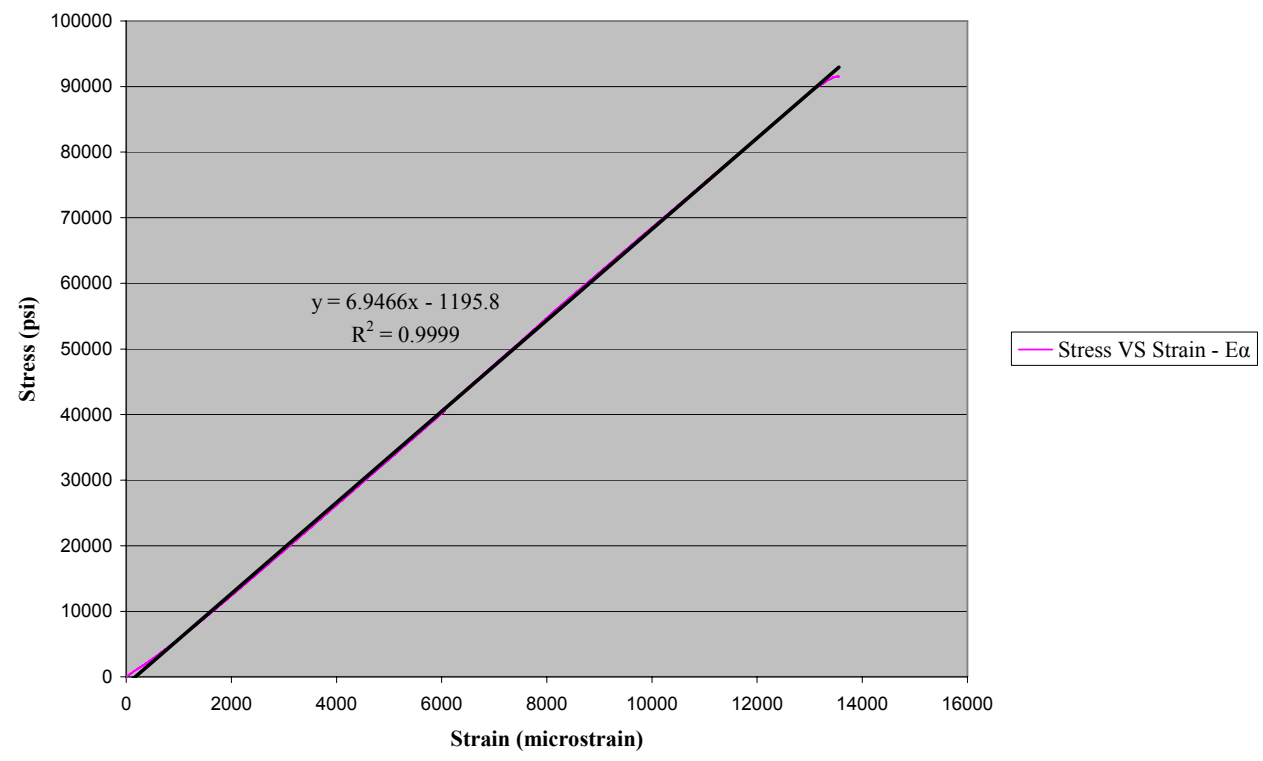

Figure 6.3 Stress-Strain plot of Unidirectional laminated Composite

Cross-ply Laminates $[0 / 90]_{28 \mathrm{~S}} \mathrm{L3}$

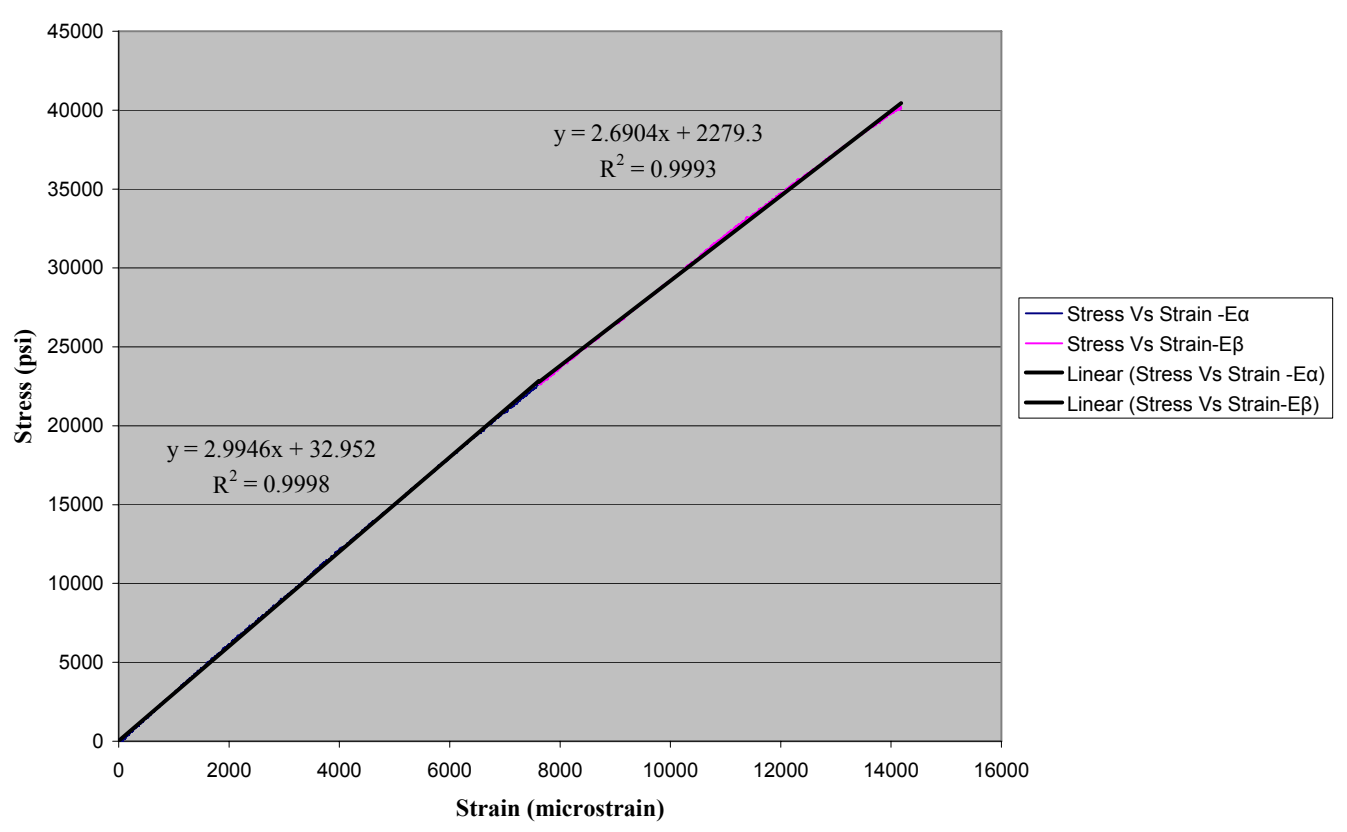

Figure 6.4 Stress-Strain plot of Cross-ply laminated Composite 
Tri-directional with CSM Laminates $[45 / 0 /-45 / C S M]_{4 S} \mathrm{L1}$

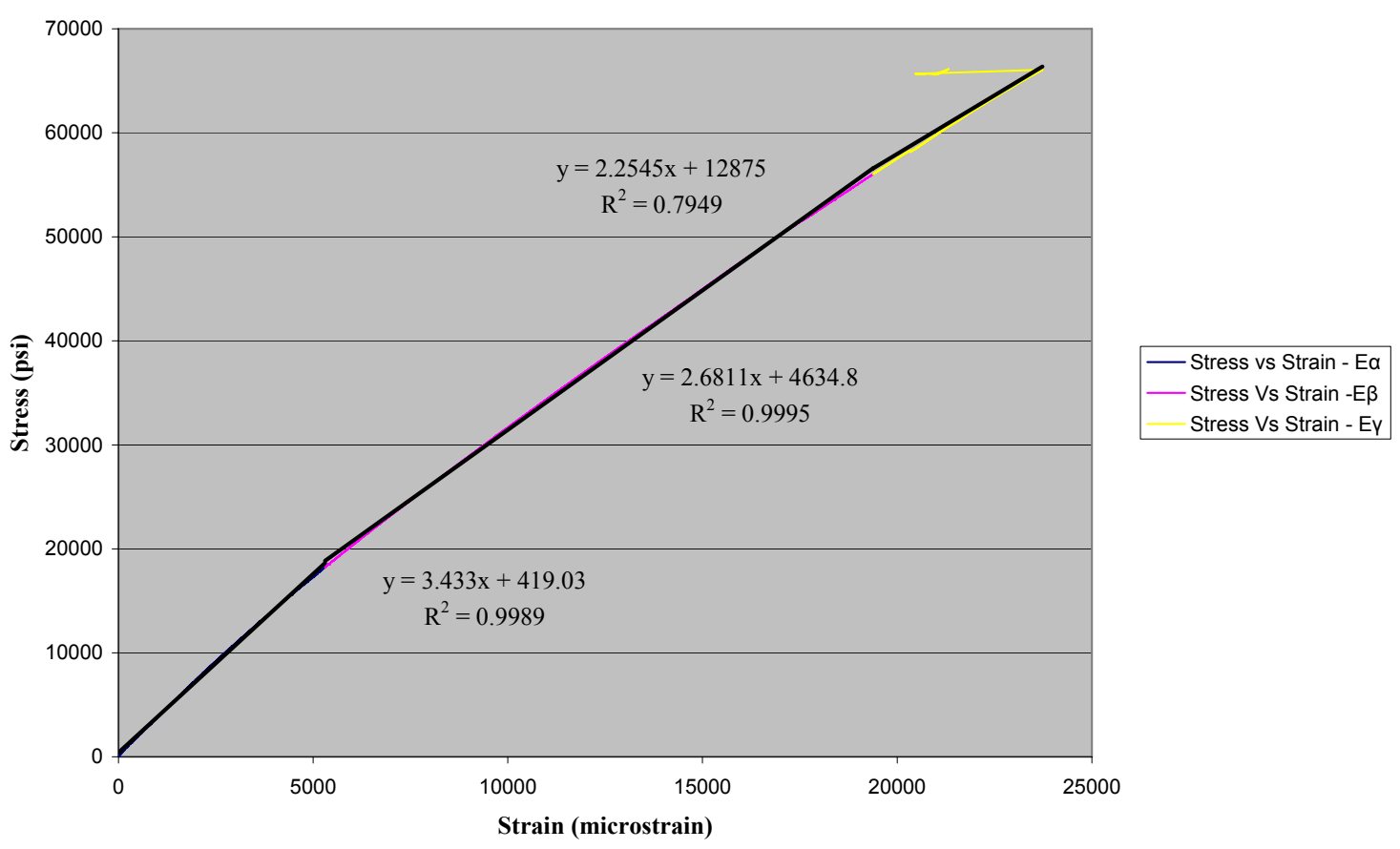

Figure 6.5 Stress-Strain plot of Tri-directional Composite with CSM

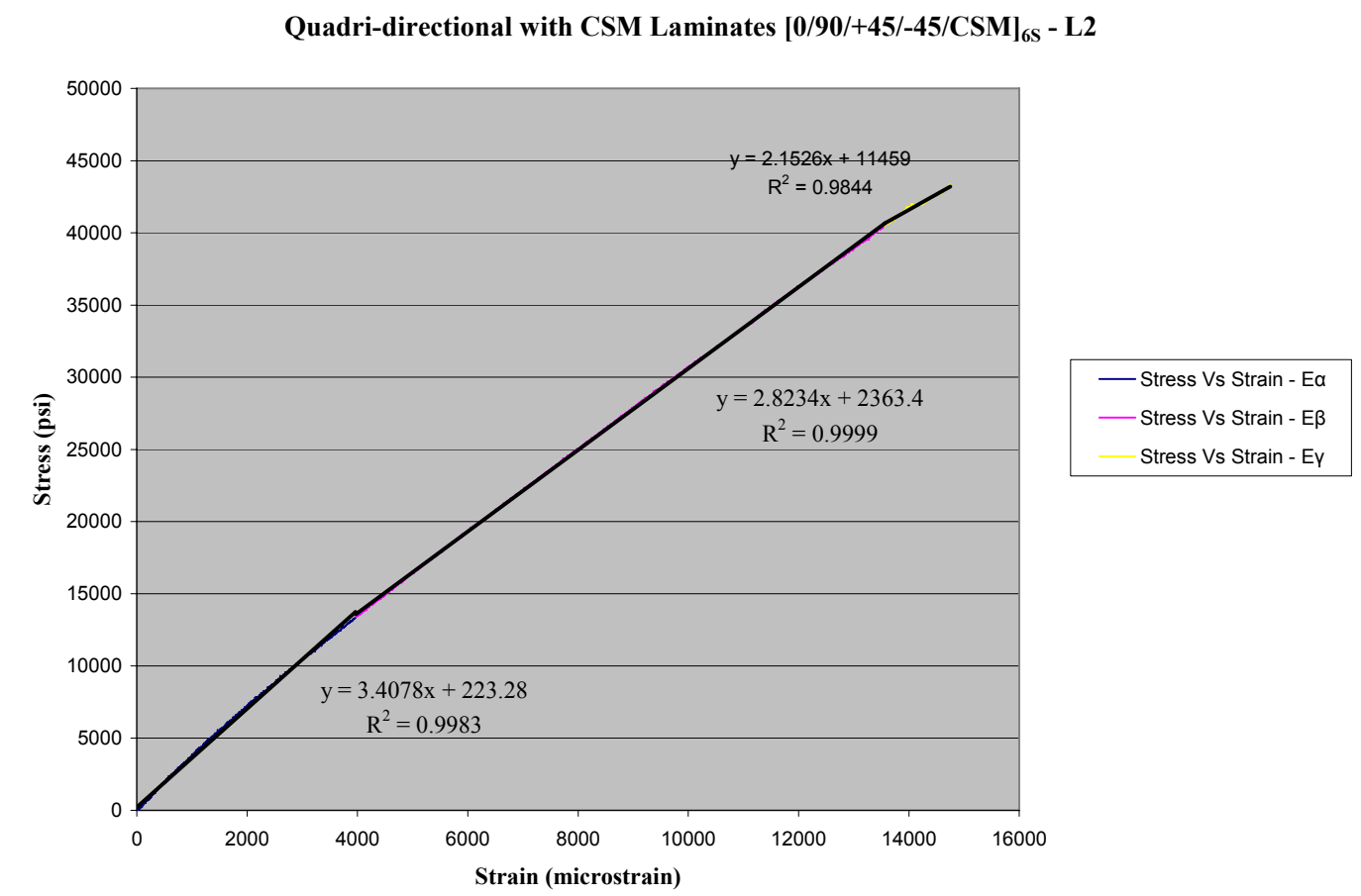

Figure 6.6 Stress-Strain plot of Quadri-directional Composite with CSM 
Quadri-directional without CSM Laminates $[0 / 90+45 /-45]_{4 S} \mathrm{L1}$

(fabricated using 10 layers of [0/90] Cross-plies)

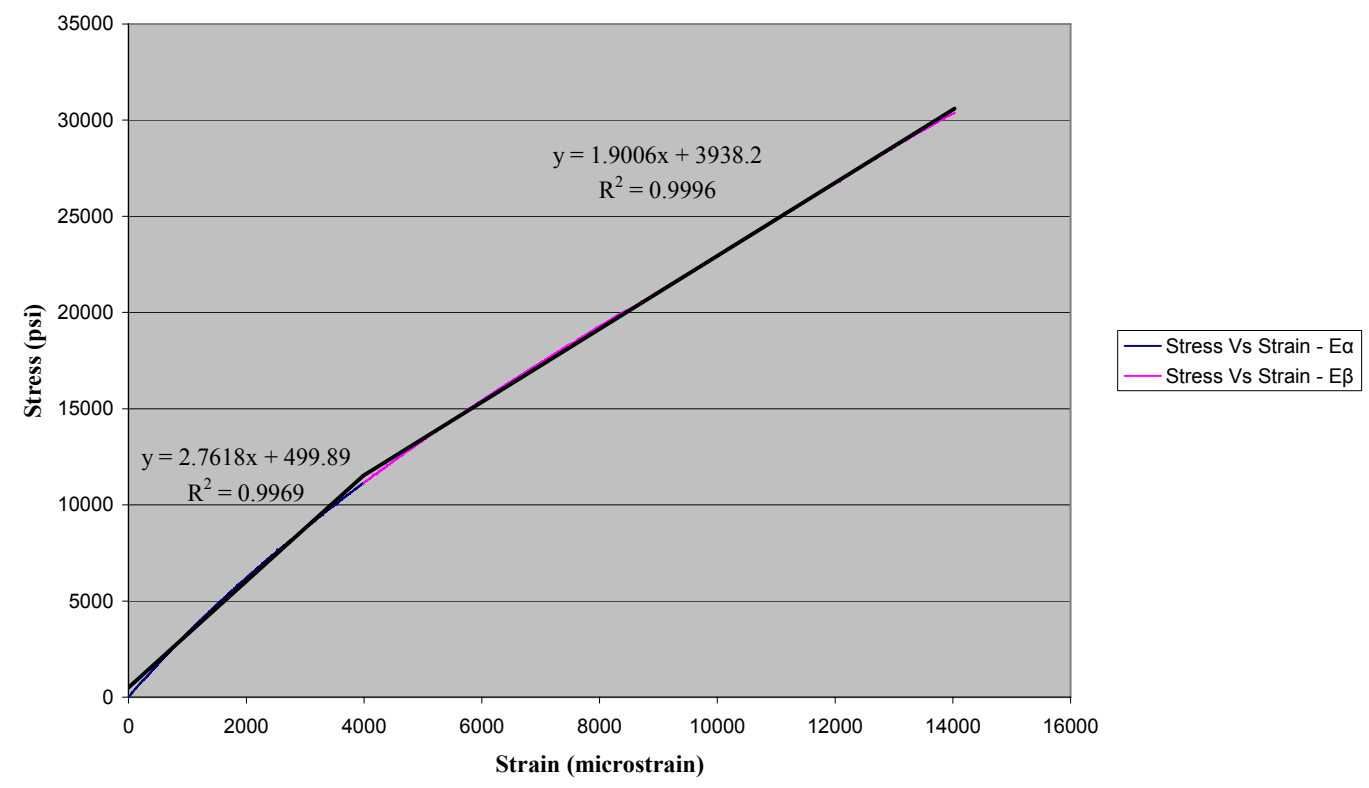

Figure 6.7 Stress-Strain plot of Quadri-directional composite without CSM

Tri-directional with CSM Laminates $[45 / 90 /-45 / C S M]_{10 S} \mathrm{L3}$

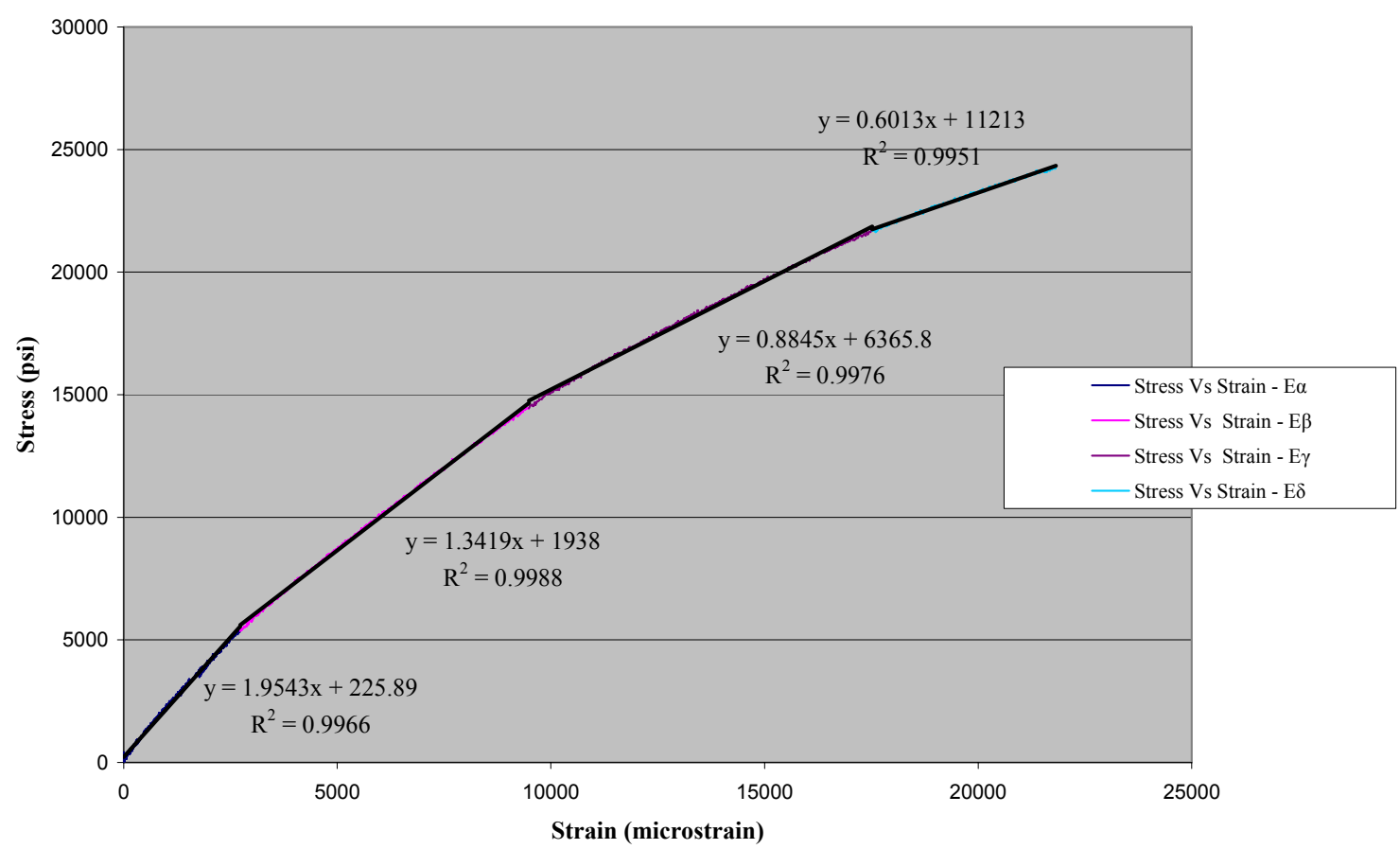

Figure 6.8 Stress-Strain plot of Tri-directional Composite with CSM 


\subsubsection{Strain energy density}

Strain energy per unit volume was obtained by calculating areas under the stressstrain curve generated from bending or tension testing (Chapter 4, Sections 4.3.1.3 and 4.3.2.2). In case of specimens with load-deflection curves, corresponding stress-strain curves are plotted and the areas under the stress-strain curves are calculated. The energy of the specimens at different stages is determined and tabulated in Table 6.1. Summation of energy at each stage multiplied with the corresponding modulus is also calculated and tabulated in a separate column. 
Table 6.1 Strain energy density of composites with different fiber architecture at different stages

\begin{tabular}{|c|c|c|c|c|c|c|c|c|}
\hline Material ID & Fiber Architecture & $\begin{array}{c}\text { Area- } \\
\text { Fi-Bi }\end{array}$ & $\begin{array}{c}\text { Area- } \\
\text { S-Bi } \\
\end{array}$ & $\begin{array}{c}\text { Area- } \\
\text { T-Bi } \\
\end{array}$ & $U_{\alpha} E_{\alpha}$ & $U_{\beta} E_{\beta}$ & $\boldsymbol{U}_{\mathrm{Y}} \boldsymbol{E}_{\mathrm{V}}$ & $\Sigma U_{i} E_{i}$ \\
\hline \multicolumn{9}{|l|}{ Bending } \\
\hline Cross-ply & {$[0 / 90]_{22 \mathrm{~S}}$} & 86.65 & 482.61 & & 326.31 & 1597.30 & & 1923.61 \\
\hline Cross-ply & {$[90 / 0]_{20 \mathrm{~S}}$} & 77.16 & 362.00 & 95.66 & 251.26 & 1023.12 & 207.98 & 1482.36 \\
\hline Quadri-directional with CSM & {$[0 / 90 /+45 /-45 / \mathrm{CSM}]_{10 \mathrm{~S}}$} & 44.18 & 261.97 & 64.94 & 176.37 & 868.71 & 165.64 & 1210.72 \\
\hline Quadri-directional with CSM & {$[0 / 90 /+45 /-45 / \mathrm{CSM}]_{4 \mathrm{~S}}$} & 96.15 & 342.24 & 72.42 & 382.49 & 1160.32 & 188.88 & 1731.70 \\
\hline Quadri-directional & {$[0 / 90 /+45 /-45]_{16 \mathrm{~S}}$} & 59.22 & 225.24 & 77.81 & 204.71 & 634.94 & 168.71 & 1008.36 \\
\hline Quadri-directional with CSM & {$[90 / 0 /+45 /-45 / \mathrm{CSM}]_{4 \mathrm{~S}}$} & 43.41 & 260.11 & & 133.90 & 694.69 & & 828.59 \\
\hline Quadri-directional & {$[0 / 90 /+45 /-45]_{4 \mathrm{~S}}$} & 64.13 & 260.44 & 26.09 & 202.38 & 650.89 & 50.15 & 903.41 \\
\hline Quadri-directional & {$[90 / 0 /+45 /-45]_{4 \mathrm{~S}}$} & 71.03 & 248.64 & 81.80 & 207.33 & 554.42 & 140.31 & 902.05 \\
\hline Tri-directional with CSM & {$[45 / 0 /-45 / \mathrm{CSM}]_{4 \mathrm{~S}}$} & 72.52 & 418.81 & 105.89 & 258.83 & 1275.98 & 248.16 & 1782.97 \\
\hline \multicolumn{9}{|l|}{ Tension } \\
\hline Cross-ply & {$[0 / 90]_{28 \mathrm{~S}}$} & 46.63 & 500.08 & 151.31 & 145.81 & 1363.17 & 320.77 & 1829.76 \\
\hline Cross-ply & {$[0 / 90]_{18 \mathrm{~S}}$} & 55.06 & 410.20 & 217.41 & 168.87 & 1025.78 & 420.52 & 1615.16 \\
\hline Quadri-directional with CSM & {$[0 / 90 /+45 /-45 / \mathrm{CSM}]_{10 \mathrm{~S}}$} & 43.05 & 328.31 & 113.58 & 139.86 & 838.34 & 225.41 & 1203.60 \\
\hline Quadri-directional with CSM & {$[0 / 90 /+45 /-45 / \mathrm{CSM}]_{4 \mathrm{~S}}$} & 42.10 & 296.99 & 63.94 & 128.94 & 723.59 & 120.01 & 972.54 \\
\hline Quadri-directional with CSM & {$[90 / 0 /+45 /-45 / \mathrm{CSM}]_{4 \mathrm{~S}}$} & 43.29 & 464.37 & 228.86 & 111.99 & 910.27 & 343.29 & 1365.55 \\
\hline Tri-directional with CSM & {$[45 / 0 /-45 / \mathrm{CSM}]_{4 \mathrm{~S}}$} & 64.48 & 438.39 & 101.59 & 209.34 & 1176.96 & 209.95 & 1596.25 \\
\hline Quadri-directional & {$[0 / 90 /+45 /-45]_{4 \mathrm{~S}}$} & 25.06 & 201.66 & & 72.55 & 415.81 & & 488.36 \\
\hline Quadri-directional & {$[90 / 0 /+45 /-45]_{4 \mathrm{~S}}$} & 44.75 & 317.16 & 154.63 & 122.86 & 605.95 & 200.89 & 929.70 \\
\hline
\end{tabular}

Table 6.2 Strain energy density of tri-directional composites with CSM tested in transverse direction at different stages

\begin{tabular}{|c|c|c|c|c|c|c|c|c|c|c|c|}
\hline Material ID & $\begin{array}{c}\text { Fiber } \\
\text { Architecture }\end{array}$ & Direction & $\begin{array}{c}\text { Area- } \\
\text { Fi-Bi }\end{array}$ & $\begin{array}{c}\text { Area- } \\
S-B i\end{array}$ & $\begin{array}{c}\text { Area- } \\
T-B i\end{array}$ & $\begin{array}{l}\text { Area- } \\
\text { Fo-Bi }\end{array}$ & $U_{\alpha} E_{\alpha}$ & $U_{\beta} E_{\beta}$ & $U_{\mathrm{Y}} E_{\mathrm{Y}}$ & $U_{\delta} E_{\delta}$ & $\boldsymbol{\Sigma} U_{i} E_{i}$ \\
\hline Tri-directional with CSM & $\begin{array}{c}{[45 / 90 /-} \\
45 / \mathrm{CSM}]_{10 \mathrm{~s}}\end{array}$ & Transverse & 18.03 & 73.42 & 128.35 & 43.76 & 39.29 & 102.79 & 119.37 & 12.21 & 273.67 \\
\hline Tri-directional with CSM & $\begin{array}{c}{[45 / 90 /-} \\
45 / \mathrm{CSM}]_{6 \mathrm{~S}}\end{array}$ & Transverse & 21.51 & 85.86 & 119.54 & 36.77 & 43.96 & 112.39 & 102.85 & 9.49 & 268.68 \\
\hline
\end{tabular}


Table $6.3 \mathrm{~K}$ values for different fiber architectures

\begin{tabular}{|c|c|c|c|c|c|}
\hline Material ID & Fiber Architecture & Direction & $\begin{array}{c}\boldsymbol{K}_{E}=\boldsymbol{E}_{\alpha} / \\
\boldsymbol{E}_{\beta}\end{array}$ & $K_{1}=\varepsilon_{1} / \varepsilon_{2}$ & $\begin{array}{l}K_{2}= \\
\varepsilon_{2} / \varepsilon_{\mathrm{p}}\end{array}$ \\
\hline \multicolumn{6}{|l|}{ Bending } \\
\hline Cross-ply & {$[0 / 90]_{22 \mathrm{~S}}$} & Longitudinal & 1.14 & 0.38 & 0.93 \\
\hline Cross-ply & {$[90 / 0]_{20 \mathrm{~S}}$} & Transverse & 1.15 & 0.39 & 0.92 \\
\hline Quadri-directional & {$[0 / 90 /+45 /-45]_{16 \mathrm{~S}}$} & Longitudinal & 1.23 & 0.34 & 0.88 \\
\hline Quadri-directional & {$[0 / 90 /+45 /-45]_{4 \mathrm{~S}}$} & Longitudinal & 1.26 & 0.41 & 0.86 \\
\hline Quadri-directional & {$[0 / 90 /+45 /-45]_{4 \mathrm{~S}}$} & Transverse & 1.31 & 0.41 & 0.87 \\
\hline Quadri-directional with CSM & {$[0 / 90 /+45 /-45 / \mathrm{CSM}]_{10 \mathrm{~S}}$} & Longitudinal & 1.20 & 0.28 & 0.86 \\
\hline Quadri-directional with CSM & {$[0 / 90 /+45 /-45 / \mathrm{CSM}]_{4 \mathrm{~S}}$} & Longitudinal & 1.17 & 0.27 & 0.87 \\
\hline Quadri-directional with CSM & {$[90 / 0 /+45 /-45 / \mathrm{CSM}]_{4 \mathrm{~S}}$} & Transverse & 1.17 & 0.27 & 0.86 \\
\hline \multirow[t]{3}{*}{ Tri-directional with CSM } & {$[45 / 0 /-45 / \mathrm{CSM}]_{4 \mathrm{~S}}$} & Longitudinal & 1.17 & 0.33 & 0.84 \\
\hline & & AVG & 1.20 & 0.34 & 0.88 \\
\hline & & STDEV & 0.05 & 0.06 & 0.03 \\
\hline \multicolumn{6}{|l|}{ Tension } \\
\hline Cross-ply & {$[0 / 90]_{28 \mathrm{~S}}$} & Longitudinal & 1.16 & 0.24 & 0.87 \\
\hline Cross-ply & {$[0 / 90]_{18 \mathrm{~S}}$} & Longitudinal & 1.23 & 0.26 & 0.84 \\
\hline Quadri-directional with CSM & {$[0 / 90 /+45 /-45 / \mathrm{CSM}]_{10 \mathrm{~S}}$} & Longitudinal & 1.26 & 0.31 & 0.89 \\
\hline Quadri-directional with CSM & {$[0 / 90 /+45 /-45 / \mathrm{CSM}]_{4 \mathrm{~S}}$} & Longitudinal & 1.26 & 0.30 & 0.89 \\
\hline Quadri-directional with CSM & {$[90 / 0 /+45 /-45 / \mathrm{CSM}]_{4 \mathrm{~S}}$} & Transverse & 1.33 & 0.26 & 0.82 \\
\hline Tri-directional with CSM & {$[45 / 0 /-45 / \mathrm{CSM}]_{4 \mathrm{~S}}$} & Longitudinal & 1.20 & 0.23 & 0.89 \\
\hline Quadri-directional & {$[0 / 90 /+45 /-45]_{4 \mathrm{~S}}$} & Longitudinal & 1.39 & 0.30 & 0.88 \\
\hline \multirow[t]{3}{*}{ Quadri-directional } & {$[90 / 0 /+45 /-45]_{4 \mathrm{~S}}$} & Transverse & 1.36 & 0.30 & 0.88 \\
\hline & & AVG & 1.27 & 0.28 & 0.87 \\
\hline & & STDEV & 0.08 & 0.03 & 0.02 \\
\hline
\end{tabular}


Table 6.4 K values for Tri-directional composite with CSM tested in transverse direction

\begin{tabular}{|c|c|c|c|c|c|c|c|}
\hline Material ID & Fiber Architecture & Direction & $\begin{array}{c}K_{E 1}= \\
E_{d} \\
E_{\beta}\end{array}$ & $\begin{array}{l}\boldsymbol{K}_{E 2}= \\
\boldsymbol{E}_{\boldsymbol{\beta}} / \boldsymbol{E}_{\gamma}\end{array}$ & $\begin{array}{c}K_{1}=\varepsilon_{1} \\
\quad \varepsilon_{2}\end{array}$ & $\begin{array}{l}K_{2}= \\
\varepsilon_{2} / \varepsilon_{3} \\
\end{array}$ & $\begin{array}{l}K_{3}= \\
\varepsilon_{3} / \varepsilon_{\mathrm{P}}\end{array}$ \\
\hline \multicolumn{8}{|l|}{ Bending } \\
\hline $\begin{array}{c}\text { Tri-directional with } \\
\text { CSM } \\
\text { Tri-directional with } \\
\text { CSM } \\
\end{array}$ & $\begin{array}{l}{[45 / 90 /-45 / \mathrm{CSM}]_{8 \mathrm{~S}}} \\
{[45 / 90 /-45 / \mathrm{CSM}]_{4 \mathrm{~S}}}\end{array}$ & $\begin{array}{l}\text { Transverse } \\
\text { Transverse }\end{array}$ & $\begin{array}{l}1.40 \\
1.42 \\
\end{array}$ & $\begin{array}{l}1.46 \\
1.47 \\
\end{array}$ & $\begin{array}{l}0.26 \\
0.25 \\
\end{array}$ & $\begin{array}{l}0.70 \\
0.66\end{array}$ & $\begin{array}{l}0.82 \\
0.80\end{array}$ \\
\hline & & $\begin{array}{c}\text { AVG } \\
\text { STDEV } \\
\end{array}$ & $\begin{array}{l}1.41 \\
0.01 \\
\end{array}$ & $\begin{array}{l}1.47 \\
0.01 \\
\end{array}$ & $\begin{array}{l}0.25 \\
0.00 \\
\end{array}$ & $\begin{array}{l}0.68 \\
0.03 \\
\end{array}$ & $\begin{array}{l}0.81 \\
0.02 \\
\end{array}$ \\
\hline Tension & & & & & & & \\
\hline $\begin{array}{l}\text { Tri-directional with } \\
\text { CSM } \\
\text { Tri-directional with } \\
\text { CSM }\end{array}$ & $\begin{array}{c}{[45 / 90 /-} \\
45 / \mathrm{CSM}]_{10 \mathrm{~S}} \\
{[45 / 90 /-45 / \mathrm{CSM}]_{6 \mathrm{~S}}}\end{array}$ & $\begin{array}{c}\text { Transverse } \\
\text { Transverse } \\
\text { AVG } \\
\text { STDEV }\end{array}$ & $\begin{array}{l}1.56 \\
\\
1.56 \\
1.56 \\
0.00 \\
\end{array}$ & $\begin{array}{l}1.52 \\
1.51 \\
0.01 \\
\end{array}$ & $\begin{array}{l}0.16 \\
0.15 \\
0.02\end{array}$ & $\begin{array}{l}0.49 \\
0.45 \\
0.05\end{array}$ & $\begin{array}{l}0.85 \\
0.84 \\
0.01 \\
\end{array}$ \\
\hline
\end{tabular}

\subsubsection{Experimental Observations}

From Table 6.3 and Table 6.4 it is clearly seen that the $\mathrm{K}$ values for all fiber architectures are in the same range with a standard deviation of less than $6 \%$. Thus the $\mathrm{K}$ values considered for theoretical development of failure strength are summarized in Table 6.5 Ratios of Longitudinal Moduli for all fabric based composites under tension and bending and Table 6.6 .

Table 6.5 Ratios of Longitudinal Moduli for all fabric based composites under tension and bending

\begin{tabular}{|c|c|c|}
\hline & $\boldsymbol{K}_{\boldsymbol{E}}=\boldsymbol{E}_{\boldsymbol{\alpha}} /$ & \\
& $\boldsymbol{E}_{\boldsymbol{\beta}}$ & $\boldsymbol{K}_{\boldsymbol{1}}=\boldsymbol{\varepsilon}_{\boldsymbol{1}} / \boldsymbol{\varepsilon}_{\boldsymbol{2}}$ \\
\hline Tension & 1.20 & 0.34 \\
\hline Bending & 1.27 & 0.28 \\
\hline
\end{tabular}


Table 6.6 Ratios of Longitudinal Moduli for tri-directional composites with CSM under tension and bending in transverse direction

\begin{tabular}{|c|c|c|c|c|}
\hline & $\boldsymbol{K}_{E}=\boldsymbol{E}_{\boldsymbol{\alpha}} /$ & $\boldsymbol{K}_{E \boldsymbol{I}}=\boldsymbol{E}_{\boldsymbol{\beta}} /$ & \\
$\boldsymbol{E}_{\boldsymbol{\beta}}$ & $\boldsymbol{E}_{\boldsymbol{\gamma}}$ & $\boldsymbol{K}_{\boldsymbol{1}}=\boldsymbol{\varepsilon}_{1} / \boldsymbol{\varepsilon}_{2}$ & $\boldsymbol{K}_{2}=\boldsymbol{\varepsilon}_{1} / \boldsymbol{\varepsilon}_{2}$ \\
\hline Tension & 1.41 & 1.47 & 0.25 & 0.68 \\
\hline Bending & 1.56 & 1.51 & 0.15 & 0.45 \\
\hline
\end{tabular}

\subsection{DEVELOPMENT OF FAILURE MODEL}

From the experimental observations (Sections 6.3.1, and 6.3.2) a strain energy density based failure theory is proposed to predict the failure strength, stresses at different damage stages and their corresponding strains. The proposed failure theory is based on a number of assumptions for simplicity in computations without any loss of accuracy. These assumptions are given in Section 6.4.1 before developing the theoretical model as described and brief comparisons in Section6.4.2.

\subsubsection{Assumptions}

The tensile and bending responses of GFRP (glass fiber reinforced polymer) composites of different fiber architectures in respect to the longitudinal and transverse directions are formulated with a strain energy density based model, by invoking the following assumptions and constraints:

1. Residual strain (i.e., strain induced during manufacture) is neglected because of small magnitudes. (Schapery, et al., 1988)

2. The percent void content in GFRP coupon specimens manufactured using compression molding process is found to be less than 1\% (SEM image of the specimen taken at CFC-laboratory).

3. The basic concept of the proposed theory is based on logical progression of mechanisms of distress and damage (matrix micro-cracking zone, micro cracking in matrix leading to inter-connection of cracks and delamination) as observed from the experimental data, which are a) matrix micro-cracking due to stress 
concentration of fibers from different direction meeting at a point, b) matrix micro-cracking, c) inter-connection of micro cracks leading to larger cracks and eventual delamination, and d) fiber pull out or fiber breakage under bending or shear induced forces leading to specimen breakage.

4. Change in initial stiffness of a coupon due to fiber kinking caused by initial fiber misalignment is neglected.

5. Strain energy density based model is developed based on uni-axial stress only i.e., neglecting bi-axial effects ad influence of anisotropic properties.

6. Fibers oriented in directions other than the loading direction contribute to stiffening of fibers in loading direction.

7. Non-linear response in the stress-strain curves, (between 0 and $\varepsilon_{1}, \varepsilon_{1}$ and $\varepsilon_{2}$, or $\varepsilon_{2}$ and $\varepsilon_{\mathrm{p}}$.), is idealized as bi or tri linear response between 0 and $\varepsilon_{0.9 \mathrm{p}}$, and only $\varepsilon_{0.9 \mathrm{P}}$ to $\varepsilon_{\mathrm{P}}$.

8. The model is based on strain energy density approach with only 3 or 4 points where changes in slope were observed in the stress-strain curves without accounting for bending-coupling effects. Piecewise linear function is considered for first two or three stages, while representation between $\varepsilon_{0.9 \mathrm{P}}$ and $\varepsilon_{\mathrm{P}}$ may be a quadratic, or cubic function.

\section{Theoretical modulus}

In this study, theoretical modulus in the loading direction of coupons are calculated using: 1) rule-of mixtures involving effective fiber volume fraction in loading direction (FVF-X), 2) ply mechanics approach (ABD matrix) involving empirical models $\left(\mathrm{E}_{\mathrm{EMP}}\right)$, semi-empirical models (E $\left.\mathrm{E}_{\mathrm{SEMI}} \mathrm{EMP}\right)$ or periodic micro structure model (PMM) (EPMM). Table 6.7 shows that none of the experimental moduli $\left(E_{\alpha}, E_{\beta}, E_{\gamma}\right)$ correlate well with that of theoretical models, and extensive research needs to be carried out to obtain at least one of the above theoretical moduli $\left(E_{\alpha}, E_{\beta}, E_{\gamma}\right)$ accurately. Hence, for this study $E_{\alpha}$ obtained from the experimental results is used as the theoretical modulus. One of the many possible approaches for accurate $\mathrm{E}_{\alpha}$ determination is to account for additional stiffness contributed by fibers in directions other than the loading direction. One simple approach to find $\mathrm{E}_{\alpha}$ is to establish equivalent stiffness (resistance) offered by the other 
Table 6.7 Theoretical modulus using different models

\begin{tabular}{|c|c|c|c|c|c|c|c|c|}
\hline Material ID & Fiber Architecture & $\begin{array}{c}\text { Density } \\
\left(o z / y d^{2}\right)\end{array}$ & $F V F(\%)$ & $\begin{array}{c}F V F-E Q \\
(\%) \\
\end{array}$ & $\mathbf{E}_{\text {ROM }}$ & $\mathbf{E}_{\text {EMPIRICAL }}$ & $\mathbf{E}_{\text {SEMI-EMPIRICAL }}$ & $\mathbf{E}_{\mathrm{PMM}}$ \\
\hline \multicolumn{9}{|l|}{ Bending } \\
\hline Unidirectional & {$[0]_{19 \mathrm{~S}}$} & 12 & 65.25 & 65.25 & 7.018 & & & \\
\hline Unidirectional & {$[90]_{28 \mathrm{~S}}$} & 6 & 69.61 & 0.00 & 1.483 & & & \\
\hline Cross-ply & {$[0 / 90]_{22 \mathrm{~S}}$} & 23.68 & 60.94 & 29.65 & 3.300 & 3.863 & 4.376 & 4.224 \\
\hline Cross-ply & {$[90 / 0]_{20 \mathrm{~S}}$} & 11.84 & 37.40 & 18.20 & 2.211 & 2.465 & 2.699 & 2.632 \\
\hline Quadri-directional & {$[0 / 90 /+45 /-45]_{16 \mathrm{~S}}$} & 39.57 & 57.43 & 30.87 & 3.446 & 3.172 & 3.575 & 3.498 \\
\hline Quadri-directional & {$[0 / 90 /+45 /-45]_{4 \mathrm{~S}}$} & 47.36 & 44.37 & 21.89 & 2.565 & 1.995 & 2.241 & 2.194 \\
\hline Quadri-directional & {$[0 / 90 /+45 /-45]_{4 \mathrm{~S}}$} & 47.36 & 44.37 & 22.49 & 2.565 & 2.169 & 2.456 & 2.403 \\
\hline Quadri-directional with CSM & {$[0 / 90 /+45 /-45 / \mathrm{CSM}]_{10 \mathrm{~S}}$} & 61.37 & 57.83 & 29.69 & 3.319 & 3.198 & 3.603 & 3.518 \\
\hline Quadri-directional with CSM & {$[0 / 90 /+45 /-45 / \mathrm{CSM}]_{4 \mathrm{~S}}$} & 61.37 & 56.49 & 29.00 & 3.253 & 3.302 & 3.673 & 3.595 \\
\hline Quadri-directional with CSM & {$[90 / 0 /+45 /-45 / \mathrm{CSM}]_{4 \mathrm{~S}}$} & 61.37 & 56.50 & 27.50 & 3.094 & 2.970 & 3.399 & 3.302 \\
\hline Tri-directional with CSM & {$[45 / 0 /-45 / \mathrm{CSM}]_{4 \mathrm{~S}}$} & 53.66 & 55.82 & 35.89 & 4.243 & 3.387 & 3.717 & 3.693 \\
\hline Tri-directional with CSM & {$[45 / 90 /-45 / \mathrm{CSM}]_{8 \mathrm{~S}}$} & 53.66 & 50.31 & 17.06 & 1.850 & 1.431 & 1.804 & 1.728 \\
\hline Tri-directional with CSM & {$[45 / 90 /-45 / \mathrm{CSM}]_{4 \mathrm{~S}}$} & 53.66 & 44.48 & 15.08 & 2.029 & 1.641 & 2.089 & 1.997 \\
\hline \multicolumn{9}{|l|}{ Tension } \\
\hline Unidirectional & {$[0]_{19 \mathrm{~S}}$} & 12 & 57.57 & 57.57 & 6.248 & & & \\
\hline Unidirectional & {$[90]_{28 \mathrm{~S}}$} & 6 & 69.61 & 0.00 & 1.483 & & & \\
\hline Cross-ply & {$[0 / 90]_{28 \mathrm{~S}}$} & 11.84 & 49.03 & 23.85 & 2.749 & 3.139 & 3.489 & 3.389 \\
\hline Cross-ply & {$[0 / 90]_{18 \mathrm{~S}}$} & 11.84 & 45.03 & 21.91 & 2.564 & 2.897 & 3.205 & 3.116 \\
\hline Quadri-directional with CSM & {$[0 / 90 /+45 /-45 / \mathrm{CSM}]_{10 \mathrm{~S}}$} & 61.37 & 54.23 & 27.83 & 3.142 & 2.879 & 3.250 & 3.175 \\
\hline Quadri-directional with CSM & {$[0 / 90 /+45 /-45 / \mathrm{CSM}]_{4 \mathrm{~S}}$} & 61.37 & 55.22 & 28.34 & 3.191 & 2.923 & 3.307 & 3.229 \\
\hline Quadri-directional with CSM & {$[90 / 0 /+45 /-45 / \mathrm{CSM}]_{4 \mathrm{~S}}$} & 61.37 & 56.46 & 28.98 & 2.993 & 2.876 & 3.246 & 3.172 \\
\hline Tri-directional with CSM & {$[45 / 0 /-45 / \mathrm{CSM}]_{4 \mathrm{~S}}$} & 53.66 & 55.82 & 36.90 & 4.243 & 3.393 & 3.719 & 3.692 \\
\hline Quadri-directional & {$[0 / 90 /+45 /-45]_{4 \mathrm{~S}}$} & 47.36 & 44.37 & 21.89 & 2.565 & 2.165 & 2.449 & 2.339 \\
\hline Quadri-directional & {$[0 / 90 /+45 /-45]_{4 \mathrm{~S}}$} & 47.36 & 44.37 & 22.49 & 2.628 & 2.165 & 2.449 & 2.339 \\
\hline Tri-directional with CSM & {$[45 / 90 /-45 / \mathrm{CSM}]_{10 \mathrm{~S}}$} & 53.66 & 56.00 & 18.98 & 2.204 & 1.834 & 2.371 & 2.267 \\
\hline Tri-directional with CSM & {$[45 / 90 /-45 / \mathrm{CSM}]_{6 \mathrm{~S}}$} & 53.66 & 59.41 & 20.14 & 2.310 & 1.951 & 2.550 & 2.281 \\
\hline
\end{tabular}


fibers in the loading direction using 'beams on elastic foundation' method or 'grid analysis'.

\subsubsection{Strain energy density based model}

A typical stress-strain curve of multidirectional fabric based composites considered in this study is represented schematically as shown in Figure 6.2. In the locations where distress/damage initiates, the stiffness reduces, redistributing the stress. Distress/damage takes place in stages, where one distress/damage event can lead to sequence of failures inside the material as represented in Figure 6.2. Similarly, typical stress - strain curves for tri-directional composites with CSM tested in transverse direction under both tension and bending is represented as shown in Figure 6.9.

As extreme delamination or even fiber breakage occurs in last stage of stressstrain plot (stage III for all fabric based composites with different fiber architectures, and stage IV for tri-directional composites with CSM tested in transverse direction), which is usually beyond $90 \%$ of ultimate load, there is no significant change in the cross-section before first ply failure (at ultimate load). However, it is known that as load increases, the damage initiation, growth, accumulation and propagation at various stages, reduces the stiffness. Hence, differentiating the strain energies under tension or bending with respect to stiffness, and keeping the remaining terms constant, we get,

$$
\begin{aligned}
& \frac{d U_{T}}{d E}=-\frac{P^{2} L}{E^{2} A}=-\frac{U_{T}}{E} \\
& \frac{d U_{B}}{d E}=-\frac{M^{2} L}{2 E^{2} I}=-\frac{U_{B}}{E} \\
& \frac{d U}{U}=-\frac{d E}{E} \\
& \int \frac{d U}{U}=-\int \frac{d E}{E} \\
& \log _{e} U=-\log _{e} E+\log _{e} C \\
& \log _{e} C=\log _{e} U+\log _{e} E=\log _{e}(U E) \\
& \frac{d U}{U}=-\frac{d E}{E}
\end{aligned}
$$


After integrating both sides,

$$
U E=C
$$

where, $\mathrm{C}$ is a function of $\varepsilon_{\mathrm{p}}$ and depends on fiber volume fraction, density of the fabric, stacking lay-up, void content, edge effects, stress concentration, wet-out, curing rate, etc, which can be further normalized for all fiber architectures with respect to effective fiber volume fraction (FVF-X) in loading direction .

Since three distinct stages are present (Figure 6.2) the tensile or bending energy corresponding to stress versus strain has been represented for stage I as OAD, which is a triangle. Area DEBA represents the strain energy of Stage II is a trapezoidal, while the strain energy of Stage III is represented by the area under the curve EFCB.

$$
U_{\alpha} E_{\alpha}+U_{\beta} E_{\beta}+U_{\gamma} E_{\gamma}=C
$$

Area OAD:

$$
\begin{aligned}
U_{\alpha} & =\frac{1}{2} \sigma_{\alpha} \varepsilon_{1} \\
\sigma_{\alpha} & =E_{\alpha} \varepsilon_{1} \\
U_{\alpha} & =\frac{1}{2} E_{\alpha} \varepsilon_{1}^{2}=\frac{1}{2} K_{1}^{2} \varepsilon_{P}^{2} E_{\alpha}
\end{aligned}
$$

where,

$$
\begin{aligned}
& \varepsilon_{1}=K_{1} \varepsilon_{P} \\
& \varepsilon_{2}=K_{2} \varepsilon_{P}
\end{aligned}
$$

$\mathrm{K}_{1}, \mathrm{~K}_{2}, \mathrm{~K}_{\mathrm{E} 1}$ are based on the experimental observations with respect to the first and second points where change of slope occurred and are as shown in Table 6.5 Ratios of Longitudinal Moduli for all fabric based composites under tension and bending . $E_{\alpha}$ is the theoretical modulus which varies with fiber architecture. However, in this study the experimental value is used, the reasons for which are explained in Section 6.4.1

Hence, $U_{\alpha} E_{\alpha}=\frac{1}{2} K_{1}^{2} \varepsilon_{P}^{2} E_{\alpha}^{2}$

Area DEBA: 


$$
\begin{aligned}
U_{\beta} & =\frac{1}{2}\left(\sigma_{\alpha}+\sigma_{\beta}\right)\left(\varepsilon_{2}-\varepsilon_{1}\right) \\
\sigma_{\beta} & =\sigma_{\alpha}+E_{\beta}\left(\varepsilon_{2}-\varepsilon_{1}\right) \\
E_{\beta} & =\frac{E_{\alpha}}{K_{E 1}} \\
U_{\beta} E_{\beta}=\frac{1}{2}\left(\sigma_{\alpha}+\sigma_{\beta}\right)\left(\varepsilon_{2}-\varepsilon_{1}\right) E_{\beta} & =\frac{1}{2}\left(E_{\alpha}^{2} \varepsilon_{P}^{2}\right)\left(\frac{K_{2}-K_{1}}{K_{E 1}}\right)\left(2 K_{1}+\frac{\left(K_{2}-K_{1}\right)}{K_{E 1}}\right)
\end{aligned}
$$

Since area EFCB represents non-linear portion, and the corresponding modulus of the curve is more involved that the other two areas, area EFG is approximated to zero and only area of the rectangular portion (EGCB) is considered.

Area EGCB:

$$
\begin{gathered}
U_{\gamma}=\sigma_{\beta}\left(\varepsilon_{P}-\varepsilon_{2}\right) \\
\sigma_{\beta}=\sigma_{\alpha}+E_{\beta}\left(\varepsilon_{2}-\varepsilon_{1}\right) \\
E_{\gamma}=\frac{E_{\beta}}{K_{E 2}}=\frac{E_{\beta}}{0.3} \\
U_{\gamma} E_{\gamma}=\sigma_{\beta}\left(\varepsilon_{P}-\varepsilon_{2}\right) E_{\gamma}=\left(E_{\alpha}^{2} \varepsilon_{P}^{2}\right)\left(\frac{1-K_{2}}{K_{E 1} K_{E 2}}\right)\left[K_{1}+\frac{\left(K_{2}-K_{1}\right)}{K_{E 1}}\right]
\end{gathered}
$$

Hence, summing up all the equations we get,

$\sum_{i=\alpha, \beta, \gamma} U_{i} E_{i}=\frac{1}{2} E_{\alpha}^{2} \varepsilon_{P}^{2} K_{1}^{2}+\frac{1}{2}\left(E_{\alpha}^{2} \varepsilon_{P}^{2}\right)\left(\frac{K_{2}-K_{1}}{K_{E 1}}\right)\left(2 K_{1}+\frac{\left(K_{2}-K_{1}\right)}{K_{E 1}}\right)+\left(E_{\alpha}^{2} \varepsilon_{P}^{2}\right)\left(\frac{1-K_{2}}{K_{E 1} K_{E 2}}\right)\left[K_{1}+\frac{\left(K_{2}-K_{1}\right)}{K_{E 1}}\right]$

Strain at ultimate stress is calculated from equations 6.6 and 6.10 (given $\mathrm{E}_{\alpha}$ )

$$
C=E_{\alpha}^{2} \varepsilon_{P}^{2}\left(\frac{1}{2} K_{1}^{2}+\frac{1}{2}\left(\frac{K_{2}-K_{1}}{K_{E 1}}\right)\left(2 K_{1}+\frac{\left(K_{2}-K_{1}\right)}{K_{E 1}}\right)+\left(\frac{1-K_{2}}{K_{E 1} K_{E 2}}\right)\left[K_{1}+\frac{\left(K_{2}-K_{1}\right)}{K_{E 1}}\right]\right)
$$

Thus, corresponding strains and stresses at different points where changes in slope occurred can be easily obtained by back substitution, and the percentage difference between theory and experimental results were found to be less than 10\% (Table 6.8). 
Table 6.8 Theoretical and Experimental Comparisons of Strains at Ultimate Stress of composites with different fiber architectures under tension and bending

\begin{tabular}{|c|c|c|c|c|}
\hline Material ID & Fiber Architecture & $\begin{array}{c}\text { Strain at } \\
\text { Ultimate }\end{array}$ & $\begin{array}{c}\text { Strain- } \\
\text { Theo }\end{array}$ & \%Diff \\
\hline Bending & \multicolumn{4}{|l|}{} \\
\hline Cross-ply & {$[0 / 90]_{22}$} & 17931.54 & 19686.00 & -9.78 \\
\hline Cross-ply & {$[90 / 0]_{20 \mathrm{~S}}$} & 17240.96 & 19984.84 & -15.91 \\
\hline Quadri-directional with CSM & {$[0 / 90 /+45 /-45 / \mathrm{CSM}]_{10 \mathrm{~S}}$} & 16801.28 & 14732.11 & 12.32 \\
\hline Quadri-directional with CSM & {$[0 / 90 /+45 /-45 / \mathrm{CSM}]_{4 \mathrm{~S}}$} & 17895.78 & 17681.09 & 1.20 \\
\hline Quadri-directional & {$[0 / 90 /+45 /-45]_{16 \mathrm{~S}}$} & 17451.73 & 15527.91 & 11.02 \\
\hline Quadri-directional with CSM & {$[90 / 0 /+45 /-45 / \mathrm{CSM}]_{4 \mathrm{~S}}$} & 17799.09 & 15772.08 & 11.39 \\
\hline Quadri-directional & {$[0 / 90 /+45 /-45]_{4 \mathrm{~S}}$} & 15255.12 & 16100.06 & -5.54 \\
\hline Quadri-directional & {$[90 / 0 /+45 /-45]_{4 \mathrm{~S}}$} & 16638.94 & 17391.94 & -4.53 \\
\hline Tri-directional with CSM & {$[45 / 0 /-45 / \mathrm{CSM}]_{4 \mathrm{~S}}$} & 18862.32 & 19997.66 & -6.02 \\
\hline Tension & {$[0 / 90]_{28 \mathrm{~S}}$} & 22086.38 & 24102.70 & 8.37 \\
\hline Cross-ply & {$[0 / 90]_{18 \mathrm{~S}}$} & 22354.08 & 23435.63 & 4.61 \\
\hline Cross-ply & {$[0 / 90 /+45 /-45 / \mathrm{CSM}]_{10 \mathrm{~S}}$} & 17513.67 & 19094.09 & 8.28 \\
\hline Quadri-directional with CSM & {$[0 / 90 /+45 /-45 / \mathrm{CSM}]_{4 \mathrm{~S}}$} & 16855.43 & 18284.29 & 7.81 \\
\hline Quadri-directional with CSM & {$[45 / 0 /+45 /-45 / \mathrm{CSM}]_{4 \mathrm{~S}}$} & 23445.72 & 25429.18 & 7.80 \\
\hline Quadri-directional with CSM & {$[0 / 90 /+45 / \mathrm{CSM}]_{4 \mathrm{~S}}$} & 20082.89 & 22181.76 & 9.46 \\
\hline Tri-directional with CSM & {$[90 / 0 /+45 /-45]_{4 \mathrm{~S}}$} & 13321.04 & 13733.78 & 3.01 \\
\hline Quadri-directional & 18550.51 & 20332.99 & 8.77 \\
\hline Quadri-directional &
\end{tabular}

$$
\begin{aligned}
& \sigma_{\alpha}=E_{\alpha} K_{1} \varepsilon_{P} \\
& \sigma_{\beta}=\left(K_{1}+\frac{\left(K_{2}-K_{1}\right)}{K_{E 1}}\right) E_{\alpha} \varepsilon_{P} \\
& \sigma_{\gamma}=\frac{\sigma_{\beta}}{0.9}
\end{aligned}
$$

\section{Special Case: Tri-directional with CSM tested in transverse direction under both tension and bending}

Since four distinct stages are present (Figure 6.9,) the tensile or bending energy corresponding to tensile or bending stress versus strain curves has been represented for stage I as OAE. Area ABFE represents the strain energy of Stage II, Area BCGF 
represents the strain energy of Stage III while the strain energy of Stage VI is represented by the area under the curve CDHG.

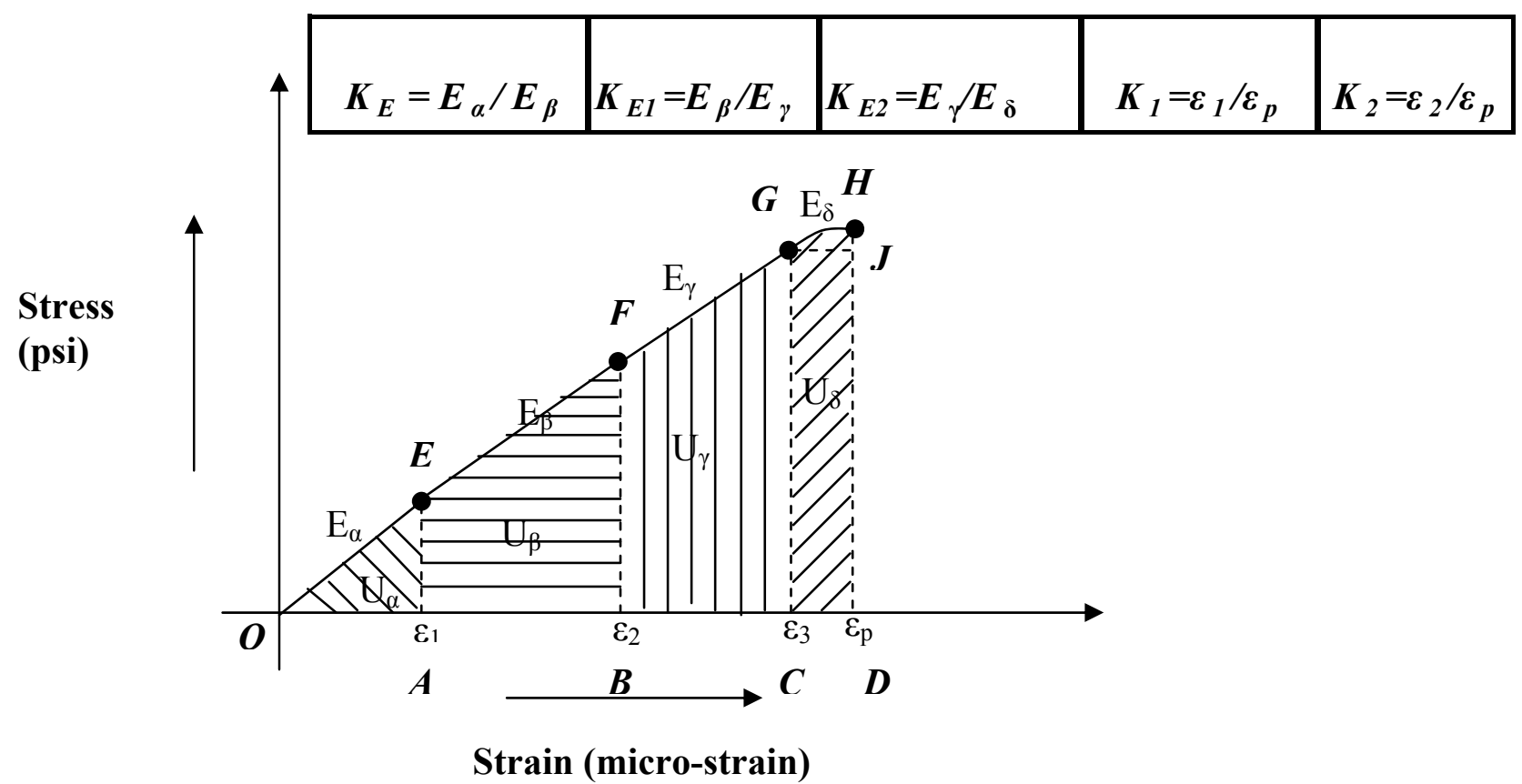

Figure 6.9 Typical Stress-Strain Curve of Tri-directional with CSM Composite

$$
\begin{array}{cl}
\mathrm{E}_{\alpha} & \text { First Modulus } \\
\mathrm{E}_{\beta} & \text { Second Modulus } \\
\varepsilon_{1} & \text { Strain corresponding to First Bifurcation Point } \\
\varepsilon_{2} & \text { Strain corresponding to Second Bifurcation Point } \\
\varepsilon_{\mathrm{P}} & \text { Strain corresponding to Peak Load } \\
\mathrm{E}_{\gamma} & \text { Third Modulus } \\
\varepsilon_{3} & \text { Strain corresponding to Thrid Bifurcation Point } \\
& \\
U_{\alpha} E_{\alpha}+U_{\beta} E_{\beta}+U_{\gamma} E_{\gamma}+U_{\delta} E_{\delta}=C
\end{array}
$$

Area OAE:

$$
U_{\alpha} E_{\alpha}=\frac{1}{2} K_{1}^{2} \varepsilon_{P}^{2} E_{\alpha}^{2}
$$

Area ABFE: 


$$
U_{\beta} E_{\beta}=\frac{1}{2}\left(\sigma_{\alpha}+\sigma_{\beta}\right)\left(\varepsilon_{2}-\varepsilon_{1}\right) E_{\beta}=\frac{1}{2}\left(E_{\alpha}^{2} \varepsilon_{P}^{2}\right)\left(\frac{K_{2}-K_{1}}{K_{E 1}}\right)\left(2 K_{1}+\frac{\left(K_{2}-K_{1}\right)}{K_{E 1}}\right)
$$

Area BCGF:

$$
U_{\gamma} E_{\gamma}=\frac{1}{2}\left(E_{\alpha}^{2} \varepsilon_{P}^{2}\right)\left(K_{3}-K_{2}\right)\left(\frac{K_{2}-K_{1}}{K_{E}}\right)\left(2 K_{1}+\frac{2\left(K_{2}-K_{1}\right)}{K_{E}}+\frac{K_{3}-K_{2}}{K_{E} K_{E 1}}\right)
$$

Since area CDHG represents non-linear portion, and the corresponding modulus of the curve is difficult to obtain, area CDHG is approximated to zero and only area of the rectangular portion CDJG is considered.

Area CDHG

$$
\begin{gathered}
\sigma_{\gamma}=\sigma_{\beta}+E_{\gamma}\left(\varepsilon_{3}-\varepsilon_{2}\right) \\
E_{\delta}=\frac{E_{\delta}}{K_{E 2}}=\frac{E_{\delta}}{0.3} \\
U_{\delta} E_{\delta}=\left(E_{\alpha}^{2} \varepsilon_{P}^{2}\right)\left(\frac{1-K_{3}}{K_{E 1} K_{E 2} K_{E 3}}\right)\left(K_{1}+\frac{\left(K_{2}-K_{1}\right)}{K_{E 1}}+\frac{K_{3}-K_{2}}{K_{E 1} K_{E 2}}\right)
\end{gathered}
$$

Hence,

$$
\begin{aligned}
& \sum_{i=\alpha, \beta, \gamma, \delta} U_{i} E_{i}=\frac{1}{2} E_{\alpha}^{2} \varepsilon_{P}^{2} K_{1}^{2}+\frac{1}{2}\left(E_{\alpha}^{2} \varepsilon_{P}^{2}\right)\left(\frac{K_{2}-K_{1}}{K_{E 1}}\right)\left(2 K_{1}+\frac{\left(K_{2}-K_{1}\right)}{K_{E 1}}\right) \\
& +\frac{1}{2}\left(E_{\alpha}^{2} \varepsilon_{P}^{2}\right)\left(K_{3}-K_{2}\right)\left(\frac{K_{2}-K_{1}}{K_{E 1}}\right)\left(2 K_{1}+\frac{2\left(K_{2}-K_{1}\right)}{K_{E 1}}+\frac{K_{3}-K_{2}}{K_{E 1} K_{E 2}}\right) \\
& +\left(E_{\alpha}^{2} \varepsilon_{P}^{2}\right)\left(\frac{1-K_{3}}{K_{E 1} K_{E 2} K_{E 3}}\right)\left(K_{1}+\frac{\left(K_{2}-K_{1}\right)}{K_{E 1}}+\frac{K_{3}-K_{2}}{K_{E 1} K_{E 2}}\right)
\end{aligned}
$$

Strain at ultimate stress is calculated from equations 6.13 and 6.15 (given $\mathrm{E}_{\alpha}$ )

$$
\begin{aligned}
& C=\frac{1}{2} E_{\alpha}^{2} \varepsilon_{P}^{2} K_{1}^{2}+\frac{1}{2}\left(E_{\alpha}^{2} \varepsilon_{P}^{2}\right)\left(\frac{K_{2}-K_{1}}{K_{E 1}}\right)\left(2 K_{1}+\frac{\left(K_{2}-K_{1}\right)}{K_{E 1}}\right) \\
& +\frac{1}{2}\left(E_{\alpha}^{2} \varepsilon_{P}^{2}\right)\left(K_{3}-K_{2}\right)\left(\frac{K_{2}-K_{1}}{K_{E 1}}\right)\left(2 K_{1}+\frac{2\left(K_{2}-K_{1}\right)}{K_{E 1}}+\frac{K_{3}-K_{2}}{K_{E 1} K_{E 2}}\right) \\
& +\left(E_{\alpha}^{2} \varepsilon_{P}^{2}\right)\left(\frac{1-K_{3}}{K_{E 1} K_{E 2} K_{E 3}}\right)\left(K_{1}+\frac{\left(K_{2}-K_{1}\right)}{K_{E 1}}+\frac{K_{3}-K_{2}}{K_{E 1} K_{E 2}}\right)
\end{aligned}
$$

Thus, corresponding strains and stresses at different points can be easily obtained by back substitution. 


$$
\begin{aligned}
& \sigma_{\alpha}=E_{\alpha} K_{1} \varepsilon_{P} \\
& \sigma_{\beta}=\left(K_{1}+\frac{\left(K_{2}-K_{1}\right)}{K_{E 1}}\right) E_{\alpha} \varepsilon_{P} \\
& \sigma_{\gamma}=\left(K_{1}+\frac{\left(K_{2}-K_{1}\right)}{K_{E 1}}+\frac{\left(K_{3}-K_{1}\right)}{K_{E 1} K_{E 2}}\right) E_{\alpha} \varepsilon_{P} \\
& \sigma_{\delta}=\frac{\sigma_{\gamma}}{0.9}
\end{aligned}
$$

Using the above equations, strains at ultimate stress, thus corresponding stresses at different points where changes in slope occurred, were calculated for all fiber architectures considered in this study, and the percentage difference between theory and experimental results were found to be less than $10 \%$ (Table 6.9).

Table 6.9 Theoretical and Experimental Comparisons of Strains at Ultimate Stress of tridirectional with CSM tested in transverse direction

\begin{tabular}{|c|c|c|c|c|c|}
\hline Material ID & Fiber Architecture & Direction & $\begin{array}{c}\text { Strain at } \\
\text { Ultimate }\end{array}$ & $\begin{array}{c}\text { Strain- } \\
\text { Theo }\end{array}$ & \%Diff \\
\hline Tri-directional with CSM & {$[45 / 90 /-45 / \mathrm{CSM}]_{10 \mathrm{~S}}$} & Transverse & 23928.54 & 20456.01 & 4.59 \\
\hline Tri-directional with CSM & {$[45 / 90 /-45 / \mathrm{CSM}]_{6 \mathrm{~S}}$} & Transverse & 26134.28 & 20933.32 & 7.98 \\
\hline
\end{tabular}

\subsection{CONCLUSIONS}

Five different balanced and symmetric composites with different fiber architectures (uni-directional, bi-directional, tri-directional with CSM, quadri-directional with and without CSM) were tested under tension and bending in both longitudinal and transverse directions. It was observed that the unidirectional composites showed linear slope almost to the ultimate stress. And the composites with different fiber architectures, except tri-directional with CSM tested in transverse direction showed two nearly linear slopes, while tri-directional with CSM tested in transverse direction showed three nearly linear slopes up to almost $90 \%$ of the ultimate stresses.

Strain energy densities, points where changes in slope, longitudinal moduli for all the materials at different stages were analyzed. Consistent results were observed regarding the points (locations where change in slope occurred), ratios of moduli, etc 
from the experimental data. Also, it was found that the sum of the product of stiffness and strain energy density up to ultimate strain is found to be constant. A strain energy density prediction model was proposed and the experimental and predicted stresses and strains were compared. The prediction was conservative for all the materials and the error involved was less than $10 \%$.

However, much work needs to be done to challenge some of the assumptions placed in the proposed theory. The conclusions drawn from the research and the recommendations for future work are presented in Chapter 7. 


\section{CHAPTER 7}

\section{CONCLUSIONS AND RECOMMENDATIONS}

\subsection{CONCLUSIONS}

Upon testing GFRP composites with different fiber architecture (uni-directional, bi-directional, tri-directional with CSM, quadri-directional with and without CSM), all of which are balanced and symmetric under tension and bending in both longitudinal and transverse directions, the following conclusions are drawn:

- Bi-linear stress-strain response up to $90 \%$ of ultimate stress was observed in case of all GFRP composites with different fiber architectures except tri-directional fabric based composites with CSM, wherein a tri-linear response was observed.

- For all composite materials with different fiber architectures except tri-directional fabric based composites with CSM, the first and second points where change of slope occurred corresponding to ultimate stresses are found to be $\left(\mathrm{K}_{1}\right) 34 \%$, and $\left(\mathrm{K}_{2}\right) \quad 87 \%$, under tension and $\left(\mathrm{K}_{1}\right) 28 \%$, and $\left(\mathrm{K}_{2}\right) 88 \%$, under bending, respectively. The ratios of the longitudinal moduli are $\left(\mathrm{K}_{\mathrm{E} 1}\right)$ 1.2, and $\left(\mathrm{K}_{\mathrm{E} 1}\right) 1.27$ under tension and bending, respectively, for all fiber architectures except tridirectional composites with CSM tested in transverse direction.

- In tri-directional composites with CSM tested in transverse direction three points were $\left(\mathrm{K}_{1}\right) 25 \%,\left(\mathrm{~K}_{2}\right) 68 \%$ and $\left(\mathrm{K}_{3}\right) 87 \%$ for tension, and $\left(\mathrm{K}_{1}\right) 15 \%,\left(\mathrm{~K}_{2}\right) 45 \%$ and $\left(\mathrm{K}_{3}\right) 88 \%$ for bending, respectively. The ratios of the modulus were found to be $\left(\mathrm{K}_{\mathrm{E} 1}\right) 1.41,\left(\mathrm{~K}_{\mathrm{E} 2}\right) 1.47$ for tension and $\left(\mathrm{K}_{\mathrm{E} 1}\right) 1.56,\left(\mathrm{~K}_{\mathrm{E} 2}\right) 1.51$ for bending.

- In case of tri-directional composites with CSM tested in transverse direction, the first and second points under tension are around $\left(\mathrm{K}_{1}\right) 0.25$ and $\left(\mathrm{K}_{2}\right) 0.68$, while $\left(\mathrm{K}_{1}\right) 0.15$ and $\left(\mathrm{K}_{2}\right) 0.45$ for bending, respectively. Ratios of first modulus to the second $\left(\mathrm{K}_{\mathrm{E} 1}\right)$, and second to the third $\left(\mathrm{K}_{\mathrm{E} 2}\right)$ are found to be in the range of 1.41, and 1.47 , for tension, and 1.56 and 1.51 for bending.

- Based on the consistency of experimental data, the distress/damage mechanism is determined to be a progression from matrix micro-cracking, due to stress concentration of fibers meeting from different directions at different junctions, 
matrix micro-cracking, and interaction of micro cracks leading to delamination under increasing loads leading to possible fiber pull out.

- A strain energy density based model was proposed and the model was used to predict strength, stresses and strains at various stages for different fiber architectures considered in the study.

- The sum of the product of stiffness and strain energy density up to ultimate stress is found to be constant.

- The experimental and predicted strains, stresses, and strengths at various damage stages were found to be within 10\% error for all different fiber architectures.

- Response of unidirectional coupon specimens under tension resulted in $112 \mathrm{Ksi}$ to failure, for $58 \% \mathrm{FVF}$, while it is $94 \mathrm{Ksi}$ for $70 \% \mathrm{FVF}$. This anomaly is attributed to inappropriate gage length of test specimens and tab length, in addition to potential wet out problems. Also, localized bending under fabric imbalances/dislocations may also lead to variations in strengths.

- Tensile strengths and flexural strengths of composites are found to increase linearly with the increasing FVF in loading direction.

- Specific strengths (w.r.t. effective FVF in loading direction) revealed that increasing in the FVF in loading direction decreases/reduces, failure strength per volume content.

- To a degree, fibers other than the ones in loading direction of fabric composites, contribute to the initial stiffness, hence first tangent modulus $\left(\mathrm{E}_{\alpha}\right)$ is typically higher than the $\mathrm{E}_{\mathrm{ROM}}$, for all fabric based composites.

- The second tangent modulus $\left(\mathrm{E}_{\beta}\right)$ for almost all fiber architectures is close to the theoretical predictions using rule-of-mixtures $\left(\mathrm{E}_{\mathrm{ROM}}\right)$ for all fabric based composites except tri-directional composites with CSM.

- In quadri-directional composites without CSM fabricated using 40oz/yd $\mathrm{d}^{2}$ fabric and tested under bending, the theoretical stiffness $\left(\mathrm{E}_{\mathrm{ROM}}\right)$ equals the first tangent modulus $\left(\mathrm{E}_{\alpha}\right)$. This is attributed to improper wet our and inadequate bond between fibers leading to lower specific strengths and stiffness per equivalent FVF than expected. 
- In case of tri-directional composites with CSM tested in transverse direction, the initial tangent modulus $\left(\mathrm{E}_{\alpha}\right)$ is nearly equal to the $\mathrm{E}_{\mathrm{ROM}}$, in tension and bending. This is attributed to low fiber volume content in loading direction, thus implicating matrix dominant behavior.

- As the effective fiber volume fraction in the loading direction increased, the stiffness increase is nearly linear.

- Specific second tangent modulus (w.r.t. effective FVF in loading direction) for all fiber architectures, it is found to be constant, and of 8.53 (msi/FVF) and 10.11 (msi/FVF) under tension and bending, respectively. This is almost equal to the glass fiber stiffness, however, it is not so with unidirectional composites.

- In case of tri-directional composites with CSM tested in transverse direction, specific first tangent modulus (w.r.t. effective FVF in loading direction) is almost constant and is $10.80(\mathrm{msi} / \mathrm{FVF})$ under tension and 11.24 (msi/FVF) under bending. However, the lower stiffness of these composites under tension is attributed to misalignment of fibers.

- The specific second tangent moduli with respect to effective fiber volume fraction in loading direction should be nearly identical to the stiffness of glass fibers.

- Strains at ultimate stresses for unidirectional composites are lower than those with fabric based composites at higher FVF, which is attributed to splitting failure of the matrix bonding the unidirectional fibers, leading to bending failure of fibers.

- Composites with different fiber architectures fail because of matrix microcracking due to stiffening effects of fibers oriented in directions other than the loading direction.

- Specific strains revealed that failure strains per volume content in loading direction are lower for higher fiber volume fraction, implying inadequate bond between fibers leading to premature delamination of fibers.

\subsection{RECOMMENDATIONS}

- The accuracy in the prediction model based on strain energy density can be much improved by considering non-linear response instead of linear response up to $90 \%$ of ultimate stress. 
- The theoretical modulus obtained from rule-of-mixtures involving effective fiber volume fraction $\left(\mathrm{E}_{\mathrm{ROM}}\right)$, ply mechanics approach involving empirical and semiempirical models ( E SEMI-EMP $_{\text {) }}$ or periodic micro structure model ( E $_{\text {PMM }}$ ), did not correlate well with the any of the experimental modulus $\left(\mathrm{E}_{\alpha,} \mathrm{E}_{\beta}, \mathrm{E}_{\gamma}\right)$, and more work needs to be done to obtain theoretical modulus accurately. One of the possible approaches for accurate $\mathrm{E}_{\alpha}$ determination is to account for additional stiffness contributed by the fibers other than the loading direction, which can be obtained by using beams on elastic foundation approach or torsionless or grid analysis approach.

- As this model is confined to coupon specimens manufactured using compression molding process, the model can be expanded by taking into account various manufacturing process, fiber architectures other than the ones mentioned in the study, stress concentration factors, notch sensitivity issues, etc.

- The sum of the product of stiffness and strain energy density up to ultimate strain is found to be constant, and the constant should be normalized considering all different fiber architectures by accounting for parameters affecting the composite strength and stiffness.

- $\mathrm{K}_{\mathrm{E} 2}$ (ratio of second modulus to the third modulus, $\mathrm{E}_{\beta} / \mathrm{E}_{\gamma}$ ) in case of all other composite materials with different fiber architectures and $\mathrm{K}_{\mathrm{E} 3}$ (ratio of third modulus to the fourth modulus, $\mathrm{E}_{\gamma} / \mathrm{E}_{\delta}$ ) in case of tri-directional composites with CSM tested in transverse directions for bending and tension are assumed to be 0.3. In order to improve the accuracy of predicted failure strength, more accurate $\mathrm{K}_{\mathrm{E} 2}$ and $\mathrm{K}_{\mathrm{E} 3}$ have to be determined either experimentally and/or theoretically. 


\section{REFERENCES}

Adams Donald F., Unidirectional Composite Axial Tensile Specimens, HighPerformance Composites - Jan 2006

Barbero Ever J., Introduction to Composite Materials Design, Taylor \& Francis, Inc., 1999.

Butalia T.S., Wolfe W.E., A strain-energy based non-linear failure criterion: comparison of numerical predictions and experimental observations for symmetric composite laminates. Kaddour A.S., Hinton M.J., Soden P.D., Failure Criteria in FRP composites: The World Wide Failure Exercise, ELSEVIER, 2004.

Eng K. M. and Mariatti M., Wagiman N. R. and Beh K. S., Effect of Different Woven Linear Densities on the Properties of Polymer Composites, Journal of Reinforced Plastics and Composites, Vol. 25, No. 13, 1375-1383 (2006)

Jiang Yijun and Hoa Suong V., A Novel Method for the Manufacturing of Thick Composites, Journal of Composite Materials, Vol. 40, No. 5, 433-453 (2006)

Jones F. R., Micromechanics and Properties of Fiber Composites, Middleton D. H., Editor, Composite Materials in Aircraft Structures, 1990

Hill, R., The Mathematical Theory of Plasticity, 'Oxford University Press, 1950

Kaddour A.S., Hinton M.J., Soden P.D. Predictive capabilities of nineteen failure theories and design methodologies for polymer composite laminates. Part B: Comparison with experiments. M.J. Hinton, A.S. Kaddour, P.D. Soden, Failure Criteria in FRP composites: The World Wide Failure Exercise (WWFE), ELSEVIER, 2004.

Kaddour A.S., Hinton M.J., Soden P.D., Failure Criteria in FRP composites: The World Wide Failure Exercise, ELSEVIER, 2004. 
Kaw Autar K., Mechanics of Composite Materials, second edition, Taylor \& Francis, Inc., 2006.

Kim, C. and White, S.R. (1996). The Continuous Curing Process for Thermoset Polymer Composites. Part 2: Experimental Results for Graphite/Epoxy Laminate, Journal of Composite Materials, 30(5): 627-647.

Kuraishi A., Tsai S.W., Liu K.S., A progressive quadratic failure criterion, part B. Kaddour A.S., Hinton M.J., Soden P.D., Failure Criteria in FRP composites: The World Wide Failure Exercise, ELSEVIER, 2004.

Liu K.S., Tsai S.W., A progressive quadratic failure criterion for a laminate. Kaddour A.S., Hinton M.J., Soden P.D., Failure Criteria in FRP composites: The World Wide Failure Exercise, ELSEVIER, 2004.

Mandell John F. and Samborsky Daniel D., DOE/MSU Composite Material Fatigue Database: Test Methods, Materials, and Analysis, Department of Chemical Engineering, Montana State University, Bozeman, MT., SAND97-3002.

Manders Peter W. and Chou Tsu-Wei, Variability of Carbon and Glass Fibers, and Strength of Aligned Composites, Journal of Reinforced Plastics and Composites, Vol. 2 , Jan 1983.

Micrograph Library University of Cambridge (2006) http://www.doitpoms.ac.uk/miclib/index.php ( last accessed on October 10, 2006)

Nahas, Mahmoud N., Survey of Failure and Post Failure Theories of Laminated Fiber Reinforced Composites, Journal of Composites Technology and Research V8, Pg 138-153, 1986.

Onal L., Adanur S., Optimization of Compression Molding Process in Laminated Woven Composites, Journal of reinforced plastics and composites, 2005, vol. 24, No 7, pp. $775-780$ 
Puck A., Schurmann H., Failure analysis of FRP laminates by means of physically based phenomenological models. Kaddour A.S., Hinton M.J., Soden P.D., Failure Criteria in FRP composites: The World Wide Failure Exercise, ELSEVIER, 2004.

Puck A., Schurmann H., Failure analysis of FRP laminates by means of physically based phenomenological models. Kaddour A.S., Hinton M.J., Soden P.D., Failure Criteria in FRP composites: The World Wide Failure Exercise, ELSEVIER, 2004.

Puck, A, and Schneider, W., On Failure Mechanisms and Failure Criteria of FilamentWound Glass/Resin composites, Plastics and Polymers. V37, pg 33-43, 1969.

Sandhu, R.S., Non-linear Behavior of Unidirectional and angle-Ply Laminates, Journal of Aircraft, V13, pg 104-111, 1974.

Wolfe W.E., Butalia T.S., A strain-energy based failure criterion for non-linear analysis of composite laminates subjected to biaxial loading. Kaddour A.S., Hinton M.J., Soden P.D., Failure Criteria in FRP composites: The World Wide Failure Exercise, ELSEVIER, 2004.

Wu, E.M., Optimal Experimental Measurements of Anisotropic Failure Tensors, Journal of Composite Materials, V6, pg472-489, 1972.

Zinoviev P.A., Grigoriev S.V., Lebedeva O.V. and Tairova L.R., The Strength of multilayered composites under a plane-stress state. Kaddour A.S., Hinton M.J., Soden P.D., Failure Criteria in FRP composites: The World Wide Failure Exercise, ELSEVIER, 2004.

Zinoviev P.A., Lebedeva O.V., and Tairova L.R., A coupled analysis of experimental and theoretical results on the deformation and failure of composite laminates under a state of plane stress. Kaddour A.S., Hinton M.J., Soden P.D., Failure Criteria in FRP composites: The World Wide Failure Exercise, ELSEVIER, 2004. 